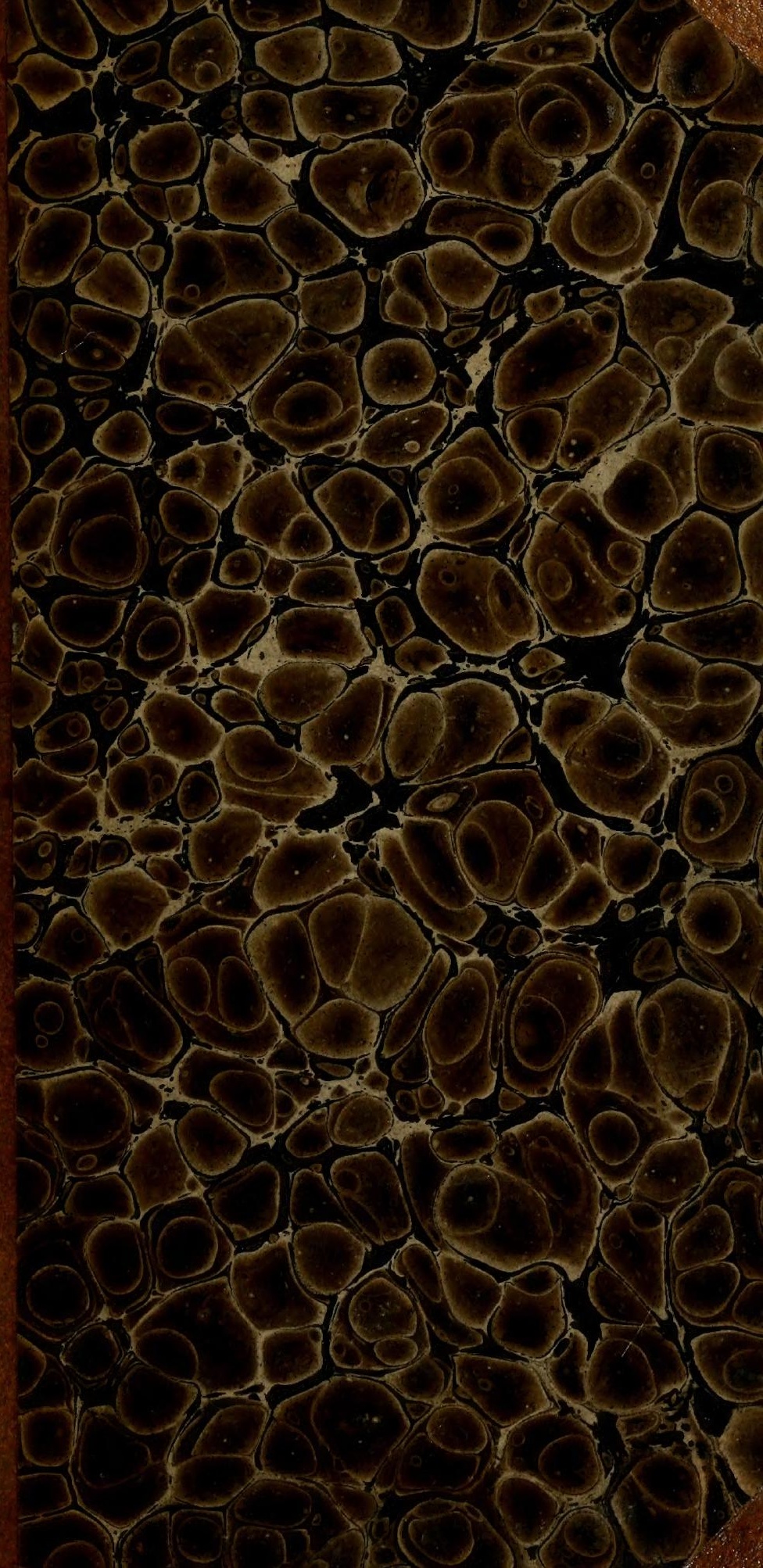




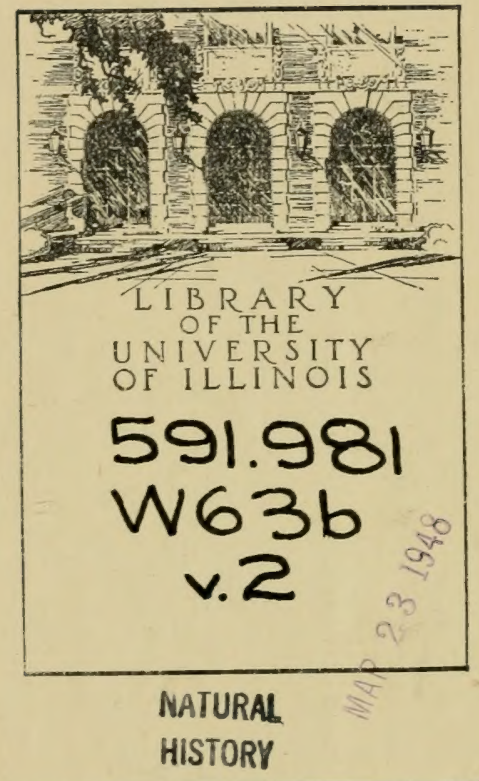

FRIEDLÄNDER \& SOHN Buchhandlung Berlin N.W.6.

11. Carlsirasse 11. 

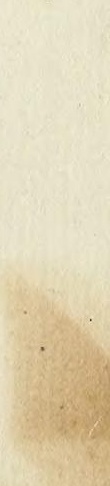
Digitized by the Internet Archive in 2010 with funding from University of Illinois Urbana-Champaign 


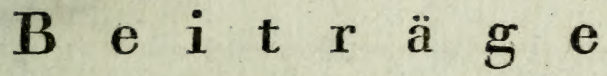

\author{
zur
}

Naturgeschichte

von

\author{
B r a s i l i e n,
}

von

Maximilian, Prinzen

$$
z \text { u W } i \text { e d. }
$$

II. $\mathrm{B}$ a $\mathrm{n}$ d.

$$
\text { Mit } 5 \text { K u p f e r t a f e } 1 \mathrm{n} \text {. }
$$

$$
\text { W e i } m \text { a } r \text {, }
$$

im Verlage des Gr. H. S. priv. Landes-Industrie-Comptoirs.

1826. 
3 \& 3 is 5 i 0 d

7316

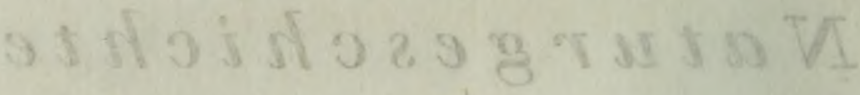

- NS:

$$
\text { eft } 9 \text { i } 1 \text { i } 2 \text { \& } 5 \text { ill }
$$

(1) wh w

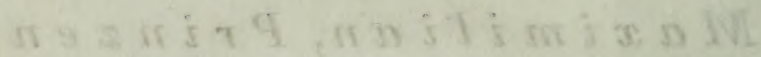
It 3 is W $\mathrm{x}=$

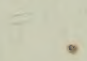

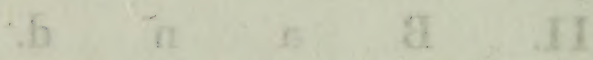

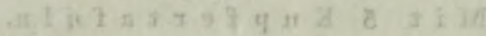

\section{i 5 hr i 9 VY}

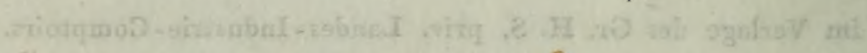

.2. \& $8 \cdot 1$ 


\subsection{1 \\ W636 \\ V. 2}

\section{Verzeichnifs}

dex

Amphibien, Säugthiere und Vögel,

welche

auf einer Reise zwischen dem 13ten und dem 23sten Grade südlicher Breite

im östlichen Brasilien

beobachtet wurden. 


\section{1 if d०}

$\geq 25$

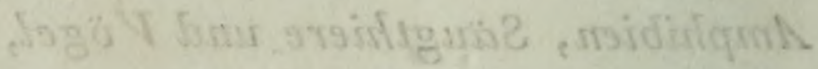

$$
\text { anis we }
$$

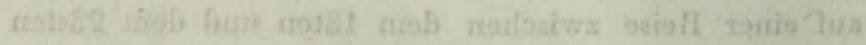

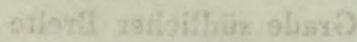

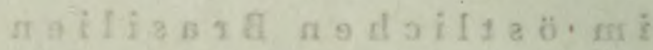

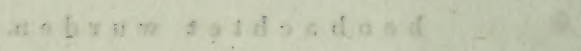

i 


\section{A vertis s e m e nt.}

\section{Nach dem Verzeichnifs meiner Insecten-}

Sammlung, 1796, habe ich meinen Freunden im In- und Auslande lein neueres, was denselben über den Bestand und Fortgang meiner Sammlung. Funde gegeben hätte, vons gelegt, sondern mich nur damit begnügt, von Zeit zu Zeit Tauschverzeichnisse zu vertheilen, um die schon länger angeknüpften Verbindungen meiner Freunde im Fortgang zu erhalten, die für meine Sammlung meist von dem besten Erfolg waren, und meine Bemühungen um Vermehrung meiner Sammlung lange reichlich lohnten. Dafs diese Quellen aber endlich mehr und mehr, besonders wie nähèr sie liegen, sich erschöpfen mufsten, liegt schon in der Natur der Sache selbst. Ich habe daher seit längerer Zeit nur aus entferntern Quellen, besonders des Auslandes, noch bedeutenden Zuwachs zu meiner Sammlung erhalten können, da hingegen die nahen und einheimischen mir nur noch Doubletten, und hin und wieder eine neue Art für meine Sammlung lieferten.

Ich sahe mich daher veranlafst ein neues vollständiges Verzeichnifs über den dermaligen Bestand meiner InsectenSammlung zu veranstalten, wovon so eben der erste Theil, welcher die Käfer enthält, unter dem Titel

\section{Catalog meiner Insecten-Sammlung}

mit $13 \frac{x}{2}$ Bogen Text und 4 ausgemalten Kupfertafeln, in gr. 8. Preis $3 \mathrm{fl}$. $36 \mathrm{kr}$. rhein. oder 2 Rthlr. säschs. erschienen ist.

Zur bequemern Uebersicht habe ich die alphąbetische Ordnung nach Gattungen und Arten gewählt, und wo ich es nöthig fand, zu den letztern die Synonyme beigefügt, und das Vaterland beigesetzt. Um diesen Catalog aber überhaupt für Sammler und Liebhaber brauchbarer zu machen, habe ich auch in einer besondern Abtheilung die 531 Gattungen (Genera) von Käfern, welche sich bis jetzt in mei- 
ner Sammlung befinden, naoh dem Latreille'schen System, mit den nöthigen Synonymen, aufgeführt, und jeder Gattung auch den deutschen Gattungsnamen beigefügt. Da der gröfste Theil derselben neu gebildet werden mufste, so ist auch die Ableitung bei solchen erklärt. Die sämmtlichen bis jetzt bekannten Käfer sind nach diesem System in 40 Familien vertheilt, und um den Typus derselben anschaulich zu machen, habe ich von jeder Familie eine Art aus meiner Sammlung ausgehoben und ausführlich beschrieben, und auf den beigegebenen 4 . Kupfertafeln getreu und vollständig abgebildet. Bis auf etliche, sind diese, wie ich glaube, vorhin noch nicht besohrieben oder abgebildet gewesen.

Aus diesem Catalog werden nun sowohl meine Freunde, mit denen ich schon die Ehre habe in näherer Verbindung zu stehen, als alle diejenigen, welche mich noch mit gütigen Zuträgen zu meiner Sammlung erfreuen wollen, exsehen, was derselben noch abgeht; alles, was, darin noch fehlt, soll mir sehr willkommen seyn, und ich werde mich bestreben, den Werth solcher Beiträge durch ein Aequivalent aus meinem Vorrathe, nach dem Wunsche des Herra Mittheilers, nach Fíräften auszugleichen.

$\mathrm{Zu}$ diesem Zwocke habe ioh auch ein besonderes Vexzeichnifs meiner dermalen vorräthigen Insecten dem Catalog beigelegt, in welchem die Bedingnisse, unter welchen ich ferner zu tauschen geneigt bin, näher bestimmt sind. Alle in diesem Verzeichnisse bemerkte Insecten, unter welchen auch mehrere ausländische und seltene sind, stehen Liebhabern, die keine Gelegenheit zum tauschen haben, auch gegen baare Zahlung um die boigesetzten Preise zu Diensten.

Alle Anfragen und Anerbietungen mufs ich mir jedoch, so weit es seyn kann, portofrei erbitten.

Nürnberg, 1826

\section{Jacob Sturm,}

in der Tucherstrafse No. 1158 . 


\section{A btheilung.}

$\begin{array}{llllllll}M & a & m & m & a & l & \mathrm{i} & \boldsymbol{a} .\end{array}$.

II, Band. 



\section{Verzeich nifs}

d e r

$\begin{array}{llllllllll}\mathrm{S} & \ddot{a} & \mathrm{u} & \mathrm{g} & \mathrm{t} & \mathrm{h} & \mathbf{i} & \mathrm{e} & \mathrm{r} & \mathrm{e} .\end{array}$

$$
\text { Einleitung. }
$$

Der Beitrag zur Naturgeschichte der Säugethiere ${ }^{*}$ ), welcher in den nachfolgenden Zeilen enthalten, ist als ein Nachtrag zu Azara's Werk, Essais sur les quadrupèdes du Para. guay, anzusehen. - Ich werde hier die Thierarten aufzählen, welche ich bei einem beinahe zweijährigen Aufenthalte in Brasilien beobach-

*) Der zweite Band meiner Beiträge wïrde, wenn man der natürlichen Verwandtschaft der Thiere gefolgt wäre, die Aufzählung der Vögel haben geben müssen, alleir ich lasse diese Classe später folgen, da ihre Bearbeitung vieler Vergleichungen bedarf. 
tete, und die, wie schon oben gesagt, grölstentheils in jenem Werke aufgeführt sind. Die ron dem spanischen und anderen Schriftstellern richtig und hinlänglich beschriebenen Arten werde ich nur nennen und hier und da einige Bemerkungen hinzufügen. Zur genaueren Versinnlichung der von mir erwähnten Thierarten werde ich in meinen Abbildungen zur Naturgeschichte Brasilien's, Zeichnungen von vielen derselben bekannt machen. Manche von ihnen waren schon abgebildet, eine solche Verrielfältigung der Figuren kann aber nie schaden, sie führt immer zur genaueren Kenntnifs des Thieres, auch ist es interessant, Abbildungen ein und derselben Thierart aus verschiedenen Gegenden der Länder zu vergleichen. - Der Reisende im östlichen Brasilien, in gleicher Höhe mit Paraguay, konnte füglich Azara's Werk zum Grunde seiner Beubachtungen legen, da eine ziemliche Anzahl von Thierarten beiden Gegenden von Südamerica gemein sind. Wenn dieses Werk auch nicht frei von Tadel ist, so stützt es sich dennoch auf genaue, richtige Beobachtungen, diese sind zuverlässig, allein hier und da ohne gewisse Hauptzüge, ohne die nöthige Critik und Synonymie, woher denn, besonders bei den Vögeln, der oft gegründete 
Widerspruch und Tadel des Herrn Sonnini entsteht. -

Azara hatte die nöthige Mufse, alle seine Beobachtungen gehörig $\mathrm{zu}$ verfolgen und $\mathrm{zu}$ vervielfältigen, dagegen ist es dem reisenden Beobachter oft unmöglich, alle nöthigen Bemerkungen aufzuzeichnen, welche zu der vollständigen Beschreibung eines Gegenstandes gehören. Es scheint aber jener Schriftsteller die Thiere nicht hinlänglich in der freien Natur beobachte zu haben, sonst würde er mehr Verwandtschaft gefunden, und viele Arten nicht unnöthiger Weise getrennt haben.

Die erste und interessanteste Betrachtung, welche sich dem Beobachter bei einer allgemeinen Uebersicht der Thiere aufdrängt, ist ihre Verbreitung über unsere Erde, und es ist dieses ein weites fruchtbares Feld, welches reichhaltigen Stoff zu voluminösen Werken geben könnte. Herr Hofrath Hellwig hat noch unlängst aus 1 liger's hinterlassenen Schriften dessen Aufsatz über die Vertheilung der Säugthiere und Vögel bekannt gemacht, und dadurch einen interessanten Nachtrag zu den früher über diesen Gegenstand erschienenen Werken geliefert. Noch fehlt es uns an Materialien, um ein solches all 
gemeines Gemälde recht vollständig entwerfen zu können; allein es wird dieses mit der Zeit möglich werden, wenn die Reisenden genau auf die Vertheilung der Thierarten und die Gränzen, in welche ihr Wohnort eingeschlossen ist, Acht haben; ein Endzweck, den auch ich mir vorgesetzt hatte. Diejenigen Reisenden, welche die horizontalen Flächen verfolgen, werden die Gränzen für die Thiere in der Länge und Breite bestimmen, andere, welche die Höhen unserer Erde besteigen, müssen die Gradationen derselben für die verschiedenen Wohnplätze der Thiere aufzeichnen. Diesen Weg hat Herr $v$. Humbboldt zuerst auch für das Thierreich eröffnet. Für eine Abhandlung über die allgemeine Verbreitung aller Thierarten über unsere Erdoberfläche, ist der Raum und die Bestimmung dieser Blätter nicht geeignet; denn nur was auf Südamerica Bezug hat, und vorzugsweise die Naturgeschichte eines kleinen Theils von Brasilien, gehört zu dem Plane dieser Zeilen. Wer daher die allgemeine Vertheilung aller bekannten Säugthiere übersehen will, der suche sie in Illiger's Ueberblick nach ihrer Vertheilung über die Welttheile, dessen Vervollständigung und Fortsetzung den Zoologen zu empiehlen ist, so wie in andern Werken. 
Es herrscht unter den Säugthieren von Südamerica zum Theil eine ziemlich weite Verbreitung. Wir finden die meisten Arten über die ganze südliche Hälfte der neuen Welt ausgedehnt. Guiana, Paraguay und Brasilien haben sehr viele Arten mit einander gemein, nach Nordamerica hingegen finden wir nur wenige dieser Thierarten verbreitet. Nur den Cuguar (Felis concolor Linn.) kann ich hierher rechnen; denn wenn gleich der Aguarachay des Azara (Canis Azarae $\left.{ }^{*}\right)$ ) viel Aehnlichkeit mit dem Canis cinereo-argenteus von Nordamerica zeigt, so mufs man beide Thiere doch als verschiedene Arten betrachten. Eben so ist es mit dem nördlichen Waschbären (Procyon Lotor); auch dieser gleicht dem südlichen (Procyon cancrivorus) sehr, bildet aber dennoch gewils eine, von demselben verschiedene Art. -

Die Vögel erhielten, in Hinsicht ihrer Verbreitung, von der Natur weit mehr Freiheit, daher finden wir mehrere der brasilianischen Arten auch über Nordamerica verbreitet, ja einige derselben kommen selbst in Europa und in

*) In meinen Abbildungen zur Naturgeschichte Brasilien's, hat man unter die Figur dieses Fuchses aus Versehen Canis brasilicnsis gesetzt, welches abgeändert werden wird. 
Africa vor, welches aber doch meistens Wasseroder Sumpfrögel sind.

Die nördliche Küste von Südamerica, Guiana, hat mit den südlichen Provinzen am La Plata und Uruguay, mit Paraguay und Chili manche Thierarten gemein: hierhin gehören manche Gürtelthiere, die Hirsche des Azara, der Capybára, Aguti, die Unze (Yauarété), die rothe Unze (Felis concolor), der Tapeti (Lepus brasiliensis), der brasilianische Fuchs (Aguarachay Az.), die Cuatís (Nasua), der Tapir (Tapirus), die Fischotter (Lutra brasiliensis) und vielleicht mehrere Fledermäuse.

Die Abwechslung und Zunahme thierischer Formen in Südamerica, ist in der Breite grölser als in der Länge, wenn wir diese Ausdrücke in geographischer Bedeutung nehmen. Man wird in der Folge die Uebereinstimmung der ron Azara und der von mir aufgezählten Thierarten einsehen; von Süden nach Norden fortschreitend, fand ich hingegen an den von grofsen Flüssen gemachten Abschnitten gewöhnlich neue Thierarten. So findet $\operatorname{man}$ z. B. in den gebirgigen Waldungen der Gegend von Rio de Janeiro den rothen Sahui (Hapale Rosalia), der aber Cabo Frio nicht zu übersteigen scheint, eben so den Mico mit getheiltem Haarbusche 
auf der Stirn (Cebus fatuellus), der mir nicht weiter nördlich als bis zum Flusse Itabapuana vorgekommen ist; der Sauassu (Callithrix personatus) zeigte sich uns vom Itabapuana bis zum Rio Doçe, kommt aber, nach Herrn $v_{\text {* }}$ Spix, auch bei Rio de Janeiro vor; am Rio Doçe ward er sogleich von einem anderen, demselben sehr ähnlichen und verwandten Affen, dem Gigó (Callithrix melanochir), abgelös't; der Sahuï mit weifsem Gesichte (Hapale leucocephalus) lebt blofs in der Gegend des Fiusses Espirito Santo; der Sahuï mit weifsem Ohrbüschel (Hapale Jacchus) geht nicht weiter südlich, als bis über die Bahía de todos os Santos hinab, und der von mir bekannt gemachte und jetzt näher zu beschreibende schwarze Sahuï (Hapale chrysomelas) scheint im Sertong des Rio Pardo und des Ilhéos zu leben u. s. w. Es scheinen überhaupt die meisten Affenärten, besonders die kleineren, nicht besonders weit verbreitet, sondern der Zartheit ihres Naturells halber, nur auf sehr enge Gränzen eingeschlossen zu seyn.

Die Fledermäuse glaube ich zum Theil ebenfalls nur auf gewisse Gränzen eingeschränkt gefunden zu haben; jedoch ist die Beobachtung des Aufenthalts dieser lichtscheuen, fliegenden 
Thierarten, weiche sich so leicht dem Auge des Beobachters entziehen, weniger zuverlässig.

Die Raubthiere sind weit verbreitet, die Affen aber, wie gesagt, am regelmäfsigsten in gewisse Gränzen eingeschlossen.

Das gemeine Faulthier (Bradypus tridactylus) habe ich nur nördlich von den Flüssen Belmonte und Alcobaca gefunden, dagegen südlich überall das mit dem schwarzen Nacken (Brady. pus torquatus).

Weit rerbreitete Thierarten erleiden gewöhnlich verschiedene Abänderungen durch Clima und Aufenthalt. - Vom Yaguarété sagt man, wiewohl vielleicht ungegründet, er sey unter dem Aequator grölser und schöner gefärbt, als in den südlichen Provinzen; so der rothe Guariba, den ich bei Cabo Frio scheinbar dunkler gefärbt gefunden habe, als mehr nördlich, wo er recht rostroth ist. -

Die rveit verbreiteten Thierarten sind ferner mannichfaltigen Benennungen unterworfen, auf welche der Reisende ebenfalls aufmerksam seyn mufs. Die Aufnahme solcher Provinzialbenennungen in die Systeme, hat schon manche Irrthümer und Mifsverständnisse veranlafst, man sollte sie daher nie wählen. Linné nahm einige jener Benennungen in sein System auf, 
welche nach Marcgrave die Thierarten in der Provinz Pernambuco trugen. Sie sind sämmtlich aus der Lingoa Geral oder der Sprache derjenigen Urbewohner entlehnt, welche die ganze östliche Küste von S. Paulo bis Maranhào bewohnten. Sie zeigte aber dennoch mancherlei Abweichungen, auch galten diese Namen gewöhnlich in allen inneren Gegenden des Landes nicht, wo mancherlei andere Sprachen der $T a-$ puyas herrschten. Von oben erwähnter Art sind die Worte Tamandua, Tangara, Anacan, Tirica, Maracaná, Aracanga, Sayaca, Gui$\mathrm{ra}$, Taiaçú und viele andere, welche nicht gewählt werden dürfen, da sie zwar in den meisten Gegenden bekannt sind, aber in den verschiedenen Provinzen oft sehr verschiedenen Thierarten beigelegt werden. - Azara giebt seinen Thieren die Namen, welche sie in der GuaraniSprache tragen, die oft mit den brasilianischen übereinstimmen, oft aber barbarisch genug klingen. Solche sonderbare Wörter hat man in neueren französischen Systemen zum Theil häufig gefunden, und obgleich Buffon schon sehr geübt in Verdrehung der brasilianischen Wörter war, so hat man in neueren Zeiten doch weit mehr gefehlt, Provinzialbenennungen aufzunehmen, wozu aber die unendliche Menge der Ge- 
schlechter zwang, die man bildete, und für welche passende Benennungen $\mathrm{zu}$ finden, allerdings oft schwierig seyn mulste *). Dafś übrigens, wie schon gesagt, dergleichen Benennungen auf einem so ausgedehnten Raume, wie der der Lingoa Geral an der Ostküste von Brasilien **), sehr vielen Abänderungen unterworfen seyn müssen, ist natürlich, und ich will davon nur einige wenige Beispiele anführen. Der rothe Brüllaffe (Mycetes ursinus) heifst nördlich Guariba, südlicher Barbado, und noch weiter hinabwärts in der Gegend von S. Paulo: Bugio; die Gürtelthiere Pichi, Muletto, Peloso und Bola des Molina sind andere als das Pichiy, Muleto, Peloso und Bolita des Azara; der Madenfresser (Crotophaga Ani, Linn.) nach Marcgrave Ani, in der von mir bereis'ten Gegend Anní; Tanagra brasilia südlich Tisé, mehr nördlich Tapiranga, in Pernambuco Tijé-piranga; unter dem Namen Jabirí be-

*) So findet man z. B. in Vieillot's Naturgesclichte der nordamericanischen Vögel eine Tanagra, unter der Benemung Piranga, von den übrigen Arten getrennt, und dieses Wort bedeutet in der Lingoa Geral roth.

**) Die Lingoa Geral ward, mit einigen Ausnalmen, Jeinahe vom sidlichen IVenclekreise bis zum Aequator ver. standen. 
greift man bald Ciconia americana, bald Tantalus Loculator, bald Mycteria americana; Marcgrave's Ibiyau ist der Bacurau des mehr südlich gelegenen Theils der Ostküste, sein Anaca ist ein kleiner Papagey, während mehr südlich Psittacus severus diesen Namen trägt, sein Andira - açú ist vielleicht das Guandirá oder Jandirá der mehr südlichern Küste $u_{\text {, }}$ s, w.

Ich kehre nach dieser kleinen Abschweifung zu dem Satze zurück: je mehr nach dem Aequa. tor hin, desto mehr neue Thierarten findet man. Welche Menge von Quadrumanen fanden $v$. Humboldt und Spix in den unter dem Aequator gelegenen Provinzen des spanischen und portugiesischen America! in den Urwäldern an den Ufern des Rio das Almazonas, des Madaleina, des Orenoco und des Rio Negro! Sieber fand zu Cametá, obgleich er durchaus nicht in das Innere des Landes eindrang, und nur an der Mündung des Tocantins bei Pará sich aufhielt, mancherlei neue Thierarten, welche jetzt eine Zierde des zoologischen $\mathrm{Mu}$ seums zu Berlin sind. - Weit weniger Quadrumanen bemerkte ich in dem östlichen Brasilien in den Capitanías von Rio de Janeiro, Espirito Santo und von Bahí, und nach Azara ist Paraguay noch weit ärmer an solchen, nur 
für die gröfseste Wärme bestimmten Thieren, da er in seinem obengenannten Werke nur drei Arten von ihnen aufzählt. -

Ich werde 82 Arten von Säugthieren in dem nachfolgenden Verzeichnisse aufführen, wovon bei weitem die gröfsere Zahl Quadrumanen, Raubthiere und Insectenfresser, die weit kleinere aber Grasfresser oder Wiederkauer sind. Ich brauche nicht darauf aufnerksam zu machen, dafs dieses Verhältnifs der natürlichen Beschafferıheit des Landes ganz angemessen ist; denn in dem offenen waldlosen Afrika, und selbst in Indien, leben eine Menge ron Antilopen und Wiederkauern; in dem von unermelslichen Urwäldern beschatteten Brasilien aber würden diese keine angemessene Stätte finden, hier müssen besonders zahlreiche Affen die Bäume nach ihren Früchten besteigen, und wir finden sie gröfstentheils, so wie noch manche andere Thierarten, mit dem merkwürdigen, ganz $\mathrm{zu}$ der Lebensart auf Bäumen eingerichteten Organe, dem Wickel - und Greifschwanze versehen, der nur für die Wälder von Südamerica geschaffen scheint. Raubthiere finden ihre finsteren Schlupfwinkel in allen Welttheilen, in Wäldern, Haiden, Felsenklüften oder dornigen wilden Einöden, daher sînd auch diese in Bra- 
silien häufig. Manche Arten sind zahlreich an Individuen, besonders die Fledermäuse, mehrere Nager und Quadrumanen. Den ersteren ist eine reichhaltige Nahrung in den unzähligen Insecten dieser warmen Länder eröffnet, sie haben dabei zum Theil das Auszeichnende, Blutsauger zu seyn, wodurch sich besonders ihre zahlreichste Familie, die Blattnasen (Phyllostoma) auszeichnet. Azara hat diese Thiere zum Theil etwas unvollkommen beschrieben, dennoch sind seine Arten aufzufinden. Ich habe aber wenige der seinigen in Brasilien beobach. tet, ein Beweis für die grofse Mannichfaltigkeit dieser Thiere in Südamerica. Sie sind zum Theil höchst originell gebildet, wie z. B, die neue Art, welche ich in der Isis vorläufig bekannt gemacht habe; eine andere Species scheint durch die Bildung der Nase mit Rhinolophus verwandt, ist aber ungeschwänzt. Sie bewohnen die Felder, die Wälder und Steinklüfte, alte Urwaldstämme, so wie die offenen Gegenden und die menschlichen Wohnungen, ihrer habhaft zu werden, ist oft schwierig. Manche von ihnen sind mir gewils entgangen, doch können im Allgemeinen nur wenige Arten von Quadrupeden und unter diesen vorzüglich nur kleine uns unbekannt geblieben seyn, da alle übrigen 
von den Eingebornen gejagt werden und defshalb gekannt sind. -

Ich fand in den von mir bereis'ten Gegenden 6 bis 7 Arten von Katzen. Zahlreicher an Individuen als die Raubthiere, sind die Geschlechter der Gürtelthiere und Cavien (Dasypus, Tolypeutes, Cavia, Dasyprocta, Coelogenys und Hydrochoerus), sie stehen aber in dieser Hinsicht auch den Quadrumanen vielleicht noch nach. - Die Capybaras (Hydrochoerus Capibara) fand $v$. Humboldt am Orenoco und Apure in unglaublicher Menge, so häufig wurden diese Thiere in den von mir besuchten Flüssen des östlichen Brasilien's nicht angetroffen. Das Aguti (Dasyprocta Aguti) und der Paca (Coelogenys Paca) leben in Menge in den brasilianischen Wäldern. Von den Gürtelthieren habe ich nicht so viele Arten kennen gelernt, als Azara, dér uns zuerst mit Recht belehrte, dafs die Zahl der beweglichen Gürtel kein sicheres Merkmal für die Unterscheidung der Arten abgebe. Diese Thiere bewohnen die ebenen wie die gebirgigen Gegenden, besonders den sandigen Boden.

Affen, Katzen und kleine Raubthiere durchstreifen die Wälder; die Brüllaffen und andere Arten lassen ihre lauten Stimmen weit durch die 
einsame endlose Wildnifs der Urwälder ersch,allen, und das rauhe abgebrochene Brüllen des Yaguar, setzt bei nächtlicher Stille den einsamen Wanderer in Schrecken. Cavia. Arten bewohnen die Wälder, die Gebüsche und die Ufer der Flüsse, während diese selbst von Fischottern (Lontras) bevölkert werden. Hirsche und der Tapir bewohnen die Dickichte der Wälder, treten in der Dämmerung und an ruhigen Stellen selbst am Tage hervor, und nehmen in Waiden und grasreichen Plätzen ihre Nahrung. In den grofsen Wäldern ziehen ferner zahlreiche Heerden von wilden Nabelschweinen umher, und gewähren dem reisenden Jäger eine angenehme, oft reichliche Nahrung. - Endlich die grofsen Campos Geraës sind von den Rehen des Campo (Cervus campestris) oder dem Guazuti des Azara, von einer Menge von Ameisenfressern (Myrmecoplaga iubata, Linn.) bewohnt, welche den zahllosen Termiten nachstellen. Der grofse furchtsame Guará oder der rothe wilde Hund (Aguara-guazu, Az.) bellt oder heult in den langen Nächten. In diesen Gegenden ist es nicht wohl möglich, ein Gemälde von den Gradationen der Höhe zu geben, in welcher die Säugthiere leben, wie uns $v$ 1. lmboldt ein solches höchṣt interessantes Bild 
von den Cordilleren entworfen hat, wo sich, der grofsen Höhe der Gebirge wegen, verschiedene Grade der thierischen und vegetabilischen Schöpfung festsetzen lassen. Die Jahreszeiten scheinen auf die Vögel einen gröfseren Einflufs zu äufsern, als auf die Säugthiere. Der Stand und Aufenthaltsort der letzteren bleibt sich mehr gleich, jedoch nöthigen in der heifsen Zeit des Jahres unzählige Stechfliegen (Mutucas) die Arten der Hirsche, die Waldungen zu fliehen, Diels ist die Zeit des hohen Standes der Gewässer, alsdann soll man jene gepeinigten Thiere in grofser Menge im übergetretenen Wasser *) sich verbergen sehen, wo blofs der Kopf ihren Aufenthalt verräth. Diese traurige Zeit der Stechfliegen magert die Thiere ab, dazu kommt alsdann die Zeit des Abhaarens, welche zweimal im Jahre einzutreten scheint, nämlich am Ende der heifsen und am Ende der kalten Zeit. Andere Ursachen, welche in Brasilien die Wanderungen der Säugthiere herbeiführen können,

*) Diese Zeit der hohen Gewässer ist dem Menschen am wenigsten zuträglich. Es entstehen bei ihrem Hinwegfallen epidemische Fieber, von welchen am Rio S. Francisco und in anderen Gegenden oft viele Menschen, besonders Ausländer, hinweggerafft werden. 
entspringen aus der Nahrung. Gewisse Früchte reifen zu bestimmten Zeiten, entweder der Küste näher, im Sandboden, mehr an den Flulsufern, in den Sümpfen oder im Inneren der Wälder, und diese Localverschiedenheiten können kleine Bewegungen unter diesen Thieren hervorbringen; allein dieses Umherschweifen ist nicht mit dem Wandern der Vögel, selbst nicht mit dem Striche derselben in heilsen Ländern zu vergleichen, man kann daher im Allgemeinen annelimen, dafs sie ihren Standort nicht verlassen.

Wärme des ganzen Jahres und Gleichheit der Jahreszeiten, scheinen in allen heilsen Ländern eine geringere Regelmälsigkeit in der thierischen Oeconomie hervorzubringen, als in unseren gemälsigten und kalten Erdstrichen. Die meisten Thierarten bringen ihre Jungen mit der warmen Zeit zur.Welt, oder wenn diese heran naht, in den Monaten September, October, No vember, December und Januar. Die Jungen finden alsdann mehr Nahrung und angemessene Temperatur, sie sind dann in der Regenzeit schon stark genug, jenen Einwirkungen der Witterung $\mathrm{zu}$ widerstehen. - 
Ueber die Kronen der hohen Waldstämme hin zieht in flüchtigen Sprüngen eive Bande von Affen, wo jede Mutter ihr Junges sicher mit sich fortträgt, welches sich fest anklammert und hier Wärme und Schutz findet. -

Auf ähnliche Art, jedoch höchst verschieden durch seine Langsamkeit, zeigt sich auch das Faulthier mit seinen Jungen beladen. Beutelthiere verbergen die zarten Jungen in ihrem Beutel, dem sonderbaren, von der Natur ihnen zugetheilten Organe. Rattenarten bringen dieselben in die Erde, in hohle Bäume, alte Vogelnester; die Fledermäuse in hohle Stämme, Felsenklüfte und selbst in die menschlichen Wohnungen; die Cavien und Gürtelthiere in Gebüsche oder Erdhöhlen, wo sie nur zu oft der Raub grofser gefrälsiger Schlangen, so wie der Katzen und anderer Raubthiere wer. den. Oft stürzt bei den Affen und Faulthieren der Schufs des Jägers Mutter und Kind zugleich von einem Baume herab, der Pfeil des sicher zielenden Wilden durchbohrt oft beide zugleich. Ueberall erblicken wir unter allen Climaten und Zonen der Erde die bewundernswürdige Vollkommenheit der Natur, deren Erforschung die gröIsten, lebendigsten Genüsse gewälurt. Sie 
mufste so viel Anziehendes haben, damit die Beobachtung, besonders der lebenden Wesen, bis in's Unendliche vervielfältiget und damit sie, besonders bei der Entfernung und Unzugänglichkeit der übrigen Welttheile, auch in diesen, aller Beschwerden ungeachtet, von uns Europäern unternommen werde. - 


\section{$M a \dot{m} m a \cdot l \quad i \quad a$.}

O R D. I. P o l l $\begin{aligned} & i \\ & c\end{aligned}$ D a $u$ m e $n$ f $\ddot{u} f s$ e $r$.

Fam. I. Quadrumana.

$$
V i e r h \ddot{a} n d e r .
$$

Nach dem neven, yon dem leider zu frühe verstorbenen $\mathrm{Dr}$. Kuhl in seinen Beiträgen zur Zoologie und vergleichenden Anatomie aufgestellten Verzeichnisse der bis jetzt bekannten Quadrumanen oder affenartigen Thiere, deren Arten man in neueren Zeiten durch Reisen in die heifsen Zonen unserer Erde bedeutend vermehrt hat, finden wir in der alten Wrelt eine gröfsere Anzahl derselben als in der neuen, und 
beide Welttheile gewähren diesen Thieren nur einen beschränkten Wohnort, der in America zwischen den beiden Wendekreisen eingeschlossen, in Africa und Asien aber noch etwas weiter ausgedehnt ist, da er dieselben nördlich und südlich etwas überschreitet. Beide Welttheile, der alte sowohl als der neue, haben für diese Thiere gesvisse, scharf unterscheidende Characterzüge, von welchen die Natur nicht abge. wichen ist. Hierhin gehört die eigene Bildung der Nase, welche mehr von der Seite geöffnet ist, der Mangel der Backentaschen und Gesälsschwielen in der neuen, und der Mangel der Wickel- und Greifschwänze in der alten Welt. Die ungeschwänzten Affen, so wie die Paviane mit hundeartig vortretender Schnautze und furchtbarem Gebisse, sind ausschliefslich der alten Welt eigen. Eben daselbst befinden sich einige Affen, welche kaum eine Stimme von sich geben, wie der Pompo des Wurmb *), die meisten übrigen haben Kehlsäcke. Die der neuen Welt zeigen zum Theil sehr ausgebildete Stimmorgane, welche denen der Vögel gleichen, und die Brüllaffen (Mycetes, Stentor) besitzen

*) Der neuesten Beobachtung zufolge höchst wahrscheinlich S. Satyrus ult. 
eine ganz eigene, höchst.merkwürdige Stimmkapsel als Anhang des Zungenbeins, wodurch ihre Stimme bis zu einem seltenen Grade rerstïrkt wird. Diese sonderbaren Thiere sind aber auch noch ohnehin durch einen höchst kräftigen Greifschwanz und einen ganz besonders geformten pyramidalen Schädel ausgezeichnet.

Alle affenartigen Thiere der alten Welt haben vier vollkommene Hände, da hingegen in der neuen eine zahlreiche, übrigens den Affen sehr verwanảte Familie kleiner Thiere, die Sahuïs (Hapale, Jacchus, Midas), gefunden wird, deren Vorderhand unvollkommen ist, wodurch sie sich, wie auch überhaupt durch ihre ganze Lebensart, den Eichhörnchen (Sciurus) nähern. Ein anderes Geschiecht (Ateles) int durch einen unvollkommenen Daumen an der Vorderhand ausgezeichnet, eine Bildung, von der übrigens auch die alte Welt eine Probe aufzuweisen hat, indem der Daumen dem Colobus polycomos und ferrugineus ${ }^{*}$ ) fehit. -

*) Das IIuseum zu Leiden besitzt Colobus polycomos und forrugineus, der letzlere ist identisch init Colobus $T_{\text {chil- }}$ minckii $K$. Ich verdanke diese, so wie viele andere interessante Bemerkungen, der Güte des Herrn Dr. Boie zu Leiden. 


\section{- $25 \quad-$}

Ueberall in beiden Welten erkennt der Mensch in diesen merkwürdigen Thieren eine gewisse, seinem eigenen Geschlechte unangenehme Aehnlichkeit, die von einer verwandten Organisation erzeugit wird. Selbst in den äufseren Gesichtszügen und der Bildung des Kopfes findet man bei vielen Völkern der heirsen Erdtheile beider Welten, sowohl bei Botocuden als andern Südamericanern, desgleichen bei Buschmännern und andern Negern u. s. w. eine auffallende Verwandtschaft mit den Affen, welche unmöglich verkannt werden kann. Die Natur scheint hier von dem Menschen zu den niederen Ordnungen der Mammalien, durch die Affen sehr deutliche Uebergänge gebildet zu haben, deren nähere Beobachtung und Bestimmung den vergleichenden Anatomen gewils ein interessantes Feld des Nachforschens darbieten würde. -

Diese unangenehme Aehnlichkeit ist es, die in den Systemen der Naturforscher den Affen gewöhnlich den ersten Platz nach dem Menschen, oder die höchste Stufe in der Reihe der niedriger organisirten Wesen anweis't. Die Benennungen, welche die Quadrumanen in beiden Welttheilen tragen, sind der Beweis dieser übereinstimmenden Aehnlichkeit; de:n in Indien kennt der Malaie seinen Orang - Utang (Wald- 
mensch), und in America schwärmen Capuchi. nos (Capuciner), i iuditas (Wittwen), Barbados (alte bärtige Männer) und dergleichen umher. - So übereinstimmend aber solche Benennungen allen Welttheilen eine gewisse Aehn. lichkeit dieser Thiere mit dem Menschen anzeigen, so erleiden sie doch in verschiedenen Gegenden grofse Abänderungen und werden ganz verschiedenen Thieren beigelegt, man mufs daher in Anwendung derselben vorsichtig seyn. Ich werde zwei Arten von Micos erwähnen, den Cebus fatuellus und Cebus robustus, welche zu den grölseren Affen der neuen Welt gehören, während auch Simia argentata Linn. diesen Namen trägt. Die Benennung Titi wird, nach v. Humboldt und Azara, verschiedenen Arten beigelegt; am Orenoco trägt Simia sciurea Linn., zu Carthagena de las Indias, Simia Oedipus Linn. und in Paraguay Simia Jacchus Linn. diesen Namen.

Die Quadrumanen der neuen Welt sind uns jetzt schon in bedeutender Anzahl bekannt und noch manche andere, besonders der kleineren, wenig verbreiteten Arten, werden wir durch spätere Reisende kennen lernen. - Um die Kenntnifs der bis jetzt beschriebenen Specien machte sich besonders Herr Professor Genffroy 


\section{$-27-$}

in Paris, Herr v. Humboldt, der Graf von Hoffmannsegg und neuerdings Herr Dr. v. Spix verdient. Der letztere vermehrte unsere Kenntnisse von ihnen durch eine bedeutende Anzahl neuer Arten, und Herr $v$. Humboldt hat uns in seinen herrlichen Schilderungen des südlichen America's, einen in der That seltenen Schatz neuer Nachrichten über diese Familie mitgetheilt. Diese Thierarten machen in den südamericanischen Wäldern ohne Zweifel den gröfsten Theil der Säugthierbevölkerung aus; denn eine jede der mannichfaltigen Specien ist gewöhnlich zahireich an Individuen. Manche Arten sind weit verbreitet, besonders die Brüllaffen (Mycetes), die kleineren aber nur auf engere Gränzen von oft sehr geringer Ausdehnung eingeschlossen.

Für diese zahlreichen Thierarten scheinen gröIstentheils die mannichfaltigen Früchte bestimmt zu seyn, womit jene Urwälder im ewigen Wechsel der immer thätigen Natur wuchern, und die der rohe Naturmensch bei seiner geringen Anzahl in jenen weiten Wildnisser nicht hinlänglich zu benutzen vermag. Ihre ganze Organisation deutet auf den Aufenthalt in einem Lande von unermefslichen Urwäldern; denn die an Bäumen und Wäldern ärme- 
ren heifsen Länder der alten Welt, erlielten ungeschwänzte Affen in Menge, deren Arme oft sehr lang sind, lind defshalb mehr auf einen Aufenthalt an der Erde schliefsen lassen; sie haben nackte harthäutige GesäIsschwielen, welche ein häufiges Sitzen an der rauhen Erde bezeugen; ihre Backentaschen sind geeignet, einmal gefundene Früchte in denen von Wald entblöIsten Gegenden mit umher zu tragen, da hingegen die americanischen Affen höchst selten die Erde berühren, und defshalb mehr zum Klettern und $\mathrm{zu}$ der beständigen Lebensart auf Bäumen eingerichtet sind. Sie haben kürzere Arme, starke, inwendig beständig feuchte Hände, einen schlanken dünnen Körper mit muskulösen Gliedern, und viele einen höchst kräftigen, dick muskulösen, zum Festhalten ganz besonders geschickten Greif - oder Rollschwanz; sie sind sämmtlich äufserst geschickt im Klettern, und nur der höchste Nothfall kann sie zwingen, die Erde zu berühren. Den Mangel des Daumens bei einigen von ihnen, hat die Natur reichlich durch Länge und Stärke der übrigen Finger, so wie durch Länge der Glieder und den um desto kräftigeren Greifschwanz zu ersetzen gewu「st.

Die innere Organisation der Quadrumanen ist den Naturforschern ziemlich bekannt; denn 
aus allen Geschlechtern hat man Beispiele von ibnen, ja selbst die meisten der bekannten Arten untersucht, Von Humbold't beschrieb den merkwürdigen Stimmapparat der Brüllaffen ( $M Y$ cetes) und anderer kleinerer Arten; andere vielfältige anatomische Untersuchungen sind in den Schriften der Naturforscher zerstreut, doch gehört ihre Zusammenstellung nicht zu dem Zwecke, den ich mir hier vorgesetzt habe.

In der Nahrung und Fortpflanzung scheinen sich die Quadrumanen von America nicht von denen der alten Welt zu unterscheiden; denn sie sind sämmtlich Omnivoren wie der Mensch, indem sie vegetabilische und animalische Nahrung, besonders viele Insecten verzehren. Sie werfen, mit Ausnahme der kleinen Sahuïs ( $\mathrm{Ha}$ pale, Jacchus, Midas), sämmtlich nur ein Junges, welches sie mit sich auf den Bäumen umhertragen. Gewöhnlich gleichen diese jungen Aeffchen ihren Eltern in Bildung und Färbung; auch mufs ich bemerken, dafs ich im Allgemeinen unter den Quadrumanen sehr wenige Abweichungen oder Varietäten beobachtet habe und dafs ich daher die meisten, in den Cabinetten als solche angesehenen Individuen, für besondere Specien halte. Ein Beispiel hiervon geben die vielen Arten des Geschlechts 
Jacchus, welche Geoffrny im dem zoologischen Museo zu Lisboa fand, die beiden Arten der Micos, die ich beschreiben werde u.s. w. Besonders die ersteren haben im Allgremeinen eine gewisse, ihnen allen eigene Bildung und Färbung, und unterscheiden sich nur durch kleine Abweichungen; sie sind aber durch die Gränzen ihres Aufenthalts sehr genau von einander getrennt. Viele Zoologen stimmen ohne Zweifel in dieser Hinsicht meiner Ansicht nicht bei, auch ist es gewils, dals wir bis jetzt über diesen Gegenstand noch kein allgemeines $\mathrm{Ge}$ setz aufstellen können. Die meisten Reisenden sind nicht selbst Jäger und Beobachter der Natur, sie verlassen sich auf oft trügerische Nachrichten; auch ist es nöthig, obne Unterschied eine grofse Mengye von Thieren zu erlegen, wenn man über die Beständigkeit der Arten urtheilen will, und von den meisten Ländern der heifsen Erdtheile fehlt es uns bis jetzt noch gänzlich an solchen Beobachtungen. Einige Arten des Geschlechts Cebus mögen allerdings eine Ausnahme von der, von mir beobachteten Re. gel machen, hierhin gehören z. B. Cebus apella und capucina, allein ich kann über diese beiden Arten nicht reden, da sie mir in Brasilien nicht vorgekommen sind, und darf daher, meiner 
Erfahrung zufolge, diesen Satz nur auf die, von mir wirklich beobachteten und in den nachfolgenden Blättern erwähnten Arten anwenden. Herr $v$. Humbold $t$ bestätigt meinen Satz; denn nach dem Zeugnisse dieses ausgezeichneten Reisenden, sind die Arten der Affen auch im spanischen America sehr deutlich getrennt und variiren wenig.

Dr. Kuhl hat in seiner Monographie der Quadrumanen 64 Arten für die neue Welt aufgezählt. Ich habe ihm einige wenige derselben mitgetheilt, die bis jetzt noch nicht bekannt waren, und in den nachfolgenden Blättern werde ich diese genannten Specien ausführlicher beschreiben. Zu dem eben genannten Verzeichnisse mufs man nun noch die sehr beträchtlichen neuen Entdeckungen des Herrn $v$. Spix hinzufügen; denn von den 34 , in dessen Werk über die Affen beschriebenen Arten, sind 21 den Naturforschern noch unbekannt gewesen. Die Eintheilung der Quadrumanen des gelehrten Reisenden in Trichuri und Gymnuri scheint sehr zweckmälsig, doch kann man sie auch noch auf folgende Art eintheilen. - 
Sect. 1. Affen mit greifendem Schwanze.

A. Mit 6 Backenzühnen und unter der Spitze nacktem Schwanze.

\section{G. 1. $A t$ e l e s. Geoffr. \\ K I a m m e r a f f e *).}

Die Affen, welche Geoffroy mit der Benennung Ateles belegt hat, bevölkern einen grofsen Theil der undurchdringlichen Wälder von Brasilien. Schon kennen wir mehrere Arten von ihnen, deren nähere Bestimmung und Auseinandersetzung wir zuerst jenem ausgezeichneten Zoologen verdanken. - Dr. Kuhl hat in seinem neuen Verzeichnisse der Quadrumanen acht Arten von Klammeraffen unterschieden, von denen ich aber in den von mir bereis'ten

*) Um eine unnöthige Wiederholung zu vermeiden, werclen bei bekannten Geschlechtern die Kennzeichen derselben nie wiederholt werden. 


\section{$-33$}

Gegenden nur eine Art zu beobachten Gelegenheit hatte. Sie alle zeichnen sich durch einen kleinen Kopf, sehr lange dünne Glieder und einen besonders kräftigen, langen und muskulösen Greifschwanz aus. Ihr Kopf ist wenig erhaben und die Schnautze etwas vortretend, der Gesichtswinkel etwa von $60^{\circ}$. - Ihr Daumen der Vorderhand ist äufserlich zum Theil nicht sichtbar, zum Theil nur als kleines Rudiment. Das Gebifs dieser Affen ist schwach, d. h. ihre Eckzähne sind kurz, auch ist ihr Naturell höchst sanft, da hingegen die Arten des Geschlechts Cebus Geoffr. mit langen kegelförmigen Eckzäbnen versehen, und oft höchst zorniger und beifsiger Natur sind.

1. Ateles hypoxanthus.

$$
\mathrm{D} \text { e } \mathrm{r} \mathrm{M} \text { i r i k }
$$

K. Haar graugelblich, an der Schwanzwurerzel und in der Aftergegend oft röthlich rostgelb; Gesicht fleischfarbig, dunkelgrau punctirt.

Meine Reise nach Brasilien. B I. pag. 92.

Kuhl, Beitr. zur Zool., pag. 25.

Schinz, das Thierreich u. s. w., B, I. pag. 126.

Brachyteles macrotarsus Spix. pag. 36 . Tab. 27.

Abbildungen zur Naturgeschichte Brasilien's

Mono, Mirikt oder Murikt der Portugiesen im östlichen Brasilien.

Kupó, botocudisch.

Dieser Affe ist die gröfste Art der Quadrumanen, welche in den von mir bereis'ten Ge-

II. Band. 
genden von Brasilien gefunden werden. Er scheint bis jetzt noch nicht gekannt gewesen zu seyn, hat aber grofse Aehnlichkeit mit Geoffroy's Ateles arachnoides, dessen sehr gute Abbildung sich in den Annales du Muséum d'hist. nat. de Paris befindet, von dem er sich aber durch das Vorhandenseyn eines äufseren Daumenrudiments unterscheidet, welches jenem gänzlich fehlt.

Beschreibung: Der schwere Körper ist dick und stark, der Bauch ziemlich dick, der Kopf klein, der Hals kurz, Arme und Beine, besonders die ersteren, sehr lang und dünn, der Greifschwanz länger als der Körper, sehr stark und muskulös.

Der Kopf ist klein, hinten abgerundet, die Stirn ein wenig erhaben, die kurze Schnautze tritt etwas vor, daher ist das Gesicht unter den Augen stark concav; Queerrunzeln machen dasselbe häfslich, und geben dem Thiere das Ansehn eines alten grämlichen Mannes; sie stehen besonders um die Augen herum und an den Seiten des Gesichts.

Gebifs: Schn. $\frac{4}{4}$; Eckz. I.I. ; Backenz. $\frac{6 \cdot 6 \text {. }}{6 \cdot 60^{\circ}}$. Im Oberkiefer stehen vier breite kurze Schneidezähne, wovon die mittleren ein wenig stärker sind; im Unterkiefer vier, die mittleren ein we- 
nig kleiner; Eckzähne sämmtlich von den Schneidezähnen getrennt; die oberen durch eine grofse Lücke, in welche der untere Eckzahn pafst; sie sind breit, kurz, an der inneren Seite mit einem starken Ausschnitte und Rande versehen. Auf jeder Seite stehen in jedem Kiefer sechs Backenzähne; die drei ersteren im Oberkiefer haben an der äufseren Seite eine Kegelspitze, die zwei nachfolgenden haben daselbst zwei stumpfe Spitzen, und der letzte Zahn nur wieder eine; alle diese oberen Zähne haben an der inneren Seite einen doppelten erhöhten Rand oder zwei parallele erhöhte Leisten. Im Unterkiefer haben die beiden ersten auf den Eckzahn folgenden Backenzähne an der äufseren Seite eine einfache Spitze, an der inneren Seite aber einige Höcker; die drei letzten Zähne zeigen sowohl an der inneren als äufseren Seite zwei seichte stumpfe Spitzen oder Höcker. - Bei alten Thieren verschwinden die Spitzen der Zähne gänzlich, die Eckzähne sind abgeschliffen wie die Schneidezähne und nur an der Grölse zu unterscheiden; alle Mahlflächen sind schwarzbraun mit erhöhten weilsen Schmelzleisten.

Das Auge ist rund, die Iris an jungen Thieren graubraun, bei alten gelbbraun gefärbt. Die beiden Nasenlöcher bestehen, beinahe ohne 


\section{- $36-$}

alle Erhöhung, blofs in ein Paar eingedrückten Ritzen, welche auf der Oberseite der Schnautze in einem spitzigen Winkel gegen einander gestellt sind; daher erscheint die Nase wie eingedrückt. Das äufsere Ohr ist klein, rund, menschenähnlich und mit Haaren dicht bewachsen.

Der Hals ist kurz, daher scheint der Kopf in den Schultern zu stecken.

Die Hände der sehr langen dümen Arme haben vier dünne, schlanke Finger, mit gewölbten schwarzbraunen Kuppennägeln. Der Daumen besteht äufserlich nur aus einem sehr kurzen Gliede, von etwas weniger als $\frac{x}{6}$ der ganzen Handlänge ohne Nagel. Die Hinterhände sind stark und lang, mit einem vollkommenen langen Daumen. Der Schwanz ist sehr dick und stark, an der Spitze auf der Unterseite über $\frac{x}{3}$ der Länge nackt, und daselbst mit feuchter schwarzbrauner Haut bedeckt; auch an seiner Wurzel befindet sich auf der Unterseite eine nackte Stelle, die jedoch in der Mitte durch einen Längsstreif von Haaren getheilt wird.

Der Rumpf dieses Affen ist nicht schlank und angenehm gebildet; dern sein Bauch ist dick, etwas hängend, und der Rücken gewöhnlich ein wenig gewölbt; an der Brust befinden 
sich zwei Zitzen, welche an alten weiblichen Thieren oft über anderthalb Zoll lang sind.

Die Geschlechtstheile des Männchens sind grofs; die Ruthe ist zum Theil verborgen und durch einen Knochen unterstützt, in der Erection gleicht sie der des Pferdes, mit breiter Eichel. Das Weibchen hat am unteren Rande der Vulva eine Verlängerung (Clitoris), welche mit harten schwarzen Borsten bewachsen ist *).

Der Miriki ist am ganzen Körper behaart, selbst am Bauche; das Gesicht ist etwas herzförmig nackt, bei jungen Thieren schwarzbraun, bei alten in der Mitte fleischröthlich, am Rande dunkelgrau, und an der Gränze beider Farben dunkelgrau punctirt. Ueber dem Auge bemerkt man eine Reihe von einzelnen schwarzen aufrechtstehenden Borstenhaaren, gleich Augenbraunen. Die Gegend um eine jede Brust ist ebenfalls nackt, von schwärzlicher Farbe, aber die lange Brustwarze und ein kleiner, dieselbe umgebender Fleck, sind fleischfarben; selbst am männlichen Thiere ist die Gegend der Brüste unbehaart. Die Geschlechtstheile des Männ-

*) Dieser Theil stimmt ziem?ich überein mit der Abbildung, welche Daubenton von den weiblichen Geschlechtstheilesn des Ateles paniscus gegeben hat, 
chens sind nackt, selbst die Testikel, weirsröthlich, fleischroth durchschimmernd, und von ihnen zieht sich eine unbehaarte Stelle nach dem After bis zum Schwanze hinauf. -

An allen seinen oberen Theilen trägt der Miriki ein dichtes, etwas wolliges Haar, an den unteren ist es kürzer. Die Farbe dieses Affen wechselt etwas ab; gewöhnlich ist sie ein fahles gelbliches Grau, oft weifslich graugelb, am Schwanze und an den inneren Schenkeln mehr gelblich, besonders an der Schwanzwurzel und am After oft stark in's Gelbrothe oder Rostgelbe fallend; eine Färbung dieser Theile, die vielleicht durch die Excremente er. zeugt wird. - Am Rücken zieht die Farbe gewöhnुlich mehr in's Graue. Manche Individuen sind mehr fahl aschgrau gefärbt, andere mehr weifslich oder graugelblich. - Einige von ihnen haben einen blafs gelblichen, bei. nahe in's Vergoldete fallenden Schwanz.

Beide Geschlechter, so wie die neugebornen Jungen, zeigen in der Färbung keinen bedeutenden Unterschied, doch scheint es mir, dals der Pelz der weiblichen Thiere weniger gelblich fahl und dagegen mehr graulich gefärbt ist. 
Ausmessung eines starken männlichen Affen:

\section{Ganze Länge}

Länge des Körpers

Länge des Schwanzes (auf seiner Ober-

$$
\text { seite gemessen) . . . } 25^{\prime \prime} 7^{\prime \prime} \text {. }
$$

Länge des Arms vom Schultergelenk

\section{bis zur Fingerspitze - . $22^{\prime \prime}$}

Länge des Beins von dem Hüftgelenke 19" $10^{\prime \prime \prime}$. Länge der Vorderhand Länge der Hiuterhand Länge des Vorderdaumens . • • 11"'. Länge von der Nasenspitze bis zum oberen vorderen Ohrwinkel - $3^{\prime \prime} 9^{\prime \prime \prime}$. Ganze Höhe des äufseren Ohres • 1" $5^{\prime \prime \prime}$. Länge des oberen Eckzahns. - • $5^{\prime \prime \prime}$. Länge des unteren Eckzahns . $\quad 4^{\prime \prime \prime}$. Ausmessung eines weiblichen Affen:

Ganze Länge • • • . . 4 47"

Länge des Körpers • • • $20^{\prime \prime} 5^{\prime \prime \prime}$.

Länge des Schwanzes (oben gemessen) $28^{\prime \prime}$

Länge des Arms vom Schultergelenk 21" 5"'. Länge des Beins von der Hüfte • $20^{\prime \prime} 2^{\prime \prime \prime}$. Länge der Vorderhand . . . $\quad 6^{\prime \prime} 1^{\prime \prime \prime}$. Länge der Hinterhand . : . $\quad 6^{\prime \prime} 9^{\prime \prime \prime}$.

Länge von der Nasenspitze bis zum oberen Ohrwinkel . . . $3^{\prime \prime} 4 \frac{\mathrm{x}}{2}{ }^{\prime \prime \prime}$. 
Ganze Höhe des äufseren Ohres

Länge des Vorderdaumens

Länge des oberen Eckzahnes

$3^{\prime \prime \prime}$.

Länge des unteren Eckzahnes

Der verstümmelte Daumen der Vorderhände besteht aus zwei Knochengelenken, wovon das vordere nur halb so lang als das hintere, und dabei vorn an seinem Ende mit einer kleinen Biegung versehen ist.

Der Miriki durchstreift in Banden von sechs bis zwölf Stücken die grofsen hohen Urwälder der niedrigen, ebenen und daher feuchten Gegenden von Brasilien, in den höheren trockenen Regionen haben wir ihn wenigstens nie beobachtet, auch haben mir die Einwohner diese Bemerkung bestätiget. So lebt er z. B. nicht in den niederen Waldungen oder Catingas, die man in den höheren inneren Gegenden der Capitanias da Bahía und ron Minas Geraës findet, dagegen in den dunkeln Küstenwäldern, die sich bis zu den hohen inneren Gegenden ausdehnen, und zwar daselbst an manchen Stellen sehr häufig. Ich fand ihn zuerst in der Nachbarschaft des Cabo Frio etwas landeinwärts in der $\mathrm{Ge}$ gend von Campos Novos, ferner am Parahyba im Inneren, am nördlichen Ufer des Rio Doçe und am Flusse Belmontc ebenfalls auf dem 


\section{- 41}

nördlichen Ufer. Sonderbar ist es, dals man diese Thiere nicht überall, sondern nur an gewissen Stellen findet. So sucht man sie z. B. am Belmonte vergebens, wenn man nicht eine gewisse Gegend des nördlichen Ufers betritt, die der sogenannten Ilha grande (oder grofsen Insel) nahe gelegen ist und as Barreiras genannt wird. Hier sind diese Affen alsdann nicht selten, und streifen landeinwärts zuweilen in ziemlich zahlreichen Banden. Sehr häufig le. ben sie in den grofsen Wäldern der niederen Gegenden der Capitania da Bahia, z. B. an den Quellen und Ufern des Flusses 1lhéos, des Rio Pardo, wo sie indessen die Serra do Mundo Novo nicht überschreiten sollen. Spix fand diesen Affen südlich in der Capitanía von $S t$. Paul, ich kann daher seinen Aufenthalt, meinen Erfahrungen zufolge, zwischen den 25̃sten oder 24sten und etwa den 14ten Grad südlicher Breite setzen. - Sie sind harmlose Thiere, die in Gesellschaft ihrer Nahrung nachziehen, immer über die hohen Baumkronen hinwegeilen und die Früchte und Insecten aufsuchen, welche ihnen zur Nahrung angewiesen sind. Der grofse Körper dieser Affen ist schwer, seine Bewegungen mäfsig schnell, dennoch aber rascher als die der Brüllalfen 
(Mycetes); die Natur ersetzte ihm aber diesen Mangel an Behendigkeit durch die Länge der Glieder; denn mit seinen langen Armen greift der Miriki aufserordentlich weit, befestigt stets zuerst den starken langen Schweif und eilt auf diese Art so schnell durch die Gipfel der höchsten Urwaldstämme hinweg, dals der Jäger durchaus keine Zeit verlieren darf, wenn er einen Schuls anbringen will. Gesund kommen diese Thiere nie auf die Erde, es müfste denn der Jurst sie zu einem nahen Wasser treiben, welches aber gewifs selten geschieht. Sie suchen die Gipfel der Bäume nach Früchten ab, und sitzen auf hohen starken Aesten, um sich zu sonnen, wo sie sich auch wohl der Länge nach ausgestreckt niederlegen. Um ihren schweren Körper sicher auf den hohen schwankenden Zweigen zu befestigen, gebrauchcı sie, wie gesagt, beständig den starken Schweif, und selbst tödtlich verwundet, bleiben sie oft noch lange an dieser fünften Hand hängen, bis der Tod siegt, die schwere Last sausend die Luft durchschneidet und unter heftigem Geräusche den Boden erreicht.

Zur Nahrung liebt der Miriki mancherlei Arten von Früchten, man sagt besonders die Beeren des Tararanga, eines hohen Baumes, 


\section{$-43-$}

welcher Früchte wie Weintrauben trägt, aus deren Saft man ebenfalls ein angenehmes Getränk bereitet; ferner die Früchte des Jiquitibá, Maçaranduba, der Issara - Palme u. s. w. Die Jäger der brasilianischen Wälder behaupten, dieser Affe liebe sehr den Palmkohl (Palmito), und verberge, wenn er sich gesättigt habe, immer ein Stück dieser Substanz in der Ruthe. Da man mir diese Sache wiederholt versicherte, so ward ich aufmerksam, und fand nun wirklich in der Vorhaut eine bläulich weifse, etwas riechende, knorpelartige Masse, von fettiger, trockener, etwas talgartiger Substanz, welche eine Vorlage vor der Eichel bildete und mit einer Spitze in die Harnröhre eindrang, aus der sie ausgeflossen zu seyn schien; sie ist wahrscheinlich die Folge einer besonders starken $\mathrm{Ab}$ sonderung der Coronaldrüsen. Der Zufall hat mich verhindert, diese Substanz zu conserviren, es ist indefs gewils, dafs man diese Beobachtung an allen männlichen Affen dieser Art machen kann. - Diese Thiere fressen viel, man findet den Magen mit zerbissenen Früchten aller Art dicht ausgestopft, und der Bauch ist oft sehr dick davon aufgetrieben; auch fressen sie mancherlei Arten von Insecten, Spinnen und dergleichen Thiere. - 
Im August und September haben wir Junge unter ihnen gefunden, welche schon ziemlich stark waren. Die Mütter tragen dieselben unter dem Arme oder auf dem Rücken. - Zieht man diese Thierchen auf, so werden sie sehr zahm, allein sie sind sehr zärtlich und sterben gewölinlich bald.

Der Jäger, wenn er den Miriki sucht, durchspäht aufmerksam die Baumgipfel und hört auch auf seine Stimme, die ziemlich laut, dennoch aber weit unbedeutender ist, als die der Brüllaffen, Gigós, Sauassus und anderer Arten. Bemerken sie den Feind, so geht es schnell über die Zweige fort; sie werfen die langen Glieder, besonders die Arme und den Schwanz vorwärts, befestigen sich schnell sehr sicher, und schleudern alsdann den grofsen schweren Körper vorwärts; auch springen sie zuweilen, jedoch weniger als die anderen Affenarten. - Angeschossen lassen sie ihren Urin sogleich und schreien zuweilen wie ein Schwein. - Die Botocuden, welche sie mit ihren langen kräftigen Pfeilen erlegen, lieben ihr Fleisch sehr, welches man für etwas schwer und hitzig hält. - Sie sengen dieses Thier, so wie alle andern Quadrupeden, im Feuer, wo es alsdanu eine klägliche Aehnlichkeit mit einem Kinde er- 
hält. - Das Fell gebrauchen die Wilden als Zierrath, sie binden die Haut des Schwanzes um die Stirn, wo die blafsgelbliche Farbe von der Schwärze der Haare gehoben wird. Die Portugiesen machen davon Regenkappen für die Schlösser ihrer Gewehre. -

Ich habe in meinen Abbildungen zur Naturgeschichte Brasilien's eine, von mir selbst in den brasilianischen Wäldern nach der Natur entworfene Skizze dieses Affen mitgetheilt, welche ein solches uännliches Thier in der helleren Farbenvarietät darstellt, viele von ihnen sind etwas dunkler grau gefärbt. - Die Figur, welche Herr Professor Geoffroy in den Annalen des Pariser Museums von dem Ateles arachnoides gab, palst sehr treu in Gestalt und Farbe auf den hier von mir berührten Affen. - Die Spixische Figur scheint von der Gestalt der Atelen gänzlich abzuweichen, sie ist unter allen, in jenem schönen Werke gegebenen Abbildungen wohl die mangelhafteste.

$$
\text { G. 2. Mycetes. Illig. }
$$

$$
\text { B r ï } 11 \text { a } f f e \text {. }
$$

Die Brüllaffen, Aluaten oder Guaribas scheinen unter allen Geschlechtern der Quadrumanen am bestimmtesten von der Natur unter- 


\section{$-46$}

schieden und am auffallendsten characterisirt zu seyn. Sie sind ausschliefslich Südamerica eigen, und sowohl durch ihre von andern Geschlechtern abweichende Körperbildung, als auch durch ihr langsames träges Naturell von den übrigen Gliedern dieser grolien Familie und allen andern Säugthieren unterschieden. Der Kopf dieser Affen allein reicht hin, sie zu unterscheiden; denn nirgends zeigt sich ein so sonderbar gebildeter Schädel, dessen pyramidale Figur mit dem breiten grolsen Unterkiefer so auffallend contrastirt. Ihr Gesichtswinkel ist etwa von $60^{\circ}$; es ist aber besonders das merkwürdige Stimmorgan in der Kehle, welches diese Affen auszeichnet, und seinen Hauptschutz durch die vorhin genannte sonderbar breite Bildung des Unterkiefers erhält. Herr $v$. Humboldt hat in seinen Abhandlungen aus der Zoologie und vergleichenden Anatomie eine Beschreibung des Kehlapparats für die Art des Simia Seniculus gegeben, welche mit einigen Abweichungen auf alle Arten dieses sonderbaren Geschlechtes paIst. - Der Kehlkopt ( $L a$ $r y n x)$ dieser Thiere ist eine grolse, weite, knöcherne Kapsel, und das darüber befestigte Zungenbein (os hyoideum) ist eine grofse rundliche oder längliche, mit Scheidungen versehene 
Knochenblase, durch deren vereinte Wirkung die ungeheuer laute, weit schallende Stimme hervorgebracht wird.

$\mathrm{Zu}$ der langsamen sicheren Art, mit welcher sie die Bäume besteigen, hat ihnen die Natur noch einen kräftigen Greifschwanz gegeben, den sie beständig gebrauchen.

Unter allen Arten der Quadrumanen in Brasilien, scheinen die Brüllaffen die gemeinsten und am weitesten verbreitet zu seyn; denn sie leben so gut in den hohen, trockenen Gegenden und Catingas, als auch in den niederen, feuchten Küstenwäldern. - Geoffroy hat zuerst ihre bekannten Arten etwas vollständig aufgeführt, dennoch scheinen seine, im 19ten Bande der Annales du Muséum d'hist. natur. aufgestellten Arten vielleicht etwas vermindert werden zu müssen. Herr $v$. Humboldt hat auf seinen Reisen interessante Beiträge zu der Geschichte dieses Genus geliefert, und ein jeder Reisende, der jene grofsen Wälder durchstreift, wird einige Zusätze zu der Zahl der Kenntnisse machen, die wir davon besitzen, wenn er nur treu die von ihm beobachteten Thatsachen berichtet. - Dr. Kuhl endlich hat in seinem neuen Verzeichnisse der Quadrumanen sieben Arten von diesen Thieren angenom- 


\section{$-48$}

men, indem er die von Herrn Genffroy aufgestellten beibehielt und noch eine neue hinzufügte.

\section{M. ursinus Humb.}

Der rothe Guariba, Barbado.

B. Bart stark und dicht; Gesicht nackt und schwoürzlich; Unterleib diün behaart; Greifschwonz stark, unter der Spitze nackt; Pelz einfürbig rothbräunlich. -

Simia ursina, Alex, v. Humb. recieil etc. T. I. p. 329. Sientor ursinus Geoff.

IIycetes ursinus, Kuhl, Beitr. z. Zool. p. 29.

? Mycetes fuscus Spixii.

Abbildungen zur Naturgeschichte Brasilien's.

Barbado südlich in der Gegend von Cabo Frio, Rio de Janeiro und am Parahyba.

Guariba am Mucurt, Belmonte u. a. O.

Ruiva im Sertam von Bahia,

Bujio harbado in S. Paulo.

Cupilick bei den Botocuden.

Die Gestalt dieses Affen kommt im Allgemeinen mit der aller Brüllaffen überein; sie sind gestreckt, vorn stark, in der Dünnung schlank; ihre Glieder sind mälsig lang, und so wie der lange, unten an der Spitze nackte Greifschwanz proportionirt und muskulös. - Der Kopf ist dick, steckt in den Schultern, wird tief getragen und die Kehle ist ron dem Stimmapparate dick aufgetrieben. - 


\section{$-49$}

Der hier zu beschreibende Affe scheint, nach genauer Vergleichung, identisch mit $v$. Humboldt's Simia ursina, obgleich die Abbildung, welche dieser ausgezeichnete Naturforscher und Reisende davon gegeben hat, nicht ganz mit den von mir in Brasilien beobachteten Thieren übereinstimmt. Ich will den rothen brasilianischen Guariba beschreiben, beide Geschlechter, wie ich sie bei Cabo Frio und am Parahyba fand, und nachher einige critische Bemerkungen folgen lassen, -

Beschreibung: Der rothe Guariba oder Barbado gleicht in seiner Gestalt den übrigen Arten dieser Familie. Sein Kopf ist ziemlich dick, pyramidal, das Gesicht mälsig vortretend, mit einer nackten schwärzlichen Haut bedeckt; die Augen mit ihrer gelbbräunlichen Iris stehen auf der Vorderfläche desselben und sind rundlich; über ihnen stehen hoch oben, an der Gränze der Stirn, lange schwarze Augenwimpern. - Die Nasenlöcher sind weit geöffnet und rund; an der Oberlippe befinden sich lange schwarze Bartborsten; Ohren menschlich, schwarzbraun, ziemlich nackt, inwendig mit dünnen, gelbbräunlichen Haaren besetzt. -

Gebifs: Schn. $\frac{4}{4}$; Eckz. $\frac{1 \cdot 1 .}{\mathrm{x} \cdot \mathrm{I}} ;$; Backenz. $\frac{6 \cdot 6 .}{6 \cdot 60^{\circ}}$ MäIsig stark; die Zähne sind schwarzbraun geII. Band. 
färbt und nur ihre Kanten sind weifs abgeschliffen. - Eckzähne im Oberkiefer mạ̈sig stark, kegelförmig, breit, etwas über den Unterkiefer heraustretend, auf ihrer vorderen Seite mit einer Längsfurche bezeichnet, von dem ersten Bakkenzahne des Unterkiefers auf der inneren Seite ausgeschliffen; untere Eckzähne kleiner als die oberen; Schneidezähne im Oberkiefer vier, sie sind klein, stehen weit von den Eckzähnen entfernt, streben vorwärts; im Unterkiefer vier etwas cylinderförmige, kleine, ziemlich getrennte Schneidezäbne, wovon der äufserste den Eckzahn beinahe berïhrt*). - Backenzähne sechs auf jeder Seite jedes Kiefers; im Oberkiefer sind die drei ersten einspitzig an der äufseren Seite, die zwei folgenden mit mehreren Spitzen, der letzte ist klein; im Unterkiefer haben die drei ersten an der äufseren Seite eine Spitze, die nachfolgenden aber mehrere. -

Die Zunge ist schwarzbraun gefärbt. Der Hals ist kurz, daher steckt der Kopf in den Schultern. - Arme und Beine sind stark und proportionirt, eben so die vier Hände; sie ha-

*) Ein jüngeres Inrlivi łuum hatte fïnf Schneidezähne, wovon also einer ein Milchzahn war. 


\section{$-51-$}

ben an ihrer innern Fläche eine immer kalte, feuchte, nackte, schwärzliche Haut, und auch die etwas zusammengedrückten Nägel haben diese Farbe ; sie reichen etwa um $1 \frac{1}{2}$ Linie über die Fingerspitze hinaus, der Nagel des Daumens aber ist kurz, abgerundet und nicht länger als der Finger selbst. Die Nägel der Hinterhände sind mehr vortretend als die der vorderen. Der Schwanz ist etwas länger als der Körper, dick und stark, mit beinahe einen Zoll langen Haaren dicht bekleidet, sehr stark greifend und an der Spitzenhälfte auf der unteren Seite mit einer nackten, feuchten, kalten, schwarzbraunen Greiffläche versehen. -

Testikel und übrige Geschlechtstheile nackt und schwarzbraun gefärbt. - Z Zei Brustzizzen. - Das Haar der Stirn ist ziemlich kurz, sehr dicht, gleich lang wie eine Bürste, oder als wenn es geschoren wäre, nahe über die Augen herabsteigend; an den Seiten des Kopfs wird es zu einem langen Backenbart und dehnt sich unter dem Kinne in einen drei bis vier Zoll und darüber langen, dichten Bart aus, der dem Thier das Ansehen eines alten Capuziners giebt; das Haar auf dem Kopfe vom Wirbel an strebt vorwärts, das des Halses und des Körpers rück$4 *$ 
wärts. - Haar auf dem Rücken etwa 1 $\frac{\mathrm{r}}{2}$ Zoll lang, dicht und an der Wurzel ein wenig wollig; in den Seiten ist es länger und alle untern Theile sind dünn behaart, auch zeigt sich hier die graulich - fleischrothe Haut beinahe nackt, doch sind manche Individuen mehr behaart.

Alle oheren Theile des Körpers sind mit schwarzbraunen Haaren bedeckt, welche in der Mitte mit einer blassen, gelblichen Binde bezeichnet und mit gelbbraunen Spitzen versehen sind, wodurch die gelbbraune Farbe auf den oberen Theilen zu herrschen scheint, doch sticht das Dunkle durch. Die Arme und Beine fallen mehr in das Dunkelbraune, doch haben die Haare auch gelbliche Spitzen; Bart - und Backenhaare sind schwarzbraun, der erstere wird nach der Spitze hin immer schwärzer; der Schwanz, mit einer stark rothbraunen Mischung, erscheint mehr rostbraun oder roströthlich. - Je älter das männliche Thier ist, desto mehr fällt seine Farbe in's Rothbraune oder Rostrothe. - Jüngere Thiere sind immer mehr schwarzbrain und mit kürzerem Barte verseherı; Scheitel und Mittelrücken gelbroth gemischt, da die Haare dergleichen Spitzen haben; Seiten des Leibes, Kopf, Bart, Glieder und Schwanz glänzend schwarzbraun, indem hier die Haare an der Wurzel 
von dieser Farbe sind und nur dunklere Spitzen haben. -

Ein erwachsenes trächtiges Weibchen glich dem jungen Männchen, da es nur einen kurzen Bart hatte, und auch dieselben Farbenmischungen zeigte; nur ist der Rücken durch die Haarspitzen mehr gelbbraun, und der Schwanz völlig schwarzbraun bis zur Spitze, da er bei dem alten männlichen Thiere völlig röthlichbraun ist. - Der Kopf ist bei dem weiblichen Geschlechte weit kleiner, auch besonders die Stimmkapsel in der Kehle. -

Dieses ist die Beschreibung des Barbado von Cabo Frio und anderer südlicher Gegenden der Ostküste, der Serra dos Orgàos bei Rio de Janeiro, der Wälder am Parahyba u. s.w.; weiter nördlich, in den Gegenden von Porto Seguro, Belmonte, Ilhéos und dem Sertam von Bahia habe ich die Männchen mehr rostroth oder fuchsroth gefunden, ob ich gleich übrigens keine specifischen Unterschiede habe entdecken können, und alle Uebergänge in den Farben da $\sin { }^{*}$ ).

*) Es ist möglich, daIs znfällig nur ältere Thiere uns in die Hände fielen. 


\section{- $54-$}

Der alte rothe Guariba aus dem Sertam von Bahía ist durchaus glänzend rothbraun oder rostroth, Arme und Hände oft kaum merklich dunkler, der Bart aber mehr schwärzlich braun gefärbt; das Haar der Stirn strebt rückwärts, das des Scheitels vorwärts, vom Hinterkopf an fällt es rückwärts hinab, es zeigen sich daher am Kopfe zwei Wirbel; am Ober- und Unterkiefer stehen schwarze, mälsig lange Borstenhaare; der Bauch ist dünn behâart, auch die Glieder an ihrer inneren Seite mit sehr hell glänzend rostrothen Haaren dünn besetzt, Betrachtet man die Haare der oberen Theile genau, so zeigen sie in ihrer Mitte eine dunklere Stelle, ihre Spitze ist aber, so wie die Wurzel, wieder mehr gelbrothbraun; Stirn und Kopf sind besonders glänzend rothbraun, und das Haar des ganzen Körpers hat eịnen vorzüglich schönen Goldglanz.

Diese Thiere variiren nach dem Alter aus dem Kastanienbraunen oder schwärzlich Braunen mit gelblich fahlen Haarspitzen in's Rostrothe, doch sind, wie gesagt, jüngere Thiere und Weibchen immer mehr schwärzlich oder dunkelbraun gefärbt. -

Die jungen Männchen kann-man sogleich in früher Jugend von den jungen Weibchen un. 


\section{$-55-$}

terscheiden; denn ihr Kopf und Gesicht sind viel grölser und länger, bei dem Weibchen mehr rund; der Bart des letzteren steht vorwärts gerichtet und ist dünner und kleiner; beide sind in der frühesten Jugend dunkelbraun, allein die Haarspitzen des Männchens sind, besonders an Stirn und Scheitel, gelbroth, am Weibchen blafsgelblich. -

Ausmessung eines alten männlichen Guariba von Cabo Frio:

Ganze Länge von der Nasen - bis zur

Schwanzspitze • . • • $41^{\prime \prime} 8^{\prime \prime}$.

Länge des Körpers bis zu der unteren

Schwanzwurzel über dem After $20^{\prime \prime} 3^{\prime \prime \prime}$. Länge des Schwanzes . . . 21" $8^{\prime \prime \prime}$.

Länge des Arms von dem Schulterge-

lenke bis zur Spitze des Mittel-

fingers - . . . . $13^{\prime \prime} 6^{\prime \prime \prime}$.

Länge des Hinterbeins, auf dieselbe

Art gemessen . . . • • 14" $9^{\prime \prime \prime}$.

Länge vom Scheitel zwischen den Oh-

ren bis zu der Nasenspitze - $\quad 3^{\prime \prime} 3 \frac{\mathrm{r}}{3}{ }^{\prime \prime \prime}$.

Höhe des äulseren Ohres . . . 1" $5^{\prime \prime \prime}$.

Breite des Kopfs von einem Ohre zu

dem anderen . . . . . $3^{\prime \prime} 3^{\mathrm{I}}{ }^{\prime \prime}$.

Länge des Bartes . . . . . $2^{\prime \prime} 9^{\prime \prime \prime}$. 
Länge des oberen Eckzahnes - . $5 \frac{2}{3}{ }^{\prime \prime \prime}$. Länge des unteren Eckzahnes beinahe $5_{\frac{2}{3}}^{\prime \prime \prime}$. Peripherie des gefüllten Bauches an der dicksten Stelle . • . $16^{\prime \prime} 8^{\prime \prime \prime}$. Peripherie des Oberschenkels . . $6^{\prime \prime} 6^{\prime \prime \prime}$. Peripherie des Schwanzes (zwei Zoll vom Leibe entfernt) . . 4 " $2^{\prime \prime \prime}$. Peripherie des Schwanzes in seiner

Mitte . . . . . $2^{\prime \prime} 9 \frac{x}{2} "$. Peripherie des Leibes vor den Hüften $10^{\prime \prime} 7_{\frac{1}{2}}{ }^{\prime \prime \prime}$. Peripherie der Oberbrust unter den

Armen . . . . . 11" $5^{\prime \prime \prime}$.

Länge der Vorderhand längs des Mit-

telfingers gemessen . . . $3^{\prime \prime} 5 \frac{1}{2}{ }^{\prime \prime \prime}$. Länge der Hinterhand . • . $S^{\prime \prime} 10^{\prime \prime \prime}$.

Der Schädel des rothen Guariba zeigt mit denen der übrigen Brüllaffen die gröfste A€hnlichkeit. Ein Hauptkennzeichen, wodurch das männliche Thier sich von dem weiblichen auszeichnet, ist die GröIse der Stimmkapsel, die sich durch ihre Figur etwas von des Aluaten (Mycetes seniculus) unterscheidet, welche wir in Herrn $v$. Humboldt's zoologischen Abhandlungen abgebildet finden. Die Luftröhre des $M y$ cetes ursinus ist an ihrem oberen Ende auf der vorderen Seite durch einen colossalen Schildknorpel umgeben, welcher an seiner hinteren 
und oberen Seite nur durch Häute verschlossen wird; in dieser grofsen, etwas zusammengedrückten, 3 Zoll 3 Linien langen und etwa 2 Zoll breiten knöchernen Kapsel beschreibt die Luftröhre einen kleinen Bogen, und an dem genannten Schildknorpel ist durch eine starke Muskelhaut das knöcherne, hohle, nach vorn rundlich aufgeblasene Zungenbein befestiget, welches 2 Zoll 5 Linien lang und durch die beiden dünnen knöchernen Schenkel an den Häuten des Schildknorpels befestiget ist. - Ich würde dieses Organs weitläuftiger gedacht haben, wenn wir nicht von einem ausgezeichneten Anatomen, Hrn. Dr. v. Spix, eine weitläuftige Beschreibung desselben zu erwarten hätten. - Bei Mycetes seniculus sind diese Theile in der Hauptsache eben so gebildet, doch weicht nach der Abbildung des Hrn, v. Humboldt die Gestalt der beiden Knochenkapseln ein wenig ab.

Die Länge des Darmkanals vom Magen abwärts, beträgt bei einem alten männlichen Affen der von mir hier beschriebenen Species $10 \frac{r}{2}$ Fufs; der Zwölffingerdarm ist so weit ausgedehnt, dafs er einem zweiten Magen ähnlich wird *). - Diese Erweiterung war mit harten

*) Eine ähnliche Bildung hat Herr Dr. Boie zu Leiden an dem Magen des Scmnopithecus entellus gefunden: „Der 


\section{$-58-$}

unverdaulichen Ueberresten von Cocos - und Palmnüssen, Fruchtsteinen und dergleichen angefüllt, auch fand man den Magen mit ähnlichen zerbissenen Fı̈̈chten vollgepfropft. Die Leber ist in sechs Lappen getheilt, mit einer grofsen, schmalen, langen Gallenblase, von recht hellgrüner Farbe; das Herz ist klein und kurz. -

Dieser Affe scheint über den grölsten Theil von Südamerica verbreitet $z u$ seyn, wenn man die kleinen Abweichungen, welchen seine Färbung hier und da unterworfen scheint, mit Recht für Abartungen erklärt. Alsdann ist v. Humboldt's Araguato der Barbado oder Bujio barbado des südlichen Brasilien's, denn Mycetes fuscus Spixii scheint mir mit meinem ursinus ganz identisch, und also diese Affenart sehr, ja wohl am weitesten verbreitet. In Brasilien lebt er in mehr oder minder zahlreichen Gesellschaf-

Magen wird daselbst durch eine Einschnürung in zwei Säkke getheilt, von denen der untere sehr länglich ist und sich als unförmliche Erweiterung des duodenum darstellt; in der That aber findet sich trotz der Länge dieser darmförmigen Erweiterung der pylorus erst am Ende desselben, worauf ein gewöhnliches sehr düınes duodenum folgt."

Herr Dr. Roie macht ferner noch auf die Aehnlichkeit aufmerksam, welche diese durch den Bau ihrer Verdauungs. werkzeuge verwandten Thiere, auch durch ilıre Langsamkeit haben. 
ten, doch selten von mehr als fünf bis sechs Individuen, in allen grofsen aneinander hängenden. Wäldern. An der Ostküste bewohnt er die weiten hohen Urwälder und mehr im Innern die von der Hitze des Sommers ausgetrockneten $\mathrm{Ca}$ tingas oder Niederwaldungen. Man findet ihn schon südlich in der Capitania von S. Paulo, in der Serra dos Orgáos bei Rio de Janeiro und bei Cabo Frio; hier erlegten die Purís viele von ihnen in den grofsen Wäldern, welche die Ufer des Parahyba decken, am Belmonte, $1 l$. héos u. s. w. - In allen bewaldeten, von uns besuchten Gegenden lieferte uns das Fleisch dieser Thiere eine kräftige Nahrung. - Schon in der Gegend des Mucurí trägt er den Namen Guariba und ich habe von hier an nördlich besonders recht alte männliche Thiere erhalten. Man hat in den Schriften, besonders der früheren Naturforscher und mancher älterer Reisenden die abentheuerlichsten, abgeschmacktesten Nachrichten von diesen Thieren gegeben, deren Wiederholung und Widerlegung gleich unnütz seyn würde, Azara hat das Verdienst, die meisten dieser albernen Nachrichten schon gerügt zu haben, ich gehe also ohne Aufenthalt über alle diese Gegenstände hinweg. 


\section{- $60-$}

Der Guariba hat ein träges Naturell, klettert langsam, oft beinahe kriechend von Ast zu Ast, sitzt gewöhnlich gebückt mit auf die Brust. gestütztem Kopfe wie ein altes Männchen da und legt sich auch der Länge nach auf einen starken Ast nieder, um sich zu sonnen. - Gewöhnlich suchen diese Thiere die obersten dürren Gipfelzweige der höchsten Waldbäume zu ihrer Warte aus und man gewahrt sie alsdann oft schon aus weiter Ferne über der Laubmasse der Riesenstämme des Urwaldes hoch erhaben, wie ihr rostrothes Haar in der Sonne glänzt. - Die Männchen lassen alsdann ihre röchelnde oder mehr trommelnde, weit durch die einsame Wildnifs schallende Stimme hören, welche bald länger, bald kürzer gerade hin ausgehalten und zuweilen von Pausen und kurzen rauhen Tönen unterbrochen wird, etwa wie sie unser europäischer Edelhirsch in der Brunstzeit hören läIst, wenn er auf den Kampf schreit. - Nur das erwachsene männliche Thier brüllt so heftig, doch müssen auch die weiblichen eine starke Stimme haben, da ihr Kehlkopf ebenfalls eine ähnliche, obgleich weit geringer ausgedehnte Bildung hat. Der Jäger hört diese Stimme gern; denn er weifs, dafs ihm das Thier nicht leicht enigehen kann, sobald es seinen Aufenthaltsort 
verrathen hat. Wir haben dieses Brüllen der Guariba's zu allen Zeiten des Jahres und des Tages vernommen, doch hört man dasselbe allerdings häufiger in der heilsen Zeit, wo die heftigen Gewitter von ihren Regenströmen begleitet, die ganze tropische Natur zu erneutem Leben erfrischen. $\quad \boldsymbol{v}$. Humboldt giebt die Entfernung, in der das Brüllen der Araguatos gehört wird, auf 800 Toisen an (Voyage au nouv. cont. Vol. 11. p. 134), doch soll man dasselbe in der stillen Nacht weiter hören können; ich habe in Brasilien bei Nacht nie eine Stimme von diesen Thieren vernommen. - Nach dem Zeugnisse jenes ausgezeichneten Gelehrten sollen die Araguatos $\mathbf{z u}$ brüllen aufhören, wenn ein Weibchen sein Junges werfen wolle; jedoch dieses ist ohne Zweifel eine Fabel der Missionarien und Indier, welche überall den Reisenden wunderbare und nicht in der Natur begründete Dinge erzählen; dafs diese Affen indessen zu brüllen aufhören, wenn man sich ihnen nähert, einen Schuls in ihre Gesellschaft thut und wohl gar einen von ihnen tödtet oder verwundet, diefs liegt in der Natur der Sache. - Da gewöhnlich nur die alten Männchen brüllen, so ist es leicht zu erklären, wenn man sagte, es befinde sich bei einer jeden ihrer. 
Gesellschaften ein Vorsänger, der auch gewöhnlich seinen Posten zu oberst gewählt habe. -

Die Guariba's kommen nicht leicht auf die Erde und nur zuweilen sollen sie von derselben Gebrauch machen, um während der gröfsten Tageshitze zu trinken; Indianer haben mir indessen versichert, dafs sie dieselben über Flüsse haben schwimmen sëhen.

Die Nahrung der verschiedenen Affen dieses Geschlechts ist so mannichfaltig als die Zahl der Früchte selbst, welche in diesen Wäldern wachsen, daher haben wir, wie gesagt, ihre Mägen mit einem Brei von zerbissenen Früchten und Fruchtkernen mancherlei Art, besonders von verschiedenen kleinen Cocosnüssen angefüllt gefunden. Im Februar und März sind diese Thiere besonders fett, die Männchen hatten alsdann über der Stimmkapsel und selbst im Leibe eine grofse Menge sehr feinen gelben Fettes, welches meine Jäger mit Vortheil zum Einschmieren der Schlösser ihrer Jagdgewehre benutzten.

Die meisten Jungen unter diesen Affen habe ich im Januar, Februar und März gefunden. Das Weibchen trägt seine Nachkommenschaft auf dem Rücken oder unter dem Arme, und das Junge schlingt sich mit seinem Wickelschwanze sehr fest an die Mutter an, so klettert sie mit 
ihrer Bürde über die höchsten Aeste dahin, Man sagt, die Araguatos verliefsen zuweilen ihre Jungen, wenn sie verfolgt würden, welches aber $v$. Humboldt schon widerlegt; denn im Gegentheile, Gefahr erhöht die Sorge der Mutter und selbst tödtlich angeschossen, verlärst sie ihr Junges nicht. Man zieht diese jungen Thierchen auf, allein in einem gewissen Alter sterben sie gewöhnlich; denn dem Zustande der Freiheit entrissen, erreichen nur wenige ihr volles Wachsthum. Ich fand, dafs diese jungen Affen gewöhnlich viel Wasser tranken, welches übrigens die Indier als ihnen sehr nachtheilig ansahen. $\mathrm{Ob}$ die erwachsenen Thiere dieser Art ebenfalls so viel Wasser trinken, kann ich nicht beantworten; doch scheint es unwahrscheinlich und es ist mit ziemlicher Gewilsheit anzunehmen, dafs dieser heftige Durst der jungen Thiere durch die ihrer Natur nicht angemessene Nahrung entstand, da sie in ihrer zarten Jugend die Muttermilch gänzlich entbehren muIsten. Erreicht der Guariba im gezähmten Zustande sein vollkommnes Wachsthum, so wird er äufserst zutraulich, da diese Thiere ein überaus sanftes Naturell besitzen, wovon ich im Sertam von Bahia ein Beispiel gefunden habe. - Ich besals am $M u$ curi einen solchen noch sehr jungen Affen, der 
sogleich kläglich schrie, wenn ich mich nur einen Augenblick von ihm entfernte. Gezähmt sind diese Thiere unangenehm, sehr träge, traurig, grämlich, lästig durch ihre knarrend röchelnde Stimme, welche die Jungen auf eine unangenehme Art beständig hören lassen, und durch ihre grofse belästigende Zutraulichkeit. Ihre Hauptkunstfertigkeit ist das Klettern; denn wenn dieses gleich nicht besonders schnell von statten geht, so geschieht es desto sicherer; dabei spielt der starke Greifschwanz die Hauptrolle. - Ulloa erzählt und giebt sogar die Abbildung einer komischen Fabel, da「s nämlich die $\Lambda$ ffen, wenn sie von dem einen Ufer eines Flusses das andere erreichen wollen, einer an den andern sich anhaltend eine Kette bilden und sich schaukelnd auf diese Art hinüber zu werfen suchen. Solche Erzählungen passen jetzt schon nicht mehr in unsere aufgeklärte, besser mit der Natur der Thiere vertraute Zeit. - v. Humboldt selbst sagt, dafs der Araguato, um nach einem anderen Baume hinüber zu gelangen, sich an seinem Schwanze schaukele, es ist mir und meinen Jägern bei häufiger Beobachtung dieser Thiere nie etwas Aebnliches vorgekommen. - Von einem hohen Baume herab geschossen, befestigt sich der Guariba oft im Vor- 


\section{$-65-$}

beistreifen mit dieser fünften Hand, und mit dem Tode ringend bleibt er oft noch Stunden lang an diesem Schwanze befestiget hängen. Die Jäger müssen bei der grofsen Höhe der tropischen Bäume oft eine bedeutende Anzahl von Schüssen thun, ehe sie einen solchen Affen erlegen; denn bei den ersteren derselben kriechen sie in die höchste Spitze des Baumes, auf welchem sie sich befinden, und nur die langen $T a$ guaris oder brasilianischen Röhre, in welche man eine starke Ladung von schweren Schroten wirft, erreichen sie alsdann, unsere europäischen Doppelflinten verschwenden bei dergleichen Affenjagden gewöhnlich sehr viel Pulver und Blei. - Die Wilden schiefsen die Guariba's mit ihren langen Pfeilen und klettern oft auf einen nahen Baum, um sie besser erreichen zu können. - Verwundet lassen die Affen gewöhnlich ihren Urin oder ihre Excremente fallen. Dobrizhofer erzählt in seiner Geschichte der Abiponer, dafs die angeschossenen Affen ihre Hand auf die Wunde drückten, allein man wird nun wohl davon zurückgekommen seyn, diesen Thieren mehr als thierischen Verstand zuzutrauen.

Das Fleisch der Brüllaffen ist ziemlich wohlschmeckend und giebt besonders kräftige Brü-

II. Band. 
hen, welche man denen der übrigen Affen vorzieht, - Nach v. Humboldt bereitet man im spanischen America aus den Därmen des Araguato oder Guariba Saiten für die Guitarren oder Violas. -

$$
\text { 2. M. } n i g \text { er } K u h l \text {. }
$$

Der schwarze Guariba, oder schwarze Brüllaffe.

B. Bart stark; Gesicht nackt und schwärzlich; Unterleib nackt oder dïnn behaart; Haar etwas lang zund schlicht, bei dem Männchen am ganzen Oberkörper glänzend kohlschwarz, bei dem alten Weibchen fahl graugelblich gefärbt. -

Caraya, Azara Essais etc. Vol. II. pag. 208.

Sténto. niger, Geoffr. Ann。 d. Mus. T. XIX. p. 10.

Simia Caraya, Humb. Rec, d'obs, d. Zool, et d'anat. comp. T. I. p. 355.

Kuhl Beiträge zur Zool. S. 30.

Mycetes, barbatus Spix.

Abbildungen zur Naturgeschichte Brasilien's.

Guariba preto der Brasilianer.

Die Gestalt im Allgemeinen ist die des vorhin beschriebenen rothen Guariba, das Gesicht scheint ein wenig kürzer und an der Nase mehr aufgestülpt.

Beschreibung eines weiblichen Thieres.

Die Ohren sind menschlich, ziemlich klein, nackt, von der Farbe des Gesichts; nur am Rande an der hinteren Seite und in den innern Ver- 


\section{- $67-$}

tiefungen ein wenig mit dünnen gelblichen Wollhaaren besetzt; die Iris des Auges ist gelbbräunlich; das Gesicht nackt, matt schwärzlich gefärbt wie an der vorigen Art, nur in der Höhlung der Backen und um die Augen herum mit einzelnen blafsgelben, dünnen, kurzen Härchen besetzt; an beiden Lippen befinden sich Barthaare, sie sind dünn, schwarz, etwas gekräuselt und etwa $\frac{1}{2}$ bis $\frac{2}{3}$ Zoll lang; Augenwimpern gelblich mit schwarzen Spitzen; innerer Mund gebildet wie an der vorhergehenden Art; Eckzähne kegelförmig, stark, mälsig lang, die obern etwas rückwärts strebend. - Vorder - und Hinterhände an der innern Fläche mit nackter, feuchter, kalter, matt schwärzlicher Haut bedeckt; Nägel sämmtlich schmale, etwas zusam. mengedrückte Kuppennägel; Daumen der Vorderhände etwas lang, da er über das Wurzelgelenk des Zeigefingers etwas hinausreicht; Daumen der Hinterhände stärker als der der vorderen, eben so verhält es sich mit dem übrigen Theile der Hand. Schwanz länger als der Körper, stark, dick, sehr stark greifend, etwa $\frac{\tau}{3}$ seiner Länge unter der Spitze ist er nackt, mit matt schwarzer Haut, und einzelnen Querfalten in den Gelenken. An der Brust befinden sich zwei Zitzen dicht unter den Armen, mit lang aus- 
gedehnten Warzen, wie an der vorhergehenden Art. - Der weibliche Geschlechtstheil ist in beiden Arten ähnlich, ein hängender Beutel von fleischröthlicher Hant, in welchem an der hinteren Seite die Oeffnung sich befindet.

Das Haar der Stirn ist dicht und gedrängt wie an der vorhergehenden Art, kurz über den Augen vorstrebend; das Gesicht ist rundum dicht. und gleichartig von den Haaren des Pelzes eingeschlossen, unter dem Kinne in einen Bart verlängert, der hei dem Weibchen etwa 1 bis Zoll lang und etwas zugespitzt ist. - Haar am ganzen Leibe sanft, zart, lang und seidenartig, in den Seiten hinter dem Schulterblatte 3 Zoll lang, am Kopf ist es seidenartig dicht, an dex Einfassung des Gesichts, den Backen, Oberarmen und Bart lang und schön hell fahl seidenartig gelb; eben so sind die Glieder angenehm. blafs glänzend gelblich, besonders rein ist die Einfassung des Gesichts, der Bart und die vier Glieder gefärbt; auf der Stirn befindet sich ein kleiner schwärzlicher Haarwirbel; Scheitel blässer weifsgelblich gefärbt; am Hinterkopf fängt ein blasses Gelbgrau an, welches sich über den ganzen Rücken erstreckt, und zuweilen etwas graubräunlich überlaufen ist. - Der Schwanz ist, mit Ausnahme der nackten Greifstelle, dicht 
und gleichartig behaart, graugelblich mit einer kleinen Mischung von Röthlich überlaufen. Bauch behaart wie an dem rothen Guariba, von Farbe blafs graulichgelb, aber mehr gelblich als der Rücken, -

Das männliche Thier, wovon ich kein recht vollständiges Exemplar zurückbrachte und defshalb meine entworfene Beschreibung auch nicht hinlänglich vervollständigen kann, gleicht dem weiblichen in der Hauptbildung vollkom. men, mit dem Unterschiede, dafs hier alle Ab. weichungen vorkommen, welche die beiden Geschlechter des, früher beschriebenen rothen Guariba von einander unterscheiden, nämlich dals der Körperbau des Männchens stärker, sein Kopf dicker, die Kehle weit mehr ausgedehnt, der Bart weit länger und stärker, und die Farbe des ganzen Thiers nicht gelblichfahl, sondern, was merkwürdig ist, gänzlich glänzend kohlschwarz erscheint. - Das Gesicht ist schwärzlich. Ich gebe in meinen Abbildungen zur Naturgeschichte Brasilien's das männliche und das weibliche Thier, das erstere nach einer von mir entworfenen Zeichnung, das letztere nach einem recht alten, in meiner zoologischen Sammlung sich befindenden Exemplare. - 
Wir haben nun auch von Herrn Dr. $v$. Spix die Beschreibung dieser Affenart erhalten, der sie für neu hält und Mycetes barbatus nennt, worin ich aber nicht mit diesem gelehr. ten Reisenden übereinstimmen kann. Wenn ich die Art beobachte, wie Azara seine Thierbeschreibungen behandelte, so glaube ich unbedingt annehmen zu können, dafs dieser Schriftsteller in seinem Caraya den Mycetes barbatus Spixii beschrieb. - Die Figur, welche Herr Dr $v$. Spix von seinem grofsbärtigen Aluaten gab, ist des Steindruckes wegen in den Farben verfehlt, da sie nicht grâu gefärbt, sondern kohlschwarz wie die Natur seyn sollte, -

Ausmessung des beschriebenen weiblichen Affen.

Ganze Länge

Länge des Schwanzes

Länge des Kopfes

Länge des Arms bis zu dem Schulter-

$$
\text { gelenke }
$$

Länge des Beins bis zu der Hüfte $40^{\prime \prime} 2 \frac{2}{3} "$. 20 " $9 \frac{1}{2} "$. $4^{\prime \prime} 1^{\prime \prime \prime}$. Länge von der Nasenspitze bis zu dem oberen vorderen Ohrwinkel $14^{\prime \prime} 6^{\prime \prime \prime}$. $14^{\prime \prime} 6 \frac{\mathrm{r}}{2}{ }^{\prime \prime \prime}$.

Höhe des äufseren Ohres $2^{\prime \prime} 5 \frac{x}{2} "$.

Länge der Vorderhand . 
Länge des oberen Eckzahnes . $5^{\prime \prime \prime}$. Länge des unteren Eckzahnes . 4"'. Ich halte, wie gesagt, die hier erwähnte Affenart für den Caraya des Azara, da die Be. schreibung dieses Schriftstellers ziemlich mit der meinigen übereinstimmt. Die Thiere von $P a$. raguay sind grölstentheils über das innere Brasilien verbreitet, indem beide Länder etwa unter denselben Graden der Breite liegen und die Verschiedenheit der Thierarten hauptsächlich von Süden nach Norden in der Zunahme ist. - Das

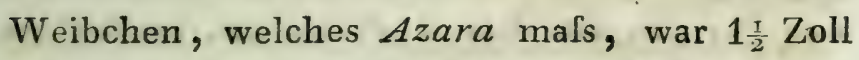
kürzer als das von mir beschriebene, er sagt, daIs die Länge des Schwanzes die Hälfte der Körperlänge ausmache, da hingegen bei dem von mir gemessenen Thiere der Schwanz beinahe um zwei Zoll länger war als der Körper, welches man, wie ich vermuthe, bei allen diesen Affen übereinstimmend finden wird, indem ein so kurzer Schwanz zum Festhalten an den Zweigen nicht geeignet seyn würde. - Uebrigens hat das von mir beschriebene weibliche Thier die Färbung derjenigen Individuen, welche Azara Albinos nennt, dieses sind aber wahrscheinlich recht alte Weibchen, die nichts mit den wahren Albinos gemein haben als den hellen fahlgraugelblichen Pelz. - 
Von dem Mycetes Beelzebul des Berliner Museums, oder Mycetes discolor Spixii, unterscheidet sich diese Art vollkommen, wie man in dem so eben erschienenen Werke dieses gelehrten Reisenden finden kann. Denn bei jenem ist auch das Weibchen schwarzbraun, aller der übrigen bedeutenden Verschiedenheiten und besonders der rothen Hände nicht zu gedenken.

Der schwarze Guariba lebt nicht an der Ostküste in den hohen feuchten Küstenwäldern, sondern in den höhern trockenen Gegenden, in $M i$ nas Geraës, am Rio S. Francisco, im Sertam der Capitanía da Bahía u.s.w., besonders in jenen trockenen niederen Waldungen, die man Catingas nennt. - Ihre Lebensart kommt mit der der rothen Guariba's überein, auch ähneln ihre Stimmen, die man besonders in warmen Regenperioden hören soll. - Sie leben in kleinen Gesellschaften und sonnen sich auf den höchsten Baumzweigen. Ihr Fleisch liebt man, wie das der rothen Art, allein ihr Fell wird besonders gesucht, zu Satteldecken, Mützen und dergleichen. - Im Sertam von Bahía kaufte man ein solches männliches Fell etwa für einen Gulden (Pataca). - Man stellt defshalb den männlichen Thieren sehr stark nach und es ist zuverlässig, dafs sie an vielen Orten im Sertam 


\section{$-73-$}

von Bahia defshalb jetzt schon selten geworden sind: -

B. Affen mit 6 Backenzähnen und einem unter der Spitze behaarten Rollschwanze.

$$
\text { G. 3. C e b u s. }
$$

Ro $1.1 \mathrm{~s} \mathrm{c} \mathrm{h} \mathrm{w} \mathrm{a} \mathrm{nz-A} \mathrm{f} \mathrm{f} \mathrm{e.}$

Die Affen dieses Geschlechts haben einen ziemlich runden Kopf, wenig vortretendes Untergesicht, lebhafte runde Augen, welche nahe bei einander stehen, menschenähnlich gebildete Ohren, proportionirte starke Glieder, einen schlanken Leib, muskulösen, dicken, durchaus stark behaarten und am Ende zum Festhalten geschickten Schwanz, welcher so lang oder länger ist als der Körper.

Sie gehören in Brasilien zu den zahlreich. sten Arten und ihre Gesellschaften machen einen grofsen Theil der Bevölkerung jener Wälder aus. - Sie sind nicht, wie die Klammeraffen und Aluaten, phlegmatisch und schwerfällig, sondern äufserst lebhaft, stets in Bewegung, gewandt, flüchtig und wenn sie entfliehen, so geschieht es unter den geschicktesten, weitesten Sprüngen. - Alle tragen ihren starken, muskulösen, völlig behaarten Schwanz, wenn er nicht 
gerade zum Festhalten gebraucht wird, in gewölbter Stellung und mit unterwärts eingerollter Spitze. - Die mit champignonförmiger Eichel versehene Ruthe des Männchens ist in beständiger Erection, welches bei den vorhergehenden Geschlechtern nicht der Fall ist. -

lhre Stimme ist ein sanftes vogelartiges Pfeifen, worin die verschiedenen Arten sich beinahe sämmtlich gleichen. Es besteht aus einem sanften, etwas tiefen, oft hintereinander wiederholten Pfiffe, auch geben sie in der Ruhe abwech. selnd Töne von sich, die dem Gezwitscher kleiner Vögel gleichen, im Affecte schreien sie sehr gellend, laut und unangenehm. - Bei den ruhigen sanften Locktönen spitzen sie, wie $A z a-$ ra sehr richtig bemerkt, den Mund, im Affecte aber zieht sich ihr Gesicht in mancherlei Falten. Im Zorne zerren sie den Mund in die Länge und entblöfsen etwas das Gebils. Ihre Nahrung besteht in Früchten aller Art und in Insecten, auch suchen sie während des ganzen Tages nach diesen Gegenständen umher. - Das Weibchen wirft ein Junges, welches ihm ähnlich ist *); auf

*) Dafs die jungen Affen ans dieser Familie schon bei der Geburt ihren Acltern gleichen, hat mir auch Herr Dr. boie zu Leiden, durch seine an Cebus apella und capucina 
dem Rücken oder unter dem Arme umher getragen und dabei sehr sorgsam behandelt, auch oft selbst gestraft und gezüchtigt wird. -

Da die Arten dieser Familie mehr oder weniger immer etwas Aehnlichkeit in ihrer Färbung, bei ganz ähnlicher Gestalt zeigen, so hat man viele von einander nur wenig abweichende Abänderungen beobachtet und war ungewils, ob sie blofs Abarten oder Specien seyen. - Besonders ein Paar dieser Affen, Cebus capucina und apella, waren immer etwas unbestimmt, und es bleibt den Reisenden aufbehalten, in dem Vaterlande dieser Thiere selbst Nachrichten über diesen Gegenstand einzusammeln. - Die beiden genannten Specien sind mir auf meiner Reise nie zu Gesicht gekommen, sie müssen also mehr im nördlichen und westlichen Brasilien, im spanischen America oder in Guiana zu Hause seyn. Dals die Affenarten in dem von mir bereis'ten Theile von Brasilien in der Regel wenig in der Färbung abändern, habe ich schon angemerkt,

gemachten Beobachtungen bestätiget. - Die besten der Natur entsprechenden, leider etwas zu kleinen Abbildungen der Affen, wo wenigstens die Gestalt nnd Stellung des Körpers sehr treu dargestellt ist, findet man in der schönen, von den Herren Geoffroy und Fr. Cuvier herausgegebenen Naturgeschichte der Säugthiere. 


\section{$-76-$}

daher sind die von mir beschriebenen oder aufgezählten Arten recht wohl unterschieden, und gar nicht zu verwechseln. - Ich denke defshalb, dals die hier nachfolgenden Bemerkungen zur Kenntnifs und Aufklärung dieser bisher zum Theil so verwickelten und unbestimmten Familie etwas beitragen mögen.

a. Rollschwanz-Affen

mit grofsen kegelförmigen Eckzähnen, welche allo übrigen Zähne an Länge weit übertreffen.

\section{C. $f$ a $t u$ e $l l u s$, Geoffr.}

Der gehörnte Mico*).

Ann, d. Mus. T. 19. pag. 109.

Kuhl Beiträge u. s. w. pag. 32.

Sajou cornu, Audeb. fam. 5. sect. 2. fig. 3.

Abbildungen zur Naturgeschichte Brasilien's.

Ṃico auch Kaité an dẹr Ostküste von Brasilien.

Beschreibung nach einem frischen Exemplare:

Grölse eines starken Katers, mit starken muskulösen Gliedern, rundem Kopfe und Ge-

*) Bei bekannten und hinlänglich festgestellten Thierarten habe ich die Diagnose weggelassen, um das Volum dieser Blạitter nicht unnöthig zu vermehren, 
sicht, starken kegelförmigen Eckzähnen, welche indessen von den Lippen bedeckt werden, die unteren stehen weiter heraus als die oberen. Gesicht um Augen und Nase herum nackt, dunkel schmutzig fleischbraun; Hände inwendig glatt und dunkel bräunlich, Nägel ziemlich menschenähnlich, der des Daumens abgerundet, die der übrigen Finger etwas mehr zugespitzt. Männliche Geschlechtstheile gebildet wie an dieser ganzen Familie, nackt, mit breiter, vorne abgeplatteter, champignonförmiger Eichel, dunkel bräunlich oder schwärzlich fleischroth, dabei in beständiger Erection. -

Backen und Seiten der Schläfe sind mit etwas dünnen weilsgelblichen feinen Haaren besetzt; Unterlippe dünn und kurz behaart; um das ganze Gesicht herum bilden glänzend schwarz: braune Haare einen Kranz; sie treten über der Nase tief herab, und bilden auf dem Scheitel einen getheilten Schopf, dessen beide Büschel 1 $\frac{\mathrm{r}}{2}$ Zoll lang sind, - In der Mitte zwischen beiden Theilen dieses Toupets ist das Haar kurz, aber auf dem ganzen Kopfe glänzend schwarz, auf dem Halse fängt es schon an bräunlich zu werden; Haar unter dem Kinn schwarzbraun; Kehle, Brust, Seiten des Halses, Bauch und Vordertheil der Oberarme gelbbräunlich, blofs 
mit dunkler braunen Haarspitzen; Haar des ganzen übrigen Körpers schwarzbraun, auf den oberen Theilen beinahe schwarz, überall mit hellgelblichen Haarspitzen. - Oberhände rein schwarzbraun, an den Fingern mit hellbräunlichen Haaren untermischt. - Schwanz länger als der Körper, stark, ziemlich dick, dabei sehr dicht behaart, selbst unter der Spitze, beinahe völlig schwarz; bei einigen Individuen sind die Haare unter der Schwanzspitze etwas abgenutzt, doch fehlte dieses bei jüngeren Thieren immer. - Innere Seite der Arme und Beine schwarzbraun, wie die äufsere. Haar am Rücken beinahe 3 Zoll lang und sehr dicht, am Bauche in der Mitte kurz und dünn. - Die Iris ist gelbbraun gefärbt. -

Weiblicher Affe: Gesicht nackt und dunkelgraubraun; die nackten inneren Hände hellgraubraun; die Vulva hat an ihrem vorderen oder unteren Theile eine drei bis vier Linien lange Verlängerung (Clitoris); die beiden Brustzitzen sind schwärzlich und lang ausgedehnt; Scheitel und Nacken schwärzlich braun; Schopf getheilt wie am männlichen Thier. Haar des Körpers etwas lang, struppig, hell gelblich graubraun, längs des Rückens hinab dunkler graubraun, eben so sind die Oberarme 
gefärbt; Schwanz an seiner Oberseite etwas schwärzlich braun, an den Seiten mehr röthlich und goldglänzend, besonders an der Wurzel; Unterarme schwärzlich braun; Hinterbeine dunkler gefärbt als die vorderen. - Der dunkle Scheitel und Hinterhals giebt diesem weiblichen Affen das Ansehen, als habe er eine Mütze auf; Seiten des Kopfs und Kinn sind gelbbräunlich; Bauch sparsam mit wenigen rostgelben Haaren bedeckt.

Abänderungen in der Farbe habe ich unter diesen Affen nicht bemerkt, daher kann ich der Vermuthung des Herrn $v$. Humboldt nicht beistimmen (Recueil de Zool. etc. T. I. pag. 324.), dals Simia fatuellus und apella vielleicht nur Abarten ton einander seyen. - Auch Dr. $v$. Spix glaubt dasselbe, dals nämlich apella ein fatuellus mit abgenutzten Stirnzöpfen sey; auch dieses kann ich nicht zugeben, da wir sehr viele Individuen der letzteren Species erlegt haben, wo sich aber beide Geschlechter immer mit star: ken Zöpfen am Kopfe zeigten.

\section{Ausmessung eines männlichen Affen:}

Länge von der Nasen- bis zur Schwanz-

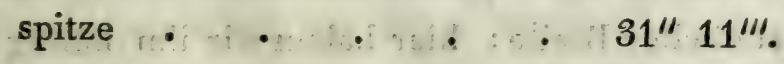

Länge des Körpers . . . . 15" $3^{\prime \prime \prime}$. 


\section{-80 -}

Länge des Schwanzes : : : $16^{\prime \prime} 8^{\prime \prime \prime}$

Länge des Arms vom Schultergelenk

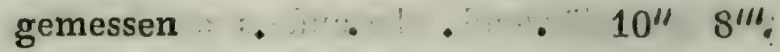

Länge des Beins von der Hüfte bis zu

der Spitze des Mittelfingers . $13^{\prime \prime} 6_{\frac{1}{2}}^{\prime \prime \prime}$ :

Länge von der Nasenspitze bis zu der

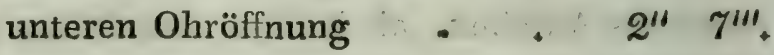

Höhe des äufseren Ohres - • $1^{\prime \prime} 5^{\prime \prime \prime}$.

Länge der Vorderhand längs des Mit-

telfingers - . . . $2^{\prime \prime} 7^{\prime \prime \prime}$.

Länge der Hinterhand . . . . $3^{\prime \prime} 6 \frac{x}{2}{ }^{\prime \prime \prime}$.

Länge des oberen, etwas rückwärts

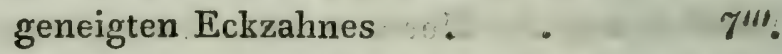

Länge des unteren starken Eckzahnes 6"'.

Ausmessung eines weiblichen Affen:

Ganze Länge des Thiers • • $28^{\prime \prime} 2^{\prime \prime \prime}$.

Länge des Körpers $\quad$ - : $\quad 12^{\prime \prime} 8^{\prime \prime \prime}$.

Länge des Schwanzes : ; : $15^{\prime \prime} 6^{\prime \prime \prime}$.

Der gehörnte Affe wird an der Ostküste von Brasilien, in der Gegend von Rio de Janeiro, in der Serra dos Orgãos u. a. grofsen Waldungen, bei Cabo Frio und bis zu den Flüssen Itabapuana und Itapemirim gefunden, also zwischen dem 23sten und dem 21sten Grade südlicher Breite; hier haben wir ihn häufig bemerkt, weiter nördlich aber keine Spur mehr 


\section{$-81-$}

von ihm gehabt, ich mufs indessen vermuthen, dafs er noch weiter südlich hinab gefunden werde. - In den grofsen Wäldern um Cabo Frio und an den mit Urwald bedeckten Ufern des Itabapuana, wurde er von unseren Jägern häufig erlegt.

Diese Thiere leben zuweilen einzeln, oder paarweise, gewöhnlich aber in kleinen Gesellschaften, steigen auf den Bäumen nach den Früchten umher und sind in beständiger Bewegung. - Ueberhaupt sind diese Affen höchst lebhaft, gewandt und schnell, in der Jugend besonders sehr komisch und gewöhnen sich leicht an ihren Herrn. - Ihre Stimme ist ein sanfter, oft wiederholter Pfiff und zuweilen ein kleines, den Vogelstimmen ähnliches Gezwitscher.

Bei der beständigen Aufmerksamkeit dieser Thiere ist es den Jägern oft nicht leicht, sie zu beschleichen, sie bewerkstelligen diefs gewöhnlich, indem sie mit dem Munde den Pfiff der Affen nachahmen. - Bemerkt die Gesellschaft den Feind, so entfliehen sie in weiten Sprüngen, selbst über die biegsamsten Zweige hinweg mit seltener Geschwindigkeit, und selbst mit Flinte sind sie alsdann leicht zu fehlen. - Das Fleisch, welches in der kalten Jahreszeit sehr II, Band. 
fett ist, wird gern gegessen. In der Gegend von Cabo Frio trägt dieser Affe den Namen Mico, in anderen Gegenden Kaité, auch belegt man ihn mit der allgemeinen Benennung Macaco (Affe). -

Die beste Abbildung eines männlichen Affen dieser Art befindet sich in Geoffroy's und Ir. Cuvier's Naturgeschichte der Säugthiere, doch ist sie auch nicht vollkommen, alle andern bis jetzt bekannten, besonders die des Audebert, sind sehr schlecht, -

$$
\begin{aligned}
& \text { 2. C. } r \circ b u s t u s \text {. } \\
& \mathrm{D} \text { e } \mathrm{r} \text { b } \mathrm{x} \text { a u n e M i c o. }
\end{aligned}
$$

$R_{v}$ : Kopf beinahe schwarz; Hände, Vorderarme und Glieder an der inneren Seite, so wie Schienbeine und Schwanz schwarzbraun; übrige Theile röthlich kastanienbraun.

Kuhl Beitr. z. Zool, u. s. w. pag. 35. *)

Schinz Thierreich u. s, w. pag. 131.

Abbildungen zur Naturgeschichte Brasilien's.

Mico an der Ostküste von Brasilien, auch Macaco.

Fieräng bei den Botocuden.

Dieser Affe scheint bis zu meiner Bekanntmachung mit dem fatuellus und einigen ande-

*) Es ist möglich, dafs die 7te Figur des Vosmaer den Affen dieser Beschreibung vorstellen soll, sie ist aber alsdann ziemlich unkénntlich. - Ganz wahrscheinlich ist es mir 


\section{$-83-$}

ren Arten verwechselt worden, oder vielleicht gänzlich unbekannt gewesen zu seyn. - Er gleicht dem vorhin beschriebenen in vielen Stücken, so dafs man ihn bei dem ersten Anblicke für mit demselben verwandt halten könnte, genauere Ansicht aber zeigt, dafs er etwas kleiner, von muskulöserem Gliederbaue, dickerem Kopfe und mehr breitem flachem Gesichte ist. Auf seinem Scheitel findet man gewöhnlich die Haare auch in einen oder ein Paar kleine Zöpfe verlängert, allein diese ersçheinen mehr als Haarwirbel, sind auch beständig unregelmälsiger und kleiner, dabei findet sich gewöhnlich auch nur einer derselben und sie haben ohnehin bei dem fatuellus gewöhnlich eine gröfsere Ausdehnung, indem dort ein jeder derselben oft die ganze Seite des Vorderkopfs einnimmt, hier aber oft nur auf dem Scheitel steht. Der Schwanz des robustus ist im Verhältnisse zu der Länge des Körpers kürzer, als der des fatuellus, der erstere Affe ist im Allgemeinen mehr röthlich braun, der letztere mehr schwärzlich braun gefärbt. -

hingegen, dafs ihn Herr Dr. v. Spix unter der Benennung des Cebus macrocephalus aufgefïhrt hat, allein nur die eigene Ansicht und Vergleichung der Exemplare kann bei Thieren entscheiden, die ohnehin in den verschiedenen Specien so viel Aehnlichkeit zeigen. 
Beschreibung eines alten männlichen Thiers:

Das Gesicht um Nase und Augen herum ist ziemlich nackt, auf Backen und Stirn treten die Haare weit hinein. - Ohren mittelmäfsig grofs, zugerundet, menschlich, ganzrandig, ziemlich nackt, inwendig mit etwas langen Haaren bewachsen. Die Zunge ist dick und fleischig, an ihrem oberen hinteren Ende stehen drei harte weifse, abgeplattete Warzen (papillae truncatae), an ihrer übrigen Oberfläche eine Menge kleinerer Wärzchen oder Papillen von verschiedener Grölse, sämmtlich aber sehr flach. - Unter der Zunge befindet sich ein kleiner Fleischfortsatz, der im Kleinen die äuIsere Gestalt einer Zunge hat *) -

Gebifs: Schn. $\frac{4}{4} ;$ Eckz. $\frac{\text { T. .r. }}{l_{0} x_{0}} ;$ Backenz. $\frac{6 \cdot 6 .}{6.6 .}$. Der Oberkiefer hat auf jeder Seite 6 ziemlich flache Backenzähne, welche nur an der äuIseren Seite eine stumpfe Erhöhung tragen, die hinteren sind kleiner; die 3 hinteren haben

*) Aehnliche Bildungen hat Herr Dr. Boie bei Stenops gracilis, den Tarsern und dem Galngo Demidoff gefunden, wo gleichsam drei gleichgeformte Zungen mit freier Spitze, die eine immer kleiner als die andere, unter ein. ander vorkommen. An den eben genaunten Kennzeichen würde man vielleicht die Identität oder Verschiedenheit des Cebus robustus und macrocephalus Spixii erkennen Lönnen, 


\section{$-85$}

ziemlich gleichartig eine schwache Erhöhung an jeder Seite und in ihrer Mitte einen seichten Ausschnitt. Im Unterkiefer sind die Backenzähne mehr flach, blofs mit einigen wenig erhöhten Leisten und Vertiefungen; der erste auf den Eckzahn folgende trägt eine etwas kegelförmige Erhöhung. - Die vier Schneidezähne sind vorwärts geneigt, ziemlich gleich, stumpf und nahe an einander gereiht; Eckzähne sehr lang und kegelförmig.

Auf dem dicken Kopfe befanden sich zwei Büschel von Haaren, ein unvollkommen getheiltes Toupet, welches aber bei den meisten Individuen nur eine kleine Haarspitze in der Mitte des Scheitels ist. Das Gesicht ist grau. lich-fleischbraun, die Iris gelbbraun gefärbt. Backenbart, Stirn und ganzer Kopf sind schwarzbraun; die vier Hände, Unterarme, unteres Schienbein und alle inneren Seiten der Glieder, so wie der dicht behaarte, muskulöse, stumpfe Schwanz glänzend schwarzbraun; alle übrigen Theile sind mit sanftem, ziemlich langem, glänzend röthlichbraunem oder kastanienbraunem Haare bedeckt; das Haar ist an der Wurzel graubraun, dann rothbraun und nach der Spitze hin in's Kastanienbraune übergehend; Bauch nur dünn behaart. - 
Die Ruthe des Männchens ist, wie an allen Affen dieses Geschlechts, mit vorn breit abgeplatteter, champignonartiger Eichel, sämmtliche äufsere Geschlechtstheile sind schwarzbraun und nackt.

Weibchen: Am Leibe stets heller, oft gelbröthlich gefärbt. Ein solches Thier, welches ich erhielt, hatte auf beiden Seiten die schwarzbraune Halsfarbe gelblichweils eingefalst, indem ein weifsgelblicher Strich rom Halse über beide Schulterblätter bis zu dem Achselgelenke herabzog, wo er sich verlor; diese Zeichnung scheint bei den weiblichen Affen dieses Geschlechts überhaupt häufig vorzukommen. -

Junges Thier: Völlig junge, neugeborne Thiere dieser Art, haben schon vollkommen die Zeichnung der Erwachsenen; der Kopf, an welchem die drei vorderen Hauptscheitelstücke noch sehr beweglich waren, hatte eine bedeutende GröIse. - Alt und Jung besitzen die beiden Schilddrüsen vorzüglich grofs. -

Der Schädel zeigt folgende Eigenheiten: Die Augenhöhle ist grofs, nicht so rund als am Miriki (Ateles hypoxanthus), die Oeffnung im Jochbogen, welche sich bei dem letzteren findet, fehlt, auch fällt der Schädel über den Augenhöhlen ziemlich flach $a b$, und der Joch- 
bogen ist mälsig heraustretend, wahrscheinlich mehr als am fatuellus, von dem ich den Schädel zur Vergleichung nicht besafs. - Die crista war nicht so stark ausgedrückt, als an Cebus macrocephalus Spixii.

\section{Ausmessung eines alten männlichen Affen:}

Ganze Länge

Länge des Körpers

Länge des Schwanzes $\cdot \dot{ } \cdot \dot{0}$.

fläche gemessen

Länge der Hinterhand auf der Sohle

\section{gemessen}

Länge des oberen Eckzahnes .

Länge des unteren Eckzahnes

81 " $10^{\prime \prime \prime}$. $15^{\prime \prime} 11^{\prime \prime \prime}$. $15^{\prime \prime} 11^{\prime \prime \prime}$. $3^{\prime \prime} 1 \frac{1}{2}{ }^{\prime \prime \prime}$. $3^{\prime \prime} 3 \frac{x}{2} "$. 7'il. $6 \frac{x}{3}^{\prime \prime \prime}$

Diese Affenart scheint, wie schon gesagt, mit dem fatuellus und andern bis jetzt verwechselt worden zu seyn, oder sie ist noch gar nicht bekannt gewesen. Wenn man vom Flusse Itapemirim der Ostküste von Brasilien weiter nördlich folgt und wegen der Gefahr vor feindseligen Wildenstämmen, am Rio Doçe die Producte der Wälder nicht gehörig kennen gelernt hat, so wird man am Mucurí und S. Matthaeus sich zu entschädigen suchen und daselbst diesen Affen finden, der dem vorhin beschriebenen in 
vielen Stücken gleicht, den man auch anfäng ich für eine Abart desselben aufnehmen, bald aber unterscheiden lernen wird. -

Von den Urwäldern an, welche die Ufer des Mucurí beschatten, bis in die Wildnisse am Flusse Belmonte, habe ich diese Art beobachtet Dort südlich erlegten wir ihrer viele in den die Lagoa d'Arara einschliefsenden bergigen Wäldern, am Alcobaça wurde er von meinen Jägern in der Nähe der Fazenda von Ponte do Gentio erlegt und am Belmonte belebten seine Gesellschaften, in Verbindung mit der nachfolgenden Art, die schattenreichen Dickichte. Ich kann dem Gesagten zufolge annehmen, dafs diese Affenart den Strich der Ostküste zwischen $13^{\circ}$ und $19 \frac{1}{2}^{\circ}$ südlicher Breite bewohne, doch kann sie vielleicht noch etwas mehr nördlich hinaufgehen. In Lebensart und Manieren hat der hier beschriebene Affe grofse Aehnlichkeit mit dem vorhergehenden, daher gilt das dort Gesagte auch für ihn. - Die Stimme ist in der Hauptsache dieselbe, wenigstens klingt der Pfiff bei beiden Arten sehr ähnlich, doch ist der eigentliche Lockton verschieden. - Diese Affen sind muntere Thiere, werden sehr zutraulich und unterhalten, besonders so lange sie jung sind, durch tausend Possen und Sprünge, 
dabei sind sie unruhig und in beständiger $\mathrm{Be}$ wegung, tragen die Schwanzspitze abwärts eingerollt und lassen häufig ihren sanften Pfiff, oder ihr vogelartiges Gezwitscher hören. Junge Affen besitzen schon die Stimme der Alten. Haben sie gezähmt einmal die zarte Jugend überstanden, so sind sie nachher sehr leicht $\mathrm{zu}$ erhalten und nehmen mit allen Nahrungsmitteln fürlieb. - Die Indier, Neger und selbst die Portugiesen, besonders die Weiber, verstehen sie recht gut aufzuziehen, welches uns Reisenden nie glücken wollte. -

Im Monat März fanden wir diese Affen schon sehr fett, überhaupt ist die kalte Jahreszeit der Zeitpunct, wo dort alle Thiere fett werden. - Bei dem Mangel des Oels in jenen grolsen, feuchten Wäldern, bedienten sich meine Jäger mit Vortheil dieses gelben Fettes, um unsere Gewehrschlösser damit einzuschmieren, weil es nicht leicht gerinnt. - Einige Indier am Mucurí und Belmonte haben mir versichert, dals es von dieser Affenart eine stets grölsere Abart gebe, allein es ist wahrscheinlich, dafs sie damit den vorhin beschriebenen Mico oder Kaité meinten. Jagd und Benutzung ist bei dieser Art wie bei der vorhergehenden, sie machen die Lieblingsnahrung der Wilden aus, 
welche ihnen eifrig nachstellen, und sie mit ihren langen Pfeilen und kräftigen Bogen recht sicher aus den höchsten Bäumen herab zu schiefsen wissen. -

3. C. xanthosternos.

D e r g e l b br üstige. Affe.

R. Scheitel, Nacken, Backenbart und Schwanz schwvarz; Arme und Beine mit schwarzbraunen gelblich bespitzten Haaren; Erust und Oberarme röthlichgelb; Rücken braun; Vorderhals und Bauch gelbrothbraun.

Abbildungen zur Naturgeschichte Brasilien's.

Kuhl Beitr, z. Zool. p. 35.

Schinz Thierreich, B. I: p. 130.

Macaco de bando oder Macaco branco am Flusse Belmonte.

Macaco de bando oder verdadeiro im Sertam von 11 héos.

Hieräng bei den Botocuden.

Diese Art hat nun wieder viel Aehnlichkeit mit der vorhergehenden, ist aber dennoch gewils verschieden. In der Gestalt gleichen sich beide und manche Individuen selbst in ihrer Färbung; allein man findet bleibende Unterscheidungskennzeichen. - Der Schwanz ist an dieser Art länger als an den beiden vorhergehenden, die Stirn scheint höher, das Gesicht ist breiter und der Kopf im Allgemeinen weniger hoch und mehr 


\section{$-91$}

breit; die Glieder sind stark und muskulös, dick behaart, der Schwanz des gelbbrüstigen Affen aber ist länger als der Körper.

Beschreibung eines erwachsenen männlichen Affen.

Der Kopf ist dick, breit, die Schnauze wenig vortretend, mit weit von einander entfernten Nasenlöchern, hoch erhabener Stirn, oben auf dem Scheitel mit dichtem ziemlich kurzem und weichem Haare, welches in der Mitte durch eine Scheidung ein wenig getheilt ist und daher zwei etwas erhabene Toupets bildet. - Gesicht sehr breit, nackt, an Nase und Lippen ein wenig mit sehr kleinen grauen Härchen sparsam bewachsen; Ohren menschenähnlich, mit gelben Haaren dünn bewachsen. -

Gebifs: Schn. $\frac{4}{4} ;$ Eckz. $\frac{\text { I. . . }}{\text { I.1. }}$; Backenz. $\frac{6.6 .}{6.6 .}$ Sehr starke kegelförmige Eckzähne; die vier oberen Schneidezähne sind stumpf, breit, die äufseren kleiner; im Unterkiefer befinden sich vier Schneidezähne, wovon die beiden mittleren etwas schmäler sind. - Backenzähne gebildet wie an der vorhergehenden Art. -

Die Glieder sind sämmtlich muskulös und stark, wie bei der vorhergehenden Art, vorzüglich die Schenkel; der Schwanz ist etwas dünner 
und weniger muskulös als an den beiden vorhergehenden Arten, im Verhältnisse zu dem Körper ist er länger und sehr dicht behaart. -

Männliche Geschlechtstheile gebildet wie an den vorhergehenden Arten, und mit schwarzen Haaren bedeckt, nur unten an den Testikeln etwas nackt.

Die Iris des Auges ist gelbbraun gefärbt, das nackte Gesicht grauröthlich-fleischbraun; nahe über den Augen fängt das Kopfhaar an; das Gesicht ist an Schläfen, Backen, Stirn und ganzen Seiten von einem Streifen silbergrauer Haare eingefalst, hinter welchem $\mathrm{zu}$ beiden Seiten des Kopfs von den Ohren herab, über die Backen bis unter das Kinn, ein dichter schwarzbrauner Backenbart oder Backenstreif von etwas langen Haaren sich befindet, von welchem sich oben nach dem Scheitel hinauf oft graugelblich fahle Haare zeigen, welche schwärzliche Spitzen haben. - Auf diesen Backenbart folgt an Brust und Oberarmen bis an die Seiten des Halses hinauf, eine angenehm röthlichgelbe Zeichnung, ohne alle Beimischung anderer Haare. - Am ganzen Bauche herrscht ebenfalls diese Farbe, sie fällt aber hier mehr in's Röthlichbraune oder Rostgelbe. Alle oberen Theile sind mehr oder weniger ka- 


\section{$-93-$}

stanienbraun, und von dieser Farbe des Oberhalses läuft über den Kopf ein Streifen nach der Stirn herab; die Seiten des Hinterkörpers sind röthlich-gelbbraun; oft ist der Rücken dunkelbraun, mit kastanienbraunen Haarspitzen; Hinterschenkel und Schwanzwurzel sind kastanienbraun mit langen schwarzbraunen Haarspitzen; Schwanz, Vorderarme, Hände und untere Hälfte der Beine sind glänzend schwarzbraun. - Diese Farben variiren öfters etwas, indem man manche Individuen findet, wo die gelbe Brust weniger rein und deutlich und alle Farben mehr verloschen sind. -

Bei jungen Thieren sind die Farben regelmälsig abgesetzt; Stirn und Scheitel blals graugelblich, Kehle, Seiten - und Unterhals, Brust, Schultern und Oberarme an ihrer Wurzel hell schmutzig gelblich, der ganze übrige Körper schwarzbraun und nur der hell röthlichbraune Fleck in den Seiten ist angedeutet; Bauch röthlichbraun; das Toupet auf dem Kopfe fehlt noch. - Andere junge Thiere haben die gelbe Brustfarbe 'mehr weifslich, selbst der Kopf ist bei ihnen sehr in's Weifsliche fallend, das Gesicht hell schmutzig fleischbraun. Eine ähnliche Varietät scheint mir der Cebus xanthocephalus Spixii zu seyn. - 
Der Schädel des gelbbrüstigen Rollaffen ist breiter und niedriger als der des robustus, auf dem Oberkopfe ein wenig mehr eingedrückt; die Nasenöffnung ist weiter, der Jochbogen ohne Oeffnung, dabei schmäler, aber weiter nach den Seiten hinaustretend, daher das Gesicht auch breiter als am robustus, und die Vorderzähne sind mehr vorwärts geneigt; ein Längskamm (crista) befindet sich auf seiner Höhe.

Ausmessung eines erwachsenen männlichen

\section{Thiers:}

Ganze Länge $\quad \ldots \ldots \ldots . .33^{\prime \prime} 4 \frac{\mathrm{r}}{2}{ }^{\prime \prime \prime}$.

Länge des Körpers • • • 15" 7"'.

Länge des Schwanzes • • . $177^{\prime \prime} 9 \frac{1}{2}{ }^{\prime \prime}$.

Länge von dem Rande der Oberlippe

bis an den vorderen oberen Ohrwinkel .

$3^{\prime \prime} 6 \frac{x}{2} " \prime$

Höhe des äufseren Ohres . . $1^{\prime \prime} 4^{\prime \prime \prime}$.

Breite des Gesichts bei den Augen $\quad 3^{\prime \prime} 4 \frac{T}{2}{ }^{\prime \prime \prime}$.

Länge vom Rande der Oberlippe bis

zu dem Stirnwinkel über der Nase $2^{\prime \prime} \quad \frac{I}{2}{ }^{\prime \prime \prime}$.

Länge des Arms . . . . 11" $6 \frac{x}{2}{ }^{\prime \prime \prime}$.

Länge des Beins (beide von ihrem obe-

ren Gelenke an gemessen) • $14^{\prime \prime} 6^{\prime \prime \prime}$.

Länge der Vorderhand • • . $\quad 2^{\prime \prime} 7^{\prime \prime \prime}$. 
Länge der Hinterhand • • - $\quad 8^{\prime \prime} 9^{\prime \prime \prime}$.

Länge des oberen Eckzahnes - - $7_{\frac{1}{2}}{ }^{\prime \prime \prime}$.

Länge des unteren Eckzahnes • • T'”. $^{\prime \prime}$.

Der gelbbrüstige Rollaffe ward von meinen Jägern zuerst am Flusse Belmonte in den Wäldern erlegt, welche den Botocuden zum Aufenthaltsorte dienen, und welche letztere ihn mit der Benennung Hieräng bezeichnen. - Er zieht daselbst in Gesellschaften von sechs bis acht in den hohen Bäumen nach Früchten umher und soll, wie mir alle Jäger versicherten, auf dem südlichen Ufer des Flusses nicht vorkommen, wo hingegen die vorhin beschriebene Art umherzieht. - Vom Belmonte an nördlich kommt dieser Affe überall in den von mir betretenen Wälden vor, so erlegten wir ihn z. B. am Tahype und Ilhéos, in den grofsen hohen Waldungen am Rio da Cachoeira im Sertam von Ilhéos und ich bezweifle nicht, dals er weiter nördlich gefunden werde. In den Niederwaldungen des offenen Sertam der Capitanía von Bahia, in den Catinga - und Carasco-Gebüschen haben wir ihn nicht zu Gesicht bekommen. Ich kann, dem Gesagten zufolge, den Wohnort dieser Affenart an der Ostküste, so weit ich ihn kenne, nur zwischen dem 14ten und 16ten Grade südlicher Breite festsetzen; 
sollte er aber identisch mit Cebus xanthocephaIus Spixii seyn, welches ich vermuthe, so geht er südlich bis zu dem 25sten Grade hinab.

Die Lebensart dieser Affen kommt mit der der übrigen Arten dieses Geschlechts überein; sie sind schnell, lebhaft, gewandt, beilsig und furchtsam, gewöhnen sich aber sehr an ihren Herrn, dem sie äufsersst zugethan sind. Am Ilhéos und Tahype fand ich sie öfters gezähmt in den Wohnungen, man nannte sie daselbst Macaco de bando, weil sie öfters in zahlreichen Gesellschaften umherstreifen. Ihre Stimme gleicht der des robustus, ist aber ein tieferer und stärkerer, oft wiederholter Kehllaut, und nicht der sanfte l'fiff des Mico und Kayté. Man schiefst und jagt sie wie die übrigen Arten und liebt ebenfalls ihr Fleisch. -

Wir besitzen jetzt ziemlich gute Abbildungen von diesem Affen; denn nachdem ich ihn in dem ersten Theile meiner brasilianischen Reisebeschreibung (pag. 371.) in der Kürze beschrieben hatte, wurde ein wahrscheinlich junges Thier von den Herren Genffroy und $\mathrm{Fr}$. Cuvier in ihrem schönen Säugthier-Werke unter der Benennung des Sä̈ à grosse tĉtc abgebildet. Wahrscheinlich haben diese Herren die Be. schreibung meiner Reise nicht gekannt, sonst 


\section{$-97-$}

würden sie sich über das ihnen bis jetzt unbekannt gebliebene Vaterland dieser schönen Affenart haben unterrichten können. -

b. Rollschwanz-Affen mit kuizen schwachen Eckzähnen *).

4. C. $c i r r$ ifer, Geoffr. Der Rollschwanz - Affe mit weifslichem Gesichtskreise.

Variété du Sajou cornu Geoffr et Fr. Cuvier mammiferes.

Abbildungen zur Naturgeschichte Brasilien's.

Macaco in der Gegend von Bahia.

Diese von Geoffroy zuerst aufgeführte Species ist, soviel mir bekannt ist, noch nicht umständlich beschrieben worden, ich will daher ein von mir während mehrerer Jahre lebend besessenes Thier dieser Art etwas genauer beschreiben, ob ich gleich auch verhindert wurde, alle seine Theile in ihrem frischen Zustande zu untersuchen, -

In den Hauptzügen seiner Gestalt kommt dieser Affe mit den verwandten Arten dieses

*) Ich habe diese Eintheilung versucht, da bei den von mir beobachteten Thieren dieser Abtheilung der Bau der Eckzähne auch im Alter nicht auf eine grölsere Stärke schlieIsen liels. -

II. Band 


\section{$-98$}

Geschlechts überein. Sein Kopf ist kleiner und melır schmal als an den frülier von mir beschriebenen Arten. - Das Gebils war schwach, die Schneidezähne etwas vorwärts geneigt und vorn etwas abgerundet, die Eckzähne kurz und schwach. - Das Haar des ganzen Körpers ist lang, dicht und ziemlich sanft, besonders war der Schwanz sehr dicht und stark behaart, etwas länger als der Körper. -

Die männlichen Geschlechtstheile sind gebildet wie an den früher beschriebenen Arten, dabei von dunkelgrauröthlicher Farbe. -

Das Gesicht ist an seinen mittleren Theilen nackt, von schwärzlicher Farbe, die Iris der Augen lebhaft gelbbraun; die Ohren sind menschenähnlich, mit flachem nicht eingerolltem Rande und mit weilslichen Haaren dünn besetzt. Die Lippen sind mit feinen weifslichen Haaren bedeckt. Farbe des ganzen Körpers schwärzlichbraun, an den Seiten des Halses und an allen unteren Theilen fahlgelblich, etwas wollig und mit schwarzbraunen Haarspitzen; an dem Rücken und den Gliedern ist die Farbe ein wenig dunkler als am übrigen Leibe, auf dem Oberhalse aber, dem ganzen Kopf, der Stirn und den Schläfen geht sie in ein sehr dunkles Schwarzbraun über, von welchem vor den 


\section{- $99-$}

Ohren nach dem Kinne ein schwarzbrauner Streif von Haaren gleich einem Backenbarte herabläuft. - Zwischen diesem Backenbarte und den nackten Theilen des Gesichts befindet sich eine, dasselbe gänzlich umgebende Einfassung von schmutzig weilsgelblichen Haaren; die Backen sind gänzlich mit solchen weifslichen Haaren bewachsen, auch läuft an einem jeden der beiden oberen äufseren Winkel der Stirn die weifsgelbliche Farbe mit einer Spitze in die schwarzbraune Scheitelfarbe hinauf, und diese dagegen zieht mit einer ähnlichen Spitze etwas nach der Mitte der Stirn herab; über den Augen stehen einige lange schwarzbraune Haare, welche eine Art von Augenbraunen bilden. - Die Hände sind dünner behaart als der Körper, aber die Haare sind lang und zum Theil von einer etwas blässer braunen Farbe, eben so ist es an der inneren Seite der Glieder beschaffen. -

Ungefähre Ausmessung eines männlichen Thiers.

Länge des Körpers bis zu der Schwanzwurzel etwa . . . . . 16". $16^{\prime \prime}$ Länge des Schwanzes etwa . . 17".

Dieser Affe ist mir in den von mir bereis'ten Gegenden im wilden Zustande nicht zu Gesicht 
gekommen, ich fand ihn in Bahia in verschiedenen Häusern gezähmt, und kaufte ein junges Thier, welches ich mit nach Europa nahm und dort einige Jahre erhielt, bis ich es endlich durch einen Zufall verlor. - Ich vermuthe, wenn ich die Worte des Herrn Professor Lichtenstein in seiner Erläuterung der Werke von Marcgrave und Piso durch die wieder aufgefundenen Originalzeichnungen, vergleiche, dals der braune, daselbst pag. 12 erwähnte und für

- den capucina gehaltene Affe, der hier ron mir aufgeführte sey; denn da er in Bahía häufig zu Kaufe war, so stammte er ohne Zweifel aus dieser oder aus der Gegend von Pernambuco her, wie man in Bahia auch selbst vermuthete. - Die Abbildung dex Herren Geoffroy und Fr. Cuvier gleicht in der Hauptsache dem von mir besessenen Thiere sehr, doch hat sie eine andere Gesichtsfarbe; denn unter allen, von mir in Brasilien beobachteten Affenarten, befindet sich keine mit hellfleischfarbenem Gesichte. -

Diese Thiere sind von furchtsamem, lebhaftem Temperamente und gewölnnen sich höchst leicht an ihren Herrn. Sie nehmen mit jeder Nahrung fürlieb, auch schien das von mir mitgebrachte Individuum unser Clima ziemlich 
gut zu ertragen. - Seine Stimme war der sanfte, oft wiederholte, allmälig von der Höhe zur Tiefe herabsinkende Pfiff, zuweilen in der Ruhe eine dem Vogelgezwitscher ähnliche kleine Stimme und im Zorn ein lautes gellendes Geschrei, wobei die Zähne entblöfst und das Gesichtchen in Falten gezogen wurde." Gestalt und Körperbau zeigt, dals auch diese Art in der Freiheit dieselbe Lebensart und Eigenschaften besitzen müsse, als die vorhin erwähnten, von welchen sie sich besonders durch schlankeren zarteren Bau der Glieder und durch etwas geringere Grölse unterscheidet.

5. C. flavus, Geoffr. Der gelbe Rollschwanz-Affe, oder Caitaia des Marcgrave.

Cebus flavus, Geoffr. S. Hil, Ann. d. Muus. T. 19. pág. 112.

Kìhl, Beiträge ứ s.l'w. pag. \$s.

Caitaia, Marcgr.; pag. 22\%.

Dieser bisher zum Theil verkannte Affe ist von Marcgrave mit wenigen Worten sehr richtig characterisirt worden. - Herr Professor Lichtenstein sagt in seimer Erläuterung der Werke von Marcgrave und Piso (pag. 12), dals der Name Ma Cai Juba dem Simia capucina zukomme; dafs aber Menzel den Caitaiaimit 
diesem für identisch gehalten habe. - Der Cai-taia des Marcgrave ist eine wohlgetrennte Species, der Cebus flavus des Geoffroy, welchen ich genau kennen zu lernen Gelegenheit hatte. -

Diese und die vorhergehende Species scheinen in denjenigen Gegenden von Brasilien zu leben, welche Marcgrave besucht hat, und ich habe sie beide lebend in Bahía gekauft, wo man mehrere derselben bemerkte, ohne jedoch genau die Gegend angeben zu können, welcher sie vorzüglich eigen sind. $\mathrm{Ob}$ sie mir gleich beide im wilden Zustande auf meiner Reise nicht vorgekommen sind, so nehme ich dennoch unbedingt die Gegend von Bahía und Pernambuco für ihren Wohnort an. Der gelbliche Rollschwanz - Affe, dessen genauere Beschreibung ich nicht geben kann, da mein lebendiges Exemplar in meiner Abwesenheit starb und nicht conservirt wurde, hat etwa die Gröfse und Gestalt des vorhin beschriebenen, einen runden Kopf, mit völlig ähnlich gebildetem Gesichte und Ohren, einen starken dicht behaarten Rollschwanz, kurze Eckzähne und selbst alle Manieren und Bewegungen des Cebus cirrifer, Geoffr. - Sein Unterschied liegt hauptsächlich in der Farbe, welche ein blasses fahles Gelbröthlich ist; die 


\section{$-103$}

Augen haben eine gelblichbraune Iris, wie an allen brasilianischen Affen und die nackte Haut des Gesichts ist dunkel gefärbt. -

Es ist dieses ein sehr lebhaftes Thier, beständig in Bewegung, auf den vier Händen mit gewölbtem Rücken und gebogenem, abwärts eingerolltem Schwanze hin und her springend, dabei äufserst behende im Klettern und Springen, aber, wie Marcgrave ebenfalls bemerkt, nicht sanft und schmeichelnd, wie der Affe der vorhergehenden Beschreibung, sondern höchst falsch und beilsig; so war das Individuum, welches ich selbst lebend besafs.

Herr Professor Geoffroy ist nach Marcgrave der erste Zoologe, welcher diesen Affen nach einem, im zoologischen Museum zu Paris befindlichen Exemplare erwähnte. - 


\section{Sect. 2. Affen mit schlaffem Schwanze.}

\section{A. Mitvollkommenén Härdeßt.}

G. 4. Callithrix, Geoffr.

$$
S \text { a } \mathrm{p} \text { a } \mathrm{j} \text { u. }
$$

Die Thiere dieses von Geoffroy aufgestellten Geschlechtes sind von den übrigen Affenarten der brasilianischen Urwälder hinlänglich unterschieden, und haben besonders durch ihren schlaffen, nicht greifenden und daher zu diesem Endzwecke nie benutzten Schwanz ein characteristisches Kennzeichen. Dennoch scheinen verschiedene Specien, z. B. Callithrix sciurea, nicht ganz zu den von mir hier aufgeführten Arten zu passen, und mit der Zeit, wenn man alle hierhin gerechneten Affen noch genauer kennen wird, dürfte wohl noch eine Zerspaltung stattfinden, bis dahin aber wird es zweckmärsig seyn, sich an die Hauptkennzeichen zu halten, in welchen diese Thiere übereinkommen. - 
Die beiden, von mir beobachteten Arten, welche ich in den nachfolgenden Blättern zu beschreiben gedenke, haben einen weit kleineren Kopf, als die Arten des Geschlechts Cebus, ihr Schädel hat weit weniger heraustretende Jochbögen und einen höheren, mit breiteren Flügeln versehenen Unterkiefer, welcher wie bei den Brüllaffen den grölseren Stimmapparat zu beschützen bestimmt scheint; es haben jedoch nicht alle Arten dieser Affen die innere Scheidung der Augenhöhlen häutig, sondern bei der zweiten von mir beschriebenen Art, dem Gigo, ist sie knöchern; ihre Glieder sind schlanker und weniger muskulös als bei den Rollschwauzaffen, ihr Körper ist mit längeren sanfteren Haaren dichte bedeckt, der Schwanz dünn, schlank und wenig muskulös, weder Roll- noch Greifschwanz. Die Eichel des Männchens ist nicht champignonförmig, sondern klein und etwa gebildet wie an den Eichhörnchen, auch bemerkt man bei diesen Thieren nicht die beständige Erection, welche den Cebus-Arten eigen ist. Ihr Kehlkopf ist dick und von besonderer Bildung *).

*) Ich muls bedauern, dafs ich die in Branntwein conservirten Stimmapparate der beiden hier erwähnten Arten des Geschlechts Callithrix nicht glücklich mit nach Europa gebracht habe, 


\section{- 106}

Sie leben in kleinen Gesellschaften von einer oder ein paar Familien, sind nicht so schnell als die Arten des vorhergehenden Geschlechtes und bewegen sich auf den Zweigen mit kurz zusammengezogenem Körper. Diese Stellung und ihr langes Haar geben ihnen ein bärenartiges Ansehen, der lange Schwanz hängt dabei gewöhnlich gerade herab, oder wird auch wohl in aufrechter Stellung getragen. - Sie entfliehen sogleich, wenn man sich ihnen nähert, welches häufig geschieht, da ihre Stimme unter allen Affen der Ostküste, nach der des Guariba oder Brüllaffen die stärkste und weitschallendste ist, auch defshalb von den Jägern benutzt wird, um heran $\mathrm{zu}$ schleichen. -

In den Gegenden, welche ihnen die Natur zum Aufenthalte angewiesen hat, sind diese Affen zahlreich und verschaffen den Bewohnern ein beliebtes Essen; man sucht sie aber besonders jung zu bekommen, um sie zu erziehen, da sie ein höchst sanftes Naturell besitzen und im höchsten Grade zahm und zutraulich wer. den. 
1. C. p p e r s $n$ at us Geoffr. D. ex $S$ a u a $s$ u *).

Geoffr, S. Hil. in den Ann. d. MIus. T, XIX, p. 113. Simia personata Humb. Rec. d'obs. d. Zool. etc, T. I. p. 357 .

Kuhl Beiträge u. s. w. p. 40.

Abbildungen zur Naturgeschichte Brasiliens.

Callithrix personata, Spix.

Sahuassú an dẹ Ostküste von Brasilien.

Der Sauassu ist eine von Herrn Professor Geoffroy zuerst bekannt gemachte Species, welche er in dem Museo zu Lisboa fand. - Die Gegend von Brasilien; wo diese schöne Affenart sich findet, kannte man nicht genau, auch besafs man von ihr noch keine umständliche Beschreibung nach dem Leben, ich will defshalb diese Lücke nach Kräften auszufüllen suchen. Beschreibung eines erwachsenen männlichen Thiers:

Der. Kopf ist klein und rund, mit wenig vortretendem Gesicht, mälsig grolsen, lebhaften, mit einer gelbbraunen Iris versehenen Augen; die Physiognomie ist der des Sahuï (Jacchus) ähnlich, nur fehlt bei ersterem der nackte Stirn. absatz des letzteren; die Nasenlöcher stehen

*) Bei diesem Namen ist zu bemerken, dals die Buclistaben a. und u getrennt ausgesprochen iverden. 
weit von einander entfernt, ihr Zwischenraum ist breiter als die Reihe der oberen Schneidezähne (nach Geoffroy schmäler, da dieser nach einem au'gestopften, vertrockneten Exemplare beschrieb); die Ohren sind ziemlich grofs, eiförmig abgerundet, von aufsen nur sparsain, von innen aber mehr behaart; Gesicht mit einer nackten, schwärzlichen Haut bedeckt, an den Backen dünn mit schwarzen, an der Nase auf eben die Art mit weifslichen sebr kurzen Härchen bedeckt und mit $\frac{2}{3}$ Zoll langen, schwarzen Bartborsten besetzt, auch in den Augenbraunen stehen einige dergleichen. -

Gebijs wie bei der nachfolgenden Art, auch schon von Geoffroy erwähnt.

Die Hände sind lang und schmal, das $\mathrm{Na}$ gelglied der Finger mit einem dicken Ballen versehen, die Finger selbst sind lang und schlank, die'Nägel kurz, am Zeigefinger der Hinterhände ein wenig aufgerichtet, an den übrigen weniger; der Daumennagel ist kürzer; Hinterhände länger als die vorderen, dabei stärker behaart. - Die männlichen Geschlechtstheile liegen weit nach hinten dicht am After und nahe am Schwanz; sie haben eine etwas andere Bildung als bei dem vorhergehenden Geschlech. 


\section{- 109}

te, indem die Eichel nicht breit oder tellerförmig gebildet ist. - Schwanz viel länger als der Körper, schlaff, schlank, mit ziemlich anliegenden Haaren bedeckt; Haar des ganzen Körpers lang, am Rücken 3 Zoll lang, etwas wollig; Bauch und innere Schenkel dünn behaart:

Der ganze Kopf von der Brust an (da der Hals seiner Kürze wegen kaum bemerkbar ist) ist bis auf die Mitte des Scheitels bräunlichschwarz; die vier Hände sind schwarz; innere Seite des Vorderarms und des Schienbeins schwarzbraun; Hinterkopf und Oberhals gelblichweifs, das ganze übrige Thier ist fahl blars graubräunlich, mit helleren, sehr blafs gelblichen Haarspitzen; an den Vorderarmen sind die Haare dunkler und haben abstehende blafsgelbliche Spitzen; Bauch graubraun mit röthlichen Haarspitzen; Vorderseite der Hinterschenkel fahl hell gelblich-grauweils; Schwanz röthlich-graubraun, auf der Unterseite und an der Wurzel rostroth. -

Weibchen: Diese sind durchgehends mehr hell fahl gefärbt, oder wei[slich-gelbgrau, da hingegen die Männchen mehr graubräunlich erscheinen; die Weibchen sind an ihren Vordertheilen 
mehr weifslich gefärbt und es fehlt ihnen der weifse Hals - oder Hinterhauptfleck, woraus es wahrscheinlich wird, dals Herr Professor Geof. froy S. Hilaire seine Beschreibung nach einem weiblichen Thiere entwarf. Die Vorderarme und Hinterbeine sind bei diesen etwas gelblich, besonders da, wo die weifsgraulichen Haare dieser Theile an die schwarzen der Hände grän. zen; Hinterbeine an ihrer inneren Seite dunkel graubraun; Vorderarme bis zu den Ellenbogen schwarzbraun. - Diese niedlichen Affen variiren etwas Weniges in ihrer Farbe; denn einige haben den weilsen Nacken deutlicher und bei den Weibchen fehlt er, wie gesagt, gänzlich; der Schwanz ist bei einigen rostroth, bei andern, besonders den Weibchen röthlichgelb, bei andern auf der Oberseite graubraun und an der Wurzel und Unterseite gelbroth oder rostroth.Das dichte, lange, an der Wurzel wollige Haar giebt diesen Affen weit mehr Umfang, als ihr Körper wirklich hat, die Männchen sind jedoch immer etwas mehr schlank. - Ganz junge Thiere haben die Finger der Hinterhände stark mit weifslichen Haaren gemischt und ihre breite Iris ist nicht gelbbraun, sondern graubraun, welches ich bei den meisten brasilianischen Affen gefunden habe. 
Ausmessung eines erwachsenen männlichen

\section{Sauassu:}

Ganze Länge . . . . . . . $\quad 31^{\prime \prime} 2^{\prime \prime \prime}$.

Länge des Körpers · 12 12 $4 \frac{1}{2} "$.

Länge des Schwanzes . • • 18" 11"'.

Länge von der Nase bis zum Anfange

des Ohrs • . . . . . $2^{\prime \prime} 1^{\frac{1}{2}}{ }^{\prime \prime \prime}$.

Höhe des äufseren Ohres . . $8 \frac{1}{2}{ }^{\prime \prime \prime}$.

Breite des Kopfs zwischen den Ohren $2^{\prime \prime} 1 \frac{1}{2}{ }^{\prime \prime}$.

Länge des Arms von dem Schulterge-

lenk gemessen .... . . . $7^{\prime \prime} 11^{\prime \prime \prime}$.

Länge des Beins von der Hüfte . $10^{\prime \prime} 9^{\prime \prime \prime}$.

Länge der Vorderhand • • • $2^{\prime \prime} 2^{\prime \prime \prime}$.

Länge des Vorder-Mittelfingers . $\quad 1^{\prime \prime} 5^{\prime \prime \prime}$.

Länge der Hinterhand . . . $3^{\prime \prime} 3 \frac{1}{2}{ }^{\prime \prime \prime}$.

Länge des Hinter - Mittelfingers . $\quad 1^{\prime \prime} 5^{\prime \prime \prime}$.

Ausmessung eines sehr grofsen weiblichen

Sauassu:

Ganze Länge . ... . . . . . $33^{\prime \prime} 10^{\prime \prime \prime}$.

Länge des Körpers $\quad$ • . . . . 13" $9^{\prime \prime \prime}$.

Länge des Schwanzes • . 20" 1"'.

Man findet Männchen, welche so grofs sind, als das hier gemessene Weibchen.

Der Sauassu wurde von uns zuerst in den grofsen Urwäldern gefunden, welche die Ufer des Itabapuana und des Itapemirim (Itapemiri) beschatten, wir fanden ihn ferner am Iritiba oder 
Reritigba, am Espirito Santo und nördlich bis über den Rio Dose hinaus. - Da ich ihn am nördlichen Ufer dieses Stromes noch fand, am Mucuri aber keine Spur mehr von ihm hatte, so setze ich seinen Wohnort an der Ostküste, meinen Erfahrungen zufolge, zwischen den S. Matthaeus und den Parahyba, also zwischen $18 \frac{x}{2}$ und $21 \frac{1}{2}^{\circ}$ südlicher Breite, allein Herr Dr, $v$. Spix erhielt ihn auch bei Rio de Janeiro. Hier leben diese harmlosen angenehmen Geschöpfe in den groisen ununterbrochenen Wäldern, wo sie nur selten beunruhigt werden. Ihre durch die stille einsame Wildnifs weit schallende Stimme wird häufig gehört, sie klingt wie ein Röcheln, welches man hervorbringen kann, indem man den Athem abwechselnd schnell hinter einander einzieht und wieder ausstöfst. - Männchen und Weibchen geben diese Stimme von sich. Diese Affen leben in kleinen Gesellschaften von einer oder einigen wenigen Familien beisammen und klettern äufserst geschickt. - Man sagt, dafs sie, so wie die meisten Quadrumanen, nach den verschiedenen reifenden Früchten etwas umherziehen; denn sie verlassen z. B. die Gegend von Muribeca am Itabapuana zu einer gewissen Zeit und kehren plötzlich wieder nach dem gewohnten Standorte zurück. 
Diese Thiere sitzen etwas zusammengebückt auf den Zweigen, der Schwanz hängt herab; bemerken sie alsdann etwas Fremdartiges, so geht es ziemlich schnell über die Aeste fort, gewöhnlich auf den dicken Hauptästen. - Man hört alsdann ihre Stimme nie, welche nur in vollkommener Ruhe, besonders bei schönem warmem Wetter Morgens und Abends erschallt. Sie werfen nur ein Junges, nach Art aller Affen, welches die Mutter so lange mit sich umher trägt, bis es stark genug ist, den Alten selbst überall folgen $\mathrm{zu}$ können. - Im Monat October fanden wir schon starke Junge, auch er. legte man in dieser Zeit stark trüchtige Weibchen. Schiefst man die Mutter von einem Baume herab, so erhält man gevölınlich das Junge lebend, welches sie auf dem Rücken oder unter dem Arme zu tragen pflegte. Dieses junge Thierchen kann man alsdann leicht erziehen und zähmen, es lernt bald fressen und wird äul'serst zahm und sanft. Alle Affen dieser Art sind nicht zornig und beilsig, wenn man sie verwundet, sondern zeigen unter alien mir bekannten Thieren dieser zahlreichen Familie das sanfteste Naturell. Wenn dem Sauassu behaglich zu Muthe ist, so schnurrt er wie eine Katze. - Sowohl die eingebornen Portugiesen nder Brasilianer,

II. Band. 
als die Neger und Indianer stellen diesen Thieren ihres Fleisches wegen nach. - Hat ein India. ner einen solchen Affen verwundet, welcher auf dem Baume hängen geblieben, oder eine kleine efsbare Frucht entdeckt, so scheut er die Dicke und Höhe des colossalen Baumes nicht, um ihn $\mathrm{zu}$ ersteigen, wo in andern Fällen oft die besten Versprechungen nicht vermögen, ihn aus seiner gewohnten Ruhe zu bringen, dann bindet sich der Purí, der die Wälder der Sauassus beherrscht, die Füfse mit einer Schlingpflanze zusammen und klettert, von dieser Erfindung kräftig unterstützt, in eine schwindelnde Höhe hinauf, indem ihm alsdann eine jede noch so kleine Unebenheit der Rinde zum Stützpuncte dient. -

2. C. $m e l a n$ o $l a h i r$.

$$
\mathrm{D} \text { e } \mathrm{r} \text {. G i g. ó. }
$$

S. Behaarung sehr lang, dicht, aschgrau; Mittclund Unterrü̈ken röthlich kastanienbraun; Hände schuarz; Schwanz weifsgelblich.

Abbildungen zur Naturgeschichte Brasilien's.

Callithrix incanescens Lichtenstcinii.

Kuhl Beiträge u, s, w. p. 40.

Schinz, Thierreich u. s. w. B. I. p. 133.

Callithrix Gigot, Spix.

Gigó am Mucuri.

Macaco branco am Alcobaça.

Gigó im Sertam von Ilhéos un 1 in Minas,

Brukäck bei den Botocuden. 


\section{$-115$}

Gestalt und Gesicht völlig vom Sauassu, Haar des Körpers sehr dicht, weich und lang, mittlerer Theil des Gesichts und innere Hände unbehaart.

Beschreibung eines männlichen Thieres: Der Kopf ist klein und rund, die Aigen mälsig grofs und lebhaft, das Gesicht wenig vortretend; die Ohren sind im Pelze versteckt, d. h. die innere und äufsere Fläche sind behaart.

Gebifs. Schn, $\frac{4}{4}$; Eckz. $\frac{\text { r. I. }}{\text { I. }}$; Backenz, $\frac{6.6 .}{6.6 .}$; Schneidezähne in jedem Kiefer vier; die oberen haben eine etwas breite, märsig scharfe Schneide und die beiden mittleren sind bedeutend gröIser als die äufseren, alle sind nach hinten durch die unteren Schneidezähne ein wenig ausgeschliffen; untere Schneidezähne gleich lang, oben stumpf abgeschliffen und dichte aneinander gereiht; Eckzähne im Oberkiefer durch eine Lücke von den Schneidezähnen getrennt, etwa um $\frac{1}{3}$ länger als die mittleren Schneidezähne des Oberkiefers, ziemlich breit und schwach, nach innen ein wenig ausgeschliffen; untere Eckzähne nur wenig länger als die Schneidezähne und von diesen nur durch eine kleine Lücke getrenrt. Backenzähne sechs in jedem Kiefer an jeder Seite, sie liaben mehrere schwache Höckererhöhungen und nehmen bis zu dem fünften Zahn an Grölse 


\section{$-116$}

$\mathrm{zu}$, der sechste ist wieder kleiner; die drei ersten Zühne im Oberkiefer haben an dem ïufse-

ren Rande eine etwas stärkere Erhöhung, der vierte und fünfte aber zwei. "Im Unterkiefer haben die beiden ersten Backenzähne nur eine kleine schwache Spitze, die nachfolgenden zeigen nur sehr abgeflächte Höcker. - Alle Zähne sind schwarzbraun, nü an den Rändern und Kanten weifs abgeschliffen. -

Der Hals ist kurz; der Nagel des Daumens ist ebenfalls kurz und abgerundet, die der Finger sind etwas scharf zusammengedrückt, ein wenig zugespitzt und aufgerichtet, besonders an den Hinterhänden, wo der des Zeigefingers überdiefs am längsten ist.

Geschlechtstheile wie am Sauassu; der Schwanz ist im Verhältnils zu der Länge des Körpers länger als am Sauassu. -

Die Stirn ist wie abgeschoren mit dichtem, sehr sanftem, völlig gleichem, etwa vier Linien langem Haar besetzt, welches sich auf diese Art bis zu den Ohren erstreckt; von hier an wird die Behaarung plötzlich noch einmal so lang, unter der Kehle und den Ohren ist sie am längsten; auf dem Halse und dem Oberrücken wird das Haar immer dichter und länger, so dals man es auf dem Mittelrücken zwei Zoll lang findet; 
unter dem Bauche ist es am kürzesten, dünnsten und dabei wollig, so dals man die Haut hindurch schimmern sieht.

Das Gesicht ist schwärzlich gefärbt, oft nur dunkelgrau, zuweilen aber auch völlig schwarz; die Iris ist gelbbraun; Haare des Kopfs an der Wurzel aschgrau, an den Spitzen weifslich; da wo das hohe Scheitelhaar anfängt, sind die. Haare auf der Scheidung völlig schwarz; unter dem Bauche ist es dunkel schwärzlich-graubraun, am ganzen Körper aber mit vielen schwärzlichen und weifslichen Queerringen abwechselnd, wodurch alle diese Theile ein gemischt aschgraues Ansehen erhalten; auf dem Oberrücken fängt es an gelbröthlich überlaufen zu seyn und diese Farbe nimmt zu, so dals der Unter - und Mittelrücken, so wie die Seiten, röthlich kastanienbraun erscheinen, indem hier, genauer betrachtet, die dunklen Stellen der Haare schwärzlichbraun, und die hellen gelbroth gefärbt sind; dieser rothbraune Theil des Rückens enthält die längsten Haare des ganzen Körpers, locker und an der Wurzel wollig; Brust, der kurze Hals, Arme und Beine, After und Schwanzwurzel haben die schwärzliche und weifsliche Mischung. Die vier Hände sind an der äufseren behaarten, so wie an der inneren unbehaatten Flache 
sclıwarz; die innere Seite der Hinterbeine ist bräunlich-schwarz, einzeln mit weilslichen Härchen gemischt; Schwanz bei einigen Individuen beinahe völlig weils, bei andern aschgrau und stark weils, oder weifsgelblich gemischt, indem die Haare an der Wurzel und Spitze weifsgelblich, in der Mitte aber schwärzlich gefärbt sind, auch ist oft die Schwanzspitze mehr weifslich; andere Gigós haben den Schwanz durchaus gelbröthlich gefärbt, welches wuhl am häufigsten vorzukommen pflegt. -

Das Weibchen ist von dem Männchen wenig verschieden, doch habe ich gefunden, dais die mit weifsem Schwanze gewöhnlich weiblichen Geschlechtes waren. -

Der Schädel des Gigó unterscheidet sich wenig von dem des Sauassu; er ist über den Augen ein wenig melır flach gedrückt, in allen seinen Theilen aber demselben ganz ähnlich; Gebifs bei beiden Thieren völlig gleich gebildet, auch sind die Zähne bei beiden schwarzbraun gefärbt. - Die Scheidung der beiden Augrenhöhlen ist knöchern und nicht häutig. - Gestalt des Schädels der des Kopfs der Hapalen sehr ähnlich. - Der Unterkiefer ist, wie gesagt, sehr hoch und breit, beinahe wie bei den Brüllaffen, um den Stimmapparat aufzunehmen. 
An den inneren Theilen dieser Affen ist mir nichts auffallend gewesen, aufser dafs die Schilddrüsen sehr grols sind.

Ausmessung eines weiblichen Thieres:

Ganze Länge .

Körperlänge

Schwanzlänge

Länge von der Nasenspitze bis zu dem

oberen vorderen Ohrrande - 1 " $10 \frac{\mathrm{r}}{2}$ "'.

Länge der Vorderhand auf der Ober-

seite . . . . $2^{\prime \prime} 4^{\prime \prime \prime}$.

Länge der Hinterhand • . . $3^{\prime \prime} 4^{\prime \prime \prime}$.

Der Gigó hat in der Bildung und Lebensart die gröfste Aehnlichkeit mit dem Sauassu, auch haben selbst einige Theile seines Körpers dieselbe Farbenvertheilung; beide bilden daher ein recht natürlich von den übrigen von mir beobachteten Quadrumanen getrenntes Geschlecht. Das lange Haar des Gigó, welches noch weicher und zarter ist als am Sauassu, verbunden mit seiner meistens kurz zusammengezogenen Stellung, wenn er auf einem Aste geht, geben ihm besonders das Ansehen eines kleinen Bären. - Da wo der Sauassu aufhörte, das Ziel der Röhre unserer Jäger zu seyn, fand sich sogleich der Gigó ein, wir bemerkten ihn zuerst am Mucurí, in den die Lagoa d'Arara umgebenden Wäldern 
und fanden ihn weiter nördlich überall, am $A l$. cobaça, Belmonte, Rio Parlo, Ilhéos, Itahype, und im Sertam von Bahía, so weit die hohen fruchtreichen Urwälder sich erstrecken, Herr Dr. v. Spix hat ihn in der Gegend von Ilhéos erhalen. Die südliche Gränze seines Aufenthaltes kann ich an der Ostküste, meinen Erfahrungen zufolge, an den Tlufs S. Matthaeus, den Cricarć der jetzt civilisirten Küstenindianer, also bis zu $18 \frac{1}{2}^{\circ}$ südlicher Breite setzen, aber nicht bestimmen, wie weit diese Art nördlich hinauf gefunden werde. -

In den grofsen Urwäldern der genannten Gegenden, besonders der Lagoa d'Arara vernahmen wir täglich die laut röchelnde Stimme dieses Affen, und waren zu Anfange überzeugt, den Sauassu zu hören; denn diese beiden Arten gleichen sich in ilrer stimme und selbst Lebens. art und Manieren vollkommen; daher überführte uns nur die genauere Untersuchung der Sache von unserem Irrthume. - Nirgends fand ich den Sauassu in den Gegenden, welche der Gigó bewohnt, übrigens zieht der letztere wie der erstere in kleinen Gesellschaften von vier bis sechs Individuen umher, nährt sich von ähnlichen Früchten, deren zerbissene Ueberreste man in seinem Magen findet, pflanzt sich fort wie 
jener, und wird auch auf eben diese Art benutzt und gejagt. Man würde das schöne Fell zu mancherlei Arbeiten benutzen können, da das Haar so zart und dichte ist. — Gezähmt sollen diese Thiere dieselben Eigenschaften zeigen, als die Sauassu's. -

B. Affenartige Thiere mit unvolliommener Vorderhand: (Sahiüs).

$$
\text { G. 5. H a } p \text { a } l \varepsilon \text {, lllig. }
$$

$$
S \text { a } h \text { u } \ddot{\text { i. }}
$$

Die Brasilianer belegen mit dem Namen Sahuim (Sahuï) alle die kleinen affenartigen Thiere, welche Herr Professor Geuffroy S. Hilaire in seine beiden Geschlechter Jacchils und Midas gebracht hat, oder Illiger's Hapalen. Diese Thiere bilden eine sehr natürliche Familie und ich glaube, dafs es wohl zweckmäfsiger seyn dürfte, die beiden Geschlechter des Herrn Geaffroy zu vereinigen, da die Unterschiede derselben nur höchst unbedeutend und, wie es mir scheint, selbst nicht recht gewils sind, Ich war selbst anfänglich entschlossen, die Midas-Arten von den eigentlichen Hapalen zu trennen, werde sie aber nun in den nachfol- 
genden Blättern nur als Unterabtheilungen betrachten.

Die Sahuïs sind kleine Thiere, welche, ihrer Gestalt und Lebensart zufolge, schon ein Bindeglied zwischen Affen und Eichhörnchen bilden. Ihr Gebils ist dem der übrigen Affen ähnlich, eben so die Bildung des Kopfes und Körpers, aber ihre Vorderhände haben keinen deutlich getrennten Daumen, welcher bei den eigentlichen Affen aller übrigen Geschlechter den andern Fingern der Hand entgegen gestellt ist. Ihr Schwanz ist länger als der Körper und völlig schlaff, und ihr Stimmapparat ist wenig ausgebildet. Sie bevölkern in zahlreichen Banden jene weiten Urwälder, welche das Continent von Süd-America beschatten, und sind so zahlreich an Individuen als an Specien. Es ist mir sehr wahrscheinlich, dafs man in den inneren Provinzen von Süd-America noch viele Arten dieser angenehmen Thierchen entdecken wird, da ich gefunden habe, dafs der Wohnort einer jeden Species an der Ostküste auf wenig ausgedehnte Gränzen beschränkt ist. Grolse Flüsse machen hier oft die Gränze, und es ist sehr interessant für den reisenden Beobachter, wenn er plötzlich die eine Art durch eine andere èrsetzt findet, welche nur durch geringe Unterschiede ron ihr 
getrennt und dennoch gewifs specifisch verschieden ist. - Die Sahuïs haben in mancher Hinsicht Aehnlichkeit mit den Eichhörnchen, und scheinen in Brasilien diese Thiere zu ersetzen, wovon man nur eine Art; Sciurus aestuans, kennt *).. Sie leben blofs auf den Bäumen, springen sehr behende von Ast zu Ast, und sitzen gewöhnlich nicht aufgerichtet, sondern mit dem Bauche platt auf den Ast gestützt, wobei der lange dick behaarte Schweif gerade schlaff herabhängt. - Sie sollen keine Nester bauen, wie die Eichhörnchen, und sind nicht an einen gewissen Aufenthaltsort gebunden, sondern ziehen gesellschaftlich umher, sind bald hier bald dort, kündigen sich in gewisser, doch nicht weiter Entfernung durch ihre vereinten Stimmen an und ziehen auf diese Art ihrer Nahrung

*) Herr Dr. Boie bemerkt in dieser Hinsicht sehr richtig, dafs die abgehende Zahl der Sciurus Arten in Brasilien durch die Hapalen ersetzt werde, dafs aber in anderen mit ersteren Thieren reichlicher versehenen Gegenden von America die letzteren selten, und dafs auf den Sunda-Inseln die Zahl der kleinen Sciurus Arten nicht minder reichhaltig sey, als die der Sahuïs in Brasilien, aber kzleinere Affenarten zu fehler scheinen, während ein neues Geschlecht eichhornartiger Insectivoren (Tupaja, Raffl.) in einer Reihe von Specien die Unfähigkeit der Eichhörnchen, auch mit von Insecten zu leben, wie die Hapalen, zu crsetzen scheine, - 


\section{$-124-$}

nach. - Ihre Stimme, die sie beständig hören lassen, ist ein kurzer Lockton, wie der mancher kleinen Vögel. - Sie nähren sich von mancherlei Früchten, auch den kleinen Nüssen mancher Cocosarten, so wie von vielerlei Insecten und Spinnen. - Sie werfen zuweilen mehrere, oft aber nur ein Junges. Die Mutter trägt ihrer zuweilen zwei, wovon das eine auf dem Rücken, das andere an der Brust sich befestiget hält. Gewöhnlich sollen sie nur ein Junges werfen, auch habe ich bei den weiblichen Thieren immer nur eine Zitze im Gebrauche gefunden. Die jungen Thierchen sind aufserordentlich klein, oft ron der Griofse einer Maus, und es ist höchst komisch anzusehen, wenn die Mutter mit ihnen davon springt.

Die lebhaften Rewegungen dieser Thiere zeugen von einem munteren Naturell, auch ist ihr Köpfchen beständig in Bewegung. Hat eine Bande von Saluuis bei der Annäherung eines Feindes nicht Zeit zu entfliehen, so verbergen sie sich hinter die dicken Baumzweige und blikken zuweilen mit dem Köpfchen hervor. So unbedeutend diese Aeffchen als Nahrungsmittel sind, so werden sie dennoch geschossen und gegessen, es ist aber ein solcher Braten nicht bedeutender als der eines Eichhörnchens. - Ge- 


\section{$-125$}

zähmt gewöhnen sie sich an ihren Pfleger, sind aber äufserst furchtsam und daher gegen Fremde beilsig, sie geben in der Angst ein Vogelgezwitscher von sich. - Schlafend rollen sie sich zusammen und bedecken sich mit dem langen, dicht behaarten Schwanze. Man bringt sie nicht selten nach Europa, sie sind aber äufserst empfindlich gegen die Kälte, und die meisten von ihnen sterben bei der Ueberfahrt. Hr. v. Humboldt erzählt uns, dafs in den unter dem Aequator gelegenen Gegenden von Süd - America, am Orenoco und in den übrigen Provinzen des spa. nischen Guiana die kleineren Arten der Quadrumanen die kältere Zeit des Jahres lebhaft empfinden und sich alsdann haufenweise zusammenballen, um einander zu erwärmen; in dem glücklichen, zu allen Zeiten des Jahres ziemlich gleichen Klima der von mir in Brasilien bereis'ten Gegenden habe ich eine solche Empfindlichkeit dieser Thierchen nicht wahrgenommen. Man kannte anfänglich nur wenige Arten dieses Geschlechts, bis Herr Professor Geoffroy S. Hilaire in dem zoologischen Museo zu Lisboa noch mehrere Brasilianische Arten desselben kennen lernte und eine kurze Notiz davon in 19ten Bande der Annales du Muséum (p. 119) mittheilte, noch mehrere andere hat man seit- 


\section{$-126$}

dem entdeckt. - Man kann diese niedlichen Thiere in folgende drei Unterabtheilungen bringen :

a. Sahuïs mit verlängertem Haarbüschel vor dem Ohre und einem dunkel und heller geringelten Schwanze, Haar am Körper meistens dreifarbig. - Eigentliche Sahuïs (Jacchus).

b. Sahuîs mit langen mähnenartig das Gesicht umgebenden Haaren, welche gleich einem Kragen aufgerichtet werden. Löwen-Sahuïs.

c. Sahuïs mit glattem Kopfe; sie haben weder Ohrbüschel noch Gesichtskragen. Eichhorn. Sahuïs.

Die von mir in den nachfolgenden Blättern zu erwähnenden Arten gehören in die beiden ersteren dieser Abtheilungen.

Manche Naturforscher haben die verschie. denen, im Allgemeinen oft geringen Abweichungen der Arten der ersten Abtheilung, oder der Jacchus-Arten wohl nur für Varietäten gehalten, und ich gestehe, dafs ich selbst dieser Meinung war; allein ich habe mich durch den Augenschein überzeugt, dals sie wirklich verschiedene Specien sind, und dafs ihnen sämmtlich von der Natur verschiedene, wenn gleich nur wenig ausgedehnte Wohnplätzè angewiesen sind, wie diefs die Fortsetzung meines $\mathrm{T}$ hierver. 
zeichnisses deutlicher erklären wird. Ich habe unter jenen affenartigen Thieren nur sehr wenige Varietäten gefunden und bin jetzt durch die Erfahrung belehrt, dals man in diesem Geschlechte die Abweichungen der Färbung und Zeichnung nur zu oft für unwesentlich zu Bestimmung der Specien gehalten habe. - Die Sahuïs mit verlängertem Haarbüschel vor dem Ohre (Jacchus Geoffr.) geben einen auffallenden Beweis für den Satz ab, dafs die Wiederholung der Thierformen in Brasilien häufig vorkomme; denn alle diese kleinen Thierarten haben die gröIste Aehnlichkeit unter einander: sie tragen nicht allein den verlängerten Ohrbüschel, sondern gleichen sich auch in der Hauptmischung und Vertheilung ihrer Farben. Ihr Körperhaar ist meistens dreifarbig, röthlich, schwärzlich und weilslich, und der lange Schwanz zweifarbig geringelt. - Es ist aus diesem Grunde manchen Naturforschern, welche nicht Gelegenheit hatten, diese Thierchen an Ort und Stelle zu beobachten, nicht zu verargen, wenn sie den Sahuï mit weifsem Ohrbüschel für das Weibchen, und einen andern mit schwarzen Ohrhaaren für das Männchen hielten *), bei-

*) Siehe Fischer in dem Mus, Mosq. pag. 57, und v. Olfers in $v$. Eschivege Journal ron Brasilien, Heft 2. pag. 203. 
de aber kommen in ganz verschiedenen Gegenden vor.

Die Brasilianer bezeichnen, wie gesagt, diese Thiere mit dem allgemeinen Namen $S a$. huim $^{*}$ ), belegen aber eine jede Art von ihnen wieder mit einer näher bestimmenden $\mathrm{Be}$ nennung. -

a. Saluüs mit verlüngertem Haarbüschel vor dem Ohre und einem dimliel und heller geringelten

Schwanze.

1. H. J a c c $h u s$, Illig.

Der Sahü mit weifsem Ohrbüschel.

Simia Jacchus, Linn, Schreber.

Jacchus vulgaris, Geoffr, Ann. d, Mus, T. XLX, p; 119. Titi, Azara.

Cagui minor, MAarcgr. p. 227.

Kuhl Beiträge zur Zool. p. 46.

Abbildungen zur Naturgeschichte Brasilien's.

Sahuim (Sahuí) in der Gegend von Bahla.

Der Sahui mit weifsem Ohrbüschel ist in Europa die bekannteste Art dieser Familie. Man besitzt verschiedene Beschreibungen dieses Thier-

*) Dieses Wort (zu deuisch auszusprechen Sahuii) ist bisjetzt in allen Sprachen unrichtig geschrieben worden. - $\operatorname{lm}$ Französischen soll man sagen Stout, tund nicht Sagouin oder Cagui, da dieses sämmilich Verdrenungen der brasilianischen Benennurg sind. - 
chens, welche zum Theil etwas unbestimmt sind, und von einem schwärzlichen Körper reden, ich will defshalb die Färbung dieses Sahuï's beschreiben, wie man sie in der Gegend der Stadt $B a$ hía findet. -

Das Gesicht um Augen und Nase ist etwas nackt, die Oberlippe mit kurzen weifslichen Härchen besetzt, wie an einem alten bärtigen Grenadier; Gesicht dunkel graulich-fleischbraun; Iris im Auge bräunlichgelb; Kopf und Hals sind matt schwarzbräunlich, oft auch nur fahl blafs graubraun; an der Stirn über der Nase befindet sich ein rundlicher schmutzigweifser Fleck; Backen, Kinn und Kehle sind verloschen fahl graubräunlich, daher etwas blässer gefärbt als der Oberkopf; das Ohr ist nackt, unberandet, schwärzlich - graubraun, blofs am äufseren Rande mit einzelnen Haaren besetzt. - Vor, über und hinter dem oberen Theile des Ohrs entspringt ein Büschel von weifsen glänzenden, etwa einen Zoll langen Haaren, welche das $\mathrm{Ohr}$ verdecken und seitwärts horizontal in Gestalt eines Fächers ausgebreitet hinausstehen, solche Ohrbüschel characterisiren die Arten der Familie Jacchus + Der Körper ist bräunlich-grau und weifslich gemischt, indem die zarten, weichen, dichten, unten wolligen Haare an der II. Band, 
TTurzel schwärzlichgrau, alsdann breit rostgelb oder hell rostroth, dann wieder schwärzlich und an der Spitze weilslich gefärbt sind, die röthli. che Farbe blickt nur wenig hindurch, wenn die Haare in der Ruhe sind, erscheint aber mehr, nenn das Thierchen in Bewegung ist; auf dem Hinterrücken bis zu dem Schwanze hin erscheinen regelmäfsig parallel laufende weifsliche Queerlinien; an den Armen sind die weilslichen Haarspitzen weniger bemerkbar, daher herrscht hier mehr die dunkelgraue Farbe vor. - Hände stark mit weifslichen Haarspitzen bedeckt, dennoch hat sie die Tafel des Audebert zu weils dargestellt, es giebt aber einzelne Individuen mit mehr weifslich gefärbten Händen; diese Abbildung ist nicht naturgetreu, sie giebt besonders eine unrichtige Vorstellung von dem Gesichte des Thiers, auch ist der Schwanz viel zu dick. - Die innere Seite der Glieder dieses Sahuï's ist dünn bräunlich-grau behaart, die Haut ist sichtbar. - An dem langen, etwas länger behaarten, aber auf den Abbildungen dennoch gewöhnlich zu dick abgebildeten Schwanze haben die Haare in der Hauptsache dieselbe Farbenabwechslung, doch ist das Rostgelbe weniger stark, und es herrscht hier die schwärzliche Farbe, auch ist der Schwanz im Allgemeinen et- 
was dunkler schwärzlich gefärbt als das Körperhaar, er hat etwa 22 weifsliche Ringe und eine weifsliche Spitze, eine Zeichnung, welche allen den verschiedenen Arten der Familie Jacchus eigen ist. Betrachtet man den Schwanz genau, so findet man, dafs die weifsen Ringe immer einen kleinen quirlförmig vortretenden Absatz bilden. -

Dieser kleine Sahuï ist sehr gut nach der Natur in dem vortrefflichen Säugthierwerke der Herren Geoffroy und Fr. Cuvier beschrieben, daher bedurfte es von meiner Seite auch keiner vollständigen Beschreibung. - Weniger deutlich ist die daselbst gegebene Abbildung; denn man erkennt daraus nicht vollkommen die seitwärts hinaustretenden Ohrbüschel, dabei scheint die Farbe des Thierchens im Allgemeinen etwas zu sehr in's Grünliche fallend. Alle übrigen Abbildungen in den verschiedenen naturhistorischen Werken, diejenige etwa ausgenommen, welche sich in Buffon (edit. de Sonnini vol. 36. pl. 76) findet, sind zu schlecht, um einer Erwähnung zu verdienen. - Es scheint übrigens, dals das von den Herren Geoffroy und Fr, Cu. vier abgebildete Thierchen durch die Versetzung in ein kälteres Klima seine völlige Grölse nicht erreicht hatte; denn ein in Bahia von mir ge- 
messenes hielt in der Länge des Körpers etwa 8" 7"', die des Schwanzes betrug 13", ganze Länge $21^{\prime \prime} 7^{\prime \prime \prime}$. -

Den Nachrichten der verschiedenen Schriftsteller zufolge findet sich der Sahuï mit weifsem Ohrbusche in verschiedenen Theilen von SüdAmerica. - Im holländischen Guiana soll er nicht vorkommen ${ }^{*}$ ), obgleich ihn Stedmann dahin versetzt hat, und ob er in Cayenne gefunden werde, bezweifle ich. - Er scheint demnach blo؟s auf Brasilien eingeschränkt zu seyn. Marcgrave fand ihn in Pernambuco, ob aber die Stelle des Pater Abbeville, die man auf diese Species deutete, auch wirklich hierhin gehöre, bezweifle ich, da man jetzt schon viele ähnliche Thiere kennt, es ist mir demnach noch ungewils, oder vielmehr unwahrscheinlich, dafs dieser Sahuï auch am Amazonenstrome vorkommen soll. An der Ostküste habe ich diese Thierart nicht weiter südlich, als in der Gegend $\operatorname{der} B a$ hia de todos os Santos gefunden, ich kann also die südlichste Gränze ihres Aufenthalts höchstens bis zu dem 14ten Grade südlicher Breite annehmen, da ich glaube, dafs sie nur bis zu dem 13ten Grade hinabgeht, -

*) Siehe v. Sack Reise nach Surinam, 2te Abtheilung, p. 208. 
Diese kleinen Sahuis finden sich in den un. mittelbaren Umgebungen der Stadt So Salvador (Bahia) und kommen daselbst in die Pflanzungen der äufseren Wohnungen, welche am Rande der benachbarten niederen Gebüsche gelegen sind. - Ihre Lebensart ist die aller nachfolgenden Specien. - Sie ziehen in kleinen Gesellschaften von einer oder ein paar Familien, also $3,4,5$ bis 8 Individuen umher und geben beständig einen kleinen fein pfeifenden oder zischenden Ton von sich, wie kleine Vögel. Buffon sagt, ihre Stimme klinge uistiti! wonach er das Thierchen benannt habe, jedoch gehört wohl eine etwas lebhafte Einbildungskraft dazu, wenn man dieses Wort in der einsylbigen Stimme des Sahuï erkennen will. Ihre Nahrung besteht in mancherlei Früchten, besonders in den Pllanzungen in Bananen, aber sie fressen auch viele Insecten, Spinnen und dergleichen, dafs man jedoch diese Thierchen sogar Fische verzehren lassen will, ist gewifs ein Irrthum; denn wenn auch im gezähmten Zustande ein solcher Fall sich ereignet, so möchte von der unnatürlichen Lage, in welcher das Thier sich befindet, wohl nicht auf den freien Zustand zu schliefsen seyn; gewöhnt sich doch das Reh im gezähmten Zustande das Fleisch seiner eigenen Art zu 
verzehrel. Am Tage sind diese Thierchen in beständiger Bewegung, bei Nacht sitzen sie stille, beugen sich zusammen, wenn sie schlafen, und bedecken den Kopf mit dem Schwanze. Das Weibchen wirft mehrere Junge, öfters soll aber nur eins aufkommen, und diese werden von der Mutter umher getragen, wie bei allen Quadrumanen. Eine höchst interessante Beschreibung der Fortpflanzung dieser Thiere in unserem Kli. ma, so wie aller ihrer Manieren und Eigenheiten haben wir in dem schönen Säugthierwerke der Herren Geoffroy und Fr. Cuvier erhalten, sie muls uns höchst interessant bleiben, da in den grofsen Wäldern, welche das Vaterland jener Thiere sind, eine nähere Beobachtung sehr schwierig ist - Höchst interessant ist die Bemerkung, dals Männchen und Weibchen einander die Last des Tragens der Jungen abnahmen, wovon ich nie bei den Affen gehört habe, da wir auch nur weibliche mit ihren Jungen beladene Affen erlegt haben. Ich selbst habe nie Gelegenheit gehabt, weibliche Individuen des Sahuil's mit weifsem Ohrbusche zu untersuchen, habe aber gehört, das sie eins bis zwei Junge erziehen - Erlegt man die Mutter und bekommt das Junge lebend, so heftet sich dasselbe sogleich fest an den Pfleger an und bleibt ihm 
auch sehr zugethan, wern es erwachsen ist. Gegen die kühle Seeluft oder die Temperatur der gemälsigten Zone sind diese Thierchen sehr empfindlich, und selbst in einem warmen Kästchen geschützt, sterben die meisten von ihnen während der Seereise. Sie haben in ihrer Lebensart viel von den Eichhörnchen, sind besonders im Springen und Klettern geschickt. Azara hat dieses Thier unter der Benennung Titè beschrieben, ein Name, welchen man in Brasilien nicht zu kennen scheint; dagegen belegt man es in der Gegend von Bahía mit der Benennung Sahuim (Sahui).

Herr Dr. v. Spix hat uns in seinem neuen interessanten Werke über die brasilianischen Affen die Beschreibung und Abbildung eines weifshalsigen Sahuï's (Jacchus albicollis $S p$.) gegeben, welche ich für eine Varietät des gemeinen Uistiti halte, da dieser ebenfalls den weifsen Ohrbusch und gänzlich denselben Aufenthalt hat, mir selbst auch mit sehr fahl graubraunem Halse vorgekommen ist.

2. H. leucocephalus Kuhlii.

Der. Sahü mit. weifsem Kopfe.

Kuhl Beitr. pag. 47.

Jacchus leucocephalus, Geoffr. Ann. d. Mus. T. XIX. pag. 119. 


\section{$-136$}

Simia Groffroii, Humb. Zool. Abhandl. T. I. p. 360. Abbildungen zur Naturgeschichte Brasilien's.

Sahuim de cara branca bei den Brasilianern.

Eine sehr schöne, von Geoffroy zuerst bekannt gemachte Art, welche noch nirgends weitläuftig beschrieben worden ist.

Beschreibung eines recht vollkommenen männ. chen Thierchens:

Gesicht, Körper, FüIse und ganze Gestalt gebildet wie an der vorhin erwähnten Art. Der Kopf ist klein, rund, die Schnauze sehr wenig vortretend, bis über die Augen sehr steil aufsteigend, wo ein sehr stark vortretender Stirnwinkel sich befindet, von welchem alsdann die Stirn sehr flachgedrückt nach hinten abfällt, welches bei allen Jacchus - Arten mehr oder weniger der Fall ist. - Die lebhaften Augen sind rund, mit gelbbrauner Iris; oberes Augenlied nackt und gelbröthlich gefärbt; Scheidung der Nasenlöcher breit, eine Nath von feinen graubräunlichen Härchen bildet hier eine Kante; Ohren sehr grofs, muschelförmig, mit wenig um. gerolltem, völlig dünnem scharfen Rande.

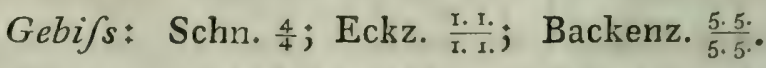
Obere Eckzähne grofs, kegelförmig, etwas nach aufsen gekrümmt und von den Schneidezähnen getrennt; die unteren sind kürzer, dicht an die 


\section{$-137$}

Schneidezähne gereiht, von deren äufserstem sie sich durch nichts unterscheiden; vier Schneidezähne oben und unten; die oberen beiden mittleren sind vereinigt mit breiter Schneide, daneben steht auf jeder Seite ein etwas getrennter, eben so langer, etwas kegelförmiger und kleinerer Schneidezahn; die vier unteren sind nahe aneinander gereihet, die beiden mittleren etwas kürzer; Backenzähne fünf oben und unten an jeder Seite; die drei vorderen im Oberkiefer haben nach aulsen eine Spitze und nach innen einen Höcker; der vierte und fünfte nach aufsen zwei Spitzen; im Unterkiefer ist es eben so, nur sind die beiden hinteren Zähne mit vier ziemlich gleichen Spitzen versehen. -

Der Hals ist kurz; der Schwanz etwa doppelt so lang als der Körper, dabei schlaff; die Vorderhände haben fünf zusammengedrückte, starke, gekrümmte Krallennägel; an den Hinterhänden sind sie eben so, nur hat der Daumen einen kurzen, platten, menschlichen Kuppennagel. - Männliche Geschlechtstheile gebildet wie am Sahuï mit weilsem Ohrbusche, dabei nackt. wie der After. -

Stirn, Backen und Kehle mit weifsen, dichten, etwas glänzenden kurzen Haaren bedeckt; sie schliefsen das kleine, nackte, graubräunliche 


\section{$-138$}

Gesichtchen enge ein, und laufen auf dem Bakken unter dem Auge mit einer Spitze in dassel. be hinein. - Vor dem oberen Theile des Ohrs steht ein langer schwarzer Haarbüschel; Rand der Oberlippe, Nase und Nasenrücken mit sehr kleinen, feinen, blafs graubräunlichen Härchen besetzt; Hände und Finger von aufsen stark behaart, von innen mit einer nackten, dunkel graubraunen Haut bedeckt, kalt und feucht wie an allen Quadrumanen. - Haare vor und um die Ohren herum, Scheitel, Hals, Schultern und Oberrücken sind schwarz; Unterhals blafs graubräunlich; Mittel - und Unterrücken, Seiten, Schwanz, Arme und äufsere Seite der Beine schwarz mit langen weifslichen Haarspitzen, aber überall stark rostroth durchschimmernd; denn die über einen Zoll langen Haare des Rückens und der Seiten sind an der Wurzel dunkelgrau, dann breit rostroth, nachher schwarz, und mit einer weifslichen Spitze versehen. - Die vier Hände sind völlig schwärzlich, ohne weifsliche Beimischung; am Schwanze bemerkt man aufser den überall verbreiteten weifslichen Haarspitzen, auch etwas undeutliche, ziemlich verloschene weilsliche Ringe, welche in der Mitte desselben am weitesten von einander entfernt und am deutlichsten sind; die Spitze des Schwanzes ist 


\section{- 139}

weilslich; der Bauch ist dünne braunschwärzlich behaart. - Die Nägel der Hände sind schwarz. braun gefärbt. -

Ausmessung des vorhin beschriebenen männlichen Thierchens:

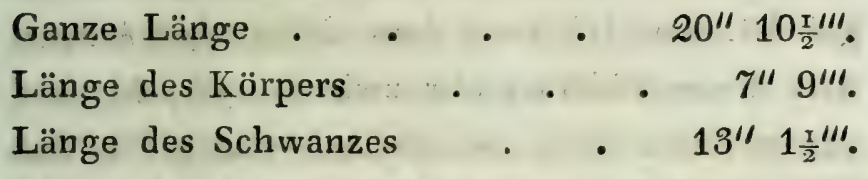

Länge des Arms rom Schultergelenk $5^{\prime \prime}{ }^{\prime \prime}{ }^{\prime \prime \prime}$. Länge des Beins von der Hüfte • $6^{\prime \prime} 5^{\prime \prime \prime}$. Länge der Vorderhand . • . 11"'. Länge der Hinterhand • • . $2^{\prime \prime} 7^{\prime \prime \prime}$. Länge von der Nasenspitze bis zu dem hinteren Ohrrande. . . $2^{\prime \prime} 3^{\prime \prime \prime}$. Länge von dem Oberlippenrande bis zu

dem vorspringenden Stirnwinkel etwa $9^{\prime \prime \prime}$. Höhe des äufseren Ohres 1 1" $1^{\prime \prime \prime}$.

Der Schädel dieser Art ist stark verlängert, auf dem Scheitel ziemlich erhaben, die Nasenknochen sind etwas gewölbt, die Vorderzähne stark vorstrebend, die Eckzähne im Verhältnifs grofs und sehr zugespitzt. - Die Augenhöhlen sind weit, der Jochbogen sehr zart und dünn.

Der Sahuï mit weifsem Kopf scheint unter den Jacchus -Arten der Ostküste diejenige, wel- 
clie am weitesten südlich hinabgeht. Ich fand ihn am Espirito Santo, kann aber nicht genau angeben, ob er nördlich den Rio Doçe erreicht oder überschreitet, da ich in den diesen Strom beschattenden Wäldern, wegen der Unsicherheit durch die Botocuden, nur sehr wenig habe ja. gen können. Ich kann dem zufolge den Aufenthalt dieser Thierart nur zwischen den 20. und 21sten Grad südlizher Breite setzen. In den Wäldern des Espirito Santo, besonders in den Vorgebüschen derselben und den die Flufsufer einfassenden Mangue - Gebüschen *), so wie in den mit niederen Palmengesträuchen ${ }^{* *}$ ) angefüllten sandigen Gegenden am Meere, unfern der Mündung des Espirito Santo, bei Cidade de Victoria, Villa Velha do Espirito Santo, und in den dem Flusse Jucú, den Fazendas von Araçatiba, Coroaba u. s. w. nahe gelegenen Wäldern waren diese niedlichen, angenehmen Thierchen nicht selten. - Sie durchziehen familienweise oder einige wenige Familien vereinigt, von Ast zu Ast springend die Gebüsche, besonders die niederen dicht verflochte-

*) Conocarpus - und Avicennia-Gebüsche.

**) Die Gebüsche der Allagoptera pumila und einiger andern Arten. 


\section{$-141$}

nen mit Cocos und der Allagoptera pumila vermischten, deren Nïsse sie aufsuchen sollen; mancherlei Früchte und Insecten sind ihre Nahrung, besonders lieben sie auch die Bananen, und kommen defshalb in die Pflanzungen. Ihre kleine zischende Stimme lassen sie beständig hören. - Sie sollen eins bis zwei Junge werfen und an der Brust und auf dem Rücken mit sich umher tragen, welches meine Jäger öfters zu sehen Gelegenheit hatten.

Man sucht diese Thierchen sehr, um sie gezähmt in den Wohnungen zu halten, zu diesem Zwecke erhält man die Jungen, wenn man die Alten schiefst, oder man fängt sie auch auf den Bäumen mit einem Fischkorbe, in welchen man Bananen legt, sie kriechen hinein und können, wegen der einwärts trichterförmig angebrachten spitzigen Stöcke, sich nicht wieder hinausfinden; oft soll man auf diese Art mehrere-zugleichfangen.

Diese schöne Art ist in Brasilien so wie in Europa wenig bekannt, auch in den Cabinetten ist sie selten, eine natürliche Folge von der geringen Kenntnils, welche man bisher von der Ostküste zwischen Rio de Janeiro und $\operatorname{der} B a$ hia de todos os Santos hatte. - Der Engländer Henderson erwähnt ihrer in seiner History 
of the Brazils (pag. 291.), einem Buche, welches grofsentheils nach der Corografia brasilica gemacht ist. -

3. H. penicillatus Kuhlii.

Sa hü mit schwarzem Ohrpinsel.

Kuhl, Beiträge u. s. w., pag. 47.

Jacchus penicillatus, Geoffr. Ann. d. Mus. T. 19. pag. 119.

Simıa penicillata, Humb. Abhandl, aus der Zool. etc.

T. 1. pag. 360.

Jacchus penicillatus, Sp.

Abbildungen zur Naturgeschichte Brasilien's.

Sahuim in der Gegend von Belmonte, am Rio Pardo und Ilhéos.

Gnick - Gnick (wie franz. ausgespr.) bei den Botocuden.

Dieser Sahuï gleicht dem vorhergehenden sehr, nur ist sein Haar etwas anders gefärbt, und der Ohrbusch weniger ausgebreitet in einen dünnen Büschel oder Pinsel vereinigt. Der Körper hat dieselbe Bildung als bei dem vorhergehenden, auch haben beide einerlei Gebils. Die Vorderhände haben fünf gleiche Krallennägel, und die innere Zehe, welche den Daumen vorstellt, ist etwas kürzer als die übrigen. Schwanz $1 \frac{1}{2}$ mal so lang als der Körper.

Beschreibung eines männlichen Thierchens:

Die Iris des Auges ist gelbbräunlich; das Gesicht nackt und bräunlich; Scheitel weifslich 


\section{$-143-$}

graubraun; Stirn über den Augen mit einem rundlichen weifsen Eleckchen bezeichnet; Bakken, Kinn und Kehle sind schmutzig weilslich, an den Backen am weilsesten; der Unterkiefer und die Einfassung des Mundes sind weifslich, die Kehle dunkelgraubraun; das Ohr ist nackt und schwärzlichbraun gefärbt, vor demselben steht ein langer glänzend schwarzer Haarbüschel; Nacken, Seiten - und Untertheil des Halses schwarzbraun, so wie Schultern und Brust. Haar am Leibe sanft und etwas lang, an der Wurzel schwärzlichgrau, dann breit rothbraun, nachher schwarz und an der Spitze weifslich; auf dem Rücken bemerkt man die rothbraune Farbe wenig; in den Seiten und an den Hinterbeinen mehr; an den vier Beinen sind die weiIsen Haarspitzen kleiner und sparsamer, und an den Vorderbeinen sind sie kaum bemerkbar. Bei manchen Individuen erscheinen die Hinterbeine dunkelröthlich - braun mit schwarzen Haarspitzen, die Vorderbeine sind alsdann beinahe schwarzbraun und die Hände völlig schwärzlich; Bauch schwärzlichbraun; Schwanz mäfsig dick behaart, schwärzlich mit langen weifslichen Haarspitzen, welche etwas stufenförmig weifsliliche Ringe bilden. 


\section{$-144$}

Der Schädel unterscheidet sich von dem der vorhergehenden Art wenig, er scheint auf dem Scheitel etwas mehr abgeflächt, auch streben die Vorderzähne nicht so stark vorwärts. Ausmessung des beschriebenen männlichen

\section{Thierchens:}

Ganze Länge • • . . $20^{\prime \prime} 11^{\prime \prime \prime}$.

Länge des Körpers • • • • $8^{\prime \prime} 5^{\prime \prime \prime}$. Länge des Schwanzes . . . 1 13" $7^{\prime \prime \prime}$.

Länge des Arms vom Schultergelenk

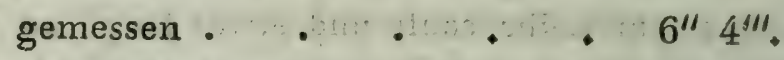

Länge des Beins von der Hüfte : $\quad 7^{\prime \prime}$ -

Länge der Vorderhand . . : : $1^{\prime \prime} 7_{\frac{1}{2}}{ }^{\prime \prime \prime}$.

Länge der Hinterhand . • . $\quad 2^{\prime \prime} 8^{\prime \prime \prime}$.

Länge des Vorderdaumen beinahe . $8^{\prime \prime \prime}$.

Länge von der Nasenspitze bis zu dem

oberen Ohrwinkel beinahe . . $9^{\prime \prime \prime}$.

Höhe des äufseren Ohres • . . 9 $\frac{\text { r }}{2}{ }^{\prime \prime \prime}$.

Länge des oberen Eckzahnes . : $2^{\prime \prime \prime}$.

Länge des unteren Eckzahnes . . . 2"'.

Ausmessung eines weiblichen Thierchens:

Ganze Länge . . . . 2 20 $6 \frac{\mathrm{r}}{2}{ }^{\prime \prime \prime}$.

Länge des Körpers : ‘ : : $\quad 8^{\prime \prime} 4 \frac{x}{2}{ }^{\prime \prime \prime}$.

Länge des Schwanzes : . . $12^{\prime \prime} 2^{\prime \prime \prime}$.

Länge des Arms vom Schultergelenk $5^{\prime \prime} 11^{\prime \prime \prime}$.

Länge des Beins von der Hüftkugel : $7^{\prime \prime} 2^{\prime \prime \prime}$.

Länge der Vorderhand : . . $\quad 1^{\prime \prime} 8^{\prime \prime \prime}$. 


\section{$-145$}

Länge der Hinterhand Länge des Vorderdaumens Länge von der Nasenspitze bis zu dem oberen Ohrwinkel . . . . 1" $1^{\prime \prime} 8^{\prime \prime \prime}$.

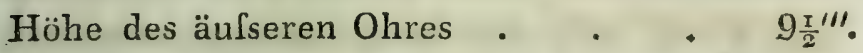

Dieser kleine Sahuï lebt an der Mündung des Flusses Belmonte in Gesellschaften von 8 bis 10 Stück in den die Flüsse einfassenden Mangue-Gebüschen, findet sich aber ebenfalls in den grofsen inneren Urwaldungen am Bclmonte, Rio Pardo, Ilhéos, bis in die Gegend der Scrra do Mundo Novo hin, wo wir ihn an der verwilderten Waldstrafse des Tenente-Coronel Filisberto erlegten. - Da er an der Ostküste südlich bis an den Sahuï mit weifsem Kopfe gränzt, so kann ich seinen Wohnort für diese Gegend etwa zwischen den 14ten und 17ten Grad südlicher Brei. te setzen, ob ich ihn gleich südlich nur am $B c$ lmonte, und nördlich bis in den Sertam von 11 héos oder des Rio da Cachoeira gefunden habe, er lebt aber, nach Spix, auch in der Provinz Minas Geraës, und soll von da bis Rio de Janeiro hinabgehen.

Diese Thierchen springen geschickt und geben einen kurzen zischenden Pfiff von sich, doch ist ihre Stimme schwächer als die der vorhergehenden Art, sie haben auch völlig die Lebens. II, Bnnd. 


\section{$-146$}

art der früher erwähnten Specien. Ich mufs hier noch anmerken, dafs die Sahuïs der hier beschriebenen Art, welche ich in den inneren Waldungen von llhéos fand, zwar mit denen vom Flusse Belmonte ganz identisch scheinen, dennoch aber kleine Verschiedenheiten zeigen. -

Der Sahuï mit schwarzem Ohrpinsel aus den Waldungen am Flusse Ilhéos hat die Backen und Seiten des Gesichts nicht weifslich, sondern gelblich-blals, auch fällt das weilse Stirnfleckchen in's Gelbe, und von ihm läuft über den Rücken der Nase herab ein Strich von kleinen weilslichen Haaren; der schwarze Haarbusch vor dem Ohre reicht kaum über dasselbe hinaus. - $\mathrm{Di}$; Iris des Auges fällt mehr in's Citronengelbe als bei allen andern von mir beobachteten Affen. Das Haar oben auf dem Scheitel ist weich, zart, beinahe vier Linien lang, aber platt aufliegend; von der weifslichen Blässe oder dem Stirnfleck aus läuft über die Mitte des Kopfes hinauf in einer Längsgrube eine undeutliche weifsliche $\mathrm{Li}$ nie. Das Gesichtchen ist rundum mit dichten, weichen, kurzen Haaren eingefafst, nur vor dem Ohre in dem schwarzen Büschel sind sie ein wenig länger. - Fin älieres Individuum als das 


\section{$-147$}

vorhin gemessene Exemplar gab folgende Ausmessung:

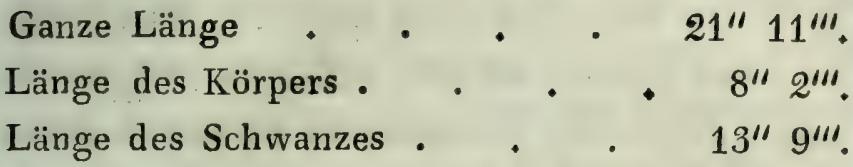

Der Hauptunterschied, welcher diese zuletzt angegebene Varietät aus dem Sertam von Ilhéos von der des Rio Grande de Belmonte unterscheidet, ist der mehr kurz behaarte Kopf, welcher oft sehr glatt ist, und der scheinhar mehr fleischige Obertheil desselben, indem man an jeder Seite des Scheitels eine durch den Schläfenmuskel verursachte Erhöhung, und auf der Mitte des Kopfs eine Längsfurche wahrnimmt. Diese kleinen Abweichungen sind jedoch nicht hinreichend, um beide, übrigens vollkommen übereinstimmende Thierchen zu trennen, besonders da die Kürze der Kopthaare den fleischigen Theil des Scheitels mehr in die Augen fallen läfst, und man sich defshalb in dieser Hinsicht leicht irren kann. -

b. Sahuïs mit langen mähnenartig das Gesichtchen umgebenden Haaren, welche gleich einem Kragen aufgerichtet werden. - Löwen-Sahuïs.

Herr Professor Geoffroy hat einige Arten dieser Abtheilung in sein Geschlecht Midas ge. 
bracht, da ihr Gebils durch mehr gleichgebildete, einander mehr genäherte Vorderzähne eine kleine Verschiedenheit zeigt. - Dieser Unterschied hat mir oft sehr unbedeutend geschienen, und ich bin defohalb hier der Illigerschen Eintheilung gefolgt. -

Die Thierchen dieser Abtheilung zeichnen sich durch ihr Aufrichten der langen Haare des Gesichtskreises aus, welches ihnen das zierliche Ansehen eines kleinen Löwen giebt. - Ihr Schwanz ist gewöhnlich etwas dünner als der der Jacchus - Arten.

\section{4. $H_{4} R$ os a $l i a$, Illig.}

$\mathrm{D}$ e $\mathrm{r} \quad \mathrm{o} \quad \mathrm{t}$ h $\mathrm{e} \quad \mathrm{S}$ a $\mathrm{h}$ u

Simia Rosalia Linn.

Midas rosalia, Geoffr. Ann. d. Mus. T. XIX. p. 121.

- - Humb. zool. Abhandl. T. I. p. 361.

- - Kuhl Beiträge u. s. w. p. 51.

Abbildungen zur Naturgeschichte Brasilien's.

Sahuin vermelho der Brasilianer.

Der rothe Sahui oder Marikina des Buffon $*$ ) ist bekannt und vielfältig von den Naturforchern erwähnt worden, auch hat man mehrere Abbildungen von ihm, welche indessen

-) Die Benenuung Marikinn hat Buffon dieser Art beigelegt, sie soll rom Maranhão stammen, scheint aber dort piner zanz anderen Thierart beigelegt zu wordou. 
sämmtlich nicht völlig naturgetreu sind. - Die beste bisjetzt bekannte Beschreibung ist die, welche die Herren Genffroy und Fr. Cuvier in ihrem schönen Säugthierwerke von einem noch nicht völlig ausgewachsenen Thierchen dieser Art gegeben haben. Da man aufser der genannten, wenig genaue Beschreibungen von ihm hat, so werde ich einen kleinen Beitrag zu der Ausfüllung dieser Lücke, nach den von uns in den Wäldern der Gegend von Cabo Frio erlegten Exemplaren geben.

Beschreibung, als Zusatz zu der der Herren Geoffroy und Fr. Cuvier :

Dieser Sahuï hat ein nacktes graubraunes Gesicht, und eine gelbröthlich-braune Iris im Auge; die Ohren sind grofs, auf ihrem Rande mit schwarzbraunen Haaren besetzt, wodurch ein schwarzbrauner Haarzopf in den gelbrothen Haaren des Kopfes entsteht. Der Stirnwinkel ist sehr vortretend und der Kopf darüber abgeplattet; Stirn und Seiten der Backen sind mit feinen, kurzen gelbbräunlichen Haaren besetzt; diese kurz und fein behaarte Stirn tritt mit einem spitzigen Winkel gegen das Kopfhaar hinauf; Haar auf dem Scheitel ziemlich lang, in zwei Toupets getheilt, welche die Farbe des Körpers haben; zwischen diesen beiden Haar- 
büscheln befindet sich eine Scheidung oder ein Längsstreif von kürzeren schwarzbraunen Haaren; die langen das Gesicht an den Seiten einschliefsenden Haare sind dunkelbraun; übriger Kopf, Kehle, Brust und Arme sind dunkel goldfarben-orangenbraun, das übrige Thier röthlich gelb, mit vortrefflichem Goldglanze; die vier Hände, besonders die vorderen sind aufsen und innen schwärzlich-braun, die hinteren aber sehr stark gelb gemischt; Schwanz an der Wurzel zuweilen gelbröthlich wie der Leib, dann schwarz gefleckt und endlich ganz schwärzlich mit einzelnen Goldhaaren, die Spitze aber ist wieder gelb, bei andern Individuen ist er gänzlich ungefleckt.

Das Weibchen soll sich vom Männchen nicht unterscheiden; die Exemplare, welche meine Jäger erlegten, waren zufällig sämmtlich männlichen Geschlechts.

\section{Ausmessung:}

Ganze Länge

Länge des Körpers

Länge des Schwanzes

Es giebt aber noch gröfsere Individuen. -

Dieses niedliche Thier findet sich in den grofsen Wäldern der Gegend von Rio de Janeiro, Cabo Frio, S. Joào u. s. w., geht aber 
nicht weit nördlich, da ich es am Parahyba schon nicht mehr beobachtet habe. - Dem Gesagten zufolge kann ich seinen Aufenthalt in den Waldungen der Ostküste nur zwischen den 22sten und 23sten Grad südlicher Breite setzen; so!lte es wirklich in Guiana vorkommen, wie man sagt, so mag es seinen Zusammenhang mit dem Süden durch die inneren Provinzen von Brasilien haben, welches ich indessen sehr bezweifle, da ich diese Thierart dem südlichen Bra:ilien allein eigen glaube. - Herr $v$. Sack sagt in seiner Reise nach Surinam (1ste Abth. pag. 208), dafs sie daselbst nicht vorkomme. Ob sie von Rio de Janeiro noch weiter südlich nach S. Paulo hinabgeht, werden die daselbst gewesenen Naturforscher bestimmen können. -

Der rothe Sahuí ist nirgends zahlreich, wir haben ihn nur einzeln oder familienweise angetrofien, besonders in der Serra de Inuć, im Wa!de von S. João und in den gebirgigen ITaldungen, welche die Gegend von Ponta Negra und Gurapina umgeben. Er scheirt even sowohl die Gebüsche der sandigen Ebenen als die hohen gebirgigen Wälder zu bewohnen und vorzüglich gern in belaubten Baumkronen sich $\mathrm{zu}$ verbergen, sobald er einen fremdartigen $\mathrm{Ge}$ genstand bemerkt. Seine Nahrung besteht in 
Früchten und Insecten. Er wirft wahrschein. lich ein oder ein Paar Junge, welche das Weib. chen auf dem Rücken und an der Brust umlierträgt, bis sie stark genug sind ihr zu folgen.

Im gezähmten Zustande sollen diese Thierchen nicht so zärtlich für den Transport auf dem Meere seyn, als die vorhergehenden. - Man liebt sie sehr wegen ihrer Schünheit, indem sie einem kleinen Löwen gleichen. Bei einem jeden Affecte richten sie den das Gesichtchen umgebenden Haarkreis auf und nehmen sich alsdann höchst niedlich aus. - Die Lebensart dieser Thiere kommt übrigens vollkommen mit der der übrigen Saluuïs überein. -

In den von mir besuchten Gegenden kennt man dieses Thier allgemein unter dem Namen des rothen Sahuï's (Sahuim vermelho), auch findet man, wie gesagt, daselbst die beiden Varietäten mit geflecktem und mit ungeflecktem Schwanze, woron man die erstere für die guianische, die letztere aber für die brasilianische hielt, welches also nun als ungegründet zu ver. werfen ist.

Man hat in den naturhistorischen Werken mehrere Abbildungen dieses Thiers. Audebert's Tafel hat wenig Werth; diese Figur ist $z u$ plump, das Gesicht in seinen Zügen verfehlt, 
so wie die herrliche Goldfarbe nur sehr matt ausgedrückt ist. - Die Abbildung der Herren Genffroy und Fr. Cuvier stellt ein noch junges Thier vor; sie ist, obgleich nicht ganz ähnlich, dennoch immer die beste bisjetzt bekannte, allein sie hat einen zu kleinen Maafsstab und zeigt den Schwanz scheinbar zweizeilig, wie bei den Eichhörnchen, welches in der Natur nicht der Fall ist.

\section{H. chrysomelas.}

Schwarz und rostfarbener Löwen - Sahü.

L. Körper schwarz; Gesichtskreis und Vorderarme rostroth; Stirn hellgelb, ein ähnlicher Streif auf der Oberseite des Schwanzes von der Wurzel. bis zu der Mitte desselben. -

Meine Reise nach Brasilien, B. II, p. 157.

Kuhl, Beiträge u. s. w. pag 51.

Schinz Thierreich, B. I. p. 140 .

Abbilảungen zur Naturgeschichte Brasilien's.

Sahuim preto oder do Sertam im Sertam von Ilhéos und des Rio Pardo.

Pakakang bei den Botocuderi.

Gestalt im Allgemeinen die des rothen Sahuï oder Marikina, mit einem hohen aufgerichteten Haarkragen, welcher das Gesichtchen umgiebt, und einem schlaffen Schwanze, welcher länger ist als der Körper. 
Beschreibung eines recht vollhommenen männlichen Thierchens:

Gesichtchen klein, wenig vortretend, mit lebhaften runden Augen; Nasenlöcher nach den Seiten geöffnet, mit breiter Scheidung; Ohr glatt, feinhäutig, glänzend, menschenähnlich und wenig behaart, mit glattem nicht umgerolltem Rande, in den langen Haaren des Kopfes verborgen; Gesicht von langen Haaren umgeben, welche im Affecte $z u$ einem strahlenartig ausgebreiteten Kragen aufgerichtet werden; von der Seite gesehen, bemerkt man in dieser Stellung des Kragens das Gesichtchen kaum, da diese Haare oft weit vor die perpendiculäre Fläche des Gesichts vortreten. Die Stirn ist bis zwischen die Augen herab behaart, bildet also nicht das nackte aufwärts zugespitzte Dreieck der Stirn des Rosalia. - Bildung des Gesichts völlig wie an der eben erwähnten Art, auch ist das Gebifs dasselbe.

Gebifs: Schn. $\frac{4}{4}$; Eckz, $\frac{\text { I.r.r. }}{1.1 .}$; Backenz. ${ }_{5.5}^{5.5}$. Die vier oberen Schneidezähne stehen nahe aneinander, die beiden mittleren sind breiter als die äufseren; von den vier unteren sind die beiden mittleren etwas schmäler, gerade wie am Rosalia, ihre Kronen sind ziemlich gleich abgeschnitten; obere Eckzähne kegelförmig, stark, 
ein wenig auswärts gerichtet, durch einen Raum von den Schneidezähnen getrennt und an ihrer Vorderseite mit einer Längsfurche bezeichnet; untere Eckzähne an die Schneidezähne anstoIsend, kleiner als die oberen, und ebenfalls ein wenig mit der Spitze auswärts gerichtet; Bakkenzähne oben und unten 10 in jedem Kiefer, die drei vorderen an jeder Seite oben haben an der äufseren Seite eine kleine Kegelspitze, die beiden hinteren jeder zwei Spitzen, allein an ihrer inneren Seite sind sie abgeflächt und ein wenig höckerig; im Unterkiefer hat nur der erste Backenzahn eine äufsere Kegelspitze, die übrigen sind abgeflächt und mit mehreren Höckern versehen.

Vorderhände schmal, mit fünf gleichartigen, zusammengedrückten Krallennägeln; der kurze Daumen ist den Fingern nicht entggegen gestelit und hat einen ähnlichen Krallennagुel; Finger dünn und schlank, auf ihrer Oberfläche behaart, der Zeigefinger etwa dreimal so lang als der Daumen, der Mittelfinger ist vier Linien länger als der Zeigefinger, der vierte Finger ist um einige Linien kürzer als der Mittelfinger, und der kleine ist etwas über vier Linien kürzer als der vorhergehende. Die Hinterhand ist vollkommen, lang und schmal, sie ist breiter 
und länger als die Vorderhand; ihr Daumen ist kurz, aber mit einem platten menschlichen Kuppennagel versehen; - Zeigefinger $3 \frac{\mathrm{r}}{2}$ Linien kürzer als der Mittelfinger, dieser um $\frac{T}{2}$ Linie lsürzer als der vierte Finger, welcher wieder um $S_{\frac{1}{2}}$ Linien länger ist als der kleine. Alle diese vier Finger der Hinterhände haben zusammen gedrückte Krallennägel wie die Vorderfinger. Schwanz länger als der Körper, glatt, rund, mäfsig lang behaart, unter der Wurzel ein wenig nackt, an der Spitze mit einem dünnen verlängerten Haarpinsel.

Geschlechtstheile etwa wie am Eichhörnchen gebildet; die Eichel ist wie an diesen, und nicht breit und champignonförm:g wie am Geschlechte Cebus; sie stehen weit nach hinten und sind nackt.

Die Nase, die Ober- und Unterlippe sind mit feinen gelblichen Härchen besetzt; Haar des ganzen Körpers sanft, zart, dicht, zwei Zoll lang, am Leibe etwas vorwärts gekrümmt, an den Schenkeln und dem Schwanze kürzer und glatt; rund um das Gesicht fangen sogleich lange, hoch goldrothbraune oder glänzend orangenfarbene Haare an, welche $2 \frac{\mathrm{T}}{2} \mathrm{Zoll}$ lang sind, sie bilden im Affecte den originellen, das Thierchen ausnehmend zierenden Kragen. Ueber der Stirn, 


\section{$-157$}

welche mit einem starken Winkel vortritt, fällt der Scheitel plötzlich flach zurück, die Stirn ist der blasseste, mehr röthlich-gelbe Theil der Gesichtseinfassung, deren übrige Theile glänzend feurig rothbraun mit einem Goldglanze erscheinen; am dunkelsten sind diese schönen Haare an Backen und Kinn. - Dieselbe goldrothbraune Farbe haben die ganzen Vorderarme vom Ellenbogen abwärts mit den Händen. - Der ganze übrige Körper, selbst die Haare vor und um das Ohr von der Mitte des Scheitels an, sind alle glänzend dunkel bräunlich-schwarz, am Hintertheil des Leibes etwas mehr in's Bräunliche ziehend, so wie sie überhaupt im Lichte einen etwas röthlichen Schimmer zeigen; - Bauch lang aber ein wenig dünner behaart als der übrige Körper, eben so die innere Seite der Schenkel in der oberen Gegend; innere Seite der Arme oder Vorderbeine grofsentheils schwarzbraun behaart; Hinterhände schwarzbraun, aber mit einzelnen rothbraunen Haaren gemischt. - Ein angenehm hell röthlich-gelber, beinahe goldfarbener Streif, etwa von der Farbe der Stirn, entspringt auf der Schwanzwurzel und läuft auf der Oberseite desselben bis zu dessen Mitte fort, wo er sich in eine Spitze endigt. - Der Glanz aller der gelben und oran- 
genfarbenen Theile dieses schönen Thierchens läIst sich am besten mit dem der sogenannten Flockseide vergleichen. - Fufssohlen und innere Seite der Hünde sind nackt, feucht, kalt und röthlich-schwarzbraun gefärbt. - Die nackten Theile des Gesichts sind dunkelgrau, mit einér schwachen Mischung von röthlichbraun. Die Iris des Auges ist dunkel graubraun; Geschlechtstheile weifsröthlich. -

Weibliches Thier: Die Brüste sind etwas nackt und die linke Brustwarze ist verlängert, welches vermuthen läfst, dafs diese Thiere gewöhnlich nur ein Junges aufbringen. -

Die Jungen sind weder in Gestalt noch Färbung von den Alten verschieden, nur fand ich auf dem Schwanze nicht einen langen gelben Streif, sondern einen kïrzeren, fahlgelben und rothbraun gemischten Fleck, der an seinem Ende rund um den Schwanz herumläuft; die Hinterhände waren an diesen jungen, überaus niedlichen Thierchen ebenfalls rothbraun; das Gesichtchen war dunkel grauröthlich, aber blässer gefärbt als an den Alten.

Ausmessung des beschriebenen männlichen Thierchens.
Ganze Länge . . : : 20" 7"'. Länge des Körpers . . . $8^{\prime \prime} 8^{\prime \prime \prime}$. 
Länge des Schwanzes . • . 11" 11"'.

Länge des dünnen Haarbüschels am

Ende desselben .. . . . $\quad 1^{\prime \prime} 4^{\prime \prime \prime}$.

Höhe des äufseren Ohres • • 11"

Länge von der Nasenspitze bis zu dem

oberen vorderen Ohrrande . $1^{\prime \prime} 7_{\frac{1}{2}}{ }^{\prime \prime \prime}$.

Länge vom Oberlippenrande bis $\mathrm{zu}$

dem Stirnwinkel . . . . $1^{\prime \prime}$ -

Länge des Arıns vom Schultergelenke

gemessen . . . . . $6^{\prime \prime} 6^{\prime \prime \prime}$.

Länge des Beins von der Hüfte $\quad 8^{\prime \prime}$ -

Länge der Vorderhand . . . $2^{\prime \prime}$

Länge eines Vordernagels beinahe - $3 \frac{2}{3} "$ "

Länge eines Hinternagels • • . $3 \frac{3}{4}{ }^{\prime \prime \prime}$.

Länge des oberen Eckzahnes über . . $3^{\prime \prime \prime}$.

Länge des unteren Eckzahnes . . $3^{\prime \prime \prime}$.

Der Schädel̉ hat im Allgemeinen die gröfste Aehnlichkeit mit dem der Jacchus - Arten, von dem des penicillatus unterscheidet er sich durch geringeren Eindruck der Stirnknochen, so wie durch etwas stärkere Concavität der Nasenknochen. -

Dieser niedliche Sahuï lebt blofs in den inneren grofsen Waldungen des Sertam von $1 l$. $h e ́ o s$, vier bis fünf Tagereisen von der Seeküste entfernt, und nach der Versicherung der Botocuden ebenfalls in den grofsen inneren Wäldern 
am Rio Pardo, bis wohin diese ihre Streifzüge ausdehnen. Der Raum, in welchem ich diese Thierart, meinen Erfahrungen zufolge, sehen mufs, ist also zwischen 14 und $15 \frac{r}{2}$ Grade südlicher Breite eingeschlossen. - Ich habe diesen Sahuï am Bclmonte zwar nicht beobachtet, man kann sich jedoch auf die Aussage der Wilden in Hinsicht der Jagd vollkommen verlassen, und sie versicherten, dafs dieses von ihnen $P a$ kakang genannte Thierchen in den inneren Waldungen nördlich vom Flusse Belmonte vorkromme, auch habe ich im 2ten Theile der Beschreibung meiner Reise gesagt, dafs diese Wil. den den Rio Pardo nicht überschreiten, da dort ihre Feinde, die Camacan *) wohnen. - In den der Seeküste nahe gelegenen Gegenden würde es diesen kleinen Thieren unmöglich gewesen seyn, ein starkes schnell fliefsendes Wasser zu überschreiten, daher findet man sie mehr

*) Die Herren von Spix und Miartius schreiben dicsen Namen etwas verschieden von mir, ich schreibe ihn nach der Aussprache der Lente selbst, übrigens ist dieses willkülırlich, auch nennt die Corografic brasilica diesen Namen gar nicht, sondern belegt dieses Volk immer mit der Benennung Mongoyós. Herr Dr. v. Spix hat in seinem interessanten Werke iber die von ihm in Brasilien beobachteten Quadrumanen und Chiropteren den Schädel eines solchen Brasilianers abbilden lassen. - 
um die Quellen des Rio da Cachoeira, wo die kleinen, den Flufs bildenden Bäche ihren Streifzügen weniger Hindernisse in den Weg legen. Meine Jäger erlegten die ersten dieser Sahuîs etwa vier Tagereisen am Ilhéos aufwärts in den grofsen Waldungen, und von hier an trafen wir sie ziemlich häufig in Gesellschaften von vier bis zwölf Stück, oft auch nur einzeln oder gepaart. - Sie klettern, wie alle diese Thiere, sehr schnell, springen geschickt, sind neugierig und nicht besonders scheu. - Bemerken sie einen fremdartigen Gegenstand, so verbergen sie sich hinter den dicken. Aesten oder dem Stamme des Baumes, auf welchern sie sich befinden, und blicken blols mit dem kleinen Ge. sichtchen hervor, auch ist, wenn sie sitzen, ihr Köpfchen beständig in Bewegung. - Jhre Nahrung besteht in Früchten und Insecten, wovon man die zerbissenen Ueberreste in ihren Mägen findet. - Sie werfen ein oder ein Paar Junge, welche die Mutter auf dem Rücken und an der Brust mit umherträgt. Oft will man auf dem Rücken der Mutter ein älteres, 'und an ihrer Brust gleichzeitig ein kleineres Junges gefunden haben; ob aber, wie man diefs bei den in Europa geworfenen jungen Uistiti's beobachtete, der Vater der Mutter zuweilen diese Last abII. Band. 
nimmt, davon habe ich kein Beispiel beobachtet. - G $\mathrm{ft}$ ziehen diese Thierchen in Gesellschaft des weifsstirnigen Sahuï mit dem Ohrpinsel (Hapale penicillatus) umher. Sie sind allerliebste kleine Thiere, deren merkwïrdig auf. gerichteter, das Gesicht umgebender Kragen ih. nen ein originelles Ansehen giebt. Dieser Haarkragen scheint noch mehr vorwärts zu streben, als an dem rothen Sahui, und giebt ihnen das Ansehen eines kleinen Löwen. Besonders interessant ist es anzusehen, wenn diese Thierchen $z u$ entfliehen suchen, und eins hinter dem anderen dahin springend von Baum zu Baum eilen. - Hat man einmal eine Bande von ihnen erreicht, so ist es nicht schwer, mehrere herab. zuschiefsen, auch fallen sie leicht und wenn sie nicht sogleich todt sind, so findet man, dals sie alsdann ihren Gesichtkragen beständig aufgerichtet tragen. In den inneren Waldungen am Rio dos llhéos oder da Cachocira waren wir aus Mangel an Nahrungsmitteln genöthiget, einige Tage von diesen Thierchen $\mathrm{zu}$ leben, obgleich ihr Körper höchst klein und etwa von dem Um. fange eines Eichhörnchens ist. -

Das schöne schwarze Fellchen hat man zuweilen zu Mützen verarbeitet. - In der Gegend des Flusses llhéos und zu Barra da Va. 
reda nennt man sie Sahuim preto (schwarzer Sahuii) oder Sahuim do Sertam, es darf aber dieser Name nicht mit dem Sahuim preto von Minas Geraës verwechselt werden. Gezähmt soll die hier beschriebene Art eine wahre Zierde der menschlichen Wohnungen seyn. -

Herr Dr. Kuhi, dem ich diese neue, von mir in Brasilien entdeckte Affenart mittheilte, hat sich sehr deutlich über diesen Gegenstand ausgedrückt (Beiträge zur Zool. und vergl. Anat. pag 51) und dennoch scheint ihn Desmarest gänzlich milsverstanden zu haben; denn er setzt das Vaterland des Thiers nach Pará, da es doch blols im Sertong dés Rio Pardo, Belmonte und llhéos vorkommt. - Kuhl stellte übrigens diese Species in das Geschlecht Midas, welches er beibehielt, und das man, meiner Ansicht zufolge, kaum von den Jacchus.Arten trennen kann, auch habe ich defshalb die Geschlechter Jacchus und Midas nur als Un. terabtheilungen für Illiger's grofses Genus $\mathrm{Ha}$ pale angenommen. 
O R. II. $C a r n i v$ o $r a$. Fle is chenteser.

Wenn ich das Wort Fleischfresser in seinem ausgedehntesten Sinne nehme, also alle diejenigen Thiere dahin rechne, welche die drei verschiedenen Arten der Zähne besitzen und sich vorzüglich von lebenden Thieren ernähren, so ist diese Ordnung unstreitig in den meisten Welttheilen eine der zahlreichsten an Arten und Individuen. Ein Blick auf die Vertheilung dieser mannichfaltigen Wesen wird auch hier interessant seyn.

Illiger hat in seinen hinterlassenen Schriften (herausgegeben von Herm Hofrath Hellwig) die Aufzählung der Säugthierarten für die verschiedenen Welttheile unternommen, und wenn auch zu seinem jetzt schon mangelhaften Ver. zeichnisse noch manche Arten hinzugefügt und andere darin ausgestrichen werden müssen, so zeigen diese Tabellen dennoch das Verhältnils der verschiedenen Thierarten in den Welttheilen unserer Erde, und geben Stoff zu interessanten Untersuchungen. Bei einer solchen Verglei- 


\section{$-165-$}

chung würde es indessen nöthig seyn, die Fledermäuse auszuschliefsen; denn für sie kann noch kein richtiges Verhältnifs festgesetzt werden, bevor nicht die entfernteren Welttheile in dieser Hinsicht besser untersucht sind. -

Australien oder der fünfte Welttheil ist so arm an Säugthieren, dafs für die Ordnung der Raubthiere nur eine ganz unbedeutende Anzahl übrig bleibt, und selbst diese, Canis Dingo ausgenommen, sind Beutelthiere. - Weit reicher ist schon Africa, obgleich wir in diesem Welttheile noch nicht so viele Raubthiere kennen, als in unserem vollkommen durchsuchten Europa, dessen geringe Ausdehnung im Verhältnisse zu dem ungeheueren Raume von Africa, noch auf interressante Entdeckungen in dem letzteren schliefsen läfst. Wirklich haben auch die neueren Reisenden, Burchell, Lalandes u. a, so viele neue Entdeckungen für dieses Feld in Africa gemacht, daIs wir ihre Bekanntmachungen erwarten müssen, um richtig urtheilen zu können, Weit mehrere Raubthierarten als in Africa, kennen wir in Asien; die neueren Reisenden, Raffles, Horsfield, Diard, Duvaucel, Reinwardt, Kuhl u. a., bringen ihre Zahl wenigstens eben so hoch als für America, für welches die Illiger'schen Tabellen die grölste Anzahl ange. 
ben. - Diese grofse Menge von Raubthieren in America läfst sich leicht aus dem weit grölseren, für diese Thiere Nahrung gewährenden Raume in diesem Welttheile, und durch unsere noch sehr mangelhafte Kenntnils des inneren Africa erklären; denn in der neuen Welt fallen die von lebenden, und besonders auf animalische Nahrung angewiesenen Thieren entblö fsten Steppen gänzlich weg, indem die Llanos und Pampas von mancherlei Raubthieren bewohnt werden.

America ernährt Raubıhiere in allen seinen Zonen und Regionen. Der Polarbär [Nenok der Eskimaux*)] bewohnt die beeis'te Zone des Nordens. - Die grofsen Nadelwälder von Labrador ernähren den schwarzen Bären (Akelak), den schwarzen Bären mit weifsem Halsring (Akelak-Kagodalik) und den grauen Bären, so wie die Wolverene (Kapwik); auiser dem Wolf (Amerok) fünf Arten von Füchsen (deren allgemeiner Name Terigeniak ist), den gemeinen rothen Fuchs (Kaiok), den Isatis (Kagotásuk),

*) Ich habe hier zu den in Labrador einheimischen Thierarten die Beneunumgen gesetzt, welclre sie bei den Eskimaux tragen, da diese Nanen den Zoologen wolnl nicht allgemein bekanit sind, - 
den schwarzen Fuchs (Kernertak), den blauen Fuchs (Kernertásuk) und den Kreuzfuchs (Sunatuinak), ferner den Marder (Kapwiaitsiak), das Wiesel (Teriak) und die Fischotter (Pamioktok). - Jene Füchse sind noch nicht hinlänglich bestimmt, sollen aber wirklich verschiedene Arten bilden, - Weiter nach Süden hinab nimmt die Zahl der Raubthiere zu. In Ca. nada und der Gegend der grufsen Seen treten der Luchs, der Kuguar, der Raton, die Stinkthiere u. a. hinzu. - Noch weiter hinab in den wärmeren Regionen, bewohnen Bären die höheren, gemäfsigten Gegenden, indem sie nicht blofs im Norden, sondern selbst in den Ketten der Anden gefunden werden. Katzenarten beherrschen in gröfserer Menge die mehr warmen Länder unter dem Aequator, wo sie zu einer gefährlichen GröIse heranwachsen, und ein prächtig geflecktes Fell zeigen. Sie sind auch auf die gemäfsigten Länder ausgedehnt, in der Kälte aber haben sie nur einen Repräsentanten mit abgekürztem Schweife. - Hundearten sind über alle Zonen dieses Continents ausgedehnt, sie haben in den kalten Ländern den kostbarsten Pelz, in den heifsen Regionen hingegen nur ein schlichtes gröberes Haar. Kleine Raubthiere, Mustela, Mephitis, Gulo, 
Mcles, giebt es überall, doch vorzüglich in den kalten und gemälsigten Ländern. -

America hat mehrere, ihm ganz eigenthüm. liche Thierformen dieser Ordnung, hierhin gehören die Geschlechter Procyon, Mephitis, $\mathrm{Na}$ sua, Cercoleptes, wovon die ersteren über beide Theile dieses Welttheils, die letzteren nur über Süd-America verbreitet sind. - Wir finden in America, besonder's in der nördlichen Hälfte, eine Menge von Plantigraden. Das Geschlecht der Bären ist daselbst besonders zahl. reich, auch ersetzt die Raubgier der grofsen Bären in den Grasfluren des Missuri für Nord America, was die grofsen Katzen für die südliche Hälfte dieses Continents sind. - Manche andere kleinere Sohlengänger leben in Nord America, als Procyon, Meles, Gulo, Mephitis, wäh. rend die warmen Gegenden von Süd-America die Geschlechter Procyon, Gulo, Mcphitis, $\mathrm{Na}$. sua, Cercoleptes besitzen, auch leben dort, wie schon gesagt, einige Bären in den höheren, lühleren Gebirgsketten und den gemärsigten Provinzen. In dieser südlichen Hälfte des americanischen Continents sind die Katzen und Beutelthiere an Arten und Individuen am zahlreichsten, auch, einige wenige Hundearten leben hier. - Die Cuatís (Nasua) und der Kinkaju 
(Cercoleptes) sind die Süd-America eigenthümlichen Raubthierformen. -

Die von mir im östlichen Brasilien beobachteten Raubthierarten sollen in den nachfolgen. den Blättern genannt werden. -

\section{Fam. 1. Chiroptera.}

H a n d f l ügler. - Fled exthi ere.

Die Thiere dieser Ordnung sind von der Natur durch sehr characteristische Kennzeichen von allen übrigen Säugthieren geschieden, indem ihr Körper an seinem äufseren Umfange von einer Menge von Hautfortsätzen umgeben ist, welche die Glieder, besonders die sehr verlängerten Arme und Finger vereinigen und zu Organen des Fluges umschaffen. -

Ihr Gebils ist das der Raubthiere, and ihre Backenzähne sind mit vịelen Spitzen versehen, womit sie die härteren Theile der vorzüglich ihre Nahrung ausmachenden Insecten zerbrechen. Diese Thiere sind über den grölsten Theil der Erde verbreitet, und ihre Arten jetzt schon höchst zahlreich, obgleich wir gewiḷ erst nur einen kleinen Theil von ihnen kennen. 


\section{$-170-$}

Im Norden finden wir, den Nachrichten der Reisenden zufolge, in America Fledermäuse bis nach Canada und der Hudsonsbai hinauf*); im Süden scheinen sie ebenfalls weit hinab zu gehen, da Molina für Chili zwei Arten dersel. ben angiebt. Azara beschrieb eine ziemliche Anzahl von Flederthieren für Paraguay, sehr viele andere kennt man nun in den heilsen Ländern, es geht daher aus dieser Betrachtung hervor, dals diese Thiere für die gemälsigten und warmen Länder bestimmt sind und den langen Winter der kalten Zonen scheuen. -

Die heifsen Climate unserer Erde sind die günstigsten für die Vermehrung der Flederthiere, daher finden wir hier eine grofse Menge von Geschlechtern, Arten und Individuen, von oft höchst merkwürdiger, abweichender Bildung, welche bestimmt scheinen, die zahllose Vermehrung der Insecten jener Länder im Zaume zu halten. Zwar haben auch die gemälsigten Erdstriche viele Fledermäuse, und erst in neueren Zeiten hahen aufmerksame Beobachter, von dem rastlos thätigen Forschungsblicke der neueren

*) Den von den Brüdermissionarien zu Labrador erhaltenen Nachrichten zufolge, soll man dort keine Fledermäuse be merkt hahen. 
Periode geleitet, diese Anzahl um vieles vermehrt - Gerade diese Entdeckungen, welche man in dem genannten Felde in unserem überall durchsuchten Europa machte, lạssen noch unendlich mehr für die heifsen Länder unserer Erde erwarten, wenn man dereinst mit derselben Aufmerksamkeit dort nachsuchen wird.

Wie in allen warmen Ländern leben in Bra. silien Fledermäuse überall, und sind daselbst eben so zahlreich an Arten als an Individuen. Sie bevölkern die Dämmerung der Urwälder, der Gebüsche, sie leben in hohlen Bäumen, in Felsen, und richten unter den zahllosen Insec. ten Verheerungen an. Mehrere von ihnen kommen mit denen unserer gemärsigten Climate überein, allein weit mehrere sind durch ganz eigene Charactere ausgezeichnet.

So wie den heifsen Ländern der alten Welt die Geschlechter Pteropus, Cephalotes, Nyctinomus, Megaderma, Nycteris u. a. eigen sind, so den heifsen Ländern der neuen Welt die Geschlechter Phyllostoma, Glossophaga, Diclidurus $^{*}$ ) u. s. w. Unter ihnen ist wohl eins der

*) Hierzu müssen jetzt noch die neuen von Herrn Dr. $v$. Spix entdeckten Thiere dieser Orduung gerechnet werden, deren Bekanntmachung kurz vor dem Abdrucke dieser Zeilen erfolgte. 
ausgezeichnetsten das der Blattnasen (Phyllostoma), welchem die Natur zu dem seltsamen äufseren Kennzeichen des Nasenblattes die eigene Weisung gegeben hat, sich von dem Blute der Thiere zu nähren. -

Auf die grofse Anzahl der Flederthiere in Süd-America kann man schon schliefsen, wenn man bedenkt, dafs Azara zwölf beinahe sämmtlich neue Arten beschrieb, welche aber von den von mir beobachteten beinahe ohne Ausnahme verschieden sind; wie viel mehrere werden die jetzt noch in Brasilien reisenden Naturforscher kennen gelernt haben!

Reisende, welche nur schnell die Länder durchștreifen, können gerade in dieser Familie der Säugethiere am wenigsten thun, da die Auffindung der Fledermäuse schwierig ist. - Viele Arten fliegen so hoch, dafs man sie mit der Flinte kaum erreichen kann, andere streichen schnell an der Oberfläche der Flüsse dahin, manche sind erst spät in der Dämmerung sichtbar, und alle sind oft schwer zu erlegen, daher gehört ein langer Aufenthalt in jenen Wäldern dazu, um in diesem Felde zu einiger Vollstän digkeit zu gelangen; dabei ist Niemand, der diese an sich wenig beliebten und beachteten 


\section{$-173$}

Thiere kennt; denn die Brasilianer verabscheuen sie unter der allgemeinen Benennung Morçego. -

Um die Aufklärung, welche heut zu Tage über die Familie dieser lichtscheuen Wesen verbreitet worden ist, haben einige ausgezeichnete Zoologen der neuern Zeit das gröfste Verdienst. Herr Professor Geoffroy S. Hilaire beschrieb und bildete diese so verschiedenartigen, und dennoch einander sehr ähnlichen Thiere genau $\mathrm{ab}$, theilte sie nach ihrer Bildung in Geschlech ter, indem er sowohl auf seinen Reisen als in den reichen zoologischen Schätzen des Pariser Museums unendlich viel Neues fand. Seine $\mathrm{Ab}$. bildungen dieser Thiere, womit die Annales und Mémoires du Muséum d'hist. naturelle de Paris geziert sind, und von welchen er uns hoffentlich noch mehrere mittheilen wird, verdienen das grölste Lob, schade nur, dafs sie nicht auch die Ansicht der Färbung geben. - Seitdem haben wir wieder eine Anzahl von neuen Arten durch den englìschen Zoologen Leach kennen gelernt, die er in den Transactions der Linne'schen Gesellschaft mittheilte. Die grolse Aehnlichkeit der Flederthiere in der Hauptbil. dung ihres Körpers macht es nöthig, um die Uebersicht des nun schon bekannten zahlrei- 
chen Heeres dieser Thiere $z u$ erleichtern, dafs sie in Geschlechter oder Abtheilungen gebracht werden, welche auf die sehr abwechselnde $A n$ zahl der Zähne und andere Hauptzüge gegründet sind. Zwvar ist es nicht immer leicht, die Zahl der Zähne bei ihnen zu erkennen, da sie oft zerstört oder im Wechsel begriffen sind, dennoch geben sie die sichersten Merkmale ab, und dürfen nicht vernachlässiget werden. Auch ich habe bei den zu beschreibenden Arten leider nur zu oft Lücken gefunden, die ich nicht auszufüllen vermag, da die gewaltsam getödte. ten Thiere oft einer Anzahl ihrer Zähne beraubt wurden. So nöthig es übrigens ist, die verschiedenen Chiropteren in gewisse Abtheilungen zu bringen, so scheint es mir dagegen eben so wenig zweckmälsig, wenn man zu viele Geschlechter bildet und ich dächte, dafs zu Bestimmung derselben nur Hauptzüge, z. B. Anzahl und Bildung der Zähne, der Nase, der Zunge und Vorhandenseyn oder Mangel eines Schwanzes, so wie ganz abweichende Bildung einzelner Theile gewählt werden sollten. - Bildung des Schädels hingegen scheint mir nicht beständig und daher nicht bedeutend genug, um als generischer Character benutzt zu werden. 


\section{$-175-$}

Was die Beschreibungen der von mir beob. achteten Fledermäuse anbetrifft, so muls ich bemerken, dafs sie zum Theil unvollständig sind, da sie oft in der Uebereilung und unter ungünstigen Umständen entworfen wurden und durch den Verlust der Exemplare zum Theil nicht vervollständigt werden konnten. -

$$
\begin{aligned}
& \text { G. 6. Phyzlos to } m a \text {. } \\
& \text { B lat thase. }
\end{aligned}
$$

Die Blattnasen oder die Geschlechter Phyl. lostoma, Vampirus und Glossophaga des Hrn. Geoffroy sind auf den ersten Blick durch das aufgerichtete Hautblatt kenntlich, welches sie auf der Nasenkuppe tragen. Sie scheinen bei weitem die zahlreichste Familie des Heeres der Flederthiere in Süd-America, wenigstens in Brasilien zu seyn, und man kann wahrscheinlich von den meisten Arten derselben annehmen, dals sie Blutsauger sind, obgleich die Brasilianer gewils zu weit gehen, wenn sie diese Eigenheit auf alle dortigen Chiropteren ausdehnen.

Die grölseren Arten der brasilianischen Fledermäuse gehören zu den Blattnasen, diese besonders sind es, welche wohl öfters schon in manchen Gegenden dem Viehstande fühlbaren Schaden zugefügt haben, und die Maulthiere der Reisenden, während sie bei Nacht grasen, 


\section{$-176$}

gewöhnlich am Widerriste mit ihren grofsen Eckzähnen verwunden und sich in ihrem Blute sättigen.

Sie erhielten zu diesem Behufe von der Natur ein wahres Saugorgan, eine muskulöse Unterlippe, deren fleischiger Rand oft nackt und mit Wärzchen besetzt ist, und vollkommen $z u$ einer Saugrinne zusammengelegt werden kann, sobald die Verwundung bewerkstelligt ist; aus dieser Ursache kommt den Blattnasen der mei. stens längere Unterkiefer sehr wohl zu statten. Die in die dicke Haut der Thiere gebissene Wunde fährt gewöhnlich lange zu bluten fort, wodurch eine bedeutende Entkräftung entsteht. - Ich habe in der von mir bereis'ten Gegend keine Bestätigung dafür gefunden, dafs auch Menschen von diesen blutdürstigen Gästen heimgesucht werden, welches übrigens viele Reisebeschreiber erzählt und eben so viele Naturforscher als Wahrheit angenommen haben. Von Humboldt traf grofse langgeschwänzte Fledermäuse [unbezweifelt Blattnasen (Phyllosto$m a)$, die am Apure seinen Hund an der Nase verwundeten, die Reisenden selbst siud indessen nie gebissen worden *). -

*) V. Itumboldt Voy, alt nonv, cont. T. II, pag, 228. 
Die Lebensart der Blattnasen kommt übrigens mit der unserer deutschen Fledermäuse vollkommen überein. Sie fliegen in der Abend. dämmerung, nachdem sie aus hohlen Bäumen, belaubten Baumkronen, Felsklüften und selbst den Schlupfwinkeln der Gebäude hervorgekom. men sind, manche Arten niedrig, schnell, ande. re, besonders die grölseren, höher und langsamer u. s. w. - Das Guandira oder die gröfste von mir zu erwähnende Art, so wie alle übri. gen verirren sich am Abend in die Zimmer der Wohnungen, wo man die Läden schliefst und sie leicht tödtet, da ihre Gröfse ihnen alsdann sehr nachtheilig ist.

Ihre Nahrung besteht in mancherlei Insecten, besonders Abend - und Nachtfaltern, deren Flügel sie nicht mit verschlucken. -

Die Brasilianer hassen und tödten sie, dabei belegt man die meisten von ihnen mit der Benennung Morçego und giebt blof's der grölsten Art von ihnen den besondern Namen Guandirá, welcher mit dem von Marcgrave gegebenen, Andira-açú, sehr verwandt ist.

Da die mit einem Nasenblatte versehenen Flederthiere mancherlei Verschiedenheiten, sowohl in ihrem Gebisse als in andern Charac- 
terzügen zeigen, so hat man verschiedene $\mathbf{G e}$. schlechter aus ihnen gebildet, und ich zähle in das hier erwähnte nur solche Thiere, welche im Oberkiefer zwei bis vier, im Unterkiefer vier Schneidezähne, dabei in jedem Kiefer zehn oder acht Backenzähne, also folgende Kennzeichen haben :

Schneidezähne: $\frac{2}{4}$ oder $\frac{4}{4}$.

Eckzähne: $\frac{1 . \mathrm{I}}{1 \cdot \mathrm{I}}$.

Backenzähnc: $\frac{5.5}{5 \cdot 5}$ oder $\frac{4.4}{5.5}$.

Nasenblatt einfach, auf eine Nasenscheibe aufgesetzt. Zunge nicht über den Mund hinaus zu verlängern, mit kleinen Papillen besetzt.

Schwanz fehlt zum Theil, er wird zu Bildung der Unterabtheilungen benutzt, eben so die beiden Verschiedenheiten des Gebisses.

Die Bildung und Gestalt der Zähne ist bei den Blattnasen sehr verschieden und ich glaube, dafs man in dieser Hinsicht nicht zu streng seyn darf, wenn man nicht die Zahl der Geschlechter zu sehr vermehren will; auch ist der Zug nicht ohne Ausnahme, dafs diese Thiere immer nur einen eingliedrigen index haben sollen. 
A. Geschwänzte Blattuasén.

Schneidez. $\frac{2}{4} ;$ Eckz. $\frac{2}{2}$; Backenz. $\frac{10}{10}$.

a. Mit Schneidezälnnen, deren Krone nicht eingekerbt ist.

1. $P h$. h a $s t a t u m$, Geoffr.

$$
\mathrm{D} \text { a s } \mathrm{G} \text { u a n dir á. }
$$

Bl.: Von ungewvöhnlicher Gröfse; Olırdeckel mäfsig grofs, lanzettförmig zugespitzt; Nasenblatt mäfsig grofs, eiförmig zugespitzt; Schuvanz kurz, knorpelartig unvollkommen, kürzer als der Sporn; Pelz einförmig braun.

Vespertilio hastatus, Linn.

Phyllostomus maximus, meine Reise nach Bras. B. II. pag. 242.

Phyllost. maximum, Schinz Thierreich, B. I. p. 163.

Abbildungen zur Naturgeschichte Brasilien's. Andira-aca *), Marcgr. pag. 213.

Niangkenat botocudisch.

Guandirá an der Ostküste von Brasilien.

Diese Art ist die grölseste von mir im östlichen Brasilien beobachtete Fledermaus, ich vermuthe, dals sie oft mit dem Linne'schen Vampyr (Vespertilio Spectrum, Linn.) verwechselt worden ist.

*) Das Wort aca ist rexdruckt und soll heifsen: açri oder assú, - 
Beschreibung : Der Kopf ist lkurz, die Stirn hocl erhaben und dicht behaart, das Auge mäfsig grofs, mit deutlicher graubrauner Iris; der Unterkiefer ist länger als der obere; das breite kurze Nasenblatt steht weit rückwärts vor der Stirn; es hat längs seiner Mitte hinauf eine erhöhte Mittelleiste, ist unten breit, an den Seiten stark gewölbt, nach oben wenig ausgeschnitten, dagegen aber zugespitzt; an seiner Basis sitzen die Nasenlöcher auf einer halbkreisförmigen Hautscheibe, welche horizontal aufliegt und durch eine Kreisrinne von der Oberlippe geschieden ist. Die Unterlippe ist an ihrer Spitze ein wenig ausgerandet, daselbst mit zwei Reihen von Hautwärzchen besetzt, welche so gestellt sind, dafs sie ein Dreieck bilden, dessen Winkel nach der Kehle hin gerichtet ist. Die Ohren sind mälsig grols, ziemlich pyramidal, oben mäfsig zugespitzt, an der äufseren Seite unter der Spitze stark ausgeschnitten. Der Ohrdeckel ist beinahe vier Linien lang, unten etwas breiter, mit schmaler lanzettförmiger Spitze.

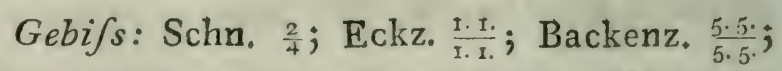
im Oberkiefer stehen zwei Schneidezähne mit breiter scharfer Schneide, etwas gegen einander geneigt; im Unterkiefer vier gleiche, kleine, 
stumpfe, dicht an einander und zwischen die Eckzähne gedrängte Schneidezähne; Eckzähne im Oberkiefer sehr grols, kegelförmig, zugespitzt, mit vier scharfen Kanten von oben herab bezeichnet, und durch eine Lücke von den Schneidezähnen getrennt; untere Eckzähne etwas kleiner, sehr spitzig, weniger gekrümmt, und nur mit zwei Kanten versehen, sie sind an die Schneidezähne angereihet. - Backenzähne sogleich an die Eckzähne anschliefsend, in jedem Kiefer zehn; die beiden ersten sind einfache pyramidale Spitzen, die folgenden mehrspitzig; die beiden äufseren Spitzen eines jeden Zahnes sind grofs, die inneren klein. -

Die Zunge ist länglich, glatt, mit einfach abgerundeter Spitze, wie an den meisten Säugthieren, hat daher keine besonders merkwürdige Bildung.

Der Hals ist kurz, die Brust sehr breit, mit starken Muskeln versehen, der Unterleib sehr schmal; die Arme sind sehr stark, Oberarme und Obertheil des Unterarms etwas behaart, eben so ist die übrigens nackte Flughaut an der Seite des Körpers und des Arms mit feinen seidenartigen weifsgrauen Haaren besetzt; der Daumen ist mäfsig stark, der Zeigefinger ohne Gelenk, der zweite Finger hat drei Gelenke und 


\section{$-\quad 182$}

einen schwachen, sehr platten, drei Linien langen Nagel; dritter Finger mit zwei Gelenken und kaum bemerkbarem Nagel; vierter Finger mit zwei Gelenken und einem etwas gröfseren Nagel. Die Hinterbeine sind mälsig lang, mit fünf gleichen Zehen und stark gekrümmten, zusammengedrückten Krallennägeln, welche an der Unterseite etwas ausgehöhlt sind. - Der Sporn oder die Fersenstütze ist stark knorpelartig, zehn Linien lang. - Der Schwanz ist kurz, ziemlich weich, schwach, mit zwei sichtbaren Gelenken, erreicht etwa $\frac{T}{3}$ der Schwanzflughaut, wo sein stumpfes Ende ein wenig aus der Haut hervortritt, welche um 1 Zoll $1 \frac{\pi}{2}$ Linien über denselben hinaus spannt. -

Die Flughaut ist stark, breit, vom Arme senkrecht hinab mit starken parallelen Adern besetzt; sie reicht an den Hinterfüfsen bis zu der Ferse hinab, wo sie von dem Sporn ausgedehnt, und von der Spitze des einen derselben zu der des andern queer hinüber gerade ausgespannt wird.

Die Ruthe des Männchens ist ein stumpfer kurzer Kegel, die Testikel im Leibe verborgen. -

Der Pelz des ganzen Thiers ist über und iiber dicht und sanft, dunkel graubraun, an den 


\section{$-183-$}

unteren Theilen ein wenig blässer, und am After befinden sich zuweilen etwas weifsliche Haare. -

Ausmessung eines männlichen Thieres:

Ganze Länge • • • . . $5^{\prime \prime} 1^{\prime \prime \prime}$.

Länge des Körpers . • . . $\quad 4^{\prime \prime} 5 \frac{1}{2}{ }^{\prime \prime \prime}$.

Länge des Schwanzes . . . . $7_{\frac{1}{2}}{ }^{\prime \prime \prime}$.

Breite des ausgespannten Thiers $22^{\prime \prime} 10^{\prime \prime \prime}$.

Höhe des äufseren Ohres über dem

Kopfe • • • • . . $8^{\prime \prime \prime}$.

Länge des Ohrdeckels beinahe . . 4 4 "

Die Schwanzflughaut lä șt sich vom

Körper ausdehnen auf • . $2^{\prime \prime} 2 \frac{1}{2}{ }^{\prime \prime \prime}$.

Länge des Daumens • • • • $5 \frac{\mathrm{r}}{2}{ }^{\prime \prime \prime}$.

Länge des Schienbeins zwischen 13 und 14'".

Länge des Fufses • • • • . $9^{\prime \prime \prime}$.

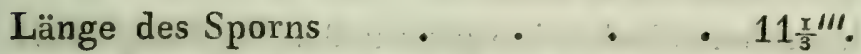

Der Kopf ist oben unter der Haut mit starkem dichtem Muskelfleisch belegt; die Lunge auf der rechten Seite ein grolser ganzer Flügel, der linke Flügel aber ist in drei Theile getheilt, welche unten sämmtlich wie stumpf abgeschnitten erscheinen, und das Herz vollkommen bedecken. - Der Magen ist häutig. -

Diese grölste Art der von mir in Brasilien beobachteten Fledermäuse hielt ich anfänglich für verschieden von Linnë's Vespertilio hasta- 
tus, ich habe aber nun durch genauere Vergleichung gefunden, dafs mein Phyllosiomus maximus mit Phyllost. hastatum Geoffr. identisch ist, und berichtige defshalb hier diesen Irrthum. Marcgrave's Beschreibung seines Andi$r a$-açi ist $z u$ unbestimmt, um sagen zu können, ob auch er das hier von mir erwähnte Thier vor sich hatte; denn seine Worte passen auf viele Blattnasen. Azara's Chauve-Souris troisième ou Ch. S. brune hat viel Aehnlichkeit mit der meinigen, doch ist die letztere bedeutend grölser und hat einen deutlichen Schwanz, welcher zwar unvollkommen und nur angedeutet ist, von dem spanischen Schriftsteller aber gewifs nicht übersehen worden wäre. -

Da man von dieser Blattnase in keinem zoologischen Werke eine genaue Beschreibung noch eine gute Abbildung fand, so hielt ich sie, wie gesagt, anfänglich für verschieden von dem $h a$ status, habe aber jetzt eine genaue Beschreibung nach dem Leben mitgetheilt, und ich hoffe, dafs meine gegebene Abbildung der Natur näher kommt, als irgend eine der früher von diesem Thiere bekannt gemachten. Es ist also Phyllostoma hastatum das Guandirá des östlichen Brasilien's und wahrscheinlich das̀ Andira-aşź des Marcgrave, - 


\section{$-185$}

Das Guandirá lebt wahrscheinlich in allen von mir besuchten Theilen des östlichen Brasilien's, doch habe ich dieses Thier erst am $M u$ curí und zu Villa Viçoza am Peruhype, Caravellas $\mathrm{u}$. s. w. näher kennen gelernt. - Sie fliegen in der dämmernden Abendluft hoch und kräftig umher, obgleich nicht sehr schnell, und gleichen alsdann den Eulen an Grölse. - Oefters kommen sie bei geöffneten Fenstern in die Zimmer, und besonders zu Villa Viçoza haben wir auf diese Art mehrere ron ihnen gefangen, sie verursachen alsdann ein lautes Geräusch an den Wänden. - Am Tage verbergen sich diese Thiere in der Nähe der Wohnungen zwischen den Blattstielen der Cocospalmen, in den Wäldern aber in hohlen Bäumen und belaubten Baumkronen.

In ihren Mägen fand ich Ueberieste verschiedener Arten von Insecten, aber nie Spuren von genossenem Blute; dennoch aber ist ès gewifs, dals die hier beschriebene und manche andere Art der Blattnasen das Blut der Thiere saugen. Ich habe nie eine solche Fledermaus in dem Momente des Saugens überrascht, wohl aber bei Mondenschein und in der Dämmerung beobachtet, wic diese grofsen Thiere in Menge unsere grasenden Lastthiere mit starkem Flü- 
Folgeräusche umflatterten, welche diese Umge. bung ruhig ertrugen, am folgenden Morgen aber an den Schultern von oben herab bis auf die Infe mit Blut bedeckt waren. - Am Rio das Contas *) fanden wir die Lastthiere von dem Llutverluste abgemattet. - Die Oeffnung, welche der starke Eckzahn macht, ist hinlänglich urn ein grofses Blutgefäfs zu verwunden, auch hört das Blut lange nach der Verwundung noch nicht zu fliefsen auf. - Es scheint, dafs die nackte, vortretende und mit Wärzchen besetzte Unterlippe, diesen Thieren bei dem Saugen des Blutes sehr nützlich ist; denn wenn der Rand der Unterlippe von beiden Seiten zusammengebracht wird, so greifen die Wärzchen in einander, und es entsteht alsdann gleichsam eine Saugrinne. - Dafs übrigens die Verwundung, welche diese Thiere verursachen, so ganz leise und schmerzlos nicht abgehen könne, wie manche Schriftsteller behauptet haben, zeigt die Oeffnung, welche der grol'se Zahn verursacht, und die Menge des verlornen Blutes. Man be-

*) Die Benemung dieses Flusses wird anf verschiedene Art seschrieben, man sagt sowoln Rio de Contas, als Rio das Contas; die Corografia brasilica gebrancht erstere Schreibast, ich wähle die letztere, weil. die Landesbewohner in jener Gegend allgemein Rio das Contas sprechelı, 


\section{$-187$}

hauptete sogar, dafs diese Thiere schlafende Menschen auf diese Art verwundeten, ohne sie $\mathrm{zu}$ erwecken, allein in der von mir bereis'ten Gegend habe ich nichts Aehnliches beobachtet und gehört. - Dobrizhofer, der das eben Gesagte bestätigt, sagt (B. I. p. 304), dals die von den Fledermäusen verursachte Wunde schwäre, wenn man sie nicht mit Asche bestreue; allein meinen Erfahrungen zufolge, bedarf es dieses Mittels nicht und unsere Tropeiros oder Maulthiertreiber überlieโsen die Heilung blofs der Natur. - Da ich übrigens, wie gesagt, nie Blut in den Mägen der Blattnasen fand, so kann diese Nahrung doch nur selten ihnen zu Theil werden, und ich wage es auch defshalb nicht zu bestimmen, ob einige oder alle, und welche Arten derselben diese Nahrung lieben; von der hier beschriebenen gröfsesten Art indessen braucht es keiner weitern Bestätigung, und ich glaube, dafs sie unter allen von mir beschriebenen Blattnasen beinahe die einzige ist, welche Blut saugt. -

Ueber die Art der Fortpflanzung kann ich nichts Bestimmtes angeben, da ich nur männliche Thiere untersucht habe, doch sollen sie mehrere Junge werfen, - - 
Die Stimme dieser Thiere, welche man be. sonders in der Paarzeit hört, soll ein Zischen seyn, doch kann ich nicht aus Erfahrung reden.

Un uns dieser Thiere zu bemächtigen, öffneten wir am Abend die Fenster und sahen gewöhnlich bald unsere Absicht erreicht. Im Walde kann man sie in der Abenddämmerung mit Vogeldunst, und wenn sie hoch fliegen mit Schnepfenschrot schiefsen.

Die Portugiesen, welche alle Fledermäuse mit der Benennung Morçego belegen, geben dieser Art den Namen Guandirá, welcher aus der Lingoa Geral herstammt, und aus den Worten Andirć und guaçú (grofs) zusammengezogen ist, also dieselbe Bedeutung hat als Marcgra. $v e$ 's Benennung Andira-açú. Die Botocuden kennen alle Fledermäuse unter dem Namen $\mathrm{Ni}$. angkenat *). -

\section{2. $P h . \quad m a c r o p h y l l u m$. D a s Gro[s b 1 at t.}

B1.: Schwanz beinahe so lang als der Kürper; Olurdeckel schmal lanzettförmig zugespitzt; Nasenblatt lang speerförmig zugespitzt, etwa $\frac{T}{4}$ der Schwanzlänge haltend; Sporn halb so lang als der Schwanz; auf der Schwanzflughaut stehen

") Kenat durch die Nase, ủas c sehr lkurz auszusprechen, 
halbkreisfürmig concentrische Linien; Pelz einfärbig: rufsbraun.

Abbildungen zur Naturgeschichte Brasilien's.

Schinz Thierreich u. s. w. B. I. pag. 163.

Beschreibung eines männlichen Thieres: Das Auge ist klein, cirkelrund und schwarz; die Ohren ziemlich grofs, sehr breit, am äuIseren Rande unter der Spitze ausgeschnitten, der innere Rand stark abgerundet; Ohrdeckel schmal lanzettförmig und sehr zugespitzt; das Nasenblatt sitzt auf einer scheibenförmigen Hautbasis, welche einfach und in der Mitte zwischen den Nasenlöchern in der Verlängerung des Blattes mit einer erhabenen Leiste, an jeder Seite aber mit einem kleinen Ausschnitte versehen ist. Das Blatt selbst ist länglich speerförmig, unter der sehr verlängerten Spitze an jeder Seite mit einem Ausschnitte und in seiner Mitte mit einer erhabenen Längsleiste versehen.

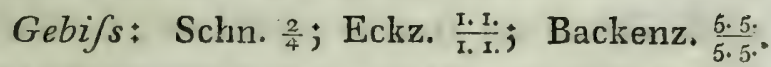
Im Oberkiefer befinden sich zwei grofse stumpfe Schneidezähne, in der Mitte nahe an einander gestellt; ein leerer Raum trennt sie von den grofsen gekrümmten Eckzähnen. - Im Unterkiefer befinden sich vier gleiche, kleine Schneidezähne, und unmittelbar daran gereihet folgen die mäfsig grofsen unteren Eckzähne; 


\section{$-190$}

unten und oben befinden sich an jeder Seite fünf Backenzähne; sie tragen sämmtlich an der inneren Seite kleine, an der äufseren aber grofse sehr spitzige Zacken oder Kegelspitzen; der erste oben und unten hinter dem Eckzahne sind kleine einfache Spitzzähne.

Die Zunge ist rundlich, walzenförmig, mäfsig lang, mit einfachen sanften Querleisten oder Quererhöhungen versehen.

Der Hals ist kurz, der Oberarm schlank, der Unterarm sanft gebogen; der Daumen ist schlank, sein vorderes Glied stark zusammengedrückt, so wie der hakenförmige Nagel; Zeigefinger mit zwei Gelenken, Mittelfinger mit vier und einem feinen spitzigen Nagel, der dritte Finger mit drei, der vierte ebenfalls mit drei Gliedern. Die Hinterbeine sind lang, mit fünf starken Zehen und grofsen bogenförmigen zusammengedrückten Nägeln, welche von innen nach aufsen an Gröfse zunehmen, so dafs der äufsere Nagel $1 \frac{2}{3}$ Linien in der Länge mifst. Der Fufs ist kürzer als der Sporn. - Der Schwanz ist lang und reicht über die Ferse hinaus, er endet mit seiner Spitze in dem Rande der langen, schmalen Schwanzflughaut, und hat sieben bis acht äufserlich sichtbare Gelenke. Die Schwanzflughaut bietet ein sehr gutes Kennzei- 
chen; denn dehnt man sie mit dem Schrvanze und den Hinterbeinen aus, so erscheint sie von dem einen Sporn zu dem andern hinüber gespannt, man bemerkt aber zu beiden Seiten der Schwanzspitze mit einander parallel laufende concentrische Bogenlinien, welche von erhöhten Reihen kleiner Knötchen, vielleicht Drüsen, gebildet werden, und auf diese Art nur bei wenigen Fledermäusen vorkommen. Die grolse Flughaut der Arme ist am halben Schienbeine befestiget. --

Die Flughäute sind nackt, dunkel graubraun gefärbt; der Körper ist mit einem dichten, zarten, etwas langen ruโsbraunen Haare bewachsen, oben wie unten.

\section{Ausmessung :}

Ganze Länge .

Ganze Breite

Länge des Körpers

Länge des Schwanzes

Höhe des äufseren Ohres . . . $7^{\prime \prime \prime}$.

Höhe des Nasenblattes beinahe - . $5^{\prime \prime \prime}$.

Länge des Daumens etwas über . . $2^{\prime \prime \prime}$.

Länge des Fufses etwas über - . $5^{\prime \prime \prime}$.

Länge des Sporns $\quad$ • $\quad \ldots, \quad 8 \frac{r^{\prime \prime \prime}}{}$

Länge des Schienbeins beinahe . . $7^{\prime \prime \prime}$. 
Diese Fledermaus, welche ich in keinem zoo. logischen Werke beschrieben finde, bildet eine schr characteristisch ausgezeichnete Species. Ich erhielt sie am Flusse Mucuri, wo sic an Felsen und alten Stämmen des Waldes am Ta. ge sitzend zubringt und in der Abenddämmerung umher schwärmt; ich habe sie aber nicht häufig beobachtet. - In ihrem Magen fand ich Ueberreste von Insecten.

\section{? 3. Ph. brevicaudum.}

Kurzgesch wänzt e B l at t nase.

Bl.: Schwanz sehr kurz, wenig länger als das Nasenblatt; Sporn so lang als der Schwanz; Ohr breit; Ohrdeckel kurz, schmal lanzettförmis; Pelz an den Obertheilen graurüthlich-braun, an den Untertheilen etwas blässer.

Abhildungen zur Naturgeschichte Brasilien's. Schinz Thierreich, B. I, pag. 164.

Beschreibung: Diese Fledermaus hat eine dicke, stumpfe, gerade vortretende, etwas kurz behaarte Schnauze, und ihr Unterkiefer ist länger als der obere; der Kopf ist zwischen den Olren erhaben; die Augen sind klein und liegen in der Mitte zwischen dem Nasenblatte und dem Ohre. - Das Nasenblatt is̀t schmal, etwas speerförmig, unter der Spitze sanft ausge. 


\section{$-193-$}

geschnitten, an der Basis ein wenig breiter; die Nasenscheibe ist rundlich und in ihrer Mitte ein wenig erhöhet, das Blatt selbst milst in der Höhe etwas über $2 \frac{1}{2}$ Linien. Das äufsere Ohr ist breit, mälsig hoch, oben mälsig zugespitzt, und an der äulseren Seite mit einem seichten Ausschnitte versehen; Ohrdeckel klein, kurz, sehr in das innere Ohr zurückgezogen, schmal lanzettförmig, an ausgestopften Exemplaren (wenn er vertrocknet ist) oft kaum bemerkbar.

Gebifs: Schn. $\frac{2}{4} ;$ Eckz. $\frac{\text { I.t }}{I .1}$; Backenz. $\frac{5 \cdot 5}{5 \cdot 5^{\circ}}$ Im Oberkiefer stehen zwei Schneidezähne nahe zusammen, welche von den Eckzähnen durch einen leeren Raum getrennt sind; im Unterkiefer vier breite und kurze, glatt abgeschnittene Schneidezähne, von welchen die äufseren schmäler sind, als die mittleren, die unteren Eckzähne schliefsen sich unmittelbar an sie an; die vier Eckzähne sind kegelförmig und stark, die beiden unteren an ihrer Basis etwas breiter als die oberen. - Backenzähne im Oberkiefer fünf auf jeder Seite; die beiden ersten mit einer Kegelspitze an ihrer vorderen Seite, die beiden darauf folgenden mit drei abgestumpften Spitzen, zuletzt ein kleiner breiter zweihöckeri. ger Zahn; im Unterkiefer befinden sich auf jeder Seite fünf Backenzähne, sämmtlich etwas

II. Band. 


\section{$-194$}

schmal z.usammengedrückt; die beiden ersteren sind einfach mit einer Kegelspitze, die drei darauf folgenden jeder mit zwei hinter einander gestellten Spitzen, die beiden zuerst genarınten haben an jeder Seite eine erhöhte Kante.

Die Zunge habe ich nicht untersuchen können, sie ist aber ohne Zweifel gebildet wie an den übrigen Blattnasen.

Der Hals ist kurz; der Körper breit in der Erust; Arme oben und unten behaart; Daumen lang, sehr fein und dünn, mit zusammengekrümmtem bogenförmigem Nagel; Zeigefinger mit zwei Gliedern, Mittelfinger mit drei Gelenken, der dritte Finger mit zwei und der vierte ebenfalls oder mit drei Gliedern. - Hinterbeine mälsig lang; der Sporn ist sehr kurz und schwach; Klauen der fünf Zehen stark und ziemlich gleich grofs. - Schwanz sehr klein und schwach; man bemerkt auf seiner ganzen Länge von drei Linien zwei Gelenke, und seine Spitze erhebt sich ein wenig über die Flughaut; die Schwanzflughaut spannt ron einer Ferse zu der anderen in einem eingehenden Bogen queer über, und ihr Rand reicht alsdann $3 \frac{\pi}{2}$ Linien über die Schwanzspitze hinaus. Die Flügel des Thiers sind im Allgemeinen kurz und breit; die Flughaut ist nackt und in den Seiten des Kör- 
pers mit parallelen Linien feiner Pünctchen bezeichnet, sie ist gerade im Gelenke des Hinterfufses, dem Sporn gegenüber befestiget.

Das Haar dieser Fledermaus ist sanft und dicht, am Grunde etwas wollig; die Wurzeln desselben sind weifsgraulich, die Spitzen röthlich graubraun, wodurch eine grauröthlich - braune Farbe entsteht, welche an den unteren Theilen des Körpers etwas blässer ist. -

Ausmessung :

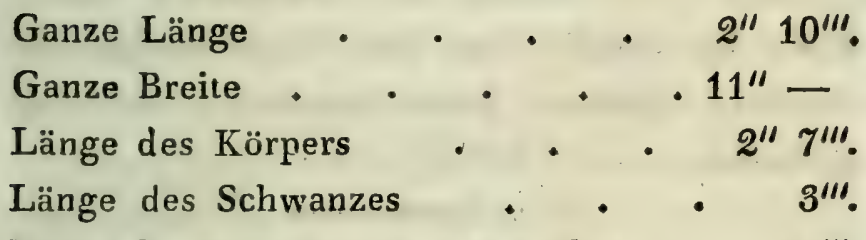
Länge des Nasenblattes etwas über . $2 \frac{{ }^{\prime \prime \prime}}{2}$. Länge des Daumens . . . . $3^{\prime \prime \prime}$. Länge, auf welche der Schenkel ent-

blöIst aus dem Pelze hervortritt . $\quad 5^{\prime \prime \prime}$. Länge des Schienbeins $6 \frac{\mathrm{r}}{2}$ bis . . . 7'". Länge des Fufses' . . . . $5^{\prime \prime \prime}$. Länge des Sporns • . . . . $3^{\prime \prime \prime}$. Höhe des äufseren Ohres auf der oberen Seite . . . . . 5 5'".

Diese Blattnase scheint nicht überall in Brasilien vorzukommen; wir erhielten eine Anzahl dieser Thiere, welche man vereinigt in einem alten Gebäude der Fazenda von Coroaba 
in den grolsen Wäldern an den Ufern des kleinen Flusses Jucú unweit des Rio do Éspirito Santo gefunden hatte. Sie hat viel Achnlichkeit mit Phyilostoma elongatum (Ann. d. Mus. $X V . p l .9$.$) , da ich aber bei der Kürze der fran-$ zösischen Beschreibung nicht zuverlässig über die Identität beider Arten entscheiden kann, so habe ich diese von mir aufgestellte Species mit einem ? versehen. - Auch mit Vampyrus soricinus Spixii scheint sie Aehnlichkeit zu haben, ihr Gebifs zeigt aber einen Backenzahn weniger, anderer Verschiedenheiten nicht zu gedenken. -

B. Ungeschwänzte Blattnasen, Lampyre (Vampyrus).

a. Mit eingekerbter Krone der Schneidezähne. Schneidez. $\frac{2}{4} ;$ Eckz. $\frac{x \cdot 1}{1 \cdot 1}$; Backenz. $\frac{5 \cdot 5}{5 \cdot 5}$.

4.Ph。brachyötum.

D e r bre it öh rige V a m p y r.

$V$.: Körper breit; Ohren kurz und breit; Ohrdeckel sehr klein und stark abgerundet; Nasenblatt schlank und schmal zugespitzt; Sporn kurz; Pelz an den Spitzen der Haare rufsfarben, an den Untertheilen heller.

Abbildungen zur Naturgeschichte Brasilien's.

Schins Thierreich $u_{0}$ s, wo, B. I. p. 164. 


\section{$<197-$}

Der Vampyr, welcher in den nachfolgenden Zeilen beschrieben wird, ist ein breites, dickes, kurzes Thier. Der Kopf ist dick und kurz, mit schmälerer kurzer Schnauze; das Ohr ist breit, mälsig hoch, oben und an dem inne. ren Rande abgerundet, auf der äufseren Seite ziemlich senkrecht abgeschnitten; der Ohrdekkel ist sehr klein, nach oben stark zugerundet, etwa so hoch als breit; auf der Nase befinden sich einige Kreisfalten, auf welchen ein $2 \frac{\mathrm{r}}{2}$ bis 3 Linien hohes schlankes Blatt steht, welches auf jeder Seite abgerundet und oben unter des Spitze seicht ausgeschnitten ist. - Unterkiefer länger als der obere.

Gebifs: Schn. $\frac{4}{4} ;$ Eckz. $\frac{x \cdot 1}{x \cdot x} ;$ Backenz. 5.5. Im Oberkiefer befinden sich zwei breite gegen einander geneigte Schneidezähne, im Unterkiefer vier kleinere, zwischen die Eckzähne gekeilt; die beiden mittleren sind gröfser, alle haben eine in der Mitte eingekerbte Schneide oder Krone; Eckzähne breit, grofs, kegelförmig in beiden Kiefern; Backenzähne im Oberkiefer fünf an jeder Seite; die beiden vordersten sind einfache starke Spitzzähne, ihre: Kegelspitze steht am vorderen Ende des Zahns, auf sie folgen zwei breitere Zähne mit drei Spitzen, wovon zwei grölsere aufsen und ein kleinerer Höcker an der 
inneren Seite steht, alsdann folgt ein kleiner ziemlich abgeflächter Zahn; im Unterkiefer befinden sich auf jeder Seite fünf Backenzähne; die beiden vorderen sind einfache grofse Kegelspitzen und haben an der äufseren Seite eine erhöhte Kante, die drei nachfolgenden haben zwei Spitzen, wovon die vordere immer die längste ist, sie nehmen nach hinten zu an Gröfse $a b$, und an ihrer inneren Seite bemerkt man mehrere kleine Höcker.

Arm, Hand und Flughaut sind stark und breit, der Daumen lang, schlank, mit nur mäIsig gekrümmtem und nicht besonders starkem Nagel; der Zeigefinger scheint zwei Glieder, der Mittelfinger vier, der dritte Finger drei, und der vierte wieder vier Glieder zu haben. Hinterbeine märsig lang, das Schienbein $7_{\frac{\mathrm{T}}{2}} \mathrm{Li}$ nien hoch, der Fufs mit fünf gleich langen Zehen, deren mäfsig starke Nägel nicht besonders gekrümmt sind, der äufsere ist der kleinste. Sporn nicht über drei Linien lang; die Schwanzflughaut ist queer über von einem Fufse zu dem andern ziemlich gerade ausgespannt; die Seitenflughaut ist nur eine Linie hoch über der Ferse befestiget. Diese Flughaut ist nackt, Ober - und Unterarme aber ein wenig behaart. 
Pelz des ganzen Thiers sanft, mälsig lang, aber dicht behaart, überall dunkel rufsfarben, die Haare an der Wurzel graubräunlich, an den Spitzen dunkel; untere Theile heller, mehr in's Graubräunliche fallend.

Ausmessung nach einem ausgestopften Exemplare:

Länge des Körpers etwa . . 2 $2^{\prime \prime} 4^{\prime \prime \prime}$. Höhe des äufseren Ohres . . . . . . $4^{\prime \prime \prime}$. Höhe des Nasenblattes . . $2 \frac{\mathrm{r}}{2}$ bis $3^{\prime \prime \prime}$. Höhe des Schienbeins . . . . $7_{\frac{I}{2}}{ }^{\prime \prime \prime}$. Länge des Fufses _ $\quad$ • $\quad \ldots \quad 5^{\prime \prime \prime}$. Länge des Sporns _.. . . . . . $3^{\prime \prime \prime}$.

Dieser Vampyr hat viel Aehnlichkeit mit dem vorhergehenden, nur scheint bei ihm das Schienbein kürzer und der Sporn länger, auch ist bei ihm die Flughaut am Schienbeine mehr vom Fufse entfernt befestiget, als bei jenem, und die Ohren sind bei dem vorhergehenden etwas höher und schmäler, auch das Gebils scheint verschieden.

Diese Art fliegt in den dämmernden Waldungen bei Annäherung der Nacht umher, und zu Morro d'Arara am Mucurí kam sie in unsere Wohnungen, wo wir sic tödteten. - 
b. Unbestimmte Arten, deren Gebifs nicht untersucht werden konnte, welches aber walirscheinlich mit dem der vorhergehenden Abtheilung übereinstimmt.

? 5. Ph. superciliatum.

Der Vampyr mit weifsem Augenstreif.

Bl.: Oltrdeckel kurz, zugespitzt, weifs gefärbt; Daumen stark; Haar dunkelbraun; ein weifser Streif von dem Nasenblatte bis zu dem Olire. -

Schinz Thierreich u. s. w. B. I. pag. 163.

? Chauve-Souris première ou Ch. S. obscure et rajée. $A z$. Ess, T. II. pag. 269.

Diese Art hat einen dicken, breiten, stumpfen Kopf; die Ohren sind an der äufseren Seite ausgeschnitten; der Ohrdeckel ist kurz, spizzig, tief in das Ohr zurückgezogen und weirs gefärbt. - Auf der Nase befindet sich ein beinahe vier Linien langes lanzenförmiges Blatt; Daumen sehr stark; Flughaut nackt und schwärzlich, an der Spitze weifslich gefärbt; der Schwanz fehlt gänzlich. Die Schwanzflughaut ist $9 \frac{2}{3}$ Linien weit vom Körper entfernt queer über gespannt und etwas behaart. Haar des ganzen Thiers dicht und dunkel graubraun, aber von dem Nasenblatte läuft bis zu dem Ohre ein netter reinweifser Streif tuber den $\mathrm{Au}$ gen hin. - 


\section{$-201-$}

Ausmessung, so viel die Umstände diese zu-

$$
\text { liefsen: }
$$

Länge des Thiers bis zu dem Ende der

Flughaut etwa . . . $4^{\prime \prime} 5^{\prime \prime \prime}$.

Die Schwanzflughaut läfst sich vom

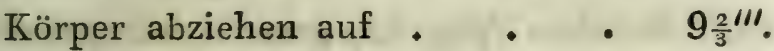
Länge des Nasenblattes beinahe - . $4^{\prime \prime \prime}$.

Die übrigen Maafse konnten wegen der Fäulnils des Thiers nicht genommen werden.

Diese schöne Blattnase, deren Beschreibung ich nicht vollständig geben kann, besonders da ich verhindert wurde, das Gebifs zu untersuchen, fand ich todt an einem Baumzweige in der Nähe eines grofsen Rohrbruches unweit der Seeküste bei der Fazenda von Tapebuçú aufgehängt, welche etwas nördlich von Cabo Frio zwischen den Flüssen $\mathcal{S}$. Joao und Macahé gelegen ist.

Aus der schon stark eingetretenen Fäulnils konnte man schliefsen, dafs das Thier schon einige Zeit in dieser Lage zugebracht haben mufste, und ohne sie zu zerreilsen, war es nicht möglich, die Flügel des Thiers zu entfalten. Die Gegend, wo ich diese schöne Art fand, ist bekannt wegen der grolsen Menge von Landseen, u. a. der Lagoa von Ponta Negra, Sagoarema u. s. w. - Es scheint übrigens, dafs 
Jiese Art blofs in den Wäldern lebt und nie in die Wohrungen kommt, da sie selbst meinen brasilianischen Leuten unbekannt war. - Ich habe sie nur einmal erhalten, wovon ich in dem ersten Theile der Beschreibung meiner Reise nach Brasilien (pag. 65) geredet habe, und sie scheint nicht weit nördlich hinauf zu gehen, da wir sie nie wieder beobachtet haben.

Azara's Chauve-Souris première ou Chanve-Souris obscure et rayée (Vol. II. pag. 269) scheint grofse Aehnlichkeit mit der meinigen zu haben; denn obgleich an dieser das Nasenblatt kleiner war, so konnte dasselbe an meinem todten Exemplare schon etwas eingeschrumpft seyn, oder Azara hat vielleicht seine Ausmes. sung auf eine andere Art genommen. - Herr Professor Geoffroy hat in dem 15ten Bande der Annales du Muséum (pag 177) Azara's Chauve-Souris première zu Phyllostoma perspicillatum gerechnet, allein diese Art schein mir, wegen der verschiedenen Bildung des Nasenblattes, doch wohl getrennt werden zu müssen.

c. Blattnasen ohne Schwanz oder Vampyre mit folgendem Gebisse :

Schneidez, $\frac{4}{4} ;$ Eckz, $\frac{T \cdot r}{1 \cdot 1}$; Backenz. $\frac{4 \cdot 2}{5 \cdot 6}$.

Der englische Zoologe Leach hat in den Transactions of the Linnean Society das Ge. 


\section{$-203-$}

nus Madataeus gebildet, welches mit der hier von mir gebildeten Unterabtheilung der Blattnasen übereinzustimmen scheint. - $\mathrm{Da}$ ich an der von mir zu beschreibenden Fledermaus nicht alle Züge so genau aufzeichnen konnte, als es Herr Leach gethan, so habe ich sie vorläufig in dem Geschlechte Phyllostoma gelassen, mit welchem sie in der Hauptsache vollkommen übereinstimmt.

6. Ph. obscurum.

Der schwarzb a u e V a m p r.

V.: Ohren mäfsig grofs, ziemlich eiförmig; Ohrdekkel sehr klein, ziemlich breit; Unterkiefer vortretend; Nasenblatt schmal eiförmig, zugespitzt; Sporn kurz; Pelz dunkel schwärzlich rufsfarben, am Unterleibe mehr aschgraulich. -

Abbildungen zur Naturgeschichte Brasilien's.

Schinz Thierreich u. s, w., B. I. p. 164.

Beschreibung: Diese Blattnase hat eine breite, gedrungene Gestalt, der Kopf steckt in den Schultern; die Stirn ist erhaben, die Schnauze ziemlich dick, kurz und stumpf; der Unterkiefer ist länger als der obere; der Mund bildet geschlossen einen völlig geradlinigen fest an einander passenden Schnitt; Lippenränder beide mit sehr feinen Papillen besetzt, welche 
diesen Theilen äufserlich eine crenulirte Gestalt geben; auf der Nase liegt eine halbkreisförmige IIautplatte und darin die Nasenlöcher, über welche sich das schmal eiförmig zugespitzte Nasenblatt erhebt, dessen Mittelleiste sehr breit ist. Das Auge ist klein, wie an allen diesen Thieren, und etwas länglich gestaltet. - Ohren mäIsig hoch, ziemlich eiförmig, an dem vorderen Rande abgerundet, an dem hinteren oder äufseren aber ziemlich senkrecht, mit einem Ausschnitte in der Mitte seiner Höhe; der sehr kleine ziemlich breite Ohrdeckel hat ebenfalls an der hinteren oder äufseren Seite einen kleinen Ausschnitt; der Rachen ist grofs, der Gaumen mit erhöhten Queerleisten bezeichnet; die Haut der inneren Mundhöhle ist mit zugespitzten Papillen besetzt.

Die Zunge ist breit, mit feinen Papillen oder Wärzchen bedeckt.

Gebifs: Schn. $\frac{4}{4} ;$ Eckz. I.I $;$; Backenz. $\frac{4 \cdot 4}{5 \cdot 5}$. Im Oberkiefer stehen vier stumpfe Schneidezähne dicht aneinander gedrängt, die mittleren sind etwas gröfser als die äufseren und mil etwas gespaltener Krone; im Unterkiefer stehen vier kleine Schneidezähne dicht aneinander und zwischen die Eckzähne gedrängt; Eckzähne im Oberkiefer dicht an die Schneidezälne an- 
geschlossen; lang, zugespitzt und kegelförmig; die unteren sind schmäler, zugespitzt, aber etwas kleiner; Backenzähne im Oberkiefer vier auf jeder Seite, der erste und zweite sind einfache Spitzzähne (Kegelzähne), die folgenden mit hinter einander gestellten zweispitzigen Erhöhungen; im Unterkiefer haben die Backenzähne nicht so viele und kleinere Spitzen. -

Die Arme mit der Flughaut sind stark und haben einen langen schlanken Daumen. Flughaut beinahe zwei Linien unter dem Fufsgelenke oder der Ferse befestiget; Fufs ziemlich klein, mit fünf gleichen Zehen und einem kurzen Sporn; die Schwanzflughaut bildet, wenn man sie auszieht, da der Schwanz fehlt, einen eingehenden stumpfen Winkel, in welchem sich an der Stelle des Schwanzes eine Mittellinie oder ein dunkler Streifen zeigt. - Männliche Geschlechtstheile wie an den übrigen Arten. -

Pelz des ganzen Thiers sanft und dicht; die Oberseite hat längeres Haar, als man es an den übrigen vorhergehenden Blattnasen findet; das Gesicht ist ziemlich stark behaart, selbst die Lippen mehr als bei den übrigen Arten; der Oberarm ist an der äufseren Seite stark behaart, auch die Flughaut ist zunächst dem Leibe sanft und wollig dünne behaart; Schenkel, Schien. 


\section{$-206$}

beine und die Schwanzflughaut in deren Nähe sind mit einzelnen, feinen Seidenhärchen besetzt.

Alle oberen Theile dieses Thiers haben eine dunkelschwärzliche Rufśarbe, die Flughaut beinahe eben so, nur mehr in's Bräunliche fallend; die unteren Theile sind mehr aschgrau und heller gefärbt, indem das Haar an der Spitze aschgrau und an der Wurzel graubräunlich erscheint; von der Nase läuft nach dem Auge ein nur schwach angedeuteter hellerer Streif. Ausmessung:

Ganze Länge (der Schwanz fehlt) . $3^{\prime \prime}$ -

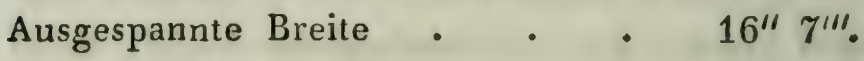
Höhe des äufseren Ohres • • • 6 $6 \frac{1}{2}{ }^{\prime \prime \prime}$. Höhe des Schienbeins beinahe - . $9 \frac{1}{2}{ }^{\prime \prime \prime}$. Länge des Nasenblattes etwas über . $\quad 4^{\prime \prime \prime}$. Länge des Sporns . • • . . $3^{\prime \prime \prime}$.

Ich erhielt diese Blattnase zu Villa Viço$z a$ am Flusse Peruhype. Ueber die Lebensart kann ich nichts hinzusetzen, welche übrigens von der der übrigen verwandten Thiere wohl nicht verschieden seyn dürfte. -

G. 7. $G$ los sophag $a$, Geoffr. $\mathrm{Zungen-B} \mathrm{lattnase.}$

Dieses von Geoffroy in den Mémoires du Muséum d'hist, naturelle (T. IV. pag. 4.11) auf- 


\section{$-207$}

gestellte Geschlecht unterscheidet sich vorzüglich durch seinen Zungenbau von den übrigen Blattnasen. - Diese Zunge kann lang aus dem Munde hervorgeschoben werden und ist an ihrem Ende, gleich der der Spechte, mit kleinen Widerhäkchen besetzt, wahrscheinlich um, wie diese Vögel, Insecten aus engen Höhlungen her. auszuziehen.

Die übrigen Kennzeichen dieses Geschlech. tes sind vier Schneidezähne im Ober - und eben so viele im Unterkiefer, dabei sechs Backenzähne in jedem Kiefer auf jeder Seite, also zusammen vier und zwanzig, ferner ein aufgerichtetes Hautblatt auf der Nase. -

In der Gestalt kommen diese Thiere übrigens mit den Blattnasen und Vampyren ziemlich überein. Ihr Kopf ist schmal, grols und verlängert, der Unterkiefer länger als der obere, das Nasenblatt ist kurz so wie der Sporn, Kennzeichen, worin wenigstens die beiden von $\mathrm{Hrn}$. Geoffroy zuerst bekannt gemachten und auch von mir vollständig zu beschreibenden Arten übereinstimmen.

Man kann sie in geschwänzte und ungeschwänzte Arten abtheilen. 


\section{$-208$}

A. Geschwünzte Zungen-Blattnasen.

1. G. amplexicauda, Geoffr.

Die Zungen - Blattnase mit verhülltem $\mathrm{Sch}$ wanze.

Z.: Hinter jedem Flügel der Basis des Nasenblattes befindet sich eine kleine rundliche Erhöhung; Olrdeckel selur hilein ind zugespitzt; Schwanz klein und in der Schuvanzflughaut liegend.

Mémoires du Muséum d'hist, natur. T. IV. pag. 411. pl. 18. A.

Glossophaga amplexicaudata; Spix.

Beschreibung: Gestalt etwa die der nachfolgenden Art; die Schnauze ist etwas verlängert und trägt über der Nase ein aufrechtes, speerförmiges, zwei Linien hohes Blatt, welches zugespitzt und an den Seiten unter der Spitze ein wenig ausgeschnitten ist; unter den beiden Grundflügeln des Blattes öffnen sich die beiden kleinen Nasenlöcher und hinter demselben befindet sich auf jeder Seite eine kleine rundliche Erhöhung; Unterkiefer nur wenig länger als der obere; Unterlippe gespalten, ihr Rand crenulirt, d. h. mit der Lupe besehen, erscheint eine jede Hälfte des Vordertheils derselben in sieber buchtige Einschnitte getheilt; ein jeder Kiefer ist an seinem Vordertheile, wie bei der nachfol- 


\section{- 209}

genden Art mit feinen Bartborsten besetzt. Die Ohren sind nackt, ganzrandig, glatt, der äufsere $R$ and sehr wenig ausgeschnitten, etwas mehr gerade aufsteigend als der vordere mehr zugerundete; der Ohrdecke] ist sehr klein, zugespitzt, schmal, wenig sichtbar und hat etwa die Gestalt des Nasenblattes.

Die Zunge läfst sich etwa einen Zoll weit aus dem Munde ausdehnen, hat eine hornartige Spitze mit rückwärts gekehrten Seitenborsten, wie man sie bei den Spechten findet. -

Gebifs: Schn. $\frac{4}{4} ;$ Eckz. $\frac{\text { T. }}{1 \cdot 1}$; Backenz. $\frac{5 \cdot 5}{6 \cdot 6}$. In jedem Kiefer stehen vier Schneidezähne, sie sind sehr klein, nur mit der Lupe zu zählen, und haben breite abgestumpfte Kronen; die beiden mittleren Zähne im Oberkiefer sind breiter als die äufseren, und die Schneidezähne des Unterkiefers sind kleiner als die des oberen. Zwei kegelförmig zugespitzte Eckzähne in jedem Kiefer. - Backenzähne fünf oben ${ }^{*}$ ) und sechs unten an jeder Seite; die beiden ersteren im Oberkiefer sind einfache Kegelspitzen, die drei hinteren haben drei bis vier Spitzen; im Unterkiefer, sind die drei ersteren Zähne einspi-

*) Der sechste Bachenzahn war ohne Zweifel ausgefallew. II. Band, 


\section{$-210$}

tzig, die drei nachfolgenden mit drei bis vier Spitzen. -

Der Körper hat etwa die Gestalt wie an der nachfolgenden Art, nur existirt hier ein kleines Schwanzrudiment von zwei Linien Länge, weich und kaum fühlbar, dennoch aber deutlich sichtbar, welches in der Schwanzflughaut liegt, darin endet, aus zwei Gelenken besteht und von der Schwanzflughaut, wenn diese ausgedehnt ist, auf etwa vier, bis vier und eine halbe Linie an Länge übertroffen wird. Die Seitenflughaut ist schmal urd lang; der Daumen ist lang, sehr schlank und zart gebaut; der Zeigefinger ohne sichtbares Gelenk; der zweite Finger hat vier Glieder, der dritte drei, der vierte ebenfalls. Der Hinterschenkel tritt kaum mehr als zwei und eine halbe Linie aus dem Pelze des Leibes hervor; das Schienbein ist sechs Linien hoch, der Sporn kurz, kaum drei Linien lang. - Die Fufszehen sind gleich lang, an dem einen Fufse auch die fünf Krallennägel, an dem andern hingegen waren die beiden äufseren Nägel bedeutend kürzer als die drei inneren. Seitenflughaut unbehaart, in der Nähe des Körpers, der Arme und der Beine mit Reihen äufserst feiner Pünctchen bezeichnet. - Kand der Schwanzflughaut völlig unbehaart; Arme blols an der 
ITurzel an der inneren Seite ein wenig behaart; Haar des ganzen Körpers sehr dicht, sanft und etwas lang, dunkel graubräunlich-rufsfarben, an der Stirn etwas gelbbräunlich; die unteren Theile des Thiers sind blässer gefärbt als die oberen.

Ausmessung:

\section{Ganze Länge}

Länge des Körpers

Länge des Schwanzes

Breite des ausgespannten Thiers

Höhe des Nasenblattes nicht völlig .

Höhe des Ohrs über dem Kopfe . . $1 \frac{r}{2}{ }^{\prime \prime \prime}$.

Länge des Daumens . . . . $3 \frac{T^{\prime \prime \prime}}{}$.

Der Schenkel tritt aus dem Pelz hervor

etwa auf

Länge des Schienbeins

Länge des Fufses etwas über

Länge des Sporns kaum

Die Schwanzflughaut läfst sich über

den Schwanz hinausziehen auf $4^{\prime \prime \prime}$ bis $4 \frac{x}{2}{ }^{\prime \prime \prime}$.

Sie läfst sich vom Körper ausziehen auf $6^{\prime \prime \prime}$.

Der Schädel dieser, so wie der nachfolgenden Art ist besonders merkwürdig durch die dünnen langen ohne alle Biegung gerade vorgestreckten Kiefer, wodurch der Kopf dieser Thiere die lange gerade Schnauze erhält. - 
Diese Flederinaus wohnt um $R$ io de $J a$ neiro, und in dem ganzen von mir bereis'ten Striclse, da ich sie an mehreren Orten erhielt, sie geht auch südlich bis $S$. Paulo hinab. In ihrem Magen findet man Insecten. -

Die Abbildung, 'welche Herr Professor $G c$ offroy S. Hilaire gab, hat einige Züge, welche mit meiner Beschreibung nicht gänzlich übereinzustimmen scheinen. Die Zunge hat in dieser Figur keine Widerhäkchen und der Schwanz ist nur an seinem Ende durch eine Verdickung bemerkbar, da er doch an meinem Thiere der ganzen Länge nach sichtbar ist; dennoch aber scheinen beide Thiere unfehlbar zu ein und derselben Species zu gehören.

B. Ungeschwänzte Zungen-Blattnassen.

2. G. ecaudata, Geoffr.

Die ungeschwänzte Zungen - Blattnase.

Z.: Schnauze schmal verlängert; Ohren kurz; Nilsenblatt kurz, etwa so lang als der Sporn; Flughaut lang und sclmal; der Schwanz fehlt. -

Mémoires du Muséum d'hist. natur. T. IV. pag. 418. pl. 18.

Abbildungen zur Naturgeschichte Brasilien's.

Das von Hrn. Geoffroy beschriebene Thier scheint unfehlbar mit dem meinigen identisch, 
nur bemerkt man einigen Unterschied in dem Gelisse, der ohne Zweifel vom Alter herrührte.

Beschreibung: Der Kopf ist grofs und lang, in eine lange Schnauze verlängert, der Körper breit und kurz. Der Unterkiefer tritt über den obern hinaus; die Unterlippe ist gespalten und an ihrem vorderen Rande mit kleinen Wärzchen oder Papillen eingefafst, auch ist die Spaltung der Lippe noch etwas durch eine nackte Linie fortgesetzt. - Beide Kiefer sind mit drei bis vier langen Bartborsten, feinen langen Haaren besetzt. - Das Auge steht ein Paar Linien weit rom Ohre entfernt; das Nasenblatt ist dreieckig, klein, an den Seiten nur wenig ausgeschnitten; das $\mathrm{Ohr}$ ist etwas eiförmig, an der äufseren Seite ein wenig ausgeschnitten; Ohrdeckel klein, eiförmig; zugespitzt. -

Die Zunge ist lang, rund, fleischig, aus. dehnbar, mit vielen feinen kleinen Papillen besetzt, ihre Spitze ist etwas hornartig und etwa drei bis vier Linien lang mit kleinen Borsten oder Franzen besetzt. -

Gebifs: Schn. $\frac{4}{4}$; Eckz. $\frac{\text { Y.I }}{\text { I.I }}$; Backenz. $\frac{6 \cdot 6}{6 \cdot 6}$. Die Vorderzähne fehlen in beiden Kiefern (es sind deren eigentlich oben und unten vier); Eckzähne kegelförmig, zugespitzt. - Backen- 
zähne auf jeder Seite im Oberkiefer sechs; die drei erstern sind einfache Kegelspitzen, die drei letztern haben vier Spitzen. Im Unterkiefer auf jeder Seite sechs; der erste hat eine Kegelspitze und am hinteren Ende einen Höcker, der zweite hat einen Höcker am Anfange und seine Kegelspitze am hinteren Ende; der dritte hat die Kegelspitze in der Mitte, am Ende und am Anfange aber einen Höcker; die drei folgenden Zähne tragen mehrere abgestumpfte Spitzen *). - Die Brust ist breit, die Arme sind muskulös, stark, der Daumen lang und dünn, der Zeigefinger ohne Gelenk, der zweite Finger mit vier, der dritte mit drei, der vierte ebenfalls mit drei Gliedern versehen. Die Flughaut ist lang und schmal, nahe am Leibe dünn und fein behaart, und eben daselbst in der Nähe des Leibes mit Reihen von kleinen Pünctchen be-

*) Vie sehr das Gebirs dieser Thiere durch dus Ausfallen der Zähne variirt, beweis't ein Exenplar dieser Fledermaus, welches Herr Natterer aus Ypanema sandte. - In Oberkiefer stehen hier zwei Sclmeidezähne paarweise beisammen; der innere ist am kleinsten und der äufsere zeigt einen Einschnitt nach aufsen, beide sind sehr klein; eigentlich nur rudimentar. - Dem Unterkiefer fehlen die Schneidezähne ganz, und der zweite Backenzahn hat drei Spitzen, wie der dritte (wahrscheinlich Altersverschiedenkeit); oben und unten auf jeder Seite sechs. - 
setzt, welche man besonders bemerkt, indem man das Thier gegen das Licht hält. - Der Schenkel des Hinterbeins tritt beinahe sechs Linien lang aus dem Pelz des Leibes hervor; Schienbein ebenfalls sechs Linien hoch. - Die gebogenen Krallennägel der fünf ziemlich gleichen Zehen werden nach innen zu etwas grö. Iser; der Schwanz fehlt und die Schwanzflughaut bildet von dem sehr kurzen Sporn an, einen Saum von anderthalb bis zwei Linien Breite längs des ganzen Beins hinauf bis an den Leib, wo sie kaum mehr vortretend ist. Dieser ganze Hautrand ist, so wie der Schenkel und selbst das Schienbein behaart, und diese Haare stehen an dem Rande über eine starke Linie breit hervor und bilden Franzen, welche ich nur bei Glossophaga gefunden habe. Das Gesicht ist behaart; der Arm ist auf der äufseren Seite bis über das Ellenbogengelenk hinaus behaart, an der inneren Seite weniger. Das ganze übrige Thier ist dicht mit sanften, rattenartigen Haaren bedeckt, welche auf dem Rücken am längsten sind; die Farbe ist auf den oberen Theilen dunkel rufsbraun, an den unteren etwas blässer, mehr in's Aschgraubrảunliche fallend. 


\section{- 216}

Ausmessung:

Ganze Länge .

Ganze Breite • • • . $111^{\prime \prime} 4 \frac{1}{2}{ }^{\prime \prime \prime}$.

Länge des Kopfs bis in den Nacken . 11'".

Länge von der Nasenspitze bis an den

vorderen Ghrrand . . . $5 \frac{\mathrm{r}}{2}{ }^{\prime \prime}$.

Höhe des Nasenblattes . • • $1 \frac{2}{3}$ " .

Höhe des äufseren Ohres, auf der in-

neren, dem Kopfe zugewandten

Seite gemessen

Länge des Schienbeins

Länge des Fufses . . . . 5 5".

Länge des Sporns . . . . $1 \frac{1}{3}{ }^{\prime \prime \prime}$.

Der Schenkel tritt aus dem Pelze her-

vor um beinahe . . . $6^{\prime \prime \prime}$.

Länge des Daumens . . • • $3 \frac{x}{2} 11$.

Die Schwanzflughaut spannt vom Lei-

be aus. . . . . $1 \frac{1}{2}$.

Es ist für mich so gut als ausgemacht, dafs Herr Professor Geoffroy Figur B. ảie hier von mir beschriebene Fledermaus abbildete, auch sind alle seine Abbildungen von diesen Thieren sehr schön und vollkommen, dennoch aber zeigt die genannte Kupferplatte einige Züge, welche das von mir beschriebene Thier von derselben unterscheiden, und hierhin gehört besonders die Zunge, welche sich an meinem Exemplare 
mehr in die Länge ziehen liefs und mit Widerhäkchen versehen war, ferner die gröfsere Kürze der Schenkel, die geringere Behaarung der Beine und Flughaut; es sind indessen diese kleinen Characterzüge nicht bedeutend genug, beide Thiere zu trennen, da sie vielleicht die Schuld des Zeichners oder daher entstanden sind, dafs man nach einem ausgestopften Exemplar arbeitete, wefshalb ich denn auch kein Bedenken trage, die Verdienste eines so ausgezeichneten und thätigen Zoologen anzuerken. nen. Herr Delalande der Jüngere fand diese Fledermaus bei Rio de Janéiro, ich entdeckte sie in alten Gebäuden der Gegend von Porto Seguro, sie scheint defshalb überall an der Ostküste verbreitet zu seyn, Ihre Stimme ist zischend, und sie giebt einen süfslichen Moschus. geruch von sich. Im Magen fand ich Ueberreste von Insecten.

$$
\begin{aligned}
& \text { G. 8. Noctilio, Geoffr. } \\
& \text { Der Kantenlefzer. }
\end{aligned}
$$

Dieses nur in Süd-America vorkommende Geschlecht ist bekannt und scheint in Brasilien ziemlich allgemein verbreitet; dennoch habe ich diese Fledermäuse nur selten, und die erstere Art nur einmal erhalten, die letztere aber in der Gegend der Küste, welche etwa unter 
dem 16ten Grade südlicher Breite gelegen ist, häufig gesehen. - Unter den Characteren dieses Geschlechts mufs angemerkt werden: Obere Schneidezähne zwei bis vier. - Alle von mir gesehenen Thiere dieser Art hatten nur zwei Schneidezähne im Oberkiefer, da hingegen an dere Beobachter vier anmerkten, es scheint daher, dafs im spätern Alter des Thiers nur zwei Schneidezähne bleiben, worauf Rücksicht genommen werden muls.

Ich werde einige recht vollkommene Thie. re nach dem Leben beschreiben. -

1. N. dorsatus, Geoffr.

Der gestreifte Kantenlefzer.

K.: Pelz graubraun, längs des Rückens hinab läuft ein gelblichweifser Längsstreif, welcher zwischen den Schultern entspringt und am Schwanze endet.

Noctilio vittatus, Schinz Thierreich u. s. w. B. I. pag. 870 .

Abbildungen zur Naturgeschichte Brasilien's.

Beschreibung: Der Kopf ist dick, kurz, mit völlig abgestumpfter Doggenschnauze; die Nasenkuppe steht beinahe eine Linie lang frei über die Lippen hinaus. - Das Auge ist klein und steht nahe vor dem Ohr; letzteres ist schmal eiförmig, mit stark zugespitztem ver. 
schmälertem Ende, auch hat das ganze Ohr beständig eine starke Neigung nach vorn. - Der Ohrdeckel ist klein, länglich schmal, aber an beiden Seiten etwas gefranzt; der hintere Ohrrand zieht sich unter der Ohröffnung herum, bildet gerade darunter eine halbcirkelförmige übergerollte Hautfalte, und sendet nun nach dem Mundwinkel in gerader Richtung vorwärts eine erhabene Hautfalte; das Ohr ist übrigens von innen und aufsen nackt, und nur mit ein Paar dïnnen Haarstreifchen bezeichnet. - Die Nasenkuppe ist doggenartig gespalten, und, wie schon gesagt, beinahe eine Linie weit frei vor die Schnauze vortretend; die beiden Nasenlöcher sind rundlich, nach vorne gestellt und mit einem erhöhten Rande versehen; die Oberlippe hängt wie an den Doggen auf jeder Seite über den Mund herab; von der Nasenkuppe läuft die Haut in zwei Falten, wie an einer Hasenscharte, nach dem Munde herab; dis Unterlippe springt über die herabhängende Oberlippe mit ihrem Rande vor, und hat an ihrer Spitze in der Mitte mehrere kleine halbkreisförmige Hautfalten; an ihrer Unterseite steht aufserdem ein Hufeisen, und hinter diesem ein isolirtes Knöpfchen. 
Gebifs: Schn. $\frac{2}{2} ;$ Eckz. $\frac{x \cdot 8}{1 \cdot 1}$; Backenz. $\frac{4 \cdot 4}{4 \cdot 4}$. Im Oberkiefer befinden sich zwei kegelförmige spitzige Schneidezähne, aber im Unterkiefer ist kaum Platz für die beiden kleinen Schneidezähne mit gespaltener Krone. - Eckzähne colossal, im Oberkiefer von den Schneidezähnen durch einen Raum getrennt, - Backenzähne in jedem Kiefer auf jeder Seite vier, der erste hat eine starke Kegelspitze, die zwei darauf folgenden haben vier starke Spitzen, welche auf den zickzackförmig aus - und einspringenden Winkeln des Zahnes stehen; der letzte Zahn ist etwas kleiner und scheinbar mit drei Spitzen versehen. - Im Unterkiefer befinden sich ebenfalls vier Backenzähne, etwa eben so gebildet; der erste ist ein Kegel - oder ein Spitzzahn, die übrigen haben vier Spitzen und mehrere Gruben auf der Oberfläche. - Alle diese Backenzähne beider Kiefer haben an ihren Seiten zwischen den Kegelspitzen so tiefe Einschnitte, dafs sie von oben betrachtet beinahe zwei aneinander gelehnte Dreiecke bilden, auf deren ausspringenden Winkeln die Spitzen in die Höho treten.

Der Rachen ist am Gaumen mit erhöhten Queerleisten versehen, wie an den meisten der früher ron mir erwähnten Flederthiere. Die 
Zunge ist länglich - walzenförmig, fleischig und glatt. Die Glieder des Thiers sind stark, die Arme lang, die Flughaut etwas schmal; der Daumen ist dick und kurz, der Zeigefinger ohne Gelenk, der zweite Finger hat drei Glieder und einen langen zusammengedrückten Nagel, der dritte Finger hat drei, der vierte eben so viele Glieder. Die Hinterbeine sind stark, mit sehr starken Fülsen, und besonders mit sehr langem, an der Wurzel platt gedrücktem Sporn, auch sind die Nägel sehr grols, gebogen und scharf, die mittleren ein wenig gröfser als die übrigen. - Der Schwanz ist kurz, hat fünf Glieder und eine Spitze, die als ein kleines Knöpfchen aus der Schwanzflughaut heraustritt; diese letztere ist sehr grofs und lang, sie übertrifft ausgespannt den Schwanz um einen Zoll zehn und eine halbe Linie an Län. ge. - Die Seitenflughaut ist fünf Linien hoch über dem Fufsgelenke an der vorderen Seite des Schienbeins befestiget.

Die Ruthe des männlichen Thieres ist länger und dünner als an den übrigen brasilianischen Fledermäısen, besonders nach der Spitze hin verdünnt; Testikel unter der Haut ver. borgen. 


\section{- $222-$}

Bis zu den Augen sind die Lippen des Thiers ziemlich nackt und nur sehr fein behaart; das Haar am ganzen Körper ist sehr kurz und fein mäuseartig; alle oberen Theile haben eine graubraune Farbe, aber zwischen den Schulterblättern entspringt ein schöner hell gelblichweifser Längsstreif, der an der Schwanzwurzel endet; alle unteren Theile des Körpers sind schön sanft hell röthlich - gelb; - die Flughäute haben so wie die Glieder eine röthlichschwarzbraune Farbe, die Klauen sind weifslichfleischroth. - Die Seitenflughaut tritt ganz besonders weit nackt in die S-iten des Thiers hinein, so wie überhaupt die Flughäute nirgends Behaarung zeigen, ausgenommen an ihrer Wurzel vor der Schulter, wo auch der Oberarm behaart ist; der Unterarm ist an seiner unteren Seite mehr behaart als an der oberen.

Ausmessung eines männlichen Thieres:

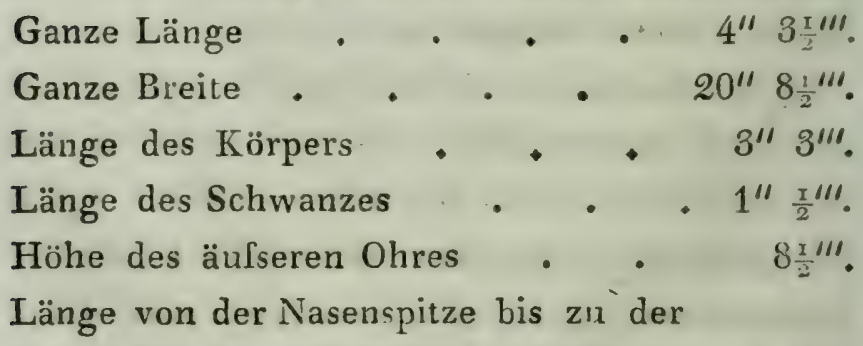

Basis des vorderen Ohrrandes . $8 \frac{I}{2}{ }^{\prime \prime}$. 


\section{$-223$}

Länge des Schienbeins

Länge des Fufses

\section{Länge des Sporns}

Länge, um welche die Schwanzflug-

haut über die Schwanzspitze hinaustritt

$$
1 \text { 1" } 10 \frac{7}{3}{ }^{\prime \prime \prime}
$$

Länge der Fufsnägel in gerader Linie

$$
\text { gemessen, beinahe . . . 4'". }
$$

Ich erhielt diese schöne Fledermaus nur einmal zu Villa Viçoza am Peruhype, wo sie sich bei kühler Witterung in die Gebäude ver. kriecht, und daselbst alsdann zuweilen in Menge zusammengeballt gefunden wird. Sie hat einen unangenehm honigartig süfslichen Ge. ruch. - Im Magen fand ich Ueberreste von Insecten,

?. 2. N. unicolor, Geoffr. Der rostrothe Kantenlefzer. K.: Pelz an den oberen Theilen einfärbig rostroth, an den unteren hell röthlichgelb.

\section{Vespertilio leporinus, Linn.}

Schreber, Tab. LX.

Schinz Thierreich u. s. w. B. I. p. 160.

Die hier von mir unter einer besondern Nummer aufgeführte Fledermaus ist ohne Zweifel die gewöhnliche Art dieses Geschlechts, wie 


\section{$-224-$}

sie in den naturhistorischen Werken meistens oberflächlich beschrieben und noch weit schlechter abgebildet wird. - Sie kommt in allen Theilen ihres Körpers, die Färbung ausgenom. men, mit No. 1. überein, aus dieser Ursache habe ich sie mit einem Fragezeichen versehen. Es ist zu vermuthen, dafs sie nur Altersverschiedenheit ist, ich habe übrigens Noctilio dorsatus nur in Gebäuden, unicolor blofs im Freien, in den Wäldern an Flufsufern gefunden. Man wird sie einstweilen als verschiedene Species aufstellen und die eine mit einem Fragezeichen versehen.

Die rothe Hasenscharte hat im Oberkiefer zwei Vorderzähne, welche von den Eckzähnen getrennt in der Mitte nahe zusammen stehen, etwas gekrümmt gegen einander geneigt; im Unterkiefer befinden sich zwei kleine kurze Schneidezähne zwischen die Eckzähne hinein gekeilt, sie haben eine eingelserbte oder etwas gespaltene Krone; Eckzähne kegelförmig und stark, unmittelbar an sie angeschlossen folgen die Backenzähne, im Ober - und Unterkiefer vier; sie sind eben so gebildet wie an der vor. hergehenden Art, bestehen aus zwei neben einander gestellten Winkeln oder Dreiecken, welche auf ihren ausspringenden Kanten Kegel- 
spitzen, und dazwischen tiefe Gruben tragen; der, erste Backenzahn ist eine Kegelspitze. -

Alle oberen Theile des Thiers haben eine hell rostrothe Farbe, der Rückenstreif fehlt; die unteren Theile sind hell rostgelblich, oder hell röthlichgelb, aber nicht so blafs als an No. 1., übrigens habe ich zwischen beiden Thieren keine Verschiedenheiten auffinden können. Der Schädel der beiden hier erwähnten Noctilionen ist breit, kurz und stark, mit einer starken, hohen crista longitudinalis versehen.

Die rostrothe ungestreifte Hasenscharte oder Kantenlefzer habe ich am Flusse Belmonte sehr häufig beobachtet. Sie flog daselbst sehr zahlreich an den Flufsufern umher, sobald die Abenddämmerung eintrat, und sie waren alsdann so häufig als die Schwalben bei uns an recht schönen Sommerabenden. - Sie fliegen sehr schnell und niedrig über dem Wasser hin und her, wo wir sie mit Vogeldunst erlegten. - Am Tage verbergen sich diese Thiere in hohlen Bäumen, belaubten Baumkronen und Felsen, auch an steilen Stellen der Flufsufer, ich habe aber diese rostrothe Art nicht aus den Gebäuden erhalten, wie ich weiter oben schon anmerkte.

II. Band. 
Ihre Stimme ist ein Zischen. - Ich habe sehr grofse Individuen unter ihnen bemerkt, deren Bauch ebenfalls sehr in's Rostrothe fiel *). Herr Dr. v. Spix beschreibt zwei Noctilionen, welche neu scheinen; die eine (Noctilio albiventris, $S p$.) gleicht in vieler Hinsicht dem dorsatus, die andere (Noctilio rufus, $S p$.) scheint verschieden von dem unicolor des Geoffroy, welches aus der Vergleichung der Maafse erhellt. -

$$
\begin{aligned}
& \text { G. 9. } D y s o p e s \text {, Mllig. } \\
& \text { H u } \mathrm{nd} s \mathrm{~m} \text { a } \mathrm{l} \text {. }
\end{aligned}
$$

Ich nehme hier dieses Geschlecht wie Illiger, der nicht, wie Desmarest, auf die Einkerbung der Schneidezähne Rücksicht nahm; denn die einzige für dieses Geschlecht von mir aus Brasilien zu beschreibende Fledermaus zeigt keine Einkerbung an ihren oberen Schneidezähnen. - Es ist übrigens bekannt, dafs diese Fledermäuse (Molossus Geoffr.) in Nord - und Süd-America vorkommen, und neueren Beobachtungen zufolge auch in Indien leben. -

*) Geoffroy's Noctilio albiventris ist vielleicht ein junges Thier? 


\section{- 227 \\ 1. D. $p$ e $r$ o $t$ i s. \\ $\mathrm{D}$ a $s \quad \mathrm{~T}$ a $s$ c $\mathrm{h}$ e $\mathrm{n}$ o $\mathrm{h}$.}

H.: Ohren grofs und selir breit, in zwei Taschen getheilt; Nase gespalten; Schwanz stark; Pelz oben dunkel röthlich-graubraun, an den unteren Theilen blässer röthlich graubrauın.

Abbildungen zur: Naturgeschichte Brasilien's.

Schinz Thierreich u, s. w. p. $8 \% 0$.

Beschreibung: Der Kopf ist dick und grofs, der Oberkiefer verlängert und mit vortretender, doggenartig gespaltener Nasenkuppe; die Nasenlöcher stehen auf der abgestumpften Vorderfläche und sind, wie bei den Schweinen, mit einem Rande umgeben, welcher oben zwischen beiden eingekerbt oder gespalten ist; der Unterkiefer ist breit, abgestumpft, kürzer als der obere; die Lippen haben einen etwas verdickten, und besonders die obere einen doggenartig herabhängenden Rand; das Auge ist klein und schweinartig, es steht nahe über dem Mundwinkel. Die Ohren sînd colossal und höchst merkwürdig gebildet, sie scheinen doppelt, d. h., sie werden in der Mitte durch einen sehr dicken hohen Längsknorpel in zwei Höhlungen oder tiefe Taschen getheilt, wovon die vorde. re inwendig fein und lang, von aufsen aber wie der Körper behaart ist; die hintere hingegen 
ist an ihrer inneren Seite nur längs des Schei. deknorpels mit einem Streifen von Haaren versehen, und von aufsen nackt; die Basis des Ohres ist so breit als die ganze Länge des Kopfs, sie fängt am Hinterhaupte an und endiget etwa drei Linien weit von der Nasenspitze, wo sich beide Ohren vereinigen; ihr Rand ist glatt, ausgedehnt etwa einen Zoll und zwei Linien hoch über dem Kopfe erhaben, beinahe halbcirkelfürmig, mit einem seichten Ausschnitte an seinem oberen Theile, die hintere Ohrtasche ist von innen mit Queerfalten bezeichnet. Der Ohrdeckel (Tragus) ist doppelt, ein gröfserer Hautansatz liegt gleich hinter dem Mundwinkel und ist länglich breit, dabei nach oben sanft abgerundet, ein kleinerer steht der Gehöröffnung näher, ist sehr kurz, schmal, und oben ein wenig abgestumpft. - Diese weiten groIsen Ohren zieht das Thier am Tage, wie eine Mütze, über die Augen herab. -

Der Rachen ist grofs und breit. - Die Zunge ist fleischig, dabei länglich-rund oder walzenförmig. -

Gebifs: Schn. $\frac{2}{0}$; Eckz. $\frac{Y \cdot I}{1 \cdot I} ;$ Backenz. $\frac{2}{2}$. An dem einzigen von mir gesehenen Individuo waren die Zähne zum Theil sehr beschädiget. - Von den Vorderzähnen befand sich im 


\section{$-229$}

Oberkiefer nur noch einer (es sind ihrer unbezweifelt zwei gewesen), hakenförmig gekrümmt; untere Vorderzähne fehlten. - Eckzähne im Oberkiefer lang, gekrümmt, zugespitzt, mit breiter Basis; im Unterkiefer stehen zwei auf eben diese Art gebildete; Backenzähne zerbrochen, sie zeigten aber noch viele scharfe Spitzen, wovon die äufseren länger sind, als die inneren.

Der Körper dieser grofsen schönen Fledermaus ist dick und stark; an der Brust bemerkt man eine grofse nackte Drüse, aus welcher eine Feuchtigkeit schwitzt, - Der Schwanz ist lang, nackt, und etwa bis zu seiner Mitte in die Flughaut eingeschlossen. - Die Flughaut ist lang und schmal, die Arme stark, aber die Firger nur mälsig lang; der Daumen ist stark, aber nicht besonders lang, und mit einem kur. zen gebogenen Krallennagel versehen, der Zeigefinger ist ohne Gelenke, der zweite Finger hat vier Glieder, der dritte hat drei, der vierte drei und seinen Nagel. - Die Hinterbeine sind stark, mäfsig lang, die Seitenflughaut ist etwa in dem Fufsgelenke befestiget; der Fufs ist kurz, mit fünf etwa gleichen Zehen und kurzen gebogenen Krallennägeln versehen. Der Sporn ist etwa einen Zoll lang; von seiner 


\section{- 230}

Spitze zieht sich die Flughaut nach der Mitte des Schwanzes hin, dessen Spitzenhälfte frei und so wie der ganze Schwanz unbehaart, rund und glatt ist. Das Gesicht ist dünn behaart, beinahe nackt; Rand der Oberlippe behaart, auch findet sich ein dichter Busch längerer Haare über der Nasenkuppe vor der Vereinigung der beiden Ohren; Unterkiefer sehr dünn mit einzelnen Härchen bedeckt; Rand der Unterlippe mit kurzen weifslichen Härchen besetzt; Haar des ganzen Körpers sehr dicht, sanft und mäuseartig, an den oberen Theilen dunkel röthlichgraubraun, an den unteren blässer röthlich graubraun; Gesicht graubraun, aber Ohren, Flughaut, Schwanz, so wie alle nackten häutigen Theile zeigen eine schwärzlich-braune Farbe; der Unterkiefer ist blässer, blafs fleischbraun gefärbt; um die Brustdrüse herum befindet sich eine etwas nackte Stelle. - Die Arme sind nur am Leibe behaart, die Flughaut aber zeigt in den Seiten des Körpers ungefähr sechs Linien weit von demselben eine dichte Behaarung, auch ist der Winkel derselben vor dem Ellenbogen, so wie die den Arm an der unteren Seite bis zu jenem berührende Haut etwas behaart; die beiden äufseren Zehen an jedem Fu. lse sind nach aufsen mit dichten, kurzen, bor- 
stigen, weifslichen Haaren besetzt, das Nagelglied einer jeden der fünf Zehen hat aber aufierdem einige glänzende lange Haare, welche bogenförmig weit über den Nagel hinausreichen. -

Ausmessung dieser Fledermaus:

Ganze Länge

Länge des Körpers

Länge des Schwanzes

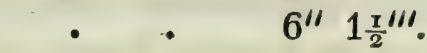

. . . $4^{\prime \prime} 3 \frac{1}{2}{ }^{\prime \prime \prime}$. - . 1 1" $10^{\prime \prime \prime}$.

Ganze Breite des ausgespannten Thieres 21" $1^{\prime \prime \prime}$. Ohr über dem Kopfe erhaben etwa $1^{\prime \prime} 2^{\prime \prime \prime}$. Länge des Fufses

Länge des Sporns etwa . . . . 1" Länge des Daumens • • . $3 \frac{1}{2}{ }^{\prime \prime \prime}$.

Ich erhielt diese schöne merkwürdige Fledermaus nur einmal zu Villa de S. Salvador dos Campos dos Goaytacases am Parahyba. Sie wurde im Monat September in einem Gebäude gefangen und ist uns nachher nie wieder vorgekommen. - In ihrem Magen fanden sich Ueberreste von Insecten. -

G. 10. $D$ e $s \quad m$ o $d u$ s. ' B ü n d e $\mathrm{l}$ z a h n.

Gebifs: Schneidezähne im Oberkiefer zwei; grofs, kegelförmig, gekrümmt, zusammen. 
gedrückt, zugespitzt, mit sehr breiter $\mathrm{Ba}$. sis. -

Schneidezähne im Unterhiefer vier, sämmtlich stark nach vorn strebend; Krone tief gespalten, die beiden Theile wal. zenfürmig verlängert und am Ende etwas abgerundet.

Eckzähıne grofs, kegelförmig zugespitzt; die unteren völlig gerade pyramidal aufsteigend.

Backenzähne im Oberkiefer .....

Backenzähne im Unterkiefer auf jeder Seite drei; durch eine kleine Lücke von den Eckzähnen getrennt; der erste und zweite einspitzig, dabei rückwärts gelrümmt, und einer fest an den anderen angeschmiegt; der dritte hat zwei Spitzen. -

Nase: mit verschiedenen behaarten Hautfalten bezeichnet, unter welchen drei wulstige etwas zugespitzte Erhöhungen sich auszeichnen. -

Ohren mit einem Ohrdeckel (Tragus) versehen. -

Zunge.......

Kopf: klein und sehr kurz; die Kürze seiner Kiefer ist auffallend. - Unterkiefer länger als der obere. 
Arme und Flughaut sehr stark; Daumen sehr grols und aus zwei Gliedern bestehend. Zeigefinger scheinbar zweigliederig.

Sporn fehlt.

Schwanz fehlt.

Die Fledermaus, welche mich bewog, dieses neue Genus aufzustellen und die in kein einziges der bekannten Geschlechter vollkom. men palst, hatte ich anfänglich zu den Kammnasen ( $R$ hinolophus) gerechnet, halte es aber jetzt für schicklicher, sie von diesen zu trennen, da sie durch mehrere sehr abweichençe Hauptzüge von ihnen unterschieden ist. - Sie trägt zwar erhöhte Hautschwielen von besonderer Bildung auf der Nase, allein ihre gleichsam in einen Bündel vereinigten Backenzähne, die Anzahl aller ihrer Zähne, das Vorhandenseyn eines Tragus u. s. w. scheiden sie hinlänglich.

$$
\text { 1. D. } r u f u s \text {. }
$$

Der rothbraune Bündelzahn.

B.: Körper ungeschwänzt, röthlich-braun; Daumen ausgezeichnet lang und stark, so lang als der Fufs; der Sporn fehlt. -

Abbildungen zur Naturgeschichte Brasilien's.

Rhinolophus ecaudatus. Schinz das Thierreich u. s. w.

B. I. pag. 168. 
$\mathrm{Da}$ ich diese Fledermaus nur einmal, und zwar schon ausgestopft erhielt, so war es unmöglich, alle ihre Ausmessungen richtig zu nehmen, ich habe indessen die Charactere, welche noch unverändert waren, gewissenhaft zusammengestellt.

Der Kopf ist klein, kurz und abgestumpft, der Unterkiefer länger als der obere, und die vordere Spitze des ersteren zeigt einen dreiekkigen, von Haaren entblöfsten Fleck an der Unterlippe; Ohren mittelmälsig grofs, etwas mehr länglich als rund, daher beinahe eiförmig; der Ohrdeckel (Tragus) ist schmal, zwei und eine halbe Linie lang, zugespitzt, an seiner Spitze ein wenig auswärts gekrümmt, wodurch auf seiner hinteren oder äufseren Seite unter der Spitze ein starker Ausschnitt entsteht, welcher derselben eine etwas sichelförmige Gestalt giebt; unter derselben befinden sich an demselben Ohrdeckelrande einige kleine Zähnchen; die beiden schief gegen einander gestellten $\mathrm{Na}$ senlöcher sind mit einem erhöhten Hautrande umgèben, der über einem jeden derselben sich in eine kleine Spitze erhebt; hinter diesen beiden zugespitzten Hautfalten, und zwar gerade hinter der sie trennenden Vertiefung, erhebt sich ein behaarter zugespitzter Wulst, und rings 
um ein erhöhter Rand, wodurch diese ganze Nasenbildung ein originelles Ansehen erhält, und sich an die Kammnasen (Rhinolophus) anschliefst.

Gebifs: Schn. $\frac{2}{4}$; Eckz. $\frac{\text { I.I }}{\text { I.I }}$; Backenz. $\frac{2}{3}$. Im Oberkiefer stehen zwei Schneidezähne, sie sind grofs, kegelförmig, gekrümmt, zusammengedrückt, zugespitzt und an ihrer Basis sehr breit; im Unterkiefer befinden sich vier Schneidezähne, sie streben sämmtlich stark nach vorn, und die Krone eines jeden derselben ist tief gespalten, beide Theile derselben walzenförmig verlängert und an ihrer Spitze etwas abgerundet. -

Eckzähne grofs, zugespitzt, kegelförmig, die unteren völlig gerade pyramidenartig aufsteigend.

Backenzähne im Oberkiefer zufällig zerstört.

Im Unterkiefer auf jeder Seite drei, durch eine kleine Lücke von den Eckzähnen getrennt; sie sind sonderbar gebildet; der erste und zweite sind einspitzig, aber rückwärts gekrïmmt und einer fest an den andern angeschmiegt; der dritte hat zwei Spitzen. -

Die Arme und die Flughaut dieses Thiers sind sehr stark, so wie die ganze Hand; der 
Daumen ist ausgezeichnet grofs und stark, er milst beinahe sieben Linien in der Länge, hat zwei starke Glieder und einen mälsig grofsen, gekrümmten, zusammengedrückten Nagel; der Zeigefinger scheint zwei Glieder zu haben, der zweite Finger vier, der dritte und der vierte jeder drei. - Der Schenkel milst etwa neun Linien in der Länge; das Schienbein ist ein wenig länger; der Sporn scheint gänzlich zu fehlen; der Fufs, welcher so lang ist als der Daumen, hat fünf starke gleich lange Zehen, mit starken, zusammengedrückten, gekrümmten Krallennägeln; der Schwanz fehlt; die Schwanzflughaut ist sieben und eine halbe Linie hoch über dem Fufsgelenke an der hintern Seite des Schienbeins befestiget, läuft mit einem Saume an demselben hinauf, und ist in einer Ausdehnung von drei Linien an dem Körper als Saum hinüber nach dem anderen Schienbeine gespannt. - Die grofse Seitenflughaut schlielst sich drei Linien hoch von dem Fufsgelenke an das Schienbein an; sie ist in der Nähe des Körpers auf ihrer oberen Seite überall stark rothbraun behaart, eben so die Schwanzflughaut; die untere Seite dieser beiden Theile ist eben so behaart, aber die Haare haben die blässer selbliche Farbe der unteren Körpertheile. - 
Haar des Körpers lang, schlicht, sanft, mäfsig dicht, an der Wurzel hellgelb, an den Spitzen rothbraun, oder röthlich-zimmtbraun, wodurch das Thier im Allgemeinen ein roströthliches Ansehen erhält; die unteren Theile sind blässer, bräunlich-schwefelgelb mit einem Goldglanze, besonders an Hals, Fülsen, Daumen und Zehen der Hinterfüfse; von eben dieser Farbenvertheilung ist die Behaarung der übrigens schwarzbraunen Flughaut; Arme, Schenkel, Schienbeine und Füfse, so wie der Winkel der Flughaut vor dem Ellenbogen, welcher von der Schulter zu dem Daumen ausgespannt wird, sind durchaus stark behaart, und zwar glänzend röthlichbraun; selbst die Ohren, das Gesicht und die Nasenfalten sind auf diese Art, obgleich nur dünn behaart. - Die Behaarung des Oberarms an der unteren oder inneren Seite ist etwas wollig, der Vorderarm aber nur wenig behaart; die Nägel an den Zehen der Hinterfüfse haben eine gelbliche Hornfarbe, und rothbraune Spitzen. -

Ausmessungen der unveränderten Theile:

Ganze Länge bis zu dem Ende der Schwanzflughaut etwa . : $3^{\prime \prime} 9^{\prime \prime \prime}$. 


\section{$-238$}

Höhe des Ohrs (auf seiner hinteren, dem Scheitel zugewandten Seite gemessen) etwas über • . . $4^{\prime \prime \prime}$. Länge des Ohrdeckels • • • . $2 \frac{r_{2}^{\prime \prime \prime}}{2}$ Länge des Daumens beinahe • • $\quad 7^{\prime \prime \prime}$. Länge des Schenkels etwa • • . $9^{\prime \prime \prime}$. Länge des Schienbeins beinahe - $10^{\prime \prime \prime}$. Länge des Fufses . • • • • $8^{\prime \prime \prime}$. Ganze Breite des Thiers etwa - $15^{\prime \prime}$

Der Schädel war leider zerbrochen, doch zeigte er noch eine merkwürdige Kürze, da in dem Unterkiefer nur für die drei genannten Backenzähne Raum war. -

Diese merkwürdige, bisjetzt unbekannte Fledermaus ward in den alten Gebäuden der Fazenda von Muribeca am Flusse Itabapuana gefunden; ich erhielt nur ein einziges Exemplar, welches meine Leute präparirt hatten, während ich abwesend war. - Lebensart und Nahrung dürften wohl von der der übrigen Fledermäuse nicht bedeutend verschieden seyn. - 


\section{$-239-$}

G. 11. $D i c l i d u r u s$.

$\mathrm{K} \mathrm{l}$ a p pens c h w a $\mathrm{n}$.

Gebifs: Schneidezähne im Oberkiefer wahrscheinlich zwei ${ }^{*}$ ); im Unterkiefer sechs, auf jeder Seite unmittelbar an den Eckzahn gereihet drei, in der Mitte befindet sich eine Lücke; sie sind klein, mit breiter, dreimal eingekerbter Schneide. Eckzähne im Oberkiefer zwei, kegelförmigr **), vorwärts gerichtet, etwas zusammengedrückt, sanft gekrümmt, an ihrer hinteren Seite mit einer zweiten kleineren Nebenspitze. - Im Unterkiefer sind sie senkrecht gestellt, gerade, an ihrer vorderen Basis mit einer erhabenen Leiste. Backenzähne im Oberkiefer auf jeder Seite fünf; unmittelbar hinter dem Eckzahne ein kleines Lückenzähnchen, dann folgt eine starke Lücke, und nun vier grofse Mahlzähne mit langen starken Zackenspitzen; der vordere ist lang und kegelförmig,

*) Wegen des ausgebrochenen Intermaxillarknochens nicht genau zu bestimmen, nur ein kleiner Zahn war noch vorhanden, der seiner Stellung wegen auf zwei Vorderzähne schliefsen liefs.

**) In der Isis ist aus Mifsverständni「s statt kegelförmig nagelförmig gesetzt. 
ctwas gekrümmt und mit scharfer, einfacher Spitze, daher beinahe einem Eckzahn ähnlich; er hat einige kleine Nebenerhöhungen und ist von dem Eckzahne durch einen leeren liaum getrennt. Im Unterkicfer fünf Backenzähne auf jeder Seite; die beiden vorderen mit einer einfachen kegelförmigen Spitze, und einigen kleinen Nebenhöckern. -

Kopf: Unterkiefer länger als der obere; letzterer am Schädel vor und zwischen den beiden Augenhöhlen durch eine grolse elliptische Vertiefung ausgezeichnet, welche die Gesichtsknochen zu beiden Seiten vor die orbita heraustreibt. - Stirn - und Schei. telknochen sind mit blasenartigen Erhöhungen aufgetrieben.

Zunge: fleischig, ganzrandig, kürzer als der Unterkiefer, am gröfsten Theile ihrer Un: terfläche befestiget. -

Schwanz: anstatt eines äufseren Schwanzes laufen die Schwanzknochen mit mehreren Gelenken in zwei äufserlich an der Haut des Körpers befestigte Hornstücke aus, welche ein aus zwei Klappen oder Kapseln zusammengesetztes Orgyan bilden. - Die obere Klappe ist halbmondförmig g horn- 


\section{- 241}

artig, scheibenförmig, mit etwas wulstig verdicktem Rande, dabei eine hohle Kapsel; die untere ist kleiner, etwas dreiekkig, zugespitzt, gegen die obere horizontal angelegt, ebenfalls von der Haut gebildet, hohl; diese beiden Hornstücke stehen mit ihrer gröIseren Fläche horizontal, lassen sich gegen oder aneinander bewegen, und von einander entfernen, und sind durch eine besondere feine Haut an ihrer Basis verschlossen oder von dem Körper getrennt. Der Schwanzknochen tritt in die obere Kapsel.

Flughaut: wie an den übrigen Fledermäusen; ihr hinterer Rand zwischen den Hinterbeinen ist unter der Schwanzklappe hindurch gespannt.

Diese sonderbare Bildung scheint geeignet, ein besonderes Geschlecht unter den Fledermäusen zu bilden. - Das einzige Exemplar dieser Art, welches ich sah und besitze, verdanke ich dem Herrn Freyreifs in Brasilien, dem es seine Jäger einbrachten, und von welchem ich dasselbe leider im ausgestopften $\mathrm{Zu}$ stande erhielt. - Die nachfolgenden Zeilen werden eine genauere Beschreibung des Klappenschwanzes enthalten. -

II. Band. 
Von der Lebensart dieser Fledermäuse wissen wir nichts, doch dürfte sie wohl wenig von der der übrigen Flederthiere versclieden seyn. - Bei genauerer Durchsuchung von Brasilien wird man vielleicht noch mehrere auf diese Art gebildete Thiere finden, und vielleic'tt haben auch unsere jetzt reisenden Naturforscher Gelegenheit gehabt, die Anatomie dieses merkwürdigen Wesens zu studiren.

$$
\text { 1. D. } \quad a \quad l \quad b \quad u s \text {. }
$$

Der weifse Klappenschwanz.

Kl: : Ohr breit, über dem Auge entspringend; Haar des Körpers sehr ciicht, lang, weifslich gefärbt; Arme stark und lang; Schienbeine lang und schlank; Sporn lang. -

Isis Jahrgang 1819. p. 1629.

Schinz Thierreich u. s, w. B. I. pag. 170.

Meine Reise nach Brasilien, B. II. p. 76.

Abbildungen zur Naturgeschichte Brasilien's.

Beschreibung nach einem ausgestopften Exemplare: Diese Fledermaus hat im Allgemeinen die Bildung unserer europäischen Arten; der Kopf ist ziemlich klein, der Körper mälsig breit, die Glieder ziemlich lang, dabei stark. Der Unterkiefer ist länger als der obere, die Nasenkuppe scheint durch eine senkrechte Furche ein wenig gespalten; die Augen scheinen 


\section{$-243$}

nicht besonders klein; über ihnen entspringt das Ohr mit breiter Basis; sein oberer Theil war an dem Exemplare beschädiget, doch ist das äufsere Ohr nicht besonders hoch; der Ohrdekkel ist breit und abgestumpft; die Arme sind stark und lang, die Flughaut ziemlich schmal; der Daumen ist mäfsig lang, mit einem kurzen Nagel versehen, und liegt bis an die Wurzel des letzteren in einem vor dem Handgelenke und dem Zeigefinger hin ausgedehnten Streif der Flughaut. - Der Zeigefinger ist stark, lang, aber nur aus einem Gliede bestehend, seine Haut ist an dem zweiten Gelenke des zweiten Fingers befestiget, welcher drei Glieder, und einen schmalen, beinahe drei Linien langen $\mathrm{Na}$ gel hat; der dritte und vierte Finger haben ein jeder drei Gelenke. - Die Vorderarmröhre ist stark gebogen; der Schenkel ist kurz und gröfstentheils im Pelz verborgen; das Schienbein ist lang und schlank, der Fufs etwa halb so lang als der Sporn, mit fünf gleichen, sehr zierlichen Zehen und starken Krallennägeln; die Schwanzflughaut ist von den Enden der beiden Sporne in einem Bogen hinüber gespannt, dabei nur nahe am Körper behaart; die Seitenflughaut ist im Fufsgelenke befestiget. - 


\section{$-244-$}

Das merkwürdigste Gilicd des Thieres ist sein Schwanz; verfolgte ich die letzten noch in dex Haut befindlichen Schwanzwirbel, so fand ich sie deutlich in die obere, vorhin erwähnte Hornkapsel endend; diese ist ein am Ende des Körpers zwischen den Hinterschen. keln unmittelhar an der Schwanzflughaut sitzender, beinahe halbmond - oder etwa bohnenför. miger, hohler Hornkörper, ein Ueberzug des letzten Schwanzwirbels, mit an seinem vorderen oder äufseren Theile etwas wulstig aufge. triebenem, abgerundetem, und in der Mitte et. was ausgeschweiftem Rande, auf seiner Oberund Unterfläche ein wenig ausgehöhlt oder ein. gedrückt; unter diesem oberen Hornstücke befindet sich sogleich eine kleinere, dreieckige, ebenfalls hohle, aber etwas zugespitzte Hornkapsel, die gegen die obere angelegt und von ihr abbewegt werden kann, zwischen welchen ich aber keine Oeffnung habe finden können, auch den Nutzen und die Bestimmung dieses sonderbaren Organes auf keine Weise zu errathen wage. - Beide Theile dieser sonderbaren Klappe sind hohl und durch eine besondere zarle Haut geschlossen und rnm Leibe getrennt. 


\section{$-245$}

Der ganze Körper dieses Thieres ist mit ei . nem zarten, sehr dichten, langen, etwas zottigen, weilslichen Haare bedeckt, welches auf dem Oberrücken vier Linien in der Länge milst. Die Behaarung fängt an der Nasenspitze an; die Seiten des Kopfs von der Nase bis zu dem Auge, der Lippenrand und das innere Ohr sind unbehaart und bräunlich gefärbt; das äufsere Ohr scheint grolsentheils, wenigstens an seiner Basis, behaart; die Flughäute sind nackt, mit Ausnahme eines weilsbehaarten Streifs längs der unteren Seite des Vorderarms hin bis zwischen den dritten und vierten Finger, des oberen Hautwinkels vor dem Ellenbogengelenk, eines Theils der Flughaut in den Seiten des Körpers und der Schwanzllughaut zu den Seiten der Schwanzklappe; die weilsen Haare des Körpers treten zu beiden Seiten der Schwanzklappe in zwei langen Büscheln etwas über die Schwanzflughaut herab. Flughäute hellbräunlich gefärbt, die Schwanzklappen schwärzlichbraun, wie die Fülse und die Nägel.

\section{Ausmessung :}

Ganze Länge etwa $2^{\prime \prime} 10^{\prime \prime \prime}$.

Ganze Breite etwa zwischen ' 13 u. 14"

Länge des Kopfs $10 ! 1 ! !$ 
Höhe des äufseren Ohres etwa . . $4^{\prime \prime \prime}$. Breite der Ohrbasis . • . . $5 \frac{y^{\prime \prime \prime}}{2}$. Länge der Vorderarmröhre . . $\quad 2^{\prime \prime} 4^{\prime \prime \prime}$. Länge des Daumens • • • . $2^{\prime \prime \prime}$. Länge des zweiten Fingers • • $3^{\prime \prime} 6^{\prime \prime \prime}$. Länge des dritten Fingers . . $2^{\prime \prime} 1 \frac{1^{\prime \prime \prime}}{}$. Länge des Schienbeins beinahe . 11"'. Länge des Fufses _ . . . $4 \frac{T^{\prime \prime}}{}{ }^{\prime \prime}$. Länge des Sporns etwa . . . $9 \frac{1}{2}{ }^{\prime \prime \prime}$. Höhe ảer oberen Schwanzklappe etwa $5^{\prime \prime \prime}$. Breite . . . . . . 5 5"'.

Der Schädel dieser merkwürdigen Fledermaus ist sonderbar gebildet. Seine Gesichtsknochen sind, wie weiter oben gesagt, an drei verschiedenen Stellen blasenartig aufgetrieben, und vor und über den beiden Augenhöhlen befindet sich eine grofse elliptische Vertiefung, welche queer über die Nasenknochen hin liegt, und die Gesichtsknochen zu beiden Seiten vor die Augenhöhle heraustreibt; an dem ausgestopften Thiere waren alle die weichen, darin befindlich gewesenen Theile (vielleicht einé grofse Drüse?) hinweggenommen, und die Haut zeigte an dieser Stelle eine grolse Dünne oder Transparenz. - Das Gebils ist bei den Kennzeichen des Geschlechtes schon finlänglich beschrieben worden, man findet aber in dem An- 


\section{- $247-$}

hange zu diesem Genus noch eine umständlichere Beschreibung des hier erwähnten Schädels, verbunden mit einer Vergleichung desselben mit den Köpfen der Spitzmaus und des Maulwurfs.

Die Jäger des Herrn Freyreifs fanden diese Fledermaus zwischen den grofsen Wedeln der zahmen Cocospalmen (Cocos nucifera) bei Canavieras an der Mündung des Rio Pardo (siehe den 2ten Theil der Beschreibung meiner Reise nach Brasilien, pag. 76), wo sie sich am Tage verbirgt. Man fand nur ein einziges Exemplar, welches sich jetzt in meiner zoologischen Sammlung befindet. Um Herrn Freyreifs meine Erkenntlichkeit für die Mittheilung dieses interessanten Thieres zu beweisen, hatte ich dasselbe nach Ihm benannt, zugleich aber den Namen albus vorgeschlagen, welchen Herr Professor Oken in der Isis vorzog. - Ich wülde der ersteren Benennung treu geblieben seyn, weun nicht aus Versehen unter die von mir gegebene Abbildung dieser Fledermaus die letz. tere gesetzt worden wäre, welche ich daher jetzt vorziehe und beibehalte. - 


\section{A $\mathbf{n}$ h a $\mathbf{n}$ g.}

Beschreibung des Schädels des Diclidurus

von. Herrn Professor Oken.

Der Schädel dieser Fledermaus ist auf der rechten Seite und unten grölstentheils zerstört; alle Knochen sind verwachsen und so dünn, dafs sie durchscheinen, - Die eigentliche Hirnschaale ist ziemlich oval; das Gesicht ist plötzlich niedergedrückt und seitwärts ausgedehnt. Das, was man für die Nasenbeine halten mufs, ist selbst schaalenförmig vertieft. Die Nasenlöcher liegen zwischen den Wurzeln der Eckzähne.

Zähne sind oben jederseits sechs, ein Eckzahn, dicht dahinter ein äufserst kleines Lükkenzähnchen; dann folgt eine Lücke und darauf vier angeschlossene Backenzähne, wovon der vorderste der kleinste ist; dann folgt in der Gröfse der hinterste; der vorletzte isı der 
gröfste. - Schneidezähne fehlen *); doch lä[st sich dieses nicht mit voller Gewifsheit entscheiden, da die Knochen hier verletzt sind. Indessen scheint das Gaumenbein ganz nach vorn zu laufen und die Kiefer ganz von einander zu trennen, so dafs der Zwischenkiefer, wenn irgend einer dagewesen, äufserst klein seyn muls, und nicht wohl Zähne fassen kann. Der Eckzahn ist der längste und hat hinten etwas über der Mitte eine kleine Nebenspitze. - -

Das Lückenzähnchen ist kaum wie ein Stecknadelkopf, hat aber doch zwei Spitzen hinter einander. -

Was die Backenzähne betrifft, so mufs zuerst etwas vom Bau der Zähne überhaupt vorausgeschickt werden.

Man kann annehmen, dafs die Backenzähne der fleischfressenden Thiere, welche alle mit Schmelz überzogen sind, einen vierseitigen

*) Sie fehlten blols jetzt an dem Schädel; es ist aber weiter oben (pay. 239) gesagt, wie es sich anfänglich mit diesen Zälmen verhielt. Herr Professor Oken hat meirer in der Isis gegebenen Notiz von diesem Thiere nicht erwähnt, sondern redet blols von dem gegenwärtigen Zustande des Schädels, an welchem wirklich das einzige noch vorhandene. Vorderzühnchen verloren gegangen ist. 


\section{$-250$}

Pfeiler vorstellen, der nach unten in mehrere Wurzeln ausläuft. Jede der vier Ecken erhebt sich über die Kaufläche in eine Spitze, so deutlich bei'm Igel. Diese vier Spitzen sind aber mancher Veränderung unterworfen. Eine der gewöhnlichsten ist die, dafs die zwei inneren sehr verkürzt werden und selbst bis unter die Kaufläche treten. Sie erscheinen dann nur als ein Absatz, der jedoch noch, in der Regel, durch eine Kerbe die ehemaligen zwei Spitzen anzeigt. Dieser Bau der Backenzähne findet sich nun ausgezeichnet bei'm Maulwurf, bei der Spitzmaus und bei den Fledermäusen, und es ist daher kein Zweifel, dafs diese Thiere in eine Zunft gehören. Bei der Spitzmaus ist der Absatz noch deutlich durch eine Kerbe in zwei Spitzen geschieden, bei dieser Fledermaus desgleichen; bei'm Maulwurf aber ist die Kerbe gänzlich verschwunden, und der Absatz erscheint nur einspitzig; die Fledermäuse stehen daher den Spitzmäusen näher als dem Maulwurf.

Die Backenzähne dieser Thiere haben noch das Eigenthümliche, dafs die zwei grofsen, äufseren Spitzen auswendig schief abgeflächt sind, und in dieser Fläche eine Längsfürche haben, so dafs die Spitzen wie durch eine Einfaltung 
entstanden zu seyn scheinen und die Zähne unter den Spitzen eine Querleiste bekommen.

Der erste Backenzahn nun unserer Fledermaus ist etwas länger als die anderen und hat eigentlich nur die vordere Spitze behalten, indem die hintere, wie es häufig geschieht, sehr niedergedrückt ist. Der Absatz hat auch die Kerbe verloren, es ist also dieser Zahn noch ziemlich wie ein Lückenzahn gestaltet, und steht auch wohl in der Bedeutung derselben.

Der 2te Backenzahn ist gröfser und hat 2 äufsere eingefaltete Spitzen mit einem groIsen Absatz, der sehr schwach gekerbt ist.

Der 3te Backenzahn ist etwas grölser, aber eben so gestaltet.

Der 4te ist zwar eben so gestaltet, aber viel schmäler, stellt nur einen Querzahn vor mit einfachem Absatz. Die Zahnlinien sind gerade, convergiren aber nach vorn.

Der Unterkiefer ist viel schmäler als der obere, so dafs dessen Zähne zwischen den oberen wie in einem Falz liegen.

Im Unterkiefer sind jederseits 9 Zähne, 3 Schneidezähne, 1 Eckzahn, 1 Lückenzahn und 4 Backenzähne, alle dicht angeschlossen; die Schneidezähne sind nur kleine Spitzen; der Eckzahn ist der längste, ohne Nebenspitze; der 
Lückenzahn ist etwas gröfser als der obere und nicht stumpf wie jener, sondern einspitzig.

Der erste Backenzahn ist etwas länger als die folgenden, hat 2 Spizen, wovon aber die hintere sehr kurz; die 3 folgenden Backenzähne sind sich ziemlich gleich, und haben je 4. Spitzen, wovon die zwei inveren um ein weniges kürzer sind. Sie sind übrigens nicht ein. gefaltet, und wenn hier überhaupt von einer Einfaltung geredet werden kann, so muls sie sich auf der inneren Seite befinden, der Um. kehrung der unteren Zähne gemäls. Das Ge. bifs steht also so:

Schnz. $\frac{0}{3} ;$ Eckz. $\frac{x}{x} ;$ Lückenz. $\frac{x}{x} ;$ Bak. kenz. $\frac{4}{4}$. -

Da der untere Eckzahn, welcher wirklich als solcher betrachtet werden mufs, vor den oberen schlägt, so kann auch dieser für nichts anderes gehaiten werden; gegen den Fall näm. lich, wenn man annehmen wollte, er stände im Zwischenkiefer.

Die geringste Vergleichung der Gebisse der Fledermaus, der Spitzmaus und des Maulwurfs macht es augenscheinlich, dafs diese 3 Thiere zusammen gehören, und dafs die Fledermäuse keinesweges in die Nachbarschaft der Affen 


\section{$-253$}

kommen, können, wofern man nicht auch den Maulwurf dahin stellen will, -

$$
\text { Maasse des Schädels: }
$$

Länge.

\section{Höhe}

Breite der Hirnschaale

Breite des Gesichts

Abstand der beiden Eckzähne

- $8 \frac{I^{\prime \prime \prime}}{3}$.

- $4 \frac{2}{3}{ }^{\prime \prime \prime}$.

$4^{\prime \prime \prime}$.

- $3^{\prime \prime \prime}$.

$1 \frac{3}{4}{ }^{\prime \prime \prime}$.

Abstand der beiden vorderen Backen:

zähne

Abstand der beiden hinteren Backen-

zähne

Länge der Zahnlinie von der Spitze

des Eckzahnes an . . . . . 4".

Länge der Linie der Backenzähne - $2 \frac{x}{2}{ }^{\prime \prime}$.

Länge des Unterkiefers

Höhe des Kronfortsatzes

Höhe des Gelenkfortsatzes

Höhe der Zahnlade

Länge der Zahnlinie im Unterkiefer

Länge der Hirnschaale unten, von den

hinteren Nasenlöchern an
- $2 \frac{2}{3} " \prime$

$3 \frac{x}{2}^{\prime \prime \prime}$. $6 \frac{2}{3} " 1$. $2 \frac{2}{3} " 1$. $2 \frac{r}{5}-1 \frac{r^{\prime \prime}}{2}$. $\frac{3}{4}^{\prime \prime \prime}$. $4 \frac{3}{4}^{\prime \prime \prime}$. - $2 \frac{1}{4} " 1$. 


\section{$-254-$}

Erklärung der Abbildungen.

$$
\begin{gathered}
\text { T a b. I. } \\
D i c l i d u r u s .
\end{gathered}
$$

Schädel in natürlicher Grölse: Fig. $a$, von oben mit dem Unterkiefer; $b$, ohne denselben; $c$. von der Seite die Zähne nicht genau; $d$. von hinten; $\epsilon$. dasselbe von oben, vergröfsert, um die Vertiefung der Nasenbeine zu zeigen und den Abstand der Eckzähne; $f$. dasselbe, viel vergröfsert, von der Seite, zeigt das Gebifs, oben voran der Eckzahn, * das Lückenzähnchen, dann die vier Bakkenzähne. Unten die 3 Schneidezähne, der Eckzahn, der Lückenzahn, die 4 Backenzähne. Der untere Eckzahn schlägt vor den oberen, und es ist mithin dieser ein ächter Eckzahn.

g. Obergebifs, Kaufläche, zeigt auswendig zwei eingeschlagene Spitzen, inwendig den $\mathrm{Ab}$ satz mit einer schwachen Kerbe. Der hinterste Zahn ist schmäler, so zu sagen nur halb, indem die hintere Spitze fast verlsümmert ist.

$h$. Untergebils, Kaufläche.

$i$. Untergebifs von innen, auswendig zwei grofse Spitzen, inwendig drei kleine. 


\section{$-255$}

$k$. Dasselbe von innen und oben.

l. Vorletzter Backenzahn oben, von der äufseren Seite, zeigt blols die drei kleinen Hökker der Randleiste, die zwei grofsen Spitzen sind weggelassen.

$m$. Derselbe Zahn mit den zwei grofsen Spitzen und der dreihöckerigen Randleiste, von der sie so aufsteigen, dafs ihre Seitenkanten je auf einem der Höcker stehen, auf dem mittleren ihrer zwei, Diese Randhöcker entstehen eigentlich durch die Einfaltung der zwei grofsen Spitzen.

$m$. Derselbe Zahn, Kaufläche. Oben sieht man die drei Randhöcker, von ihnen aus gehen die zwei grofsen Spitzen nach innen. In. wendig zeigen sich die zwei Spitzen des Absatzes, die ebenfalls einwärts geschlagen sind.

n. Derselbe Zahn des Unterkiefers von innen; zeigt die drei Randhöcker, welche hier, nach der regelmälsigen Vordrehung der unteren Zähne inwendig stehen, die zwei grofsen Spitzen auswendig. Der Absatz, welcher auswendig stehen müfste, fehlt hier.

Spitzmaus, zur Vergleichung.

a. Gebils, oben 8 , unten 6 Zähne, dort, dem Scheine nach, 1 Nagezahn, 3 Lückenzähne, 


\section{$-256$}

4 Backenzähne, hier 1 Nagezahn, 2 Lückenzähne und 3 Backenzähne. Da aber bei allen verwandten Thieren unten 4 Backenzähne sind und der erste einem Lückenzahn ziemlich gleich sieht; so muls auch hier der hintere Lückenzahn für den ersten Baklienzahn genommen werden. So wären oben 3, unten nur 1 Lückenzahn. Betrachtet man aber dieses Gebils genau, so bemerkt man, dafs der untere Nagezahn die 3 vorderen Zähne oben deckt, und sie mithin zu seinen Gegenzähnen hat. Es sind demnach die zwei vorderen Lückenzähne oben für Schneidezähne zu halten, und so hätte die Spiizmaus auch dann oben drei, wie der Maulwurf und die meisten Thiere. Es wird aber erst strerg erwiesen werden können, wenn man weils, dals sie im Zwischenkiefer stecken. Bisjetzt war es uns nicht möglich, junge Spitzmäuse mit unverwachsenen Schädelknochen aufzutreiben. Unsere Ansicht gewinnt aber auch dadurch an Gervicht, dafs bei Scalops und Sorcx moschatus wirklich 3 Schneidezähne oben vorhanden sind. Es ist demnach oben und unten nur ein Lückenzahn, und das Gebils stcht so: Schn. $\frac{3}{1}$; Lïckenz, $\frac{7}{1}$; Backenz. $\frac{4}{4}$. - 
Nach dieser Ansicht dürften wohl Sorex, Mygale und vielleicht Scalops zu vereinigen seyn. -

b. Obergebils verkehrt, von innen gesehen; die 3 ersten Backenzähne zeigen 2 äufsere eingefaltete Spitzen, wie bei der Fledermaus, und einen inneren Absatz ebenfalls mit 2 kleinen Spitzen oder einer Kerbe. Der hinterste Backenzahn ist nur halb, wie bei der Fledermaus.

c. Obergebils, Kaufläche, auf eine andere Art dargestellt, um die Einfaltung besser zu zeigen. Inwendig der Absatz mit der Kerbe, auswendig die Randleiste mit drei Höckern, wie bei der Fledermaus.

d. Vorletzter Backenzahn oben, von aufsen gesehen, zeigt die zwei Spitzen und darunter die Kranzleiste mit den drei Höckern.

$\boldsymbol{e}$. Derselbe von innen; die zwei kurzen Spitzen gehören dem Absatz; die Spitze * der Kranzleiste.

f. Derselbe, Vorderseite, nämlich stehend gedacht. Die zwei Spitzen * gehören der Kranzleiste, die zwei kürzeren gegenüber dem Absátz.

g. Derselbe Zahn von der Vorderseite und nur die vorderen, an den drittletzten Zahn stoII. Band. 
Isenden Spitzen gezeichnet. Die niederste Spitze ist der Absatz, die mittlere die ächte Zahnspitze, die äufsere der vordere Höcker der Randleiste. -

h. Ebenso von der Fledermaus.

i. Ebenso vom Maulwurf. Diese einzige Ansicht beweist allein, dafs diese drei Thiere in eine Zunft gehören.

\section{$M \quad a \quad u l l w$ u $r$ f.}

a. Gebils von der äufseren Seite. Oben 3 Schneidezähne, 1 Eckzahn, 3 Lückenzïhne, 4 Backenzähne. Davon hat der erste die hintere Spitze fast ganz verkümmert; die zwei folgenden sind je zweispitzig und haben die dreihöckerige Randleiste; der letzte ist halb. Unten scheinbar 4 Schneidezähne (jederseits), dann 1 Eckzahn, 2 Lückenzähne und 4 Backenzähne. Da aber dieser Eckzahn hinter den oberen, ächten Eckzahn stöIst; so ist er mir ein Schein-Eckzahn, und es muls der hintere Schneidezahn als der ächte Eckzahn anerkannt werden. Es sind also hier auch nur 3 Schneidezähne, 1 kleiner Eckzahn, 3 gröIsere Lückenzähne und 4 Backenzähne. - Von diesen hat der vordere die Hinterspitze verkümmert, 


\section{$-259$}

die drei folgenden, wovon der hintere auch der kleinere ist, sind zweispitzig. Die kleine Spitze, welche vor den zwei gröfseren erscheint, gehört zur inneren Reihe.

b. Dasselbe, von innen. Die 3 hinteren Bakkenzähne oben zeigen die zwei Spitzen und den Absatz, welcher nur einspitzig ist ohne Kerbe. Dieselben 3 Zähne haben inwendig drei halbhohe Spitzen, wie bei der Flederund Spitzmaus, Diese Spitzen entsprechen den drei äufseren Höckern der Randleiste der Oberzähne.

c. Gebils, geschlossen, um zu zeigen, dals alle unteren Zähne vor die gleichnamigen oberen schlagen, deutlich der erste Backenzahn von den vier, so wie die drei Lückenzähne. Was man unteren Eckzahn nennt, liegt hinter dem oberen, und ist es daher nicht. - Dagegen hilft er gesetzmälsig die Zahl drei füllen, wenn er als Lückenzahn betrachtet wird. Das kleine Schneidezähnchen, welches vor den oberen Eckzahn schlägt, ist mithin der ächte Eckzahn, und es bleiben nur drei Schneidezähne, die regelmälsige Zahl, welche nur von einigen Beutelthieren übertroffen wird. 


\section{- 260}

d. Obergebils, Kaufläche. An den zwei grofsen Backenzähnen auswendig die dreihökkerige Randleiste, dann die zwei einschlagenden Spitzen, inwendig der Absatz, einfach, ohne Kerbe, steht also der Fledermaus ferner als der Spitzmaus: der hintere Zahn fast halb.

e. Dasselbe Gebils in einer anderen Manier, um die Einfaltung der zwei Zahnspitzen und die Einfachheit des Absatzes zu zeigen.

f. Untergebifs, Kaufläche, auswendig die zwei grofsen Spitzen, inwendig die drei kleinen oder Randhöcker.

h. Unterer Backenzahn, von innen, zeigt die drei kurzen inneren Spitzen oder Randhökker, und die zwei grofsen äufseren.

i. Oberer Backenzahn von der Vorderseite, Absatz und die zwei Spitzen sich deckend. -

$k$. Unterer Backenzahn von derselben Seite, zeigt deckend die drei inneren und die zwei äufseren Spitzen.

Die Zahnformeln stehen also so:

Fledermaus: $\frac{6}{9}$; Sch. $\frac{0}{3}$, E. $\frac{T}{1}$, L. $\frac{T}{1}$, B. $\frac{4}{4}$. Spitzmaus: $\frac{8}{6}$; Schn. $\frac{3}{x}$, E. $\frac{\circ}{0}$, L. $\frac{1}{1}$, B. $\frac{4}{4}$. Scalops: $\frac{10}{8}$; Schn. $\frac{3}{1}$, E. $\frac{1}{1}$, L. $\frac{2}{2}$, B. $\frac{4}{4}$. Mygale: $\frac{1}{1} \frac{T}{1}$; Schn. $\frac{3}{3}$, E. $\frac{T}{1}$, L. $\frac{3}{3}$, B. $\frac{4}{4}$. Igel: $\frac{10}{8} ;$ Schn. $\frac{3}{2}$, E. $\frac{1}{1}$, L. $\frac{2}{1}$, B. $\frac{4}{4}$. 


\section{$-261$}

G. 12. Vespertilio. Fle derma us.

Das Geschlecht Vespertilio habe ich in den nachfolgenden Blättern genommen, wie es die meisten der neueren Schriftsteller aufgestellt haben : mit vier Schneidezähnen im Oberund sechs im Unterkiefer, mit vier, fünf bis sechs Backenzähnen auf jeder Seite eines jeden Kiefers, mit einem Ohre, das mit einem Ohrdeckel versehen ist, mit einer einfachen, weder mit Hautfortsätzen, noch mit Falten und Kämmen versehenen Nase, so wie mit glatten Lippen, welche nicht mit Papillen besetzt sind.

Liebhaber der grofsen Menge neuer Geschlechter können leicht auch diese Familie noch trennen, z. B. wenn sie die Zahl der Bak. kenzähne gelten lassen; allein ich glaube, dafs zu viele Geschlechter eher schaden als nützen, auch konnte ich von der gegebenen Eintheilung nicht füglich abgehen, da ich von einigen der von mir zu beschreibenden Arten die Zahl der Backenzähne nicht genau angeben kann. Der Verlust mehrerer Exemplare meiner zoologischen Sammlung hat mir bei einigुen Arten die Gelegenheit benommen, die auf günstigere Augenblicke verschobene Untersuchung dieses 


\section{$-262-$}

Theils des Gebisses vornehmen zu können und es sind dadurch Lücken in meinen Beschreibungen entstanden, die ich nun nicht mehr auszufüllen vermag; ich gebe indessen diese Beschreibungen, wie ich sie bei dem ersten Anblicke des Thiers entwarf. -

Das Geschlecht Vespertilio ist in Europa das herrschende, während in America die Blattnasen bei weitem die stärkste, und die eigentlichen Fledermäuse, die am wenigsten zahlreiche Familie ausmachen. -

Die Lebensart der brasilianischen Thiere dieses Geschlechtes scheint mit der der europäischen Arten übereinzustimmen, auch sind sie gewifs nicht Blutsauger, da man bei ihnen nie den Rand der Unterlippe und den Vordertheil des Unterkiefers nackt und warzig findet; die Brasilianer behaupten übrigens von allen dortigen Flederthieren, dals sie diese Eigenheit besitzen.

$$
\text { 1. V. } c a n i n u s \text {. }
$$

Die Fledermaus mit der Hundsschnauze.

Fl.: Oberkiefer verlängert und etwuas aufgetworfen; Nasenkuppe etwas gespalten; Schwvanz kurz und in der Flughaut endend; Ohr etwuas kegelförmig; 


\section{$-263-$}

Ohrdeckel selır kurz, an der Wurzel schmäler; Sporn stark und über $\frac{1}{2}$ Zoll lang. -

Schinz Thierreich u. s. w., B. I. p. 179.

Abbildungen zur Naturgeschichte Brasilie:n's.

Beschreibung: Die Stirn dieser Fledermaus ist durch den dichten Pelz hoch erhaben; das Auge ist klein, glänzend, und steht nahe unter dem vorderen Rande des Ohres; Oberkiefer etwas aufgeworfen, gerade vorgestreckt, länger als der untere; der Mund ist breit, mit gegen den Mundwinkel hin aufgeschwollenen Lippen; die Nasenkuppe ist etwas gespalten, mit zwei kleinen runden Nasenlöchern, welche an ihrem erhabensten Theile nahe bei einander stehen; Unterlippe nur scheinbar ein wenig gespalten, mit zwei dickeren, dreieckigen, glatten Hautfleckchen vorn an ihrer Spitze, welche einen Fettglanz zeigen; - Unterkiefer viel kürzer als der obere; das Ohr ist von seiner oberen Seite vom Kopf aus gemessen fünf und zwei Drittheil Linien hoch, ziemlich kegelförmig, oben ein wenig, aber nicht breit abgerundet, an seiner inneren Fläche mit erhabenen Querl-isten bezeichnet; in der Mitte seines äufseren Randes ist es mit einem kleinen sanften und an der Basis desselben noch mit zwei bogigen Ausschnitten versehen; der vordere oder inne. 
re Ohrrand ist breit nach innen umgeschlagen, und nach dem Tragus hin befestiget; dieser ist sehr kurz, an der Wurzel schmäler als an der Spitze, dabei abgerundet.

Gebifs: Schn. $\frac{4}{6}$; Eckz. $\frac{1 \cdot T}{1.1}$; Backenz. $\frac{4-5}{?}$. Im Oberkiefer vier Schneidezähne, die beiden äufseren etwas zugespitzt, die inneren breit; im Unterkiefer sechs, mit einmal eingekerbter Krone. Eckzähne kegelförmig, im Oberkiefer von den Schneidezähnen etwas getrennt.

Backenzähne im Oberkiefer auf jeder Seite vier, vielleicht fünf; der erste ist ein Kegelzahn, die übrigen mit vier bis fünf Spitzen; von oben auf die Kaufläche gesehen, bilden sie zwei spitzige, aneinander geschobene Dreiecke; im Unterkiefer stehen zuvörderst zwei zugespitzte Kegelzähne, hernach sind sie vierspitzig. -

Die Zunge ist fleischig, länglich, wie an den übrigen Arten, und glatt. -

Der Daumen ist schmal und schlank, mit einem kleinen Nagel; der Zeigefinger vereinigt sich mit dem zweiten Finger bei dessen zweitem Gelenke; die Flughaut ist schmal, lang und nackt; die Hinterfüfse haben fünf gleiche Zehen, mit zusammengedrückten Krallennägeln; an jeder Ferse befindet sich ein starker, sechs und zwei Drittheil Linien langer Sporn, die 
Schwanzflughaut ist daher auch lang und breit, sie lälst sich leicht bis auf einen Zoll vier und zwei Drittheil Linien weit vom Körper ausdehnen, wefswegen denn auch der acht Linien lange Schwanz noch nicht die Hälfte derselben erreicht. - Wenn das Thier mit zusammengefalteten Flügeln in Ruhe sitzt, so tritt die Schwanzspitze ein wenig aus der Haut hervor, da dieselbe hingegen im Fluge völlig unsichtbar in der Fläche der ausgedehnten Schwanzhaut erscheint. -

Das Haar des ganzen Thiers ist gleich dicht und sanft, überall ziemlich lang, besonders an Stirn, Rücken und Brust; die Farbe ist ein dunkles schwärzliches Braun, etwa dunkel rufsfarben, am Bauche und allen unteren Theilen etwas heller, dabei etwas in's Röthliche fallend. Gesicht ziemlich nackt, aber etwa von derselben Farbe wie das Haar. - Die Schwanzflughaut ist an ihrer äufseren und inneren Seite mit sehr kleinen, kurzen Härchen dünne besetzt.

Ausmessung eines weiblichen Thicres:
Ganze Länge .
Länge des Körpers
Länge des Schwanzes
Ganze Breite des Thiers

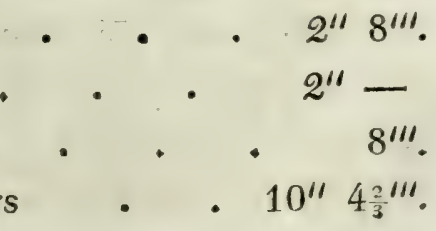


Höhe des äufseren Ohres, vom Kopfe aus gemessen . . . . $5 \frac{2}{3} 11$. Länge des Sporns • • . . $6 \frac{2}{3}{ }^{\prime \prime \prime}$. Die Schwanzflughaut läfst sich vom Körper ausdelonen auf • . 1 1" $4 \frac{2}{3}{ }^{\prime \prime \prime}$. Der Schädel hat zwischen den Augen einen tiefen Eindruck, und gleichsam eine Einschnürung vor den Sisten, vor der Augenhühle treten aber die Knochen wieder weit hervor, und geben dem vorderen Theile des Gesichts eine breite Abrundung. -

Diese Fledermaus hat in der Bildung ihrer Schnauze einige Aehnlichkeit mit den Molossen oder Hundsmäulern, allein die Ohren sind nicht auf diese Art gebildet, und das Gebils ist verschieden.

Ich erhielt diese Art am 20. November in einem alten Gebäıde, und fand bei ihr einen grofsen, schon ausgebildeten foetus, dessen Ohren an den Seiten des Kopfs herabhingen. -

- Im Magen fanden sich Ueberreste von Insecten.

2. V. nigricans.

Die schwärzliche Fledermaus.

Fl.: Ohr mittelmäfsig grofs, unter der Spitze an der änfseren Seite ausgreschnitten; Ohrdeckel beinuhe linienfürmig; Schnauze hurz; Nasenkuppe 
durch eine Furche getheilt; Schwanz in der Flughaut liegend, halb so lang als der Körper; Pelz schwärzlich rufsfarben.

Schinz Thierreich u. s. w, B. I. p. 179.

Beschreibung: Diese Fledermaus ist klein, eben so der Kopf; die Schnauze ist kurz; zwischen den aufgeschwollenen Nasenlöchern befindet sich eine Furche; Ohr mittelmälsig grofs, an der oberen dem Kopfe zugewandten Seite drei und ein Drittheil Linien hoch, an dem vorderen oder inneren Rande ein wenig abgerundet, an dem hinteren ziemlich senkrecht abgeschnitten, die Spitze ist ein wenig nach dem äufseren Rande übergeneigt, indem sich unter derselben ein kleiner Ausschnitt befindet; Ohrdeckel nicht halb so lang als das äufsere Ohr, sehr schmal, lanzett- beinahe linienförmigg und zugespitzt. -

Gebifs: Schn. $\frac{4}{6}$; Eckz. $\frac{\text { I.I }}{1 \cdot I}$; Backenz ? Im Oberkiefer vier Vorderzähne, wovon zwei gepaart an jeder Seite stehen und in der Mitte einen Zwischenraum lassen; im Unterkiefer stehen sechs gleiche Vorderzähne ohne Zwischenraum; die Eckzähne sind stark, die oberen am längsten; die Backenzähne konnten bei dem Verluste des Exemplars nicht untersucht werden. 


\section{$-268$}

Die Zunge ist länglich walzenförmig, fleischig, glatt, und nicht dehnbar. -

Die Flughaut ist schmal und lang; der Schwanz liegrt gänzlich in der Schwanzflughaut, er ist halb so lang als der Körper; die Fülsce haben fünf gleiche Zehen; der Sporn ist ziemlich lang. -

Die Flughaut ist nackt, blofs in dem Schulterwinkel behaart, und von bräunlich-schwarzer Farbe; Nägel der Füfse weifslich, übrigens ist das ganze Thier völlig dunkel rufsfarbig, oder dunkel schwärzlich graubraun, doch hatte der Bauch eine hellere Farbe als der Rücken.

Ausmessung:

Ganze Länge .

Länge des Körpers

Länge des Schwanzes

Ganze Breite des Thiers

Höhe des Ohrs an der oberen, dem

Kopfe zugewandten Seite . - $3 \frac{r}{3}{ }^{\prime \prime \prime}$.

Diese kleine Fledermaus erhielt ich auf der Fazenda de $A g a ́$, in der Gegend des Flus. ses Iritiba oder Reritigba (siehe den 1. Theil meiner Reisebeschreibung, pag. 173). - Sie scheint viel Aehnlichkeit mit Azora's Chauvesouris douzième ou brune obscure (Vesperti- 


\section{$-269$}

lio albescens, Geoffr.) zu haben, wenn nicht die Farbe verschieden wäre,

3. V. calcaratus.

Die, langgespornte Fledermaus.

Fl.: Schnauze etwas zugespitzt; Schwanz kurz und in der Flughaut liegend; Fufs klein; Seitenflughaut im Fufsgelenke befestiget; Sporn sehr lang, mit ihren Enden einander beinahe berührend; Pelz rötlzlich-braun.

Abbildungen zur Naturgeschichte Brasilien's. Schinz Thierreich u. s. w., B. I. p. 180.

Die Schnauze ist etwas zugespitzt, der Oberkiefer länger als der untere. Die Ohren sind schmal lanzettförmig, und ihre Spitze et. was nach der äufseren Seite über gekrümmt; der Ohrdeckel ist breit und stumpf

Gebifs: Schn. $\frac{4}{6}$; Eckz. $\frac{\text { I.T }}{I \cdot I}$; Backenz. $\frac{4 \cdot 4}{4 \cdot 4}$. oder vielleicht $\frac{5 \cdot 5}{5.5}$. Vorderzähne oben vier, unten sechs; Eckzähne mälsig grofs; Backenzähne im Ober - und Unterkiefer an jeder Seite vier bis fünf, sämmtlich mit Kegelspitzen.

Der Daumen ist klein und zart; Fufs klein und kurz, die Seitenflughaut ist an demselben weiter hinab befestigt, als an allen übrigen von mir beobachteten Arten; denn sie entspringt an der Zehenwurzel, und ist übrigens mit sich 
kreuzenden punctirten Linien bezeichnet; das Schienbein ist lang und dünn, es milst neun und eine halbe Linie in der Länge; der Schenkel ist beinahe gänzlich im Pelze verborgen; Schwanz sehr kurz, er erreicht nur einen Theil der Schwanzflughaut, dagegen sind die Sporne so lang, dals sich ihre Spitzen beinahe berühren, wenn die Schwanzflughaut mit den Beinen möglichst auseinander gezogen wird. Die Seitenflughaut ist am Rande des Körpers, eben so die Schwanzflughaut behaart; die letztere ist, wie gesagt, mit punctirten Linien bezeichnet, und längs ihrer Mitte hinab mit feinen wolligen Härchen besetzt. Haar des Thiers zart und ziemlich lang, an den oberen Theilen röthlich-braun, an den unteren blässer, röth. lich-fahl.

\section{Ausmessung:}

Ganze Länge etwas über . . $\quad 2^{\prime \prime} 4^{\prime \prime \prime}$. Länge des Körpers . . . . . 1" $11^{\prime \prime} \frac{\text { I'" }}{2}$ Länge des Schwanzes _. . $5 \frac{2}{3}$ ' . Ganze Breite etwa . . . . 11" $3^{\text {in. }}$ Höhe des Ohres etwa . . . . $5^{\prime \prime \prime}$. Länge des Sporns beinahe • • $1^{\prime \prime} 2^{\prime \prime \prime}$. Länge des Schienbeins • : . $9 \frac{r}{2}{ }^{\prime \prime \prime}$.

Es ist zu bemerken, dafs bei der hier an. gegebenen Länge des Körpers, die Haarspitzen 


\section{$-271$}

abgerechnet sind, welche noch etwas auf die Schwanzflughaut hinüber fallen.

Diese Fledermaus wurde auf der Fazenda zu Coroaba am Flülschen Jucú, unweit des Rio do Espirito Santo gefunden.

$$
\text { 4. V. leucogaster. }
$$

Die Fledermaus mit weifslichem Bauche.

Fl.: Schnauze sehr kurz; Ohr an den Seitenrändern geradlinig; Ohrdeckel mäfsig lang und lanzettförmig; Schwanzspitze kaum befreit; Sporn kaum länger als das Ohr; Pelz an den Obertheilen schwarzbraun, gelblich bespitzt, weifsgraulich am Bauche. -

Abbildungen zur Naturgeschiclite Brasilien's. Schinz Thierreich u. s. w. B. I, pag. 180.

Der Kopf ist kurz, ganz besonders aber die Schnauze; die Nasenkuppe ist breit; Nasenlöcher nach den Seiten geöffnet; das Auge ist klein und steht nahe vor dem Ohre; dieses hat eine längliche Gestalt, steht gerade aufgerichtet, ist oben etwas zugerundet und an beiden Rändern nicht ausgeschnitten, sondern ziemlich geradlinig; der Ohrdeckel ist mälsig lang, lanzettförmig oder länglich schmal.

Gebifs: Schn. $\frac{4}{6}$; Eckz. $\frac{I \cdot I}{1 \cdot 1}$; Backenz. $\frac{5 \cdot 5}{5 \cdot 5}$. Im Oberkiefer stehen vier Vorderzähne, wovon 
immer zwei gepaart sind, indem sich in der Mitte eine Lücke befindet; im Unterkiefer scheinbar sechs Schneidezähne, mit etwas eingekerbter oder getheilter Krone, Eckzähne lang, spitzig, kegelfürmig, die des Unterkiefers sind etwas kleiner; Backenzähne oben auf jeder Seite fünf, wie im Unterkiefer; der erste ist sehr klein mit zwei Spitzen, die vier folgenden gröfser, nach aufsen mit grofsen, nach innen mit kleineren sehr zugespitzten Fort. sätzen. Untere Backenzähne gebildet wie die oberen. -

Die Zunge ist fleischig, walzenförmig, mit einigen Querleisten bezeichnet.

Der Hals ist wegen seiner Kürze unbe. merkbar. - Die Seitenflughaut ist unmittelbar an dem Fufse befestiget, daher an der Wurzel breit, und nach dem Ende hin mehr zugespitzt. - Der Daumen ist lang und schlank, mit langem, dünnem gekrümmtem Nagel; der Zeigefinger hat zwei Gelenke, der zweite Finger drei, der dritte drei, der vierte €benfalls. - Arme und Finger sind lang; die Fülse haben fünf gleiche Zehen und starke bogenförmige Nägel; der Sporn ist etwas länger als der Eufs; ron dem ersteren lâuft die Flughaut gerade fort und bildet einen kleinen Win- 


\section{$-273$}

kel, alsdann zieht sie sich nach der Schwanzspitze hinaus, welche um eine halbe Linie frei ist. - Auf der Seitenflughaut befinden sich an der Seite des Körpers parallele Reihen kleiner Pünctchen, welche von dem Oberarme nach dem Schienbeine gerichtet sind, auch die Schwanzflughaut ist mit zerstreuten Pünctchen besäet. - Geschlechtstheile gebildet wie an den europäischen Flederthieren. -

Vorderkopf von der Nase an sehr dicht und lang behaart; Hinterbeine bis an das Knie behaart; die Nagelglieder der Füfse sind mit langen gelblichen Haaren besetzt; der Schwanz liegt etwa um ein Drittheil seiner Länge im Pelze verborgen, welcher auch den ganzen Hinterschenkel verdeckt. - Flughaut, Ohren, Gesicht, und alle nackten Theile sind bräunlich-schwarz; der dichte, zarte Pelz aller oberen Theile schwarzbraun, mit fahl gelblichen Haarspitzen; Kehle und Seiten der Brust sind schwarzbräunlich; Mitte der Brust blafs graubräunlich; Bauch und Aftergegend weifsgraulich; Haare in den Seiten des Körpers, welche die Flughaut decken, weirslich. -

Ausmessung eines männlichen Thieres:

Ganze Länge . . . . $2^{\prime \prime} 10^{\prime \prime \prime}$. Länge des Körpers _ . . . 1" 1" $^{\prime \prime}$. II, Band. 
Länge des Schwanzes . . . 1 $1^{\prime \prime} g^{\prime \prime \prime}$.

Ganze Breite • • • • $8^{\prime \prime} 11 \frac{1}{2}{ }^{\prime \prime \prime}$.

Höhe des Ohrs • • • . $4 \frac{7}{2}{ }^{\prime \prime \prime}$.

Länge des Daumens • • $2 \frac{x^{\prime \prime \prime}}{}$

Länge des Schienbeins • + $\quad 6 \frac{1}{3}{ }^{\prime \prime}$.

Länge des Fufses etwa . . • 4 " .".

Länge des Sporns • • • $4 \frac{2}{3}{ }^{\prime \prime \prime}$.

Diese lledermaus fanden wir am Tage an den Felsen und alten Stämmen der grofsen Urwälder sitzend, welche die Ufer des Flusses Mucurí beschatten; man traf sie auch wohl aufgehängt, wo sie in der Kühlung des Wassers ruhete und in der Dämmerung den Insecten, ihrer Nahrung, nachflog.

\section{V. $N$ a $s$ o.}

Die Fledermaus mit verlängerter Nase.

Fl.: Nasenkuppe verlängert, gespalten, und über den Kiefer vortretend; Sporn lang; der Schwanz erreicht ein Drittheil der Schwanzflughunt, seine Spitze ist etwas frei; Flughäute ziemlich behaart.

Schinz Thierreich u. 9. w. B. I. pag. 179.

Reise nach Brasilien, B. I. pag. 251.

Abbildungen zur Naturgeschichte Brasilien's.

Beschreibung: Der Kopf ist klein, zugespitzt, mit einer Nase, welche ùm eine starke Linie über den Unterkiefer vortritt, und deren 


\section{$-275$}

Kuppe gespalten ist. - Das Ohr ist etwa fünf Linien hoch, sehr schmal, beinahe lanzettförmig, dabei an seinem äu[seren Rande unter der Spitze mit einem Ausschnitte versehen, und an seiner inneren Fläche mit Querreifen bezeichnet; der Ohrdeckel ist so kurz, dafs man ihn kaum bemerkt; er erscheint frei, sobald man das äufsere untere Ohrläppchen zurückklappt; das Auge ist klein. -

Gebifs: Schn. $\frac{4}{6}$ bis s; Eckz. $\frac{1 \cdot 1}{1-1}$; Backenz. $\frac{5.5}{5.5}$. Im Oberkiefer befinden sich vier Schneidezähne, wovon die beiden mittleren grölser und gegen einander geneigt sind; im Unterkiefer sechs bis acht Schneidezähne, in ihrer Mitte durch eine kleine Lücke getrennt, so dals immer drei zusammen stehen; sie haben dreifach eingelserbte Kronen, und neben ihnen scheint an jeder Seite neben dem Eckzahne noch ein kleinerer zu stehen, der später vielleicht ausfällt. — Eckzähne im Oberkiefer grofs; die unteren haben nach vorn und hin. ten an der Wurzel eine Neberspitze; Backenzähne im Oberkiefer auf jeder Seite fünf, im unteren eben so viele; der erste der oberen hat eine lange Kegelspitze in seiner Mitte und kleine Nebenhaken an der Basis, die übrigen tragen lange Spitzen; im Unterkiefer ist der 
erste Backenzahn von dem Eckzahne, so wie von seinem Nachfolger durch eine Lücke getrennt, beide haben eine Mittelspitze und hinten und vorn kleine Nebenzacken, die übrigen tragen lange Zackenspitzen; von oben auf die Krone gesehen, zeigen sie mehrere aus - und eingehende Winkel zickzackförmig gestellt, beinahe wie bei den Noctilionen. -

Die Zunge ist fleischig, länglich - rund und mit äufserst feinen, seidenartigen Papillen besetzt,

Der Hals ist kurz, die Seitenflughaut breit und ziemlich zugespitzt, dabei im Gelenke des Hinterfufses befestiget; der Daumen ist lang und dünn, der Zeigefinger besteht aus zwei Gliedern, die drei übrigen Finger haben ein jeder drei Glieder; der Schenkel ist kurz und im Pelze versteckt; das Schienbein ist dünn und lang, der Sporn sehr lang; denn wenn man die beiden Beine möglichst weit von einander entfernt, so bleiben die Spitzen der Sporne nur drei und eine halbe Linie von einander entfernt. - Der Schwanz ist zum Theil im Pelze versteckt, er reicht nur bis auf ein Drittheil der Schwanzflughaut und hat hier seine Spitze eine halbe Linie lang frei; an getrockneten Exemplaren verschwindet dieser 
knorpelartige Schwanz beinahe gänzlich durch das Vertrocknen. - Der Fufs hat fünf gleiche Zehen mit zusammengedrückten Krallennägeln. Die Schwanzflughaut ist von den beiden Enden der Sporne gerade querüber gespannt.

Der weibliche Geschlechtstheil ist von einer nackten gelblichen Haut umgeben. -

Der Pelz des ganzen Thiers ist oben und unten sanft, dicht und ziemlich lang, an den oberen Theilen dunkel gelblich-graubraun, unten bläsøer gelblich-grau; Gesicht bis zur Na. senspitze behaart; Ohren bräunlich, die Flughaut schwärzlich-braun gefärbt. - Die Arme bis zu dem Handgelenke sind büschelweise mit gelblichen Haaren besetzt, zwischen welchen einzelne feine Härchen stehen, und von dem Ellenbogen ziehen nach den Hinterfüfsen hinab feine parallellaufende Haarlinien; die Hinterbeine sind bis zu den Füfsen büschelweise mit gelblichen Haaren besetzt; der Schwanz ist ebenfalls stark gelblich behaart, und üher die Schwanzllughaut laufen zu seinen beiden Seiten vom Leibe gerade hinab, parallele Linien von gelblichen Haaren, welche etwa die Mitte dieser Flughaut erreichen. Die innere oder untere Seite der Flughäute ist nur wenig 
behaart, hier stehen blofs einzelne feine Härchen. - Das Ohr ist an seinem inneren Rande mit gelblichen Haaren besetzt; das äufsere untere Ohrläppchen ist mit weifsgelblichem Haar bedeckt, wodurch an dieser Stelle ein weifser Fleck entsteht; vor dem vorderen Ohrrande steht über dem Auge ein ähnliches hell gelbliches rundes Fleckchen.

Junge Thiere dieser Art sind an Flügelund Schwanzhaut behaart wie die Alten; man findet auch einige dieser Thiere, welche auf dem Rücken einige gelbliche Haarbüschel, und daher eine Art von gelblicher Zeichnung tra. gen.

Ausmessung :

Ganze Länge bis zu dem Ende des

Schwanzes

Länge des Körpers

Lünge des Schwanzes

Ganze Breite ungefähr

Höhe des äufseren Ohres

Länge des Daumens beinahe

Länge des Schienbeins

Länge des Fufses

Länge des Sporns

Diese kleine Fledermaus bildet eine von der Natur in jeder Hinsicht sehr ausgezeich- 
nete Species, besonders durch die merkwürdige rüsselartige Verlängerung ihrer Nase, welche dem Gesicht einen sonderbaren Character mittheilt. Sie lebt nie in Oertern und Gebäuden, sondern wurde von uns blofs in den groIsen Urwäldern beobachtet, wo ich sie an den Ufern" der Flüsse unmittelbar über dem Wasser an übergeneigten Baumstämmen oder an Felswänden, in dunkeln Winkeln gefunden habe. - Besonders am Flusse Mucurí, in der Gegend von Morro d'Arara (s. den 1. Band meiner Reise nach Brasilien, pag. 251) waren dicse Thiere häufig, und wir bemerkten sie zu zehnen bis zwanzigen, gleich grauen Flecken an den Stämmen oder Felsen des Ufers. Schols man mit Vogeldunst unter eine solche Gesellschaft, so zerstob sie nach allen Richtungen, um sogleich wieder in dunkeln Schlupfwinkeln Schutz zu suchen. Sie ruhen alsdann, feste gegen den Felsen geheftet, bis zum Abend, wo sie schnell umher fliegen. - Ihre Nahrung besteht in Insecten und die Stimme ist zischend. 
Fam. 2. Plantigrada.

$$
\text { S o hl le ng änge r. }
$$

Die sohlengehenden Raubthiere, die Geschlechter Cercoleptes, Nasua, Procyon, Gulo, Meles, Ursus, Mydaus, Paradoxurus, Arctictis Temm., zeichnen sich, abgesehen von ihren eigentlichen Characteren, grofsentheils durch eine dicke, stark behaarte Haut und einen zu gewissen Zeiten des Jahres sehr fetten Körper aus. Einige von ihnen haben stark riechende Absonderungen. - Ihr Skelett ist stark gebaut, das Schlüsselbein mehr oder weniger ausgebildet vorhanden, so wie ihr Körper muskulös, etwas plump, gewöhnlich niedrig und gestreckt; der Schädel ist flach, stark von Kno. chen, das Gebils stark, obgleich die Eckzähne nicht so lang und weniger kräftig als an den zehengehenden Raubthieren, auch sind die Bakkenzähne zum Theil weniger schneidend, Sie besitzen die Eigenheit, dafs sie bei'm Gehen die ganze Fufssohle bis zur Ferse aufstiutzen, welches ihnen viel Sicherheit im Klettern und zum Theil im Graben und Einkriechen in die Erde giebt, dagegen aber ihrem Gange und Laufe eine gewisse Schwerfälligkeit mittheilt. - Sie haben in der Regel die Eigen- 
heit, ungeachtet ihres Raubthiergebisses (das jedoch stumpf ist), dennoch nicht blofs fleischfressend, sondern Omnivoren zu seyn, indem sie sich grofsentheils von Fleisch, Obst und Früchten aller Art ernähren. -

America hat vielleicht von allen andern Welttheilen die gröfste Menge von sohlengehenden Raubthieren; die grölsere Zahl von ihnen kommt jedoch auf die gemälsigten und kalten Theile dieses Continents. - Im Norden von America sind besonders zahlreich die Bären.

Süd-America besitzt aus der Familie der Sohlengänger die Geschlechter Ursus ${ }^{*}$ ), Nasua, Procyon, Gulo, Cercoleptes, Mephitis, und ich habe in Brasilien nur Thiere aus zweien dieser Geschlechter beobachtet, welche indessen an Individuen zum Theil zahlreich sind. -

*) Die Bären scheinen in Süd-America blors den Ketten der hohen Anden treu zu seyn, v. Humboldt erwähnt jedoch eines solchen als am Flusse Temi einheimisch, den man dort Osso caniceiro benennt, um ihn von dem Osso palmeiro (Myrmecophaga iubata) oder dem Osso hormigeiro (Mrrin. tetradactyla) zu unterscheiden. - Die erste gründliche Nachricht über einen süd-americanischen Bären verdanken wir Cuvier (siehe dessen Recherches sur les ossem. foss. nouvelle édition Vol, V. 2ième partie, pag. 514). - 


\section{G. 13. $N$ a s $u a$.}

C u a $t$ i, $N$ a $s$ e $n$th $i$ e $x$.

Die Cuatís sind Thiere, deren Gestalt etwa zwischen der des Fuchses und der des Bären in der Mitte steht, und ihre Grölse ist etwa die des ersteren. Sie zeichnen sich durch ihre lange rüsselartig verlängerte Nase aus, und variiren vorzïglich stark in ihrer Färbung. Man hat bisjetzt in den naturhistorischen Wer. ken nicht bestimmt die Arten der Cuatís angeben können, und selbst Azara hat die Kenntnifs dieser Thiere nicht in's Reine gebracht; auch mir ist es nicht besser gelungen, diese beiden vielleicht wirklich in der Natur begründeten Arten unterscheiden zu lernen, ich will indessen hier berichten, was ich über diesen Gegenstand sagen kann.

Irrig ist es, wenn man diese Thiere nach der Färbung unterscheiden will; denn sie variiren in dieser Hinsicht noch weit mehr als unsere europäischen Füchse. - Daher sind alle Benennungen, welche von der Farbe hergenommen wurden, unzweckmälsig, als Nasua rufa und subfusca, dagegen glaube ich, dals es besser seyn würde, diese Thiere nach ihrer Lebensart zu benennen. - Ich selbst fand häufig das gemeine Cuati, welches die INasua 
rufa oder Viverra Nasua der Schriftsteller ist, von sehr verschiedener Zeichnung, in ein - und derselben Familie finden sich rothe, graue und mehr bräunliche zugleich. - Ich hielt daher diese Thiere nur für eine einzige Art, bis die der Wälder vollkommen kundigen Indianer, diese geübten Jäger und Thierkenner, mich einstimmig versicherten, dafs es zwei Arten gebe, wovon die eine kleiner und schlanker sey und in zahlreichen Gesellschaften lebe, die an. dere gröfser und weniger schlank, hingegen mehr einsam oder blofs familienweise umherziehe; die erstere nennen sie Cuati de Bando, die zweite Cuatí Mundéo. -

Da ich von letzterer Art nur ein einziges Individuum erbalten habe, so kann ich nicht hinlänglich über den Grund dieser Behauptung entscheiden; doch glaube ich der Aussage der brasilianischen Jäger trauen zu dürfen. - Ich werde beide Thiere beschreiben. -

1. N. socialis.

Gesells chaft 1 iches Guati.

Viverra Nasua, Linn.

Coati Marcgr. 228. Piso 38.

Couati Azara, T. I. pag. 334.

Lie Coati roux $\{$ Fr. Cuvier. 
Cuati de Bando an der Ostkiiste vou Brasilien. Hakijäck botocudisch.

Gestalt etwas bärenartig, jedoch schlanker, in vielen Theilen Aehnlichkeit mit dem Fuchse. - Der Kopf gleicht etwas dem eines jungen Schweines; das Auge ist klein und schwarz, das Ohr etwas länglich, oben zugerundet; die Schnautze ist lang und schmal, in einen beinahe anderthalb Zull langen Rüssel verlängert, an dessen Ende sich die grofse, feuchte, etwas aufgestülpte, und mit grofsen weiten Nasenlöchern versehene Nasenkuppe befindet. Die Zunge ist mit spitzigen weichen Papillen besetzt.

Gebifs: Schn. $\frac{6}{6}$; Eckz. $\frac{\text { I.1 }}{\mathrm{I} \cdot \mathrm{1}}$; Backenz, $\frac{6 \cdot 6}{6 \cdot 6}$. Im Ober - und Unterkiefer befinden sich zwei kegelförmige, sehr comprimirte Eckzähne, wahre Pyramiden; sie sind nicht gekrümmt, nur die oberen stehen etwas auswärts gebogen, die unteren sind etwas rückwärts gekrümmt. -

Im Ober - und Unterkiefer befinden sich sechs Schneidezähne; die unteren sind schief nach vorn geneigt, stumpf und dicht aneinander gereiht; zwischen ihnen und den Eckzähnen befindet sich ein leerer Raum; von den sechs oberen Schneidezähnen stehè die vier mittleren dicht aneinander gereihet und passen 
auf die unteren; dann folgen zwei Lücken und nun auf jeder Seite noch ein kegelförmiger, etwas isolirter Schneidezahn. - Backenzähne im Oberkiefer sechs auf jeder Seite; nach dem Eckzahne folgt eine Lücke, dann drei einfache Spitz - oder Kegelzähne, die an Gröfse zunehmen, der vierte oder Reilszahn (carnassière, Cuv.) ist nenig gröfser als die übrigen; diese haben breite Kronen, mit einigen stumpfen Zacken. - Im Unterkiefer stehen zuvörderst drei Kegelzähne, wovon der erste sehr klein ist, und dann drei Zackenzähne, deren Mittelspitze die grölste ist. -

Der Hals des Thiers ist kurz, die Fülse mälsig hoch und dabei stark. - An Vorderund HinterfüIsen befinden sich fünf Zehen; Nägel lang und gekrümmt, die drei mittleren des Vorderfufses acht und eine halbe Linie lang und gröfser als die übrigen; die innere Zehe ist die kürzeste. - An den Hinterfü [sen sind die Nägel kürzer; der zweite und dritte von aufsen vier und zwei Drittheil Linien lang, stark; die äufsere Zehe und die vierte von aufsen sind etwa gleich lang, die innerste ist die kürzeste. - Die Sohlen sind bis zur Ferse nackt und schwärzlich-grau gefärbt. - 
Am Bauche befinden sich acht Zitzen, nur die vier hinteren schienen im Gebrauch gewesen zu seyn. Die Vulva liegt dicht unter dem After. - Der Schwanz ist lang, kürzer als der Körper, allmälig ein wenig mehr zugespitzt, mit langen, ziemlich dünnen, etwas harten IJaaren beselzt. - Haar des ganzen Körpers dicht, etwa einen Zoll drei Linien lang und etwas hart, darunter befindet sich ein anderes etwas wolliges Grundhaar. Untere Theile in geringer Menge mit etwas Wollhaar bedeckt. -

Der Rüssel bis zu den Augen ist schwärzlich gefärbt, so wie die Einfassung derselben, auf dem Nasenrücken ein wenig weifslich, auch über den Augen zeigt sich noch etwas von der schwärzlichen Farbe, wefshalb denn im Allgemeinen das ganze Gesicht diese Zeichnung hat, es ist übrigens durch eine weifsliche Einfassung von der rothen Kopffarbe geschieden; unter jedem Auge befindet sich ein weifser runder Fleck, und ein ähnlicher über oder ein wenig hinter dem Auge; die äufsere Seite des Ohrs ist schwarz, die innere länger behaarte gelblich, der Rand weilslich. - Kinn, Unterkiefer und Einfassung des Mundes sind weils, die vier Fülse schwarzbraun; Vorderarmè gelbröthlich, aber heller gefärbt als der Körper; Stirn 


\section{- $287-$}

rostroth oder rostgelb (fuchsfarben), eben so alle oberen Theile, die langen Haare haben aber hier schwarzbraune Spitzen, daher er. scheint die Färbung an diesen Theilen dunkler; in den Seiten ist sie noch dunkler röthlichbraun gemischt. Die Kehle bis zu den Ohren hinauf, Brust, vordere und innere Seite der Arme sinnd schön gelbröthlich, rein und unge. mischt; der Bauch ist hell röthlich-gelb; der Schwanz hat acht rothbräunliche und sieben schwarzbraune Ringe, dabei eine lange Spitze von dieser Farbe. - Die Hinterschenkel sind stark graubraun und weniger roth als der Körper. Diefs ist die gewöhnliche Varietät, welche man Nasua rufa genannt hat, und welche zuweilen mehr rein, zuweilen mehr bräunlichroth gefärbt erscheint. - Die Ausmessung des beschriebenen Exemplars ist folgende:

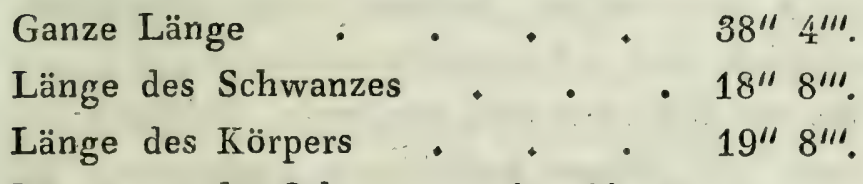
Länge von der Schnautzenspitze bis zu dem Anfange des Ohrs . . 5 $5^{\prime \prime} 8^{\prime \prime \prime}$. Breite des Kopfs von einem Ohre zu dem anderen, am vorderen Rande gemessen $2^{\prime \prime} 3_{\frac{1}{3}}^{\prime \prime \prime}$. 
Der Rüssel tritt über die Unterlippe vor uin

Höhe des äufseren Ohres $1^{\prime \prime} 4^{\prime \prime \prime}$.

Länge des Vorderfufses auf der Sohle gemessen . . . $2^{\prime \prime} 4^{\prime \prime \prime}$. Länge des Hinterfufses bis zu der Ferse

Ein anderes weibliches Thier hatte folgende Zeichnung:

Der ganze Körper war über und über gelblich-aschgrau; Stirn, Seiten des Halses und untere Theile sehr blafs gelbröthlich gefärbt; Rücken dunkler grau, die Seiten mehr gelbbräunlich, jedoch von der rothen Farbe des vorhin beschriebenen Thiers war nichts $z u$ sehen; das Gesicht schwarz mit der weilslichen Einfassung wie an jenem; Fülse ebenfalls nicht verschieden; Schwanz sehr blals grauröthlich und schwarzbräunlich geringelt; am Bauche befanden sich nur sechs sichtbare $\mathrm{Zi}$. tzen. - Dieses Individuum hatte etwa 22 Zoll 6 Linien Körperlänge und etwa 18 Zoll 8 Linien' Schwanzlänge. Seine Jungen, von welchen man zwei fing, waren verschieden gefärbt, das eine grau wie die Mutter; das andere roth. - In der Zeichnung des Kopfes glichen 
sie übrigens ihrer Mutter vollkommen; ihre Stirn war ebenfalls weifs eingefafst, ein weilsliches Fleckchen befand sich hinter, ein anderes unter, und ein drittes über dem Auge. -

Das männliche Thier scheint von dem weiblichen nicht verschieden zu seyn. - Es hat einen Knochen in der Ruthe. - Aus dem Angeführten wird deutlich hervorgehen, wie sehr diese Thiere in den Farben abändern, und es ist bei ihnen in dieser Hinsicht wie bei den meisten Raubthieren, den Wölfen, Füchsen, Luchsen, Bären u. s. w.

Die Cuatís sind sonderbare Thiere, und in den brasilianischen Wäldern noch zahlreicher als die Füchse bei uns. - Die eben beschriebene Art, das kleinere oder gesellschaftliche Cuatí lebt in Banden von zwölf bis achtzehn Stücken, und zieht auf diese Art nicht blofs bei Nacht, sondern während des ganzen Tages in den Wäldern umher. - Ihre Manieren sînd eine Mischung von denen des Fuchses und denen des Bären. - Die Gesellschaften der Cuatís kommen ziemlich schnell einhergezogen, indem sie kurze, rauhe, sonderbare Töne hören lassen, auf diese Art wirft sich die ganze Bande plötzlich auf einen ho:hen Baum, ersteigt denselben und nährt sich II, Band. 
von dessen Früchten, bis sie nichts mehr darauf findet und nun eben so schnell wieder an dem Stamme hinabeilt, um zu einem anderen Baume zu ziehen. - Ihr Lauf ist ein Galopp, etwas schwerfällig, da sie auf der ganzen Sohle gehen, aber sie entfliehen dennoch ziemlich schnell, dabei pflegen sie den Schwanz hoch zu tragen. - Im Klettern sind sie sehr geschickt und schnell; sie suchen alle Zweige nach den Früchten ab, und lassen dabei beständig ihre rauhe kurze Stimme hören. Gezähmt geben sie im Zorn durchdringende pfeifende Töne von sich. -

Ihre Nahrung besteht nicht blofs in Baumfrüchten, sondern sie fressen auch Fleisch und sind defshalb Raubthiere; auch sagt schon Dobrizhofer (Geschichte der Abiponer, B. I. S. 388), dafs sie gern Hühner und Eier fressen, so wie kleine Vögel, deren Nester sie zerstören. - Dieser Schriftsteller hält übrigens komisch genug das Cuatí für einen Bastard. Nach Art der Schweine oder vielmehr der Dachse, sollen diese Thiere selbst die Erde nach Würmern durchsuchen, in dem Laube und den trockenen Zweigen wenigstens, welche den Boden der Urwälder bedecken, su- 


\section{- 291}

chen sie mit ihrem Rüssel nach abgefallenen Baumfrüchten und Würmern. -

$\mathrm{Da}$ sie in Erdhöhlen vier, fünf bis sechs Junge werfen, so kann man es leicht erklären, dafs ihre Gesellschaften zahlreich sind, meh. rere Familien vereinigen sich, und man trifft oft noch ziemlich kleine Junge dabei an. Im Februar fanden wir diese Thiere sehr fett, doch sollen sie zu andern Zeiten des Jahres, besonders in der kalten Zeit, noch weit mehr Fett besitzen; die Brasilianer essen sie alsdann sehr gern. - Sie haben ein zähes Leben und der Jäger mufs sie gut treffen, wenn sie nicht entkommen sollen. - Findet man eine Bande Cuatís auf einem Baume, so kann man gewöhnlich mehrere davon schiefsen, bevor sie, auf allen Zweigen vertheilt, den Boden wieder erreichen, und in diesem Augenblicke sind sie leicht zu fangen, wenn man Hunde hat; denn diesen können sie nicht leicht entgehen, obschon sie sich wehren und um sich beirsen. Man fängt sie häufig in den Schlagfallen, wel. che die Brasilianer Mundeos nennen, und deren Einrichtung ich in der Beschreibung meiner Reise (Band I. pag. 255) gegeben habe. Jung gefangen werden die Cuatís sehr zahm und es ist nicht selten, dals man diese Thiere 
in den in Europa reisenden Menagerien findet. Sie geben einen etwas unangenehmen Moschusgeruch von sich. Azara beobachtete gezähmte Cuatís, daher lese man seine Beschreibung über diesen Gegenstand nach. -

Den Balg des Cuatí benutzen die brasilia. nischen Jäger zu Regenkappen für die Schlösser ihrer Gewehre.

\section{?2. N. solitaria.}

F. ins a mes oder gröfstes Cuatí. Nasua solitaria Schinz das Thierreich u. s. w, B. I. pag. 199.

Nasua Mondé Illig.

Counti Mondé Azara, T. I. p. 343.

Coati Mondi Marcgr. 223.

Cuati Mundéo der Brasilianer an der Ostlüste. Hakijäck botocudisch.

Dieses Cuatí (wofern es eine besondere Species bildet) mit etwas bärenartiger Gestalt, gleicht sehr dem vorhergehenden, scheint aber gröfser und dicker zu seyn; seine Beine sind kurz, dick, eben so der Kopf und Hals; die Nase ist in einen langen knorpelartigen Rüssel verlängert; die Zunge ist dicht mit feinen, weichen, spitzigen Papillen besetzt.

Gebifs: Schn, $\frac{6}{6}$; Lckz. $\frac{\text { T.I }}{1 \cdot 1}$; Backenz. $\frac{6 \cdot 6}{6 \cdot 6}$. Im Oberkiefer befinden sich sechs Schneide- 
zähne, die vier mittleren sind klein, dicht an einander gedrängt, gleich, dann folgt eine Lücke, und nun auf jeder Seite ein getrennter etwas kegelförmiger und etwas gröfserer Schneidezahn; untere Schneidezähne vorwärts geneigt, stumpf, alle gleich und dicht an einander gereiht; die äufsersten sind an ihrer äufseren Seite ein wenig schräge abgeschliffen. Eckzähne im Oberkiefer nach einer grofsen Lücke folgend, grols, pyramidal, nach vorn vom unteren Eckzahne ausgeschliffen, spitzig, weder vor - noch rückwärts, sondern auswärts gekrümmt, nach vorn und hinten zweischneidig, in ihrer Mitte mit einer erhabenen Längsleiste. - Untere Eckzähne viel gröIser, gebildet wie an dem europäischen wilden Schweine, stark, sehr spitzig, etwas rückwärts gekrümmt, etwas dreieckig, nach vorn mit einer Kante, nach aufsen mit einer seichten, und nach innen mit einer tieferen Furche. - Backenzähne im Oberkiefer sechs an jeder Seite; die drei ersten sind kegelförmige Spitzzähne, der erste ist sehr klein, die folgenden nehmen an Grölse zu; der vierte hat zwei grofse Spitzen und zwei kleine Höcker, der fünfte vier gleiche, der sechste drei gleiche Spitzen. Im Unterkiefer sind sechs Backenzähne an je- 


\section{- $294-$}

der Seite; die drei ersten sind einspitzig, der erste klein und die anderen nehmen zu wie im Oberkiefer, der vierte mit einer grofsen und zwei kleinen Spitzen, der fünfte und sechste mit Furchen, Vertiefungen und schwachen Höckerspitzen.

Die vier dicken starken Füfse haben starke, sanft gekrümmte Krallennägel, wovon die mittleren vorn neun und eine halbe Linie, die mittleren an den Hinterfüfsen sieben Linien lang sind. - An dem Vorderfulse ist die innere Zehe die kürzeste, dann die äufsere, nachher die zweite von innen, die beiden übrigen sind die längsten und einander gleich Der Hinterfuls ist gebildet wie der vordere, aber seine Sohle ist länger.

Die Testikel des männlichen Thieres lie. gen frei vor dem After; die Ruthe wird durch einen drei Zoll langen Knochen unterstützt.

Das Haar des Körpers ist dicht und ziemlich sanft, dabei von zweierlei Art, auf der Haut unmittelbar bemerkt man ein etwas wolliges und darüber ein längeres, schlichtes, ziem. lich hartes.

Die vier Fülse sind schwarz wie das Gesicht; über, unter und hinter dem Auge befinden sich kleine, runde, undeutliche, weifse Fle- 
cke; Unterkiefer und innerer Ohrrand sind weifs; der Schwanz ist grauröthlich - braun mit sieben bis acht schwarzbraunen Ringen und einer langen ähnlichen Spitze; er ist mälsig dicht und lang behaart; alle oberen Theile von den Augen bis zu dem Schwanze sind gelb. bräunlich und schwarzbraun gemischt; jedes braune Haar hat eine gelbliche Spitze und darunter eine schwarzbraune Binde. - Kehle, Seiten - und Unterhals, Brust, Bauch, After und innere Seite der Beine sind rein gelbröthlich gefärbt, der Hodensack weifslich. -

\section{Ausmessung :}

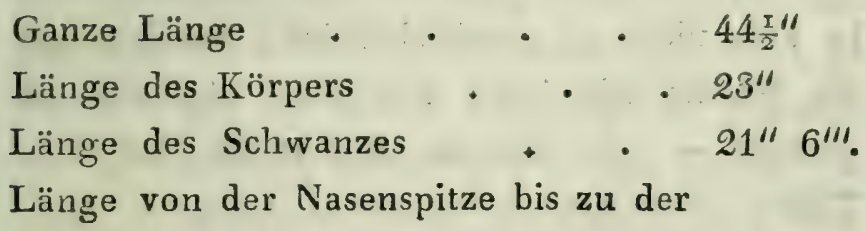
vorderen Ohrwurzel . . . $6^{\prime \prime \prime}$. Höhe des äufseren Ohres $\quad 1^{\prime \prime} 7$ bis $8^{\prime \prime \prime}$. Breite des Kopfs zwischen den Ohren $3^{\prime \prime} 4^{\prime \prime \prime}$. Länge des Vorderbeins bis zu dem Ellenbogen . . . . 7 7" 8"', Länge des Hinterbeins bis zu dem Knie hinauf . • • . $9^{\prime \prime}$

Die Nase tritt über dem Unterkiefer vor um $1^{\prime \prime} 3^{\prime \prime \prime}$. 
Länge der Sohle des Vorderfufses . $\quad 3^{\prime \prime}$

Länge der Sohle des Hinterfufses $3^{\prime \prime} 9^{\prime \prime \prime}$.

Länge des oberen Eckzahnes . . $6 \frac{1}{2}{ }^{\prime \prime \prime}$.

Länge des unteren Eckzahnes • . 9"'.

Ich habe nur ein einziges Individuum von dieser firt zu sehen bekommen, die Indier haben mich aber versichert, dafs sie vollkommen in der Farbe abändere, wie die vorhin beschriebene, dals hier also besonders Gröfse und Verhältnifs der Theile, so wie die Lebensart als Kennzeichen dienen müsse. - Das grö. fsere oder einsame Cuati hat im Allgemeinen die Lebensart der früher erwähnten Species, nur lebt es mehr einsam oder familienweise, ist also nicht so gesellschaftlich, besteigt aber die Bäume wie jenes und wird ebenfalls gegessen. - Im Februar und März sind diese Thiere sehr fett. -

Auch Azara spricht (Vol. I. p. 343) von einem einsamen Cuati, welches er Mondé nennt, also ziemlich mit der brasilianischen Benennung übereinstimmend bezeichnet. Es ist möglich, dafs seine Vermuthung gegründet ist, wenigstens ist alles wahrscheinlich, was er über diesen Gegenstand sagt. Nach inm wäre das einsame Cuatí nur ein sehr altes Thier, wofür auch die stärkere Ausbildung der Eck- 


\section{$-297$}

zähne reden würde; die Zeit und fernere Beobachtungen werden uns über diesen Gegenstand belehren. Gewifs ist es indels unrichtig, drei Arten von Cuatís aufzuzählen, Nasua rufa, obfuscata und Narica, wie im zweiten Theile von Eschwege's Journal von Brasilien (pag. 227) geschieht, oder vier Arten, wa man alsdann Nasua pusilla Geoffr. noch hinzufügt, welche wahrscheinlich ein junges Thier ist. Höchstens zwei Arten des eigentlichen Cuatí kann man als in den von mir bereis'ten Gegenden einheimisch annehmen, wenn sie nicht auf eine reducirt werden müssen, die Farbe aber kann, meinen Beobachtungen zufolge, keine Species derselben bestimmen. - Herr Fr. Cuvier sagt in seiner vortrefflichen Naturgeschichte der Säugthiere, dafs die beiden von ihm aufgestellten Arten der Cuatís sich blofs durch ihre Farbe unterscheiden; diese Ansicht widerspricht meinen Erfahrungen vollkommen, da ich in ein und derselben Familie beide von Herrn Cuvier beschriebene Farbenkleider selbst geschossen und beobachtet habe. - Auch Marcgrave giebt seinem Coati Mondi eine dunklere Farbe, worin aber, wie gesagt, der Character der Species nicht zu bestehen scheint; übrigens ersieht man aus dem Gesagten, dals 
in ganz Brasilien und Paraguay die eine Art unter dem Namen Cuati Mondi oder Mundéo von der andern unterschieden wird. -

$$
A \quad n \quad m \text { e } \quad r \quad k \quad u \quad n g .
$$

Ich habe ein anderes Thier unvollkommen kennen gelernt, welches in das Geschlecht der Cualis zu gehören scheint, von den vorhin genannten Arten aber durch seine Lebensart ein wenig verschieden ist. In den nachfolgenden Zeilen werde ich davon mittheilen, was ich mit Gewirsheit sagen kann.

$$
\text { ? Nasua nocturna. }
$$

Das Jupar ${ }^{*}$ ) oder nächtliche Cuatí.

Man kennt in den grofsen Urwäldern der Ostküste von Brasilien ein Thier, welches nach den Fellen, die ich daron gesehen, und nach den erhaltenen Nachrichten höchst wahrscheinlich ein Cuatí ist; da aber dessen Kopf grölstentheils an den Häuten fehlte, so konnte nicht zuverlässig über das Genus des Thiers entschieden werden. - Es hatten die grölsesten der mir vorgekommenen Felle etwa die Hälfte der Länge des rothen Cuatí; der Schwanz war

*) Das $I$ wird hier weich wie in Französischen ausgesprochen. 
lang und mit zarteren, weicheren Haaren bedeckt, als an den beschriebenen Specien, eben so das Haar des ganzen Körpers. - Von den anderen Cuatís zeichnet sich das Jupará durch ein sehr zartes, sanftes, dichtes Haar am ganzen Körper aus, welches an den oberen Theilen von einer fahl graugelblichen, an den unteren aber von einer angenebm fahl gelbröth. lichen Farbe ist; der Schwanz zeigt keine farbige Ringe, sondern ist von derselben Mischung wie die oberen Theile des Körpers. -

Den Nachrichten der brasilianischen Jäger zufolge, lebt das Jupará am Tage in hohlen Bäumen verborgen und verläfst nur bei Nacht seinen Schlupfwinkel, alsdann hört man häufig seine etwas zischende Stimme, während es die Bäume nach ihren Früchten besteigt. Am Tage soll man dieses Thier nie sehen, und es wird zufällig durch Hunde, oder bei'm Umhauen der Bäume entdeckt, wefshalb ich auch, aller Versprechungen ungeachtet, im vollkom. menen Zustande nie ein solches Thier erhalten habe. - Es ist also diese Art von den übrigen hier erwähnten Cuatís, wenn sie hierher gehört, sowohl durch ihre Lebensart, da sie nur bei Nacht geht, als auch durch ihr zartes 
feines Haar und den ungefleckten Schwanz unterschieàen.

v. Humboldt's nächtliches Thier Guachi (Voy. au nouv, cont. T. II. pag. 494) könnte wahrscheinlich hieher gehören. --

Herr Dr. v. Spix spricht bei Gelegenheit einer neuen von ihm entdeckten Art der Quadrumanen, des Nyctipithecus vociferans, von einem Thiere, welches er Xupará nennt, und für Mustela barbara hält. - Der Name dieses Thiers hat die grölseste Aebnlichkeit mit dem von mir hier angegebenen, nur spricht man das $X$ hart, also Schupará und das $I$ weich wie im Französischen aus. - Es ist übrigens zuverlässig, dals das von mir erwälnte Thier verschieden von Mustela barbara, dagegen wahrscheinlich, dafs es eine kleinere nächt. liche Art der Cuatís ist, welches auch brasilianische Jäger mir bestätiget haben. -

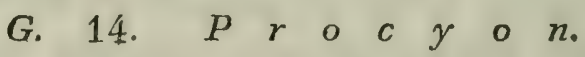

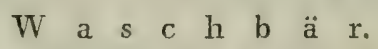

Dieses feschlecht ist sehr bekannt, da die in Nord-America einheimische Art häufig nach Europa gebracht und leicht lebend und gezähmt erhalten wird. - Süd-America besitzt cine andere Art, welche schon von Azara be. 


\section{$-301$}

schrieben wurde und worüber ich rorh die nachfolgenden Bemerkungen mittheilen will. -

1. P. cancrivorus, Illig.

D a $s$ Guassini oder Guaschin i.

Ursus cancrivorus der Schriftsteller.

Agouara popé, Azara, T. I. p. 324.

Guachinim (Guaschini oder Guassini) der Brasilianer an der Ostküste.

Hakijäck-gipakiú botocudiscl.

Das Guassini hat im Allgemeinen so viel Aehnlichkeit mit dem nordamericanischen Waschbären oder Schupp (Procyon Lotor), dals ihn die Herren Geoffroy und Fr. Cuvier in ihrer Naturgeschichte der Säugthiere für identisch mit dem letzteren angenommen haben, dennoch scheint er mir specifisch verschieden. Ich finde ihn höher von Beinen, an diesen Theilen kürzer behaart, das Ohr ist weit kürzer, die Nägel an den Zehen mehr abgenutzt und kürzer. - Da Azara das weibliche Thier beschrieb, so will ich die kurze Beschreibung eines männlichen geben.

Beschreibung: Der Oberkiefer ist um einen Zoll länger als der untere, in eine bräun. liche, sehr feuchte Nasenkuppe endigend; die Schnautze ist ziemlich kurz und zugespitzt, ein wenig aufwärts gestülpt, Kopf im Allge- 


\section{- 302}

meinen breit und kurz; Oberkopf sehr breit; Ohren klein, länglich - eifürmig, oben ein wenig abgerundet, kurz und dicht behaart; das Auge ist gelb und glänzend, bei Nacht leuchtend wie am Fuchs.

Gebifs: Schn. $\frac{6}{6}$; Eckz. $\frac{I \cdot x}{1 \cdot I}$; Backenz. $\frac{6 \cdot 6}{6 \cdot 6}$. Im Ober - und Unterkiefer befinden sich sechs sehr kleine Vordcrzähne; die oberen sind grö. fser, und die beiden äufseren derselben länger als die übrigen; im Unterkiefer ist der äufsere Vorderzahn an der äufseren Seite ausgeschnitten. - Eckzähne oben und unten zwei, kegelförmig, sehr stark, die oberen sind gekrümmt, die unteren gerade. - Backenzähne in jedem Kiefer an jeder Seite sechs; vorn stehen drei kegelförmige Spitzzähne, welche nach hinten immer an Grölse zunehmen, alıdann folgt der ḋreispitzige Reifzahn (carnassic̀re) und nun noch zwei fünfspitzige Zähne, von welchen der letztere der kleinste ist.

Der Hals i`t kurz; die Beine ziemlich hoch und schlank; Füfe sohlengehend; vorn und histen fün Zehen, zusammengedrückt, mit kur. zen, kaum über den Finger vortretenden Kral. lennägeln; an den Vorderfüfsen ist die innere Zehe die kürzeste, die äufsere ist etwas länger, die zweite und dritte von aufsen sind die 


\section{- 303.}

längsten; an den Hinterfüfsen ist die innere die kürzeste, dann folgt die äufsere, die dritte: von aufsen ist am längsten; Nägel etwas aufgerichtet und bogig gewölbt, allein sehr abgenutzt und daher kurz. - Der Schwanz reicht etwas über die Ferse hinab:-

Die männlichen Geschlechtstheile sind, wie an unserem Furhse, äufserlich etwas im Pelze verborgen; die Ruthe hat einen langen, starken, vorn etwas getheilten Knochen.

Haar am ganzen Körper von der Textur des Wolfshaars, aber kürzer; an den vier Beinen ist es fein, sehr glatt und zerschlissen abgenutzt; Füfse nur mit einzelnen Haaren besetzt, beinahe unbehaart (durch das Gehen im zähen Schlamme der Mangesümpfe). Schwanz etwas länger behaart als der Körper, sein Haar ist stark und hart; am Ober- und Unterkiefer und hinter dem Mundwinkel befinden sich lange schwarze und weilse Bartborsten. - Die Farbe des Körpers ist graugelblich mit schwarzen Spitzen der Haare, also gemischt, auf Rücken und Hintertheil am schwärzesten, wie an einem jungen Wolfe; Vor. derfüfse und untere Hälfte der IHinterschenkel sind gänzlich schwarzbraun, die mehr nackten Füfse blässer, nur graulich gefärbt; - Einfas- 
sung der Augen schwarzbraun; Einfassung des Mundes, Kehle und Mitte der Brust weifslich, so wie die innere Seite der Ohren; Stirn, Scheitel, äufseres Ohr schwärzlich grau, mehr ungemischt; Spitze des Ohres schwärzer, Rand desselben weifslich; über der schwarzen Einfassung des Auges befinden sich etwas weifse Haare; Bauch ungemischt weilslich-gelbgrau; Schwanz mit vier bis fünf schwarzbraunen und graugelblichen Ringen abwechselnd und mit einer langen schwarzbraunen Spitze.

\section{Ausmessung:}

\section{Ganze Länge}

Länge des Körpers

Länge des Schwanzes

Länge von der Nasenspitze bis zu -

$$
\text { dem Ohre . . . . . } 5^{\prime \prime}
$$

Höhe des äufseren Ohres • • $1^{\prime \prime} 9^{\prime \prime \prime}$. Höhe des Vorderbeins, von der Ferse

$$
\text { bis zum Ellenbogen : •. } 5^{\prime \prime} \text {. } 4^{\prime \prime \prime} \text {. }
$$

Höhe des Hinterbeins von der Ferse

bis zum Knie beinahe . . . ."

Länge des Vorderfufses . . . . $3^{\prime \prime}$

Länge des Hinterfufses . • . 5" $10^{\prime \prime \prime}$.

Zur Vergleichung mit der hier gegebenen Ausmessung des Procyon cancrivorus werde 
ich jetzt die Ausmessung des nord-americanischen Lotor nach Daubenton folgen lassen:

Länge von der Schnautzenspitze bis

zum After . . . $\quad 22^{\prime \prime} 6^{\prime \prime \prime}$.

Länge des Schwanzes ohne das Spi.

tzenhaar . . . 1 1 1

Länge von der Nasenspitze bis zum

vorderen Augenwinkel . . $1^{\prime \prime} 11^{\prime \prime \prime}$.

Länge von der Nasenspitze bis zum

Ohre ... . . . $44^{\prime \prime} 5^{\prime \prime \prime}$.

Höhe des äufseren Ohres • . $1^{\prime \prime} 10^{\prime \prime \prime}$.

Länge des Vorderarms . . . $\quad 4^{\prime \prime} 8^{\prime \prime \prime}$.

Länge der Hand . . . . . $3^{\prime \prime}$

Länge des Unterschenkels (tibia und

fibula) - . $\quad 5^{\prime \prime} 8^{\prime \prime \prime}$.

Länge des Hinterfufses (wie oben die

Nägel mitgerechnet) . . 4" $4^{\prime \prime}$ '”.

Der Magen des Guassiní ist häutig, die Gedärme sind kurz und dick; jede Lunge ist in fünf Lappen *) getheilt, zwei derselben befinden sich an jeder Seite und ein kleinerer unten in der Mitte. - Die Leber ist grofs und in sieben Lappen ${ }^{* *}$ ) getheilt. -

*) Daubenton giebt für den Lotor sechs Lungenlappen an.

*) Daubenton giebt fïr den Lotor füinf Lappen der Le. ber an.

II. Band. 


\section{$-306$}

Dieses Thier ist an der ganzen von mir bereisten Ostküste unter dem Namen Guassiní oder Guaschiní (Guaxinim oder Guachinim) bekannt, und lebt besonders in den den Flufsund Seeufern benachbarten Gebüschen, wo es in dem weichen Schlammboden der von der Fluth benetzten und bei der Ebbe wieder be. freiten Mangue-Gebüsche (sie bestehen aus Conocarpus, Avicennia oder Rhizophora) seine Nahrung sucht, welche besonders in Krab. ben besteht, wie mich die eigene Untersuchung des Magens gelehrt hat. - Es soll hauptsächlich bei Nacht auf den Raub ausgehen und im Allgemeinen die Manieren des Waschbären von Nord-America haben. - Es klettert auf die Bäume und sucht sie nach ihren Früchten $a b$, benutzt auch die von Füchsen und Gürtelthieren gegrabenen Erdhöhlen, soll aber selbst nicht graben. - Das Zuckerrohr soll es ger. ne fressen und defshalb die Pflanzungen be. suchen. -

Ueber die Art seiner Fortpflanzung habe ich nicht Gelegenheit gehabt, Erfahrungen zu machen, doch dürfte sie wohl von der der Cuatís und des Raton nicht bedeutend verschieden seyn. - Der Geruch dieser Thiere ist nicht angenehm, besonders wenn man sie lebend 
hält, wo sie sehr zahm werden, da ich aber nie selbst das Guassiní im gezähmten Zustande gesehen habe, so kann ich über seine Manieren nichts hinzufügen. - Man ilst in Brasilien das Fleisch dieser Thiere, jedoch nicht allgemein. Im Januar und Februar fand ich sie sehr fett. Aus dem Felle bereiten die Brasilianer Regenkappen für ihre Gewehrschlösser. - Ob mir gleich nie ein solches Thier im Walde begegnete, so habe ich doch sehr häufig ihre Spur in dem weichen Schlammboden der Flufsufer gesehen, besonders am $\mathbf{P e}$ ruhype, Mucuri und andern Flüssen. -

Manche der unkundigern brasilianischen Jäger pflegen das Guassini mit dem Fuchse (Cachorro do mato) und der Raposa zu verwechseln, einem andern Thiere, wovon einige reden, welches ich aber nicht kennen gelernt habe; es wurde mir beschrieben wie Procyon Lotor. -

Da das Guassiní, wie d'Azara uns belehrt, in Paraguay lebt, und in Guiana gefunden wird $\left.{ }^{*}\right)$, so dürfte dasselbe wohl über den grölsten Theil von Süd-America verbreitet

*) Herr v. Sack in seiner Reise nach Surinam (pag. 201) redet davon unter dem Namen Crabodago. 
seyn. - Koster redet davon, er fand es in der Gegend von Pernambuco *), hatte dasselbe aber nicht selbst gesehen. -

Die Botocuden, in deren Wäldern dieses Thier lebt, kennen es unter der Benennung Hakijäck-gipakizi oder grofses Cuatí. -

Buffon hat eine Abbildung seines RatonCrabier gegeben, welche eine richtige Idee von der Gestalt des Kopfs giebt; man ersieht aus derselben, so wie aus der Vergleichung der weiter oben von Daubenton und von mir angegebenen Ausmessungen, dafs der süd-americanische. Waschbär weit kürzere Ohren hat, als der,nord-americanische. -

\section{F a m. III. A $g$ i $l$ i a. Marderartige Raubthiere.}

Diese von Illiger aufgestellte Familie zählt in America viele Arten, jedoch mehr in den kalten und gemälsigten, als in den warmen Theilen dieses Continents. - In Brasilien habe ich nur zwei Thierarten kennen gelernt, welche hierher gehören, die Hyrare (Mic-

*) Koster's travels etc. pag. 313 . 


\section{- $309<$}

stela barbara) und die Fischotter (Lutra brasiliensis). - Die erstere hat Aehnlichkeit mit den Vielfrafsen (Gulo), da sie mit der ganzen Hintersohle auftritt, auch hatte ich sie früher für verschieden von Mustela barbara gehalten, wo sie Herr Dr. Schinz in seiner Uebersetzung von Cuvier Règne Animal unter der Benennung Mustela gulina aufnahm; ich halte sie aber jetzt für identisch mit Mustela barbara. - Die Fischottern hat man auch hieher gestellt, ob sie gleich durch die Bildung ihrer mit Schwimmhäuten versehenen Füfse und durch ihren Aufenthalt im Wasser wohl von ihnen getrennt werden dürften.

$$
\text { G. 15. } M \text { u } s \text { e } l a \text {. }
$$

In allen Welttheilen gleichen sich die marderartigen Thiere durch ähnliche Organisation, äufsere Gestalt und Lebensart; überall sind sie kleine, kühne, blutdürstige Raubthiere, welche vermöge der Gewandtheit ihres Körpers fähig sind, die kleinsten Schlupfwinkel zu durchkriechen. Sie gehen nächtlicher Weise oder nur selten gesehen ihrem Raube nach, der in allerlei lebenden Thieren besteht. Gewöhnlich morden sie was sie erreichen können, dem Fe- 


\section{- $310-$}

derviehe beifsen sie die Köpfe ab und saugen das Blut aus. Sie werfen mehrere Junge, gewöhnlich vier bis fünf, welche sie in Erdhöh. len, hohlen Bäumen und selbst in den menschlichen Wohnungen verbergen.

\section{M. barbara, Linn.}

Die Hyrare, der fahlköpfige Marder.

M.: Vorn mit ganzer, hinten mit halber Solhle auftretend; Gestalt marderartig; Schwanz lang, mäfsig dick; Körper schwarzbraun, Kopf fahl graugelblich; unter dem Halse ein gelber Fleck. -

Mustela poliocephala, Oken.

Le grand furet, Azaris Essais etc. Vol. I. pag. 197. d'Azara voyages etc. Atlas tab. II.

Mustela gulina, Schinz Thierreich, B. I, pag. 209.

Abbildungen zur Naturgeschichte Brasilien's.

Hyrara oder Irara, auch häufig Papamel bei den Brasilianern der Ostliuiste *).

Jupiunn bei den Botocuden.

Dieses Thier habe ich früher mit dem Namen Mustela gulina belegt, da ich vermu-

*) Marcgrave scheint in der Beschreiburg der brasilianischen Fischotter Jiga oder Carigueibeiu auch einige Züge der Hyrare durch Verwechslung mit eingemischt zu haben. In der Menzel'schen Sammlung brasilianischer 'Thierabbildungen befindet sich, wie uns Herr Professor Lichtenstein sagt, eine Abbildunr mit der Benennung Eirara; der Na- 


\section{- 311}

thete, dafs $M$. barbara von meiner Hyrare vęrschieden sey, öftere Vergleichung hat mich indessen seitdem bestimmt, beide Thiere $\mathrm{zu}$ vereinigen, indem die von Azara angegebenen Verschiedenheiten doch nur unbedeutend sind. - Nach ihm hat sein grofser Marder (grand furet) einen sehr dicken Schwanz, welcher bei meinem Thiere nur mälsig lang behaart ist, auch habe ich den Kopf nie weifslich, sondern höchstens fahl graugelblich, oft aber ziemlich dunkel gefärbt gefunden; von einer die Zehen vereinigenden Haut, so wie von einer Verdoppelung des Ohrrandes habe ich an Ort und Stelle nach dem frischen Thie. re nichts aufgezeichnet, an den in den Samm. lungen aufgestellten Exemplaren sind diese Theile vertrocknet und daher nicht mehr zu untersuchen. Ich werde eine starke männliche Hyrare im frischen Zustande beschreiben. -

Beschreibung: Dieses Thier ist weit gröfser und stärker als unsere europäischen Marder, hat aber ziemlich die Gestalt derselben,

me ist der meines Thieres, vielleicht ist dasselbe damit gemeint? Desmarest in seiner Mammalogie hat in der Diagnose den Character des fahlgefärbten Kopfs und Halses ausgelassen, welcher sehr characteristisch ist; er setzt das Thier zu den Vielfrafsen (Gulo). 
nur ist Kopf und Schnautze dicker, Kopf und Hals sind ziemlich gleich dick, sehr breit, stark und muskulös; der Unterkiefer ist kürzer als der obere; Auge ziemlich klein; das dichtbehaarte äufsere Ohr ist abgerundet wie am Marder, aber kürzer; die etwas dickere Schnautze trägt an ihrem Ende eine starke, feuchte, schwärzliche Nasenkuppe. - Ober - und Unterkiefer sind mit feinen, zarten, kurzen, schwärzlichen Bartborsten besetzt, auch stehen ein Paar solche über den Augen. -

Die Zunge ist dicht mit weifslichen, zugespitzten Papillen besetzt. -

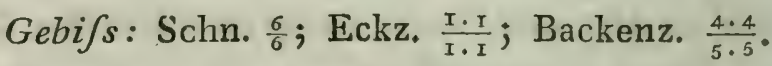
In jedem Kiefer stehen sechs Schneidezähne; im Oberkiefer ist der äufsere an jeder Seite gröfser, länger, und hat an der inneren Seite einen kleinen Ausschnitt, so dafs er in der Gestalt sehr den Eckzähnen gleicht; die vier mittleren sind stumpf, dahingegen der äufsere an jeder Seite etwas kegelförmig gestaltet ist; untere Schneidezähne kleiner als die oberen, vier derselben sind von gleicher Grölse, die beiden mittleren aber weit kleiner. - Eckzähne in jedem Kiefer zwei, grofs, gekrümmt, kegelförmig. - Backenzähne im Oberkiefer vier auf jeder Seite; zuerst ein kleiner Spitz- 
zahn, dann ein gröIserer einspitziger, dann der Reilszahn mit einer grofsen Mittelspitze, einem Absatze nach vorn und einer kleinen Spitze nach hinten, endlich ein einwärts quer gestellter, schmaler, langer, etwas platt zweihökkeriger Zahn. - Im Unterkiefer stehen fünf Backenzäbne an jeder Seite; zuerst ein kleiner, stumpfer, dann zwei einspitzige, nachher ein dreizackiger Reilszahn, dann ein kleiner, runder, abgestumpfter Zahn. -

Die Glieder dieses Thieres sind stark, die Vorderbeine ziemlich kurz, dick, mit dicken breiten fünfzehigen Fü 5 sen und Krallennägeln; die innere Zehe ist die kürzeste, ihr folgt in der Länge die äufserste, alsdann die vierte von aufsen oder der Zeigefinger, dann die zweite von aufsen, und der Mittelfinger ist noch um sehr weniges länger.

Die Ballen der Nagelglieder sind stark, rauh und etwas vortretend; die Krallennägel stark, gebogen, zusammengedrückt, ein wenig aufgerichtet und überhaupt gestaltet wie an unseren Mardern; die Sohle des Vorderfufses ist beinahe bis $\mathrm{zu}$ der Ferse nackt oder von Haaren entblöIst; Hinterbeine dick, muskulös, länger als die vorderen, sie haben fünf Zehen, deren Verhältnifs der Länge dasselbe ist als 


\section{- 314}

an den Vorderfüfsen, der Fufs selbst ist aber schmäler und die Klauen weit kleiner; die Sohle ist hier weniger nackt als an den Vorderfürsen. - Der Schwanz ist lang, jedoch kürzer als der Körper, weit dünner oder kürzer behaart als an unserem Marder, allmälig etwas zugespitzt. -

Testikel des männlichen Thiers sehr stark, sie sitzen äufserlich nahe unter dem After; die Oeffnung für die Ruthe befindet sich in einem dicken, nackten, häutigen und hängenden Beu. tel, vier und einen halben, oder fünf und einen halben Zoll vor den Testikeln. - Die Ruthe selbst hat einen Knochen, der bei dem alten hier beschriebenen Thiere zwei Zoll zehn Linien lang, ziemlich gerade, etwas zusammengedrückt und vorn mit einer kleinen kreisförmigen horizontalen Ausbreitung versehen war.

Die Behaarung des ganzen Thiers ist glatt, kurz und ziemlich hart; Nase und Kopf sind mit höchst kurzen, sehr glatten, graubräunlich und gelblich gemischten Haaren bedeckt, das Gesicht fällt mehr ungemischt ins fahl-Graubraune; Gegend der Ohren und Seiten des Halses sind mehr fahl gelblichgrau gefärbt; nach dem Körper hin nehmen die Haare ein 


\section{$-315-$}

wenig an Länge zu, an den Seiten sind sie noch etwas länger, an Bauch, Beinen und Schwanz aber am längsten. - Der ganze Körper ist schwarzbraun gefärbt, am dunkelsten die Beine, der Bauch und der Schwanz, doch sind die Farben nie abgesetzt, sondern verlaufen allmälig ineinander. - Schon an den Schulterblättern wird das schwarzbraune Haar mit einzelnen gelblichen und weilsgraulichen gemischt, welches nach dem Halse hin schnell zunimmt, so da「s Hals und Kopf im Allgemeinen eine fahl graugelbliche Farbe zeigen; Gesicht und untere Seite des Kopfs sind gewöhnlich etwas dunkler, mehr in's Graubräunliche fallend, und unter der Mitte des Halses befindet sich ein unregelmäfsiger, schön röthlichgelber, bald gröfserer, bald kleinerer Fleck, etwa von der Farbe des Kehlfleckens bei unserem Buchmarder (Mustela Martes). - Die Haare des Schwanzes sind hart, höchstens anderthalb Zoll lang, und so wie am ganzen Thiere glänzend. - Die Zehen sind mit ziemlich langen, zum Theil über die Klauen hinausreichenden Haaren bedeckt; Hinterbauch und innere Hinterschenkel sind etwas dünner behaart, zum Theil etwas nackt. - Die Sohlen der Fülse sind schwarzbraun, und von der 


\section{- 316}

Spitze der Zehen an gemessen zwei und einen halben Zoll lang nackt.

Die Farbe des Kopfs und Halses variirt etwas; denn oft ist sie mehr fahl graugelblich und zuweilen mehr aschgraulich, gewöhnlich aber mehr in's Gelbliche fallend, auch ist der gelbe Kehlfleck zuweilen dreieckig, rundlich, viereckig, oft sehr klein, oft grofs, an dem hier beschriebenen Exemplare hielt er zwei Zoll zwei Linien in der Länge, und eben so viel in der Breite.

Ein weibliches Thier, welches ich erhielt, war etwas kleiner, hatte einen gröfseren gelben Fleck unter der Kehle und vier Bauch. zitzen.

Ausmessung des beschriebenen männlichen Thieres:

Ganze Länge - . . . . $39^{\prime \prime} 4^{\prime \prime \prime}$. Länge des Körpers . • . $\quad 23^{\prime \prime} 11^{\prime \prime \prime}$. Länge des Schwanzes • • $15^{\prime \prime} 5^{\prime \prime \prime}$. Länge von der Nasenspitze bis zu der vorderen Ohrwurzel . . . . . $3^{\prime \prime} 9^{\prime \prime \prime}$.

Breite von einer Ohrwurzel zu der anderen . . . . . 2 $2^{\prime \prime} 9 \frac{\mathrm{r}}{2}{ }^{\prime \prime \prime}$.

Länge des Vorderbeins bis zu dem Ellenbogen $\because \quad . \quad 5^{\prime \prime} 8^{\prime \prime \prime}$. 
Länge des Hinterbeins bis zu dem

Knie . . . . . . $7^{\prime \prime} 9^{\prime \prime \prime}$.

Breite des Vorderfulses bei den

Klauen • . . • $\quad 1^{\prime \prime} 11^{\prime \prime \prime}$.

Länge des oberen Eckzahnes . . $8^{\prime \prime \prime}$.

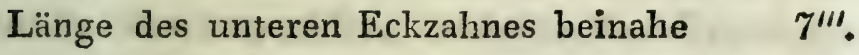

Dieses kleine, aber kräftige und blutgierige Raubthier kommt in allen von mir besuchten brasilianischen Waldungen vor und ist daselbst von den einsamen Bewohnern der Wald-Fazendas, von den Negern und Indiern wohl gekannt, gewöhnlich Papamel, Hyrara oder Irara benannt, doch wird die letztere Benennung in manchen Gegenden auch dem Yaguarundi des Azara beigelegt.

Die Hyrare hat vollkommen die Lebensart des Vielfralses und des Marders, - Sie streicht in verborgenen Schlupfwinkeln umher, in den dichtesten Wäldern, hohlen Bäumen, Klüften, vieỉleicht auch in Erdhöhlen, wovon aber die Botocuden nichts wissen wollten. Sie streift besonders bei Nacht umher, besteigt geschickt die Bäume, plündert die Nester der Vögel, sucht ämsig den wilden Honig in hohlen Bäumen auf (daher die Benennung Papa$m e l)$, jagt alle kleinere lebende Thiere, als Agutis, Pacas, Cavien, Eichhörnchen u. s. w. 
und wagt sich selbst an das Reh, welches sie oft bis in die Nähe der menschlichen Wohnungen verfolgt haben soll. - Sie läuft zwar nicht besonders schnell, hält aber sehr lange die Spur des angejagten Thieres ein, wodurch sie dasselbe oft ermüden und fangen soll. Man will gesehen haben, dals sie ein Reh müde jagte, und als sich dieses aus Ermüdung niederlegte, dasselbe lebend anfrafs. - In die Hühnerställe bricht die Hyrare wie unser Marder und Iltis ein, beifst die Köpfe ab und saugt das Blut aus.

Sie wirft, nach der Versicherung der brasilianischen Jäger, besonders der Botocuden, drei bis vier Junge, welche sie gewöhnlich in einem hohlen Stamme oder Baumaste verbirgt.

Finden die Hunde die Spur dieses Raubthiers, so baumt es gewöhnlich bald, und wenn man zeitig genug hinzukommt, so ist es leicht, dasselbe von dem Baume herab zu schiefsen. Oefter fängt man die Hyrare bei dunkelen Nächten in den Schlagfallen oder Mundeos, wenn sie im Walde umher läuft, zu Morro d'Arara lieferten uns diese Fallen in einigen Wochen vier dieser Thiere. - Aus der Haut bereitet der brasilianische Jäger Regenkappen 
für die Gewehrschlösser. - Die Botocuden essen das Thier, ziehen aber zuvor nicht die Haut ab, sondern sengen sie im Feuer, wie sie es bei allen erlegten Thieren zu halten pfle. gen. Azara's Abbildung scheint die beste von dieser Thierart bisjetzt belannte zu seyn, ei ne höchst schlechte, mit völlig verunstaltetem Halse (wahrscheinlich nach einem sehr schlecht ausgestopften Exemplare) findet man in den Schriften der Wernerian Society, Vol. III. pag. 440, unter der Benennung Viverra polio. cephalus.

$$
\begin{gathered}
G e n .16 . \quad L \text { u } t: r \text {. } \\
\text { Fis c hot ter. }
\end{gathered}
$$

Die Fischottern bilden ein über die meisten Länder unserer Erde verbreitetes Geschlecht der Raubthiere, welches die Flüsse bevölkert und den mit Schuppen bedeckten Bewohnern derselben nachstellt. Ihr Gebifs ist stark, der Schädel sehr flach gedrückt, der Körper schmal verlängert, fett, mit langem Ruderschwanze und kurzen, starken, mit Schwimmhäuten versorgten Füfsen versehen, daher vollkommen zum Schwimmen und zu der Lebensart im Wasser eingerichtet. 


\section{- 320}

Die Fischottern bewohnen die gemälsigten und heifsen Zonen unserer Erde, doch findet man nirgends viele Arten von ihnen, auch vermuthe ich, dafs man für die warmen Länder von Süd-America zu viele Arten angenommen hat. In Paraguay und Brasilien giebt es, wie d'Azara bestätiget, wahrscheinlich nur eine einzige Art dieses Geschlechtes, über welche ich nachfolgend einige Bemerkungen mittheilen werde.

1. L. brasiliens $i s$ Raii. Die brasilianische Fischotter.

Jiga Marcgrr. pag. 234.

La Loutre, Azara Essais etc. T. I. p. 348.

Luntra bei den Brasilianern.

Ariranha (Arirannia) am Rio S. Francisco. Nomerick*) bei den Botoculden.

Azara hat die brasilianische Otter hinlänglich beschrieben, ich werde defshalb nur noch einige Worte hinzufügen

Dieses Thier hat in Allgemeinen die gröIste Aehnlichkeit mit unserer europäischen Fischotter, doch unterscheidet es sich von derselben auf den ersten Anblick durch die Bil-

*) Vor dem $N$ hört man kaum ein $G$ in der Kehle; $e$ wird kurz ausgesprochen. 


\section{$-321$}

dung des Schwanzes, welcher bei der europäischen Art rund, bei der brasilianischen aber an beiden Seiten scharfkantig, oder von oben etwas plattgedrückt erscheint, auch ist das Haar bei der letzteren am ganzen Leibe kürzer.

Kurze Beschreibung einer männlichen Otter: Die Bildung des ganzen Thieres gleicht in der Hauptsache der europäischen Art; der Kopf scheint etwas stärker und mehr rund, hat daher in seiner Bildung etwas Aehnlichkeit mit dem der grölseren Katzenarten; die Schnautze ist vielleicht etwas breiter, der Oberkopf erhabener und nicht so platt gedrückt, als an unserer europäischen Flufsotter. An beiden Kiefern und hinter dem Auge stehen lange gølbliche Bartborsten; Nasenkuppe behaart wie das Gesicht, ziemlich breit, die Nasenlöcher etwas nach der Seite geöffnet; äufsere Ohren klein und abgerundet; Auge klein und weit nach vorn gestellt; die vier Beine sind kurz und stark, die Füfse oder Pfoten abgerundet, mit ganzen Schwimmhäuten versehen, welche zuweilen in ihrer Mitte einen kleinen Ausschnitt zeigen; innere Zehe an allen Füfsen die kürzeste, alsdann folgt in der Länge die äufsere, die drei mittleren sind einander ziem-

II. Band, 


\section{- 322}

lich gleich und die längsten. - Nägel ziemlich stark, zugespitzt, sanft gekrümmt, unten etwas ausgehöhlt, an den Hinterfü 5 sen dicker und kürzer. - Schwanz lang, aber kürzer als der Körper; er hält an der Wurzel fünf bis fünf und einen halben Zoll im Querdurchmesser, in seiner Mitte drei' Zoll zwei Linien, nimmt dann an Breite etwas $z u$, etwa bis $z u$ drei Zoll drei bis vier Linien, wird hier völlig platt, an den Seiten scharfrandig, nach dem Ende rundlich zugespitzt, und ist über und über behaart wie der Körper. - Die Testikel befinden sich kurz vor dem After unter der Haut verborgen, scheinen aber zuweilen, wahrscheinlich in der Paarzeit, etwas hervorzutreten. - Etwa drei und einen halben Zoll weiter nach vorn befindet sich die Oeffrung für die Ruthe, am Rande ein werig nackt; die Ruthe selbst hat eine länglich walzenförmige Gestalt, und eine etwas verdickte abgestumpfte Eichel; sie wird von einem Knochen unterstützt.

Das ganze Thier ist mit einern schünen, kurzen, sanften bräunlichen Haare, kürzer als an unserer europäischen Otter, überzogen. Der Unterkiefer ist weifs, und der ganze Unterhals bis zur Brust mit länglichen, oft sehr 


\section{- $323-$}

abwechselnden weifslichen Flecken, oft weniger, oft mehr bezeichnet; einige Individuen sind an diesen Theilen weit weniger und nur undeutlich weils gezeichnet, mehr gelblich, besonders blofs der Unterkiefer, und der Unterhals ist alsdann hell graubraun, in's Weifsgraue fallend, und auf der Brust befindet sich ein runder kleiner röthlich-gelber Fleck von ein bis anderthalb Zoll im Durchmesser. Bauch und übrige untere Theile haben immer die Farbe des Rückens, die Fülse hingegen eine etwas dunkler bräunliche Mischung. -

Ausmessung eines männlichen Thieres, welches jedoch nicht von den grö/sesten war:

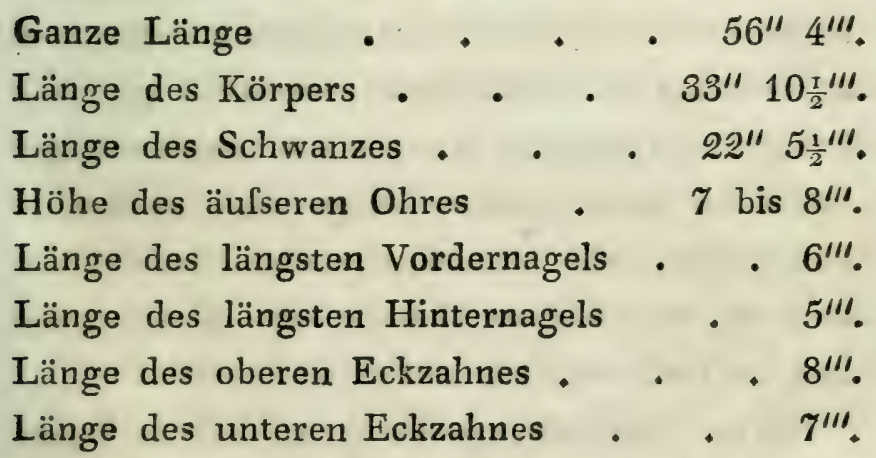

Der Schädel der brasilianischen Fischotter ist in der Hauptsache gebildet wie der der europäischen. - Ein solcher in meiner zoolagischen Sammlung hält fünf Zoll fünf Linien 


\section{$-\quad 524$}

in der Länge, und in der Breite des Jochbogens drei und einen halben Zoll. - Mit dem Schädel der europäischen Fischotter verglichen, ist er an der Stirn weniger platt gedrückt, hinten etwas breiter und runder gewölbt. Der Jochbogen ist an beiden Thieren völlig gleich gebildet, bei der europäischen Fischotter von oben gesehen in seiner Mitte ein wenig mehr geradlinig, auch ist bei der brasilianischen der Raum von der Nasenöffnung bis zu der vorderen Wurzel des Jochbogens kürzer als an der europäischen; die hintere Wurzel des Jochbogens ist bei der brasilianischen Art weniger breit und horizontal liegend als bei der europäischen; das Gebils zeigt an beiden Thieren keine Verschiedenheit. Die Eckzähne der brasilianischen Art sind ihrer ganzen Länge nach hohl, und springen, wenn sie vertrocknen, gewöhnlich ihrer ganzen Länge nach an beiden Seiten auf; ihre Wurzel ist etwas bauchig, blasenartig, mit dünnen Wänden und einer cirkelrunden Oeffnung am Ende.

Der Knochen, welcher sich in der Rutlue des männlichen Thieres befindet, mals bei einem Individuo von 48 Zoll 8 Linien ganzer Länge, zwei Zoll neun und eine halbe Linie in der Länge; er ist gerade, walzenförmig ver- 


\section{$-325$}

längert, an seinem vorderen Ende ein wenig verdickt, sanft aufwärts gebogen, und an dieser Stelle an der unteren Seite ausgehöhlt. -

Die Lunge ist in sechs Lappen getheilt; die Leber ist grofs und zeigt sieben Lappen, wovon vier klein sind. - Der Magen ist gekrümmt, häutig, er war mit Fischresten angefüllt. - Das Herz war durch den Schufs zu sehr verletzt. - Der Darmcanal milst vom Kopfe an dreizehn Fuls in der Länge. - Unter dem Pförtner befindet sich am Zwölffingerdarm ein weiter Sack, eine weite faltige Ausbreitung. -

Die brasilianische Fischotter lebt sehr zahIreich in allen nicht zu oft beunruhigten Flüs. sen, mehr einzeln in den bewohnteren Gegen. den. - Sie ist überall unter dem Namen der Lontra bekannt, wird aber wohl zuweilen mit einem Thiere verwechselt, welches man dort Cachorro d'Agoa (Wasserhund) nennt, und welches ich nicht zu sehen Gelegenheit gefunden habe, das aber vielleicht der Quiya des Azara (Myopotamus) seyn dürfte. - Gewils ist die Fischotter über ganz Süd-America verbreitet und lebt in Guiana, wo man ohne Zweifel mehrere Arten aus ihr gemacht hat.In den wenig besuchten Flüssen von Brasilien 
findet man diese Thiere in zallireichen Banden. - Selten haben wir den Belmonte, den Itabapuana, Ilhéos und andere Flüsse beschifft, ohne durch die sonderbare Erscheinung sol. cher Gesellschaften von Fischottern unterhalten zu werden. Sie haben die Manieren unserer europäischen, geben aber gewöhnlich sehr sonderbare Töne von sich, welche durch ihre gemeiniglich vereinte Anzahl verstärkt und vermehrt werden. - Wo eine solche Bande ankömmt, da hört man schon von ferne laute pfeifende und andere katzenartige Tüne von heftigem Schnauben und Schnarchen begleitet; das Wasser ist in Bewegung, und die äufserst gewandt schwimmenden Thiere kommen öfters mit dem Kopfe, ja mit dem halben Leibe über das Wasser empor, einen Fisch in dem Rachen, als wollten sie ihre Beute zeigen. - So steigen sie, gesellschaftlich firchend, gegen den Strom hinauf, oder lassen sich von dem Wasser gemächlich hinabtreiben. Um die ihnen begegnenden Canoes tauchen sie gaukelnd umher, obschon man sie gewöhnlich mit der Flinte begrülst.

Nahrung und übrige Lebensart scheint mit der der europäischen übereinzustimmen, doch kann ich über ihre Fortpflanzung nichts binzu- 
fügen. - Sie verzehren eine grofse Menge von Fischen, wahrscheinlich meistens am Ufer oder auf einem Steine oder Felsstücke im Flus. se. Besonders am Flusse Belmonte habe ich häufig die Ueberreste ihrer Mahlzeiten auf den Felsblöcken oder den Sandbänken gefunden, sie bestanden in Schuppen, Gräten und dem Panzer oder der Knorpelschaale eines gewissen gefleckten Fisches, welchen man hier Roncador nennt. - Die Fischottern wandern auch über Land von einem Flusse zu dem andern, und fangen sich dann zuweilen in den Schlagfallen oder Mundeos. - Im Februar und März fand ich sie sehr fett. - Da die Lontra ein schönes Fell hat, so würde man es bei uns gleich dem europäischen schätzen, allein bisjetzt bezahlt man dasselbe in der von mir bereis'ten Gegend schlecht, in der Nähe groIser Städte, oder in sehr̉ bewohnten Gegenden ist diefs indessen schon anders. Koster erzählt, dafs man in der Gegend voñ Pernambuco ein Fischotterfell höher schätze, alș ein Unzenfell. - Diese Fischottern werden weit grö Iser als ihre europäischen Verwandten, besonders in den von Menschen wenig beunruhigten Flüssen. Im Rio S. Francisco, wo man sie Ariranha (Arirannia) nennt, sollen sie 
eine colossale GröIse erreichen. In jenen wenig beunruhigten Flüssen ist es höchst leicht, ein solches Thier zu erlegen, sie gaukelten ohne Scheu so nahe um unsere Canoes heruım, dafs es unmöglich gewesen seyn würde, sie zu fehlen; allein sobald sie den tödtlichen Schufs erhielten, tauchten sie unter, und wir bekamen sie nicht mehr zu Gesicht. Daher lam es, dafs ich der vielen nach diesen Thieren gethanen Schüsse ungeachtet, dennoch nur drei männliche, aber kein weibliches Individuum zu untersuchen Gelegenheit fand. - Da wo der alles beunruhigende Europäer seine Herrschaft schon ausgebreitet hat, würde es so schwer werden wie bei uns, wenn man diese Thiere ïberlisten wollte*). Manche ande. re Nachrichten, besonders die Beschreibung der weiblichen Lontra giebt Azara, auf dessen Werk ich verweise. - Marcgrave beschreibt unter der Benennung Jija oder Carigueibeiu ein Thier, welches, nach ihm, die brasilianischen

*) Jung gezïlımt werden diese Fischottern sehr zahm, an der europäischen Art kann man sich überzeugen, wie selır Zähmung das Naturell wilder Thiere umwandeIt; dem man liest u, a, in v. Wildungen's WVerken (Feierabende, B. VI. 1821) von einem solchen Thiere, ivelches die Fischnahrung verabschenete, und olne die grö「ste Strenge nicht in das Wasser zu bringen war, 


\section{$-329$}

Portugiesen Lontra nennen, das also unbeziveifelt unsere Fischotter seyn soll, es passen jedoch nicht alle seine Worte auf dieselbe, und wahrscheinlich ist eine Verwechselung mit der Hyrare (Mustela barbara) vorgegangen. Laborde und Sonnini reden von verschiedenen Farbenvarietäten der guianischen Fischotter, mir ist in Brasilien nichts ähnliches vorgekommen, vielleicht haben jene Schriftsteller den Coypu und andere dort lebende Wasserthiere für Fischottern gehalten. Nach einigen sollen die Thiere des Katzengeschlechts, der Yaguar und der Cuguar (Susuaranna) den brasilianischen Fischottern nachstellen, allein ich kann nicht glauben, dafs dieses im Wasser lebende Thier von jenen grofsen Katzen leicht überrascht werden könnte. - Desmarest vermuthet, dals bei jungen Thieren dieser Otter die untere Seite des Halses weilslich und mit der I ückenfarbe gefleckt sey, während alte Thiere diesen Theil ungefleckt weifslich zeigten; allein ich kann versichern, dafs dieses kein Kennzeichen der Jugend ist, sondern dafs diese weifsliche Kehle bald mehr bald weniger gefleckt ist, gerade wie an unserem europäischen Steinmarder (Mustela Foina, Linn.). 


\section{- 330 \\ F a m. 3. S a n g u in a ria. R a u b h i e r e.}

Illiger hat in dieser Familie die Geschlechter der blutdürstigsten Raubthiere vereint, welche zwar alle Zonen unserer Erde bewohnen, dennoch aber in den heifsen Erdgür. teln zu der gefährlichsten Gröfse und Kühn. heit heranwachsen und die furchtbarsten Wesen der belebten Schöpfung sind. - Sie zeichnen sich sämmtlich durch ein starkes Fleischgebifs aus, gehen auf den Zehen und rauben lebende Thiere, auf deren Blut sie vorzüglich gierig sind. Die heifsen Länder besizzen viele Arten von ihnen, und unter diesen sind dort die Katzen besonders zahlreich, welche sich durch die Schönheit ihres Felles auszeichnen. Die alte Welt besitzt mehrere Thiere dieser Familie als die neue, und selbst meh. rere Geschlechter von Raubthieren hat sie vor derselben voraus. -

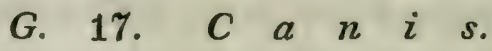

$$
\begin{aligned}
& \mathrm{H} u \mathrm{u} \text { d。 }
\end{aligned}
$$

Bekanntlich ist das Hundegeschlecht über alle Weltheile unserer Erde verbreitet und 
zeugt unter allen Thieren von der grölsten Ge. schmeidigkeit des Naturells. Man findet Hunde in dem kalten Norden und zwischen den Wendekreisen, auch sind selbst die wilden Arten dieses Geschlechts sehr weit verbreitet. Der Haushund, dieser nützliche Begleiter des Menschen, übertrifft in dieser Hinsicht alle seine Geschlechtsverwandten, er verlälst uns nirgends und dauert in allen Climaten aus, welche sein Gebieter bisjetzt erreicht hat. In der neuen Welt scheinen die Hunde durch die Europäer eingeführt worden zu seyn ${ }^{*}$ ); denn der gröfsere Theil der wilden Völker im Inneren besitzt dieses nützliche Hausthier noch nicht. Dennoch ist der Hund schon aufserordentlich weit verbreitet, selbst unter den Urbewohnern von Süd-America, und schnell dehnt sich seine Verbreitung weiter aus. Die Indianer erkennen den Nutzen, welchen sie für ihre Hauptbeschäftigung, die Jagd, von diesen

*) Die Raçen der Hunde sirid mancherlei. Der bellende Hund scheint doch wohl aus Europa nach America gebracht zu seyn, es giebt jedoch im Norden dieses Continents Hunde, welche blols heulen und nicht bellen, diese könnten wohl vielleicht von Wölfen abstammen und alsdann einheimisch seyn. - Siehe über diesen Gegenstand v. Humboldt Voyage au Nouveau Continent, T. II. p. 624. und Tableaux de la nature, Tom. I, p. 117 bis 124. 
Thieren haben können und pflegen sie defshalb selbst zuweilen den Europäern zu entwenden. - Es giebt einzelne Völker im In. neren, welche schon viele Hunde besitzen, und Herr v. Sack scheint dasselbe für Guiana zu bəstätigen, indem er in seiner Reisebeschreibung sagt (2ter Theil p. 109), die Buschneger tauschten ihre Hunde von den Acuri-Indianern ein. -

Diese Thiere gedeihen vortrefflich in jenen heifsen Ländern, und es ist garz ungegründet, wenn man sagt, sie verlören dort die Stimme; dagegen bestätiget man in Brasilien die Aussage des Stedmann und Anderer, dals die Hundswuth oder Wasserscheu daselbst höchstselten oder nie vorkomme, eine Krankheit, welche in den heifsen Ländern der alten Welt nicht selten ist.

Wenn auch die Natur der Hundearten im Allgemeinen durch den Einflufs der Climate nicht verändert wird, so ist es doch nicht zu läugnen, dafs die äufsere Bedeckung oder das Haar derselben durch die Einwirkung des Clima's abgeändert werde. - In kalten Ländern finden wir an den genannten Thieren einen sehr feinen, dichten und zarten Pelz, in den heifsen hingegen ist ilır Haar schlicht, hart, 
grob und dünner gestellt, daher für den Menschen von geringem Nutzen.

Verschiedene Reisebeschreiber reden in Süd-America von wilden Hunden, als komme daselbst unsere europäische Hundeart im verwilderten Zustande vor, allein hievon ist mir kein Beweis bekannt und diese wilden Hunde sind gewils immer andere Thiere aus diesem Geschlechte, deren man überall findet. - Der Hund verwildert übrigens leicht, wovon wir in Europa in allen Ländern einzelne Beispiele aufweisen können. Henderson in seiner Geschichte von Brasilien redet (pag. 315) von wilden Hunden bei llhéos, und $J$. Luccock will Schaaren wilder Hunde in Brasilien gesehen haben. Erstere Nachricht ist ungegründet und die letztere scheint genauerer Untersuchung zu bedürfen.

Süd-America scheint aus dem Hundegeschlechte ursprünglich nur wenige Arten $\mathrm{zu}$ besitzen; denn ich bin überzeugt, dafs in Brasilien und Paraguay nur die beiden von $A z a$ ra erwähnten Arten, der Aguaraguazu und der Aguarachay, vorkommen; der Culpaeus des Molina ist zu unbestimmt beschrieben, um entscheiden zu können, ob er der Aguarachay des Azara oder Canis antarcticus ist. - Dals 


\section{$-334-$}

der Chien Crabier des Buffon nichts anderes ist, als der Aguarachay, scheint mir wahrscheinlich, da die hundeartigen Thiere in America wie in Europa in der Hauptsache einander sehr ähnlich sind und in der Farbe etwas variiren. - Ich werde nun einige Zusätze $z u$ Azara's Beschreibungen hinzufügen.

$$
\text { 1. C. c a mpestris. }
$$

Der Guará, oder rothe americanische Wolf.

Aguara-guazú, Azara Essais etc. T. I. p. 30\%. Canis iubatus, Desm.

Guará in Minas und im Sertong von Bahia, auch $L o^{\circ}$ bo (Wolf) in Brasilien genannt. Aguarí Dobrizhofer, B. I. p. 404.

Man hat in der französischen Uebersez. zung von Azara's Werk über die Säugthiere von Paraguay den Aguara-guazú für eine Bärenart ausgegeben, welches er durchaus nicht ist. Dobrizhofer gab uns zuerst unter der Benennung des Aguará, oder wie die Spanier ihn nennen, des Zorro grande (des grofsen Fuchses), Nachricht von dem rothen Wolfe des inneren Süd-America, bis ihn Azara genauer beschrieb. Marcgrave erwähnt seiner nicht. Herr Professor Lichtenstein hat seitdem in der Menzel'schen Sammlung Gemälde von die. 


\section{$-335-$}

sem und dem nachfolgenden Thiere aufgefunden, welche er vollkommen zu Azara's Beschreibung passend fand, die wir aber bisjetzt noch nicht kennen. -

Der rothe Wolf oder Guará ist nicht blofs in Paraguay einheimisch, sondern in dem ganzen mehr waldlosen Theile von Brasilien, wo er im Allgemeinen von den Portugiesen Lobo (Wolf), in anderen Gegenden, z. B. in Minas, Guará genannt wird. Es ist gewifs, dafs dieser grolse rothe wilde Hund nicht die Waldungen, sondern mehr die offenen, mit einzelnen Gebüschen und Gesträuchen bewachsenen Heiden bewohnt, also nicht blofs Brücher und Sümpfe; denn in der von mir besuchten Gegend giebt es dergleichen wenig. Ich denke daher, dals man ihn von diesem Aufenthalte in offenen Gegenden (den Campos der Portugiesen) Canis campestris nennen könnte, zumal da diese Benennung ihn von den meisten anderen Hundearten unterscheiden würde -

Dafs dieses Thier unserem Wolfe an Grö. fse nichts nachgiebt, beweist eine in meiner zoologischen Sammlung sich befindende unvollständige Haut, deren Beschreibung ich hier gehen werde, da ich diese Thierart im frischen vollkommenen Zustande nicht gesehen habe. - 
Lünge der Haut, woran der ganze Kopf fehlt, bis zum Anfange des Schwanzes . . . . 37" 3" Länge des Schwanzes • • . 13"

Das Haar ist wolfsartig, schlicht, lang, an den Schulterblättern über drei Zoll in der Länge haltend; über dem Halse und den Schulterblättern befindet sich eine Art kurzer Mähne ron drei und einen halben Zoll langen Haaren. Die ganze Haut ist von einem sehr schönen, lebhaften Rothbraun, in den Seiten ein wenig blässer, über den ganzen Rücken hinab dunkel rothbraun, oben auf dem Halse aber bis über die Schulterblätter hinaus ist die Mähne schwarzbraun. - Der Schwanz ist rothbraun wie der Körper, aber seine Spitze fahl gelblich. - Die Vorderbeine fehlten; die Hinterbeine haben längs der vorderen Kante des Schenkels hinab einen schwarzbraunen Streif, und von der Ferse abwärts sind sie gänzlich schwarzbraun.

Der Guará lebt in den grofsen Campos geraës des inneren Brasiliens, am Tage in den einzeln zerstreuten Gesträuchen auf den offenen trockenen Heiden sich verbergend und in der Nacht nach Nahrung umher trabend, wo man alsdann seine laute, weitschallende Stim- 
me hört. In unbewohnten Gegenden geht er auch am Tage umher. - Nach der Versiche. rung der Pflanzer und Hirten (Vagueiros oder Campistas) ist er dem Rindviehe und den Schaafen nicht gefährlich, sondern lebt blofs von kleinerem Raube. Azara sagt, er nähre sich blofs von Krabben, Krebsen und Mollusken, die er aber wohl im Campo geral nicht häufig finden dürfte. - Er ist feige und furchtsam, steht sogleich von Ferne stille, sobald er etwas Fremdartiges bemerkt; geht man auf ihn $\mathrm{zu}$, so entflieht er sogleich sehr schnell. - Aus dem grofsen schön brandro. then Felle macht man Satteldecken. -

Dobrizhofer nennt diesen rothen Wolf den Wasserhund und sagt, er halte sich in Seen und Flüssen auf; in den ebenen niede. ren Gegenden von Paraguay mag er allerdings die Ufer der Flüsse und die Sümpfe nach Krabben und Sumpfthieren durchsuchen und da. selbst seinen Aufenthalt nehmen, jedoch das Local muls hier eine Verschiedenheit verursachen. - Der Name Canis brachyurus scheint für dieses Thier nicht passend; denn sein Schwanz ist nicht viel kürzer als der des Wolfs; zweckmäfsiger dürfte demnach der Name $\mathrm{Ca}$ tnis jubatus seyn, welchen Desmarest ihm bei-

II. Band. 
legt, der sich indessen wieder darin irrt, dals er die schwarze Mähne über den ganzen Rükken des Thiers ausdehnt, da sie in der Natur nur auf dem Halse und über den Schulterblättern vorkommt. -

$$
\text { 2. C. } A z a r a e \text {. }
$$
Der brasilianische $F$ uchs.

F.: Körper fahl graugelblich, Rüiclien und obere Theile schwärzlich; ein schwärzlicher Streif an der Vorderseite des Vorderbeins; Spitze der Lippen weifs; Unterkiefer schwärzlich graubraun; untere Theile weifslich; Schwanz am Ende schwarz. -

Agouarachay, Azara essais etc. Vol. I. p. \$17.

Schinz Thierreich u. s. w. B. I. pag. 220.

Abbildungen zur Naturgeschichte Brasilien's.

Cachorro do mato, zuwenlen auch Raposa, im östlichen Brasilien.

Azara hat diesen Fuchs sehr gut beschrieben, ich will indessen hier folgen lassen, was ich davon in Brasilien Leobachtet habe. -

Dieses Thier hat in der Hauptsache die Bildung unseres Fuchses, wenn man davon die kürzere Behaarung des Schwanzes ausnimmt, auch findet man bei Durchlesung der Beschreibung jenes Schriftstellers, dafs beide Thiere in ihrer Lebensart rollkommen übereinstimmen. 
Das in meiner zoologischen Sammlung sich befindende Exemplar hat folgende Hauptzüge: An den Vorderfüfsen befinden sich fünf, an den hinteren vier stark behaarte Zehen; die Nägel der Vorderzehen sind weilslich und in den Haaren etwas verborgen, wovon der längste drei Linien mifst; die der Hinterzehen sind länger, sie messen beinahe fünf Linien, sind bräunlich von Farbe urd mehr entblöfst. Körperhaar ziemlich dicht und etwas wollicht; betrachtet man die einzelnen Haare, so sind sie an der Spitze schwarzbraun, darunter befindet sich eine weilse Binde, alsdann folgt wieder Schwarzbraun und der übrige Wurzeltheil ist graugelblich. - Diese bunte Zeichnung der Haare giebt im Allgemeinen dem Thiere eine fahl graugelbliche, weilsliche und schwärzliche Mischung; der Rücken und die oberen Theile fallen mehr in's Schwärzliche; an den Schenkeln und Vorderblättern herrscht die graue Farbe etwas vor, an den Seiten des Halses und den äufseren Beinen die fahlgelbliche oder blafs röthlich - gelbe; ein mehr schwärzlich gemischter Streif läuft auf der Vorderseite des Vorderbeins bis zu dem Fulswurzelgelenke hinab; innere Seite der Vorderbeine blafs gelblich; innere Seite der Hinterschenlsel etwas blässer; 


\section{$\rightarrow 340$}

Stirn und Oberkopf gelblich-braun und weilslich gemisclıt; Nase von den Augen vorwärts gelblich graubraun; Gegend unter den Augen mit schwärzlichen Haaren gemischt; Spitze beider Lippen weils; Unterkiefer schwärzlichgraubraun; Kehle, Unterhals, Brust und ganze Vorderseite der Hinterbeine weils, welches an der letzteren Stelle gegen die äufsere Schenkelfarbe nett absticht; äufseres Ohr gelblichgraubraun; der Schwanz ist länger behaart als der Körper, erscheint aber dünner als an unserem europäischen Fuchse im Sommer, er ist graugelblich mit dunkleren Haarspitzen, das Ende oder die Spitze aber ist gänzlich schwarzbraun mit einigen langen weifsen Haaren gemischt.

\section{Ausmessung:}

Ganze Länge - - : 34" 6"'.

Länge des Körpers: • • • 21"

Länge des Schwanzes • • 13" $3^{\prime \prime \prime}$.

Höhe des Ghrs über dem Kopfe an

der dem Scheitel zugewandten

Seite

Länge von der Nasenspitze bis zu

dem vorderen Ohrrande : . 4" 6"'.

Länge des längsten Vordernagels . . $3^{\prime \prime \prime}$. 


\section{$-341-$}

Länge des långsten Hinternagels beinahe . . . . . $5^{\prime \prime \prime}$.

Dieser Fuchs ist yon Azara in Paraguay beobachtet und lebt über ganz Brasilien verbreitet, ja es scheint selbst, dafs Buffon's Chien Crabier *) hierher gehört? Demnach wäre der brasilianische Fuchs weit verbreitet und wahrscheinlich in seiner Färbung manchen Abänderungen unterworfen. Betrachtet man die Behaarung genau, so bemerkt man selbst einige Aehnlichkeit in der Vertheilung der Farben mit dem dreifarbigen Fuchs von Pennsyl vanien (Canis cinereo-argenteus), ob ich gleich nicht hinlänglich über die Verwandtschaft beider Thiere urtheilen kann, da ich nicht im Stande bin, sie in der übrigen Bildung ihres Körpers genau zu vergleichen. - Der brasilianische Fuchs erscheint in allen seinen Farben, im Vergleich mit dem pennsylvanischen sehr blafs, und gleichsam wie abgeblichen, man wird ihn daher immer als eine besondere Species aufstellen müssen, wenn er auch nur eine durch das Clima erzeugte Abart seyn sollte; neueren Vergleichungen zufolge, sol-

*) Dictionn, des sc. natur. T. VIII. d. 558. 
len indesten beide Thiere wirklich specifisch verschieden seyn. -

In seiner Lebensart hat der brasilianische Fuchs die gröfste Aehrílichkeit mit dem europäischen. Er hält sich in Wäldern und offenen Gegeuden auf, trabt überall umher, verbirgt sich am Tage meist in Erdhöhlen und entflieht sehr schnell, sobald er einen Menschen erblickt. Den menschlichen Wohnungen nähert er sich bei Nacht, raubt Hühner und anderes ficdervieh, so wie alle kleinere lebende Thiere, auch soll er in der Nähe des Meeres die Flufsufer besuchen, um bei der Ebbe in den sie einfassenden Mangue-Gebüschen Krabben und ähnliche zurückbleibende Thiere aufzulesen. - Selbst todte Thiere dienen ihm zur Nahrung, wie unserem europäischen Fuchse. - Seine Jungen soll er in Erdhöhlen werfen. - Er ist listig und wittert scharf wie unser Fuchs, läfst sịch zähmen wie dieser, hat aber übrigens keinen Nutzen, da man den Balg nicht benutzt. Er wird auch defshalb nicht anders verfolgt, als wenn er Federvieh geraubt hat, oder wenn man ihn zufällig antrifft. In manchen Gegenden, besonders der Seeküste näher, nannte man dieses Thier $\mathrm{C} a$ chorro do mata (Waldhund), im Sertong von 
Bahía hingegen Raposa. Herr Professor Lichtenstein hält den Aguarachay, der Menzclschen Abbildung zufolge, für eine von dem cinereo-argenteus verschiedene Species, welches auch anzunehmen ist, obgleich eine Aehr. lichkeit in der Vertheilung der Farben wohl nicht gelüugnet werden kann. Desmarest in seiner neuen Mammalogie (Paris 1820. pag. 204) hat ihn mit dem dreifarbigen Fuchs von Pennsylvanien (Canis cinereo-argenteus) vereinigt. - -

$$
\text { Gen. 18. F e l is. }
$$

$$
\mathrm{K} \text { a } \mathrm{t} \text { z } \text { e. }
$$

Dieses von der Natur so characteristisch unterschiedene Geschlecht ist über die meisten Welttheile verbreitet, und zeigt überall seine Hauptbildung, den geschmeidigen starken Körper, kleinen runden Kopi, furchtbares Gebils, meist langen Schwanz, gefährliche in besondere Scheiden zurückziehbare Klauen, eine sanfte, weiche, oft auf das regelmälsigste abwechselnde schön gezeichnete Behaarung, dabei ein blutdürstiges, listiges Naturell.

Diese Thiere erlangen in den warmen Ländern unserer Erde ihre höchsie Vollkommenheit. Dort findet man die gröfste Man- 
nichfaltigkeit ihrer Arten, und sie erreichen daselbst eine furchtbare Stärke und Gröfse, welche Mensch und Thier in Schrecken sfizt. - Was der Löwe und der Tiger für die hoifien Theile der alten Welt sind, das ersetzt für die neue der Yaguar, jedoch vielleicht in einem etwas geringeren Grade. Aber in allen diesen Ländern, Atistralien ausgenommen, findet man eine Menge verschiedener Katzenarten, deren Zahl durch die Reisen der Natur. forscher noch vermehrt werden wird. - Ame. rica, besonders der südliche Theil, in dessen warmem Clima sie recht zu gedeihen scheinen, ernährt viele dieser Thiere, welche der Schrekken der kleinen und gröfseren Waldbewohner sind. Azara fand in Paraguay sechs Katzenarten, mein Verzeichnifs erwähnt deren für einen Theil von Brasilien sechs oder sieben, wo. von aber die meisten auch von jenem Schriftsteller gefunden wurden,

$$
\text { 1. F. O } n c a \text {, Linn. }
$$

Die gefleckte Katze, Yaguar:

Jaguara, Marcgr. p. 235.

Yaguarété, Azara cssais etc. T. I. p. 114.

Onça pintada der Jrasilianischen Portugiesen,

Cuparack-gipaliu bei den Botocuden.

Jo bei deu Malalis. 
Cumang bei den Maconis.

Jaké-déré bei den Camacans.

Die grofse Katze dieser Beschreibung ist sehr bekannt, häufig erwähnt, und dennoch erst jetzt in dem Werke der Herren Geoffroy und Fr. Cuvier richtig und treu nach dem Leben abgebildet worden. Da ich keines dieser Thiere im frischen vollkommenen Zustande während der Dauer meiner Reise habe erhalten können, so kann ich keine genaue Beschreibung davon geben, werde indessen einige Bemerkungen über ein in den Wäldern des Flusses Belmonte kurz vor meiner Ankunft daselbst erlegtes Thier dieser Art mittheilen, des. sen Haut ich besitze. -

Was die Färbung anbetrifft, so kommt diese mit der von Azara beschriebenen Haut in den Hauptzügen überein, Die Anzahl der Ringflecken, welche auf dem Queerdurchschnitte der Seite des Thiers gezählt werden, ist etwa die von Cuvier angegebene, also vier bis fünf, und es gehört daher dieses Thier zu der Varietät mit grofsen sparsamen Flecken. Dafs es in Ansehung der Anzahl und Grölse der Flecken auch bei der brasilianischen Unze Varietäten giebt, davon habe ich mich durch den Augenschein überzeugt. - Das vorhin 
erwähnte Fell ist männlichen Geschlechts und gehört, wie gesagt, zu der groísgefleckten $\mathrm{Ab}$. art, ein etwas dichter gellecktes weibliches besitze ich ebenfalls, welches in dem Queerdurchschnitte der Seite fünf Flecken zählt, und eine etwas dunklere Grundfarbe hat. Im Sertong von Bahia, zu Varcda, in den ausge. delunten Viehtriften zeigte man uns ein Fell, welches viel mehrere und kleinere Flecke hatte, dabei dickeren Kopf und stärkere Glieder besessen haben sollte und ebenfalls von einem männlichen Thiere herstammte, leider hat es mir nicht geglückt, beide Thiere im vollkommenen Zustande vergleichen zu können.

Im Sertong nannte man die kleiner gefleckte Art Cangussú, in anderen trägt die gröfser gefleckte diesen Namen. - Es ist höchst wahrscheinlich, dal's diese kleinen Verschiedenheiten nur Varietäten ein und derselben Thierart sind, ja es wird jetzt selbst wahrscheinlich, dafs der schwarze Tiger auch nur ein und dieselbe Species mit der gefleckten Unze ausmacht, wofür auch die Brasilianer stimmen. Ihrer Aussage zufolge begatten sich alle diese Varietäten mit einander, und bringen auf diese Art mancherlei Abänderungen in der Zeich. numic hervor. - dzara redet ebenfalls von 
mehreren Abarten der Unze oder des Yagua. rété, wovon er die eine Yaguarété-Popé nennt, ein Beweis, da「s überall Abänderungen unter diesen, wie unter den meisten Raubthieren vorzukommen pflegen,

Schon in der ersten zarten Jugend zeichnet sich der Yaguar von anderen ähnlichen gefleckten Katzen, aus; von dem Mbaracayá z. B. dadurch, dafs er auf dem Halse mit Flekken, jener mit Längsstreifen bezeichnet ist; von den Katzen der alten WeIt hat uns $\mathrm{Cu}$ vier ịn hinlänglich unterscheiden gelehrt.

Die beste Beschreibung des Yaguar nach dem Leben, von schönen Abbildungen begleitet, besitzen wir nun in der Naturgeschichte der Säugthiere, welche die Herren Geoffroy und $\mathrm{Fr}$, Cuvier herausgeben, dorthin verweise ich meine Leser und bemerke nur, dafs die Gestalt des Yaguar im Allgemeinen die der grofsen gefleckten Katzen der alten Welt ist; die Nase ist etwas gewölbt, die Glieder sind stark, die Klauen hakenförmig, zusammengedrückt und grünlich-weịs von Farbe, wie bei dem indischen Tiger, - v. Humboldt redet ${ }^{*}$ ) von wei[sen Spielarten des Yaguar, wo-

*) Voyage au nouveau cont, T, II, p. 166. 
rou ict indessen in den von mir bereisten Gestnden von Brasilien keine Nachricht erhalten habe.

Ueber die Gröfse dieser Thiere hat man verschicden geurtheilt, weils aber nun recht wohl, dals sie den gröfsten Tigern und Löwen der alten Welt in dieser Hinsicht nicht viel nachgeben. - v. Humbôldt giebt uns interessante Nachrichten über die Grölse, die Menge und die Raubgier der Yaguare an den Ufern des Orenoco, des Apure, Sarare u. s.w. *).

Eine Yaguarhaut, welche ich besitze, die aber nicht zu den grofsen gehört, hat etwa folgende Ausmessung:

Länge von der Nasenspitze bis zu der

\section{Schwanzwurzel}

Länge des Schwanzes

Länge von der Nase bis an den vor-

deren Ohrrand etwa

Der Aufenthalt dieser Raubthierart ist über ganz Süd-America ausgedehnt; denn sie wird in Guiana gefunden und geht ziemlich weit südlich bis unter Paraguay**) hinab, für Chili führt sie Molina hingegen nicht auf. - In

*) Voyrge au nouveau cont. T. II. p. 216, 584 u. a, a. O.

**) Ueber diesen Gegenstand siehe Azara essais ctc. 
Brasilien findet man sie überall da, wo der Mensch die Waldungen und Wildnisse noch nicht gelichtet oder ausgerottet hat, also bei weitem in dem gröfsesten Theile. - Zuverlässige Männer haben mir versichert, dafs sie zu der Zeit der Gründung ihrer Niederlassungen oder Pflanzungen mit ihren Jagdhunden zwanzig bis vier und zwanzig solcher Thiere in einem Monate aufgefunden und erlegt haben; bald aber nahm die Zahl ab und man konnte daran denken, die jetzt in jenen Gegenden so blühende Rindviehzucht einzuführen.

Azara hat im Allgemeinen die Lebensart und die Manieren des Yaguar recht gut beschrieben. In den von mir bereisten Gegenden, wo diese Thiere ebenfalls nicht selten sind, hat man indessen nur selten Beispiele, dafs sie Menschen angefallen haben, doch bewahrt man in allen Gegenden das. Andenken an einzelne solcher Fälle auf. - Da wo man zur Jagd dieser Thiere gut abgerichtete Hunde besitzt, wie in den bewohnten Gegenden von Brasilien, läfst man sie gewöhnlich nicht so alt und grols werden, um dem Menschen gefährlich zu seyn; in unbewohnten Gegenden hingegen, wie an den Ufern des Orenoco, 
fürchtet man sich mehr vor ihnen, aurh scheint man dort ihre Jagd nicht so gut zu verstehen, wie in Brasilien. - Die Haupt. räubereien dieser grolsen Katzen sind gegen die Hirsche, Rehe, Cavien, Capybaras, wilden Schweine und dergleichen Thiere gerichtet, sie sollen aber nur werige lebende Thiere verschmähen, da sie selbst die Waldschildkröte Jabutí ( Testudo tabulata) verzehren, deren rein ausgeleerte Panzer wir häufig in den grofsen Wäldern gefunden haben, wenigstens behaupten die brasilianischen Jäger, es sey die Unze (Onça), welche diese Panzer ausleere. Oefters waren diese Schalen der Schildkröten rein ausgeleert, wahrscheinlich mit den Klauen, und dabei übrigens nicht beschädiget, öfters aber war ein Theil des Panzers weggebissen. Seitdem man im Lande Rindvieh erzieht, stellen sie vor allen anderen Thieren diesen besonders nach. - Wittert das Rindvieh im Sertong den Yaguar bei Nacht, so rottet es sich zusammen, die Stiere traben umher und brüllen unaufhörlich. Die Unze greift einen vorbereiteten Stier nicht leicht an, dagegen Och. sen, Kühe, Kälber, Pferde, Maulthiere und Schaafe desto eher. - Fängt siè ein Kalb, so hat man oft die Mutter gegen den Räuber an- 
rennen gesehen. - Fin Stück Vieh soll sie tödten, indem sie ihm auf den Rücken springt, mit der Tatze die Nase ergreift, den Kopf rückwärts zieht und auf diese Art das Genicke bricht, welches aber allerdings nur eine Fabel ist; alsdann fafst sie, wenn sie stark ist, das getödtete Thier mit dem Gebisse und zieht es gravitätisch an eine sichere Stelle. - Hat die Unze einen solchen Raub vollbracht, welches bei Nacht geschieht, so saugt sie demselben das Blut warm aus, frifst gewöhnlich sogleich etwas von der fetten, weichen Halshaut und der Brust, verscharrt den Rest und ruhet nun nicht gar weit von demselben entfernt in einer verworrenen, mit Dornen, Bromelien und ähnlichen undurchdringlichen Gewächsen angefüllten Wildnifs aus, um in der folgenden Nacht noch einmal zu dem Raube zurückzukehren. - Am gefährlichsten ist die Unze, wenn sie Junge hat. - In dieser Periode hat man öfters das Junge gefangen oder geschossen und alsdann gehört, wie die Mutter unter heftigem Brüllen in der ganzen Gegend umherirrte und über den Verlust ihrer Nachkommenschaft untröstlich war. - Zu Trancozo stellte man in einem solchen Falle der Mutter Selbstschüsse und erlegte sie ebenfalls bald. - 


\section{$-352-$}

Um den Yaguar zu jagen, sucht man ihn gewöhnlich sogुleich am folgenden Morgen, nachdem er einen Raub begangen hat. - Finden die Hunde die frisclie Spur, so erreichen sie atich bald den Schlupfwinkel und der Räuber ist gewöhnlich verloren. - Sie verbellen ihn, klug seinen gefährlichen Klauen ausweichend, und geben den Jägern Zeit herbei zu schleichen. - Junge oder noch nicht selır alte erfahrene Thiere pflegen gewöhnlich ei. nen schief geneigten Baumstamm zu erklettern und von dort herab geschossen zu werden, ältere recht grofse Thiere aber bleiben häufig an dem Boden stehen und warten gelassen alle Angriffe ab, - Gervöhnlich unterstützen mehrere Jäger einander, damit sie im Nothfalle im. mer einen Rückhalt haben. - Bei dieser Art der Unzenjagd ist immer eine gewisse Vorsicht nöthig; denn im Falle des Anschiefsens oder Verwundens hat man oft Beispiele gehabt, dafs der Jäger kläglich zugerichtet wurde. Erfal1rene brasilianische Jäger haben mir versichelt, dafs sie einen nicht besonders grofsen Yaguar, während er von rorn durch die Hunde beschäfiget wurde, mit einem, an einer Stange befestigten Messer ron hinten getödtet haben, als er auf einem schief geneigten Laumstam- 


\section{- 353}

me stand. - Einen heftigen Kampf mit einem colossalen Thiere dieser Art habe ich in dem 2ten Theile der Beschreibung meiner Reise nach Brasilien erzählt. $v$. Humboldt sagt uns *), dals die Indianer am Apure und Orenoco sie mit ihren Lanzen tödten. - Häufig bringen die Brasilianer auf den Pfädchen (Wechseln in der deutschen Jägersprache) der Yaguare oder Unzen in der Gegend, wo sie einen Raub vollführt haben, Selbstschüsse an, auch Schlingen, und tödten sie auf diese Art, auch in Fallgruben (Fojos) fängt man sie öfters, zuweilen Mutter und Junges zugleich. Man bringt unten in àer Mitte der Grube einen zugespitzten Pfahl an. - Solche Fanganstalten wissen die Indier vortrefflich zuzurichten, sobald sie nur den wahren Aufenthalt des Raubthiers ausgeforscht haben, der sich durch die häufige Spur verräth, auch kratzt die Unze an der Rinde starker Waldbäume, um, wie die Indier behaupten, ihre Waffen zu schärfen. Henderson sagt in seiner Geschichte von Brasilien (pag. 301), die Unze fliehe die Kälte der westlichen Gegenden und suche die Nähe der See, wo es wärmer sey, sie raube rom April

*) Voyage au nouveau continent etc, T. II. p. 216.

II. Band. 


\section{$-\quad 354$}

bis in den August, also in der küllesten Zeit des Jahres, an der Küste, allein ich habe nie von diesen Wanderungen der Unzen oder Yaguare in Brasilien gehöıt, noch eine Bestätigung dafür gefunden. -

Abgesehen von dem Schaden, welchen diese gefährlichen Raubthiere dem Viehstaude zufügen, jagt man sie auch ihres schönen Fel. les wegen, wonach die Brasilianer sehr lüstern sind, und welches man zur Zeit meiner Anwesenheit in Brasilien selten unter einem Carolin verkaufte, in der Nähe grofser Städte aber weit theuerer bezahlte. Die Brasilianer gebrauchen es um Pferdedecken davon zu machen. - Junge Thiere, welche man in den Fallgruben lebend gefangen hat, werden in die Städte verkauft, dort aufgezogen, und gewöhnlich nach Europa gebracht. Die Botocuden, welche den Yaguar Cuparack - gipakiú (die grofse Katze) nenren, essen sein Fleisch.

Der schwarze Yaguar oder der schwarze Tiger. Onça preta oder Tigre.

Jaguarété Marcgr, p. 235 (soll Jaguara heilsen); Yagouarété noir, Azara etc, T. I. p. 116. Tigre oder Onça preta dex Brasiliaǹer.

Cuparack-him bei den Botocuden. Jaké-hyä bei den Camacans. 
Ich habe den schwarzen Yaguar oder den schwarzen Tiger für eine von dem gefleckten verschiedene Species angesehen, da ich selbst nicht Gelegenheit hatte, beide Thiere im frischen vollkommenen Zustande kennen zu lernen; seitdem haben aber die Entdeckungen, welche ein ausgezeichneter Naturforscher und Reisender, Herr Professor Reinwardt in Indien machte, gezeigt, daIs in ein und demselben Wurfe bei Felis Pardus oder Leopardus gefleckte und schwarze Junge (Felis melas) gefunden werden, ich bin daher nun auch der Ansicht der meisten Naturforscher beigetreten, welche schon längst den schwarzen brasilianischen Yaguar für blofse Spielart von dem gefleckten ansahen. - Was mich für den Glauben der Verschiedenheit beider Thiere stimmte, war ein grolses Katzenfell, das ich im Sertong von Bahia sah und welches auf einem sehr dunkelbrauren Grunde, runde, kleine, volle schwarze Flecke trug; man sagte mir, es sey vom Tigre oder der Onça preta und ich vermuthete daher, dals diese Verschiedenheit in der Zeichnung wohl dieser Species eigen. thümlich seyn möchte. - Die gewöhnlichen schwarzen Yaguarfelle zeigen auf glänzend schwarzem Grunde matte nicht glänzende Âu- 
genflecken von derselben Farbe, die in der Anzahl und Gestalt variiren, da ich an einigen Häuten mehrere, an anderen eine geringes $e$ Anzahl von ihnen gezählt habe. Sie bestehen aus kleineren im Kreise gestellten Fleckchen, doch scheint es mir, als wenn die Augenflekken bei diesem schwarzen Yaguar immer kleiner seyen, als an dem gewöhnlichen. - In der Gestalt und Grölse soll der schwarze Yaguar, selbst nach dem Zeugnisse der Brasilianer, mit dem gefleckten übereinkommen. An den Fellen desselben findet man grofse grün. lichweifse Klauen, die starken Bartborsten so wie das ganze Thier sind kohlschwarz*). Lebensart und Manieren sind bei beiden Thieren gänzlich gleich, doch behaupten einige Brasilianer, die schwarze Art sey viel blutgieriger und gefährlicher, welches aber ungegründet ist. - Schon viele Reisende haben von SüdAmerica bezeugt, dals man daselbst unter den Yaguaren schwarze Individuen finde, hiermit stimmt der Glaube der Brasili?ner überein, welche sagen, die verschiedenen Varietäten der Yaguare seyen sämmtlich fruchtbar unter ein-

*) Nie habe ich an diesen Fellen etwas Weifs an den Lippen gesehen, wie u. a, Desmarest in seiner Mammalogie (pag. 220) sagt. 


\section{$-357$}

ander und aus ihrer Vermischung würden mancherlei Abarten erzeugt.

Dals der schivarze Yaguar mit seinem durchaus glänzend kohlschwarzen Felle ein prachtvolles Thier seyn müsse, ist leicht zu begreifen, besonders wenn er eine bedeutende Gröfse erreicht hat. - Seine Augen blitzen wie glühende Kohlen aus dem schwarzen Körper hervor, besonders bei Nacht oder im Dunkel der Gebüsche. Ein Jäger versicherte mir, dafs er einst einem solchen Thiere zufällig so nahe gekommen sey, dals es unmöglich war, auszuweichen. - Der Yaguar lag unter dunkelen Gebüschen und beobachtete, die glühenden Augen unverwandt nach dem Manne hinrichtend, dessen Bewegungen genau. Der Jäger, vom Schrecke beinahe gelähmt, fafste sich, und fuhr anscheinend ruhig in der einmal begonnenen Beschäftigung des Holzlesens fort, entfernte sich aber allmälig, und der Yaguar blieb unbeweglich in seinem Lager. Andere dieser Thiere sollen Menschen angefallen haben, wovon man mir mehrere Beispiele mitgetheilt hat.

Aus allen Nachrichten über diese Thierart scheint mir hervorzugehen, dafs noch Niemand genau die beiden Varietäten oder Abar. 
ten des Yaguars, sowohl nach ihrem äufseren als inneren und besonders osteologischen Baue verglichen hat, defshalb künnen wir hier blofs vermuthen und nicht aburtheilen und wir müssen hoffen, dals uns bald eine gründliche Nachricht über diesen immer noch dunkelen Gegenstand mirgetheilt werden möge. - Die Botocuden nennen den schwarzen Tiger $\mathrm{Cu}$ parack-him, die schwarze Katze, und die Camacans Jaké-hyä, welches in ihrer Sprache dieselbe Bedeutung hat. - Die Felle dieser schwarzen grofsen Katzen werden theurer be. zahIt, als die der gefleckten Unze oder Onça pintada, auch suchen sie selbst die Brasilianer sehr, um Decken für ihre Pferde daraus zu bereiten.

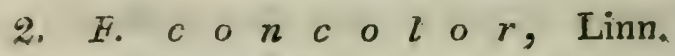

D e r Cuguar.

Çuğuaçuarana, MIarcgr. pag. 235.

Felis concolor et discolor, Schreb. Tab, CIV, und CIV. B.

Gouazouara, Azara T. I. p. 18 .

Onça Çuçuaranna der Brasilianer. Çuçuaranna in der Lingoa Geral. Cuparack - Nimpruck bei den Botocuden. Jaké - Coatá bei den Camacans.

Dieses über den gröfsten Theil von Ame. rica, selbst nürdlich bis Canada, und südlich 
bis Paraguay verbreitete Raubthier ist sehr bekannt, und wird öfters in den europäischen Städten in umberziehenden Menagerien gezeigt. - Obgleich auch diese völlig ungetleckte Art eine bedeutende Grölse erreicht; denn ich habe Felle aus Pennsylvanien gesehen, die denen des gefleckten und schwarzen Yaguar an Grölse wenig nachgaben, so ist sie dennoch weit furchtsamer und wird gar nicht gefürchtet, ja sie soll selbst nur junges Vieh rauben. - Ihr Kopf ist klein, kurz, die Glie. der lang und stark, die Zehen mit gewaltigen blafs grünlich - weifsen Klauen bewaffnet. Die Farbe des Thiers ist ein fahles röıhliches Braun, auf dem Rücken und den oberen Theilen gewöhnlich dunkler, mehr rothbraun; die Schwanzspitze und das äufsere Ohr sind schwarzbraun *). Obgleich ich in Brasilien nicht so glücklich war, ein vollkommenes Individuum $\mathrm{zu}$ erhalten, so haben mir die Felle, welche ich dort in Menge sah, in der Farbe die vollkommenste Uebereinstimmung mit den-

*) Ich habe diese Charactere sowohl an nord-americanischen als an den brasiliauischen Fellen immer übereinstimmend gefunden, dagegen selten das Kennzeichen einer cauda claviformis Leobachtet, und nie in's Aschgraue ziehende Felle gesehen. 


\section{$-360$}

jenigen gezeigt, welche ich aus Nord-America erhielt. -

Man findet die Cuçuaranna in allen grofsen brasilianischen Wäldern, wo sie zuweilen von dem umherschleichenden Jäger selbst von hohen Bäumen herabgeschassen worden ist. In den grofsen Viehständen ist sie besonders den Kälbern und jährigen Rindern gefährlich, auch jagt sie alle Arten des kleineren Wildes, selbst die Rehe. - Hunde treiben dieses Thier sogleîch auf einen Baum, wo ihm der Jäger ohne Gefahr nahen kann. - Man fängt sie auch in Schlagfallen (Mundeos). Ich habe die Spur dieser grofsen Katze überall auf den Sandbänken an den Ufern der Flüsse gefunden, vorzüglich des Belmonte, auch in der einsamen Wildnils zwischen dem Rio Doçe und Mucurí, überhaupt überall, wo der Mensch, seine verheerenden Waffen noch nicht gebraucht. - In allen Gegenden des von mir bereisten Striches von Brasilien habe ich in den Wohnungen der Bewohner Felle von diesem Thiere vorgefunden, welche weit weniger Werth haben, als die der gefleckten und schwarzen Unze; man benutzt sie ebenfalls zu Pferdedecken. - Neger und Indier essen das Fleisch. 
Die Herren Geoffroy und Fr. Cuvier haben das Verdienst, die beste Abbildung dieser Species geliefert zu haben, auch wird in ihrem schönen Werke sehr richtig bemerkt, dafs auf Schreber's Tafel CIV. B, die Farbe richtiger angegeben ist, als auf Tafel CIV. - Marcgrave nennt dieses Thier ruguaçuarana, woraus wahrscheinlich das Wort Cuçuaranna zusammengezogen ist, doch darf man bei allen diesen brasilianischen Benennungen das $c$ nie wie $k$, sondern immer wie das französische $c$ aussprechen. Es irrt aber Marcgrave, wenn er den portugiesischen Namen Tigre der rothen Unze beilegt, da er nur der schwarzen Art zukommt.

\section{F. pardalis, Linn.}

Der Mbaracayá oder Schibiguasu.

Temmink Monogr. de Mammal, pag. 144.

Abbildungen zur Naturgeschichte Brasilien's.

Maraguao sive Maracaid, Marcgr. pag. 233.

Chibiguazú, d'Azara T. I, p. 152.

Maracaya, Mbaracayá oder Gato do mato pintado grande, auch wohl Onça pequena bei den Brasilianern.

Mbaracayá in der Lingoa Geral,

Cuparack-nig-mäck ( $g$ kaum hörbar) bei den Botocuiden.

Kuichhuá bei den Camacans. 
Die schöne Katze von mittlerer Grölse, welche ich in den nachfolgenden Zeilen beschreiben werde, scheint mir identisch mit Felis pardalis, Linn, ob sie gleich eben so viel Aehnlichkeit mit Felis mitis, Cuv. zeigt. Beide Thiere sind sich auf jeden Fall sehr ähnlich, wenn sie nicht sogar zu ein und derselben Species gehören. Unbedingt würde ich meinen Mbaracayá für den wahren Ocelot halten, wenn man nicht für letzteren als Hauptkennzeichen lange Seitenstreifen angäbe, welche von den Schultern bis gegen die Schenkel fortlaufen. So lang ausgedehnt habe ich diese Flecken an vielen Fellen der von mir zu beschreibenden Katze nie gesehen, sie erscheinen hier mehr als verlängerte Flecken und ich war defshalb sogar geneigt, meinen $M b a-$ racayá für Felis mitis zu halten. Seitdem habe ich in einer Menagerie zu London zwei sehr schöne Exemplare meiner hier zu beschreibenden Katze lebend gesehen, und an ih. nen die Seitenflecken sehr lang ausgedehnt ge: funden, ich glaube defshalb, dafs diese Katzen in dieser Hinsicht etwas variiren, und dal's mein Mbaracayá zu Felis pardalis zu zählen ist. Dafs er ebenfalls mit Azara's Chibigua$z u$ identisch ist, glaube ich bestimmt, wenn 
gleich dieser Schriftsteller gänzlich vergafs, die genaue Zeichnung der Kehle und des Unterhalses seiner Katze anzugeben. Der Mbaracayá ist sowohl Felis mitis als Felis pardalis sehr ähnlich, doch weicht er von den Beschreibungen, die man von beiden giebt, etwas ab, Felis mitis möchte ich wohl für ein junges weibliches Thier halten. Die nachfolgende Beschreibung wird den Mbaracayá näher kennen lehren.

Da wir zu Morro d'Arara am Mucurí mehrere dieser Thiere in den Schlagfallen oder Mundeos fiengen, so will ich ein altes männ. liches in der Kürze beschreiben, welches ein wenig kleiner war als dasjenige, dessen sich d'Azara zu seiner Beschreibung bediente.

Die Gröfse dieser Katze ist etwa die eines Luchses; sie ist schlank und ziemlich hoch auf den Beinen, welche letztere sehr stark und muskulös sind. - Der Kopf ist gebildet wie am Panther, die Nase gewölbt; Ohren im Verhältnifs kürzer als an der Hauskatze, dabei mälsig abgerundet; Körper schmal und zusammengedrückt; Beine und Pfoten dick, stark, rund und muskulös; Klauen weifslich, stark gekrümmt, in Scheiden zurückziehbar. Schwanz mälsig dick, nach der Spitze hin et- 


\section{$-364$}

was verdünt, reicht ein paar Zoll über die Ferse hinab, berührt aber die Erde nicht. Geschlechtstheile nahe unter dem After wie an der Katze; die Oeffnung für die Ruthe steht nach hinten dichte unter den Testikeln; die Eichel ist, wenn man sie entblöfst, nach Art aller Katzen mit einer Menge feiner Widerhäkchen oder Stacheln besetzt, welche rück. wäits gekehrt stehen. - Da Azara das Gebifs und die Gestalt des Thiers angegeben hat, so werde ich die Farbe beschreiben, wie ich sie an meinen Exemplaren gefunden.

Die Nase ist bräunlich; die Iris schien bräunlich, doch war ihre Färbung mit Sicher. heit nicht mehr zu bestimmen; äufseres Ohr schwarz mit einem weilslichen Fleck in seiner Mitte nach dem äufseren Rande hin; an seiner inneren Fläche ist es dünne weilslich behaart, am Rande gelblich. - Haar des ganzen Thiers kurz, weich und glatt. Grundfarbe des Kopfs auf der Oberseite, der Ohrgegend, des Halses an den Seiten und aller oberen Theile fahl gelblich-braun, eben so die Schulterblätter; Grundfarbe an den Seiten des Körpers weilslich-grau, an den Hinterschenkeln etwas mehr gelblich; Kinn, Kehile, Brust, innere Seite der Glieder und des Schwanzes, so 
wie dessen Seiten weilslich-grau; Gegend um die Nase, Backen und Einfassung der Augen sind gelblich weils; lange steife, theils weilse, theils schwarze Bartborsten am Oberkiefer, kleinere am Unterkiefer; Augenlieder schwarzbraun; von dem vorderen Winkel des Auges zieht sich nach der Nasenkuppe hinab ein undeutlicher schwarzbrauner Fleck oder Streif von dem hinteren Augenwinkel zieht sich bis unter das Ohr hin ein starker schwarzbrauner Streif, unter diesem steht ein ähnlicher, mit ihm beinahe parallellaufender auf der gelblich - weifsen Backenfarbe; an ihrem hinteren Ende vereinigen sich diese Streifen beinahe, und von diesem Puncte zieht ein groIser schwarzbrauner halbmondförmiger Strich unter der Kehle hindurch, welcher bei einigen Exemplaren mit einem anderen schwarzbraunen Längsstriche in Verbindung steht, der längs der Seite des Halses hinabzieht; unter dem Ende dieses Seitenstreifs zeigt sich bald wieder ein schwarzbrauner langer Querstreif, welcher an dem oberen Rande der Brust quer über die weilse Farbe des Unterhalses hinüber und mit dem Kehlstreif etwa parallel läuft; zwischen beiden, so wie an der Kehle befinden sich noch einige kurze schwarzbraune 
Querstriche und Fleckchen; an der Seite des Halses stehen einige Längsflecke und Streifen, deren Zahl etwas variirt; über dem vorderen Winkel eines jeden Auges entspringt ein schwarzbrauner Streif, der bis in die Gegend über dem Ohre hinauf läuft, hier vereinigen sich beide Streifen durch einige Flecken, der Raum auf der Stirn zwischen ihnen ist mit Fleckchen oder starkenschwarzbraunen Puncten angefüllt; bei jüngeren Thieren ist diese Zeichnung weniger deutlich. - Auf dem Hinterkopfe entspringen fünf schwarze Streifen, welche bis zu den Schulterblättern hinlaufen; die drei mittleren vereinigen sich an ihrem Anfange beinahe; der mittlere ist der feinste und endiget bei vielen Exemplaren, indem er sich in zwoi feine $\mathrm{Li}$. nien theilt; der äufserste dieser fünf Streifen an jeder Seite entspringt ron den drei mittleren Linien getrennt, unmittelbar hinter dem Ohre und senkt sich etwas über die Seite des Halses hinab bis zu dem Schulterblatte hin. Ueber den Rücken hinab ziehen drei bis vier Reihen schwarzbrauner, voller, dicht aneinan. der gereihter, länglicher Flecken, zu deren Seiten alsdann ähnliche, aber irreguläre, bald län. gere, bald mehr runde bräunliche, breit schwarz. braun eingefafste Flecken stehen, deren man 


\section{$-367$}

in der Seite etwa vier irreguläre Reihen zählt; Bauch und Hinterschenkel sind mit runden schwarzen Flecken bezeichnet, an den letzteren sind sie zum Theil hohl, bräunlich mit dunklerer Einfassung; die Schulterblätter sind mit schwarzen Längsstrichen und Flecken marmorirt, die an dem oberen Theile hohl und bräunlich ausgefüllt sind; Schienbeine und Vorderarme sind mit Querreihen runder Flecken und Querstreifen besetzt, welche nach unten immer an Gröfse abnehmen. - Die Pfoten sind fein punctirt; Hinter - Mittelfuls ebenfalls fein schwarz gefleckt und punctirt; innere Seite der Beine mit blässeren schwarzen Querstrichen und Flecken besetzt; Schwanz mit dreizehn bis vierzehn schwarzbraunen Querbinden, die unten offen sind, oder mit Querflecken bezeichnet, welche durch schmälere weifsliche Ringe getrennt werden; die drei letzten Binden an der Schwanzspitze bilden beinahe völlige Ringe; bei dem einen meiner Exemplare ist die äufserste Schwanzspitze schwarz; Unterseite des Schwanzes weifslich mit schwarzen runden Flecken; Testikel weifslich-grau dichte behaart; Sohlen bis zur Ferse schwarzbraun; Ballen bräunlich. 
Es ist zu bemerken, dafs man in der Grundfarbe dieser schünen Katze kleine Abän. derungen findet, indem dieselbe bei einigen mehr gelblich oder röthlich, bei anderen mehr weifslich-grau ist. - Das Münnchen, welches ich beschrieb, war regelmälsiger gezeich. net als andere, doch gleichen sie sich in der Hauptsache mit hellerer mehr weifslicher oder mehr röthlicher Grundfarbe, auch scheinen jüngere Thiere weniger regelmälsig gezeich. net. -

\section{Ausmessung:}

\section{Ganze Länge}

Länge des Körpers

Länge des Schwanzes

Länge des Koples bis zu dem Anfan-

Breite des Kopfes von einem Ohre bis

$\mathrm{zu}$ dem anderen . . $\quad 3^{\prime \prime} 1$ bis $2^{\prime \prime \prime}$.

Höhe des äufseren Ohres . 2 $2^{\prime \prime} 11^{\prime \prime \prime}$.

Länge des Vorderbeins bis zu dem El-

lenbogen * • . . . $10^{\prime \prime} 2^{\prime \prime}$.

Länge des Hinterbeins mit der Krüm-

mung bis zu dem Knie $12^{\prime \prime} 2^{\prime \prime \prime}$.

Breite der Vorderpfote . . . . $2^{\prime \prime} 6^{\prime \prime \prime}$.

Länge des oberen Eckzahnes über • $g^{\prime \prime \prime}$. 


\section{$-\quad 369$}

Die Herren Geoffroy und Fr. Cuvier haben in ihrem Säugthierwerke unter der Benennung Chati (Felis mitis) ein Thier abge. bildet, welches sowohl in den Verhältnissen seines Körpers, als in der Vertheilung seiner Flecken grofse Aehnlichkeit mit dem brasilianischen Mbaracayá zeigt, so dafs ich dasselbe, wie weiter oben gesagt, für einen jungen weiblichen Mbaracayá zu halten geneigt wäre, wenn sich nicht hier auch wieder einige Verschiedenheiten zeigten; denn Felis mitis ist mit kleinen, isolirten Flecken sparsam bezeich. net, der Mbaracayá hingegen mit zum Theil gröfseren, gelbröthlichen, schwarzbraun regelmälsig eingefalsten, oft in die Länge gezogenen dichte bedeckt; sein Schwanz hat zuweilen eine völlig schwarzbraune Spitze, und die 3 letzten Querflecken an der Spitze werden beinahe zu völligen Ringen u. s. w., Züge, welche man sämmtlich nach meiner genauen Beschreibung vergleichen kann. - d'Azara's Chibiguazú ist höchst wahrscheinlich mein Mbaracayá; dern dieser Schriftsteller sagt in seiner Beschreibung nichts von völlig aneinanderhängenden Seitenstreifen, er beschreibt in der Hauptsache ganz meinen Mbaracayá, nur erwähnt er nichts von den schwarzbraunen,

II. Band. 
deutlich und dunkel abgesetzten Kehlstreifen, welche sich hei allen diesen Katzen höchst regelmälsig immer gleichartig wiederfinden. Diese Streifen sind zum Theil in der Abbildung des Herrn Fr. Cuvier angedeutet, allein in einem weit schwächeren Grade, als bei den von mir beobachteten Thieren. Sollte Felis mitis mit dem Mbaracayá identisch seyn, so wäre das von Herrn Cuvier abgebildete Thier ein sehr junges gewesen, welches viele Verschiedenheiten von meinen männlichen Thieren zeigt. Eine möglichst genaue Darstellung der Färbung des Mbaracayá wird sich in meinen Abbildungen zur Naturgeschichte Brasilien's finden.

Der Mbaracayá lebt in allen grofsen Wäldern von Brasilien und ich habe ihn vorzüglich am Mucurí, Alcobaça, Peruhype, Belmonte und in dieser Gegend beobachtet, ob es gleich nicht $\mathrm{zu}$ bezweifeln ist, dafs er überall vorkommt. Er geht, wie wir schor durch Azara wissen, ziemlich weit südlich hinab, ob er aber in Chili vorlsommt, ist nicht bestimmt. Zu Morro d'Arara am Mucurí fingen wir in Zeit von vier Wochen vier dieser Katzen in den Schlagfallen, wenn sie bei dunkelen Nächten am Ufer des Flusses wahrscheinlich den $\mathrm{Pa}$ - 


\section{$-371$}

ca's, Aguti's und Capybara's nachgestellt hatten.

In dem Magen des einen dieser Thiere fand ich ein noch ziemlich unverdautes Aguti. -

Der Mbaracayá streift weit umher und ist ein kühnes Raubthier, alles Lebende, was er bezwingen kann, wird von ihm verzehrt, ein Reh vermag er zu fangen, und selbst die Bäume besteigt er. - Haben die Hunde ein solches Thier gefunden, so baumt es sogleich und wird leicht herabgeschossen. - Die Neger und selbst einige Urbewohner essen das Fleisch, obgleich diese Thiere, wie alle Katzen, einen etwas unangenehmen Geruch von sich geben. - Aus dem schönen Felle, welches für Pferdedecken zu klein ist, bereiten die brasilianischen Jäger Regenkappen für ihre Gewehrschlösser.

$$
\text { 4. F. macroura. }
$$

Die kleine oder langgeschwänzte Tigerkatze.

K.: Oberkörper fahl grauröthlich; Unterkörper weifslich; beide unregelmäfsig graubraun oder schwarzbraun, zum Theil fast augenförmig gefleckt; auf dem Oberhalse fünf dunkle Längs. streifen, an der Stirn zwei schwarzbraune Streifen, dazwischen Puncte; an den Seiten des Kopfs zwei dunkele Längsstreifen; unter der Kehle ein 


\section{$-372$}

duntiler Querstreif; Fufssohlen graubraun; Schuvanz mifst über halbe Körperlänge. -

Abbildungen zur Naturgeschichte Brasilien's.

Felis, Widii Schinz das Thierreich u. sow. B. I. pag. 235.

Gatto do mato pintado der Brasilianer an der Ostkïste. Kuparack-Kuntiack bei den Botocuden. Kuichhua-dan (an franz.) bei den Camacans.

Ich fand die in den nachfolgenden Zeilen zu beschreibende Tigerkatze in denselben Wäldern, welche auch die vorhergehende Art beherbergen und glaubte, durch die grofse $A$ ehnlichkeit ihrer Zeichnung verführt, sie sey ein junger Mbaracayá, bis genauere Vergleichung mich die sehr abweichenden Verhältnisse beider Thierarten erkennen liefs. - Die Tigerkatze hat schlankeren Körper und Glieder, kleineren Kopf und weit längeren Schwanz, ihre Zeichnung kommt übrigens sehr mit der des Mbaracayá überein. - Da diese Art noch von keinem Schriftsteller erwähnt worden, so will ich sie weitläuftiger beschreiben.

Beschreibung fines männlichen Thieres: Der Kopf ist ziemlich klein, mit grofsen, nach dem Tode bräunlich gelben Augen, deren Pupille wahrscheinlich länglich gestạltet war. Die Nase ist etwas gewölbt, die Nasenkuppe bräunlich gefärbt; Ohren länger als am Mba- 
racayá, etwas eiförmig abgerundet, inwendig nur wenig behaart.

Gebifs: Eckzähne sehr grofs und kegelförmig zugespitzt; von den sechs in jedem Kiefer völlig gleich langen Vorderzähnen ist der äufserste an jeder Seite der gröfseste. Körper und Fülse sind schlank; die fünf Zehen der Vorderfülse haben starke, gekrümmte, weifs. liche Klauen, die vier Zehen der Hinterfülse ebenfalls. - Der Schwanz ist lang, und weit länger als am Mbaracayá. - Die äufseren Geschlechtstheile sind gebildet wie an jener Art. - Der ganze Körper ist auf eine ähnliche Art mit sanften, ziemlich kurzen Haaren bedeckt, am Schwanze sind sie am dichtesten, wolligsten und weichesten. - Am Oberkiefer befinden sich drei und einen halben Zoll lange theils weifse, theils schwarze Bartborsten, auch stehen über jedem Auge ein Paar solche. -

Die Farbenvertheilung dieser Katze ist im Allgemeinen der des Mbaracayá so ähnlich, dafs man, ohne das Verhältnifs ihrer Theile zu Rathe zu ziehen, beide Thiere für identisch zu halten bestimmt seyn würde. - Die Grundfarbe des Oberkopfs, der Stirn, Augengegend und aller oberen Theile, auch der Schulterblätter; ist ein fahles röthliches Grau, zuweilen 


\section{$-374$}

mehr in's Gelbröthliche fallend, die Seiten mehr röthlich-weifsgrau, alle untere Theile weifslich, so wie Backen, Kinn, Kehle und Brust; innere Seite der vier Beine etwas mehr in's Gelbliche fallend; Einfassung der Augen oder Augenlieder und Lippen schwarzbraun; Nase, ein Streif unter dem Auge, Gegend zwi schen den Augen röthlich-gelb, über dem Auge aber bemerkt man einen weifslichen Fleck; gerade wie am Mbaracayá laufen an der Seite des Kopfes hin zwei schwarzbraune Streifen, wovon der obere am hinteren Ende des Auges, der untere an der Seite der Nase entspringt; sie vereinigen sich ziemlich nahe an der Seite der Kehle, und ron hier geht quer über diese hin ein starker schwarzbrauner Querstreif; zwei Zoll drei Linien von diesem Kehlstreif entfernt, steht ein ähnlicher, zuweilen in der Mitte etwas unterbrochener am Unterhalse; zwischen diesen beiden Querstreifen zeigt sich an jeder Seite der weilsen Farbe des Unter. halses ein breiter anderthalb Zoll langer Längsfleck und vor diesem ein kleiner, runder, ähnlicher Fleck; Brust, Bauch und innere Seite der Beine sind mit runden, theils grölseren, theils kleineren schwarzbraunen Fleckchen bezeichnet; äufseres Ohr schwarzbraun, aber in 
der Mitte des hinteren Randes befindet sich ein aschgraulicher Fleck. - Von dem oberen Theile eines jeden Auges entspringt ein schwarzbrauner Streif, der bis gegen die Mitte des Ohres hinaufläuft, hier treten diese beiden Streifen verdickt näher zusammen, ihr Zwischenraum ist gerade wie am Mbaracayá mit kleinen Puncten ausgefüllt. - Auf dem Hinterkopfe entspringen fünf, oft mehr, oft weniger deutliche Längsstreifen, wovon der äufsere an jeder Seite sich ein wenig hinter dem $\mathrm{Oh}$. re herabsenkt und über der Seite des Halses hin bis in die Gegend der Schulter läuft; die drei mittleren Streifen sind an ihrem Ursprun. ge vereint, der mittlere ist der feinste, sie laufen ebenfalls bis über die Gegend der Schultern. - Ueber die Mitte des Rückens hinab bemerkt man etwa drei Reihen von schwarz. braunen länglichen Flecken oder Strichen, wovon besonders die mittlere mehr linienartig schmal und zusammenhängend ist; in der Seite stehen etwa drei Reihen etwas viereckiger graubrauner Flecken, welche schwarzbraun eingefalst sind, sie scheinen mehr fahl und verloschen als am Mbaracayá, werden aber durch die hellere Grundfarbe der Seiten gehoben; an dem oberen Theile der Schenkel sind die 
zahlreichen Flecken auch grofsentheils noch hohl und mit dunklerer Einfassung, allein am Unterschenkel arten sie melir in schwarzbrau. ne Längsflecken und Striche aus; an den vier Beinen stehen zahlreiche rundliche Flecke; der Schwanz ist auf seiner oberen Seite gefärbt wie der Rücken, an der unteren weifslich, er hat sieben schwarzbraune Querbinden und eine solche Spitze, die vier oberen sind an ihrer unteren Seite nicht geschlossen. Die Fufssohlen sind nicht schwarzbraun wie am Mbaracayá, sondern graubraun. -

Diese schöne Katze variirt ein wenig in der Grundfarbe oder durch die mehr vder minder regelmäIsige Vertheilung der Flecken. -

Ausmessung :

Ganze Länge

Länge des Körpers

Länge des Schwanzes

Länge von der Nas

\section{deren Ohrrande}

Höhe des äufseren Ohres

Länge des oberen Eckzahnes

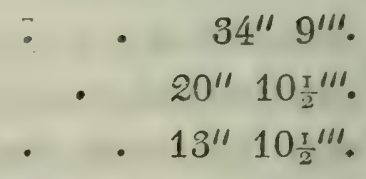

dem vor-

Diese Tigerkatze lebt in allen von mir bereisten Gegenden und ward anfünglich von mir für einen jungen Mbaracayá gehalten, bis ich 
beide Thiere genauer verglich. - Von dem Margay oder der den Naturforschern schon längst bekannten Tigerkatze ist sie verschie. den. - Ihre schlanke Gestalt, das schöne Fell, welches übrigens, sonderbar genug, mit dem des Mbaracayá höchst übereinstimmend gezeichnet ist, machen sie zu einem der schöneren Thiere des Katzengeschlechts. - Sie kam meinen Jägern an verschiedenen Orten vor und lebt in den grofsen Urwäldern am $\mathrm{Pa}$ rahyba, Espirito Santo, Mucurí, Belmonte, $1 l$ héos, so wie im Sertong von Bahia. - Ueberall trägt sie bei den Brasilianern oder brasilianischen Portugiesen den Namen der gefleckten wilden - oder Waldkatze (Gatto do mato pintado) und wird von ihnen ihres schönen Felles wegen geschossen. Da diese Katzen weit leichter sind, als die Mbaracayás', so steigen sie besonders an den Cipo's oder Schlinggewächsen auf und $a b$ und durchsachen die Bäume nach mancherlei Thieren und Vogelnestern, auch verzehren sie alle kleineren warmblütigen Thiere, vorzüglich die verschiedenen Arten der Ynambús oder. Tinamús, die Capueren ( $\mathrm{Per}^{-}$ dix dentata Temr.) u. s. w., die für ihr scharfes Gebifs und ihre grausamen Klauen erreichbar sind. - Den menschlichen Wohnungen 
nähern sie sich, um Federvieh zu rauben

Ihre Wohnung schlagen sie in hohlen Stämmen, Felsklüften, oder Erdhöhien auf, wo sie ganz nach Art unserer wilden Katze ihre Jungen zur Welt bringen.

Gewöhnlich fängt man sie in den Mundeos oder Schlagfallen. - In den grofsen Urwäldern zu Morro d'Arara am Mucuri erhielt ich auf diese Art in Zeit von vierzehn Tagen drei solche Katzen; eine vierte schols einer meiner Jäger am Espirito Santo von einem hohen Baume herab, wollte sie greifen, allein sie setzte sich zur Wehr und entsprang, da sie nur leicht verwundet war. - Diese Thiere gehen nicht blofs bei Nacht, sondern zu allen Stunden des Tages auf den Raub aus, - Ein Hund, welcher ein solches Thier findet, treibt es augenblicklich auf einen Baum, wo man es leicht herabschiefst; übrigens kann nur der Zufall dem Jäger das schöne Fell in die Hände führen, welches die Brasilianer zu Mützen und zu Regenkappen benutzen, um ihre Gewehrschlösser vor der Nässe zu schüzzen. - Die Botocuden und Neger essen ihr Fleisch.

Cuvier (Recherches sur les ossemens fossiles, T. IV. pag. 435; hält diese Katzenart für 


\section{$-379$}

identisch mit dem Chati, allein dieser ausgezeichnete Naturforscher dürfte vielleicht nach meiner hier weitläuftiger gegebenen Beschreibung eine genauere Vergleichung anzustellen jetzt im Stande seyn. - Schwer bleibt es immer über diese einander so ähnlichen Katzenarten zu urtheilen, wenn man sie nicht selbst einander genau vergleichen kann; denn die beiden letzteren von mir beschriebenen Katzenarten z. B gleichen sich in der Färbung so sehr, dafs man sie ohne die Berücksichtigung ihrer Körperverhältnisse für eine und dieselbe Thierart halten würde.

\section{F. Yaguarundi.}

Der Yaguarundi des $A z a r a$.

d'Azara essais etc. Vol. I. pag. 171.

d'Azara Voyage etc. Atlas Tab. X.

Gatto murísco bei den Brasilianern.

Hyrara an einigen Orten in Brasilien.

Poknienn bei den Botocuden.

Der Yaguarundi ist zuerst von Azara be. schrieben, kommt aber überall in Brasilien vor, wie ich hiervon an verschiedenen Orten durch Felle überzeugt worden bin. In den meisten Gegenden ist diese Katze unter dem Namen des Gatto murisco oder der Mäusekatze bekannt, am Rio Doçe und in einigen anderen 
Gegenden zeigten mir die jagenden Soldaten solche Felle, die sie Hyrara oder Irara benannten, ein Name, der gewöhnlich dem brasilianischen weiter oben beschriebenen Marder (Mustela barbara) zuzukommen pflegt. Während ich mich zu Morro d'Arara aufhielt, fing man, gerade als ich abwesend war, in einer dunkelen Nacht ein schönes Paar dieser Katzen im Mundeo, welches ich leider nicht im vollkommenen Zustande gesehen habe, wir müssen uns also bei diesem Gegenstand an Azara halten. - Obgleich diese Katze in allen Wildnissen der von mir bereisten Gegend gefunden wird, so soll sie dennoch weniger zahlreich seyn, als die vorhin beschriebene Tigerkatze. - Aufenthalt und Lebensart haben alle diese wilden Katzen mit der vorlin beschriebenen gemein. Der Yaguarundi stellt besonders den Tinamús, als Macucas, Sabélés, Schororongs, Ynambús und anderen älınlichen Vögeln nach, und beschleicht listig diese schwerfälligen Flieger. - Im Sertong lebt er in den Catinga - und Carasco-Gebüschen, verbirgt sich aber in Höhlen und alten Stäm. men oder Klüften. Das zarte kurze und dicht behaarte Fell gebraucht man zu Mützen und Regenkappen über die Gewehrschlösser. Er 


\section{$-381$}

soll schwerer zu schiefsen seyn als die vorhergehende Art, da er nicht lange vor den Hunden aushält oder steht wenn er gebaumt hat. -

$$
\text { 6. F. } E \text { y } r \text { a Azarae. }
$$

$D$ i e E y r a K a t z e.

Azara Essuis etc. Vol. I. pag. 177.

Gatto vermelho oder Gatto murisco von den Brasilianern genannt.

Azara beschrieb diese Katze zuerst, und wenn ich sie gleich selbst nicht gesehen habe, so erhielt ich dennoch öfters Nachricht von ihr. Sie lebt in den inneren grofsen Waldungen und in den Catingas und Carascos der inneren Sertongs. - Sie ist stark und raubsüchtig, auch stellt sie allem kleinen Wild eifrig nach. - Den Wohnungen nähert sie sich um das Federvieh zu rauben. - Die Jäger haben mir einstimmig versichert, dafs diese Art wilder und mehr scheu sey, als alle übrigen Katzen, dals man daher höchst vorsichtig zu Werke gehen müsse, um heran zu schleichen, nachdem sie von dem Jagdhunde auf einen Baum getrieben sey.

Diese Katze soll grölser werden als der Yaguarundi, hell gelblich-roth ohne Flecken und andere Abzeichen, aber mehr hell oder 


\section{$-\quad 382$}

brennender röthlich gefärbt seyn, als die Ç.ucuarana; ihr Schwanz ist lang. - Die Beschreibung von Felis unicolor (Spotlefs Cat), welche in den Schriften der Wernerian Society (Vol. III. p. 170) enthalten ist, gehört vielleicht hieher. - Die Abbildung ist eine höchst verzerrte Gestalt, wahrscheinlich nach einem sehr schlecht ausgestopften Exemplare gemacht.

\section{Or D. III. Marsupialia.} B e ute $1 \mathrm{th}$ i e re.

Die Beutelthiere sind durch ihre merkwürdige Organisation von allen andern Säugthieren sehr deutlich getrennt, obgleich auch unter sich wieder durch verschiedenartige Bildung. Dennoch hat man sie in neueren Zeiten ihres sonderbaren beutelförmigen Organes wegen, ungeachtet der verschiedenen Bildung jhres Gebisses und ihrer Füfce, in eine besondere Ordnung zusammengestellt. Illiger wies ihnen die Stelle in seiner zweiten und dritten Ordnung (Pollicata und Salientia) an und bildete aus ihnen die fünfte Familie der ersteren (Marsupialia) und die erste Familie der drit- 
ten oder derselben Ordnung (Salientia). Wenn gleich diese Eintheilung sehr zweckmä• Isig scheint, so kann man diese Thiere dennoch auch mit Cuvier in eine besondere Ordnung zusammenfassen, und alsdann mehrere Fami. lien, zu Folge der Bildung des Gebisses oder der Fürse, als Unterabtheilungen bilden. -

Da ich für Brasilien nur Thiere aus der ersten Familie der Beutelthiere, oder derjenigen zu erwähnen habe, welche mit einem Gebisse der Raubthiere, auch völlig mit ähnlicher Lebensart begabte, dabei aber im weiblichen Geschlechte mit einem Beutel versehene Pedimanen sind, so hat mir Cuvier's Eintheilung am zweckmälsigsten für dieses Verzeichnifs geschienen, indem alsdann die Beutelthiere den Uebergang von den Fleichfressern zu den Nagern, vorzüglich den Ratten und Mäusen bilden.

Die Beutelthiere sind über die alte und neue Welt verbreitet, und wir finden die gröfseste Mannichfaltigkeit ihrer Geschlechter und Arten in dem beinahe ausschliefslich von ihnen bevölkerten fünften Welttheile. Dort tragen, wie bekannt, beinahe alle Säugthiere das originelle Organ des Beutels und zeigen die zum 
Theil sonderbarsten und merkwürdigsten Bildungen.

$$
\text { G. 19. } D i d \text { e } l p h \quad h \quad s \text {. }
$$

B e ute l thier.

America besitzt blofs eine Familie der Beutelthiere und zwar diejenige, welche mit rattenartiger Gestalt, lang zugespitztem Kopfe, Fleischfressergebils, mit nackten rattenartigen Ohren, langem, zum Theil nacktem Greifschwanze, Händen an den hinteren Extremitäten, zum Theil mit dem sonderbaren Beutel bei dem weiblichen, und bei dem männlichen Geschlechte ebenfalls mit sonderbar eingerichteten Geschlechtstheilen versehen ist.

Von diesen Thieren labt nur eine Species in der nördlichen Hälfte dieses Continents, die südliche hingegen hat viele Arten, zahlreich an Individuen, da sie sämmtlich, wie die Mäuse und Ratten, eine Menge von Jungen zur Welt bringen.

Ueber die Bildung und Lebensart dieser americanischen Thiere sind die Naturforscher in der Hauptsache ziemlich genau unterrichtet, doch bleiben immer noch einige Beobachtungen zu machen übrig, besonders über die Fortpflanzung der Beutelratten. - Azara hat 


\section{- 385 -}

ihre Kenntnifs mit bedeutenden Beiträgen bereichert. Sein Werk zählt sechs Arten auf, mir hingegen sind in Brasilien nur etwa vier bis fünf Arten bekannt geworden, ohne dafs ich jedoch an dem Vorhandenseyn mehrerer zweifeln könnte. - Azara belegt sie mit dem allgemeinen Namen Micuré, der mir in Brasilien nie vorgekommen ist; dagegen kennt man sie in der von mir bereisten Gegend unter den Benennungen Gambá und Jupatí. -

Alle americanischen bisjetzt bekannten Arten sind Raubthiere, welche zugleich in ihrer Natur und Lebensart grofse Uebereinstimmung mit den Ratten zeigen, zum Theil Omnivoren wie diese sind, daher diese Aehnlichkeit selbst von den ersten europäischen Ansiedlern in Nord-America, den Franzosen in Canada sogleich erkannt und die einzige dort einheimia sche Art, Rat des bois genannt wurde. Sie sind Vielfresser und haben den unangenehmen Geruch der Mäuse, aber in einem höheren Grade. - Ihr Aufenthalt ist in Feldern und Wäldern, wo sie vermöge ihrer Hinterhände zwar geschickt, aber nicht besonders schnell an den Stämmen und Zweigen auf- und absteigen. - Sie nähern sich den menschli-

II. Band. 
chen Wohnungen, plündern die Nester und tödten alles, was in den Hühnerställen lebt. -

Ihre merkwürdige Fortpflanzungsart ist bekannt; man hat in verschiedenen naturhistorischen Werken die sonderbaren Geschlechtstheile, ja selbst die im Knochengebäude des Thiers schon sichtbaren Abweichungen beschrieben, obgleich über das Gebären der Jungen und ihren Eintritt in den Beutel noch viel Dunkelheit herrscht.

Diese Familie hat für den Menschen wenig Nutzen und Annehmlichkeit; denn die americanischen Arten liefern weder ein brauchbares Fleisch, noch benutzt man ihr Fell, und ein übeler Geruch macht sie überall verhafst.

Da diese Thiere im Allgemeinen viel Aehnlichkeit unter einander zeigen, so haben sich zum Theil viele Verwechslungen und Unrichtigkeiten in ihre Beschreibungen eingeschlichen, und erst in neueren Zeiten hat man diese etwas aufgeklärr, obgleich noch vieles zu thun übrig bleibt. - Alle die älteren zu unvollkommenen Beschreibungen sollte man nie citiren, da sie mehr dazu beitragen, die Kenntnifs dieser Thiere zu verwirren, als aufzuklären, auch künnen in dieser Familie nur sehr genau nach der Natur entworfene Beschreibun- 


\section{- $387-$}

gen nützen, welche alle einzelne Theile des Thiers genau angeben. Herr Temminck hat seit Kurzem eine Monographie des Genus Didelphis bekannt gemacht, welche ohne Zweifel die vollständigste Uebersicht der bisjetzt bekannten Arten giebt, ich werde öfters Gelegenheit haben, über diesen Gegenstand zu reden.

A. Beutelthiere, deren Pelz eine Wolle, und darüber lange weifsliche Stachelhaare ${ }^{*}$ ) zeigt.

Sie sind langsame, dickleibige, beilsige, übelriechende Thiere.

1. D. marsupialis, Linn. D a s G a m bá.

D. cancrivora.

Carigueya, Marcgr. pag. 222.

Le Sarigue Crabier ou Pian, Geoffr. et Fr, Cuv, hist. nat. d. Mammif.

Abbildungen zur Naturgeschichte Brasilien's.

Temminck Monographies de Mammal, pag, 32, pl. V. Gambá an der Ostküste von Brasilien.

Ntiunn-tiú botocudisch.

*) Dem einzeln über die kürzere Grundwolle des Pelzes hervortretenden langen Haare haje ich die Benenmung Stachelhaar gelassen, welche sie gewölnnlich bei den Kürschnerii zi tragen pflegen. 


\section{$-388$}

Obgleich Azara's Micouré premier ou Micouré proprement dit (T. I. pag. 244) in allen Hauptpuncten mit dem hier von mir zu beschreibenden Thiere übereinstimmt, auch besonders in der Grölse und den Verhältnissen des Körpers, so sind dennoch einige Züge bei beiden Thieren verschieden, und ich glaube defshalb Herrn Temminck folgen zu müssen, welcher das Micouré premier des Azara für eine besondere Species hält und mit dem Namen Didelphys Azarae belegt. Der Hauptunterschied, welcher hier stattzufinden scheint, besteht in den zweifarbigen Ohren, welche keine der von mir zu beschreibenden brasilianischen Arten besitzt, einige andere kleine Unterschiede nicht in Betrachtung gezogen, es ist also das in dem von mir bereisten Theile von Brasilien gemeinste Beutelthier oder das Gambá identisch mit dem Pian von $\mathrm{Ca}$ yenne, obgleich die Abbildung der Herren GeofYfroy und Fr. Cuvier, wenn sie getreu ist, einige von mir an diesen Thieren nie bemerkte Züge zeigt $*$ ).

*) Herr $T_{c m m i n c k}$ hat sämmtliche in meiner zoologischen Sammlung befindliche Beutelthiere geseheir, ich bin also von der Uebereinstinmung hinlänglich ïberzeug่t, 
Beschreibung eines weiblichen Thieres: Gestalt rattenartig, etwas dick; Kopf schmal, zugespitzt; Nase etwas rüsselförmig verlängert; Nasenkuppe durch eine senkrechte Mittelrinne ein wenig gespalten; am Oberkiefer befinden sich lange schwarze Bartborsten, und auf den Backen stehen ähnliche, welche aus einem ge. meinschaftlichen Puncte entspringen; diejenigen, welche unter dem Unterkiefer stehen, sind weilslich oder gelblich-braun gefärbt. - Das Auge ist rattenartig schwarz; Ohren wie an der Ratte, nackt, ziemlich breit, oben abgerundet, schwarzbraun gefärbt, einen Zoll und eine Linie hoch. - Die Fülse sind stark, mit zusammengedrückten weifslichen Krallennägeln, die an den Vorderfüfsen kürzer sind, als an den hinteren; der Daum der Hinterhände ist lang und stark, ohne Nagel, sein vorderes Glied etwas platt gedrückt. - Der Schwanz ist an der Wurzel zwei Zoll vier Linien weit wie der übrige Körper behaart, alsdann nackt, mit Hautschuppen und einzelnen kleinen Borsten besetzt; der Beutel ist geräumig, und enthielt im September zehn nackte kleine Junge, doch wa: ren mehrere Zitzen vorhanden.

Das die Haut unmittelbar bedeckende Haar ist am ganzen Thiere eine dichte, schmu- 
tzig blafs grauliche Wolle, deren Haare schwärzliche Spitzen zeigen, aus dieser unteren Wolle treten lange gelblich - weifse Stachelhaare hervor, die an ihrer Wurzel weifs, an der Spitze aber gelblich gefärbt sind, wodurch das Thier ein weifslich und schwarzbraun gemischtes Ansehen erhält; der Kopf ist etwas mehr schwarzbräunlich überlaufen, eben so Oberhals und Rücken, wenn man an dem letzteren die weifslichen Stachelhaare wegnimmt, welche an Kopf und Hals gänzlich fehlen. - Mehr oder weniger deutlich bemerkt man an dem Kopfe drei undeutliche schwärzlich-braune Streifen, wovon der eine über die Mitte der Stirn hinauf, von den beiden andern aber ein jeder durch das Auge nach dem Ohre hinaufzieht, wodurch über dem ersteren eine etwas hellere Stelle entsteht. - Die Grundfarbe der Wolle des Kopfs ist etwas $\mathrm{n}$ :hr gelblich als am übrigen Körper. - Der Kopf des männlichen Thieres scheint dunkeler gefärbt zu seyn, als der des Weibchens. An den vier Beinen herrscht die schwarzbraune Farbe; der Pelz ist hier kürzer und mit einzelnen weifsen Haaren gemischt; Schwanz an der Wurzelhälfte seines nackten Theiles schwarzbräunlich, an der Spitzenhälfte aber blässer oder weifslich, auch 


\section{- 391}

sind auf diese Art seine einzelnen Borsten verschieden gefärbt. Herr Temminck sagt (Monographies etc, pag. 35), der Unterschied des Didelphys Azarae und des cancrivora oder marsupialis bestehe darin, dals das erstere die langen Haare des Pelzes gänzlich weils, und das andere dieselben mit schwärzlichen Spitzen zeige, allein ich bezweifle, dafs diefs ein beständiger Unterschied beider Arten ist; denn man findet cancrivora ebenfalls, besonders in der kalten Jahrszeit, mit völlig weifslichen langen Haaren.

Ausmessung dieses weiblichen Thieres:

Ganze Länge

Länge des Körpers

Länge des Schwanzes

Höhe des Ohres über dem Kopfe $26^{\prime \prime} 2 \frac{1}{2}{ }^{\prime \prime \prime}$ - $15^{\prime \prime}$ $11^{\prime \prime} 2 \frac{1}{2}$ ".

Die Schwanzwurzel ist behaart auf eine Länge von . $\quad$. . . $2^{\prime \prime} 4^{\prime \prime \prime}$.

Männchen und Weibchen sind nicht bedeutend verschieden, das letztere schien mir etwas heller gefärbt. Die Testikel aller dieser männlichen Beutelratten hängen, wie bekannt, frei lang herab, an einer dünnen Verbindung. Die einzige, diesem Thiere ähnliche Abbildung, welche ich kenne, befindet sich in dem Säug- 


\section{- $392-$}

thierwerke der Herren Geoffroy und $\mathrm{Fr}$. $\mathrm{Cu}$ vier, dennoch ist die Färbung jener Abbildung sehr von meinem Thiere verschieden, welches entweder durch das Alter, oder vielleicht die Erziehung in der Gefangenschaft erzeugt worden seyn kann, wofern die Schuld nicht an dem Illuminator liegt. - Man sieht an dieser Abbildung den ganzen Kopf scheinbar nackt und fleischroth, statt dafs er an meinem Thiere mit drei schwärzlich-braunen Längsstreifen bezeichnet ist, und überhaupt eine dunkel gefärbte dichte Behaarung hat; von den langen weilsen Stachelhaaren des Rückens auf schwärzlich-brauner Grundwolle ist ebenfalls nichts angegeben, 6o dafs diese Abbildung, wenn sie auf das hier besohriebene Thier bezogen werden mufs, immer noch sehr grofse Mängel behält.

Dieses Beutelthier ist die gemeinste Art in den von mir bereisten Gegenden. - Es scheint über den gröfsesten Theil von SüdAmerica verbreitet, da man es von Cayenne bis südlicher als Rio de Janeiro findet. $A z G$ ra scheint es nicht gefunden $\mathrm{zu}$ haben, eben so wenig Molina. - Mit dem nord-americanischen Beutelthier hat es grofse Aehnlichkeit 


\section{- 393}

in Gestalt und Färbung, weeswegen es oft mit demselben verwechselt worden ist.

In der Gegend von Cabo Frio, wo ich im Monat September das vorhin in der Kürze beschriebene weibliche Thier mit noch nackten Jungen erhielt, so wie in den meisten von mir bereisten Gegenden von Brasilien kennt man diese Species unter der Benennung Gam$\left.b a^{*}\right)$. Sie ist in vielen Gegenden höchst gemein in den Wäldern, entflieht nicht besonders schnell, steigt geschickt auf die Bäume und ist beifsig wie eine Ratte, mit der diese Thiere in der Lebensart überhaupt sehr viel Aehnlich. keit zeigen.

Das Gambá ist ein gefrälsiges, wenige Nahrungsmittel verschmähendes Thier, es schleicht sich in die Hühnerhöfe und raubt das Federvieh und die Eier. - Dals es mehr von Krabben leben solle, als die übrigen Beutelthiere, scheint mir unwahrscheinlich, auch habe ich in den Mägen dieser Thiere nie eine Spur von Krabben gefunden, welshalb mir der Name cancrivora ganz uneigentlich scheint. -

*) Der Engländer J. Luccock erwähnt dieses Thiers unter der Benennung Gambá, oder brasilianisches Stinkthier, siehe dessen Reise (deutsche Uebersetzung) B, I. p. 461, - 
Man fängt das Gambá oft im Mundéo oder der Schlagfalle. - Es geht nicht blofs bei Nacht; denn wir haben es auf unseren Jagdexcursionen oft am Tage gefunden, wo es in den grofsen Wäldern in Bewegung war, ob dieses gleich in bewohnten Gegenden wohl seltener vorkommen mag. In der kalten Jahrszeit wird es sehr fett, und hat alsdann sein langes weilsliches Haar in gröfsester Vollkommenheit, welshalb es nach der Versicherung der brasilianischen Jäger in der kalten Zeit weit mehr weilslich gefärbt ist, als in der heifsen, wo es mager ist. - Die Botocuden essen das Gambá ohne Widerwillen, so wie die Neger, es wird hingegen von den Europäern und ihren Abkömmlingen des Geruches halben verabscheut. Sein Fleisch hat man mit dem des Haasen vergleichen wollen, allein es kann wohl höchstens mit dem einer Ratte Aehnlichkeit haben. Marcgrave beschreibt das Gambá ziemlich deutlich, und nennt es Carigueya, sein Taiibi ist ein anderes, mir nicht vorgekommenes Beutelthier.

Die Nachrichten, welche Azara von sei. nem Micouré premier giebt, so wie die gute Beschreibung des nordamericanischen Opossum, welche wir den Herren Geoffroy und Fr. Cu- 
vier verdanken, passen beinahe wörtlich auf das Gambci und alle verwandte Thiere, ich verweise defshalb dorthin. - Dieses zeigt, wie schwierig es ist, die Beutelthiere genau zu unterscheiden, nur eigene Ansicht der verschiedenen Arten kann durch Vergleichung entscheiden, sie gleichen sich zum Theil in der Hauptsache vollkommen, und nur kleine Abweichungen bestimmen manche Specien. Herr Temminck, dieser eifrige Forscher, welcher in allen europäischen Cabinetten die Vergleichung der Exemplare unternommen hat, kann in die. ser Hinsicht wohl den sichersten Aufschlufs geben. Er citirt in seinem neuen Werke: Monographies de Mammalogie (pag. 34.) die 1ste Figur der 58sten Tafel des Seba zu der hier erwähnten Art, allein ich finde, dafs diese Abbildung kaum in der Gestalt, viel weniger aber noch in der Färbung unserem Thiere gleicht.

$$
\text { 2. D. a urita. }
$$

Lang gétries Beutel thier.

B.: Färbung und Bildung Didelphys marsupialis sehr ähnlich, allein Kopf und Ohren weit gröfser, der Schwanz länger, die Stirn mehr eingedrückt.

Gumbi an dex Ostküste voin Brasilien.

Nitunn-tiu botocudisch.

Ich habe das Beutelthier, weiches der Gegenstand der'nachfolgenden. Beschreibung ist, 
nru einmal erhalten, und zwar ein weibliches Individuum. - Seinem stark abgenutzten Gebisse zufolge, schien es ein altes Weibchen zu seyn. Dieses Thier hat im Allgemeinen die gröfste Aehnlichkeit mit der vorhin beschriebe. nen Art, weicht aber in den Verhältnissen seines Körpers etwas ab, wefshalb ich dasselbe der Aufmerksamkeit der reisenden Naturforscher empfehle und einstweilen als besondere Species aufzustellen versuche, ohne jedoch die Diagnose nach dem einzigen Exemplare gänzlich feststellen zu können.

Beschreibung: Gestalt im Allgemeinen die der vorhergehenden Art; Nasenkuppe etwas gespalten und aufgetrieben wie an jener; $\mathrm{Au}$ ge und Bartborsten eben so gebildet, das Ohr aber ist höher, grofs, beinahe scheibenförmig; breit, oben abgerundet, nackt und schwarz. braun gefärbt. -

Zunge wie an der vorhergehenden Art, gerade wie sie Azara von seinem Micouré premier beschreibt. Gaumen mit erhöhten Querreifen versehen.

Gebifs: Schn. $\frac{10}{8}$; Eckz. $\frac{2.2}{1.1}$; Backenz. $\frac{0.7}{9 \cdot 9}$. Vorderzähne im Oberkiefer zehn; die beiden vorderen stehen nahe zusammèn, auf jeder Seite vier andere, sämmtlich etwas kegelförmig, kurz, rundlich abgenutzt; vor dem Eck- 
zahne eine Lücke; Vorderzähne im Unterkiefer: in der Mitte eine kleine Lücke, dann auf jeder Seite vier schräge vorwärts geneigte, etwas kegelförmige, abgenutzte kleine Zähne. Eckzähne im Oberkiefer: ein gröfserer vorn, dann ein kleinerer, beide kegelförmig, aber stark rundlich abgenutzt, nun fồlgt eine Lükke. - Im Unterkiefer: unmittelbar neben den Schneidezähnen steht ein schräge vorwärts geneigter kegelförmiger Eckzahn. - Backenzähne im Oberkiefer: nach der genannten Lücke folgen zwei grofse kegelförmige, mit ihrer Spitze ein wenig nach hinten gerichtete Reifszähne, sehr abgenutzt und stumpf, dann drei sehr kleine abgeschliffene Zähnchen, und nun zwei etwas dreieckige, abgeplattete Hökkerzähne (in allem acht und zwanzig Zähne im Oberkiefer). - Im Unterkiefer: nach dem vorwärts strebenden Eckzahne folgen zwei sehr kleine Zähnchen, dann zwei grofse kegelförmige Reilszähne, nun zwei kleine einfache Stumpfzähne, und zuletzt drei breite abgeplatte. te Mahlzähne, mit einigen flachen Höckern versehen (im Ganzen acht und zwanzig Zähne). -

Die Beine sind ziemlich schlank, die Vorderfülse mit fünf ziemlich kurzen Zehen versehen, wovon die innerste die kürzeste ist. - 
Nägel, Zehen und Daumen der Hinterhände sind gebildet wie an der vorhergehenden Art. Der Schwanz ist gröfstentheils nackt und mit Hautschuppen bedeckt, an seiner Wurzel etwa zwei Zoll weit behaart. - Der Beutel dieses weiblichen Thieres war weit und enthielt neun Zitzen, welche wenig sichtbar waren. -

Der ganze Körper ist, wie an der vorhergehenden Art, zu unterst mit einem kurzen wolligen Haare bedeckt, und darüber mit langen dünnen Stachelhaaren versehen, doch fehlen letztere oft bei den Thieren dieses Geschlechts, besonders in der warmen Zeit, und zeigen sich oft nur auf dem Rücken. - Der Kopf und die vier Beine sind mehr schwarz. braun gefärbt; der erstere zeigt von der Gegend zwischen den Augen bis über den Scheitel hinauf einen schwarzbraunen Streif; ein ähnlicher mehr undeutlicher zieht vom Auge nach dem Ohre hinauf, und die Gegend zwischen diesen drei dunkelen Streifen ist blässer gefärbt; denn hier blickt die gelblich-graue Wolle des Pelzes zwischen den dunkleren Haarspitzen hindurch. An den Seiten des Kopfs und Halses haben die Haare eine etwas rostgelbliche Mischung; das dichte wollige Haar am Körper ist weifsgraulich, dessen Spitzen 
schwärzlich braun, in demselben sind einzelne, lange, weifsliche Haare vertheilt. Auf dem Rücken herrscht mehr das schwärzlich-braune Haar; die innere Seite der Beine, so wie die Gegend des Beutels sind ein wenig mehr rothgelblich gemischt. Der nackte Theil des Schwanzes ist an der Wurzelhälfte schwärzlich-braun oder dunkel graubraun, an der Spitzenhälfte weilslich oder gelblich-weilsgrau gefärbt. -

Ausmessung :

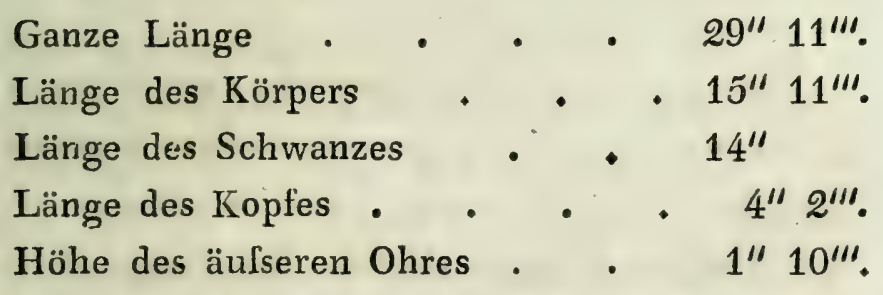

Der Schädel ist auf der Stirn mehr eingedrückt und flach, als an der vorhergehenden Art.

Dieses Beutelthier, welches man bei dem ersten Anblicke für identisch mit dem vorhergehenden hält, scheint seiner verschiedenen Verhältnisse wegen eine besondere Species $\mathrm{zu}$ bilden, ob es gleich die brasilianischen Jäger ebenfalls für dasselbe Thier halten und unter der allgemeinen Benennung Gambá ver- 
wechseln. Ich erhielt ein einziges Exemplar dieser Art zu Villa Viçoza am Flusse Peruhype im Monat Juni, wo es sehr fett war. -

Diese Art lebt in den Wäldern und $\mathrm{Ge}$ büschen, nähert sich bei Nacht, wie die vorhergehende Art, den Wohnungen, um zu rauben, und hat eben denselben unangenehmen Geruch.

B. Beutelthiere mit kurzem mäuseartigem Pelze, der keine Stachelhaare zeigt.

Sie sind schlank, gewandt, zierlich und haben weniger übelen Geruch als die der vorhergehenden Abtheilung. Die Brasilianer an der Ostküste belegen sie mit dem allgemeinen - Namen Jupatí.

\section{D. myosuros, Temm.}

Das Schupati mit dem Rattenschwanze.

B.: Pelz dicht und wollig, röthlich braun, auf dem Rücken etwas dunkeler; über jedem Auge ein hellrother Fleck; Ohren nackt und graubraun; Schwvanz länger als der Körper, an der Wurzel kaumi, einen Zoll lang behaart; nackter Theil an der Wurzellälfte graubraun, ain der Spitzenhälfte weifslich. - Bauch gelblich gefärbt. - 
Sarigue Myosure, Temm. Monogr. pag. 38.

Jupcti ${ }^{*}$ ) in der Lingoa Geral und bei den brasilianischen Portugiesen.

Ntiähäm bei den Botocuden.

Beschreibung: Gestalt ziemlich schlank und angenehm. - Der Kopf ist schlank verlängert und zugespitzt, märsig grofs; Auge ziemlich grofs, lebhaft, rattenartig dunkel; Oberkiefer etwas länger als der untere; die Nasenkuppe ist nackt, bräunlich, in der Mitte durch eine senkrechte Furche ein wenig ge. theilt, die beiden Hälften etwas aufgetrieben, an der äufseren Seite steht das längliche Nasenloch; Ohr mäIsig grofs, nackt, häutig, eiförmig breit, oben abgerundet, fein punctirt. Gebifs: Schn, $\frac{10}{8} ;$ Eckz. $\frac{x \cdot 1}{1 \cdot 1}$; Backenz. $\frac{7 \cdot 7}{7 \cdot 7}$. Schneidezähne im Oberkiefer zehn, die beiden mittleren stehen nahe zusammen, von den übrigen etwas getrennt und sind kleiner; an jeder Seite stehen neben diesen vier etwas gröIsere Zähne nahe an einander gereiht, welche nach aufsen hin immer an Grölse zunehmen; ihre Krone ist an der Wurzel mälsig breit und läuft in eine sanfte Spitze aus; im Unterkiefer befindet sich in der Mitte eine kleine Lük-

*) Das $I$ am Anfange des Worts wird ausgesprochen wie in der französischen Sprache,

II. Band.

26 
ke, neben welcher sich auf jeder Seite vier vorwärts strebende Vorderzähne dicht aneinander gereihet befinden; ihre Krone hat eine sanft zugerundete Schneide, und ist nach hinten ein wenig ausgehöhlt. - Eckzähne im Oberkiefer durch eine Lücke von den Schneidezähnen getrennt, grofs, kegelförmig, gelkrümmt, zugespitzt; im Unterkiefer sind sie weit kleiner, dicht an die Schneidezähne gereiht, etwas vorwärts strebend und aufwärts gekrümmt. - Backenzähne im Oberkiefer sieben auf jeder Seite; die drei vordersten sind zusammengedrückt, kegelföınig und zugespitzt; der vorderste ist der kleinste und hat zwei stärkere Nebenhöcker als die beiden nachfolgenden; die vier hinteren Zähne bilden, auf ihrer Mahlläche besehen, schiefe Dreiecke, de. ren Basis nach aufsen gekehrt ist; die Mahlflächen haben drei Höckerspitzen, der hinterste Zahn ist der kleinste. - $1 m$ Unterkiefer stehen zuvörderst drei einfache Spitzzähne, die an ihrer vorderen Schneide einen Winkel zeigen; der vorderste ist der kleinste, und der mittelste der gröfseste; die vier nachfolgenden Zähne sind fünfspitzig; an ihrem vorderen Ende haben sie eine kleine Spitze, dann in der 
Mitte zwei hohe gepaarte Kegelspitzen, und hinter diesen am Ende noch zwei niedere Höcker.

Beine ziemlich schlank, die FüIse zierlich; Vorderfufs mit fünf Zehen; der Mittelfinger ist am längsten, der Zeigefinger und der vierte sind gleich lang, dann folgt der kleine Finger, der Daumen ist am kürzesten, alle haben sehr kleine horizontale, kurze, zusammengedrückte, zugespitzte Nägel, welche kürzer sind, als die weiter vortretenden, starken, an ihrer Sohle kantig zusammengedrückten Vorderballen. Hinterfülse mit fünf Zehen; der Daumen ist lang und stark, scheinbar ohne Nagel; die drei mittleren Finger sind am längsten und einander ziemlich gleich; äufsere Zehe etwas länger aḷ der Daumen; Nägel der vier äufseren Zehen etwas aufgerichtet, zusammengedrückt, zugespitzt, weifslich gefärbt, sie treten nur wenig über die Ballen vor. - Das Vorderbein ist an der inneren Seite von der Sohle herauf ziemlich weit nackt, das Hinterbein an dieser Stelle dünn behaart. - Die kugelrunden Testikel hängen frei an einem dünnen Strange von etwa drei Linien Länge herab. - Der Schwanz ist lang, xund, zugespitzt, kaum einen Zoll lang an der Wurzel behaart, übrigens mäuse. 


\section{$-\quad 404$}

artig mit klcinen viereckigen Hautschuppen netzartig bedeckt und überall, besonders an den Seiten und der unteren Fläche, mit feinen weilslichen Seidenhärchen besetzt. -

Hinter der Nase stehen über der Oberlippe lange schwärzliche Bartborsten, welche bis über das Auge hinauf reichen, ein Paar andere entspringen über dem Auge. Ganzer Pelz dicht, wollig, mäuseartig, ohne langes Stachelhaar; Füfse nur mit feinen zarten Härchen bekleidet. - Scheitel und Stirn bis zwischen die Augen sind schwarzbraun, ganzer übriger Oberkopf, Nase, Ohrgegend und alle oberen Theile dunkel graubraun, mit rothgelben Haar spitzen gemischt; die Haare sind zwei Dritttheile ihrer Länge an der Wurzel dunkelgrau; nach den Seiten des Kopfs, Halses und Körpers hinab nimmt an jedem Haare die fahl bräunlich-rothe Farbe die Oberhand, so dafs diese Theile mehr ungemischt eine röthliche Farbe zeigen. - Vorderblätter, Schenkel und Schwanzgegend sind etwas mehr grau oder schwärzlich gemischt; Füfse fahl graubräunlich und etwas glänzend; das Auge hat eine schmale schwarzbraune Einfassung und darüber neben der schwarzbraunen Stirn ein hell gelbrothes rundes Fleckchen, - Ohren dunkel grau- 
braun. - Alle unteren Theile zeigen eine angenehm fahl röthlich-gelbe, oft nur gelblishe Farbe. - Der Schwanz ist an dem nackten Theile seiner Wurzelhälfte graubraun, an der Spitzenhälfte weilslich gefärbt. -

Das weibliche Thier habe ich nicht erhalten, nach Herrn Temminck soll es aber einen Beutel besitzen.

\section{Ausmessung des beschriebenen männlichen}

\section{Thieres:}

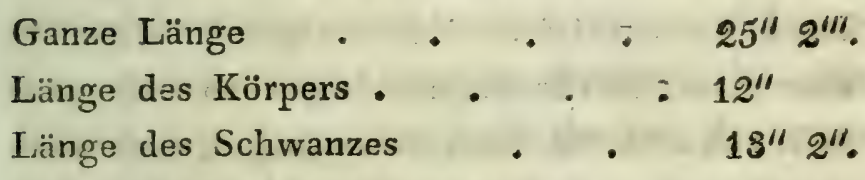
Höhe des äufseren Ohres etwa . 11"'. Länge des Kopís etwa . . . 3" 3" 3".

Diese nach frischen Exemplaren genommenen Ausmessungen kann man den bisher bekannten rorziehen, welche nur nach ausge: stopften Bälgen genommen, und daher oft un-: richtig sind. -

Das rattenschwänzige Beutelthier ist dem Opossum (Quatre-oeuil ou moyen Sarigue de Cayenne, Cuv. Régne Animal, T. I. pag. 173) sehr ähnlich, scheint aber von demselben verschieden zu seyn. d'Azara hat dasselbe in Paraguay nicht gefunden, dagegen lebt es an der Ostküste von Brasilien, wo ich es zu Co- 


\section{- 406}

mechatibi unter $17^{\circ}$ südlicher Breite erhielt. - Es ist mir diese $\Lambda$ rt nicht häufig vor. gekommen, doch kann ich defslsalb noch nicht behaupten, dafs sie wirklich selten sey. Nur zu Comechatibá, zwischen den Flüssen Prado und Corumbas, erhielt ich zwei männliche Thiere, welche die Neger in den Schlagfallen ge. fangen hatten.

Diese Ait trägt daselbst die Benennung Jupati, und wird von den Negern gegessen. Die Lebensart ist die der übrigen Beutelratten, aber diese, so wie die nachfolgenden Arten sind weit schneller in ihren Bewegungen, weit zierlicher und angenehmer, als die mit langem Stachelhaar versehenen.

$$
\text { 4. D. } c i n \in r \in a \text {. }
$$

Asch gra ues $S$ c hu pat i.

B. : Körper schlank und kürzer als der Schwanz; dieser an der IVurzel behaart; der nackte Theil zur Hälfte schwärzlich, zur Hälfte weifslich gefärbt; Haar mäuseartig, röthlich-aschgrau, am Bauche gelbröthlich-isabellfarben; um das Aun ge ein schwärzlicher Fleck.

Abbildungen zur Naturgeschichte Brasilien's,

Temminck Monographies etc. pag. 46.

Jupati in der Lingor Geral und bei len brasilianischen Portugiesen.

Niähăin bei den Botocuden. 
Beschreibung eines männlichen Thieres: Der Kopf ist zugespitzt, mit nackter fleischro. ther Nase, und einer von einer Furche getheilten Nasenkuppe; die Augen sind grols, glänzend schwarz, vortretend wie bei den Ratten; am Oberkiefer befinden sich lange, feine, schwarze Bartborsten; Ohren grofs, nackt, sehr glänzend, breit eiförmig geformt. -

Die Zunge ist lang, walzenförmig, lälst sich beinahe sechs Linien weit aus dem Munde hervorziehen, und ist mit feinen seidenartig erscheinenden Papillen besetzt; in den Mund zurückgezogen liegt sie mit Querrunzeln.

Gebifs: Schn, $\frac{x 0}{8}$; Eckz. $\frac{x \cdot 1}{1 \cdot 1}$; Backenz, $\frac{6 \cdot 6}{7 \cdot 7^{\circ}}$. Schneidezähne im Oberkiefer zwei grölsere nahe bei einander und getrennt von den übrigen; dann auf jeder Seite vier kleinere dicht aneinander gestellt, nun folgt eine Lücke. Im Unterkiefer in der Mitte der Schneidezäh. ne eine kleine Lücke, dann auf jeder Seite vier kleine nahe aneinander gereihte und schräge nach der Mitte geneigte Schneidezähne, auf welche der Eckzahn folgt. Eckzähne im Oberkiefer: auf den leeren Raum folgt ein grofser spitziger und gekrümmter Eckzahn, im Unter. kiefer ist der Eckzahn einer jeden Seite eben. 


\section{- $408-$}

falls gekrünmt. - Backenzähne im Oberkiefer: nach dem Eckzahne folgt ein kleinerer Kegelzahn, dann einer mit zwei Spitzen, und nun vier Backenzähne auf jeder Seite, welche Zackenkronen haben. - Im Unterkiefer folgt nach dem Eckzahne ein kleiner Kegelzahn, ein grofser schief abgestutzter, ein kleiner einfacher Zahn, und vier bis fünf Mahlzähne mit vier bis fünf zugespitzten Zacken auf ihrer Krone.

Die Gestalt des Körpers gleicht etwas der des Myoxus Glis. - Die Vorderfüfse sind rund und klein, ihre Zehen kurz und ziemlich gleich lang, die innerste ist die kürzeste, die nächstfolgende und die äufsere sind gleich lang, die beiden mittleren sind am längsten und eirander gleich. Die Ballen des Nagelgliedes treten vor und sind so lang als die feinen gekrümmten Krallennägel. - Die Hinterhände sind klein, rundlich, mit kurzen Fingern, aber gröfseren zusammengedrückten Krallennägeln und einem getrennten stumpfen Daumen, der keinen sichtbaren Nagel hat. Der Schwanz ist länger als der Körper, an der Wurzel beinahe zwei Zoll lang dicht behaart wie der übrige Körper, alsdann aber ist er sehr glatt, ohne alle Borsten, blofs mit einer sehr zart geschupp. 
ten, beinahe chagrinartigen Haut bedeckt; an seinem greifenden Ende ist er nach unten mit. einigen Querfalten bezeichnet.

Bei dem männlichen Thiere liegen die Testikel frei unter dem Leibe vor dem After; sie sind mit gelblichem Pelz bedeckt und die. Ruthe tritt aus der Afteröfinung hervor. -

Der ganze Körper ist mit einem feinen, äufserst dichten, etwa sechs bis sieben Linien langen, sanften und wolligen Haare bedeckt; Backen, Kinn, Kehle, Brust, Bauch, After und innere Seite der Beine sind schön dunkel röth. lich-gelb oder röthlich-isabellfarben, eine schöne Färbung, welche sich bei diesen für zoolo. gische Sammlung präparirten Fellen gänzlich verliert und alsdann in ein fahles gelbliches Grauweils verbla[st *). - Alle oberen Theile sind röthlich-aschgrau; indem die Haare eine aschgraue, und ihre Spitzen eine grauröthliche Farbe haben. - An den unteren Theilen und dem Kopfe ist das Haar kürzer als an den oberen. - Jedes Auge ist rundum von einem

*) Herr Temminck hat in seinen Monographien dieses unter der Benennung Didelphis cinerea von mir mit/retheilte Thier nach einem ausgestopften Exemplare beschrieben, wodurch in seiner Angabe der Farben einige kleine Unrichtigkeiten entstehen muIsten. 


\section{$-410$}

schwärzlichen Flecke eingefafst. Der Fufs selbst mit den Zehen ist nackt und fleischroth, nur mit einzelnen feinen Seidenbärchen besetzt; der Schwanz ist an seinem nackten Theile in seiner grölsesten Ausdelınung von einer fleischrothen Farbe, an der Wurzel aber, da wo die Behaarung endet, einen Zoll vier Linien lang dunkel blaugrau oder schwärzlich gefärbt.

Ausmessung:

Ganze Länge : • • • 14" $8^{\prime \prime \prime}$.

Länge des Körpers . . . . . 6" $6^{\prime \prime} 5^{\prime \prime \prime}$. Länge des Schwanzes . . 8 " g"'. Höhe des Ohrs an seiner äulseren

Seite . . . 1 10".

Länge des Kopfs bis zu seinem vor-

deren Ohrrande . . . $1^{\prime \prime} 4^{\frac{1}{2}}{ }^{\prime \prime}$.

Dieses Beutelthier lebt im östlichen Brasilien. Ich erhielt es in den Wäldern des $M u$ curí zu Morro d'Arara, wo man es unter der Benennung Jupatí mit den übrigen verwandten Arten verwechselt. In Minas Geraës soll es Quica*) genannt werden, - Es raubt stark

*) Herr Temminck hat diese Benennung einer anderen Species beigelegt. 


\section{- $411-$}

und beifst in den Ställen, gleich dem Marder und Wiesel, eine Menge von Hühnern todt, saugt ihnen das Blut aus und verzehrt auch die Eier. Es klettert geschickt, wobei ihm der Schwanz zum Festhalten dienen soll, Zu Morro d'Arara fanden die jagenden Indier eine Schlange, welche eben ein solches Thier verzehrte. Es hat einen eigenthümlichen unangenehmen Geruch, unterscheidet sich aber übrigens in der Lebensart und den Manieren nicht von den übrigen Jupati's.

Das weibliche Thier habe ich nicht zu sehen bekommen, Herr Temminck aber, der seitdem mehrere Exemplare untersuchte, versichert uns, dafs der Beutel dem weiblichen Thiere fehle.

$$
\text { 5. D. } m u r i n a \text {. }
$$

Das mäuseartige Beutelthier.

Abbildungen zur Naturgeschichte Brasilien's.

Temminck MIonographies etc. p. 50.

Jupati im östlichen Brasilien.

Ntiähäm bei den Botocuden.

Das mäuseartige Beutelthier scheint über den gröfsten Theil von Süd-America verbreitet. - Ich erhielt es in den grofsen Wäldern des Flusses Mucuri. - Alle seine oberen Theile sind von einein röthlich-fahlen Grau- 


\section{- 412}

braun, die unteren Theile gelblich - weils; von der Nase durch die Augen hinauf zieht ein breites schwärzliches Feld; die Ohren sind dünn, nackt, durchsich!ig, länglich - eiförmig; die Zehen sind zart, mit etwas aufgerichteten Nägeln und lang vortretenden Ballen an den Nagelgliedern; männliche Geschlechtstleile wie an der vorhergehenden Arl; Srhwanz an seiner Wurzel nur sehr wenig behaart, mit röllig nackter, höchst fein chagrinartiger, glatter Haut bedeckt, länger als der Körper und röth. lich-weils *) ohne dunklere Zeichnung: -

\section{Ausmessung:}

Länge des Körpers etwa

- $\quad 5^{\prime \prime}$ und einige Linien.

Länge des Schwanzes etwas über 6" Höhe des Ohres über dem Kopfe etwa $\quad 6^{\prime \prime \prime}$.

Anmerkung: Ich habe in der von mir bereisten Gegend nur die genannten Arten der Beutelthiere selbst $\mathbf{z u}$ untersuchen Gelegenheit gehabt, allein eine sehr schöne kleine Art, deren Fell auf bräunlichem Grunde mit Längs.

*) Man hat auch dieses Beutelthier bisher nur nach ausgestopften Exemplaren beschrieben, daher finden sich in den Beschreibungen gervöhnlich die Farhen einiger Theile unrichtig angegeben. 


\section{$-413-$}

reihen weifser Flecken bezeichnet ist, habe ich mir leider nicht verschaffen können, ob ich gleich Nachricht davon erhielt. -

Da die in diesem Verzeichnisse erwähnten Beutelratten zum Theil unter sich, zum Theil mit anderen bekannten Arten viel Aehnlichkeit zeigen, so will ich, der Uebersicht wegen, hier ihre Hauptzüge noch einmal in der Kürze zusammenfassen. -

A. Beutelthiere, deren Pelz eine Wolle, und darüber lange Stachelhaare zeigt.

Der nackte Theil ihres Schwanzes ist an der Wurzel schwärzlich, nach der Spitze hin röthlich-weifs gefärbt. Ohren einfärbig.

1. Didelphys marsupialis, Linn. Schwanz kürzer als der Körper, und an der Wurzel etwa auf $\frac{x}{6}$ seiner Länge behaart; Ohren gänzlich einfärbig schwärzlich -braun; Wollhaar des Körpers grau mit schwärzlichen Haarspitzen, Stachelhaare weifslich mit gelblichen Spitzen; Kopf mit drei etwas undeutlichen schwarzbraunen Längsstreifen bezeichnet. - 
2. D. aurita. In Gestalt und Farbe Didel. phys marsupialis sehr ähnlich, allein Kopf und Ohren gröfser, der Schwanz länger.

B. Beutelthiere mit hurzem mäuseartigem Pelze, der keine Stachelhaare zeigt.

3. D. myosurus, Temm. Pelz röthlich-braun, aut dem Rücken etwas dunkler; über jedem Auge ein hell rother Fleck; Ohren graubraun, und wie an allen diesen Thieren nackt; Schwanz länger als der Körper, an der Wurzel kaum einen Zoll lang behaart, nackter Theil desselben an der Wurzel graubraun, an der Spitzenbälfte weifslich. -

4. D. cincrea. Schwanz länger als der Körper, an der Wurzel stark behaart; der nackte Theil zur Hälfte schwärzlich, an der Spitzenhälfte wei̊slich; obere Theile des Körpers röthlich-aschgrau, untere Theile gelb. röthlich-isabellfarben; um das Auge ein schwärzlicher Fleck.

5. D. murina, Linn. Obere Theile fahl röthlich-graubraun; untere Theile gelblich-weifs; von der Nase durch die Augen hinauf zieht ein breites schwärz!iches Feld; Schwanz an der Wurzel wenig behaart, röthlich-weils, olne dunklere Zeichnung. - 


\section{$-415$}

Ich bemerke schliefslich noch, dafs aus den beiden hier aufgeführten Unterabtheilungen des Genus Didelphys vielleicht zwei besondere Geschlechter gebildet werden könnten, nach der verschiedenen Bildung des Gebisses, des Haares u. s, w.

\section{O R. IV+ $G l i r e s_{+}$ $N$ a $g$ e e r.}

Die Nagethiere bilden eine von der Natur völlig abgesonderte, durch die beiden grofsen meifselartigen Vorderzähne im Oberkiefer kenntliche Ordnung. Wenn gleich die Anzahl dieser Thiere sehr grofs und ihre Bildung sehr mannichfaltig ist, so haben sie doch gewisse Aehnlichkeiten, die sie in allen Welttheilen einander nähern. Sie sind über alle Theile unserer Erde verbreitet, besonders zahlreich an Arten in Asien, doch auch in America, hier und in Europa aber mehr an Individuen. - Unter ihnen findet man die an Individuen und Arten zahlreichsten Geschlechter, die Mäuse, Haasen, Eichhörnchen u. s. w. Welch eine ungeheuere Anzahl von Haasen und 
Mäusen sind allein über unser Deutschland verbreitet!

America hat manche dieser Geschlechter mit den übrigen Weltheilen gemein, hierher gehören die Biber, Haasen, Eichhörnchen, Mäuse, Stachelthiere; allein America hat auch mehrere ihm eigenthümliche Thierformen aus dieser Ordnung, wohin die Geschlechter Coelogenys, Hyclrochoerus, Dasyprocta, Cavia, Loncheres und Fiber gehören, von welchen die fünf ersteren in Brasilien vorkommen, und daselbst zum Theil die besten Arten der jagdbaren Thiere enthalten. Alle nehmen ihre Nahrung aus dem Pflanzenreiche und sind sehr fruchtbar, daher zahlreich an Individuen. Ich habe für diese Ordnung die von Illiger aufgestellten Familien angenommen.

\section{$\mathrm{F}$ a m. I. II u $\mathrm{r}$ i $\mathrm{n}$ a. Mäuseartige Thiere.}

Brasilien und die übrigen heilsen Länder unserer Erde sind nicht so reich an Mäusen und mäuseartigen Thieren als die gemälsigten Zonen, und alle anderen Länder werden in 
dieser Hinsicht von den grofsen Ebenen des russischen Asiens übertroffen.

Azara hat für Paraguay etwa fünf bis sechs Arten von Mäusen aufgezählt, ich habe in Brasilien eine noch geringere Anzahl kennen gelernt.

$$
\begin{aligned}
& \text { G. 20. } M u \text { s. } \\
& \text { M a u s. }
\end{aligned}
$$

Ueberall bekannte, oft verwünschte Thiere, die indessen in den brasilianischen Wäldern und Wildnissen nie zu einer solchen Menge heranwachsen, als bei uns. Vielleicht werden dereinst, wenn der Ackerbau auch in jenen Gegenden mehr ausgebreitet und die vielen Raubthiere vermindert seyn werden, diese Thiere auch dort an der Zahl zunehmen und dem Landmanne so lästig werden, wie bei uns in manchen Jahren. Bisjetzt bemerkt man in Brasilien wenig mäuseartige Thiere, und nur mit Mühe ist es mir gelungen, einige wenige Individuen aus dieser Familie zu erhalten. -

Die Brasilianer belegen in ihrer portugiesischen Sprache die Mäuse im Allgemeînen mit der Benennung Rato. -

II, Band. 


\section{- $418-$}

1. M. pryrhorhinus. Die Catinga - Maus.

M.: Schwanz sehr lang; Haar graugelb; Nase, Oltren und der hintere Theil der Schenkel rothbraun.

Abbildungen zur Naturgeschichte Brasilien's. Schinz Thierreich u. s. w., B, I. p. 288. Rato bei den Brasilianern.

Beschreibung eines weiblichen Thieres: Gestalt im Allgemeinen die der grofsen Feldmaus (Mus sylvaticus), aber der Schwanz länger, der Leib stärker, und die Ohren im Verhältnifs kürzer. - Die Augen sind wie an jener grofs, glänzend, schwarz und vortre. tend; die Ohren grofs und beinahe nackt; lange schwarze Bartborsten am Oberkiefer, welche zurückgelegt bis über das Ohr hinausreichen.

Gebifs: Schn. $\frac{2}{2}$; Backenz. $\frac{3 \cdot 3}{3 \cdot 3}$. - Schneidezähne im Oberkiefer mälsig grols, senkrecht gestellt, dicht aneinander geprefst, zusammen gedrückt, die Schneide ein wenig abgerundet und an ihrem Hintertheile nur mälsig ausgeschnitten, von Farbe gelb; im Unterkiefer sind sie schmal, schlank und zugespitzt, etwas nach vorn geneigt; Backenzähne im Oberkiefer an 


\section{- 419}

jeder Seite drei, der hinterste ist der kleinste, die beiden vorderen sind länger, sie haben abgeflächte Mahlflächen mit ziemlich flachen, abgenutzten Höckern an dem Rande, welche ziemlich gepaart stehen und dazwischen einige seicht erhöhte Querleisten; der vordere hat etwa fünf seicht abgeflächte Höcker, von denen der erste das vordere Ende des Zahnes einnimmt, wo er einen erhöhten Rand bildet, und alsdann an jeder Seite, sowohl der inneren als der äulseren, zwei Höcker, welche ziemlich gepaart stehen; der zweite Zahn hat an jedem Rande zwei Höcker, welche schief gepaart stehen und von den Schmelzleisten gebildet werden, die an jeder Seite zwei nach auIsen gerichtete Winkel bilden; der dritte Bakkenzahn hat an jedem seiner Seitenränder einen seichten stumpfen Höcker und nach hinten einen abgerundeten scharfen Rand. Im Unterkiefer sind drei Mahlzähne an jeder Seite, wovon der hinterste der kleinste ist. Sie haben rundum einen erhöhten Schmelzrand und einige solche winklige Querleisten; an dem vorderen Zahne macht der Schmelzrand an jeder Seite etwa zwei mit ihren Spitzen nach aufsen gerichtete Winkelfiguren, die an ihrer Spitze einen seichten Höcker bilden; ei- 
nen ähnlichen trägt der Zahn an seinem Vorderende, wodurch derselbe also auch etwa fünf Höcker erhält, von denen vier gepaart stehen, beinahe wie an Mus decumanus, nur Ủafs hier der vordcre Höcker etwas gabelförmig getheilt ist, und also der erste Backenzahn der Wanderratte eigentlich sechs immer gepaarte Höcker trägt. Bei der eben genannten Ratte ist aber die Mahlfläche des vorderen Backenzahnes mit weit stärkeren Vertiefungen versehen, ein Character, worin Mus decumanus, sylvaticus und andere von der von mir beschriebenen brasilianischen Art etwas abweicht. Der zweite Backenzahn meiner brasilianischen Maus hat sowohl an der inneren als äufseren Seite zwei Höcker, die ebenfalls wieder die Spitze eines nach aufsen gerichteten, winklig gestalteten Schmelzrandes bilden; der dritte Zahn hat rundum blofs einen erhöhten Schmelzrand, der an der inneren Seite ziemlich geradlinig ist, an der äufseren aber in der Mitte einen eingehenden Winkel zeigt. Man ersieht aus dem Gesagten; dafs die Bildung der Mahlflächen dieser Maus einige Verschiedenheit von der des Mus decumanus und sylvaticus zeigt; dennoch aber ist die ganze äufsere Gestalt, die Zahl und Hauptbildung ihrer Zähne voll- 
kommen mit der unserer europäischen Mäuse übereinstimmend *).

Vorderfülschen zart, die Daumenwarze glatt mit einem Kuppennagel bedeckt; von den vier Fingern sind die beiden mittleren am längsten; die Hinterfülse treten beinahe bis zu der Ferse auf, der Daumen hat einen kleinen, zarten Krallennagel, die äufsere Zehe ist die kürzeste, die drei inneren sind einander ziemlich gleich; Nägel zart und stark gekrümmt. Der Schwanz ist an der Wurzel einige Linien lang mit den Haaren des Körpers überzogen, übrigens nackt, mit Hautringen und kleinen Schüppchen bedeckt, wie an Mus sylvaticus, auch mit sehr feinen, weifslichen Borsthärchen besetzt, dabei viel länger als der Körper. Drei Paar Zitzen befinden sich unter dem Leibe, wovon das hintere zwischen den Schenkeln, das vordere an der Brust steht.

Haar des Körpers fein und mäuseartig, an allen oberen Theilen schwärzlich und gelblich gemischt, durch diese Mischung entsteht die graugelbe Farbe; die Spitze der Nase am

*). Wer bei allen Thieren des Mäusegeschlechtes eine Zahnbildung olne die geringste Abweichung zum Grunde legen wollte, der würde dieses Genus noch mehrmals zer.spalten müssen. 
Oberkiefer ist etwa halb bis zum Auge hin hell rostroth gefärbt, eben so, nur heller, die beiden beinahe nackten, sehr sparsam und fein behaarten Ohren. Unterer Theil der Hinterbeine etwa so weit als sie nackt (d. h. sehr dünne behaart) sind, hell gelbröthlich gefärbt. - Ueber den Hinterschenkeln fängt der Rücken an stark hell rostroth gemischt zu werden, und diese Farbe nimmt zu, so dafs sie an der Schwanzwurzel die rein herrschende ist; alle unteren Theile von dem Unterkiefer bis zu dem After, so wie die innere Seite der Glieder sind rein weils. -

Ausmessung :

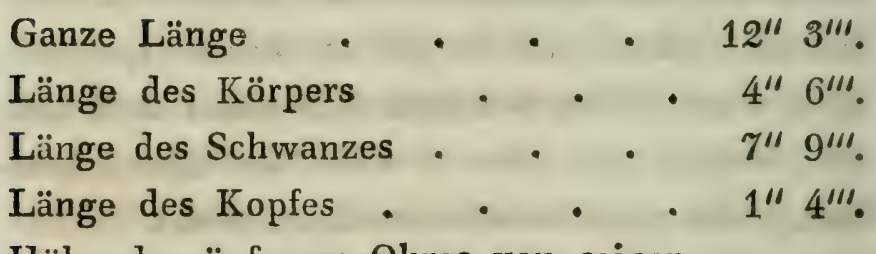

Höhe des äufseren Ohres von seiner

höchsten Stelle am Kopfe aus gemessen

Schwanz an der Wurzel behaart et-

wa auf

Diese schöne Maus fand ich im Sertong der Capitania da Bahia, und zwar in den niederen trockenen Cating $\alpha$-Waldungen und den 


\section{$-423$}

Gebüschen, die man Carasco nennt, von beiden Ausdrücken habe ich die Erklärung in dem zweiten Theile der Beschreibung meiner Reise nach Brasilien gegeben. Wir fanden nur einmal eine solche Maus mit ihrem Neste, nachher ist sie mir nie mehr zu Gesichte gekommen. Von dem Orte, wo ich sie fand, schliefse ich, dafs sie nicht in der Erde, sondern in den Gebüschen lebt, wie unsere Haselmäuse (Myoxus), und eine wahre Waldmaus ist, worüber fernere Reisende die Bestätigung geben werden.

In der Mitte des Februars fand ich ein Nest mit fünf schon behaarten Jungen, die Mutter war sehr schnell und geschäftig, sie lief $a b$ und $z u$, als sie die Gefahr herannahen sah. - An einem niederen Baume hatte sie ihre Jungen in einem jener sonderbaren Nester des Anabates rufifrons verborgen, welche aus einer, an einer Schlingpflanze aufgehängten grofsen Masse von dürren, quer durch einander gefilzten Reischen bestehen, oft drei bis vier Fufs lang sind, und dadurch entstehen, dafs der Vogel alljährlich das neue Nest auf das alte setzt. - Hier bewohnte der Vogel das obere neue Nest, und die Maus mit ihrer Familie eines der älteren, beide vertru- 


\section{- $424-$}

gen sich friedlich in republicanischer Einigkeit. -

Die fünf im Neste gefundenen Jungen glichen, obgleich sie noch klein waren, vollkommen der Mutter, nur waren ihre röthlichen Theile weniger lebhaft gefärbt und ihre Köpfe dick, -

Diese Maus ist, wie gesagt, leicht und schnell, sie besteigt die Bäume sehr geschickt und hat eine zischende oder fein pfeifende Stimme.

\section{F a m. II. Cunicularia.}

$$
\text { E r d }
$$

Diese Familie scheint in Brasilien sehr wenig zahlreich, ich setze indessen ein Thier hieher, dessen Lebensart ich selbst nicht hinlänglich kennen zu lernen Gelegenheit fand.

$$
\text { G. 21. H y } p u d a \text { e u s. }
$$

$$
\mathrm{W} \text { ü } \mathrm{h} 1 \mathrm{~m} \text { a u s. }
$$

Die Thiere dieses Geschlechtes zeichnen sich vor den Mäusen des vorhergehenden besonders durch blätterige Backenzähne, mehr zugespitzte untere Schneidezähne, ein kurz ab- 


\section{$-425-$}

gerundetes behaartes $\mathrm{Ohr}$, einen dickeren mehr behaarten Kopf und Körper, und kurzen mehr behaarten Schwanz aus. Dennoch sind die Uebergänge in der äulseren Gestalt unter diesen Thieren sehr auffallend. - Die hier erwähnte Maus z. B. hat einen ziemlich dünn behaarten, mit schuppigen Hautringen versehenen Schwanz, steht also etwa in der Mitte zwischen beiden Geschlechtern. -

\section{H. dasytrichos.}

Die rauchhaarige Wühlmaus.

W.: Schwanz ziemlich behaart, mit häutigen Schuppenringen versehen, kürzer als der Körper; Ohr kurz und behaart; Pelz sehr dicht, schwarzbraun, gelbröthlich bespitzt. -

Mus dasytrichos, Schinz das Thierreich u. s, w, B. I. p. 288.

Rato Bubo in der Gegend von Camamú unweit Bahia:

Rato am Mricurt.

Beschreibung: Diese Maus hat einen dik: ken Kopf mit sehr kleinen Augen;-die Bartborsten sind zart und erreichen zurückgelegt das Ende des Ohrs; dieses ist im Pelze versteckt, kurz, abgerundet, von seiner Mitte an bis zum Rande mit glatten anliegenden Haaren besetzt. - Die Backentaschen scheinen zu 
fehlen, doch war diese Untersuchung schwierig, da der Kopf zerschlagen war.

Gebifs: Schn, $\frac{2}{2} ;$ Backenz. $\frac{3 \cdot 3}{3.3}$. Schneidezähne des Unterkiefers pfriemförmig zugespitzt; Backenzähne auf jeder Seite im Oberund Unterkiefer drei, quergefurcht.

Vorderfüfse fünfzehig; die innerste ist eine Daumenwarze mit einem gekrümmten Krallennagel, welcher gebildet ist wie an den übri gen Zehen, nur kleiner; äufsere Zehe viel kürzer als die drei mittleren, von welchen die innere nur um ein weniges kürzer ist, als die beiden äufseren; die Nägel dieser Zehen sind über anderthalb Linien lang und dabei sanft gekrümmt. Die Hinterfüfse treten beinahe bis zur Ferse auf; äufsere Zehe am kürzesten, die innere ein wenig länger, die drei mittleren um ein Glied länger, - Schwanz beinahe nackt, mit schuppigen Hautringen wie an der vorhergehenden Art, dabei mit einzelnen feinen Borstenhaaren besetzt.

Haar des ganzen Körpers sehr dicht, sanft, über drei Linien lang; am Grunde seí. denartig wollig, dunkel grau, dann nach aufsen zu schwarz'sraun uuid mit rostrother oder rostgelber kleiner Spitze. - An der Mitte des Rïckens und den hinteren Theilen sind die 


\section{- 427}

röthlichen Haarspitzen wenig bemerkbar, daher herrscht hier die schwarzbraune Farbe; an dem Kopfe, den Seiten des Halses und der Brust sind dagegen die Haare stark rostroth bespitzt, daher sind diese Theile stark mit der genannten Farbe gemischt. - Die untere Seite des ganzen Thiers vom Munde bis zum Schwanze ist heller gefärbt, blafs röthlich-graugelb. - Die Füfse und der Schwanz sind einförmig dunkel graubraun.

Ausmessung eines solchen Thieres am Mucurí.

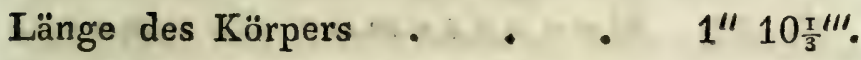
Der Schwanz war abgebrochen.

Ein anderes Exemplar aus Camamú hielt ohne den Schwanz etwa drei Zoll in der Länge.

Diese Maus scheint längs der ganzen Ostküste verbreitet, ja vielleicht über ganz Brasilien. Ich fand sie am Mucuri und erhielt ein Exemplar von Herrn Freyreifs aus Camamú, südlich der Bahia de todos os Santos, wo man sie Rato Bubo nennt. In den grofsen Urwaldungen am Ufer der Lagoa d'Arara habe ich sie ebenfalls bemerkt. Sie scheinit in der Erde zu wohnen, ob sie aber darin Gänge anlegt, kann ich nicht bestimmen. 
Nirgends habe ich im östlichen Brasilien aufgeworfene Erdgänge beobachtet, wie wir sie von den Maulwürfen und Feldmäusen bei uns wahrnehmen, auch scheint der dortige, meistens aus Thon und Letten bestehende Boden nur an wenigen Stellen für dergleichen Erdwühler günstig zu seyn. -

\section{Fam. III. P a lmipeda. $S \mathrm{ch}$ w i $\mathrm{mm}$ f fötler.}

G. 22. Myopotamus Commers. W a siserm a us.

Ich habe dieses Geschlecht hieher gesetzt, nicht als wenn ich die Existenz dieser Thiere an der Ostküste von Brasilien bekräftigen könnte, sondern weil ich vermuthe, dafs das Thier, welches man daselbst Cachorro d'Agoa (Wasserhund) nennt, wahrscheinlich der Coypus des Molina seyn dürfte. - Ich habe das Thier nicht gesehen, welches die Brasilianer an der Ostküste unter dem eben angegebenen Namen kennen, es soll in den Flüssen leben, und einige geben ihm ein weifs und schwarz geflecktes Fell, doch vereinigen sich die besseren Be- 


\section{$-429$}

obachter darin mit einander, dais es in Ge. stalt und Farbe der Fischotter ähnlich sey. Auch die Corografia brasilica erwähnt im 1sten Bande (pag. 62) des Cachorro d'Agoa als eines Thieres, welches mehr den Gewässern des innern Landes eigenthümlich sey. -

\section{F a m. IV. A g i 1 i a. S c h w i p p e.}

Die Thiere dieser Familie finden wir beinahe über alle Theile unserer Erde verbreitet. Sie lehen unter allen Climaten von den Sämereien der Waldbäume oder von Früchten, und sind daher meistens Thiere der Wälder und Gebüsche. In den kälteren und gemäfsigten Theilen unserer Erde giebt es mehrere Arten, auch ist daselbst ihr Pelz zum Theil brauchbar, welcher hingegen in wärmeren Ländern keinen Nutzen gewährt. -

$$
\text { Gen. 23. } S c \text { c } u \text { u } u \text { s. }
$$

E ic h h or n.

Ich habe an der Ostküste nur eine Art dieser Familie gefunden, die aber über die 


\section{$-450-$}

ganze von mir bereiste Gegend verbreitet ist, das heifst rom 13ten bis zum 23sten Grade südlicher Breite.

1. S. $a$ e $s$ t u a $n$ s, Linn.

Das brasilianische Eichhorn.

S. brasiliensis Brifs.

Brasilian Squirrel Penn.

Abbildungen zur Naturgeschichte Brasilien's.

Cachingélé der Brasilianer.

Jukeneck (en durch die Nase) bei den Botocuden.

$\mathrm{Da}$ dieses Thier sehr bekannt in den $\mathrm{Ca}$ binetten ist, so will ich nur einige Bemerkungen nach den frischen Exemplaren hinzufügen. -

Das Auge ist grols, lebhaft, dunkel ge. färbt; die Ohren sind mittelmälsig lang, abge. rundet, von aulsen und innen behaart, jedoch bei einigen Exemplaren nur sehr dünne, bei den Weibchen gewöhnlich mehr nackt. Die Geschlechtstheile sind gebildet wie an unserem Eichhorn, die Hoden grols. - Die Weibchen hatten vier Paar sehr starke Zizzen. - Die vier Nagezähne sind gelb. Die Farbe des ganzen Thiers ist dunkel graubraun, alle Haare mit gelblichen Spitzen; von oben gesehen hat dieses Eichhorn einen olivengrünlichen Anstrich; alle unteren Theile sind 
blafsgelb; auf der Mitte der Brust befindet sich ein weifser Strich. -

\section{Ausmessung :}

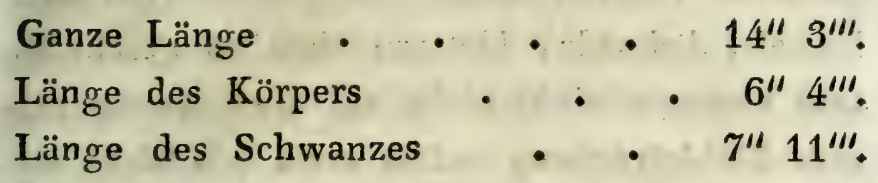

Es giebt Exemplare, welche in der Länge 16. bis 17 Zoll halten. -

Marcgrave redet (pag. 230) von einem Eichhorne, dessen Beschreibung in allen Theilen auf das hier aufgeführte palst, wenn man den weifslichen Längsstreifen in jeder Seite ausnimmt, eine Bemerkung, die auch Herr Professor Lichtenstein in seiner Erläuterung der Marcgrave'schen Thiere durch die Gemälde der Menzel'schen Sammlung (pag. 16) machte. - Auch die bläuliche Pupille scheint mir nicht mit meinem Thiere übereinzustimmen; denn dieses hat ein Auge, welches grols, schwarz, lebhaft, und dem unseres europäischen Eichhornes ähnlich ist. Herr Dr. Boie bemerkt, daIs Buffon's grand Guerlinguet wahrscheinlich Sciurus aestuans sey; denn es kommt im holländischen Guiana häufig vor. Desmarest in seiner Mammalogie hat beide Thiere ebenfalls vereinigt. 


\section{- $432-$}

Das brasilianische Eichhorn lebt überall in den grofsen Waldungen dieses Landes und gleicht in Lebensart und Manieren den europäischen Thieren dieses Geschlechts. Sie sind lebhaft, behende, klettern eben so geschickt, und kommen nicht mehr auf die Erde als unsere Eichhörnchen, sollen auch wie diese ein Nest für ihre Jungen erbauen. $\mathrm{Ob}$ sie in einem warmen Lande wie Brasilien, nach Art unserer Eichhörnchen Vorräthe sammeln, bezweifle ich, da es in den brasilianischen Wäldern nie an Früchten mangelt. Ueber die Zahl ihrer Jungen habe ich nie Gelegenheit gehabt, zuverlässige Beobachtungen anzustellen, nach der Aussage der Jäger indessen sollen sie drei, vier bis fünf zur Welt bringen. - Im Magen fand ich zerbissene Früchte und Saamen. Eine Stimme habe ich nie von ihnen gehört. Das Fleisch dieser Thierchen soll wohlschmekIrend seyn. - Aufser dem alles zerstörenden Menschen sind Raubvögel und kletternde Raubthiere, besonders die Hyrare, ihre Feinde. 
Fam. V. A c u l e a $t$ a.

$$
\text { S t a c h e lt r äg e r. }
$$

Die mit Stacheln bedeckten Nager kommen in den meisten Theilen der alten und neuen Welt vor. America besitzt die mit Rollschwänzen versehenen Stachelthiere und die Stachelratten als ihm eigenthümlich, -

$$
\begin{aligned}
& \text { Gen. 24. } H \text { r } s \text { t } r \text { i } x . \\
& \text { St a chelthier. }
\end{aligned}
$$

Brasilien besitzt mehrere Arten von Stachelthieren, welche sich sämmtlich durch einen Rollschwanz auszeichnen und nicht, wie die der alten Welt, auf der Erde, sondern meistens auf Bäumer leben. - Sie sind langsame Thiere, welche weder Fähigkeiten noch empfehlende Eigenschaften verrathen, auf ein und der. selben Stelle oft lange unbeweglich bleiben, kaum eine Stimme von sich geben, dem Menschen weder Nutzen noch Annehmlichkeit verschaffen, und deren einförmige stille Lebensart nur darauf beschränkt scheint, nach Früchten auf die Bäume zu steigen, oder gewisse Wurzeln aufzusuchen. Sie sind besonders zahlreich an Individuen.

II. Band. 
1. H. insidios $a$, Licht. Der Cuiy des Azara.

Couiy, Az. essais etc. Vol. II. p. 105. Kuhl's Beiträge, p. 71.

Abbildungen zur Naturgeschichte Brasilien's. Acoró - io bei den Botocuden.

Ouriço-Cacheiro bei den Brasilianern oder brasilianischen Portugiesen,

Der Körper ist dick, Fülse kurz, Kopf kurz und abgestumpft; Schwanz an der Wur-

- zel dick, aufwärts greifend, daher an der oberen Seite nach der Spitze hin nackt, an der unteren hingegen mit Borsten besetzt.

Beschreibung: Kopf rundlich, die Schnautze nach vorn wie stumpf abgeschnitten, mit muskulöser Haut überzogen und mit zwei rundlichen Nasenlöchern an der Vorderseite versehen; Oberlippe ein wenig gespalten; Auge klein, mit schön hell graubrauner Iris; äufseres $\mathrm{Ohr}$ fünf Linien hoch, halbcirkelförmig, dünn, mit feinen gelblich wolligen Haaren be. deckt.

Gebifs: Schneidez, $\frac{2}{2}$; Backenzähne $\frac{5 \cdot 5}{5 \cdot 5}$. Die beiden Vorderzähne in jedem Kiefer sind lang, schmal, hinten mit einem Ausschnitte, der beinahe bis auf das Zahnfleisch herabgeht. In jedem Kiefer auf jeder Seite stehen fünf 


\section{$-435$}

Backenzähne, mit breiten, gefurchten, schmelzfaltigen Kronen.

Die Füfse sind stark und kurz, sehr mus kulös und zum Klettern eingerichtet; die vor. deren haben vier Zehen, wovon die innere und äufsere etwas kürzer sind, alle haben etwas zusammengedrückte, glatte, gekrümmte, mittelmäIsig lange Krallennägel, die beiden mittleren sind länger als die übrigen; an der inneren Seite des Fufses steht ein starker abgerundeter Ballen mit einer kleinen Daumwarze. Hinterfüfse mit vier Zehen, wovon die äufsere etwas weniges kürzer ist; die Nägel der drei inneren Zehen sind etwas stärker als die der VorderfüIse, sechs und eine halbe Linie lang, übrigens eben so gebildet; an der inneren Seite steht ein abgerundeter stark vortretender Kletterballen, der an seinem vorderen Theile eine von einem fühlbaren Knochengliede unterstützte Daumwarze trägt. - Schwanz kegelförmig, an der Wurzel dick, allmälig dünn auslaufend und nicht nach der gewöhnlichen Art der Thiere unterwärts, sondern oberwärts nackt und greifend. An dieser nackten Stelle, welche etwas weniger als ein Drittheil der Schwanzlänge einnimmt, befinden sich viele kleine Hautquerfalten. 


\section{Die männlichen Geschlechtstheile sind un-}

ter der Haut verborgen und bilden eine von aufsen sichtbare Erhöhung vor dem After; die Testikel haben eine längliche Gestalt. - Das hier beschriebene männliche Thier hatte zwei Brust - und zwei Bauchzitzen, ein Weibchen habe ich zufällig nicht erhalten. -

Die Nase, Umgebung des Mundes, die Augenlieder und Ohren des Thiers sind mit einer nackten röthlich-grauen Haut bedeckt; schon vorn zwischen den Augen und unter denselben auf den Backen fangen kurze Stacheln an, welche den Hals oben und an den Seiten, die Schultern, Rücken, Seiten, kurz alle oberen und Seitentheile des Thiers bedek. ken, und mit einem Streifen bis über die Hälfte des Schwanzes auf seiner Oberseite hinlau. fen; auf dem Rücken, den Schenkeln und Seiten sind sie am längsten, einen Zoll zwei Linien lang, sämmtlich hell citrongelb mit schwarzbraunen Spitzen, welche äufserst feine und fühlbare Widerhäkchen zu haben scheinen; die Wurzel dieser Stacheln ist ein verdünntes Ende von der Länge einer Linie, welche nur sehr wenig fest in der Haut eingea pflanzt ist. Zwischen den Stacheln steht ein sehr sanftes, weiches, seidenartiges, graubrau- 


\section{- 437 -}

nes Haar, welches noch einmal so lang ist, als die ersteren, auf dem Rücken selbst ist es an zwei Zoll länger als die Stacheln, auch haben an diesem letzteren Theile die Haare lange hell röthliche Spitzen. Der vordere Theil des Gesichts hat ein sanftes kurzes Haar ohne Stacheln, es ist graubraun mit hell gelblichen Spitzen; an dem Hinterkopfe ist das Haar lang. Die Beine an ihren unteren und inneren Theilen, Seiten und Bauch, so wie die Seiten des Schwanzes sind dunkel graubraun behaart, und alle diese Haare haben röthlich-gelbe Spitzen; an Stirn und Bauch besonders ziehen dieselben stark in's Röthliche, auch haben die Stacheln der Stirn, als einzige Ausnahme, gelbröthliche Spitzen, sie sind dabei schwarzbraun und an der Wurzel wieder blafsgelb gefärbt. - Der Schwanz ist auf seiner unteren Seite mit dichten, aneinander liegenden, harten, gelbröthlichen, gegen ihr Ende rothbraunen Borsten besetzt, die beinahe bis zur Spitze verbreitet sind, sie scheinen ihn bei dem Aufschleifen zu schützen; an seinen Seiten hat er lange schwärzlich - braune Haare mit röthlich - gelben Spitzen. Zehen beinahe nackt, nur mit einzelnen Haaren besetzt, die nackten Fufssohlen! sind gelblich - grau gefärbt. Die Stacheln des ganzen 


\section{$-438$}

Leibes sind dichte, aber kreuz und quer un. ordentlich durch einander gestellt. - Am Leibe sind die Haare so lang und dicht, dals wenn man sie beistreicht oder niederdrückt, die Stacheln kaum ein wenig hindurch blicken. Die Nase hat an jeder Seite lange, feine, irreguläre, schwarze Bartborsten. -

Ausmessung :

Ganze Länge

Länge des Körpers

Länge des Schwanzes

Höhe des äufseren Ohres

Länge des längsten Hinternagels . $6 \frac{1}{2}{ }^{\prime \prime \prime}$.

Der Magen ist ein gekrümmter häutiger Sack, mit ziemlich dünnen Wänden. -

Der Geruch des Thiers ist, meiner Erfahrung zufolge, sehr stark und unangenehm; denn im Monat November wurde das ganze Haus von einem solchen Stachelthiere verpestet, welches von den Drüsen des Afters zu entstehen scheint. Azara hat diesen unangenehmen Geruch nicht bemerkt, es kann derselbe aber vielleicht nur in der Paarungszeit oder nach dem Tode des Thiers vorhanden seyn. -

Das hier von mir beschriebene und von Lichtenstein benannte Thier scheint identisch 


\section{$-439$}

mit dem Cuïy des Azara zu seyn, nur hatte letzterer einen etwas kürzeren Schwanz und einige kleine Abweichungen in der Färbung der Stacheln, diese Unterschiede können aber im Geschlechte oder Alter begründet seyn.

Dieses Stachelthier habe ich schon ziemlich weit südlich, am Espirito Santo und nachher weiter nördlich gefunden, ich glaube dasselbe daher über ganz Brasilien verbreitet, da es auch von Azara in Paraguay beobachtet wurde. Es ist langsam und lebt beständig auf den Bäumen, die es sehr geschickt besteigt. Wenn es seiner Nahrung halben, die besonders in Baumfrüchten besteht, auf den Zweigen bemerkt wird, so kann man es leicht herabschiefsen. Von den Europäern wird es, seines unangenehmen Geruches wegen, nicht gegessen, allein die weniger ekelen Wilden verzehren sein Fleisch. Ueber seine Manieren und Lebensart giebt Azara umständliche Nach. richt, er hatte das weibliche Thier erhalten. Man hat auch auf diese brasilianischen Thiere die Fabel von dem Wegschiefsen der Stacheln ausgedehnt, welche noch heut zu Tage oft für das europäische Stachelthier geglaubt wird *). -

*) Siehe J. Luccock's Reise nach Brasilien (deutsche Uebers.) B. I: p. 504 . 
Die brasilianischen Portugiesen nennen diese Thiere im Allgemeinen Ouriço-Cacheiro, die Botocuden belegen sie mit dem Namen Ahó.

2. H. $s u b s p i n$ os $a$, Lichtenst. Das kurzbestachelte Stachelthier.

Abbildungen zur Naturgeschichte Brasilien's.

Schinz Thierreich u. s. w. B. I. pag. 315.

Kuhl's Beiträge u. s. w. pag. 71.

Diese Art ist von Sieber aus Cametá im nördlichen Brasilien gesandt worden und befindet sich daher auf dem zoologischen Museum zu Berlin, wo man ihr die hier aufgenommene Benennung beilegt. - Ich habe diese Art aus der Gegend von Bahia durch Herrn Freyreifs erhalten und lasse eine kurze Beschreibung derselben nach einem ausgestopften Exemplare folgen.

Dieses Stachelthier unterscheidet sich von dem vorhergehenden durch eine etwas längere schlankere Gestalt, kleineren Kopf, längeren Schwanz und verschiedene Bildung der Stacheln.

Das Ohr ist durchaus unbemerkbar, gänzlich in den Stacheln verborgen; die Igrolsen Nagezähne sind röthlich.gelb gefärbt, übrigens gleicht das Gebils dem der vorhergehenden 
Art. Die vier Zehen der Vorderfülse sind mit starken, gekrümmten, bräunlichen Krallennägeln, der längste von sechs Linien Länge, versehen; an den vier langen Zehen der Hinterfüfse sind sie stärker, der längste sieben Linien lang; hier befindet sich ein breiter Kletterballen an der inneren Seite des Fufses; Schwanz kürzer als der Körper. -

An der Nase befinden sich vier und einen halben Zoll lange, feine, schwarze Bartborsten, und einige ähnliche lange schwarze Haare stehen einzeln zerstreut $\mathbf{z w i s c h e n}$ der graugelben Borstenbedeckung der Vorder - und Hinterbeine; blofs die Spitze des Ober- und Unterkiefers sind von Stacheln entblölst, der ganze übrige Körper, Kopf, Kinn, Backen, Kehle und die Stirn bis auf die Nase sind mit denselben und ähnlichen Borsten dicht und geschlossen bedeckt, selbst die Beine sind damit dicht überzogen, nur der Fufs ist davon frei, und mit schwarzbräunlichen kurzen harten Haaren dünn bedeckt.

Kopf, Hals, Schulterblätter und der Rükken unmittelbar über den letzteren sind mit Stacheln bedeckt; sie sind an diesen Theilen kurz, dick, blafs gelblich und weifslich-grau gemischt; vom Kopfe an nehmen sie allmälig 


\section{- $442-$}

an Länge zu, so dafs sie über den Schulterblättern vierzehn Linien lang sind, auch erhalten sie hier schon eine wellenförmig gebogene Gestalt und eine weilsgrau und graugelb abwechselnde Zeichnung. - Von hier an nach den Seiten, dem Mittel-und Hinterrücken zu, werden sie nun immer dünner und länger, und sind nicht mehr stechend, sondern stark bor. stenartig, dagegen desto mehr gewellt, und auf dem Hinterrücken einen Zoll zehn Linien lang; sie sind hier völlig gleichartig, dicht anliegend, und geben dem Thiere ein glattes, dicht behaartes Ansehen, auch ist die Farbe im Allgemeinen ein Gemisch von gelblichem Graubraun mit Weifsgrau, überall untermischt und gefleckt. - Am Unterkiefer und den Backen hinter dem Mundwinkel zeigt sich eine etwas mehr röthlich-braune Farbe. - Der Schwanz ist auf der oberen Seite an der Wurzel vier Zoll weit mit langen, wellenförmig gebogenen Borsten von zwei Zoll sieben Linien Länge be deckt, so dafs die mit mäuseartig schuppigen Ringen bezeichnete Haut desselben zu erken. nen ist, seine Spitze ist mehr von Borsten entblölst. - After mit gelblichen Borsten umgeben, eben so ist die ganze untere Seite des Thiers; die innere Seite der vier Beine ist mit 
anliegenden, etwas glänzenden graugelben Borstenhaaren dicht bedeckt.

Ausmessung dieses ausgestopften Exemplares:

Ganze Länge

Länge des Körpers

Länge des Schwanzes

Länge des Kopfes etwa

Länge der gröfsten Vorderklaue

Länge der grölsten Hinterklaue

$\mathrm{Da}$ ich diese Art nicht selbst in dem $\mathrm{Zu}$ stande der Natur gesehen habe, so kann ich über ihre Lebensart und Manieren nichts hinzufügen. - Sie scheint über einen grofsen Theil, wenigstens über den mittleren und nördlichen von Brasilien verbreitet zu seyn. -

Gen. 25. $L$ o $n c h \in r e s$, lllig. $S t a c h$ e l r a t t e.

Herr Professor Lichtenstein, welcher in der Lage ist, durch das an brasilianischen Thieren so reichhaltige und vollständige $\mathrm{Mu}$ seum der Universität zu Berlin, manche interessante neue Thierbeschreibung uns mittheilen zu können, hat sich auch durch eine Aufzählung der bekannten Arten der Stachelratten 
verdient gemacht, welche man in den Abhandlungen der Berliner Academie (1818, p. 187) findet. - Azara theilte von diesen Thieren nur eine Art mit, Loncheres brachyura, Illig., eine zweite (Loncheres paleacea, Illig.) brachte Sieber aus Cametá, die dritte ist der längst bekannte Hytrix chrysurus, Schreb. (Loncheres chrysura), eine vierte Art, von welcher hier die Rede seyn wird, habe ich zuerst gefunden, und Herr Professor Lichtenstein hat sie von meinem Reisegefährten auf einem Theile meiner brasilianischen Reise, dem Herrn Freyreifs erhalten, und benannt. Mehrere andere Arten führt Desmarest auf, welche ich nicht gesehen habe. Diese Thiere, welche erst seit Azara und Sieber bekannt, zu einem besonderen Genus erhoben und von den franzüsischen Naturforschern Echings benannt wurden, haben, von der von mir beobachteten Art zu schliefsen, vollkommen die Lebensart unserer Feldmäuse und bringen den grölsten Theil ihrer Zeit in der Erde zu. - Sie nähren sich von Gewächsen, Wurzeln und Früchten und richten defshalb in den Pflanzungen manchen Schaden an. - Ihre Nahrung ist übrigens viel. artig wie die der Ratten, und wie diese werfen sie mehrere Junge. 


\section{- $445-$}

Im östlichen Brasilien habe ich nur eine Species von ihnen kennen gelernt. - Thompson's Mus anomalus *) hat viel Aehnlichkeit mit derselben, allein ich habe keine Backentaschen an meinem Thiere bemerkt, Azara redet eben so wenig davon, auch zeigt Mus anomalus manche andere Abweichungen, ich stimme daher bisjetzt in dieser Hinsicht Herrn Kuhl nicht bei, der in seinen Beiträgen zur Zoologie beide Thiere vereinigt hat.

\section{L. myosuros, Lichtenst.}

Die langgeschwänzte Stachelratte.

Siehe Lichtenstein in den Verhandlungen der Königl. Academie der Wissensch.

Abbildungen zur Naturgeschichte Brasilien's.

Rato d'espinho im östlichen Brasilien.

Beschreibung: Gestalt völlig unserer Ratte; Ohr etwas stumpf, an der Wurzel am breitesten, nackt, schwärzlich gefärbt, an seinem vorderen Rande befindet sich ein Büschel von längeren Haaren; Auge grofs und schwarz, wie an unserer Ratte.

*) Siehe Transact. of the Linn, Soc, XI. pag. 161, Tab. X. Illiger hat aus diesem Thiere seinen Lonoheres anomalo gebildet. 
Gebifs: Schn. $\frac{2}{2}$; Backenz. $\frac{4.4}{4.4}$; - Die gro「sen Vorderzähne sind gelb; Backenzähne in jedem Kiefer auf jeder Seite vier; sie stehen dicht aneinander gereihet, sind rundlich, mit flachen, platten, schmelzfaltigen Kronen und mehreren Wurzeln. -

Der Hals ist kurz, der Leib ziemlich dick, der Schwanz lang aber etwas kürzer als der Körper, nackt, mit Ringen von viereckigen Hautschildchen und einzelnen sehr feinen Bor. sten, die an der Schwanzspitze nur ein wenig länger sind. - Die Hinterbeine sind länger als die vorderen; der Vorderfufs ist sehr klein und zierlich mit vier Zehen und einer kleinen rückwärts gestellten Daumwarze mit einem kleinen Nagel; neben der Daumwarze folgt der längere Zeigefinger und nun die beiden längsten völlig gleichen Zehen, die äufsere ist wieder kürzer. - Hinterfülse mit vier eben so gestalteten aber weit längeren Zehen und stärkeren wenig gekrümmten Krallennägeln; der Daumen oder die innere Zehe ist hier gröfser und mit einem mälsigen Krallennagel versehen; die Zehen sind unten quer gestreift. - Die nackten Testikel des männlichen Thieres befinden sich äufserlich unter dem After; die Ruthe ist etwas rückwärts 


\section{$-447-$}

gestellt, und befindet sich unmittelbar davor.

An jeder Seite der Nase befinden sich lange braune Bartborsten, welche rückwärts bis über die Ohren hinausliegen. - Haar des Thiers, besonders auf dem hinteren Theile des Körpers und dem Rücken, mit Stacheln gemischt, sie sind in der Nähe des letzteren elf Linien, auf dem Hinterrücken vierzehn Linien lang, länglich schmal lanzettförmig mit einer kleinen dünnen Wurzel, dabei zusammengedrückt, auf der äufseren Seite mit einem erhabenen Rande versehen und etwas ausgehöhlt, auf der inneren aber etwas convex wie an Loncheres paleacea. - Schultern, Hals und Kopf zeigen kleine Stacheln, diese stehen auf dem Mittel - und Hinterrücken dicht zusammen gedrängt, und sind sehr steif und stechend, auch bemerkt man bei dem ersten Anblicke kein Haar zwischen ihnen; an den Seiten der Hinterschenkel stehen die Stacheln sehr dünn, sie sind hier nicht mehr steif, sondern weich und biegsam.

Die Farbe des Thiers ist an allen unteren Theilen rein weifs, eben so die innere Seite der Beine und die vier Fülse. - Alle obere Theile sind röthlich-graubraun, auf dem Rük- 
ken, wo die schwarzbraunen Stacheln befindlich sind, schwärzlich-braun, auf den Schultern stark mit rothbraunen Haaren gemischt, auch läuft die dunkle Farbe der Obertheile aufsen an den Beinen hinab, wodurch diese nett weifs eingefafst erscheinen; Backen und Seiten des Halses ziehen stark in's Röthliche; Rand des Oberkiefers, Unterkiefer und Seiten desselben, so wie alle unteren Theile weils gefärbt, welche Farbe an den Backen recht nett absticht. Der Schwanz ist auf der ganzen Oberseite schwärzlich, auf der unteren weifslich, nur etwa einen Zoll von der Spitze entfernt läuft die untere weilse Farbe ganz um diesen Theil herum und bildet auf der Oberseite einen weiIsen Fleck. - Die Sohle des VorderfuIses ist weils, die des Hinterfulses schwarz gefärbt. -

\section{Ausmessung:}

Ganze Länge . . . . : $15^{\prime \prime} 11^{\prime \prime \prime}$.

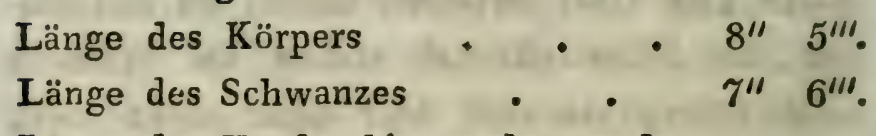

Länge des Kopfes bis zu der vorderen Ohrwurzel . . . 1" $11^{\prime \prime}$, Breite des Ohres in der Mitte . $6 \frac{\mathrm{r}}{2}{ }^{\prime \prime \prime}$. Höhe des äufseren Ohres etwa - • $9^{\prime \prime \prime}$. Länge der Hintersohle bis zur Ferse $1^{\prime \prime} 10^{\prime \prime \prime}$. 


\section{$-449$}

Diese Stachelratte lebt an der ganzen Ostküste; denn ich fand sie am Parahyba, am Peruhype und Belmonte, zweifle also nicht, dals sie auch mehr nördlich vorkomme. Sie lebt in Pflanzungen und in den grofsen Waldungen, wo sie in Erdhöhlen oder hohlen Bäumen, vielleicht auch alten Vogelnestern wohnt. - Sie nährt sich von mancherlei Früchten und Wùrzeln und soll besonders dem Mays sehr gefährlich seyn, auch die Mandioca benagen. - Man fängt sie in Schlingen, auch in den Mundeos oder Schlagfallen. Der brasilianische Landmann, so wie die Wilden essen ihr Fleisch. - Sie sind schüchter. ne Thiere, die man, wie alle Mäuse, selten zu sehen bekommt.

\section{Fam. VI. Duplicidentata.}

$$
\text { D o p p e l z äh ner. }
$$

Die Familie der doppelzähnigen Nager ist über die meisten Länder unserer Erde verbreitet, und bewohnt die kalten wie die warmen Zonen. Nirgends sind diese Thiere sehr zahlreich an Arten, dagegen aber in manchen Ländern desto reicher an Individuen.

II. Band. 
- $450 \div$

America zählt wenige Arten derselben und Süd-America wahrscheinlich nur eine. -

$$
\begin{array}{ccccccc}
G e \text { n. 26. } & L & e & p & u & s . \\
\mathrm{H} & \text { a } & \text { a } & \mathrm{s} & \mathrm{e} . & &
\end{array}
$$

Die einzige in Brasilien bisjetzt gefundene Species dieses Geschlechts hat Azara näher beschrieben, sie scheint defshalb über ganz Süd-America verbreitet. Ob Molina's Cuy (pag. 272 der deutschen Uebersetzung) auch hierher zu rechnen ist, wage ich wegen der Unvollkommenheit seiner Beschreibung nicht zu bestimmen, doch vermuthe ich es. -

\section{L. brasiliens $i s$, Linn.}

Der brasilianische Haase.

Tapiti, Azara Essais etc. Vol, II. p. 57.

Tapeti, Marcgr. p. 223.

Abbildungen zur Naturgeschichte Brasilien's.

Coelho bei den brasilianischen Portugiesen oder Brasilianem.

Da Azara dieses Thier schon beschrieben, so will ich seine Färbung und Ausmessung nach meiner Erfahrung noch hinzufügen

Alle oberen Theile sind mit gelbbräunlichen Haaren bedeckt, welche schwarze Spitzen haben, daher besonders auf dem Rücken 


\section{$-451$}

schwarz gemischt, doch zeigt sich hier auch viel rostrothes Haar wie auf der Stirn; die Unterseite des Kopfes ist weifs; Hals unten gelbroth; Füfse röthlich-gelb, alle übrigen un. teren Theile weils. - Die Ohren sind bei einigen dieser Thiere ziemlich nackt, oben sehr stumpf abgerundet; über dem Auge befindet sich ein gelblich - weilser Rand; Barthaare schwärzlich.

Diese Art ist sehr kenntlich durch den sehr kurzen kaum bemerkbaren Schwanz, welcher bräunlich-gelbroth und schwarz gemischt wie der übrige Körper ist. - Sehr richtig bemerkt Herr Professor Lichtenstein in seiner Erläuterung der Marcgravischen Holzschnitte (pag. 15), da「s der Ausdruck dieses Schriftstellers "nullam habet caudam" anders zu deuten und dals hierunter nur ein sehr kurzer Schwanz zu verstehen sey.

\section{Ausmessung :}

Ganze Länge

Länge des Körpers

Länge des Schwanzes kaum Höhe des Ohres $15^{\prime \prime} 7^{\prime \prime \prime}$. $12^{\prime \prime} 8^{\prime \prime \prime}$. $11^{\prime \prime \prime}$. $2^{\prime \prime} 5^{\prime \prime \prime}$.

Dieser Haase scheint, wie gesagt, über ganz Süd-America verbreitet, man findet ihn 
südlich von Rio de Janeiro, und weiter nördlich überall einzeln. - In der Gestalt und Gröfse gleicht er unserem wilden Kaninchen, in der Lebensart aber, da er nicht in die Erde geht, mehr dem Haasen. - Er verbirgt sich in den dichten den Boden bedeckenden Kräutern und sitzt daselbst so fest als unser europäischer Haase. - Hier bringt er auch seine Jungen. Er ist nirgends häufig und scheint in den inneren grofsen Urwäldern nicht vorzukommen. Er wird seines Fleisches wegen getödtet, wenn man ihn zufällig findet, dieses Fleisch hat aber nicht die Schmackhaftigkeit unseres europäischen Haasenfleisches. -

Fam. VII. $s$ u bu n g u $l$ a $t$ a. Hufkrallige Nager.

Eine Süd-America ganz eigenthüınliche Familie, die überall in diesem Continente zahlreich an Individuen verbreitet ist und theils die Flufsufer, theils die Wälder und steinigen Berge bewohnt, lauter harmlose völlig unschädliche Thierarten enthält, welche ihres 


\section{$-453$}

schmackhaften Fleisches wegen die Hauptbeute der brasilianischen Jäger ausmachen. -

Bei diesen Thieren haben die Männchen eine merkwürdige abweichende Bildung der Geschlechtstheile, indem diese beinahe wie bei den Katzen mit Stacheln und scharfen Haken versehen sind.

Gen. 27. Co $e l \circ g e n y s$, Fr. Cuv. B a c k e n t hier.

Wegen seines in mancher Hinsicht von den übrigen Thieren dieser Familie abweichen. den Baues hat man den Paca von denselben getrennt und $\mathrm{zu}$ einem besondern Genus erhoben, welches auch vollkommen in der $\mathrm{Na}$. tur begründet zu seyn scheint. Die bisher den Naturforschern bekannt gewesene Species dieses Thieres ist über den gröfsten Theil von Süd-America verbreitet; Herr Fr. Cuvier hat aber seitdem zwei Arten des $\mathrm{Paca}$ angenommen. - Ich kann über diesen Gegenstand nicht entscheiden, da ich in Brasilien nur eine Art kennen gelernt habe, welche auch Marcgrave und Azara erwähnen. - Ueber diese will ich in den nachfolgenden Zeilen einige Bemerkungen mittheilen. 


\section{- $454-$}

1. C. $f u l v u s$, Fr. Cuv.

Der gemeine Paca.

Cávia Paca, Linn.

Paca, Murcgr. p. 224.

Pay, Azara Essais etc. Vol. II. pag. 20.

Cavia Paca, Gcoffr. catal. p. $16 \%$

$P$ áca in der Lingoa Geral und bei den Portugiesen. Acoróng bei den Botocuden.

Kávy ( $v$ beinahe wie ä) bei den Camacans.

Der Paca ist ein sehr bekanntes Thier, welches in der neueren Zeit von Azara genauer beschrieben worden ist, ich will indessen noch einige Bemerkungen hinzufügen. Die Herren Genffroy und Fr. Cuvier hahaben in ihrer vortrefflichen Naturgeschichte der Säugthiere eine Abbildung eines Paca unter der Benennung Coelogenus subniger gegeben, welche durchaus nicht mit dem von mir beobachteten Thiere übereinstimmt. - Der von Marcgrave erwähnte und später auch von mir gesehene Paca ist gewils Coelogenys fulvus, welcher von Geoffroy in dem Catalogue des mammifères des Pariser Museums erwähnt wurde, auch deuten Azara's Worte durchaus nicht auf ein schwärzliches Fell, sondern auf ein braunes. - Alle von mir in Brasilien eingezogenen Nachrichten sprechen nur für eine Art des Paca in jenen Gegenden, ich mufs da. 


\section{$-455$}

her vermuthen, dafs Ccelogenus subniger in einer anderen Gegend gefunden werde, auch sind alle von mir weiter unten zu gebenden Notizen auf die fahlbraune Art dieses Thieres $\mathrm{zu}$ beziehen.

Höchst merkwürdig ist der Schädel dieses Thieres, höchst auffallend die grofsen Backenhöhlen, welche von Iden. Backentaschen ausgefüllt werden. - Vor jedem Ohre hat der Paca eine grofse Parotis, welche von aufsen auf der Haut bemerkbar und mit langen Borsten besetzt ist. Die Zunge ist schmal und lang, mit sehr feinen punctähnlichen Papillen besetzt. Die Zeugungstheile des männlichen Thieres sind merkwürdig. Die Testikel liegen unter der Haut und treten in einer leichten Erhöhung vor; die Ruthe tritt lang aus ihrer Scheide hervor und hat an ihrer äufseren unteren Seite hinter der Eichel zwei aufrechte Knochenplatten, jede mit vier Widerhaken; die Eichel selbst ist etwas schaufelförnig, vorn ausgerandet, und mit feinen Stacheln besetzt. Kehrt man die Ruthe noch mehr um bis zû ihrem Ende, so treten zwei runde, harte, weifse Kegelstacheln hervor, und vor einem jeden derselben stehen kleine gekrümmte Stacheln, so wie auch die ganze innere Haut mit fei- 
nen weilsen Häkchen bedeckt ist; aulser den genannten sonderbaren Stacheln besitzt die Ruthe des Paca auch noch einen Knochen, von etwa einen Zoll Länge, welcher sie unterstützt. Ich habe alle diese Theile auf der 2ten Tafel Fig. 22. 23. 7." 8. 9. abbilden lassen. - Die Haut dieses Thieres ist äuIserst weich und gebrechlich; dabei dehnbar, und in den Monaten Februar und März, wo ich die meisten dieser Thiere erhielt, sehr fett. Der braune Paca ist über den gröfsten Theil von Süd-America verbreitet, er lebt nớrdlich in Pernambuco und südlich bei Rio de Janeiro, wovon ich mich selbst überzeugt habe und ich vermuthe, dals auch Azara von dieser Art redet, Molina hingegen hat dieses Thier für Chili nicht. - Ueberall scheint man es unter dem Namen Paca zu kennen, nur in Paraguay trägt es, nach Azara, die Benennung Pay und ist daselbst selten. Nebst dem Aguti und verschiedenen Arten der Gürtelthiere ist der Paca das gemeinste Wildpret in den Waldungen des östlichen Brasiliens, in den inneren höheren Gegenden hingegen ist er mir nicht vorgekommen, mag aber daselbst dennoch, nur in geringerer Mengè, existiren. Sehr häufig fanden wir ihn in den Wäldern 
des Mucurí, weil wir da über hundert Schlagfallen angelegt hatten, würden ihn aber mit dieser Vorrichtung wahrscheinlich auch in anderen Gegenden häufig erhalten haben. An bewohnten Orten, z. B. in der Gegend von Rio de Janeiro, ist er schon selten geworden, wird daher gut bezahlt. - Er ist ein Landthier, welches aber die Nähe der Flüsse sucht, und daselbst von Vegetabilien, Früchten und Wurzeln lebt. - Er gräbt sich Höhlen in der Nähe der Flufsufer, besonders in den Ufern und unter den Wurzeln der Bäume und soll daselbst zwei Junge werfen. - Seiner Nahrung geht er besonders bei Nacht nach und wird alsdann, wenn kein Mondschein ist, häufig in den Schlagfallen gefangen. - Er schwimmt sehr gut. - Seine Jagd geschieht mit Hunden, wo man ihn schielst. Das Fleisch ist sehr schmackhaft und beliebt. -

Von Varietäten und $A$ bänderungen unter diesen Thieren habe ich in der von mir bereisten Gegend nicht reden gehört. - Der Paca, dessen Lery erwähnt, gehört gewils nicht zu der schwärzlich gefärbten Art (Coelogenys subniger) der Herren Geoffroy und Fr. Cuvier; denn die frisch von den Tägern zu Markt gebrachien Thiere dieses Geschlechts, welche 


\section{$-458$}

ich in Rio de Janeiro sah, waren sämmtlich hellbraun gefärbt. - Da Desmarest in seiner Mammalogie über die beiden aufgestellten Arten des Paca gänzlich Herrn Fr. Cuvier folgt, so gilt alles was ich über diesen Gegenstand gesagt habe, auch auf das genannte vortreffliche Werk, zu welchem wir recht bald neue Zusätze und mit der Zeit eine neue Ausgabe hoffen müssen, da man heut zu Tage bei dem regen, dem Zeitalter eigenthümlichen Forschungsgeiste alljährlich eine Menge von neuen Entdeckungen in die Systeme einzutragen bekömmt. -

Gen. 28. $D$ as $y p r o c t a$. A $g$ u $\mathrm{t}$.

Ein mit dem vorhergehenden sehr nahe verwandtes Thiergeschlecht und nur in neueren Zeiten erst getrennt, nicht zahlreich an Arten, aber in den Urwäldern von Süd-Ameri. ca desto zahlreicher an Individuen.

1. D. $A$ g $u$ t $i$, Illig. D a s A g u $t$.

Cavia Aguti, Linn. Aguti vel Acuti, Marcgr. p. 224.

Acuti, Azara Essais etc. Vol. II. pag. 26.

Cotía oder Cutia an der Ostlüste von Brasilien. Maniang - kiin bei den Botocuden. Hohiong bei den Camacans. 


\section{$-459$}

Der Aguti hat unter allen Cavien die angenehmste, zierlichste und leichteste Gestalt; der Kopf ist länglich eiförmig, der Hals zierlich, so wie die schlanken zarten Beine. Das Haar des ganzen Thiers ist hart und glänzend und besonders auf dem Hinterrücken fünf Zoll lang, hier wird es im Affecte von dem Thiere aufgerichtet. - Auch das männliche Aguti trägt in seiner Ruthe zwei knorpelartige, weifse, völlig runde, etwa einen halben Zoll lange Stacheln, wie am Paca, nur sind sie etwas kleiner; auch äufserlich bemerkt man noch an jeder Seite der Ruthe eine knochigte Lamelle, deren äufserer Rand sägeförmig eingeschnitten ist. Diesen sonderbaren Bau der männlichen Geschlechtstheile hat schon Daubenton beschrieben und abgebildet; er gab die genaue Beschreibung der äufseren Oberfläche der Eichel, allein der beiden inneren langen weilsen Stacheln erwähnt er nicht.

Der Aguti ist in den meisten Gegenden noch häufiger als der Paca, da man ihn mehr vom Wasser entfernt in den grofsen und selbst den höheren trockenen Waldungen oder $\mathrm{Ca}$ tingas antriff. - Er vertritt in den brasilianischen Waldungen etwa die Stelle, welche unser Haase in den europäischen Wäldern ein- 
nimmt. Ueberall, sowohl in den hohen feuchten Urwaldungen der Ebenen und Küsten, als in inneren höheren Gegenden jagten unsere Hunde die Aguti's. - Sie sind sehr schnelle gewandte Thierchen, ihr Lauf ist pfeilschnell, besonders gerade aus. Gewöhnlich findet man sie über der Erde oder in Höhlen, in hohlen Bäumen nahe an der Erde, wo sie von den Hunden verbellt und alsdann von dem Jäger hervorgezogen oder ausgegraben werden. Ich habe sie öfter allein als in Gesellschaften gefunden. Ihre Stimme ist ein kurzer sehr lauter Pfiff, der öfters wiederholt wird, besonders wenn man sie plötzlich erschreckt. -

Die Nahrung dieser harmlosen Thiere besteht in mancherlei Gewächsen und Früchten, welche in jenen Urwäldern in Menge wachsen ${ }^{*}$ ) und sie sollen gewöhnlich drei, vier bis fünf Junge zur Welt bringen. -

Man fängt sie in Schlagfallen und schiefst sie vor dem Hunde, sie fahren aber sogleich in das erste beste Loch, sobald sie einen Feind

*) Ueber die Art wie die Aguti's und Paca's mancherlei harte, auf die Erde herabfallende Baumfrüchte der brasilianischen Urwälder verzehren, z. B. die Nüsse der Bertholletic und des Supucaya (Lecythir) siehe $v$. Humboldt Foyage au nouv. cont. T. II. pag. 561. - 
bemerken. - Da ihr Fleisch sehr wohlschmeckend, zart und weifs ist, so finden sich sowohl unter den Menschen als unter den Raubthieren viele die ihnen nachstellen, hierhin gehören besonders die verschiedenen grölseren Katzenarten vom Mbaracayá aufwärts, und ich habe selbst einen ganzen Aguti in dem Magen der eben genannten Katze gefunden. -

Da das Aguti sehr zahm wird, so erzieht man öfters ihre Jungen und ich habe solche gesehen, welche in den Städten oder Dörfern frei umherliefen und in dem Hause ihres Herrn ab- und zugingen. - Cuvier und andere Naturforscher haben die Manieren und Lebensart dieses Thieres schon hinlänglich bekannt gemacht, ich verweise defshalb auf Buffon's Werke, die Menagerie du Muséum d' hist. natur. und Geoffroy's und Fr. Cuvier's Naturgeschichte der Säugthiere. -

$$
\begin{aligned}
& \text { Gen, 29. C avia. } \\
& \mathrm{C} \text { a v i e, F e r e l m a u s. }
\end{aligned}
$$

Auch diese Thierchen sind dem südlichen America ausschliefslich eigen und waren früher mit den vorhergehenden in ein und dasselbe Geschlecht vereinigt, jedoch unterscheiden sie sich durch mancherlei characteristische 


\section{$-462$}

Züge. - Sie sind in vielen Gegenden von Brasilien sehr gemein, dennoch aber weniger bekannt, als die vorhergehenden. -

Ich habe in dem von mir bereisten Landstriche zwei Arten kennen gelernt, wovon die eine den Naturforschern bisjetzt noch unbekannt war. Nachdem ich in der Isis schon eine Nachricht von derselben gegeben hatte, redete Herr Fr. Cuvier in seinem Werke über die Zähne der Säugthiere von ihr, als einer Entdeckung des Herrn S. Hilaire. - Er trennt sie unter der Benennung Kerodon von dem Aperea oder Preyá, der schon längst bekannten Species des Genus Cavia.

1. C. $A$ p e $r$ e $a$, Linn.

$\mathrm{D}$ a s P r e y á.

Aperea, Marcgr. p. 223.

L'Apéréa, Azara Essais etc. Vol. II. p. 65.

Abbildungen zur Naturgeschichte Brasilien's.

Preyá an der Ostküste von Brasilien.

Pattick bei den Botocuden.

Azara hat dieses Thiers Erwähnung gethan, eine Beschreibung würde daher Wiederholung seyn. Dieser Schriftsteller irrt, wenn er die Farbe des Preyá mit der der Ratte vergleicht; denn sie ist von dieser sehr verschieden. - Die Haare dieses Thiers sind an der 
Wurzel grau, dann schwarzbraun und haben an der Spitze eine röthlich gelbe Farbe, wodurch eine schwarzbraun und gelblich gemischte Zeichnung entsteht; Bauch und alle unteren Theile sind blafs gelblich-grau.

Das Gebifs, dessen Azara nur oberflächlich erwähnt, ist folgendes: Schn. $\frac{2}{2}$; Backenz. $\frac{4.4}{4.4}$; in jedem Kiefer stehen zwei grofse Nagezähne, mit nach hinten schräge ausgeschnitte. ner Schneide; Backenzähne vier auf jeder Seite eines jeden Kiefers; sie sind schmelzfaltig gefurcht, mit platten Kronen, und ihre Mahlflächen geben die Figur von zwei neben einan. der gesetzten spitzwinkligen Dreiecken; die Wurzel ist einfach.

Ein weibliches Thier mals in der Länge neun Zoll acht Linien, das männliche Thier des Azara war etwas grölser. - In dem weit ausgedehnten uterus des ersteren fand ich im Monat October ein schon völlig ausgebildetes der Mutter ganz ähnliches Junges. Die Lunge des Thiers ist in drei Lappen getheilt; die Leber ist grofs und hat vier Lappen auf jeder Seite. Der Magen ist weit und gewöhnlich mit grünem Futter angefüllt.

Dieses Thierchen scheint gleichförmig über einen grofsen Theil von Süd - America verbrei- 


\section{$-464$}

tet zu seyn, man findet es südlich von Rio de Janeiro, in Paraguay, und nach Azara selbst noch südlich vom La Plata-Strome. - Nördlich hinauf bewohnt es ganz Brasilien und vielleicht Guiana. - Dieses kleine muntere Geschöpf wird im östlichen Brasilien Preyá genannt, es lebt daselbst überall in Menge, besonders da wo dichtes Gras und andere niede. re Pflanzen die Erde bedecken, ferner unter dichten Hecken an den Wegen, in den gedrängten Zuckerpflanzungen und Gebüschen. Es soll eins bis zwei Junge werfen, wie die Indier versichern. - Es ist ein schnelles Thierchen, indessen leicht zu schiefsen, besonders wenn man es auf dem Anstande erwartet. Wir haben es an dicht bewachsenen Waldbächen und an Flufsufern in der Nähe der Pflanzun. gen oft häufig angetroffen. - Die Eingebornen essen sein Fleisch, welches jedoch weichlich ist. - Man zähmt diese Thierchen und sie gewöhnen sich alsdann an alle Arten von Hauskost. Ihre Haut ist, wie die der Cavia Cobaya, äufserst dünn, weich und gebrechlich, kann daher durchaus nicht benutzt werden. Das Preyá hat in der Gestalt und Lebensart so viel Aehnlichkeit mit unserèm sogenannten Meerschweinchen (Cavia Cobaya, Linn.), 


\section{$-465$}

dafs man wohl glauben sollte, dieses stamme von jenem ab. Marcgrave fand das Cobaya in Pernambuco, doch sagte er nicht, dafs es daselbst wild gefunden werde, welches auch nie der Fall ist. Es scheint dieses also das in dem gezähmten Zustande ausgeartete Preyá zu seyn; denn dafs die weit mehr unförmliche, plumpe, schwerfällige Gestalt in dem gezähmten Zustande bei vielen Thieren sich bald einzustellen pflege, ist eine überall in der Natur begründete Thatsache. - Eine genaue Verglei. chung der inneren Theile beider Thiere, besonders ihres Knochengebäudes, wird hier viel entscheiden, und es wird nicht schwer seyn, eine solche anzustellen, - In der von mir bereisten Gegend ist mir Cavia Cobaya nicht zu Gesichte gekommen, dennoch kann ich nicht behaupten, dafs man sie in den Städten nicht wirklich vorfinden würde.

Unter den wilden Preyá's findet man in der von mir bereisten Gegend keine Spur von Abarten in der Farbe. -

Pennant scheint in seiner Benennung Rock-Cavy dieses Thier mit dem nachfolgenden verwechselt $\mathrm{zu}$ haben; denn man findet das Preyá nicht in den Felsen, wohl aber die nächstfolgende Art. -

II. Band. 
2. C. $r u p e s t r i s$.

Das Mok6 oder die Felsen-Gavie.

C.: Pelz aschgrau, schwärzlich und röthlich-gelb gemischt, auf dem Rücken am schuärzesten; Untertheile weifslich; After und Hintertheil der Schenkel rost-röthlich. -

Abbildungen zur Naturgeschichte Brasilien's.

Isis Jahrgang 1820. Heft I. p. 43.

Schinz Thierreich u, s, w. B. I. p. 322.

Fr. Cuvier des dents des mammif. 5. livr. pag. 151. No: XLVIII.

Mocó im östlichen Brasilien und im Sertong von Bahia.

Hoké bei den Camacans.

Beschreibung eines männlichen Thieres: Gestalt in der Hauptsache völlig die des. Preyá, allein grö¡ser, mehr gestreckt, schlank, Körper hinten gewölbt, Beine kurz; die Hinterfüfse treten bis zur Ferse auf; der Schwanz fehlt gänzlich; der Kopf ist schmal, gestreckt, auf der Stirn stark abgeflächt. - Stirn und Vorderkopf bilden eine beinahe geradlinige Fläche und sind nur wenig gewölbt; Nase wenig schmäler als der Kopf; am Oberkiefer auf jeder Seite steht ein langer Büschel schwarzer Bartborsten; das Ohr ist gestaltet etwa wie am Aguti, am vorderen höheren Theile mit einer kleinen Spitze aufsteigend, dahinter ein wenig 
ausgerandet und nach hinten $\mathrm{zu}$ abgerundet, über dem Kopfe kaum acht und eine halbe Linie erhaben.

Die Zunge ist beinahe glatt, mit äufserst feinen kleinen Papillen besetzt.

Gebifs gleicht dem der Cavia Cobaya in der Hauptsache; die Mahlflächen der Backenzähne stellen zwei spitzwinklige, an einander geheftete Dreiecke 'dar, deren Grundlinie im Oberkiefer nach aufsen, im Unterkiefer aber nach innen gekehrt ist. - Diese Zähne haben rundum einen erhöhten Rand; Vorderzähne in jedem Kiefer zwei, mit scharf abgeschnittener von hinten ausgeschnittener Schneide; die oberen Nagezähne sind dicker und kürzer als die unteren, welche gerade vorgestreckt stehen.

Vorderfüfse kurz und zierlich mit vier $\mathrm{Ze}$ hen, mit etwas erhaben gekielten, mälsig zusammengedrückten kurzen Kuppennägeln, welche die zusammengedrückten, vorn rundlich verdickten Zehen nicht überlängen. - Von den vier Zehen des. Vorderfufses ist die äu. Iserste am kürzesten, dann folgt in der Länge die innerste oder der Daumen, nun der vierte Finger, und der Mittelfinger ist der längste. Die längeren Hinterfüfse treten bis zu der Fer- 


\section{- 468}

se auf, wenn das Thier sitzt und in Steinhöh. len rutscht; man bemerkt vor der Ferse einen langen Ballen, und zwei kleinere hinter den drei Zehen. - Die Zehen an den Hinterfü. fsen sind länger als an den vorderen, schmal, vorn scheibenförmig zugerundet und zusammengedrückt; die mittlere ist um drei Linien länger als die beiden anderen, welche gleichlang sind. - Die Nägel der zwei äufseren Zehen sind kurz wie an den Vorderfüfsen, nur der innere ist ein wenig länger, aufgerichtet und ausgehöhlt. - An der Vordersolile befinden sich fünf rundliche, nahe aneinander gestellte Ballen. - Die ganze innere Seite der Vorderhandwurzel ist mit einem schmalen langen callus bedeckt, der dünn mit kurzen seidenartigen Härchen bedeckt ist; die drei Ze. hen der Hinterfüfse sind an der Wurzel mit einem kurzen Spannhäutchen vereint, welches auch an den Vorderfüfsen, aber in einem geringeren Grade bemerkbar ist. -

Die Testikel des männlichen Thieres liegen im Leibe verborgen, eben so die Ruthe, welche aus einer kleinen Oeffnung zwischen den Hinterschenkeln hervortritt. - Der After steht über sieben Linien weit von dieser Oeffnung entfernt, und beide Oeffnungen sind 


\section{- $469-$}

durch zwei erhöhte, harte Hautlängsfalten vereinigt. - Die Ruthe ist inwendig mit zwei harten glatten Knochenstacheln versehen, wie die des Aguti und Paca, die Eichel ist an der äufseren Seite mit kleinen, knorpelartigen, weilslichen Knöpfchen rauh bedeckt und an ihrer Seite befindet sich eine Knochenplatte mit mehreren Stacheln wie am Paca, jedoch in viel kleinerem Maafsstabe. -

Das Haar des ganzen Thierchens ist kurz, dicht, glatt, weich und sanft wie an den Ratten und Mäusen, dabei etwas glänzend. - Al. le oberen Theile haben ein schwärzlich und gelbröthlich gemischtes Aschgrau, beinahe haa. senfarben; Gegend hinter der Nase, um die Augen, äufsere Seite des unteren Vorderbeines, so wie der Hinterbeine etwas hell gelblich ïberlaufen; untere Seite des Kopfs bis zur Kehle weifslich; Unterseite des Halses gelbgrau gemischt, von da an aber sind alle unteren Theile und die innere Seite der vier Beine weils; After, hintere Seite der SchenkeI und der ganzen Hinterbeine bis zur Ferse hinab sind hell rostroth oder röthlich-zimmtfarben; die Iris des Auges ist̃ gelblich-braun gefärbt. - - 


\section{$-470$}

Ausmessung :

Ganze: Länge

Länge des Kopfs

Länge des Kopfs bis zu dem vorderen

Winkel des Ohrrandes . . $\quad 2^{\prime \prime} 5^{\prime \prime \prime}$.

Länge von der Nase bis zu dem vor-

deren Augenwinkel . . . $1^{\prime \prime} 6^{\prime \prime \prime}$.

Höhe des äufseren Ohres • 1. 1 1" $1 \frac{1}{2}$ "'.

Länge des Vorderbeins bis zu dem

Gelenke im Schulterblatte . $\quad 4^{\prime \prime} 6^{\prime \prime \prime}$.

Länge des Hinterbeins bis zum Hüft-

gelenke $\quad 5^{\prime \prime} 10^{\prime \prime \prime}$.

Länge des nackten Theiles der vor-

deren Fufssohle ". . . $1^{\prime \prime} 2^{\prime \prime \prime}$.

Länge des nackten Theiles der hin-

teren Fufssohle bis zur Ferse ¿ $2^{\prime \prime} 4^{\prime \prime \prime}$.

Ein wcibliches Thier war etwas weniges gröIser. - Die Vulva befindet sich am hinteren Theile zwischen den Schenkeln. - Ein halb erwachsenes junges Thier hatte vollkommen die Farbe der Alten, vielleicht etwas weniger lebhaft an den rostrothen Stellen. Der Magen ist grofs, weit, dünnhäutig und zusammengekrümmt; die beiden Nieren sind grols; Testikel grofs und verlängert. -

Koster ist der einzige Reisende, welcher bisjetzt noch dieses gänzlich unbekannten 
Thierchens Erwähnung that, wir finden Seite 95 seiner Reisebeschreibung eine Stelle, wo er sagt: das Mocó sey eine Art Kaninchen, welche im Sertam von Açú lebe. - Pennant scheint dieses Thier, wie schon vorhin bemerkt, mit dem Preyá zu verwechseln; denn der Name Rock-Cavy deutet auf den Aufenthalt in felsigen und steinigen Gegenden, welcher dem hier beschriebenen Thiere zukommt. - In niederen, ebenen, von hohen Wäldern beschatteten Gegenden fand ich das Mocó nicht, sondern blofš wenn man den Flüssen von ihrer. Mündung in das Meer bis zu einer gewissen Entfernung oder vielmehr Höhe aufwärts folgte, wo es sich alsdann zu zeigen anfing. Diese höhere Region kündiget sich in Brasilien durch eine Menge von Fels. trümmern und trocknere, mit Niederwald bewachsene Felsgebirge an, in welchen, besonders in der Nähe des Wassers, diese Thierchen wohnen. - Hier scheint das Mocó etwa die Stel. le für America auszufüllen, welche in Africa der Klippdafs (Hyrax) einnimmt. - Ich fin. de übrigens das Mocó weder unter diesem, noch einem anderen Namen von den Schriftstellern erwähnt, nur die Corografia brasili. ca giebt eine kurze Notiz davon. 


\section{$-472$}

Von diesen Thierchen finden sich schon welche in den oberen Gegenden des Flusses Belmonte, über der Cachoeira do Inferno, wo sie von den Mineiros mit demselben Namen belegt werden. - Ob sie südlicher hinabge. hen und vielleicht schon am oberen Rio Doçe gefunden werden, kann ich nicht beantworten, doch bezweifle ich es, und alsdann wäre ihre Verbreitung im östlichen Brasilien südlich bis $\mathrm{zu} 16 \frac{\mathrm{r}}{2}$ oder 17 Graden südlicher Breite festzusetzen, es werden aber fernere Reisende uns über diesen Gegenstand, so wie über die nördliche Ausdehnung der Gränzen ihres Wohnortes belehren. -

Ich fand das Mocó mehr nördlich im Ser. tong der Capitania da Bahía am Rio Pardo, wo ich dasselbe zu Barra de Vareda zuerst durch einen geübten und gewandten Jäger von der Camacan-Nation erhielt. - Es lebt ferner in allen steinigen und felsigen Gegenden, besonders an Flufsufern des inneren Brasilien's die mit Felsblöcken belagert sind, an den Ufern des Rio S. Francisco in den Salpeter erzeu* genden Höhlen, und Koster erwähnt sein Vorkommen in der Capitanía von Pernambuco.

Das Mocó ist ein schnelles Thierchen, das in den Felshöhlen und zwischen den Felsblök- 


\section{$-473$}

ken wohnt, an glatten sehr schräge geneigten Felstafeln geschickt hin und her läuft, Abends und Morgens besonders, an ruhigen Stellen aber selbst am Tage zum Vorschein kommt und seiner Nahrung nachgeht, welche in Vegetabilien besteht. -

Die Camacan-Indianer versicherten, dafs es die kleinen abgefallenen Cocosnüsse mit seinen scharfen Meifselzähnen benage, um den Kern zu essen. - Während der Hitze des Tages verbirgt es sich unter Gebüschen und Steinen. - Es soll eins bis zwei Junge werfen, und zwar in Felsenhöhlen. - Ich fand im Anfange des Monats Februar bei einem solchen Thierchen ein kleines nacktes Junges, mit grolsem rundem Kopfe, -

Um das Mocơ zu erlegen, erwartet es der Jäger Abends auf dem Anstande. - Die $C a$ macan-Indianer erlegen sie sicher und geschickt mit ihren langen Pfeilen. Sie sowohl als die portugiesischen Pflanzer lieben das Fleisch dieser Thiere sehr, das Fell aber wird nicht benutzt. Die Corografia brasilica erwähnt nur kurz dieser Thierart und sagt, es lasse sich leicht zähmen, und fange alsdann Mäuse trotz der besten Katze. - 
Herr Fr. Cuvier hat das Preyá von dem Mokó getrennt und aus diesen beiden Thieren die Geschlechter Anoema und Kerodon gebil. det. - Mir schienen ihre Abweichungen nicht bedeutend genug, um zu einer Trennung zu berechtigen. Das Gebils beider Thiere zeigt nur geringe Abweichungen, wie auch selbst die Abbildungen des Herrn Cuvier darthun; die Gestalt des Körpers stimmt bei beiden in den Hauptzügen überein; beide sind ungeschwänzt, und haben gleiche Anzahl der Fulszehen, die auch in einerlei Verhältnifs der Länge stehen. - Die Nägel an den Fülsen des Preyá sind länger und mehr zugespitzt, unten ausgehöhlt (an den Hinterzehen viel länger als an den vorderen), auch ist das vordere Glied der Zehen ein wenig abweichend gebildet, indem dieses bei dem Mocó mit einem etwas verdickten, zusammengedrückten Ballen, und kürzerem, etwas aufgerichtetem Nagel versehen ist. Beide Thiere haben übrigens die Hintersohle gleichweit nackt, indem sie dieselbe håufig auf den Boden aufstützen. -

Gen. 30. Hydrochoerus, Erxl.

$$
\mathrm{C} \text { a } \mathrm{p} \text { i b ár a. }
$$

Der Capibára ist ein Thier, welches mit Recht ein Geschlecht für sich zu bilden ver. 


\section{$-475$}

dient, ob es gleich ehemals mit den Cavien vereint war. - Man kennt bisjetzt nur eine Species, die aber höchst zahlreich an Individuen und über den gröfsten Theil von SüdAmerica verbreitet ist. - Da dieses Thier von Azara hinlänglich beschriebea worden, und überhaupt den Naturforschern vollkommen bekannt ist, so werde ich nur einige Bemerkungen hier folgen lassen, welche auf die von mir bereiste Gegend von Brasilien Bezug haben, und alles vermeiden, was Wiederholung genannt werden könnte.

$$
\begin{aligned}
& \text { 1. H. } C a p i b \text { a } \quad \text { a. } \\
& \text { D e r C a p i bára. }
\end{aligned}
$$

Capybara, Marcgr. p. 230.

Cavia Capybara, Linn.

Capiiguarà, Dobrizhofer Gesch. d. Abip. B.,I. p. 406. Capiggoua, Azara Essais etc. Vol. II. p. 12.

Capibára oder Capivára in der Lingoa Geral oder Tupi-Sprache.

Niimpoon bei den Botocuden.

Azara's Nachrichten von diesem Thiere sind sehr richtig. - Auch in Hinsicht der Geschlechtstheile unterscheidet sich der Capibára von den übrigen Cavien, die männlichen liegen im Leibe verborgen und haben eine Oeff. nung, durch welche man verleitet wird, das 
Thier für ein weibliches $z u$ halten. - Die Ruthe ist gekrümmt, sie hat in ihrem vorderen Theile einen Knochen, der die Eichel unterstützt und an seinem vorderen Ende verdickt ist. - Die beiden weifsen Knochenstacheln des Aguti und Paca fehlen hier gänzlich, auch ist die Eichel glatt und ohne Häkchen oder Dornen. -

Der Capibára ist über ganz Süd-America verbreitet; denn er lebt in Guiana, in allen Gegenden von Brasilien, Paraguay und wird südlich noch am La Plata gefunden. - Nach Herrn v. Humboldt ist dieses Thier im spanischen Guiana am Orenoco und Apure unendlich viel häufiger, als in der von mir bereisten Gegend von Brasilien und dabei nicht schüchtern. - Dieser ausgezeichnete Gelehrte und Reisende sah im Canno del Ravanal bei Uritucu Gesellschaften von achtzig bis hundert Stück dieser Thiere, besonders waren sie am S. Domingo, Apure und Arauca häu. fig $*$ ). -

Sie leben überall an den mit Wald bedeckten Flufsufern der Ostküste und werden

*) Ueber den Capibára oder Chiguire siehe v. Inunbolit Vij. au nouv. cont. 'T. II. p. 217 und an vielen anderen Stellen. 
an bewohnten Stellen seltener, und gewöhnlich nur Abends und Morgens gesehen, in menschenleeren, wenig besuchten Gegenden hingegen findet man sie am Tage an den Ufern und auf den Sandbänken, wo sie bei Erblikkung der Menschen sogleich in's Wasser hinabtauchen. - Als wehrlose Thiere finden sie eine Menge von Feinden; denn auf dem Lande werden sie von mancherlei Raubthieren beschlichen und im Wasser ist ihr Hauptfeind die grofse Sucuriuba (Boa), welche manche dieser Thiere fängt, wie ich selbst ein solches Beispiel erlebt, wovon ich in dem ersten Theile meiner Reisebeschreibung (S. 358) Nachricht gegeben hahe. - Die Nahrung des Capibára besteht, meinen Erfahrungen zufolge, einzig und allein in Vegetabilien und nicht in Fischen, wie mehrere Schriftsteller behauptet haben, meine eigenen Untersuchungen, so wie die Aussagen aller indianischen und portugiesischen Jäger haben mich hievon vollkommen überzeugt. -

An der Ostküste von Brasilien liebt man das Fleisch dieser Thiere nicht, nur Neger und Indianer pflegen dasselbe wohl $\mathrm{zu}$ essen, Nach v. Humboldt wird es im spanischen America von den Mönchen als eine Fastenspeise 


\section{$-478$}

genossen; sie rechnen das Tatú, den Chiguire oder Capibára und den Lamantin mit den Schildkröten in eine Classe, theils wegen der harten Schaale des ersteren, theils weil die letzteren im Wasser und auf dem Lande zugleich leben. - Die Botocuden schiefsen den Capibára mit $\mathrm{Pfeilen,} \mathrm{wenn} \mathrm{ein} \mathrm{günstiger} \mathrm{Zu}$ fall sie ein solches Thier beschleichen läfst, sie stecken alsdann das Fleisch an einen Bratspiels von Holz, braten und essen dasselbe mit Wohlgefallen. Als wir einst am Flusse Belmonte ein solches Thier einer Riesenschlange abnahmen, welches sie gefangen und erdrückt hatte, übergab ich das Fleisch meinem botocudischen Jäger $A h o$, der einen grolsen Theil davon gebraten aufbewahrte und nach ein paar Tagen bei seiner Rückkunft nach dem Quartel Dos Arcos seiner Frau und Kindern mitbrachte, welchen es viel Freude verursachte. -

$\mathrm{O}_{\mathrm{R}} \mathrm{D} . \quad \mathrm{V}_{+} \quad \boldsymbol{B} \quad \boldsymbol{r} u \quad t \quad a_{+}$ Thiere ohne Vorderzähne.

Sie haben Backenzähne, aber weder Ecknoch Vorderzähne, und eine höchst originelle 


\section{- 479}

Organisation. Die einen sind für den Aufenthalt auf Bäumen geschaffen, die andern für das Leben in der Erde. Sie bilden zwei gänzlich originelle, blofs in Süd-America einheimische Familien, welche ich hier zusammenzubringen gewagt habe. -

\section{F a m. I. T a r d i g r a d a.}

$$
\text { Schleicher. }
$$

Diese Familie enthält die Faulthiere, welche durch ihren höchst merkwürdigen, sonder. baren Bau ausgezeichnet und nächst den Quadrumanen und mit Wickelschwänzen versehenen Thieren ganz für die grofsen Wälder dieses Welttheiles und für das Leben auf Bäumen geschaffen scheinen. -

Gen. 31. B r a d y $p$ us.

$$
\text { F a u l t h i e r. }
$$

Die Faulthiere, höchst belkannt durch ihre ganz sonderbare, zum Theil sehr unvollkommene Organisation, sind Geschöpfe, welche nur in grofsen wenig bewohnten Wäldern leben können und deren Existenz daher mit der der 
Wälder auf das engste verknüpft. ist. Sie sind überall zu finden, wo die grolsen Urwaldungen, durch Feuchtigkeit und die aufregenden Strahlen der Sonne zum üppigsten Stande gebracht, ihre mannichfaltig gedrängten Laubmassen entwickeln. - Die zunehmende Bevölkerung hat diese hülflosen Wesen in vielen Gegenden schon gänzlich ausgerottet; denn völlig harmlos, wehrlos, blofs zum Steigen und Anheften an ihr Element, die Bäume gebildet, werden diese sonderbaren Geschöpfe gänzlich von unserer Erde verschwinden, sobald die Axt, dieses in Süd-America so wichtige Instrument, ihr Reich weiter ausbreitet. Bisjetzt findet man die Faulthiere in den grofsen einsamen Wäldern von Brasilien überall, doch nirgends sehr häufig, da sie sich nicht stark vermehren. Sie würden übrigens noch immer mehr an Zahl abnehmen, wenn die Natur sie nicht durch ein unansehnliches, von der Rinde der Bäume laum zu unterscheidendes Fell geschützt hätte, auch sind sie vor gröIseren Raubthieren ziemlich sicher, da sie selten auf die Erde kommen. Kleinere Raubthiere halten sie mit ihren langen Klauen ab, welche übrigens die besten zum Anhängen an die Zweige geeigneten Haken sind. - Die langen starken Vorderglieder 


\section{$-481=$}

und die kurzen Hinterbeine sind völlig zum Klettern eingerichtet, ja sie sind geeignet, das hängende Thier ohne Beschwerde ganze Tage und Nächte ohne Ermüdung in dieser Stellung zu tragen, auch ist der lange Hals und kleine Kopf völlig für die aufrechte Stellung an den Bäumen geeignet, dafs er indessen auf die Brust aufgestützt werde, habe ich nie bemerkt und ist auch nicht gegründet.

So viel ausgezeichnete und sonderbare $\mathrm{Zü-}$ ge die Faulthiere aber auch haben, so hat man ihre Langsamkeit dennoch ein wenig übertrieben. - Man kannte früher zwei Arten von ihnen, das zwei- und das dreizehige, ein drittes erwähnte llliger in seinem Prodromus Mammalium et Avium unter dem Namen Bradypus torquatus, welches er aber irriger Wei. se in sein Genus Choloepus setzte, da es wirklich drei Zehen an allen Fülsen und das Ge. bils des Aï hat. Herr Temminck hat seitdem diese Unrichtigkeit in seiner Abhandlung über die Faulthiere in den Annales générales des sciences physiques (T. VI. pag. 206) berichtiget. Mehrere Irrthümer befanden sich bisher noch in den Naturbeschreibungen der Faulthiere, besonders war man von der Bildung ihrer Geschlechtstheile nicht gut unterrichtet. Die

II. Band. 
Herren Quoy und Gaimard haben über diesen Gegenstand nun schon das Nöthige bekannt gemacht, so wie sie überhaupt in ihrem zoolo. gischen Werke mehrere interessante Notizen, als Berichtigung der Naturgeschichte dieser sonderbaren Geschöpfe mittheilten, welche ich sämmtlich bestätigen mufs.

1. B. $t r i d a c t y l u s$, Linn.

Das gemeine Faulthier, Aï.

Ai, Marcgr: p. 221.

T.mminck in dem 6sten Bande Ann. gen, d. sc. phys. pag. 211.

Abililungen zur Naturgeschichte Brasilien's.

Preguiza portugiesisch.

Ihó kudgi botocudisch.

Da das gemeine Faulthier in den meisten 7.0ologischen Cabinetten gefunden und häufig zergliedert worden ist, so bedarf es keiner genauen Beschreibung von meiner Seite, es ist indessen nöthig, eine gute $\Lambda$ bbildung zu liefern, da die bekannten zu schlecht und unvollkomimen sind. -

Das Gesicht dieses sonderbaren Thieres ist nackt und schwärzlich, an Mund und Nase mit eiszelnen weirslichen Härclien besetzt. Das Haar des Körpers ist von zweierlei Art; 


\section{- $483-$}

zu unterst eine dichte Wolle, kurz und sehr fein, an welcher man die wahre Zeichnung des Thieres am besten wahrnehmen kann, und darüber ein langes, trockenes, hartes, etwas plattes Haar. Die Farbe des Körpers ist ein blasses röthliches Aschgrau, am Bauche silbergrau, die Haare sind aber stark mit weilser Farbe gemischt, und oft mit blafsgelblichen Spitzen versehen. - Auf jeder Seite des Rückens zieht von den Schultern bis in die Schwanz. gegend ein zuweilen sehr deutlicher, zuweilen etwas mehr undeutlicher breiter Längsstreif von weifslicher Farbe hinab, auch herrscht vorzüglich an den Oberarmen diese weilsliche Zeichnung. - Schneidet man das lange Haar des Rückens bis auf die darunter befindliche Wolle $a b$, so zeigt sich alsdann die wahre Zeichnung des Thiers, indem man längs des Rückgrates hinab einen dunkel schwarzbraunen Längsstreifen und jeder Seite desselben einen ähnlichen weifslichen bemerkt; durch das lange Haar verschwindet die Bestimmtheit und genaue Absetzung dieser Farbenvertheilung. - Vor der Stirn hin über die Augen weg zieht eine breite weifsliche Binde, die Einfassung der Augen und ein Streifen von denselben vor den Schläfen hinab sind schwarz- 
braun. - Die Klauen sind gelblich oder bräunlich-gelb gefärbt. -

Die weiblichen Thiere scheinen gewöhnlich weniger weifse Haare zu besitzen, sie sind mehr ungefleckt schmutzig röthlich-grau, eben so die jüngeren Thiere. Ich erhielt ein Weibchen im Monat Januar, welches sein Junges noch auf dem Rücken trug, und beinahe gar nichts Weifses in seiner Färbung zeigte. Das Junge war noch völlig ungefleckt, und selbst die weilsliche und schwärzliche Zeichnung des Gesichts war nur angedeutet. -

Gewöhnlich bemerkt man graugelbe anders als das übrige Fell gefärbte Flecke auf dem Rücken der Faulthiere, hier sind alsdann die Haare abgenutzt. Besonders häufig findet man dieses bei den weiblichen Thieren, an welchen gewöhnlich die Stelle, wo das Junge zu sitzen pflegt, vom Urin desselben getränkt und auf die oben bemerkte Art veränciert wird, ja man findet öfters Stellen, wo die Klauen des jungen Thieres die langen Haare der Mutter bis auf die darunter befindliche Wolle ausgerissen oder abgeschnitten haben. -

Das gröfseste von mir beobàchtete männ. liche Thier hatte etwa folgende Ausmessung: 


\section{- 485}

Ganze Länge

Länge des Schwanzes • • •
Länge des Arms vom Ellenbogen bis

zu der Klauenspitze nicht völlig 11"

Länge der längsten Vorderklaue . $2^{\prime \prime} 3^{\prime \prime \prime}$.

Länge der längsten Hinterklaue . $\quad 1^{\prime \prime} 8^{\prime \prime \prime}$.

Herr Temminck giebt die gewöhnliche Länge dieser Thiere auf 17 Zoll an. -

In den von mir bereisten Gegenden habe ich diese Species nicht weiter südlich gefunden, als bis zum Flusse $S$. Matthaeus, wo wir das erste Thier dieser Art erlegten, mehr nach Süden hinab fanden wir nur die nachfolgende Art mit dem schwarzen Nacken. - Da die Wälder am Rio Doçe durch die Botocuden unsicher gemacht werden, so haben wir daselbst nicht jagen können und es ist möglich, daf's diese Thierart selbst bis $\mathrm{zu}$ jenem Flusse hinab verbreitet ist. - Am Espirito Santo haben wir sie während der langen Zeit, in welcher unsere Jäger daselbst die Wälder durchstreiften, nie beobachtet, man kann also wahrscheinlich ihre südliche Gränze an der Ostkü ste bis etwa $z u \quad 19 \frac{\pi}{2}$ Grad südlicher Breite ausdehnen. - Hier leben diese Thiere auf hohen und niederen Bäumen und werden nur selten auf der Erde überrascht. Obgleich ihre 
Langsamkeit grols ist, so scheint sie dennoch ein wenig übertrieben worden zu seyn *). Sie klettern sehr geschickt und heften sich mit ihren starken Klauen sehr fest an die Zweige und Stämme an. - Dafs sie sich von den Bäumen herabfallen lassen ist eine Fabel, auch hört man ihre Stimmen nur höchst selten und besonders nur wenn man sie beunruhigt. Sie ist ein gerade hin ausgehaltener, feiner, kur. zer, schneidender Ton, aber nicht ein auf- und absteigender Septen-Accord, wie Kircher sagt, auch haben wir diese Stimme nie in der Nacht vernommen, dem Worte Aï gleicht sie nicht; denn sie ist nicht zweitönig, sondern nur einstimmig.

Die Nahrung der Faulthiere besteht in Blättern von mancherlei Bäumen und Gewäch. sen, auch wie ich glaube Früchten, womit man den Magen angefüllt findet. - Man hat gesagt, dafs sie das Laub der Cecropia-Stämme besonders liebten, wir haben sie jedoch häufiger auf anderen hohen Waldbäumen gesehen. - Da sie hoch oben in dem dichtesten

*) Gaimard erzählt, da cis cin Faulthier in,Zeit vor $20 \mathrm{Minu}$. ten ïber das Taurverk bis $z u$ der Spitze des gro[sen Mastes hinaufstieg. - 
Theile der belaubten Baumkronen leben, so ist es schwer, ihre Art zu fressen, so wie ihre übrigen Manieren und Gewohnheiten zu beobachten, ohnehin ist es wohl einleuchtend, dafs ihre Lebensart die einfachste unter allen Säugthieren seyn mufs. Herr $v$. Sack sagt in seiner Reise nach Surinam, dort fresse das Faulthier hauptsächlich die Blätter des Sapadillbaumes (Achras Sapota). - Einige Schriftsteller haben behauptet, das Faulthier fresse auch Ameisen, wovon ich aber in ihren Mägen nie eine Spur entdeckt habe; nach Anderen soll es nie trinken, auch über diesen Punct habe ich keine Gelegenheit gehabt, Beobachtungen zu machen *). Gegründet ist es, dals diese sonderbaren Geschöpfe lange hungern können und ein sehr zähes Leben haben. -

Oft ist man genöthiget, viele Flintenschüsse $\mathrm{zu}$ thun, um ein solches Thier von einem hohen Baume herab zu schiefsen, - Lebensart und Eigenheiten haben die verschiedenen Arten der Faulthiere mit einander gemein. Trifft man sie auf dem Boden zufällig an, so kann man sich des Staunens über dieses sonderbare Gebilde der Natur nicht enthalten. -

*) Nach Gaimard's Zeugnifs schwimmen sie sehr gut. 
Seine wahrhaft komischen, langsamen Bewegungen geschehen mit einem stupiden, kläglichen Ausdrucke; die matten, kleinen, feuchten Augen sind ohne Glanz und Leben, der lange Hals mit dem kleinen Kopfe wird hoch ausgestreckt, der Vorderkörper ist etwas aufgerichtet und einer der Arme bewegt sich sogleich langsam und gleichsam mechanisch mit den langen Klauen im Halbcirkel gegen die Brust hin, um den Feind zu umklammern, welches die einzige Vertheidigung dieser hülflosen Thiere ist. - Die Stärke ihrer Arme ist übrigens beträchtlich und nur mit Mühe kann man sich von ihnen befreien. : -

Diese sonderbaren Geschöpfe werfen während der warmen Zeit des Jahres ein Junges, welches in der Gestalt und Farbe der Mutter gleicht, aber ohne Flecken und Streifen ist; dieses klammert sich mit seinen starken Klauen auf dem zottigen Rücken der Mutter fest an, und läfst sich auf diese Art von ihr herumtragen, bis es schon stark genug ist, sich selbst zu helfen; seine Stimme gleicht der der Mutter vollkommen, nur ist sie schwächer.

Zur Jagd der Faulthiere bedarf man langer scharfschiefsender Flinten, welche mit ei- 


\section{- $489-$}

nem starken Schufs groben Schrotes geladen sind, ist aber dennoch oft genöthiget, viele Schüsse zu thun, wenn man zufällig ein solches Thier in den hohen Baumzweigen entdeckt hat, - Verwundet verändert das Faulthier seine Stellung nicht, klammert sich immer fester an, und nur der Tod oder die völlige Zerstörung der Beine machen es herabfallen. Die Wilden schielsen sie mit Pfeilen und steigen oft auf den Baum, um das Thier herabzureifsen; sowohl sie, als auch die Weifsen und Neger in Brasilien essen diese Thie. re, doch sollen sie, ihres unangenehmen Geruches wegen, von vielen nicht gegessen werden, wie auch Dobrizhofer sagt, dals die Indier im spanischen America dieses Fleisch für ekelhaft halten. -

Die Botocuden nennen diese Art Ihó-kudgi (kleines Faulthier), weil das nachfolgende gröfser wird. - Das Fell der Faulthiere ist höchst zähe und stark.

2. B. torquatus, Illig.

Das Faulthier mit schwarzem Nacken.

Illiger Prodr. Mamm. etc. pag. 109.

Temminck in den Ann, gén. d. sc. phys. T. VI. p. 212.

pl. 19.

Quoy et Gaimard Voy, de l'Uranie, part. Zool. 


\section{$-490$}

Abbildungen zur Naturgeschichte Brasilien's. Preguiça bei den brasilianischen Portugiesen. Ihó gipakiú bei den Botocuden.

Diese Art ist, wie schon früher bemerkt, aus Versehen von 1lliger zu seinen zweizehigen Faulthieren (Choloepus) versetzt worden, ob sie gleich alle Kennzeichen mit dem Aï gemein hat. - $\mathrm{Da}$ dieses Thier im Allgemeinon noch wenig bekannt ist, so will ich das. selbe etwas weitläuftiger beschreiben. -

Sein Körper ist dick, schwer, der Kopf klein, die Arme fast so lang als der Körper, es wird grölser als der Aï, wefshalb es die Botocuden Ihó-gipakiú (grolses Faulthier) nennen, zum Unterschiede von der vorhergehenden Art, - Der specifische Character dieser Art besteht in einem Fleck langer, sanfter, schlich. ter, kohlschwarzer Haare, welche den Nacken, die obere Seite des Halses und zuweilen selbst den Oberrücken bedecken, dessen Ausdehnung aber an verschiedenen Individuen etwas abändert; auch der Kopf giebt ein Kennzeichen ab, indem das Gesicht an den Backen, der Stirn und dem Kinne mit einem dichten kurzen Haare eingefafst ist, welches wie vèrbrannt aus. sieht. - Die nachfolgende Beschreibung wird 
eine anschaulichere Vorstellung von diesem Thiere geben. -

Beschreibung: Der Kopf ist klein und rund, die Schnautze kurz und kaum vortretend, die Augen klein, nur halb geöffnet und dabei feucht; die schwärzliche Nase ist der einzige von Haar entblöfste Theil des Körpers; die Ohren sind in dem dichten Pelze verborgen. Das Gebifs ist das der vorhergehenden Art. Ein jeder Fufs hat drei Klauen, von denen die mittelste am längsten, die äufsere aber die kürzeste ist; der Schwanz ist ein kurzer Stumpf oder Kegel, mit Haaren bedeckt, gleich denen des Körpers. - Die Geschlechtstheile sind noch unlängst von Gaimard beschrieben worden. -

Das sonderbare klägliche Gesicht ist von dichten, etwas krausen Haaren eingefarst, welche wie verbrannt aussehen; sie fassen dasselbe rundum ein, selbst Kinn und Kehle sind damit bedeckt; ihre Farbe ist dunkel rothbraun, schwärzlich gemischt, mit gelblich-weifsen oder rostgelben Spitzen. Der obere Theil des Ko. pfes, seine Seiten und der Hals sind mit längeren Haaren von gelblich-rostrother, graubraun gemischter Farbe bedeckt, welches sich an der unteren Seite des Halses in's schwärzlich-Rost- 
rothe verwandelt. Auf dem oberen Theile des Halses entspringen lange, schlichte und sehr kohlschwarze Haare, welche den oberen Theil des Rückens mit den Schultern bedecken, und sich selbst bis gegen die Brust hinab erstrekken. - Der übrige Körper ist mit langen etwas plattgedrückten Haaren, von einer graubraunen und gelblich-weifsen Mischung bedeckt, unter welchen man ein kurzes wolliges, dunkel graubraunes Grundhaar bemerkt. Die Haare am Bauche sind kürzer als die des übrigen Körpers und von einer mehr in's Rothbraune fallenden Farbe, die man auch an den Oberarmen und in einer blässeren Mischung an der inneren Seite der Glieder, so wie an den Füfsen der Vorderbeine unmittelbar über den groIsen Klauen bemerkt, welche eine graugelbe Hornfarbe haben. -

Das Weibchen ist etwas verschieden gezeichnet: sein Kopf ist nicht roströthlich, sondern alle Theile des ganzen Thiers haben eine graubräunlich-weifsgraue Farbe, das schwarze Haar im Nacken ist viel weiter ausgedehnt, indem es zuweilen auf dem Occiput anfängt und bis auf den halben Rücken hinabreicht, auch hat dieses schöne schwarze Haar oft die Länge von sechs Zollen. - Kopf und Arme ha- 
ben dieselbe Färbung als der Körper, nur bemerkt man zuweilen, dals die Haare in der Umgebung des Gesichtes eine etwas mehr in's Röthliche fallende Färbung haben.

Diese Thiere ändern in den Farben etwas ab und ich habe einige männliche gesehen, welche sich der hier angegebenen weiblichen sehr näherten, andere aber, welche ein schwar. zes, den Hals rund umgebendes Halsband trugen. -

Jungen Thieren fehlt in der früheren Periode ihres Lebens die schwarze Zeichnung gänzlich, sie haben blofs die bräunlich-weifsgraue Mischung der Mutter. -

Ausmessung eines erwachsenen Thieres, $o b$ es gleich noch grölsere Individuen giebt: Länge von der Nase bis zum Ende

des Schwanzes . . . . 22" 7"'.

Länge des Vorderarms bis zu der Spi-

tze der Klauen . . . . . $15^{\prime \prime} 11^{\prime \prime \prime}$.

Länge des Hinterbeins . . . . 9 9" $9^{\prime \prime \prime}$.

Länge der mittelsten Vorderklaue • $2^{\prime \prime} 4^{\prime \prime \prime}$.

Länge der längsten Hinterklaue • $1^{\prime \prime} 11^{\prime \prime \prime}$. Länge des Schwanzes • . . 1 1" $10^{\prime \prime \prime}$.

Die Anatomie dieses Faulthiers bietet eine Eigenheit dar, die ich leider zu spät beobach. tet habe, um sie an mehreren Individuen zu 
untersuchen. Es scheint nämlich, dafs es 8 Halswirbel hat; denn Quoy und faimard fanden diese Anzahl bei einem von ihnen zergliederten Br.torquatus, und ein junges Thier derselben Art, welches sich in meiner zoologischen Sammlung befindet, hat ebenfalls 8 Hals. wirbel. - Ueber die Abweichungen in dem Baue der Schädel der beiden erwähnten Faulthierarten lese man in dem Anhange zu diesem Genus nach, wo eine Vergleichung dieser beiden Köpfe, so wie die Anatomie eines foetus gegeben ist, Aufsätze, welche ich der Güte eines ausgezeichneten Anatomen verdanke. Aus dem Gesagten geht hervor, dafs Desmarest in seiner Mammalogie (pag. 304) irrt, wenn er das Faulthier mit dem schwarzen Nacken als Varietät des gemeinen betrachtet, wovon man in dem Anhange die Bestätigung findet.

Das schwarznackige Faulthier wird schon in den südlichen Gegenden von Brasilien gefunden. In den Rio de Janeiro benachbarten Wäldern der Serra dos Orgàos kommt es vor und bei Cabo Frio erlegten unsere Jäger die ersten dieser Thiere. - Es scheint über den gröIsten Theil von Brasilien verbreitet; denn Sieber hat es aus Cametá im nördlichen Brasilien für das Museum zu. Berlin eingesandt. - 
Aus Herrn $v$. Sack Beschreibung seiner Reise nach Surinam (pag. 130) scheint es wahrscheinlich zu werden, dafs dieses Faulthier auch in Surinam lebt. Wir haben es in den grolsen Wäldern an der ganzen Ostküste, an den Flüssen Parahyba, Itabapuana, Itapemirim, Es-. pirito Santo, Jucú, Mucurí, in den Waldungen von Araçatiba und Morro d'Arara gefunden. - Von hier an nördlich lebt es überall mit der vorhin erwähnten Art gemeinschaftlich.

In der Lebensart und seinen Manieren soll das Faulthier mit dem schwarzen Nacken dem Aï vollkommen gleichen. - Zu Cabo Frio erhielten wir im Monat September ein Weib. chen mit seinem schon ziemlich grofsen Jungen, und im October in den grofsen Urwaldungen des Itabapuana ein anderes trächtiges Weibchen, mit einem starken völlig ausgebildeten Fötus. Diese Thiere werfen nur ein Junges, welches den Rücken der Mutter nicht verlä Ist, so lange es saugt. 


\section{A $n \mathrm{~h}$ a $\mathrm{n} \mathrm{g}$.}

I. Beschreibung und Zergliederung eines Fötus von Bradypus torquatus; vom Herrn Professor Oken.

Dieser Fötus hatte noch die Nabelschnur und war noch ganz nackt, übrigens vollständig ausgebildet und besonders die Klauen schon sehr grols und hornig. Er muls also fast ausgetragen gewesen seyn. Um die Armgefälse zu untersuchen, wurden Versuche zum Einspritzen gemacht, die aber, da er bereits lange in Branntwein gelegen, nicht gelangen. Uebrigens weifs man hinlänglich, dafs die Meinung von den vertheilten Armgefäfsen nur auf einer Verwechselung mit dem Lemur tardi. gradus beruhte. Auch hat Gaimard wirklich gezeigt, dafs bei'm Faulthier diese Vertheilung nicht stattfindet.

$\mathrm{Zu}$ beachten an diesem Fötus ist nur der uterus, welcher dem des Menschen ähnlich ist. 


\section{in $497-$}

Ein Blinddarm, überhaupt eine Gränze zwischen Dünn- und Dickdarm war nicht zu finden.

Die Zunge ist lang, schmal und ganz, von Zähnen noch keine Spur.

Der vordere Theil des Oberkiefers, worin die kleinen vorderen Zähne stecken, ist durch keine Nath getrennt; mithin ist dieser Theil kein Zwischenkiefer, und es giebt also bei diesen Thieren wirklich keine Schneidezähne. -

Das Jochbein mit dem Oberkiefer schon verwachsen.

Auf der Brust, fast unter den Armen, sind zwei kleine Zitzen. -

Das Ohr ist mit einem dünnen, dreieckigen, fast lanzettförmigen Läppchen, von hinten nach vorn bedeckt, wie mit einem Deckel.

Die mittlere Klaue ist an allen Füfsen die längste, die äıfserste ist die kürzeste.

\section{Ausmessung:}

Länge von der Nase bis an das

Schwanzende - . . . $4^{\prime \prime} 2^{\prime \prime \prime}$.

Länge des Schwanzes . . . . . . $3^{\prime \prime \prime}$. Länge des Kopfes . . . . . 1" 1" $1^{\prime \prime \prime}$. Länge von der Nasenspitze bis zu dem Auge . . . . . $5^{\prime \prime \prime}$. II. Band. 


\section{- 498}

Länge des Oberarms . . . . $8 \frac{1}{2} "$.

Länge des Vorderarms . . $10_{\frac{2}{3}}^{211}$.

Länge des ganzen Vorderbeins bis zu

der Klauenspitze • . • . 2" $4^{\prime \prime \prime}$.

Länge der gröfsesten Vorderklaue . $4^{\prime \prime \prime}$.

Länge des Schenkels . . . . . $8^{\prime \prime \prime}$.

Länge des Schienbeins . . . $66_{3}^{2} "$.

Länge der längsten Hinterklaue • . $3 \frac{1}{2}{ }^{\prime \prime \prime}$.

Erklärung der Abbildung dieses Fötus auf Taf. III.

Fig. 1. Fütus von der Seite, in natürlicher Gröfse; hat überall drei Klauen, die allein aus der Haut vorragen. Die eigentlichen Zehen stecken ganz im Fleisch.

Fig. 2. Von vorn, der Bauch mitten durch den Nabel geöffnet.

a. Leber sehr grofs, füllt fast beide Bauchhälften aus, wie bei allen Fötus; doch ist die linke Leberhälfte etwas kleiner;

b. Magen;

c. Därme, ziemlich gleich dick; kein Blinddarm, während doch die verwandten Ameisenbären deren zwei haben'sollen;

d. Mastdarm; 


\section{$-\quad 499$}

e. Harnblase, hat die Harnschnur nicht mehr;

$f$. After.

Fig. 3. After, davor die Vulva.

Fig. 4. a. Rechte Vorderfufsklauen eingeschlagen.

Fig. 4. b. Linker Hinterfuls von innen.

Fig. 5. Bauch geöffnet.

aaa. Leberlappen;

b. Magen;

c. Milz;

d. Stück vom Dünndarm;

e. Mastdarm;

f. Harnblase;

g. After;

h. Nieren;

i. Eierstöcke;

k. Muttertrompeten;

l. Uterus.

Fig. 6. Magen von vorn.

a. Speiseröhre;

b. der eigentliche Magen, häutig;

c. Zwölffingerdarm ziemlich derb;

d. Dïnndarm;

e. ein zipfelförmiger Blindsack an der rechten Seite des Magens;

f. Milz. 


\section{$-500$}

Fig. 7. Dasselbe von hinten, und der Magenzipfel ausgestreckt. Der Magon hat keine Scheidewände.

II. Vergleichung der Schädel von Bradypus torquatus und Brady.pus tridactylus von Hirn. Prof. Oken.

Der Schädel von Bradypus torquatus ist von derselben Grölse wie der von Bradypus tridactylus; er muls daher, obschon er noch seine Näthe hat, für ausgewachsen betrachtet werden und mithin für tauglich zur Vergleichung. Daraus ergiebt es sich, dafs beide Thiere wirklich von einander verschieden sind und als zwei besondere Species betrachtet werden müssen. Beide Schädel, von oben betrachtet, zeigen schon hinlängliche Verschiedenheit auch ohne Rücksicht auf die Näthe, welche bei Bradypus tridactylus gänzlich verschwunden sind, ohne Zweifel, weil dieses Thier viel älter war als das andere. Der von Bradspus tridactylus nämlich erscheint mehr niedergedrückt und vierschrötig, indem die beiden äufseren Gränzen des Stirnbeins ziemlich parallel laufen; 
bei Bradypus torquatus aber ist die Stim mehr gewölbt und die Gränzen der beiden Stirnbeine haben in den Schläfen einen Ausschnitt. Der auffallendste Unterschied aber und der als specifisch angenommen werden mufs, liegt im Jochbein. - Bei Bradypus tridactylus hat es nämlich in der Mitte nach oben einen Fortsatz, welcher von hinten zum Theil das Auge umschliefst; dieser Fortsatz fehlt gänzlich bei Bradypus torquatus. Bei jenern ist ferner der Winkel des Unterkiefers spitzig verlängert, bei torijuatus dagegen stumpf; eben so ist bei jenem die Symphyse des Unterkiefers nach oben zungenförmig verlängert, bei torquatus dagegen nicht. Auch zeigt sich ein Unterschied in den Backenzähnen, worauf wir jedoch nicbt viel Gewicht legen mögen, da ex vielleicht durch das Alter hervorgebracht ist; bei Bradypus tridactylus nämlich sind sie schmäler und querstehend; bei torquatus aber mehr rundlich; übrigens bei beiden dreieckig. Im ersten Zahn unten dagegen, der den Schein eines Eckzahnes hat, ist ein bedeutender Unterschied, wovon nachher.

Bei Bradypus tridactylus sind alle Knochen ohne Unterschied so mit einander verwachsen, dâfs keine Näh mehr zu unterschei. 
den ist; bei Bradypus torquatus ist dagegen nur die Verbindungsnath beider Stirnbeine verwachsen, doch noch erkennbar, und eben so das Jochbein mit dem Oberkiefer, aber auch hier erkennt man noch auf der Unterseite die Nath. Das Warzenbein, Schuppenbein und die Pauke sind gleichfalls dicht mit einander verwachsen, doch vom Hinterhauptsbein abgeson. dert. Der Kronfortsatz ist bei Brad, tridactylus spitziger und höher als bei $B r$. torquatus; der Unterkieferwinkel ziemlich flach, bei $B r$. torquatus aber inwendig ziemlich ausgehöhlt. Die anderen im Schädel befindlichen Unterschiede sind nicht von solcher Bedeutung, dafs sie verdienten herausgehoben $\mathrm{zu}$ werden.

Beide Kiefer ruhen, auf eine Tafel gestellt, hinten auf der Pauke, vorn auf dem nach unten gezogenen Fortsatz des Jochbeins, nicht auf den Zühnen. Die processi pterigoidei reichen fast ebenfalls bis auf den Boden.

Die oberen Zähne stehen alle im Oberkie. fer, der Zwischenkiefer ist so klein, dafs er deren keine enthalter kann. Sie stehen in zwei geraden, nach rorn auseinander laufenden $\mathrm{Li}$ nien, also umgekehrt von dem, 'was fast bei allen Thieren stattfindet, wo die Zähne nach 
vorn sich näher kommen. Es sind jederseits oben 5 , wovon die 4 hinteren ziemlich gleichförmig, der vordere aber viel dünner ist. Unten sind jederseits nur 4, wovon die 3 hinteren gleichförmig, der vordere aber bedeutend gröIser, von vorn nach hinten zusammengedrückt und also quer gestellt ist. -

Was die Gegeneinanderstellung der Zähne betrifft, so stofsen die 3 vorderen von oben und unten gegen einander; die 2 hinteren oben aber kaum allein gegen den hinteren un. ten, den sie zwischen sich nehmen. Uebrigens ist hier die sonderbare Abweichung, welche sich nur bei Centetes und Chrysochloris wiederfindet, dafs nämlich die oberen Zähne zum Theil vor die unteren schlagen. - Da bei allen Säugthieren der umgekehrte Fall ist, und nach diesem Vorschlagen die Bedeutung der Zähne bestimmt werden mufs; so gehören die 4 unteren Zähne nur den 4 hinteren oben an, und es ist daher der vorderste oben überschüssig oder ohne Gegenzahn. Nennt man nun die 4 hinteren Zähne Backenzähne wegen ihrer Gleichförmigkeit; so mülste der vordere oben ein Lückenzahn oder unächter Backenzahn seyn: 
Das Gebifs steht mithin so:

Schneidezähne $\frac{\circ}{0}$, Eckzähne $\frac{\circ}{0}$, Seitenz. $\frac{5}{4}$ oder wie sie aufeinander stofsen:

$\frac{T}{I}, \frac{T}{1}, \frac{r}{I}, \frac{2}{I} \cdot-$

Der vordere Zalun oben ist eine etwas nach hinten gebogene Walze, kaum $\frac{7}{3}$ so grofs als die anderen. Unten ist er eine querstehende, gleichfalls nach hinten gebogene Schneide, etwas breiter als die anderen Zähne. Bei Brad. tridactylus hat dieser Zahn rorn eine Längsrinne, bei torquatus zwei, ist auch breiter, und hat nach hinten einen schwachen Winkel, wodurch er sich zum Dreieck neigt. Da nun dieses Thier offenbar jünger ist als $B r$. triáactylus, und doch einen gröfseren vorderen Zahn hat, überdiefs mit 2 Rinnen; so kann man nicht zweifeln, dafs der torquatus eine eigene von $\mathrm{Br}$. tridactylus verschiedene Species ist.

Die anderen Zähne, $\frac{4}{3}$, sind dreieckige Prismen nach der Quere etwas mehr gedehnt, und so, dafs der äufsere Winkel oben der schärfere ist, und unten der innere. -

Die Kauflächen bilden sich so, dals bei den oberen die vordere Linie vom äufseren Winkel zum inneren eine Leiste wird, von der der äufsere Winkel zipfelartig hervorragt; die 


\section{$-505$}

hintere Kauleiste wird nur vom hinteren Winkel gebildet und ist niedriger. Unten ist der Bau gerade umgekehrt, wie es aus der Bedeu. tung des Gebisses ncthwendig folgt, indem die gleichnamigen Seitenflächen der Unterzähne überall verkehrt liegen.

Der hinterste Zahn oben und unten weicht etwas von der Dreieckgestalt ab und wird mehr viereckig; oben ist er wenig, unten aber bedeutend grölser als seine Nachbarn, hier auch mehr von vorn nach hinten gezogen. Oben ist der erste Backenzahn (den vorderen Lükkenzahn ungerechnet) und der letzte Backen. zahn der gröIste, jener selbst noch etwas mehr, so dafs man ihn in dieser Hinsicht als einen Eckzahn betrachten könnte. Unten ist der hinterste durchaus der gröIste.

Die Zähne haben einen fast von allen Zähnen aufser der Zunft der zahnarmen Säugthiere abweichenden Bau. Es sind nämlich ganz einfache, hohle Cylinder von Knochenmasse, ohne wahren Schmelz, ausgefüllt mit einem unorganisirten Kern, der wie vertrockneter Leim aussieht, und auch auf ähnliche Art zerklüftet. Diesen Bau hat übrigens Cuvier hinlänglich klar dargestellt. 
Maafse der Schädel, rheinländisch.

Von Bradypus tridactylus.

Länge . . . . . . 2 $2^{\prime \prime} 9^{\prime \prime \prime}$.

Höhe, die Zipfel des Jochbeins unge-

rechnet . . . . $1^{\prime \prime} 4^{\prime \prime \prime}$.

Breite der Hirnschaale, das Schuppen-

bein mitgerechnet . . . $1^{\prime \prime}$ y"'. $^{\prime \prime}$

Breite der Stirn . . . . . 11"'.

Länge der Zahnlinie . . . $10^{\prime \prime \prime}$.

Abstand der beiden vorderen grofsen

Backenzähne, als welche am wei-

testen auseinander stehen . . 5 5".

Abstand der 2 vorletzten, als welche

sich am nächsten stehen - . $3 \frac{1}{2}{ }^{\prime \prime \prime}$.

Länge des Unterkiefers in gerader

Linie . . . . $2^{\prime \prime} 3^{\prime \prime \prime}$.

Höhe desselben . . . . $1^{\prime \prime} 4^{\prime \prime \prime}$.

Höhe des Gelenkfortsatzes • . 1" $2^{\prime \prime \prime}$.

Höhe der Zahnlade . . . . 6"'.

Unterer Zipfel des Jochbeins von der

Augenhöhle an . . . . $\quad 6^{\prime \prime \prime}$.

Gesichtswinkel ungefähr $40^{\circ}$.

Von Bradypus torquatus:

Länge

Höhe, den Zipfel des Jochbeins un. gerechnet

$1^{\prime \prime} 5^{\prime \prime \prime}$ 
Breite der Hirnschaale, das Schuppen-

bein mitgerechnet : $\quad$ : 1" $7^{\prime \prime \prime}$.

Breitè der Stirn . . . . . 1"

Länge der Zahnlinie _ . . . 11"'.

Abstand der beiden vorderen grofsen

Backenzähne, als welche am wei-

testen auseinander stehen - . 4 II $_{2}^{\prime \prime \prime}$.

Abstand der zwei vorletzten, als wel-

che sich am nächsten stehen - $2 \frac{\mathrm{I}}{2}{ }^{\prime \prime \prime}$.

Länge des Unterkiefers in gerader

Richtung . . . . $2^{\prime \prime} 1^{\prime \prime \prime}$.

Höhe desselben . . . . 1" $3^{\prime \prime \prime}$.

Höhe des Gelenkfortsatzes . . . 11"'.

Höhe der Zahnlade . . . . $\boldsymbol{7}_{\frac{1}{2}}{ }^{\prime \prime \prime}$.

Unterer Zipfel des Jochbeins von der

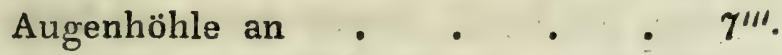

Gesichtswinkel ungefähr $50^{\circ}$.

Erklärung der Abbildungen Taf, IV. und V.

Fig. 1. Beide Schädel von der Seite.

Fig 2. von oben.

Fig. 3. von unten. Bei B. tridactylus ist die Basis cranii zerbrochen. Bei * zeigt die Schattirung die aufgebrochene Höhle an, welche wie die Sinus frontales sich hier 
im Schläfenbein, grofsen Keilbeinflügel und im Stimbein befindet.

A. Hinterhauptswirbel.

1. Körper (Keilbeinfortsatz des Hinterhauptsbeins).

2. Bogen (Gelenkfortsatz). Die eigentlichen Gelenkknöpfe sind aber beim Ablösen des Kopfes mit dem Messer weggeschnitten worden.

3. Stachelfortsatz (oberes Hinterhauptsbein), einfach, wahrscheinlich ein Zwickelbein damit verwachsen.

B. Scheitelwirbel.

1. Körper (hinterer Keilbeinskörper).

2. Bogen (grofser Flügelfortsatz), in der Nath vorn das runde, hinten das ovale Loch. -

3. Stachelfortsatz (Scheitelbeine).

C. Stirnwirbel.

1. Körper (vorderer Keilbeinkörper).

2. Bogen (kleiner Keilbeinflügel), das Sehloch ist darin; sie sind nicht viel grölser als das Loch. Dicht am Sehloch, auswendig daran liegt die obere Augenhöhlspalte. 3. Stachelfortsatz (Stirnbeine).

D. Nasenwirbel.

1. Körper (Scharbein), nach hinièn gyespalter. Das Scharbein ist eine ganz düune Wlatte, 
hinten söhlig, vorn in der Nase senkrecht, bildet die ganze Scheidewand der Nase.

2. Bogen (Riechbein); nicht sichtbar, grols und gewunden.

3. Stachelfortsatz (Nasenbein); abschüssig, daher der Gesichtswinkel bei Bradypus torquatus grölser.

a. Warzenbein.

b. Schläfenbein, $b$. * der Jochfortsatz desselben.

c. Pauke, Diese drei Knochen verwachsen. Durch das Ohrloch sieht man den Ham. mer. Ambos und Steigbügel sind auch da. Bei Brad. tridactylus fehlt die Pauke, so wie die Keilbeine; $c$. bezeichnet das Felsenbein, weil die Pauke weggebrochen ist. Beide Knochen sind nicht mit einander verwachsen. Bei $B$. torquatus ist die Grube gleich hinter der Pauke für den Griffelfortsatz; das grolse Loch in der Nath ist das Foramen lacerum; dahinter im Hinterhauptsbein ein kleines Loch für den Zungenfleisch-Nerven, der äufsere Fleck ist nur eine Grube.

d. Jochbein; reicht nicht bis an den Jochfortsatz des Schläfenbeins, Darunter geht 
ein enger Canal durch, wie bei den Nagethieren.

e e. Oberkiefer. Obenan der Verbindung mit dem Jochbein ist das Unter-Augenhöhlenrand-Loch.

$f$. Gaumenbeine; zwei dünne, entfernte, senkrechte Platten hinter den Oberkieferbeinen, welche längs der Gaumennath $h$ fast zusammenstolsen

g. Processus pterigoideus; sehr grols; weggebrochen bei $\mathrm{Br}$. tridactylus. - Ein Thränenbein ist nicht $\mathrm{zu}$ unterscheiden.

i. Zwischenkiefer, besteht aus zwei verwach. senen Biättern, jedes mit einem Ausschnitt in der Mitte des äufseren Randes. Diese Ausschnitte bilden die Gaumenlöcher. Die aufsteigenden Aeste der Zwischenkiefer feh. len. Ein Zahn ist nicht darin. Bei $\mathrm{Br}$. torquatus ist der Zwischenkiefer weggebrochen.

$k$. Unterkiefer.

l. Fig. 5. Dieser Zwischenkiefer vergröIsert, $a$. von oben; $b$. von unten.

Fig. 4. Schädel von Br. torquatus von hinten gesehen.

Fig. 5. Br. torquatus Obergebils', Kaufläche, schief von vorn gesehen. - 
Fig. 5. zeigt den Oberkiefer des Brad. tridactylus von innen.

Fig. 6. Die Zähne jederseits ergeben sich von selbst.

Fig. 6. b. Oberkiefer des Br. tridactylus von innen.

Fig. 7. Unterkiefer, Kaufläche.

Fig. 8. Ober - und Unterkiefer von vorn. Im Oberkiefer sieht man die zwei vorderen Zähne jederseits, irn unteren nur den vordersten, welcher dem zweiten oben entspricht Zwischen dem Nasenbeine 3 und dem Oberkiefer $\boldsymbol{e}$ zeigt sich die grolse Nasenöffnung. Bei $B r$, tridactylus sieht man den Zwischenkiefer $i$, welcher ganz horizontal zwischen den beiden Gaumenfortsätzen des Oberkiefers liegt. Hier steht der vorderste Zahn gerade vor dem zweiten; bei $B r$. torquatus aber mehr eingerückt. -

\section{F a m. II. Effodie ntia.} Scharr - oder Gürtelthiere.

Sie bilden ein an Arten und Individuen zahlreiches süd-americanisches Geschlecht, dessen merkwürdiger mit Panzerfeldern überklei- 
deter Körper mit starken Füfsen zum Graben ausgeri̊stet ist.

Gen. 28. Das y p u s.

$$
\text { G ür.te } 1 \text { t h i e r. }
$$

Die Gürielthiere, deren allgemeiner brasilianischer Name Tatú ist, verdienen zwar ei. gentlich nicht die Benennung Dasypus, welche ihnen Linné beilegte, dürfen aber dieselbe wohl behalten, da sie einmal hergebracht ist. Sie gehören zu den origirıellsten Geschöpfen der neuen Welt und sind zahlreich über den gröIsten Theil der südlichen Hälfte derselben verbreitet, Sie geben daselbst zum Theil das gemeinste und schmackhafteste Wildpret, und werden sowohl in offenen, besonders sandigen als in beholzten Gegenden mit Thonboden gefunden. Ueberall verbergen sich die meisten Arten dieser Thiere in Höhlen, welche sie in die Erde graben, und man trifft sie in bewohnten Gegenden am Tage selten über der Erde an, in weniger besuchten Gegenden kommt dieser Fall nicht selten vor, man kann defshalb die Tatús nicht $z u$ den nächtlichen Thieren zählen:

Sie scheinen besonders von Würmern, Maden, Mollusken, mancherlei Insecten, so wie 
von Früchter, Blättern, Wurzeln u. s. w. zu lehen, und da einige selbst todte thierische Körper verzehren, so kann man sie mit allem Rechte Omnivoren nennen. - Ich habe ihre Mägen oft leer, oder mit einem Gemische angefüllt gefunden, welches nicht leicht zu enträthseln war, doch unterschied man darin Ue. berreste von Insecten und grünen Pflanzentheilen. - Nach Azara sollen sie sich auch von Ameisen und Termiten nähren, woran ich gar nicht zweifle, indem der schmale zugespitzte Bau ihrer Zunge, die ein oder ein Paar Zolle aus dem Munde hervortritt, auf eine solche Nahrung zu deuten scheint.

Ueber die Art ihrer Fortpflanzung kann ich mit Bestimmtheit keinen Bescheid geben; denn ich habe kein trächtiges Weibchen erhalten, doch sollen sie in ihren Erdhöhlen oder Bauen mehrere Junge zur Welt bringen.

Die Gürtelthiere im Allgemeinen sind über der Erde nicht besonders schnell, ein Hund und selbst ein Mensch kann sie leicht einholen, sie fangen aber augenblicklich an zu graben, sobald sie Gefahr merken und machen bei dieser Arbeit mit ihren starken Grabeklauen sehr schnelle Forischritte, so dals sie oft schon mit dem kalbon Körper in der Erde sind, beII. Band. 
vor man sie aus geringer Entfernung erreichen kann. - Ihre Muskelstärke ist selır grofs und wenn sie einmal ein wenig in die tirde eingedrungen sind, so hält es sehr schwer, sie wieder herauszuziehen. - Ein Theil von ihnen erhielt von der Natur die Fähigkeit, bei herannahender Gefahr sich zusammenzukugeln, diese Arten hat Illiger in ein besonderes Geschlecht, unter der Benennung Tolypeutes vereinigt und sie von den Gürtelthieren, welchen diese Fähigkeit mangelt, Dasypus, getrennt. -

Ich habe von den ersteren keine Art in dem von mir bereisten Striche von Brasilien zu Gesicht bekommen, ob ich gleich wohl von einer kleinen Art derselben, als dort zuweilen vorkommend reden gehört habe.

Azara zeigte zuerst, dafs die Zahl der beweglichen Gürtel kein sicheres Unterscheidungszeichen der verschiedenen Arten sey, auch mufs ich, meiner Erfahrung zufolge, seine Beobachtung bestätigen, da ich dieses eben so befunden habe. - Es ist übrigens auch leicht, durch eine Menge von anderen characteristischen Zügen diese Thiere hinlänglich von ein. ander zu unterscheiden, ohne gèrade die trü. gerische, öfters abändernde Zahl der Gürteỉ 


\section{$-515$}

zu Hülfe zu nehmen. - Die von Buffon u. a. Schriftstellern gegebenen halben und oberflächlichen Beschreibungen nach verstütnmelten, zusammengetrockneten, ausgestopften Exempla. ren, begleitet von den barbarisch verdrehten Provinzialnamen, welche die Gürtelthiere in den Sprachen der brasilianischen Urvölker tragen, schaden freilich der wahren Kenntnifs dieser Thiere mehr, als sie Nutzen bringen. Azara's Beschreibungen sind in dieser Hin. sicht die einzigen bisjetzt bekannten, welche Werth haben. - Er zählt acht Arten von Gürtelthieren auf, da ich hingegen im östlichen Brasilien nur vier selbst kennen gelernt habe, indessen wohl weils, dafs deren mehrere daselbst vorkommen. Die in den französischen Werken über die Naturgeschichte der Gürtelthiere vorkommenden sonderbar verdrehten Provinzialbenennungen dieser Geschöpfe sollte man gänzlich verabschieden, so z. B. Encoubert, Apar, Peba, Tatouay u. s. w.; denn ab. gesehen davon, dafs sie gewöhnlich verdreht sind und im Lande selbst ganz verschieden klingen, so gelten sie auch nur auf einem ganz kleinen Raume und werden in verschiedenen Gegenden oft sehr verschiedenen Thierarten beigelegt. 


\section{$-516$}

A. Gürtchthiere mit fünf Zehen an allen Füfsen, und einem gepanzerten Scluvanze.

\section{Das. Gigas, Cuv. \\ $D$ a s grofse G ïr te t thier.}

Tatou premier ou grand Tatou, Azara ctc. Vol, II. pag. 132.

Tatoú -açú oder assú in der Lingoa Gerat.

Tatú-canastra in manchen Gegenden von Brasilien, besonders in Minas und dem Sertong ron Bahia. Kuntschung - gipakiú bei den Botocuden.

Es ist ein schwieriges Geschäft, die rerschiedenen Arten der Gürtelthiere aufzuklären, wenn man die bisjetzt in den zahlreichen Werken der Naturforscher gegebenen Beschreibungen berücksichtigen will - Sie sind in der Regel zu mangelhaft und oft völlig ohne Angabe der Hauptzüge. Marcgrave's Tatí-Peba z. B. scheint, wie auch Herr Prefessor Lichtenstein in seiner Abhandlung über die Menzel'schen Gemälde sehr richtig bemerkt, ein junges Thier des hier aufgeführten Tatú-açú oder guassí zu seyn, welches schon die in Pernambuco ihm beigelegte Benennung zeigt.

Ich habe dieses Thier nie zu Gesichte bekommen, erhielt aber in den von mir bereisten Gegenden überall Nachricht davon, beson. ders am Mucuri, Alcobaça und Prado, so wie 
in der Gegend von Caravellas; es lebt also dieses Thier nicht blofs in Paraguay, sondern auch über den gröIsten Theil von Brasilien verbreitet, ja es ist über die ganze Breite von Süd-America ausgedehnt. In den grolsen inneren Wäldern des Sertong der Capitania da Bahía und von llhéos haben wir die Höhlen oder Baue gefunden, welche diese Thiere in die Erde graben, besonders unter den Wurzeln alter Bäume, von ihrer Weite konnte man einen Schlufs auf die Grölse des Thieres fällen. Ich fand am Rio Grande de Belmonte unter den Botocuden Sprachröhre, welche sie selbst Kuntschung-kokann (Tatú-Schwanz) nennen, deren Grölse beweist, dals diese Schwanzhäute von dem grofsen Gürtelthiere herrühren. -

Der gröfste dieser Tatúschwänze, welche ich besitze, mifst in der Länge 14 Zoll und hat an der Wurzel einen Durchmesser von beinahe 3 Zoll, bei einer Peripherie von $9 \frac{\mathrm{r}}{2}$ Zoll, auch fehlt die Spitze, welche das Ganze bedeutend verlängert haben würde. - In der Beschreibung meiner Reise ist dieses Instrument auf der 14ten Tafel (Fig. 1) abgebildet.

Der Schwanz des grofsen Gürtelthiers ist, wie man aus jener Abbildung wahrnehmen kann, geschuppt, d. h. mit kleinen abgerunde- 
ten, grolsentheils aber etwas viereckigen Schuppen oder Hornschildchen bedeckt, welche nicht in regelmälsigen lingen, wie am gemeinen Tatú (Tatou noir Azara), gestellt, sondern etwa in sich kreuzende Reihen etwas unregelmälsig vertheilt sind. - An der Wurzel des Schwanzes sind sie sehr abgerundet, in der Mitte desselben aber ist ihre Gestalt mehr viereckig. - Dic Abbildurg, welche sich in der Beschreibung meiner Reise befindet, wird das Gesagte am deutlichsten erläutern. Aus den weiter oben angegebenen Maafsen dieses Schwanzes wird man ersehen, dafs dieses Thier eine bedeutende Gröfse erreichen müsse, doch kann ich übrigens keine genaue Nachricht davon geben. - Die Jäger versichern einstimmig, dafs es bei Nacht seine Höhle verlasse, ein menschenscheues starkes Thier sey, welches selten gesehen und erlegt werde, die Grölse eines starken Schweines erreiche und ein ungesundes widerliches Fleisch habe, indem es Aas und mancherlei andere unsaubere Gegenstände verzehre. -

Azara beschreibt den Schwanz seines $T a$ tou premier ou grand Tatcu auf folgende Art: "Celles (les écailles) qui coùrent la queue sont arrondies, un peu plus faibles que dans 


\section{$-519$}

mẹs Tatous second, quatrì̀ne et cinquième et ne sont pas en anneaux, si ce n'est à la racine de la queue; parce que dans le reste, elles forment une espèce de quadrille, dont les interstices font à leur tour des spirales pour la queue. - Cellé-ci est aigue, et a dix pouces un quart de circonférence à sa naissance."

Man ersieht aus dieser Beschreibung, da[s Azara höchst wahrscheinlich von demselben Thiere redet; denn selbst sein hier angegebenes Maals für die colossale Dicke dieses Schwanzes an seiner Wurzel ist sehr übereinstimmend mit dem von mir angegebenen. Bei dem von mir beschriebenen Schwanzstücke fehlt die äufsere Spitze und der dickere Wurzeltheil, wo sich nach Azara mehr regelmälsige Schuppenringe zeigen; es ist übrigens gewifs, dals die Bildung des Schwanzes als ein wichtiges Kennzeichen bei der Bestimmung der verschiedenen Gürtelthier-Arten angesehen wer. den mufs. -

Der von Marcgrave (S. 231) in der Beschreibung seines Tatú-Peba angegebene Holzschnitt, stellt übrigens ganz deutlich, wie auch Her Proiessor Lichtenstein sehr richig be. 
merkt, Azara's Tatou noir (meinen Dasjpus longicaudus) vor.

2. D. $s \in t o s u s$.

Das borstige T a t ú.

Tatou second, Tatou Poyou ou Tatou à main jaune, Azara Vol. II. pag. 142.

Dasypus gilvipes, Illig.

Abbildungen zur Naturgeschichte Brasilien's.

Tatú-Peba im Sertong von Bahia.

Da ich vermuthe, dafs Azara bei der Beschreibung seines zweiten Tatú, das von mir hier aufgeführte vor sich hatte, dafs er aber ein älteres Thier besals, als das meinige ist, so will ich dasselbe etwas genauer beschreiben.

Die Gestalt des Thiers ist plump, dick und gedrungen; Hals sehr kurz, Kopf dick, breit, Ohren und Fülse kurz; der Schwanz ist kürzer als der Körper und gepanzert; sechs bewegliche Gürtel am Oberpanzer, zwischen dessen Schilderreihen weifsliche Borsten stehen; im Nacken ein isolirter Querpanzer, der aus neun kleineren Tafeln zusammengesetzt ist.

Beschreibung: Der Kopf ist sehr dick, plump, grofs, schweineartig, mit sehr breiter, flacher Stirn und Vorderfläche, nach dem stumpfen Rüssel hin sich verschmälernd; der Stirn- 


\section{$-521$}

panzer ist zwischen den Ohren stumpf, beinahe geradlinig abgeschnitten und an den beiden Ecken gegen die Ohren hin etwas abgestutzt, er ist aus vielen Stücken zusammengesetzt, welche grofsentheils unregelmälsigg sechseckig und auch unregelmäfsig gestellt sind, den oberen Stirnrand des Panzers ausgenommen, wel. cher zwischen den Ohren etwa sieben, beinahe viereckige, etwas gefurchte Tafeln zählt; auf der Stirn selbst befinden sich einige sehr kleine Felder zwischen den übrigen; fünf bis sechs Linien hoch über der Nasenspitze hört der Stirnpanzer auf und über dem Auge hat er einen Ausschnitt. Die Ohren stehen etwas seitwärts hinaus, wie am Ochsen, sind etwas breit eiförmig und oben stark abgerundet, sie bestehen aus dicker lederartiger Haut und sind chagrinartig mit kleinen Knöpfchen besetzt. Das Auge ist klein und länglich gestaltet, wie am Schweine, unter demselben stehen auf der nackten Seitenhaut des Kopfes einige Reihen kleiner Schildchen $\mathrm{zu}$ einer Masse von elf $\mathrm{Li}$ nien Länge vereint, und unter diesen eine Warze mit einem Büschel langer schwarzer Borsten; die Nasenkuppe ist abgestumpft wie am Schweine, aber ohne ausgebreiteten hervortretenden Rand, die rundlichen Nasenlöcher sind 


\section{- 522}

nach vorne geöffnet. Die Zunge ist lang, schmal, fleischig und zugespitzt. - Das Gebils ist von Azara beschrieben. - Der Gaumen ist mit erhöhten Querleisten bezeirhnet.

Im Nacken unmittelbar an der hinteren Gränze der Ohren steht ein zwei Zoll zwei Linien breiter und acht Linien langer Panzer, der aus acht viereckigen Tafeln zusammengesetzt ist, deren äufserste an der linken Seite noch ein kleines Stückchen trägt, welches später wahrscheinlich die neunte Tafel gebildet haben würde; diese Schildchen sind sämmtlich in ihrer Mitte mit zwei Längsfurchen bezeichnet, so wie überhaupt sämmtliche Panzerstücke des Thiers. - Der eben genannte Nakkenpanzer ist rundum von Haut umgeben, welche nach den Ohren und der Kehle hinab ein breites, nacktes, ungepanzertes Feld bildet; der Schulterpanzer steht nahe hinter dem Nackenpanzer und ist an den Seiten des Kopfes mit seiner unteren Ecke vor dem Ohre befestiget; sein hinterer Rand ist glatt abgeschnitten, auch der untere Seitenrand ganz und nicht gezähnt; er besteht auf seiner Höhe aus fünf etwas unregelmäfsigeu Querreihen von Schildchen, die hintere Randreihe ausgenommen, welche aus fünt und dreilsig grolsentheils regelmälsigen, 
länglichen Vierecken besteht, die an ihrem Vordertheile noch eine fünfte kleine Spitze zeigen, mit welcher sie immer zwischen zwei Schildchen der Vorderreihe eindringen; an den Seiten des Schulterpanzers stehen die Reihen nicht regelmälsig, indem, wie Azara sich ausdrückt, ein Paar der obern Reihen auseinander weichen, und andere Schilde dazwischen eingeschoben sind. Alle diese Schildchen sind auf ihrer Mitte durch ein Paar Längsfurchen bezeichnet, von welchen senkrecht auf den Rand wieder andere solcher Furchen laufen, wodurch mehrere undeutliche kleine Randschildchen entstehen, Die Schilde der hinteren Randreihe haben zwei deutliche regelmäfsige Längsreifen und an ihrem vorderen, dem Kopfe zugewandten Ende noch ein kleines rund. liches Plättchen. - Auf den Schulter - oder Brustpanzer folgen sechs breite völlig getrennte Gürtel, der siebente oder hinterste ist nur an den Seiten getrennt, oben aber mit dem Hüftpanzer verwachsen, daher ich ihn auch zu dem letzteren Theile zähle. - Die beweglichen Gürtel sind aus Rectangelstücken zusam. mengesetzt, die zum Theil an der hinteren und vorderen schmalen Seite etwas buchtig irregulär gebildet sind; alle haben in ihrer Mitte 
zwei Lïngुffurchen und ein jedes Schildchen ferner am hinteren Ende in der Mitte seines Randes zwei etwa zwölf bis vierzehn Linien lange weifsliche Borstenhaare, die in eben dieser Vertheilung auch am hinteren Rande des Schulterpanzers gefunden werden. - Der llüftenpanzer ist über dem Schwanze in der Mitte ausgeschnitten, an seinem Rande treten die Schildchen sägenförmig vor; eben so erscheint der Rand der beweglichen Gürtel abwechselnd vortretend oder gezackt. Der Hüftenpanzer besteht aus zehn regelmäfsigen Querreihen, von welchen die letzte durch den Schwanzaus schnitt unterbrochen wird. - Die Schildchen sind länglich, beinahe sechseckig, oder abgerundet viereckig, blofs die Randschuppen deutlich viereckig. - Die ersten beiden Querreihen hinter den Gürteln haben an der Hinterseite eines jeden Schildchens zwei weifsliche lange Borsten, die übrigen Schüppchen aber sämmtlich nur eine. - Auch am hinteren Rande des Stimpanzers, so wie am Nacken- und Schulterpanzer stehen ebenfalls an der Hinterseite der Schildchen zwei gepaarte Borsten, sind aber an diesen Theilen sehr klein und nutzen sich nach und nach immer mehr ab. Die Feldchen des Hüftenparizers haben in ihrer Milte cin et. 
was längliches, und rund darum her einen Rand von kleinen Plättchen. Der Schwanz hat ein. und zwanzig bis zwei und zwanzig Panzerbinden; die vier ersteren sind stark, beweglich und haben nur eine Reihe von beinahe vierek. kigen Schildchen; die acht folgenden Querbinden habe jede zwei Querreihen, deren Schildchen etwas fünfeckig geformt sind; die folgenden bis zum Ende des Schwanzes sind weniger regelmäfsig und bestehen aus viereckigen kleinen Schildchen, meistens ebenfalls aus zwei irregulären Querreihen; alle diese Schwanzschilde haben an ihrem hinteren Ende eine, zwei, oder drei abgenutzte Borsten. -

Der Bauch des Thiers ist etwas hängend, am Männchen mit einer elf Linien lang herabhängenden Ruthe, welche vor dem After steht und etwas zugespitzt ist; Testikel äufserlich nicht sichtbar. - Die vier Beine sind sehr dick und plump, mit fünf Zehen; die drei äuIseren Zehen der Vorderfüfse haben lange Grabeklauen, die dritte ist die längste, sie tritt einen Zoll lang aus der Haut hervor; nach ihr folgt in der Länge die zweite von aulsen, der Zeigefinger ist kürzer, und die innerste oder der Daumen ist die kürzeste; die beiden innersten Zehen haben, wie Azara richtig bemerist, 
ihre scharfe Grabeschneide nach innen, die drei anderen aber nach aufsen gerichtet. Die Hinterfüfse treten bis zur Ferse auf, Zehen und Nägel sind hier kleiner als an den Vorderfüfsen; die äufserste steht am weitesten zurück, nach ihr die innerste, dann die zweite von aufsen, die beiden übrigen sind einander gleich und am längsten. - Die Unterseite des Kopfs, Füfse und Bauch sind mit starker Haut bedeckt, welche mit Querreihen von flachen, glatten, rundlichen Warzen besetzt ist; alle diese Warzen sind an ihrem unteren Rande mit elf Linien langen, schwärzlichen Borstenhanren besetzt, gewölnnlich vier an jeder Erhöhung. An der Unterseite des Kopfs sind die Borsten kleiner und seltener, am Bauche sind sie weifslich; Vorderseite der Vorderbeine nach oben mit Querreihen von gelblichen Hornplättchen besetzt, die Warzen sind hier von der Masse der Panzer; weiter an dem Beine hinab stehen sie vereint und sind vier-, fünf-oder sechsekkig, eben so ist es auf der Oberseite des Vorderfufses, hier sind inảessen die Schildchen klei. ner und in geringerer Arzahl. - Farbe der Panzer bräunlich-gelb, auf den oberen Theilen graubräunlich-schmutzig, am Rañde der Panzer mehr rein gelb; untere Theile des Thiers 


\section{- 527 -}

blafs bräunlich-gelb, Beine mehr graubraun; Schwanz und Stirnschild sind mehr abgeschliffen, daher mehr gelblich gefärbt. -

Ausmessung:

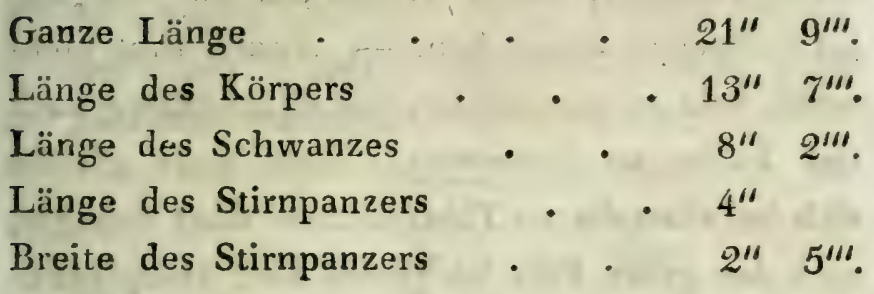

Länge des Schulterpanzers . • $2^{\prime \prime}$

Länge von der Nasenspitze bis zu dem

vorderen Augenwinkel . . $2^{\prime \prime} 1^{\prime \prime \prime}$.

Länge von dem vorderen Augenwin.

kel bis zu der vorderen Ohrbasis $1^{\prime \prime} 6^{\prime \prime}$. Höhe des äufseren Ohres . . 1" $4^{\prime \prime \prime}$.

Der Magen dieses Thiers war häutig, und von länglich nierenförmiger Gestalt.

Um die verschiedenen Arten der Gürtelthiere richtig unterscheiden zu lernen, wird man genöthigt seyn, alle diese Thiere genau zu beschreiben; man wird alsdann besonders die Bildung ihrer einzelnen Schildchen bémerken müssen, gerade wie dieses auch bei den Schildkröten nöthig ist, und die Verhältnisse ihrer einzelnen Körpertheile zu einander bemerken. 


\section{$-528$}

Das hier beschriebene Thier schien nicht ganz vollkommen ausgewachsen, woher wohl die Abweichungen von Azara's Exemplaren entstanden seyn können, welche mich übrigens nicht abhalten, beide Thiere für ein und die. selbe Species anzusehen. - Azara thut nicht wohl, wie es mir scheint, die Gürtelthiere nach der Farbe zu benennen; denn diese gleicht sich bei allen diesen Thieren mehr oder weniger, und der gelbe Fufs ist gewils kein Hauptkennzeichen, daher scheint mir auch die Benennennung gilvipes nicht recht wohl gewähIt. -

Wir fanden diese Art in den grofsen Campos Geraës und den angränzenden Gegenden des Sertong, sie lebt auch in Minas Geraës und wenn sie, wie ich bestimmt glaube, $A z a-$ ra's zweites Iatú ist, auch in Paraguay, scheint also über die ganze Breite von Süd-America ausgedehnt zu seyn. -

Ich erhielt nur ein Individuum dieser Species, welches ziemlich schnell war und wie diese Thiere überhaupt, am Tage umherging, zufällig in den niederen Gebüschen einem meiner Jäger begegnete und von diesem geschossen wurde. - Sein Magen enthielt Ucberresto ven Kufern und grüren Glättem. - Der 
Geruch des Thiers war unangenehm süfslich, daher wird es im östlichen Brasilien selten gegessen.

B. Gürtelthiere mit fünf Zehen an allen Füfsen, und einem beinahe völlig nackten, $d, h$, ungepanzerten Schwanze.

3. D. gymnurus, Illig.

Das Gürtelthier mit nacktem Schwanze.

Tatou troisième ou Tatou Tatouay, Azara Essais etc.

Vol. II. pag. 155.

Abbildungen zur Naturgeschichte Brasilien's.

Tatú de rabo molle, auch Tatú-Chima im östlichen

Brasilien.

Azara hat ein grofses Thier dieser Art beschrieben, meine Exemplare waren kleiner. - Mit seinem plumpen, ungeschickten Körper gleicht dieses Tatú dem Rhinoceros im Kleinen. - Der Kopf ist kurz, breit und plump, die Augen klein, die Nase stumpf, die Ohren sind breit, etwas rundlich, schlotternd und chagrinartig gekörnt. - Die Zunge ist länglich zugespitzt, fleischig und kann einen Zoll lang aus dem Munde treten. Stirn und Vorderkopf sind mit grofsen sechseckigen ir regulären Tafeln belegt; unter dem Auge sind II. Band. .34 


\section{$-550$}

keine Panzerstücke; im Nacken stehen drei bewegliche Querbinden von Schilàen, wovon die hintere etwas weniger getrennt vom Rückenpanzer ist, als die vorderen. - Der Bauch ist mit Reihen von runden Hornwärzchen besetzt, welche eine gewisse Anzahl von Borsten tragen. - An den Schildchen der Panzer stehen am Hinterrande zwei weilsliche Borsten; sie sind stets einzeln so in die Ecken gerückt, dafs sie dicht neben der einen Borste des folgenden Schildchens zu stehen kommen, und auf diese Art überall zwei dicht beisammenstehende Borsten zum Vorschein kommen; der Gürtel sind dreizehn an der Zahl; die Nägel der Vorderfüfse sind besonders grofs, der längste mals an dem einen meiner Exemplare einen Zoll acht Linien in der Länge; der Schwanz ist mit einer nackten, runzlichen, rauhen, harten Haut bedeckt und nur unter der Spitze mit rundlichen, gelblichen Schildchen belegt, welche am hinteren Rande mit einer weilslichen Borste versehen sind, sie gleichen denen des Bauches, - Die Ruthe des Männchens hing bei meinen Exemplaren fünf Linien lang herab; die Testikel sind verborgen. 


\section{- $531-$}

Die Farbe des Thiers ist ein blasses Graubräunlich, alle Panzerstücke sind gelblich-weifs gefärbt. - Dieses Tatú ist ein häIsliches, langsames, aber äufserst stark grabendes Thier, welches an der Ostküste nie gegessen wird, da es einen unangenehmen Geruch hat. Es frifst Aas und soll selbst Leichen ausgraben, wird übrigens im Inneren wie an der Küste gefunden und ist daher wahrscheinlich über den gröIsten Theil von Südamerika verbreitet.

Schreber's Tafel LXXV. hat einige Aehnlichkeit mit diesem Thiere, doch ist sie sehr unrichtig, wenn sie auf diese Species bezogen werden mufs.

C. Gürtelthiere mit vier Zehen an den Vorder- und fünf an den Hinterfüfsen, dabei mit gepanzertem Schwanze.

4. D. longicaudus.

Das g e m e ine Gürtelthier.

Tatu-été, Marcgr. p. 231.

Dasypus novemcinctus, Linn.

Tatou cinquième ou Tatou noir, Azara Essais etc. Vol. II. pag. 175.

Abbildungen zur Naturgeschichte Brasilien's.

Tratú-Peba am Parahyba do Sul.

Tatú-verdadeiro an der Ostliuste und im Sertong von Bahia. 
Diese Art ist in den von mir bereisten Gegenden die gemeinste, auch hat sie in jeder Hinsicht die empfehlendsten Eigenschaften; denn sie verbindet mit einer schlanken zierlichen Gestalt ein sehr schmackhaftes angenehmes Fleisch. Das gemeine Tatú ist hinlänglich bekannt und beschrieben, ich werde daher nur noch einige wenige Bemerkungen hinzufügen.

Ich habe die Anzahl der Gürtel bei diesen Thieren abwechselnd gefunden, oft hatten sie deren neun, zuweilen zehn, und ein ganz besonders grofses Thier zeigte nur acht Gürtel. Das sicherste Kennzeichen giebt der Schwanz, der unter den acht von Azara beschriebenen Arten der Gürtelthiere an dieser bei weitem am längsten ist, da er nur zwei Zoll weniger milst, als der Körper. -

Die Farbe ist, wie Azara richtig bemerkt, mehr schwärzlich als an den übrigen Arten, allein an vielen Stellen vom Einkriechen in die Erde weirslich abgeschliffen. - Die Zunge ist lang und schmal, da der Bau des Un. terkiefers keine andere Gestalt zuläfst, sie lä「st sich zwei Zoll lang aus dem Munde hervorziehen. 


\section{$-533$}

Die Leber ist in vier ganzrandige Lappen getheilt, der Magen ein grofser, häutiger, nach dem Darmende verdünnter und gekrümmter Sack.

Marcgrave giebt $\mathrm{S}, 231$ einen Holzschnitt von diesem Tatu und auch Schreber, hat es Tab. LXXIV. schlecht abgebildet, doch ist es nicht $\mathrm{zu}$ verkennen. -

Dieses Thier scheint über ganz Südamerica verbreitet zu seyn; denn es lebt in Guiana, Brasilien und Paraguay, sowohl in zusammenhängenden Wäldern, als in offenen Heiden oder Campos und besonders gern in sandigem $\mathrm{Bo}$ den. - In manchen Gegenden sind diese Thiere äufserst zahlreich; ihre Höhlen oder Baue findet der Jäger leicht, auch ist die Spur des Thieres im Sande leicht zu erkennen, indem es mit dem Schwanze eine kleine Rinne zieht. Ihre Nahrung besteht in vegetabilischen und animalischen Substanzen, doch soll diese Art nichts Faulendes verzehren, wefshalb man ihr weifses fettes Fleisch allgemein liebt. Man bratet oder röstet es in dem Panzer des Thiers selbst, nachdem es zerstückt worden ist, auch ist es alsdann wirklich sehr wohlschmeckend. -

Ueber die Zahl ihrer Jungen habe ich keine Erfahrungen gemacht, sie werfen dieselben 
in ihren Erdhöhlen. - Die jungen Thierchen sind allerliebst, ihre Farbe ist mehr weilslich als die der alten. Diese Gürtelthiere sind ziemlich schnell, doch kann sie ein Mensch im freien Felde einholen, ist aber Gebüsch in der Nähe, so verliert man sie leicht, wenn man keinen Hund hat; denn sie graben sich zu schnell in die Erde ein, eine Fertigkeit, worin indessen die beiden vorher erwähnten Arten, wegen der Grölse ihrer Klauen noch gewandter sind. Die vier von mir hier erwähnten Specien haben nicht das Vermögen sich zusammenzukugeln, können sie daher gar nicht mehr ausweichen, so fangen sie an mit grofser Schnelligkeit zu graben, oder drücken sich etwas zusammengezogen unter einen dichten Strauch nieder.

Um das gemeine Tatú zu fangen, sucht man zum Theil seine Baue (Höhlen) auf, und gräbt es aus, auch fängt man es häufig in den Schlagfallen oder Mundeos. - In den Wäldern am Mucuri erhielten wir auf diese Art in drei Wochen dreifsig Gürtelthiere von dieser Art, welche sämmtlich der Mannschaft zur Speise dienten. - Oft fanden wir diese Thiere unter den schweren Schlagbäumen nach zehn bis zwölf Stunden noch lebend, indem der Sei- 
tenpanzer das Gewicht des Fallholzes etwas bricht, ja man hat selbst Beispiele, dafs sich diese Thiere unter dem Schlagbaume herausgegraben haben. -

Man kann diese Gürtelthiere leicht lebend erhalten, auch hat man in Europa schon manche von ihnen gesehen, sie müssen jedoch in sehr feste Behältnisse gebracht werden, damit sie sich nicht durchgraben; ich besals mehrere dieser Thiere, die mir auf eine solche Art entkamen. - Eine Stimme habe ich nie von ihnen gehört, auch haben sie als Hausthiere keine andere empfehlende Eigenschaften, als ihre sonderbare Gestalt. -

Anmerkung. Es giebt aufser den hier aufgezählten Gürtelthieren noch mehrere Arten im östlichen Brasilien, u. a. eine kleine, sich zusammenrollende, Tatú-Bola genannt, wahrscheinlich Azara's Tatou-Mataco, und eine andere sehr kleine Art, welche die Jäger unter der Benennung Tatü kennen; jedoch der das Land flüchtig durcheilende Reisende findet nicht Gelegenheit, alle diese Gegenstände zu erschöpren. 


\section{$-536$}

\section{O R: VI. $E d$ e $n t a t a_{+}$}

Zahnlose Säugethiere.

Iöchst merkwürdige, meist völlig zahnlose Geschöpfe, deren in der alten und neuen Welt vorkommen. Sie sind den warmen Ländern unserer Erde eigen, und Südamerika zählt ein Geschlecht von ihnen. -

Gen. 33. Myrmecophaga.

A meisenb är oder Ameisenfresser.

Das Geschlecht der Ameisenfresser ist wohl die sel samste und originellste Säugthierbildung, welche die neue Welt, und zwar der südliche Theil dieses Continents, ausschliefslich hervorbringt; in den andern Welttheilen giebt es wohl ähnliche, aber keinesweges eben so gebildete Geschöpfe. -

Auch diese Thiere sind wieder gänzlich der Localität auf eine bewundernswürdige Art angepaIst. Ihr starker Greifschwanz, verbunden mit den grofsen hakenförmigen Klauen und der überaus merkwürdigen, wur̀martigen, lang ausdehnbaren, klebrigen Zunge, eignen diese an sich hülflosen Thiere gainz vorzüglich für die Vertilgung der unendlich zahlreichen 
Termiten und Ameisen in jenen grofsen, ausgedehnten, aber von Menschen noch nicht beherrschten Wäldern; denn sobald der Mensch sein Reich dorthin auszudehnen beginnt, sobald jene Urwaldstämme vom Schlage der Axt fallen, verschwindet immer mehr von der Erde das hülflose Thiergeschlecht, von welchem hier die Rede ist. -

Die höchst abweichende Organisation der Ameisenbären ist bekannt. - Jhr Mund ist gänzlich von Zähnen entblöIst, sie schlürfen ihre Nahrung ein; denn der Unterkiefer besteht blofs aus zwei langen, schmalen, gänzlich kraftlosen Knochenplatten, ist also gar nicht zum Kauen geeignet, und der Mund ist so klein, dals ihn das Thier nur höchst wenig öffnen kann.

Drei oder vier Arten sind bisjetzt den $\mathrm{Na}$ turforschern bekannt; zwei davon habe ich in Brasilien gefunden; die eine lebt auf Bäumen und hat einen Greifschwanz, die andere, grölsere bewohnt den Boden und trägt einen schlaffen Schwanz.

1. M. iubata, Linn.

Der grofse Ameisenfresser.

Tamandua-guaçu, Marcgr. pag. 225, mit einem ziemlich deutlichen Holzschnitte. 
Gnourouni ou Yogoui, Azara Essais etc. Vol. I. p. 89. Tamandua Cavallo oder Tamandua Bandcira bei den Pórtugiesen in Brasilien.

Tamandua-guaçu oder Tamandua-açı in der Lingoa Geral.

Kuiann-gipakiu bei den Botocuden.

Potoigriang bei den Maconis.

Perd bè den Cámácans.

Azara hat dieses merkwürdige Thier weitläuftig beschrieben und ich kann seine Nachrichten über die Lebensart desselben nicht anders als bestätigen. - In den bewohnten $\mathrm{Ge}$ genden des östlichen Brasilien's ist dieses harmlose Geschöpf jetzt völlig ausgerottet, in den grofsen Wäldern lebt es jedoch noch und ist überall nicht gar selten, wird aber besonders häufig in den grolsen inneren Campos Geraës, oder den höheren, waldlosen Gegenden des Inneren angetroffen, wo es auf die Eröffnung der unzähligen Termitengebäude angewiesen ist, von deren Bewohnern es sich ernährt. Es besteigt nie die Bäume, sondern lebt blofs an der Erde. Wenn die Einwohner in jenen inneren offenen Gegenden der Capitanias von Bahía, Pernambuco, Goyaz und Minas Geraës Abends am Saume der Gebüsche umherschleichen, so erblicken sie nicht selten diese Thiere und erschlagen sie leicht mit einem Stocke. Sie $\epsilon$ - 


\section{$-539$}

reichen daselbst eine bedeutende Gröfse, ich habe colossale Felle dieser Art gesehen, welche ohne den Schwanz an fünf Fuls in der Länge hielten. - Neger und Indier essen den grofsen Tamandua, die Portugiesen aber nicht, und obgleich diese Thiere für die Vertilgung der Ameisen von grolsem Nutzen sind, so werden sie von den Bewohnern des Landes dennoch getödtet, so oft sie ihnen begegnen. -

Das Fell wird zuweilen gebraucht. - Ich selbst habe nie das Glück gehabt, ein solches Thier im vollkommenen Zustande zu erhalten, dagegen haben wir Skelette und Felle gefunden. -

2. M. te tradactyla, Linn.

Der mittlere Ameisenfresser.

Tamandua-i, Marcgr. pag. 225.

Cagouaré, Azara Essais etc. Vol. I. p. 103. Abbildungen zur Naturgeschichte Brasilien's.

Tamandua-collete an der Ostküste von Brasilien südlich von Pernambuco.

Tamandua-miri in der Lingoa Geral.

Kuiann-kidgi botocudisch.

Fedari bei den Gamacans.

Azara beschreibt dieses Thier gerade wie ich dasselbe in Prasilien beobachtet habe. Er giebt einige Abänderungen in der Farbe an, 


\section{$-540$}

die mir nicht vorgekommen sind; ich kann defshalb nicht bestimmen, ob diese letzteren wirklich nur Abarten oder ob sie vielleicht verschiedene Species bilden, welches ich indessen sehr bezweifle. - Alle mir vorgekommenen Individuen dieser Art trugen in der Hauptsache einerlei Zeichnung, den schwarzen Hinterkörper, hellgelben Kopf, Hals und Vorderrücken mit einem schwarzen Streifen über die Schultern, und dieses Vorhandenseyn eines abgesetzten Schulterstreifen kommt bei beiden hier erwähnten Arten der Ameisenfresser vor. Wenn gleich Azara eine gute Beschreibung des mittleren Ameisenfressers gegeben hat, so will ich dennoch der Vollständigkeit halben ein männliches in den Wäldern des Mucurí erhaltenes Thier dieser Art beschreiben. -

Diese Species unterscheidet sich von der vorhergehenden auf den ersten Anblick durch die weit geringere Grölse, das kürzere Haar, die Farbe, die längeren Ohren, und den glatten Rollschwanz:

Beschreibung: Der Kopf ist länglich, walzenförmig, dabei sanft gekrümmt und nach dem Munde hin sich verdünnend. - Oberlippe etwas länger als die untere; der Mund sehr klein. - Die Nasenlücher sind nach den 


\section{- $541-$}

Seiten geöffnet, sie bilden schräge längliche Ritzen. - Das Auge ist klein und schwarz; der Rand des Augenliedes ist nackt; das Ohr ist länglich, oben abgerundet, beinahe nackt, nur mit wenigen Haaren dünne besetzt, nach den Seiten horizontal hinausstehend und ungefähr in der Mitte der Kopfhöhe befestiget.

Die Zunge ist walzenförmig, glatt, fleischig, rund, allmälig in eine stumpfe Spitze auslaufend und zieht sich acht Zoll elf Linien weit aus dem Munde hervor. Der Hals ist kurz und so dick als der Kopf in der Ohrgegend; der Leib ist dick, die Beine plump, stark, sehr dick und muskulös; Vorderfufs mit vier Zehen; der zweite Nagel von aufsen ist sehr grofs, einen Zoll neun und eine halbe Linie lang, zum Scharren und Klettern eingerichtet, wie am Faulthier gebildet, gekrümmt und zugespitzt; die äufsere Zehe ist kurz, der Nagel nur sieben Linien lang, die dritte eben so, aber der Nagel etwas über neun Linien lang; die innerste Zehe ist klein und der Nagel nur drei Linien lang; der Ballen des Fufses ist dick, weich, mit einer lederartigen Chagrinhaut bedeckt. - Der Hinterfufs hat fünf Zehen; die innerste ist am kürzesten, der Nagel milst sechs Linien; die zweite ist länger, der Nagel 


\section{- $542-$}

sechs und zwei Drittheil Linien lang; die dritte und vierte Zehe sind einander ungefähr gleich, die fünfte so lang als die zweite. Der Schwanz ist am Leibe stark, er hält daselbst zwei Zoll im Durchmesser, wird allmälig dünner und endet mit einer etwa vier Linien dicken, abgerundeten Spitze, er ist greifend, fast seiner ganzen Länge nach nackt, mit geschuppter Haut bedeckt und nur mit einzelnen steifen Borsten ziemlich dünne besetzt.

Die Geschlechtstheile liegen nahe vor dem After; man bemerkt einen nach vorn geneigten, kegelförmigen Sack, auf dessen Spitze die Oeffnung sich zeigt, aus welcher die Ruthe hervortritt; die Testikel liegen im Leibe verborgen; der genannte Beutel ist nackt, nur mit einzelnen Borsten dünne besetzt. - An der Brust befinden sich zwei Zitzen. -

Das Haar des ganzen Thieres ist etwas borstenartig hart, darunter befindet sich eine harte Wolle; an der hinteren Hälfte des Körpers ist es lang, an manchen Individuen selbst bis auf die Mitte des Schwanzes, doch ist dessen Unterseite immer kurz behaart. - An manchen dieser Thiere hat das Haar über der Schwanzwurzel eine Länge von drei und einem 


\section{- $543-$}

halben Zoll, auf der Oberseite des Schwanzes selbst von drei Zoll, nimmt aber nach der Spitze hin allmälig an Länge $a b$, so dafs diese an ihrer Oberseite nur einen Streif von etwa zehn Linien langen Borsten zeigt. - Bei anderen, wahrscheinlich älteren Thieren, fand ich alle diese Theile nur kurz behaart, wozu indessen auch die warme Jahrszeit beigetragen haben mag. - Ueber den Schulterblättern befindet sich ein Haarwirbel, die Haarscheide; denn von hier an liegen sie vorwärts bis nach dem Scheitel, die des Körpers aber sämmtlich rückwärts.

Nase und Lippen sind nackt und schwärzlich gefärbt; die Schnautze von den Augen an vorwärts ist dünn mit weifslichen Borsten besetzt; Stirn und oberer Nasenrücken bis zur Nasenkuppe sind länger und dichter gelblichweifs behaart. - Oberkopf, Hals, Vorderbeine und Vorderrücken sind hellgelb, und diese Zeichnung verschmälert sich spitzzulaufend allmälig in einen schmalen Streifen, der über die Schulterblätter und den Rücken läuft und über den Hüften endiget; die Hinterbeine sind von unten auf bis zum Knie hell gelblich, oder schmutzig gelblich-weifs; die Hinterschenkel, Schwanzwurzel vier bis fünf Zoll lang und der 


\section{- $544-$}

ganze Rumpf sind glänzend schwarz, mit langen, starken, harten Haaren; von dieser Farbe läuft auf́ jeder Seite über das Schulterblatt ein Streifen, etwa anderthalb bis zwei Zoll breit bis gegen den Hals vor. - Unterhals, Brust, Vorderfüfse und Oberarme bis etwa zu der zweiten Rippe haben wieder die blals gelbliche Farbe. - Der Schwanz ist in seiner Mitte weifslich, die Spitze dunkel aschgrau gefärbt; einige Flecke von dieser letzteren Farbe bezeichnen den weilslichen Theil. - Die Klauen sind schwärzlich -hornbraun. -

Ich habe unter diesen Thieren in der Zeichnung keine bedeutende Abweichung gefunden, doch muls ich bemerken, dafs ich nicht viele von ihnen gesehen habe. - Die Alten haben mit ihrem netten schwarzen und hell. gelben Felle ein hübsches Ansehen, an jüngeren Thieren habe ich die hellgelb gefärbten Theile mehr in's schmutzig Röthliche fallend gefunden, welches auch Azara bemerkt, übrigens aber scheint die Vertheilung der Farben immer dieselbe zu seyn. -

Ausmessung dieses männlichen Thieres:

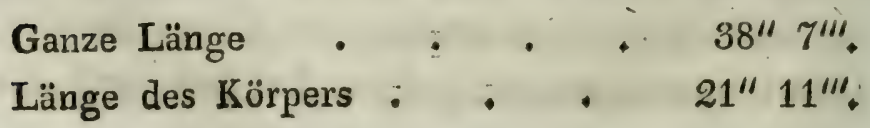




\section{$-545$}

Länge des Schwanzes

Länge von der Nase bis zu dem vor-

deren Augenwinkel . . . $\quad 2^{\prime \prime} 9 \frac{1}{2}{ }^{\prime \prime \prime}$.

Länge von dem vorderen Augenwin-

kel bis zu der vorderen Ohrbasis 1" 10". Höhe des äufseren Ohres • • . 11'".

Länge des Halses vom hinteren Ohr-

rande an gemessen . . $11^{\prime \prime} 10_{\frac{\mathrm{x}}{2}}^{\prime \prime \prime}$. Breite des Vorderbeins unter der

Schulter $\quad \bullet^{-} \quad \cdot \quad \cdot \quad 3^{\prime \prime} 3^{\prime \prime \prime}$

Länge der nackten Sohle des Vorder-

fufses mit dem Ballen gemessen $2^{\prime \prime} 9_{\frac{1}{2}}^{\prime \prime \prime}$. Länge der Hintersohle etwa • $\quad 2^{\prime \prime} 9 \frac{I}{2} "$.

Innere Theile: Die Zunge theilt sich im Anfange des Halses in ihre langen Schenkel, die, wie Herr v. Humboldt bemerkt, am Brustbein und den Rippen, nahe über dem Magen entspringen und daselbst befestiget sind. Diese beiden Schenkel sind muskulöse hohle Gänge. Merkwürdig ist das aus ein paar Gelenken bestehende Zungenbein, welches an dem höchst einfachen, aus vier knochigten, mit Haut verbundenen, beweglichen und gleich Schuppen über einander liegenden Stücken bestehenden larynx befestiget ist. - Jeder Lurigenflügel ist in drei Lappen getheilt; der Magen ist ein dünner, eiförmig häutiger Sack II. Band. 35 
Der Darmcanal vom Magen abwärts milst etwa zehn Fufs drei Zoll in der Länge; das rectum ist von aufsen mit Längsfurchen und Streifen bezeichnet; da wo dieser Darm beginnt oder die Reifen sich zeigen, befindet sich eine sackförmige Erweiterung des colon. - Die Leber war mit vielen weifslichen Flecken und Oeffnungen bedeckt, wahrscheinlich krankhaft. Zwei grofse, dunkel violette bohnenförmige Nieren von der Grölse eines Taubeneies. Zwei starke Testikel im Leibe; die Ruthe ist ein rundlicher, häutiger, weicher Körper, sie tritt aus dem weiter oben beschriebenen äufserlichen, häutigen Beutel hervor. - Die Herren Quoy und Gaimard geben in ihren zoologischen Bemerkungen der Rieise um die Welt (S. 22 in der Note) einige Notizen über die Anatomie dieses Ameisenfressers. Auch sie haben den Magen mit Ameisen angefüllt gefurıden. Sie nennen das colon gestreift, einen $\mathrm{Bau}$, den ich nur an dem letzten Theile des Darmcanals bis zum After wahrnahm. -

Dieses sonderbare Thier lebt überall in Brasilien, in einsamen bewaldeten Gegenden und unterscheidet sich von der vorhergehenden Art besonders dadurch, dals es die Bäume ge. schickt besteigt; man findet es jedoch auch in 
den Gebüschen und wir haben selbst ein sol. ches Thier am Seestrande nahe bei einer be. wohnten Gegend getödtet, wohin es vielleicht gekommen war, um Wasser zu suchen. - Sein Hauptaufenthalt ist in hohen geschlossenen Urwäldern, wo es langsam die Bäume besteigt. In seinem Magen fand ich nur Termiten, Ameisen und deren Puppen, die es mit seiner merkwürdigen Zunge aufzunehmen weifs, vielleicht frifst es auch Honig? Es ist ein träges stupides Thier, von dem man keine Stimme hören soll.

Das Weibchen wirft ein Junges, welches es, wie man mir versicherte, überall auf dem Rücken mit umher trägt. - Diese Thiere haben einen sehr starken eigenthümlichen Geruch; dennoch afsen unsere Neger und Indier diejenigen, die wir in den Wäldern des Mucu$r i$ in den Schlagfallen gefangen. - Die Botocuden essen ebenfalls dieses Fleisch, so wie uns dieses Herr $v$. Humboldt für das spanische America bestätiget. Die portugiesisch-brasilianischen Jäger machen aus der starken Haut Regenkappen für ihre Gewehrschlösser.

Koster erwähnt in seiner Reise nach Brasilien (S. 313 der englischen Ausgabe) einer kleinen Art der Amejsenfresser, sechs Zoll lang, 


\section{- $548-$}

Schwanz zwölf Zoll, mit sanftem Haare, ohne Zweifel ein junges Thier; denn die beiden in Brasilien bisjetzt bekannten Arten haben im erwachsenen Zustande ein hartes Haar. - Der Engländer J. Luccock verwechselt in seiner Reisebeschreibung (deutsche Uebers. B. I. S. 360) den Tamandua mit dem Armadil oder Tatú. -

Or D. VII. Multungula. $\mathrm{V}$ i e l h u f e r.

Die neue Welt ist viel ärmer in dieser Ordnung, als die alte; denn America zählt nur wenige Geschlechter dieser Thiere, da hingegegen in Indien und Africa die colossalesten, seltsamsten Gebilde der Natur in diese Ordnung gehören.

\section{F a m. I. $\mathbf{N}$ a $s$ u $t$ a. Langnasigte Vielhufer.}

Diese von Illiger aufgestelltè Familie enthielt blofs Thiere der neuen Welt, bis man jetzt 
auch in Indien eine hierher gehörige Species entdeckte. - Bisjetzt gehört nur ein Geschlecht hieher.

Gen. 34. T a p i r u s.

$$
\mathrm{T} \text { a } \mathrm{p} \text { i } \mathrm{r} \text {. }
$$

Man kannte, wie eben gesagt, bis auf unsere neueste Zeit nur eine noch lebende Species des Geschlechts Tapirus, welche ganx Süd-America bewohnt, und daselbst das grölste Landthier ist; reisende Naturforscher haben uns aber jetzt mit dem Maiba, einer neuen in Sumatra entdeckten Art dieses Geschlechts bekannt gemacht, wodurch dasselbe nun der alten und neuen Welt zugleich angehört. -

1. T. americanus, Linn.

$$
\text { D e r T a pir. }
$$

Tapiirete, Maregr. p. 229.

MMborébi, Azara Essais etc. Vol. I. p. 1.

Trapirété in der Lingoa Geral.

Anta portugiesisch.

Hochmereng botocudisch.

'Tschaá bei den Maschacarís.

Amachy (ch deutsch mit der Zungenspitze) bei den Pataschós.

Amajö bei den Malalís.

Tia bei den Maconi's.

Herä bei den Camacans *).

*) Herr v. Humboldt giebt in dem zweiten Theile seiner Voy, au nouv. cont. (pag. 371) die Namen des Tapir aus 


\section{$-550$}

Der Tapir, jenes längst bekannte und beschriebene Thier, ist über den gröliten Theil von Süd-America verbreitet. An der Ostküste ist er häufig und ein gemeines Wildpret, in jenen weiten, flufsreichen Wäldern, wo der Mensch noch nicht zahlreich sich ausgebreitet hat. Wenn man dort am frühen Morgen oder am Abend leise und ohne Geräusch die Flüsse beschilft, so bekommt man häufig diese Thiere zu sehen, wie sie sich baden, um sich zu kühlen, oder vor den Stechfliegen zu sichern. Wirklich weifs kein Thier sich besser gegen diese lästigen Gäste zu schützen, als der Tapir; denn eine jede Schlammpfütze, ein jeder Bach oder Teich wird von ihm aus dieser Ursache aufgesucht und benutzt, daher findet man auch oft seine Haut mit Erde und Schlamm bedeckt, wenn er erlegt wird. - Es ist auffallend, wenn ein neuerer Keisender sagt, dafs der Tapir nur selten und zwar blofs auf der Flucht in's Wasser gehe; denn diese Aeufse. rung zeigt, dafs sie aus einer mit der Natur

einigen Sprachen des spanischen America; so heifst er z. B. bei den Spaniern Donta; tamanackisch: Uariari; maypurisch: Kiema; in der Mbaya-Sprache:, Apolicanagi-guc$\mathbf{g}^{a}$; in der Moxo-Sprache (an den Ufern des MLainore): Samo; in der Chiquito-Sprache: Oquitopaquirs etc. 


\section{$-551$}

tur dieses Thieres völlig unbekannten Quelle flofs.

Wie in der Gestalt, so hat auch der Tapir vieles in seinen Manieren mit den Schweinen gemein. Sein Körper ist plump und schwer, er geht mit etwas gewölbtem Rücken und ziemlich horizontal vorgestrecktem Kopfe, einzeln oder paarweise und folgt auf diese Weise seinen durch die Dickung der hohen alten Wälder schon gebahnten Pfädchen, die man recht wohl erkennt, so wie auch unser europäisches Rothwildpret gewöhnlich solche Pfade einzuhalten pflegt, welche der deutsche Jäger Wech. sel nennt. Auf eine kurze Entfernung ist der Tapir ziemlich flüchtig, doch kann er einem raschen Hunde nicht entgehen, und pflegt sich vor diesem bald zu stellen. - Begegnet man zufällig einem solchen Thiere im Walde, so pflegt es heftig zu erschrecken und schnell mit grofsem Geräusche durch die dichteste Verflechtung des Waldes zu entfliehen. - In bewohnteren Gegenden, d. h. da, wo die Pflanzungen der Bewohner an den Aufenthalt dieser Thiere gränzen, sieht man sie nicht bei Tage, in ruhigen einsamen Gegenden aber, besonders in den inneren grofsen Urwäldern ha ben wir sie zu allen Zeiten des Tages gese- 


\section{$-552$}

hen, doch ruhen sie während der Mittagshitze aus. - Ihre Nahrung besteht in Vegetabilien, wefshalb sie den Pflanzungen, besonders dem Zuckerrohre grofsen Schaden zufügen. - Gewöhnlich brechen in solchen Fällen mehrere dieser Thiere aus ihrem Schlupfwinkel hervor, wenigstens eine Iamilie vereint; denn das Junge, welches anfänglich wie unser wildes Schwein gelblich gestreift ist, folgt der Mutter lange nach. - Sie pflegt es bei herannahender Gefahr zu vertheidigen, so lange dasselbe noch jung ist, wie mir die brasilianischen Jäger versicherten, und in solchen Fällen werden diese harmlosen Thiere oft so zornig und kühn, dafs sie den Feind mit iliren Zähnen fassen und ihn tiichtig herumzerren, indem sie den Fufs auf. zusetzen suchen, um besser reifsen zu können. - Angeschossen pflegen sie die verfolgenden Hunde oft auf diese Art zurück zu schlagen, wenn diese nicht sehr brav sind. Ich habe einen bei einer solchen Gelegenheit von einem Tapir schwer verwundeten Knaben vom Stamme der Maschacaris gesehen, dessen eines Schulterblatt und die ganze Seite von dem zornigen Thiere aufgerissen worden war. -

Die Jagd des Tapir wird von den Brasilianern auf eine unzweckmälsige Art betrieben, - 
Um ein so schweres grofses Thier *) zu erlegen, bedienen sie sich nicht der Kugeln, sondern schiefsen es mit Schrot, gewöhnlich wenn sie es schwimmend in den Flüssen am frühen Morgen oder gegen Abend überraschen. Der Tapir sucht gewöhnlich durch dieses Hülfsmittel seinen Verfolgern zu entgehen, da ihm das Schwimmen sehr leicht ist; allein die Bra.. silianer pflegen mit ihren Canoen äufserst schnell heran zu rudern und das Thier einzuschliefsen. - Dieses taucht alsdann sehr geschickt und häufig unter, selbst oft unter den Canoen hindurch, bleibt lange unter Wasser und kommt nur zuweilen mit dem Kopfe an die Oberfläche um Luft zu schöpfen, wo als . denn sogleich alle Röhre nach diesem Theile zielen, und besonders die Ohrgegend zu fassen suchen. Oft erhält ein Tapir auf diese Art zwölf bis zwanzig Schüsse, bevor er getödtet wird und häufig entkommt er dennoch, wenn nicht ein Jagdhund bei der Hand ist. - Mit einer Kugel würde man das ermüdete Thier in geringer Entfernung sehr sicher erlegen können, allein die Brasilianer bedienen sich nie

*) Ein gro「ser Tapir, welchen ich ma「s, hielt in der Länge sechs Fufs einen Zoll, wovon der nackte, dicke Schwanzkegel vier Zoll eine Linie wegnahm. 


\section{$-\quad 554$}

der Kugeln, damit sie im vorkommenden Falle mit ihren groben schweren Schroten sowohl einen Tapir als eine Jacutinga oder Jacupemba (Penelope leucoptera und Penelope Marail) erlegen können.

Die Wilden pflegen gewöhnlich diese Thiere $\mathrm{zu}$ beschleichen, doch umstellen sie sie zuweilen förmlich und treiben sie den Schützen $\mathrm{zu}$, wenn ihr Aufenthalt erspäht worden ist, wozu ihre genaue Kenntnils der Spur (Fährte) ihnen behülflich ist. -

Der Nutzen, welchen die Bewohner jener Länder von dem Tapir ziehen, besteht in der Benutzung des Fleisches, welches etwa dem Rindfleische $z u$ vergleichen ist und von allen Bewohnern der Ostküste gegessen wird, auch sollen diese Thiere innerlich und äufserlich viel weilses Fett oder Speck ansetzen, wonach die Wilden besonders lecker sind. Diese letzteren benutzen alle Theile des Thiers, selbst die schon übelriechenden Füfse fand ich in ih. ren Hütten und auch die Haut wird von ih. nen gebraten und verzehrt. - Die Camacans machen ihre musikalischen Instrumente aus den Hufen des Tapirs, welche ihnen bei'm Tanze den Tact angeben, und aus der dicken harten Haut bereiten die Brasilianer Peitschen, sie ist 
leichter zu gerben, wenn das Thier mager gewesen ist. -

Gezähmt wird der Tapir sehr zutraulich, besonders so lange er jung ist, und begleitet alsdann seinen Herrn in den Wald, folgt ihm überall, ja wenn er ihn einige Augenblicke vermifst, so wird er unruhig und sucht ihn überall, eine Sache, welche Azara unrichtiger Weise abläugnet. - Nach ihm scheint der Tapir in Paraguay nicht besonders häufig zu seyn, in Brasilien hingegen ist er nichts weniger als selten und in den Gegenden des Mucurí habe ich gewöhnlich bei meinen Jagdschifffahrten auf den Flüssen und Landseen, wenn wir frühe ausfuhren, von diesen Thieren zu sehen bekommen. - Azara glaubt bei beiden Geschlechtern einen Unterschied in der Farbe wahrgenommen zu haben, doch glaube ich die. ses für blofse Spielart in der Farbe halten zu müssen, da man einige findet, die mehr fahl, andere, die mehr graulich und noch andere, die mehr gelblich oder bräunlich gefärbt sind, gerade wie wir dieses auch bei uns an allen wilden Thieren, Hirschen, Rehen, Füchsen, Wölfen u. s. w. beobachten, dieses bestätiget selbst die Corografia brasilica (T. I. p. 62). - Azara hat übrigens eine sehr richtige gute 
Beschreibung dieser sonderbaren Thierart geliefert und alle die mannichfaltigen Erdichtungen und ungegründeten Sagen widerlegt und berichtiget, womit Reisende ihre Bücher anfüllten, welche nicht Kenner und Beobachter der Natur waren, und alle die vielen von den Eingebornen ihnen aufgebürdeten Wunderdinge für Wahrheit nahmen. -

\section{F am. II. $S$ e $t$ i g e $r$ a.}

$$
\text { B orstenthiere. }
$$

Thiere aus dieser Familie giebt es in den meisten Ländern der gemäfsigten und heifseı Zonen unserer Erde, nur die grofse Kälte scheint ihrer Natur nicht angemessen zu seyn. - Europa besitzt nur eine Art, Asien, Africa und America mehrere, die man ilres Fleisches wegen jagt und welche der 'Zïh. mung fähig sind. -

Gen. 35. Dic ot $t y l e s$, Cuv. $\mathrm{Nab}$ e Is c h we i n.

Die Unterscheidung der beiden Arten von wilden Schweinen, welche man bísjetzt in Ame. rica gefunden hat, verdanken wir Azara, dex' 
von ihnen die erste genaue Nachricht gab. Beide verdienen in ein Geschlecht vereinigt, und von den Schweinen der alten Welt getrennt zu werden, da sie mehrere auffallende Characterzüge mit einander gemein haben, weIshalb auch Cuvier sie unter der Benennung Dicotyles absonderte. -

In der Gestalt gleichen diese Thiere unseren wilden Schweinen, auch haben sie dieselben Schneide - und Backenzähne, allein ihre Eckzähne sind gestellt wie bei den Raubthieren; der Schwanz ist ein sehr kurzer Ansatz; an den Hinterfülsen fehlt die innere hintere $\mathrm{Ze}$ he und auf dem Kreuze nach hinten befindet sich eine Oeffnung, unter welcher eine Drüse liegt, die eine fettige Flüssigkeit absondert. -

Beide Arten dieses Genus sind gewöhnlich mit einander verwechselt worden, ob man sie gleich in ganz Brasilien und Paraguay überall sehr wohl von einander unterscheidet. - Ich will es versuchen, einige Bemerkungen über diesen Gegenstand mitzutheilen. -

\section{D. torquatus, Cuv.}

Das Káytetu, Táytetu oder das kleinere Nabelschwein.

Taiaçú-Caaigoara, Marcgr. pag. 229,

Le. Pecari, Buff. 


\section{$-558$}

Cuvier Règne-Animal, Vol. I. pag. 237.

Taytélu, Azara, Vol. I. pag. \$1.

Káytetu an der Ostküste von Brasilien oder in der Lingoa Geral.

Ho-kuäng bei clen Botocuden.

Der Kaytetu oder Taytetu ist die schon längst aus Guiana bekannte Art der beiden südamericanischen Schweine, welche dort in jenen nördlichern, dem Aequator näher gelegenen Ländern die gemeinere zu seyn scheint, da hingegen die nächstfolgende weniger bekannte, in den grofsen Wäldern von Brasilien bei weitem die zahlreichere ist. - Er scheint über den gröfsten Theil von Süd.America verbreitet. - Eine Beschreibung von diesem Thiere zu geben, würde Wiederholung seyn, ich will daher nur einige Bemerkungen mittheilen.

Der Kaytetu, oder wie ihn Azara nennt, der Taytetu ist die kleinere Art der beiden brasilianischen Schweine, welche sich, besonders in der Jugend, durch eine weifse Linie auszeichnet, welche bogenförmig nach dem Schulterblatte läuft und die im Alter öfters zu verschwinden pflegt; alsdann auch tritt für dieses Thier eine mehr schwärzliche gemischte Farbe ein. - In der frühen Jugend soll der Kaytetu völlig röthlich-braun gefärbt seyn und später ist er durch seine Zeichnung leicht von 
der folgenden Art, Azara's Tagnicati zu unterscheiden, wo hingegen im Alter dieser letztere wieder mehr kenntlich durch seinen weils gefärbten Unterkiefer ist. - Aus dem Gesag. ten geht hervor, dals beide Thiere nie zu verwechseln sind.

Wenu gleich Marcgrave's Beschreibung zu unvollkommen ist, um gewifs über dieselbe entscheiden zu können, so scheint er doch von dem Kaytetu zu reden, obgleich der Name Taiaçu, welchen die Völker der Lingoa Geral in den von mir besuchten Gegenden dem Tagnicati (Dicotyles labiatus) beilegen, hier ir. re führen könnte. Das Wort Taiaçú war in der Lingoa Geral zugleich der allgemeine Na. me der wilden Schweine, es kann daher in diesem Puncte zwischen der Gegend von Pernambuco und den mehr südlich gelegenen Provinzen leicht eine kleine Verschiedenheit der Benennungen vorkommen, welches bei der weiten Ausdehnung ein und derselben Küstensprache selbst sehr natürlich ist und einen neuen Grund für die Verbannung aller Provinzialbenennungen aus den Systemen abgiebt. -

Ein schätzbarer Naturforscher und berühmter Reisender, Herr Professor Lichtenstein, hat in seiner Abhandlung, Erläuterung der Werke 
des Marcgrave und Piso, an der Richtigkeit von Azara's Aufstellung beider Arten der america. nischen Schweine gezweifelt; allein ich kann, meinen Erfahrungen zufolge, dieselben nur bestätigen. Er hat vollkommen richtig die Irrthümer der verschiedenen Schriftsteller beleuchtet, welche den Kaytetu oder Taytetu und den Tagnicati unter dem gemeinschaftlichen Namen des Pecari begriffen haben, und alles was er über diesen Gegenstand sagt, halte ich für rollkommen richtige Ansicht und Beobachtung dieses Gegenstandes. Eine schwarze und eine braune Raçe von diesen Thieren braucht man nicht anzunehmen; denn in der Jugend ist das Thier bräunlich, im Alter mehr schwärzlich. Den Namen torquatus glaube ich demselben wohl beibehalten zu dürfen, da die weifse Linie doch ein beständiges Kennzeichen bei jüngeren Thieren, und oft im Alter selbst vorhanden ist. - Die Benennung Dicotyles Taiassu würde ich nicht wählen, da dieses eine Provinzialbenennung und dabei der allgemeine $\mathrm{Na}$ me aller Schweine in der brasilianischen Küstensprache ist. - Endlich glaube ich kaum die Corografia brasilica und den Pater Dobrizhofer widerlegen zu müssen; denn ersteres Buch kann, was seinen geographischen und 


\section{$-501$}

geschichtlichen Werth anbetrifft, sehr gut seyn, in naturhistorischer Hinsicht aber giebt es durchaus keine brauchbare Nachrichten. Hier redet der Verfasser von drei Arten von wilden Schweinen, wovon ich indessen nirgends die dritte kennen gelernt habe, welche unbezweifelt nur eine Farbenvarietät ist; denn diejenige Art, welche er gänzlich schwarz nennt, ist unbezweifelt der Tagnicati, bei welchem einzelne Ausnahmen vorkommen, wo der weilse Unterkiefer fehlt, oder doch nur sehr wenig weils gezeichnet ist. - Auch $v$. Humboldt sagt ${ }^{*}$ ), dals es nach einigen Aussagen auch am Orenoco drei Arten wilder Schweine geben solle, allein diese dritte Art ist wahrschein. lich nur Varietät, wenigstens kennen wir sie noch nicht. - Am Orenoco (Atures und Maypuris) nennt man das Kaytetu Chacharo, tamanackisch Paquira, den Tagnicati aber Api$d a$.

Dobrizhofer nennt vier Arten wilder Schweine für Paraguay, dafs er sich aber geirrt haije, beweist Azara, welcher die ganze Provinz vielfältig durchreiste und nur zwei Arten kennen lernte. - Die Spanier geben, nach Er-

*) Voy. au nouv, cont, T. II. pag, 330.

II. Band. 
sterem, den Abiponern Schuld, dafs sie von den Juden abstammten, weil sie das Fleisch der zahmen Schweine nicht essen; demnach würden die wilden Völker der Ostküste von Brasilien nicht von den Israeliten abstammen können, da sie das Schweinefleisch sehr lieben. - Alle brasilianischen Jäger, so wie alle der Wälder vollkommen kundige Indianer bestätigen einstimmig Azara's beide Schweinearten, und auch ich habe mich in den von mir bereisten Gegenden von dem Vorhandenseyn derselben überzeugt; denn nirgends fand ich eine dritte Art, auch stimmen hiermit alle andere Nachrichten überein, die ich über ganz Süd-America $\mathrm{zu}$ vergleichen im Stande war. Selbst der Missionär Eckart*) bestätigt dieses vom Maranhào. Dort kennt man nach ilım zwei Arten wilder Schweine, wovon das kleinere Taytétú, das gröfsere (Dicotyles labiatus) aber Taiaçí genannt wird. In anderen Gegenden der Provinzen des spanischen America belegt man, dem Missionär Weigl zufolge, die wilden Schweine mit dem allgemeinen $\mathrm{Na-}$ men Guangana, und nennt die kleinere Art

*) Siehe v. Murr, Reisen einiger Missionäre der Gesellschaft Jesu, pag. 512 und 199. 
Cahucuma. Herr $v$. Sack sagt in seiner Reise nach Surinam (pag. 196), dafs man daselbst zwei Arten wilder Schweine kenne, den Bakkire und den Pingo. Auch die Botocuden un. terscheiden beide Arten, indem sie den Kayte. tu - Hokuäng, und die nachfolgende Art Kuräck nennen.

Nicht blofs durch sein Aeufseres unterscheidet sich der Kaytetu von dem Tagnicati, sondern auch durch die Lebensart, wie Azara sehr richtig bemerkt. Der erstere lebt nicht in grofsen Heerden wie der letztere, sondern einzeln oder in kleinen Gesellschaften und soll am Tage gewöhnlich in dichten Gebüschen, zwischen umgefallenen Baumstämmen, ja selbst in den an der Erde befindlichen Höhlungen alter, fauler Urwaldstämme sich verbergen, wo er oft von den Jägern gefunden wird. - Er ist schwächer und furchtsamer als die nachfolgende Art, dabei auch an der Ostküste überall die am wenigsten zahlreiche. - Sein Fleisch liebt man sehr und jagt ihn daher wo nur möglich, wobei Hunde vom grölsten Nutzen sind. - Seine Nahrung und Lebensart ist übrigens vollkommen die der anderen Schweine; denn wie diese wühlt er in der Erde (ein dem Jäger willkommenes Zeichen seines Vorhanden- 
seyns), um alle Arten von Wurzeln, Schwämmen, Würmern, Maden und Früchten zu suchen. - Man jagt ihn wie die nachfolgende Art, da er jedoch mehr in versteckten Schlupfwinkeln sich verbirgt, so wird er weniger häufig geschossen, - Aus der vortrefflichen Beschreibung der Herren Geoffroy und $\mathrm{Fr}$. Cuvier ersehen wir in welchem hohen Grade diese Thierart der Zähmung fähig ist.

\section{D. labiatus, Cuv.}

Das. Nabelschwein mit weilsem Unterkiefer.

Tagnicati, Azara Essais etc. Vol. I. p. 25.

Cuvier Règne Animal, Vol. I. pag. 233, wo aber die

Namen verwechselt sind.

Abbildungen zur Naturgeschichte Brasilien's.

Porco de queixada branca oder Porco do mato verdadeiro an der Ostküste von Brasilien.

Kuräck bei der Botocuden.

$K a$-hiá bei den Camacans.

Das Schwein mit weifsem Unterkiefer ist, wie bekannt, die gröIsere der beiden brasilianischen Arten und bei weitem die gemeinere und zahlreichste in den Wäldern des östlichen von mir bereisten Theiles. - Illiger nannte diese Art Sus albirostris, doch würde diese Benennung mehr passen, wenn der Oberkiefer weifs wäre; da aber nur der untere mit dieser Farbe bekleidet ist, so ziehe ich Cuvier's Benennung, 
labiatus vor. - Azara's Beschreibung dieses Schweins ist richtig, auch finde ich alles gegründet, was er von der Lebcnsart desselben sagt. - Er mals ein solches Thier, welches vierzig Zoll sechs Linien in der Länge hielt, da das gröfseste von mir beobachtete zwei und vierzig Zoll gab; ich werde dasselbe in den nachfolgenden Zeilen kürzlich beschreiben.

Die Gestalt ist gedrungen, dickleibig, aber höher von Beinen als unser europäisches wildes Schwein; der Kopf ist etwas kleiner, dabei dick; der Rüssel ist an der Spitze breit, das Auge etwas grölser als an unserem Scluweine; Ohren etwas kurz abgerundet, aufsen und in. nen dünn mit langen Borsten besetzt. Der obere Eckzahn ist von oben gerade abwärts gerichtet, und tritt selbst bei geschlossenem Munde unter der Oberlippe hervor; er ist kegelförmig, gerade und dreieckig. - Die vier Beine sind schlank, höher als am europäischen wilden Schweine; die vorderen mit zwei langen Hinterzehen (Afterklauen, ungulae succenturiatae, Illig.), die hinteren nur mit einer solchen an der inneren Seite; sie ist kürzer als die beiden des Vorderfufses. An der Stelle der fehlenden Hinterzehe befindet sich nackte Haut. - Auf dem Hinterrüicken trägt das Thier 
seine Drüsenöffnung, aus welcher eine riechende Feuchtigkeit ausschwitzt, die mir aber öfters geruchlos geschienen hat. - Der Schwanz ist ein sehr kurzer, unten nackter, oben borstiger Stumpf.

Die Oeffnung der Ruthe des Männchens befindet sich unter der Mitte des Leibes und ist mit einem kleinen Haarpinsel versehen; die Testikel sind grols und eben so gebildet wie an unserem europäischen wilden Schweine, sitzen aber scheinbar etwas tiefer.

Das ganze Thier ist dünne mit starken, dicken, eckigen, harten Borsten besetzt, zwischen welchen man überall die Haut bemerkt, auf dem Hinterkopfe sind sie am längsten, über den ganzen Rücken hin ebenfalls lang und stark, jedoch weit weniger als an unserem wilden Schweine, sie messen da, wo sie am längsten sind, etwa zwei Zoll neun Linien in der Länge; Haar auf der Stirn mälsig lang und dicht; Ober- und Unterkiefer mit langen Bartborsten besetzt, auch befindet sich eine Reihe derselben über den Augen. - Die steifsten Borsten bedecken den Körper, in den Seiten sind sie sparsamer und unter dem Bauche noch seltener. - Die vier Beine sind an 
ihrer inneren Seite beinahe nackt, eben so der Bauch zwischen den Schenkeln.

Alle Borsten des Thiers sind graulich. schwarz gefärbt und haben in ihrer Mitte eine röthlich-gelbe Binde; am Mundwinkel und Ende des Unterkiefers steht an der Seite ein grofser weifser Fleck, daher die Benennung de queixada branca. - Jüngeren Thieren fehlt der weilse Fleck am Unterkiefer öfters noch, und ganz junge, welche noch an der Mutter saugen, haben eine ganz verschiedene Zeichnung, wie folgt:

Sie sind sehr niedlich, mit hoher Stirn, noch ohne Zähne, doch bemerkt man schon den oberen und unteren Eckzahn, welche etwa drei Linien lang sind; das Haar ist dichter, weicher und kürzer als an dem erwachsenen Thiere, von röthlich gelber, etwas schwärzlich gemischter Farbe; denn die Haare haben schwärzliche Wurzeln und lange röthlich gelbbraune Spitzen, so dars diese letztere Farbe die herrschende ist; ein völlig schwarzbrauner Streif läuft über den Rücken hinab; die Beine sind rein und ungemischt hellgelb, so wie die Seiten des Kopfs; Stirn schwärzlich und gelblich gemischt; Augenlieder nackt und aschgrau; Ohren von aufsen hellgelblich behaart; Hufe 
rïthlich-grau. - Ein solches junges Thierchen, welches Ende Februar gefangen wurde, hielt fünfzehn Zoll in der Lünge, ich habe dasselbe abbilden lassen.

Ausmessung des weiter oben beschriebenen, alten, männlichen Thieres:

\section{Ganze Länge}

$42^{\prime \prime}$

Der kleine Schwanzansatz nimmt davon

Länge des Kopfs bis zum vorderen

Ohrrande

$12^{\prime \prime} 2^{\prime \prime \prime}$

Länge von der Spitze des Rüssels bis

$$
\text { zu dem vorderen Augenwinkel } q^{\prime \prime}
$$

Höhe des äufseren Ohres . . $g^{\prime \prime} 7^{\prime \prime \prime}$.

Höhe des Vorderbeins bis an den

$$
\text { Leib . . . . . . . 12 } 12^{\prime \prime} 2^{\prime \prime} \text {. }
$$

Länge des Hinterbeins, wenn es aus-

gestreckt worden, bis zu dem

Schwanze . . . . $19^{\prime \prime} 2^{\prime \prime \prime}$.

Länge der Vorder-Afterklaue • • 1" $5^{\prime \prime \prime}$.

Länge der Hinter-Afterklaue . 11"'.

Länge des oberen Eckzahnes . . 1" $1^{\prime \prime \prime}$.

Länge des unteren Eckzahnes . 1" 4."'.

Breite des Rüssels . . . . 2 2 2" $9 \frac{1}{2}{ }^{\prime \prime \prime}$.

Höhe des Vorderhufes in der Mitte $1^{\prime \prime} 8^{\prime \prime \prime}$.

Höhe des Hinterhufes in der Mitte $1^{\prime \prime} 5_{\frac{\pi}{2}}^{\prime \prime \prime}$. 
Das Schwein mit weifsem Unterkiefer lebt überall in den von mir bereisten Gegenden. Dort wo der Mensch die Ruhe der grofsen Waldungen selten unterbricht, findet man diese Thiere in Gesellschaften (Rudeln) von fünfzig, sechzig und darüber, auch haben wir in einem Tage vierzehn und mehrere dergleichen Heerden angetroffen, woraus man auf die Menge dieser Thiere schliefsen kann; dafs einige Reisende hingegen von Rudeln dieser Schwei. ne von 1000 Stück reden, ist wohl eine etwas starke Uebertreibung. Sie sind auf diese Art über den gröfsten Theil von Süd-America verbreitet; denn in Guiana leben höchst wahrscheinlich beide hier aufgeführte Arten. Ue. ber Brasilien sind sie verbreitet und in Paraguay unterscheidet sie Azara zuerst richtig. Ihre Nahrung ist mannichfaltig, wie die unserer europäischen Schweine, auch findet man in ihrem Magen grofse, etwas abgeplattete aegagropilae von elliptischer Gestalt, die aus Wurzeln, Haaren und unverdaulichen Pflanzenfasern bestehen *). - Die Heerden dieser

*) Ich besitze eine solche Magenkugel von vier Zoll Länge, und zwei und einem halben Zoll Breite, bei anderthalb Zoll Dicke, mit einer bräunlich-granen festen Rincle überzogen, welche ich habe ablilden lassen. 
Schweine ziehen ihrer Nahrung nach in den Urwäldern umher, wo die Jäger an den aufgewühlten Stellen ihr Daseyn und ihre Richtung erkennen, auch hört man ihre Stimmen oft weit in jener stillen schauerlichen Einsamkeit. Irrig ist es, wenn Azara behauptet, man dürfe sich ohne Gefahr jenen Kudeln nicht nähern; denn meine Jäger schossen ihre mit Schrot geladenen Doppelflinten häufig auf dieselben ab, erlegten von einer Gesellschaft oft vier, fünf und mehrere Thiere, ohne dals sie sich $z u$ widersetzen wagten. Wir würden weit mehrere von ihnen erlegt haben, wenn wir gute Hunde besessen hätten, da sie sich vor diesen gewöhnlich sogleich zu stellen pflegen, wodurch der Jäger Zeit erhält öfters zu schie. fsen. - Dennoch aber soll sich der Fall zuweilen ereignen, dafs Jäger, welche zu unvor. sichtig zwischen diese Thiere hineingingell, nachdem sie mehrere von ihnen angeschossen hatten, von ihnen angefallen wurden und Hunde, welche zu brav sind, sollen sie zuweilen zerreilsen, gerade wie unsere zahmen Mastschweine thun. - Die brasilianischen Jäger sind äulserst geübt in Beschleichung dieser Thiere, besonders aber die Wilden, welche sie mit ihren langen Pfeilen erlegen. - Man fängt 
sie häufig in Fallgruben (Fojos), welche einen Deckel von Flechtwerk bekommen. - Gegen die Hunde pflegen sich diese wilden Schweine zu wehren, indem sie von oben herab mit ihren Gewehren (Eckzähnen) schlagen oder stofsen. Unter allen Thieren der brasilianischen Urwälder sind nach den Affen die wilden Schweine diejenigen, welche von den Wilden am meisten gejagt werden. - Sie ziehen ihnen förmlich nach und viele vereinigen sich oft zu einer solchen Tagd. - Am Flufs Belmonte suchten einige Botocuden schon Hunde zu dieser Jagd zu gebrauchen. - Sie sengen das erlegte Schwein am Feuer, lassen aber weder Kopf, Haut noch Eingeweide verloren gehen, sondern essen alle Theile, und nur die härtesten Knochen bleiben übrig. - Zähmen lassen sich diese Nabelschweine recht leicht, die Wilden binden sie oft $\mathrm{zu}$ ihrer Sicherheit in der Nähe der Hütten an, wenn sie mit anderen Völkern im Kriege sind; denn sie sollen gewaltig schnauben und toben, wenn sie etwas Fremdartiges bemerken.

Die Benennungen, welche dieses Schwein in den verschiedenen Gegenden von Brasilien trägt, sind mannichfaltig. In der Lingoa Geral ward es ursprünglich Taiaçu genannt, die 
Portugiesen nennen es schlechtweg Waldschwein (Porco do mato) oder ächtes wahres Waldschwein (Porco do mato verdadeirc), aber gewöhnlich auch Qucixada branca, die Botocuden kennen es unter der Benennung Kuräck, und die Camacan-Indianer in der Capitania da Bahía nennen es Küá-Hyä, zum Unterschiede von dem europäischen zahmen Schweine, wel. ches bei ihnen den Namen Küá-Hirochdá (deutsch auszusprechen) trägt. -

\section{OnD. VIII. $B$ isulca. $\mathrm{Z}$ w e i hufer.}

Die Thiere mit gespaltenem Hufe oder die Wiederkauer bilden eine völlig in der Natur begründete Ordnung, gegen welche selbst die kühnste Neuerungssucht der Naturforscher bisjetzt noch nichts vermochte. - Angeneh. me Gestalt mit schlanken zierlichen Gliedern und damit verbundene Schnelligkeit in ihren Bewegungen, eine gehörnte Stirn, ein nutzbares Fell, angenehm geniefsbares Fleisch und ihre Milch, so wie die Naturgabé, der Zähmung bis $z u$ einem hohen Grade fähig zu seyn, 
machen diese Thiere $\mathrm{zu}$ den angenehmsten und nützlichsten für den Menschen, dem manche Arten von ihnen nun schon unentbehrlich geworden sind. - Aber auch durch die merkwürdige Organisation des Magens und die daraus entspringende Eigenheit des Wiederkauens sind diese Thiere dem Naturforscher höchst interessant und bilden in dieser Hinsicht eine eigene getrennte, ganz für sich bestehende $\mathrm{Ab}$ theilung in der Reihe der Säugthiere. - Mit ihren empfehlenden Eigenschaften vereinigen die Wiederkauer ein Naturell, welches die grölste Verbreitung erträgt; denn diese Thiere gedeihen unter allen Zonen, wohin sie der Mensch verpflanzte. In allen Welttheilen findet man Thiere mit gespaltenem Hufe, wenn wir Australien etwa ausnehmen; dennoch besitzt die alte Welt eine bei weitem grölsere Menge dieser nützlichsten und schönsten der Säugthiere, America oder die neue Welt hingegen eine weit geringere Anzahl.

Augenscheinlich ist die Organisation der wiederkauenden Thiere weniger für die grofsen Wälder von America, als für die Steppen und ausgedehnten ebenen Triften von Africa und Asien, für die Savannen des südlichen NordAmerica eingerichtet, daher finden wir im süd- 
lichen America aus dieser Ordnung nur Hirsche, rveil diese unter allen wiederkauenden Thieren, einzelne Ausnahmen abgerechnet, beinahe die einzigen für das Dickicht der Wälder geschaffenen sind.

So gering im Allgemeinen in Süd-America die Zahl der wilden, ursprünglich daselbst einheimischen Wiederkauer ist, so bedeutend haben sich jetzt in allen von Europäern bewohnten Provinzen dieses Continents die ron Europa mit herüber gebrachten Hausthiere vermehrt. Sie gedeihen selbst in den heifsen Gegenden und sind zahlreich, vermehrten sich aber ungeheuer in den grofsen Ebenen des schon mehr südlichen und gemärsigteren Theiles, worüber wir in den Werken $v$. Humboldt's und anderer Schriftsteller, welche über das spa. nische America geschrieben haben, nachlesen können. Bekannt ist es, wie das so nützliche Rindvieh, z. B. selbst in der brasilianischen Provinz Rio Grande sich so aufserordentlich vermehrt hatte, dafs man ihm grofse Niederlagen beibrachte, blofs um die Felle der getödteten Thiere zu benutzen, das Fleisch liefs man ungenutzt verfaulen. Seitdem aber hat man angefangen, auch dieses $z u$ benuizen, dasselbe einzusalzen und unter der Benennung von car. 
ne seca oder carne do sertán in die verschiedenen Provinzen zu verschiffen. -

Das brasilianische Rindvieh ist stark, wohl gebaut, die Stiere mit starken Hörnern versehen, seine Farbe ist meistens dunkel oder schwärzlich.braun, auch fahl graugelblich, zuweilen, jedoch seltener, weifs gefleckt. Die Ziegen und Schaafe gedeihen in Brasilien ebenfalls recht gut. In der Gegend von Rio de Janeiro sind die ersteren nicht grols, auch fand ich sie nicht stark behörnt, allein ihr Haar ist hart, sehr glatt und meistens schön glänzend gelbroth mit schwarzen Abzeichen an Kopf und Beinen und einem ähnlichen Längsstreifen über den Rücken hinab. Den Nachrichten der Reisenden zufolge, gedeihen diese Thiere auch in Surinam sehr gut, die Schaafe bekommen daselbst hartes Haar, wie die Ziegen, die europäischen werden mager und sollen kränkeln. Das Rindvieh ist daselbst klein, ein Ochse wiegt vier - bis fünfhundert Pfunde, selten sechshundert und soll selten über vier Fuls lang seyn.

$$
\begin{aligned}
& \text { Gen. 36. C e r v u s. } \\
& \text { H i r s c h. }
\end{aligned}
$$

Eine vollständige Kenntnifs der verschiede. nen Arten des Hirschgeschlechtes ist bisjetzt 


\section{$-576$}

von den Zoologen vergebens gewünscht worden. In den neueren Zeiten hat jedoch die Kenntnils dieser schönen angenehmen Thiere wahre Riesenschritte zu ihrer Verrollkommnung gemacht, so dafs man am Schlusse eines jeden Jahres über die neu hinzugekomnienen Vermehrungen und Verbesserungen erstaunen mufs. - Die französischen Naturforscher haben sich in diesem Felde besonders verdient gemacht, und zwar ganz besonders für Ost-Indien. - Schon konnten Cuvier und Desma. rest in ihren neuesten Werken *) vortreffliche Uebersichten der bekannten Hirscharten liefern, die jetzt die vollständigsten in dieser Hinsicht sind, es bleibt aber auch in diesen Abhandlungen noch vieles dunkel und unaufgeklärt, und dieses gilt ganz besonders für Süd-America. Buffon und Pennant beschrieben einige dortige Hirsche sehr oberflächlich und unvollständig, man wufste also beinahe gar nichts über jene Thiere, bis uns Azara vier Arten genauer unterscheiden lehrte.

Diese vier von Azara beobachteten Hirsche sind es, welche, wie es mir scheint, über

*) Cuvier recherches sur les ossemens fossiles, nouvelle édition; und Desmarest Mammalogie. - 
ganz Süd-America verbreitet sind und von den meisten Reisebeschreibern erwähnt werden. Welche Arten dieses Geschlechts in Guiana vorkommen, ist zwar noch unbestimmt, allein wenn ich alle Nachrichten über diesen Gegenstand vergleiche, so glaube ich die genannten Thiere doch immer wieder zu erkennen, und diefs gilt auch für die Uebersicht der lebenden Hirscharten in Cuvier recherches sur les ossemens fossiles. - Das in jenem vortrefflichen Werke (Tom. IV.) Tab. III. Fig. 46. abgebildete Gehörn ist unläugbar das des Guazuti, Tab. V. Fig. 23. könnte wohl das des Guazupucu seyn, die Biche des bois ist wahrscheinlich der Guazupita und der Cariacou der Guazubira, womit auch die Farbe des Thiers zusammentrifft. - Ueber Brasilien sind diese Hirsche des Azara verbreitet; denn dafs er den Aufenthalt derselben blofs auf ein gewisses Local, z. B. Sumpf oder die Dickungen der Wälder eingeschränkt glaubt, scheint mir ungegründet. Da ich den Guazupita und Guazubira beide in einem jeden Local, also den letzteren nicht blofs in Niederwald angetroffen habe, so glaube ich zu dem Schlusse berechtigt zu seyn, daIs auch der Guazupucu in den inneren hohen Waldgebirgen leben kün-

II. Band. 
ne, und es ist gewifs, dafs daselbst ein grofser Hirsch vorkommt, welcher seines mehr beendeten oder zackigen Geweihes wegen von den Brasilianern Veado Galiero oder Cuçuapara ge. nannt wird.

Dieses ist meine Ansicht der vier Hirsche des Azara, und soviel ich auch über diesen Gegenstand in den Berichten der Reisenden nachlas, so glaubte ich doch nie mehr als vier wohl unterschiedene Hirscharten in allen Provinzen von Süd-America zu erkennen. - Die Matacanis in den Ebenen von Calabozn schienen mir zu dem Guazuti des Azara zu gehören, nur passen hier freilich die weifsen Fleckchen nicht recht, ich glaubte aber, dafs v. Humboldt vielleicht nur junge Thiere sah. -

In ảen nachfolgenden Blättern habe ich aus eigener Ansicht blofs von den drei kleineren Hirscharten des Azara zu reden, von dem Guazuti auch nur theilweise, aber den groIsen Hirsch Guazupucu habe ich in der von mir bereisten Gegend gar nicht angetroffen, ich werde indessen in den nachfolgenden Zeilen meine Ansichten näher entwickeln.

$\mathrm{Da}$ die Zahl der uns bisjetzt bekannten Hirscharten schon beträchtlich ist, so könnte 
man sie vielleicht unter folgende Unterabtheilungen bringen:

A. Hirsche mit breitem schaufelförmigem Gehörn ohne Augensprossen.

Z. B. Cervus Alces, Linn.

$B$. Hirsche mit breitem halbschauflichtem Gehörn mit schaufelförmigen Augensprossen. Diese beiden ersten Familien haben behaarte Nasenkuppe.

Z. B. Cervus Tarandus, Linn.

C. Hirsche mit schauflichtem Gehörn und runden Augensprossen.

Z. B. Cervus Dama, Linn.

$D$. Hirsche mit rundem astigem Gehörn, und einem Schwanze.

Z. B. Cervus Elaphus, Linn.

E. Hirsche mit rundem astigem Gehörn dabei ungeschwänzt.

Z. B. Cervus Capreolus, Linn.

F. Hirsche mit einfachem ungetheiltem Gehörn und einem Schwanze.

Z. B. Cervus rufus, Illig. *).

*) Sollte es sich bestätigen, dars gewisse indische Hirsche nur drei Enden oder Spitzen an ihrem Gehörne ausbilden, so würden diese noch eine siebente Familie bilden können, mit rundem, astigem, dreiendigem Gehörn und einem 


\section{$-580$}

1. Nirsche mit rundem astigem Gehörn und einem Schuvanze.

1. C. paludosus, Desm.

Der Guasupucu.

Cervus dichotomus, Illig.

Guazupucu d' Azara essais etc. Vol. I. p. 70.

? Çuçuapara oder Veado Galhciro in Brasilien.

Es ist ansgemacht, dafs in dem inneren Lrasilien ein grofser Hirsch lebt und es scheint mir, dals die Corografia brasilica irrt, wenn sie (T. I. pag. 71) sagt, dafs dieser . Cuçuapara und das Veado Galhciro (auszusprechen Via. do Galiero) zweierlei seyen; denn sowohl $M i$ neiros als andere Bewohner des inneren Bra-

Sclnwanze; allein ich bezweifle sehr die Beständigkeit dieser Abtheilung. Die Natur diurfte bei ilmen wohl nicht immer bei drei Enden stehen bleỉsen. Ther als Jïger dic Arten der Hirsche beobachtet, der wird auf die geringe Beständigl.eit der Enclenzahl bei diecen Thieren sehr bald aufmerlsam, defshalb müssen die Naturforscher bei Beolo. achtung der fremden, in Menagerien anferzogenen, Hirsche besonders vorsichtig seyn; dem im gezilinten Zustunde, wo noch dazu gewöhnlich diesen Thieren die DeVriecligung des Geschlechtstriebes alggeht, weichen sie in dieser Hinsicht noch weit melx $\mathrm{ab}$, als in der freien $\mathrm{Na}-$ tur. - Gewöhnlich werden ihre Geweihe im Alter monstruös, und ich habe bei solchen zahmen Hirschen bemerlit, dafs ihr Gehöm alljährlich um ein Pfund an Gewicht zunahm. 
silien's haben mir versichert, beide Benennungen würden in verschiedenen Gegenden ein und derselben Thierart beigelegt. In der Lingoa Geral benannte man im Allgemeinen alle Hirscharten Cucuaçı́ oder Çuguaçí, auch reeu açi, hatte aber für jede derselben noch eine besondere Benennung, daher kam es, dafs das Thier, welches ron, jenen Stämmen der Lin. goa Geral Cucuapara genannt wurde, von den Portugiesen die Benennung Veado Galheiro oder des Hirsches mit astigem Gehörn erhielt.

Ich habe nie selbst Gelegenheit gehabt, diese Hirschart zu sehen, wohl aber hat man mir gesagt, dafs sie die inneren hochgelegenen Waldungen von Minas, Goyaz, Cuiaba, Matto Grosso bewohne, man findet sie z. B. in der Serra da Canastra. - Sie soll sich vorzugsweise in den unbewohnten menschenleeren Gegenden aufhalten. Da nun Azara für seinen Guazubira den Aufenthalt nicht ganz richtig angab, so kömnte dieses auch für seinen Guazupucu der Fall seyn und alsdann wäre es möglich, dafs das Veado Galhciro und der Guazupucu ein und dieselbe Species bildeten, $\mathrm{Da}$ dieses indessen blofs eire als Frage aufgestellie Vermuthung von mir ist, so bleibt es 


\section{$-582$}

anderen Reisenden aufbehalten, das Veado $G a$. lheiro näher kennen zu lernen

Das Gehörn dieses Hirsches soll nicht immer blofs zweitheilig seyn, wie es Illiger nannte, sondern zuweilen, wie an unserem Hirsche, oben eine Krone von drei Enden oder Spitzen ausbilden, dabei hoch und astig mit vielen En. den seyn, doch kann ich die Wahrheit dieser Aussage nicht verbürgen. Die Mineiros behaupten übrigens von diesem grofsen americanischen Hirsche, dafs er angeschossen öfters auf den Jäger und den verfolgenden Hund losgehe.

Ich nehme bis zu weiteren und genaueren Nachrichten über diesen Gegenstand den Cuçuapara für Azara's Guazupucu an, ob. gleich gegen die Vereinigung wieder der Einwurf zu machen ist, dafs Azara sehr streng auf den Aufenthalt seines grofsen Hirsches in sumpfigen Brüchern (Esteres) hält. - So viel scheint mir höchst wahrscheinlich, dafs der grofse Hirsch der Anden, von welchem La Condamine und $v$. Humboldt reden, und welchen letzterer bis zu einer Höhe von 2000 Fufsen in jenen Gebirgen beobachtete, dabei aber nicht von dem europäischen Hirsche zu unterscheiden vermochte, das Veado Galheiro des inne- 
ren Brasilien's ist. - Sollte indessen der Gua. zириси von dem eben genannten Hirsche specifisch verschieden seyn, welches ich nicht glaube, so würde ihm vorzugsweise eine Benennung zukommen, welche sich auf seinen Aufenthalt in Sümpfen bezöge, und die von Desmarest gegebene wäre alsdann beizubehalten.

2. C. campestris, Fr. Cuv.

Der Hirsch der offenen. Ebenen.

Guazuti, Az, essais etc. Vol. I. pag. 77.

Abbildungen zur Naturgesch. Bras. - Das Gehörn.

G. Cuvier: Recherches sur les ossem. foss, Vol. IV. Tab. III. Fig. 46. Das Gehörn.

Veado Campeiro der Portugiesen in Brasilien.

Çuguaçu-apara, Marcgr. pag. 235.

Cervus leucogaster, Goldf.

Azara's Guazuti ist eine sehr kenntliche Hirschart, die durchaus nicht zu verwechseln ist. - Cuvier hat in" der neuesten Ausgabe seines vortrefflichen Werkes über die fossilen Thiere das Gehörn des Guazuti deutlich abgebildet, wovon man sich sogleich überzeugen kann, wenn man die 46ste Figur der 3ten Tafel des 4ten Bandes, mit der von mir in der Isis und in meinen Abbildungen zur Naturgeschichte Brasilien's bekannt gemachten Zeich- 
nung eines solchen Gehörns vergleicht. Es ist ausgemacht, dafs dieser Guazutii oder Hirsch der offenen, waldlosen Gegenden über einen grofsen Theil von Süd-America verbreitet ist; denn er lebt im Inneren der Provinzen Bahía, Minas Geraës u. s. w. und geht bis Paraguay hinab; ob er in Guiana vorkommt, ist mil nicht bekannt, doch ist es mir wahrscheinlich. - Die Hirsche, welche v. Humboldt truppweise in den Steppen von Calabozo fand, und die man dort Matacani nennt, wïrde ich unbedingt hieher rechnen, wenn sie im erwachsenen Zustande ungefleckt wären, worüber ich nicht genau unterrichtet bin. Dieser ausgezeichnete Gelehrte und Rieisende könnte vielleicht junge Thiere gesehen haben, da er auch weilser Individuen erwähnt, wie Azara. -

Der Hirsch der offenen Ebenen oder der Guazuti des Azara ist seines Aufenthaltes so wie der Bildung seines Gehörnes wegen mit den übrigen americanischen Hirschen nicht zu verwechseln. - Er wählt zu seinem Aufenthalte offene, öde, mit hohem Grase bewachsene, weit ausgedehnte Gegenden, die Campos Geraës, welche nicht mit Wald, sondern nux abwechselnd mit einzelnen Gesträuchen bewachsen sind, auch soll diese Hirschart nie in die 
Wälder treten. - Man findet diese Thiere in kleinen Gesellschaften oder Rudeln, doch sollen sie sich zuweilen auch zahlreich beisammen finden. - Sie sind scheu und sehr flüchtig, wittern den Jäger weit, entfliehen alsdann mit grofsen Sprüngen, ja sie sollen die flüchtigste der brasilianischen Hirscharten seyn, Sie werden zu Pferd und mit Hunden gejagt, umringt oder beschlichen und geschossen, in anderen Gegenden auch mit dem Laço (Schlinge) und den Bolas (Kugeln) erlegt. -

In der Gestalt, Grölse und Farbe haben diese Thiere viel Aehnlichkeit mit dem euro. päischen Rehbocke (Cervus capreolus, Linn.); denn das Gehörn weicht sehr wenig von dem des Rehbocks ab, wird auch etwa eben so hoch, allein das Vorhandenseyn eines Schwanzes ist schon hinlänglicher Unterschied für beide Thierarten. - Unter den von Cuvicr erwähnten americanischen Hirschen und jungen Thieren dieses Geschlechts, welche das Museum zu Paris aus America erhielt, befindet sich auch dieser Hirsch, der in der Färbung dem Guazubira des Azara ähnelt. -

Da ich das Reh des Campo nicht selbst gesehen habe, ob man es gleich an den Gränzen der Provinz Bahia, unfern von Minas Gerä̈s 
schon findet, wo ich mich einige Zeit aufhielt, so kann ich nur die Abbildung des Gehörnes geben, deren ich mehrere von den dortigen Jägern und Pflanzern erhielt. Sie kamen alle in der Gestalt und Grölse vollkommen überein, so wie auch alle jene Jäger auf das vollkommenste in ihren Nachrichten übereinstimm. ten.

Alles, was Azara von dieser Hirschart sagt, scheint gegründet, wenn ich damit die Nachrichten vergleiche, welche mir über diesen Gegenstand mitgetheilt wurden. Von einem unangenehmen Geruche indessen, welchen ihr Azara beilegt, wollten die brasilianischen Jäger nichts wissen; wahrscheinlich ist er eine Art von Brunftgeruch gewesen, wie bei unserem Hirsche, den man indessen bei unserem Rehbocke nicht wahrnimmt. Die Brasilianer essen das Fleisch gern, nennen es aber sehr trocken.

Das Leder dieser Hirschart ist dünner als das der folgenden Art, wird aber zu den Anzügen der Vaqueiros sehr gesucht. -

Das Gehörn dieses Hirsches habe ich sehr genau abbilden lassen. Einige derselben haben den unteren Theil der Stange mehr rauh und mit kleinen Knöpfchen oder Perlen besetzt, bei 


\section{- $587-$}

anderen ist er mehr glatt, gerade wie diefs bei unseren europäischen und allen übrigen Arten dieses Geschlechtes der Fall ist. - Das höchste dieser Gehörne hielt in der Länge sieben Zoll zehn Linien, von àer Rose oder dem unteren rauhen Rande bis zu der oberen Spitze des längsten Endes gemessen, deren jede Stange gewöhnlich drei trägt, wie bei unserem europäischen Rehbocke. Eine gröfsere Ausdehnung soll dieses Gehörn selten erlangen, -

B. Hirsche mit einfachem Gehörn ohne Enden, und einem an seiner unteren Fläche dicht behaartem Schwanze.

3. C. $\quad r u f u s$, Illig.

Der rothe Spielshirsch, Guasupita.

Çuguaçu-été, Marcgr. pag. 235.

Gouazoupita, Azara Essais etc. Vol. I. pag. 82.

Cervus rufus, Goldf. Forts. d. Schreb. Säugth. p. 1130. Abbildungen zur Naturgeschichte Brasilien's.

Veado-mateiro der Brasilianer.

Bocling - Niack bei den Botocuden.

Der rothbraune Hirsch mit einfachem Gehörne ist die gemeinste Art dieses Geschlechtes in Brasilien und überall über Süd-America verbreitet, wo nur Wald den Boden überzieht. 


\section{$-588$}

Er ist an der Ostküste unter dem Namen des Waldhirsches oder Viado-Matero (Veado-Mateiro) bekannt, so wie in Minas Geraës, der Capitanía da Bahia und vielen anderen Gegenden. - Seine Beschreibung hat Azara ge. liefert und ich bemerke nur, dafs er in den einzelnen Theilen von unseren Hirschen etwas abweicht, im Allgemeinen aber die Gestalt und Grölse unseres Rehes hat. Sein Kopf ist mehr gestreckt, das Auge und Ohr kleiner, die Sclnautze breiter und dicker als an unserem Rehbocke, dabei hat er einen unten stark behaarten Schwanz, der unserem Rehe gänzlich fehlt. - Das Gehürn des männlichen Thieres hat keine Nebenspitzen oder Enden, ob man gleich auch zuweilen kleine Ausnahmen von dieser Regel findet; denn wie bekannt zeigt die Natur an den Gehörnen der Hirscharten aller Weltheile mancherlei Abweichungen des Bil. dungstriebes. - Unter sehr vielen dieser Gehörne, so versicherten mir erfahrene Jäger, hat man nur einmal ein etwas gabelförmiges gefunden; ich selbst sah ein anderes mit einem kleinen Nebenauswuchse, welches ich sammt dem Schäd l habe abbilden lassen, doch sind diese Ausnahmen von der Regel selten, - Im Monate September erlegie einer meiner Jüger ei- 
nen solchen Rehbock am Flusse Belmonte, der eben sein Gehörn zur Hälfte abgeworfen hatte; dafs aber, wie Azara behauptet, die Zeit des Abwerfens für diese Thiere nicht regelmälsig an eine gewisse Periode gebunden sey, bezweifle ich. - In den Monaten Juni, Juli, August und September habe ich das Gehörn dieser Thiere in seinem vollkommenen Zustande gefunden, nie aber dasselbe in der Epoche erhalten, wenn es mit Haut (Bast in der deutschen Jägersprache) überzogen, oder noch unreif war. Ich werde nun die Beschreibung eines männlichen und eines weiblichen Thieres folgen lassen:

Beschreibung eines Schmalthiers im Frühjahre, welches noch die Winterhaare hatte:

Der Kopf ist schmal und verlängert, etwa wie am weiblichen Edellirsche, jedoch im Allgemeinen nicht so knochig und eckig, mehr fleischig und die Schnautze im Verhältnifs etwas dicker; das Auge ist ziemlich klein, die Thränenhöhle (Sinus lacrimalis) auf etwa sechs und eine halbe Linie von Auge endigend, und nur eine kleine Oeffnung. - Das Ohr ist kurz und ziemlich abgerundet. - Die Verhältnisse des übrigen Körpers sind etwa wie 
an unserem Reh, der Vorderkörper ist jedoch niedriger, der Schwanz war an diesem Thiere unten nackt (an anderen nicht), eben so die Ge. gend um den After und das Feigblatt, doch zeigen sich hier, wie an der Zusammenfügung der Schenkel einzelne lange Haare, auch sind die genannten scheinbar nackten Theile genauer besehen mit sehr kleinen, feinen Haaren bedeckt, die wahrscheinlich nach und nach mehr hervorwachsen.

Das Haar an Kopf und Hals ist aschgraubraun, besonders über den Angen und an der Stirn, wo es schon stark rothbraun gemischt ist, an den Backen aber etwas gelbröthlich, auch befinden sich an der Stelle, wo das männliche Thier sein Gehörn trägt, zwei kleine niederliegende Haarbüschel. - Am Munde bemerkt man keine bunte Zeichnung. - Die obere Seite des Halses und das äufsere Ohr sind dunkel aschgraubraun, am unteren Winkel weifslich; inneres Ohr weifs, blofs am unteren Rande ein breiter gelblich-graubrauner Randstreif; untere Seite des Kopfs und Kehle weifslich; die untere Seite des Halses ist blafs gelb. lich-grau; der ganze Körper röthlich-braun, nach dem Rücken hin dunkler, 'am Bauche aber und an allen unteren Theilen blässer; 


\section{- 591 -}

Schenkel und Beine sind dunkler rothbraun, die äufsere Seite des Schienbeins und die Ferse der Hinterbeine sind etwas schwärzlich angelaufen, die Bürsten oder Haarbüschel an den Fersen fehlen. - Innere Seite der Vorderschenkel nach hinten zu weils; innere Seite der ganzen Hinterschenkel, der Euter mit den vier Inguinalzitzen, After, nackter Theil der Schenkel und untere Seite des Schwanzes mit dessen Seitenhaaren sind milchweirs; Schwanz auf der Oberseite rothbraun wie der Rücken, die Spitze aber erscheint durch die langen Endhaare weils, so wie der untere Rand rundum, wenn man den Schwanz von oben besieht. - Das untere oder Fufsgelenke der vier Beine ist röthlich braun, die Hufe schwärzlich braun mit blässeren Rändern. - Stellung der Afterklauen wie an unseren europäischen Rehen:

Ausmessung dieses weiblichen Thieres:

Ganze Länge bis zum Ende der

Schwanzhaare . . . . $42^{\prime \prime} 4^{\prime \prime \prime}$.

Länge des Schwanzes ohne das am

Ende übertretende Haar . . 4" $3^{\prime \prime \prime}$.

Länge des Schwanzes mit den End-

haaren . . . . . $6^{\prime \prime} 4^{\prime \prime \prime}$.

Länge des Kopfs bis zum unteren

Winkel der Ohröffnung T" $1 \frac{\text { I }}{2}{ }^{\prime \prime}$. 


\section{$-592$}

Länge des Kopfs bis zum vorderen

\section{Augenwinkel}

Höhe des Ohrs auf der oberen Scite am Scheitel gemessen

$3^{\prime \prime} 10^{\prime \prime \prime}$

Houle des Ohrs auf der oberen Scite

Länge des Vorderbeins bis zu dem

oberen hinteren Gelenkwinkel des

Vorderschenkels oder der Speiche $13^{\prime \prime} 9^{\prime \prime \prime}$.

Länge des Hinterbeins ausgestreckt

bis zu dem Schwanzwinkel hin-

auf . . . . 23" $1^{\prime \prime \prime}$.

Kurze Beschrcibung eines starken männlichen Thicres: Der Unterschied des Bockes von dem weiblichen Thiere war schon im September zicmlich bedentend. - Der ganze Leib hatte eine recht lebhaft rothbraune Farbe, die unteren Theile aber waren melir hell rothgelblich; der Oberhals ist rothbraun wie der Iörper, der Unterhals hat eine starke Beimischung ron Grau; Unterseite des Kopfs und Kehle sind weifs; Gegend um die Geschlechtstheile, After und innere Schenkel bis zum Schwanze hinauf sind weils; innere Seite der Vorderschenkel hell gelbroth; die vier Beine sind rothbraun, nur am Fersengelenke der Hinterbeine etwas schwärzlich; Stim und Nasenrïcken etwas schwärzlich gemischi, und über den Augen ein rothbrauner Streif; Ohren an ih- 
rer äufseren Seite beinabo nackt und graubraun gefärbt, inwendig weifslich behaart. - Die innere Seite der Hinterschenkel ist nicht so nackt als an dem beschriebenen Schmalthiere, Kopf und Hals aber sind dicker und stärker. -

Ausmessung des Bockes:

Länge von der Schnautzenspitze bis

zu dem Schwanzende mit den

Haaren . . . . . $46^{\prime \prime} 10^{\prime \prime \prime}$.

Länge des Schwanzes mit den Haaren $6^{\prime \prime} 1 \frac{1}{2} "$.

Länge von der Schnautzenspitze bis

zu dem Anfange der Thränen-

höhle . + . . . . $3^{\prime \prime}$ q $^{\prime \prime \prime}$.

Länge von der Schnautzenspitze bis

zu dem vorderen Rande der un-

teren Ohröffnung . . . . $8^{\prime \prime} 1^{\prime \prime \prime}$.

Höhe des Ohres auf der oberen dem

Scheitel zugewandten Seite gemessen, etwa . . . . . $3^{\prime \prime} 5^{\prime \prime \prime}$.

Höhe des einen noch vorhandenen

Spiefses oder Gehörns . . $\quad 2^{\prime \prime} 8^{\prime \prime \prime}$.

Länge des Vorderbeins bis zu dem

oberen hintern Gelenkwinkel des

Vorderschenkels oder der Speiche 14"

Länge des Hinterbeins (bis zu dem

Schwanze gemessen) etwa . $27^{\prime \prime} 5^{\prime \prime \prime}$.

II. Band. 


\section{$-594$}

Ein anderer Bock, der zu S. Pedro dos Indios in den die Layoa de Araruama umgebenden Urwäldern erlegt wurde, hatte, ob er gleich viel jünger war, dennoch ein längeres Gehörn; seine Spiefse betrugen von der Rose bis zu der Spitze zwei Zoll neun Linien in der Länge, und ich habe ein drittes Gehörn gesehen, das wohl vier Zoll lang seyn mochte, man kann also drei bis vier Zoll für die wahre Länge desselben festsetzen. - Dicser zuletzt genannte Bock hatte auch über der Thränenhöhle am Anfange des rostrothen Augenbraunstreifen einen kleinen, runden, röthlich-weiIsen Fleck; Eckzähne, oder wie der deutsche Jäger sich ausdrückt, Haken, habe ich an dieser Hirschart so wenig gefunden als Azara *). Der Kopf des zuletzt genannten Bockes hatte folgende Ausmessung: Von der Nase zu dem unteren Winkel der Ohröffnung . $\quad y^{\prime \prime}$ Höhe des Ohrs * . . . • 4"! Breite der Stirn über den Augen . $2^{\prime \prime} 4^{\prime \prime \prime}$.

Diese und die nachfolgende Art der brasilianischen Hirsche scheinen am weitesten verbreitet zu seyn, da man sie beinahe überall in Süd-

*) Auch das Vorhandenseyn der Eckzähne'könnte zu einer Unterabtheilung im Geschlecht der Hursche benutzt werden. 
America's Waldungen findet. Ueberall lebt der rothe Waldhirsch einzeln oder familienweise, aber nie haben wir ihn in grofsen Rudeln angetroffen. An ruhigen Orten sucht er Morgens und Abends die freien Stellen, als Wiesen und Blöfsen im Dickicht auf, in der Hitze des Tages im Dickicht und in der Nähe des Wassers der Kühlung genielse - $d$ und im Nothfalle gegen die Stechfliegen (Mutucas) sich bis an den Hals darin verbergend. Diese Thiere quälen die Hirscharten auf das heftigste und die Häute derselben sollen zu gewissen Zeiten mit Engerlingen angefüllt seyn. - Das weibliche Thier führt sein Junges mit sich umher, nach Art unserer europäischen Hirsche, auch ist dasselbe weifs gefleckt und hat über das Kreuz einen dunklen Längsstreifen. Azara sagt, diø männlichen Thiere seyen viel seltener als die weiblichen, welches ich gerade umgekehrt ge. funden habe, die Natur wird also auch hier das richtigste Verhältnifs beobachtet haben, und ich glaube, dafs dasselbe etwa auf dieselbe Art stattfindet, als bei Cervus Capreolus. - Gezähmt gewöhnen sich diese Thiere sehr an den Menschen.

Man jagt diese Hirsche mit Hunden und sie gehen gerne in's Wasser, wo man sie als- 
dann ochic:st, gewühnlich aber stellen sich die Schützen auf den Wechseln an, wenn die Hunde jagen, und erwarten auf diese Art das flüchtige Reh. - Das Wildpret ist im Vergleich mit dem unserer europäischen Hirsche, äufserst schlecht, fade, von sehr groben dicken Fasern, gleich denen einer alten Kuh. - Die Haut benutzt man mit Vortheil, die Vaqueiros bereiten daraus zun Theil ihre Anzüge von Le: der.

Die Botocuden, weIche alle Hirscharten im Allgemeinen mit dem Namen Bocling be: zeichnen, nennen diese Art Bocling-Niack und die Camacans die Hirscharten im Allgemeinen Herá.

In meinen Abbildungen zur Naturgeschichte Brasilien's findet man die Zeichnung eines Bockes, der im September erlegt wurde, den Umrifs des Kopfs und den Schädel eines anderen starken alten Bockes in natürlicher Grölse.

4. C. simplicicornis, Jllig.

Das Catinga-Reh, das Reh der Niederwaldungen, Guasubira.

Gouazoubirn, Azara Essais etc. Vol. I, pag. 86.

Cervus nemorivagus, Fr, Cuv. 


\section{- $597-$}

Veado-Catingeiro oder Corģe im östliøhen und mitt. leren Brasilien.

Bocling - Niomm bei den Botocuder.

Einige Bemerkungen über ein weibliches Thier. Ein niedliches, zartes, zierliches Geschöpf. - Gestalt im Allgemeinen die unseres Hirsches, nur schlanker und kleiner von Kopf; Schwanz stark und lang behaart wie an der vorhin erwähnten Art; $K^{\sim}$ nf schmäler und länger als am europäischen Reh, übrigens giebt demselben das Catinga-Reh an Zierlichkeit der Gestalt nichts nach. - Das Ohr ist beinaho völlig unbehaart; an der Stelle, wo das männ. liche Thier sein Gehörn trägt, hat das Weib. chen zwei kleine Erhöhungen, welche mit etwas verlängerten Haaren bewachsen sind, sie sind aber nur für das Gefühl kenntlich. - Die Beine sind äufserst zart und schlank, mit niedlichen Hufen versehen. - Weder am Munde noch an der Nase zeigen sich Flecke; vier Inguinalzitzen; das Thier hatte noch unlängst gesäugt, es war im Anfarge des Monats April, wo man dasselbe in einer Fallgrube gefangen hatte.

Die Färbung dieser Hirschart variirt etwas. Das hier erwähnte, in der kalten Zeit des Jahres gefangene Thier hatte folgende 


\section{$-598$}

Zeichnung. - Alle oberen Theile, Seiten und die Schenkel waren dunkel graubraun, glänzend, auf dem Rücken mehr in's Graue als in's Braune fallend; an allen unteren Theilen fahl werfslich; Oberseite des Schwanzes graubraun, die untere mit langen, völlig weifsen Haaren besetzt, aber die nackte Stelle, welche unser Hirsch in der Nähe des Afters hat, fehlt bei diesen beiden zuletzt erwähnten brasilianischen Hirschen gänzlich. - Besieht man die oberen Theile des Thiers genau, so findet man, dafs jedes einzelne Haar dunkel gefärbt ist und unter seiner Spitze eine gelbröthliche Binde trägt, dieses Kennzeichen ist untrüglich; denn es fehlt allen übrigen brasilianischen Hirschen. - Das hier beschriebene Thier trug einen grofsen weifsen Fleck an der inneren Seite des Fersengelenkes des einen Hinterbeines, auch soll man öfters ganz weilse Individuen unter diesen Hirschen finden. - Die unteren Theile sind weifslich gefärbt, an der inneren Seite der Beine fällt die weifse Farbe etwas in's Gelbliche; die inneren Hinterschenkel und der Bauch sind am reinsten weifs, eben so die Unterseite des Schwanzes; die innere Seite der Schienbeinröhre ist graubraun gefärbt; die Unterseite des Halses ist hell graubräunlich.weifs gemischt. - 
Es variiren diese Thiere übrigens etwas in der Farbe, besonders nach den verschiedenen Jahrszeiten; denn im Winter fand ich sie mit etwas mehr röthlich-braunen, aber stets bunt gemischten Haaren, Stirn und Vorderfläche des Kopfs, so wie die Schienbeine und Kniee waren mehr schwärzlichbraun gerärbt. Ausmessung des eben erwähnten weiblichen

\section{Thieres:}

Ganze Länge über die Stirn gemessen $36^{\prime \prime} 10^{\prime \prime \prime}$. Länge des Kopfs bis zu der vorde.

ren Ohrbasis . . . . 6" 7 $^{\prime \prime \prime}$.

Länge des Halses vom hinteren

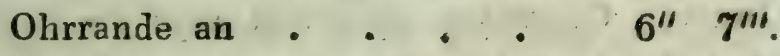

Höhe des Ohrs an der äuIseren Seite

gemessen . . . . $3^{\prime \prime} 5_{\frac{1}{2}}^{\prime \prime \prime}$.

Breite des Ohrs in der Mitte - 1" $10 \frac{r}{3}$ "'.

Länge des Körpers bis zu der un-

teren Schwanzwurzel . . 19"10"

Länge des Schwanzes ohne das Spitzenhaar - . . . . $2^{\prime \prime} 9 \frac{2}{3}$ "

Länge des Schwanzes mit dem Spitzenhaare $\quad . \quad$. $\quad 4^{\prime \prime} 8 \frac{3}{3}$ "

Länge des Vorderbeins bis zu dem

Ellenbogen . . . . . $12^{\prime \prime}$

Länge des Hinterbeines bis zu dem

Schwanze hinauf . . . . $22^{\prime \prime} 3^{\prime \prime \prime}$. 


\section{- 600}

Der Bock oder männliche Hirsch trägt ein kurzes, gerades, einspilziges Gehörn, welches vollkommen die Bildung von dem der vorhergeheriden Art zeigt.

Auch diese zierliche Hirschart scheint über den gröfsten Theil von Süd-America verbreitet zu seyn; denn da sie in Guiana lebt, so wird sie alle von da an südwärts gelegenen Länder bis nach Paraguay hinab bewohnen, von wo sie uns Azara zuerst beschrieb. In den niederen, ebenen Gegenden an der Ostküste von Brasilien lebt diese angenehme Thierart in den hohen Urwäldern, in den höheren inneren Gegenden aber soll man sie mehr in den Niederwaldungen oder Catingas finden, daher die Benennung. -

In den Wäldern von Morro d'Arara am Mucurí fing man ein Paar dieser Thiere in einer Fallgrube, als ich mich daselbst aufhielt. Ich bekam jedoch den Bock durch einen $\mathrm{Zu}$ fall nicht vollständig $\mathrm{zu}$ sehen, er hatte im Monat Februar sein Gehörn abgeworfen. In Minas Gerciës, wo man die Waldungen weniger an einander hängend findet, lebt diese Hirschart in mehr isolirten Gebüschen ron Niederwald, sie soll aber nirgends so zahlreich und auch nicht so allgemein verbreitet seyn, 
als das rothe Waldreh der vorhergehenden Beschreibung, findet sich also auch nicht blofs in den sumpfigen Gebüschen an der Seeküste, sondern unausgesetzt in allen Arten von Wal. dungen.

Auch diese zuletzt erwähnte Hirschart soll nur ein Junges werfen, welches anfänglich weifs gefleckt ist. Das Fleisch soll wohlschmeckender seyn, als das der vorhergehenden Art, besonders schätzt man die Leber. Das Leder ist dünn, auch die Haut nur klein. -

\section{O n D. IX. Natantia.} Schwimmende Säugthiere.

$$
\text { Fam. I. } S \text { i } r \text { e } n \text { i a. }
$$

Ge n. 37. $M$ a $n$ a $t$. $u$ s.

$$
M \quad a \quad n \quad a \quad t \quad i \text {, }
$$

Süd-America ernährt, wie bekannt, nur ein Thier aus diesem Geschlechte, welches ich im frischen Zustande nicht zu sehen bekommen habe, ich werde indessen mittheilen, was ich 


\section{$-602-$}

über diesen Gegenstand in Erfahrung habe bringen können.

1. M. americanus, Desm. Der americanische Manati, Seekuh. Pexe-Boi der Brasilianer.

Der americanische Manati lebt in den brasilianischen Flüssen, dennoch habe ich, aller angewandten Bemühungen ungeachtet, kein solches Thier im vollkommenen Zustande zu Gesicht bekommen.

Er lebt in der von mir bereisten Gegend zwischen Rio de Janeiro und Bahia nur noch in den Umgebungen des Flusses S. Matthaeus, und geht zuweilen aus diesem durch die See längs der Küste hin in den Flufs Alcobaça *). Bei S. Matthaeus lebt er in dem Flusse und in einer grofsen, mit demselben in Verbindung stehenden grasreichen Lagoa, welche sich weit

*) Nach v. Humboldt (Voy, au nouv, cont. T. IT. p. 606) giebt es an einigen Stellen der americanischen Meere süfse Quellen, und hier halten sich die Manatis auf. Die Bewohner von Alcobaça versichern, der Manati scheue das Salzwasser nicht, um von einem Flusse in den anderen zu gelangen. 
südlich nach dem Quartel de Juparanán hinab ausdehnen soll. Sie ist mit mancherlei Pflanzen und Grasarten durchwachsen, welche die Nahrung dieser unförmlichen Thiere aus. machen. - Hier schiebt der Jäger leise sein Canoe umher, spähet das grasende Thier aus und harpunirt es. - Zu S. Matthaeus lebte zu der Zeit meiner Anwesenheit ein Mann, der in dieser Art von Jagd sehr geübt war, und alljährlich mehrere Manatis fieng. - Im Jahre 1815 hatte er sieben Thiere dieser Art erlegt und unter diesen ein weibliches, welches 14 Mann kaum fortzuziehen vermochten. Der unförmliche Körper des Manati, der bei. nahe so dick als lang ist, da er die Gestalt einer Blase haben soll, verdünnt sich gegen den Schwanz schnell. Der Kopf ist klein, ganz besonders aber das Auge. - Die Haut ist aschgrau und nur mit wenigen Borsten besetzt, dabei sehr stark. Solche Thiere geben sehr viel Thran, auch hebt der Landmann in Brasilien den massiven ausgehöhlten Knochen als officinell häufig auf, den man unter der Benennung des Lapis manati kennt ${ }^{*}$ ) und oft theuer bezahlt.

*) Siehe Blumenbach Handb. der vergl, Anatomie, pag. 384. 
$-604-$

Herr von Humboldt theilt uns in seinen herrlichen Schilderungen der von ihm bereis. ten Theile von Süd-America sehr interessante Nachrichten über diese im Orenoco und anderen Flüssen häufig vorkommende Thierart mit *).

*) IIumb, Vog. au nouv. cont. VI. pag. 236.226 u. a. a, O. 


\title{
Zusätze, Berichtigungen und Nachträge
}

\author{
$z u$ dem
}

ersten Bande dieser Beiträge.

$\mathrm{Zu}$ Seite 20. Die Indier am Orenoco haben Hrn. v. Humboldt erzählt, die Schildkröte befeuchte den Sand mit ihrem Urin, wenn sie beschäftigt sey, die Grube für ihre Eier zu graben; allein ob ich gleich der arbeitendene Schildkröte unmittelbar lange zugesehen und alle ihre Bewegungen genau beobachtet habe, so ist doch an dem Sande nicht die geringste Nässe zu bemerken gewesen. In der Nähe der Seeküste hat übrigens der Sand in einer gewissen Tiefe ohnehin hinlänglich Feuchtigkeit, um stehen $\mathrm{zu}$ bleiben.

$\mathrm{Zu}$ Seite 125. Herr Dr. Boie hat das Geschlecht Agama zerspalten. Diejenigen Arten, welche Gaumenzähne haben, nennt er Ophryessa und hierhin soll Agama picta und vielleicht catenata gehören. Caup (s. Isis Jahrg. 1826 1tes Heft S. 89.) will, meine Agama picta sey Azara's Caméléon second, und also Merrem's Pneustes prehensilis. Allein Merrem dachte ganz anders über diesen Gegenstand, indem er mein Thier verglich und für eine neue Species hielt; auch muls ich bekennen, dạs ich bei genauer Durchlesung der Beschreibung des Azara, mit meiner Agama nur sehr wenig Aehnlich. 


\section{$-606$}

keit auffinden kann, ohnehin sind ja Azara's Amphibien-Beschreibungen viel zu oberflächlich, um sie in die Systeme aufnehmen zu können. Es ist auch ganz überflüfsig, dafs Herr Caup Azara's Caméléon premier in meiner Agama catenata wiederzufinden glaubt. Herr Caup bemerkt ferner, dafs die jungen Agamen lebhafter gezeichnet seyen, als die Alten; ich mufs aber bemerken, dafs man dieses nicht allgemein sagen künne; denn sie sind wohl mehr gestreift und gefleckt, allein ihre Farbe ist nicht sn lebhaft und schön, als die der alten Thiere. Nach Azara sollen die Agamen sich mit ihrem Schwanze festhalten, ich habe dieses nie bemerkt, auch k 2 m man nach den Beschreibungen jenes Schriftstellers durchaus nicht wissen, was für Eidechsen er vor sich hatte.

Nach Boie soll Lophyrus rhombifer meine Aguma catenata im ausgewachsenen Zustande seyn. Dieseskamn ich nicht glauben, da ich viele Exemplare der von mir beschriebenen Eidechse gesehen, und sie immer gleichartig gezeichnet gefunden habe. Herr Dr. Boie (Isis Jahro. 1826. 1tes Heft S. 120.) nennt die Querbinden in den Seiten des Teius Ameiva weifs, allein sie sind in der Natur schön gelb. Es hält ferner Hr. Boie meinen Teius cyanomelas für das junge Thier des Ameiva; allein er int bierin, indem beide Species sehr verschieden gebildet sind.

Edw. Jumes in seiner Beschreibung: Account of an expedition from Pittsburgh to the Rocky-Mountains etc. (Isis 1824. Bd. II. S. 290.) beschreibt eine Agama, die mit meiner picta sehr viel Aelnnlichlkeit zu haben scheint.

$\mathrm{Zu}$ Seite 139. In der Synonymie des Tropidurus torquatus streiche man die Lacerta Quctz-paleo des Seba aus. Beide Thiere haben gewisse sehr claracteristische Züge mit einander gemein, gehören aber dennoch 


\section{- 607}

nicht einmal in ein und dasselbe Genus. Ich habe seitdem den ächten Quetz-paleo kennen gelernt, und werde ihn nächstens in dem 13ten Bande der Nova Acta Phys. Med. beschreiben. Die Charactere des Genus Tropidurus müssen berichtigt, und etwa auf folgende Art gestellt werden:

Tropidurus: Kopf geschildet; Zähne an jeder Seite mit einem Ausschnitte; $\mathrm{Ohr}$ an seinem vordern Rande mit verlängert zugespitzten Schuppen (Stachelschuppen) besetzt; Kehle schuppig, ohne Kehlsack; Schwanz mit mälsig grofsen, stacheliggekielten Schuppen bedeckt, welche mehrere Längskiele bilden; Schenkelöffnungen fehlen; Rücken und Bauch schuppig.

$\mathrm{Zu}$ Seite 209. Die Geschichte, welche Henderson (History of the. Brazils p. 506.) von einer colossalen Schlange erzählt, die 21 Fufs in der Länge hielt, ist gewifs unrichtiger Weise auf den Surukuku gedeutet, und gehört, wenn sie gegründet ist, für eine Boa. Es sind auch alle von jenem Schriftsteller über die Thiere gegebenen Notizen ohne wissenschaftlichen Werth, da sie auf Verivechslungen und zum Theil oberflächliche, zum Theil unwahre Nachrichten der Landesbewohner gegründet sind. Sie scheinen grölstentheils aus der Corografia brasilica entlehnt. Ueber die Art, wie die Schlinger (Boa) ihren Raub verzehren siehe Ferussac Bull. d. sc. 1825. Nro. 12. p. 429.

$\mathrm{Zu}$ Seite 265. Coluber liocercus hat sehr viel Aehnlichkeit mit $C$. ahaetulla, sie könnte vielleicht die letztere seyn, welche ihre Oberhaut verloren hat. Genauere Vergleichung wird entscheiden.

$\mathrm{Zu}$ Seite 277. Man hat mir bemerkt, dafs Coluber Nattereri von punctatissima Spiixi verschieden sey, weil die letztere glatte Schuppen habe; allein ich kann noch nicht unbedingt widerrufen, da ich meine Natter auch schon mit beinahe glatten Schuppen gesehen habe, 
ma in dieser Hinsicht leicht Abänderungen vorkommen können.

Zu Seite S71. Nach Langsdorf soll Coluber poccilogyrus eine Geschlechts - Verschiedenheit von Coluber Merremii seycn; allein ich bin vollkommen übcrzeugt, dafs beide Arten verschieden sind.

$\mathrm{Zu}$ S eite 42S. Es ist num errviesen, dals das Gift der ron mir erwähnten todten Jararaca noch schaden komnte; denn Desmoulins (s. dessen machfolgend citirte Abhandl. im Journal de Physiol.) sah an dem Gifte einer schon seit 4 Tagen getöiteten Viper die damit verwundeten Vögel schnell sterben.

$\mathrm{Zu}$ S cite 429. Ueber die Backenöffnung der Giftschlangen besitzen wir nun einige Arbeiten. Desmoulins (Journal de Physiologie Vol. IV. p. 264.) fand, dafs der Nerve des fünften Paares besonders ausgebildet ist und sich zum Theil in der Backenhöhle verbreitet, die also wahrscheinlich zum Geruche dient. Nach seinen Intersuchungen befindet sich keine andere Giftdrüse in dem Kopfe der Schlangen, als die grofse, das Auge ringförnig umgebende Thränendrüse, sie giebt in ein und derselben Flüssigkeit zugleich die Thränen, den SpeicheI und das Gift.

Man liest in Froriep's Notizen aus dem Gebiet der Natur und Heilkunde (B. II. S. 302.) von zwei von einer Viper in das Euter gebissenen Stuten, und hier wird die Irage aufzeworfen, ob die Schlangen die Milch liebten und etwa durch ihren Geruch angelockt wurden? Ich kann diese Frage durch ein zuverläIsiges Beispiel beantworten. Auf einem einsamen, in der Nähe des Rheins in gebirgiger waldiger Gegend gelegenen Pachthofe trieb man das Vieh täglich in den Wald und die benachbarten Wiesen und Abends wieder zu Hause. Eine starke Kuh kehrte jeden Abend mit gänzlich leerem. Euter nach Hause, wovon man durchaus den Grund nicht einsehen konnte 


\section{$-609$}

Der Hirte beobachtete nun genau und bemerkte bald, dafs diese Kuh sich von der Heerde trennte und heftig zu brüllen begann, worauf eine grofse Ringelnatter ( $C_{0}$ luber Natrix Linn.) erschien, die sich an dem Hinterbeine des Thiers hinauf schlang und auf diese Art das Euter leerte. -

$\mathrm{Zu}$ Seite 433. Eben so wenig als ich an das Bezaubern der Giftschlangen glaube, kann ich auch die Nachrichten für wahr halten, wo man der gelben Viper (Trigonocephale fer-de-Lance) den wilden Instinct zuschreibt, sich unangegriffen auf die Vorïbergehenden zu stürzen (s. Férussae Bull. d. sc. natur. 1826. Nro. 12. p. 433.); auch würde diese Schlange durch die an der angeführten Stelle ihr zugeschriebene grofse Schnelligkeit, eine Ausnahme von den meisten süd-americanischen Giftschlangen machen.

Der Chirurg Johnson sagt (Indian Fieldsports p. 213.), der Zahn der Giftschlangen dringe auf den vierten Theil der Länge eines Zolles in das Fleisch; allein ich bin über. zeugt, dals er zuweilen $\frac{1}{2}$ bis $\frac{3}{4}$ Zoll tief hineingedrückt wird.

Zu Seite 446. Desmoulins zeigt im Journal de Physiologie (Vol. IV. p. 279.) die Unvollkommenheit des Auges bei den Amphisbänen. Er glaubt übrigens, dafs diese Schlangen eben so gut rückwärts als vorwärts kriechen, wovon mir indessen kein Beispiel vorgekommen ist. 


\title{
$-610$
}

\section{Nachträge, Berichtigungen und Zusütze}

\author{
$\mathrm{zu}$ dem
}

z weiten Bande dieser Beiträge.

Zu Seite 63. Neucre Schriftsteller wiederholen, dals der Guariba (Mycetes ursinus) ein wildes zorniges Thier sey. Man hat also eine ganz falsche Idee von seinem Naturell; denn er ist höchst sanft, furchtsam und phlegmatisch.

$\mathrm{Zu}$ Seite 90. Hr. Dr. Schinz hïlt (siche dessen Werk: das Thierreich u. s. w. Bd. IV. S. 264.) den Cebus macrocephahis (Sajou ì grosse tête der Hrn. Fr. Cıvier. und Geoffroy) für meinen Cebus robustus; allein er scheint mir unbezveifelt mein xanthosternos zu seyn.

$\mathrm{Zu}$ Seite 177. Waterton will die Wampyre ( $\mathrm{Phyl-}$ Zostoma) bei Nacht Bananen fressen und die Blüthen des Savaribaums abbeilsen gesehen haben (s. Notizen aus dem Gebiete der Natur - und Heilk. 12. S. 275.).

$\mathrm{Zu}$ Seite 200. Die Unterabtheilung (b.) der unbestimmten Blattmasen, wohin einzig und allein Plıyllostoma superciliatum gehürt, ist aus Versehen des Setzers zwischen die Blattnasen mit eingekerbten Schneidezähnen gesetzt worden, sie sollte am Ende des Genzis stehen.

$\mathrm{Zu}$ Seite 223. Die Benennung Noctilio rufus, welche Dr. v. Spix einer seiner Fledermäuse beileğte, scheint nicht ganz wohl bestehen zu künnen, weil sie auch vollkommen auf Geoffroy's Noctilio unicolor pafst.

Zu Seite 253. Spix's Diphylla ecaudata hat eiuige Achnlichkeit mit meinem Desmodus rufus; allein das Gebils ist zu verschieden, mehrever anderer $\mathrm{Abwei-}$ clungen nicht zu gedenken. 


\section{$-611=$}

Zu Seite 274. Hr. Dr. v. Spix beschreibt zwei Arten langnasiger Fledermäuse, und vereinigt sie in seinem Genus Proboscidea. Schinz (s. das Thierreich u.s.w. Bd. IV. S. 302.) hält die von mir beschriebene, mit den obigen verwandte Fledermaus für Proboscidea rivalis Spixii, welches ich indessen bezweifeln mufs, die Abbildung mülste denn sehr fehlerhaft seyn. Vespertilio Naso hat an den unteren Eckzähnen sowohl nach vorn als nach hinten eine Nebenspitze, da hingegen Spix an den oberen Eckzähnen nur einen Nebenzahn anmerkt. Ferner heifst es bei Spix: "membrana interfemoralis pedibus brevior, caudam usque dimidium longitudinis involvens, extus marginata." Dieses ist bei meiner Fledermaus gänzlich verschieden; denn man braucht bei ihr die Schwanzflughaut blofs aufzurollen oder auszuspannen, um zu bemerken, dafs dieselbe weit über den sehr kurzen Schwanz hinausreicht. Hat also Hr. Dr. $v$. Spix die Schwanzflughaut seiner Fledermaus gehörig ausgedehnt, so ist bestimmt das von mir beschriebene Thier eine von den seinigen verschiedene Species. Er sagt ferner: "cauda membrana interfemoralis longior ad dimidium involuta, reliqua libera exserta", welches durchaus nicht auf Vespertilio Naso pafst. Von seiner Pro. boscidea saxatilis sagt er "membrana interfemoralis plicata", welches ich ebenfalls an meinem Thiere nicht beobachtet habe. Was übrigens Spix's beide Species anbetrifft, so ist ihre Beschreibung nicht umständlich genug, um eine zuverläfsige Vergleichung anstellen zu können. Er erwähnt z. B. durchaus nicht der an meiner Fledermaus so sehr ausgezeichneten Behaarung, welche an den Armen und andern Theilen büschelförmig ist u.s. w. Will man übrigens das stärlkere oder geringere Vortreten der Nasenkuppe für hinreichend zur Bildung eines neuen Geschlechtes annehmen, so muls doch wenigstens in dem Character essentialis die Stelle 


\section{$-612$}

abgeändert werden, wo es heifst "Schwanzflughaut den Schwanz zur Hälfte einschliefsend"; denn an meiner Species ist sie dreimal so lang, als der Schwanz.

$\mathrm{Zu}$ Seite 289. Das Coati soll sich nach Azara von einem Baum herabfallen lassen, sobald es ersclireckt wird, diefs ist ungegründet.

Henderson in seiner History of the Brazils verwechselt die Eigenschaften und die Benennung der Coatis geradezu; denn er sagt, die kleine Art gehe in Gesellschaft und werde Cuati monclé genannt.

$\mathrm{Zu}$ Seite 310. Henderson sagt, die Hyrare habe, in der Entfernung gesehen, das Ansehen eines Affen, es dürfte jedoch viel Einbildungskraft dazu gehören, um einen Marder für einen Affen zu halten.

$\mathrm{Z} u$ Seite 325. Nach Harlan (Fauna Americana) soll die brasilianische Fischotter in Nord-America vorkommen, allein ich mufs dieses sehr bezweifeln, da dieser Naturforscher in der Characteristik seiner Species des plattgedrückten Schwanzes nicht erwähnt.

$\mathrm{Z} u$ s'eite 334. Von dem Guará (Canis campestris) sa⿳⺈t Henderson, er sey ein grofser Feind der jungen Kälber (S. 502.), welches gerade den von mir allgemein eingezogenen Nachrichten widerspricht. Dieser Schriftsteller redet (S. 512.) von einer grofsen wilden Hundeart, die er Guaracão nennt, und die durchaus nichts anders seyn kann, als der Guará selbst. S. 502 redet er von dem Cão silvestre oder Cachorro do mato, der in den südlichen Gegenden des Rio clas Contas vorkommen solle; allein diese Nachricht ist fabelhaft.

$\mathrm{Zu}$ Seite 338. Canis cancrivorus (The Crabwolf, Griffith Uebers. von Cuv. Règne Animal part. VI. Nr. 375) ist bestimmt nichts anderes, als der Aguarachay des Azara. Er scheint mir der Koupara des Barrère und Pennant's Surinam-Dog zu seyn. 


\section{$-613$}

$\mathrm{Zu}$ Seite 344. Der Yaguar soll nach Harlan (Fauna Americana p. 96.) auch im südlichen NordAmerica vorkommen.

Was Henderson (Hist. of the Brazils) von der Jagd des Yaguar sagt, ist weit übertrieben.

$\mathrm{Zu}$ Seite 354. Eben die Bewandnifs, als mit dem schwarzen Yaguar dürfte es auch wohl mit den in Spanien und Frankreich vorkommenden schwarzen Wölfen haben. Es entstand einst in den Wäldern des rechten Rheinufers eine Abart von Wölfen, welche meistens schwarz mit weilser Blässe und vier weilsen Füfsen waren. Ein schwarzer Fleischerhund hatte sich mit einer Wölfin belaufen, man erlegte beide Eltern, und in eir Paar darauf folgenden Jahren 13 jener Bastardwölfe, welche dem Rothwildstande bedeutenden Schaden zuggefügt hatten.

Zu Seite 358. Azara sagt, der Cuguar (Guazuara) liebe mehr offene als waldige Gegenden, und der Yaguar könne nicht auf Bäume steigen, beides ist ungegründet.

Zu Seite 369. Hr. Temmink, welcher Gelegenheit gehabt hat, Felis mitis genauer kennen zu lernen, sagt (Monogr. de Mammal. p. 149.), dafs diese Katzenart von dem Mbaracaya (Felis pardalis) verschieden sey. Dafs sie von Felis macroura verschieden ist, zeigt ihre ganze Gestalt, so wie ihre Färbung und Körperverhältnisse. Felis mitis gehört ihrer Gestalt nach zu der Familie der Mbaracaya's oder schlank gebauten Katzen von Mittelgröfse, Felis macroura hingegen zu den schlanken kleineren Arten, wovon etwa unsere Hauskatze ein Beispiel abgeben kann.

Nach Harlan soll auch der Mbaracaya im südwestlichen Nord-America vorkommen ( $F$. Amer. $p$. 98.). 


\section{$-614-$}

Zu Seite 371. Griffith gab in seincr Uebersetzung des Pìgne Animal eine Figur dieser Katze. Sie ist in der Gestalt ziemlich gut, allein die Flecken scheinen nicht völlig genau nachgebildet, und ich muls in dieser Hinsicht die Fignur empfehlen, welche ich in meinen Abbildungen zur Naturgeschichte Brasilien's gegeben habe.

$\mathrm{Zu}$ Seite 394. In einem neueren Werke über Brasilicn wird das Beutelthiẹr zu den Köstlichen Braten gezählt, welches indessen einen ganz eigenen Geschmack zu verrathen scheint (s. Major Schäffer Brasilien, als unabhängiges Reich u. s. w. S. 15.). -

$\mathrm{Zu}$ Seite 430. Von diesem Eichhorne sagt Henderson, es sey viel gröfser als unser europäisches, und sein Schwanz sey wenig behaart (S. 502.), welches ungegründet ist.

Zu Seite 471. Henderson erwähnt des Mocó (S. 364.) auch für die Provinz Pernambutco. Nach ihm soll man (S. 397.) eine Art von Frettchen (Ferret) gebrauchen, um das Mocó und Preyá aus ihren Höhlen zu treiben, wovon ich indessen nie etwas gehört habe.

$\mathrm{Zu}$ Seite 486. Einige Reisende vergleichen die Stimme des Faulthiers ziemlich unrichtig. So lies't man z. B. von dem ,gleichsam um Hülfe rufenden Faulthier, " da dach dieser Vergleich sehr wenig palst.

Waterton (s. Froriep's Notizen aus dem Gebiete der Natur- und Feilkunde Bd. 12. p. 212.) macht das Faulthier gar zu cinem Schiffe, indem er es mit dem Winde sich bewegen lïrst, eine wirklich überaus komische Idee! denn für's erste ist es in den geschlossencu tropischen Urwäldern gewölnnlich windstill, 2weitens ist hier auch lein Wind nöthiog, damit sich die Baumäste berühren, und drittens ist die ganze Ge- 


\section{$-615-$}

schichte eine sehr alberne Fabel. Eben dieser Reisende (ebendaselbst S. 274.) nennt das Fleisch des Faulthiers wohlschmeckend, welches doch höchstens für Botocuden- oder Negermägen erträglich seyn kann.

$\mathrm{Zu}$ Seite 489. Im 6ten Bande von Griffith's Uebersetzung des Règne Animal ist eine Abbildung des Faulthiers mit schwarzem Nacken gegeben, die mit der Natur gar keine Aehnlichkeit hat. Der Kopf ist gänzlich unähnlich und gleicht dem eines Schaafes, der lange Hals des Faulthiers fehlt hier gänzlich, welchen dasselbe nie einziehen kann, das Gesicht scheint glatt, das Haar bildet eine Perrüque, auch ist die ganze Stellung des Thiers sehr unrichtig, und kommt auf diese Art in der Natur nicht vor, kurz diese Abbildung muls sogleich verbannt werden, wenn sie nicht eine völlig unrichtige Idee dieser Thierart verbreiten soll.

$\mathrm{Zu}$ Seite 549. Henderson sagt (S. 501.), man finde den Tapir von allen Farben, welches unrichtig ist.

Man sagt, dals die Portugiesen dem Genusse des Tapirfleisches Augenentzündungen zuschrieben, ich habe aber nie etwas hiervon gehört (S. 382.).

$\mathrm{Zu}$ Seite 556. Henderson (S. 501.) schreibt der Corografia brasilica nach, es gebe drei Arten von wilden Schweinen in Brasilien; auch führt Schinz in dem 4ten Bande seiner Uebersetzung des Règne Animal ( $p$. 511.) eine dritte Art von Nabelschweinen unter der Behennung des Dicotyles minor auf, die aber höchst wahrscheinlich nur ein junges Thier der von mir erwähniten längst bekannten Arten ist.

$\mathrm{Zu}$ Seite 557. Dicotyles torquatus findet sich, neueren Nachrichten zufolge, auch in den südlichen vereinigten Staaten und soll am Red River nach Nuttall 
gemein seyn (s. Fauna Americana p. 220.). Von dex Tapferkeit dieses Schweines, das in Menge vereint den Yaguar tödten soll, hat man mir in Brasilien nie etwas gesagt, auch ist diefs gewifs ungegründet, da $D$. torquatus weit schwächer ist, als D. labiatus, dem man eher eine Vertheidigung zutrauen könnte. 


\section{V e r z e c h n ils}

$d \in r$

diesem Bande beigefügten Abbildungen.

Tab. I.

Schädel des Diclidurus, des Máulwurfs (Talpa) und der Spitzmaus (Sorex). Die Erkklärung der Figuren siehe im Texte pag. 254.

Tab. II.

Fig. 12. Knochen aus der Ruthe des männlichen Cọati-Mundéo, von der Seite gesehen.

Fig. 13. Die Spitze desselben, von unten gesehen.

Fig. 17. Knochen aús der Ruthe des männlichen Guassini (Procyon cancrivorus).

Fig. 20. Knochen aus der Ruthe der männlichen Hyrare (Mustela barbara), von der Seite.

Fig. 21. Derselbe, von oben gesehen.

Fig 14. Ruthe der männlichen brasilian. Fischotter (Lutra brasiliensis), von der Seite. a. Die Eichel.

Fig. 15. Der Knochen aus dieser Ruthe. b. Die Höhlung am unteren Theile der Spitze.

Fig. 16. Die Höhlung in dem vorderen Theile die. ses Knochens, von unten gesehen.

Fig. 18. Eckzahn der brasilianischen Fischotter von aufsen. a. bis b. Die blasenartige Wurzel des Zahnes. b. Die kreisförmige Wurzelöffnung desselben.

Fig. 19. Durch Eintrocknen gespaltener Eckzahn. b. Die Wurzelöffnung.

Fig. 5. Schädel des Didelphys myosuros in natürlicher Gröfse.

Fig. 6. Schädel des Didelphys cinerea in natürlicher Grölse.

Fig. 3. a. Obere Reihe der Backenzähne (der linken Seite) des Mus pyrrhorhinus, um ihre Mahlflächen zu zeigen. 
Fig. 3. b. Rechter Schenkel des Unterkiefers derselben Maus, ebenfalls um die Mahlflächen der drei Backenzähne zu zeigen. Beide Abbildungen sind etwas über sechsmal vergröfsert.

Fig. 4. a. Obere Backenzähne derselben Maus, von der Seite gesehen. $b$. Der Unterkiefer von der Seite, etwas über" sechsmal vergröIsert.

Fig. 22. Die entblöfste Eichel des Paca (Coelogen nys $P$ aca), von unten gesehen.

Fig. 23. Derselbe Theil, entblölst, von der Seite gesehen.

Fig. 7. Die Eichel des männlichen $\mathrm{Paca}$, günzlich umgekehrt.

Fig. 8. Knochen aus der Ruthe des männlichen Paca, von der Seite gesehen.

Fig. 9. Derselbe, von unten gesehen.

Fig. 10. Knochen aus der Ruthe des Capibára, von unten gesehen.

Fig. 11. Derselbe, von der Seite,

Fig. 1. Schädel des Moco (Cavia rupestris), von der Seite, in natürlicher Grölse.

Fig. 2. Derselbe, auf seiner Oberfläche betrachtet. Tab. III.

Fig. 8. Unterkiefer des Moco, von oben gesehen.

Fig. 9. Der Oberkiefer desselben Thiers, von unten gesehen, beides in natürlicher Gröfse.

Fig. 1, 2, 3, $4 a, 4 b, 5,6,7$, zur Anatomie des Tab. IV. Fötus von Bradypus torquatus, siehe pag. 498.

Fig. 1, 2, 3, 4, 5, 6, 7, 8, zur Beschreibung des Tab. V. Schädels von Bradypus torquatus, s. pag. 507.

Fig. $1, k, 2,3,5 a, 5 b, 6,6 b, 7,8$, zur Beschreibung des Schädels von Bradypus tridacty. lus, siehe pag. 507. 


\section{R e g i s $t$ e $r$}

der in diesem Bande aufgeführten Säug-

\section{thiere.}

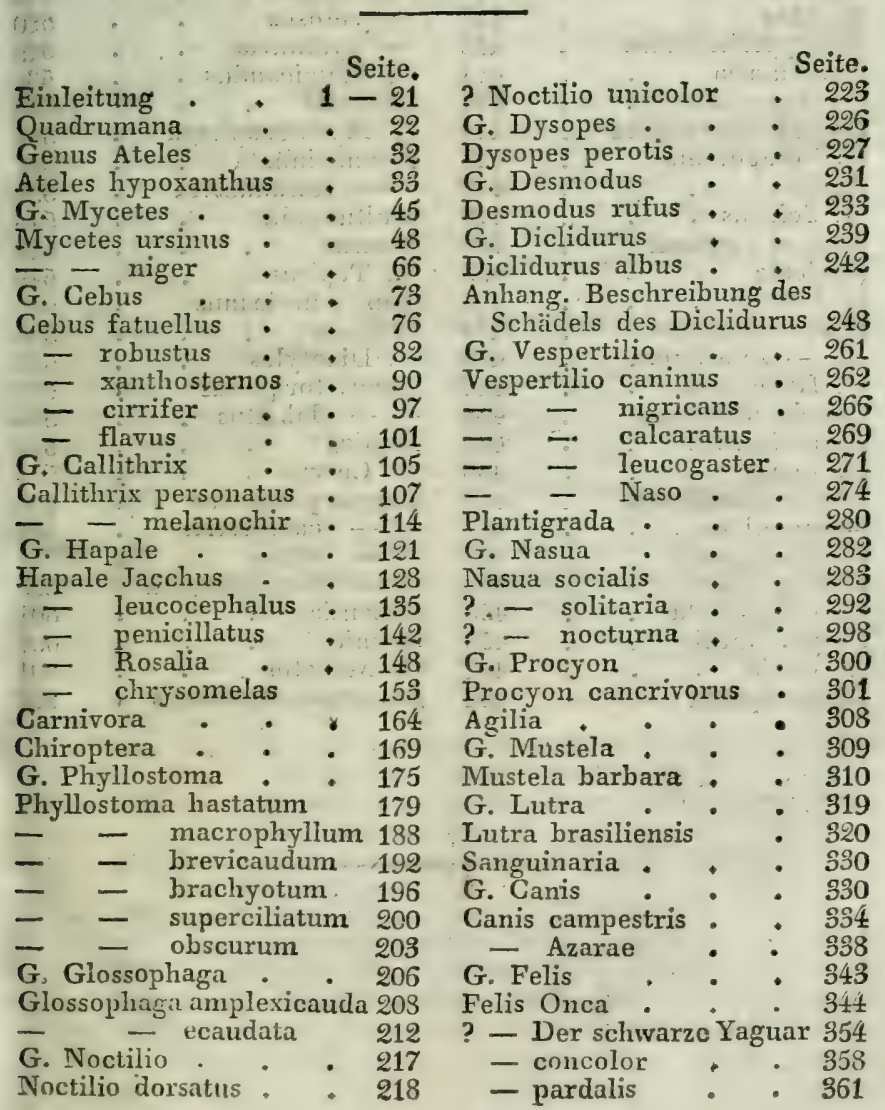




\begin{tabular}{|c|c|c|c|c|c|}
\hline & & & & & \\
\hline & & 371 & upestris & - & 46 \\
\hline Yaguarux & & 379 & Hydrochoerus & - & \\
\hline Eyra & . & 381 & Hydroch. Capibara & . & 47 \\
\hline Tarsupialia & - & 3 & Bruta & & 478 \\
\hline Didelphys & & - & Tardigrada & . & $4 / 5$ \\
\hline idelph. marsup & bial & 3 & G. Bradypus & . & 479 \\
\hline aurita & - & 395 & Brad. tridactylus & - & \\
\hline - myosuro & & 400 & - torquatus. & & \\
\hline cinerea & & 40 & Anhang, Vergleichun & & \\
\hline murina & & 41 & del und Zer & & \\
\hline ebersicht obige & $\mathrm{er} \cdot \mathrm{Be}$ & utel & 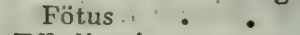 & . & 496 \\
\hline thiere & 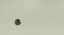 & - & ffo & & \\
\hline lires & & - & $\mathrm{D}$ & . & \\
\hline urina & 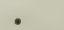 & - & Das. & - & \\
\hline Mus & & - & $-s$ & - & 120 \\
\hline us pyrrhorhinu & & - & $-g$ & - & \\
\hline ic & & & icaudus . & - & \\
\hline eu & $\cdot$ & & Eden & - & \\
\hline 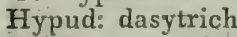 & & & phaga & & \\
\hline $\operatorname{tam}$ & & 4 & Myrm & & 5 \\
\hline$\because$ & & & dactyla & & 59 \\
\hline . & 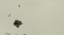 & & • & - & \\
\hline stuans & & & $\because$ & - & \\
\hline & - & - & ร. $T$ & & \\
\hline 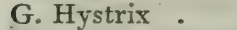 & • & 4 & ricanus & & 54 \\
\hline ystrix & & & Setige & - & 556 \\
\hline spin & & & G. D & & 556 \\
\hline$T$ & . & & Dicot. & - & 557 \\
\hline suros & & 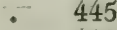 & - - labiatus & & \\
\hline tata & $\therefore$ & $\because$ & • & & 572 \\
\hline & & • & - & & 5 \\
\hline iliensi & & & dosus & - & \\
\hline & . & a & estris & - & \\
\hline s & . & - & - & - & \\
\hline & & & licicornis & : & \\
\hline & & & - & 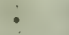 & \\
\hline & & & & & \\
\hline & & & . & - & \\
\hline${ }_{0}$ & & 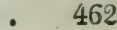 & mericanus & i & \\
\hline
\end{tabular}




\section{Verzeichnifs der Druckfehler}

in dem

zweiten Bande meiner Beiträge.

S. 3. Zeile 6. (Einleitung) setze statt, Säugthiere, welcher in den"

- 4. - 3. ist hinter, ,dem spanischen" - das Wort ${ }^{6} \mathrm{Na}=$ turforscher" ausgelassen.

- 4. - 11. setze statt, schon abgebildet" - schon algebildet;

- 4. - 4. von unten setze statt, Beobachtungen, diese" „Beobachtungen. "Diese"s"

- 8. obere Zeile setze statt ",ivelches " - wélches"

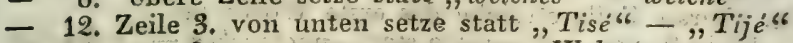

- 15. - 6. von unten setze statt ,Wohnungen, - ,Wohnungen;

- 16. - 12. setze statt, ,unglaublicher Menge, - ,unglaublicher Menge;

- 25. - 20. setze statt "Pompo - "Pongo"

- 25. in der Note setze statt "Satyrus ult - , Satyrus alt"

- 26. Zeile 5. setze statt, Benennungen allen Weltheilen Benennungen in allen Weltheilen"

-. 38. oben setze statt, chens sind nackt, selbst die Testikel, - ,chens, selbst dic Testikel"

- 56. - 21. setze statt, "etwas von des Aluatin - etwas von der des Aluaten

- 60. - 11. - - "hoch erhaben, wie ihr - ,hoch erhaben, wo ihr

- 64. - 4. zwischen die Worte, knarrend röchelnd"6 -

- 65. - 10. setze statt, Taguaris -, Taquaris

- 66. - 14 - - , stento - , Stentor

- 135. - 10. - - "Tite -, Titi

- 136. - 8. - , "chen Thierchens: - , lichen Thierchens:

- 136. - 5. von unten setze statt, scharfen - , scharfem

- 141. - 12. setze statt, ,zu halten, - ,zu halten;

- 165 - 16. - - , interressante - ,interessante

- 172. vorletzte Zeile schreibe das Wort, ,Niemand - klein.

- 173. Zeile 4. von unten setze statt, Linnéschen - Linreischen

- 185. - 11. setze statt, ein;

- 201. - 2. von unten lese man statt, Sago- - ,Sagoa(es ist hier falsch abgebrochen.)

- 212. - 6. setze man statt, Se - ,Seof (auch hiex ist. falsch abgebrochen.)

- 212. Zeile 11. von unten setze man, Blattnasen - statt Blattnassen.

- 269. - 7. setze statt ,Sporn - ,Sporne

- 281. - 6. von unten setze statt "canicero - ,carnicero

- 337. - 3. setze statt, ,Vagueiros -, Vaqueiros

- 344. - 6. von unten setze statt, ,Katze-, Unze

- 405. - 3. - - - 
S. 415. - 1 und2. von unten setze statt, "Hansen - "Hasen - 416. - 5. setze statt "Huasen- „Hasen

- 450. '4 und 14. derselbe Felıler.

- 452. lies an verschiedenen Stellen statt „Haase - „Hase

- 454. Zeile 14. streiche das Wort ${ }, \mathrm{Ha}$

- 469. - 14. setze statt,, $\mathrm{Haa}$ - ${ }^{\mathrm{H}} \mathrm{Ha}$

- 511. - 12. fehlt der Punct hinter dem Worte: spricht.

- 516. - 6. setze statt „Tatou-açú - ,Tatí-açú

- 519. - 3. von unten setze statt "angegebene - gegebene

- 525 - 5. setze statt, vierek- - viereck-

- - 7. - , habe - ,haben

- - - 11. - - : Schildchen.

- 535. vorletzte Zeile setze statt „erschö- - „erschöpf-

- - letzte Zeile - - ,pfen - , en

- 551. oberste Zeile streiche das erste Wort : $t u r$

- - Zeile 9. von unten setze statt, erschrccken - "sclurecken

-- 554. letzte Zeile setze ein ; hinter das Wort: Peitschen.

- 561. Zeile 18. setze statt ,puris - "pures

- 564. - 19. lies: Kïri-hiä

- 580. - $\%$ in der Note streiche das, hinter dem Worts:

- auferzogenen

- 587. - 12. setze statt: "behaartem - "behaniten 


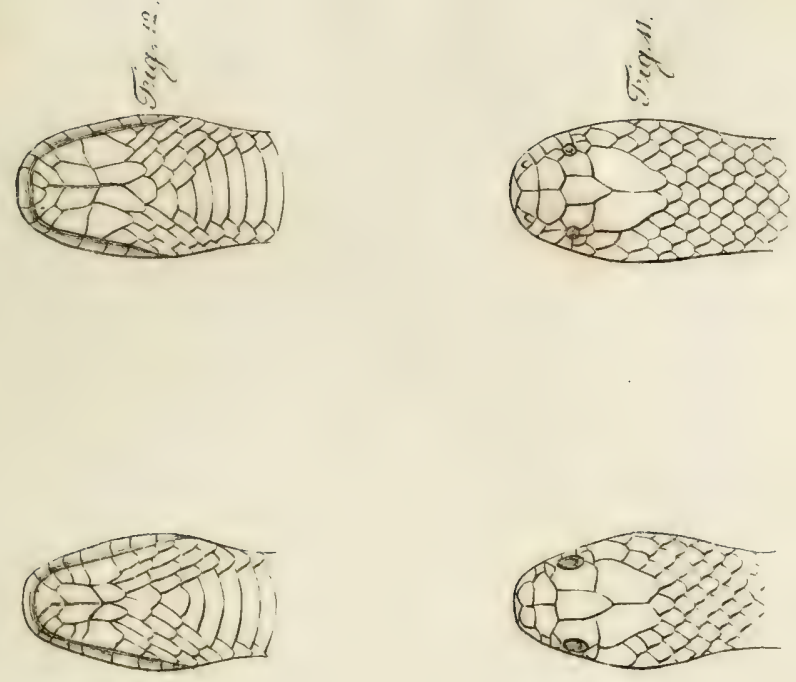

$\infty$
6

है
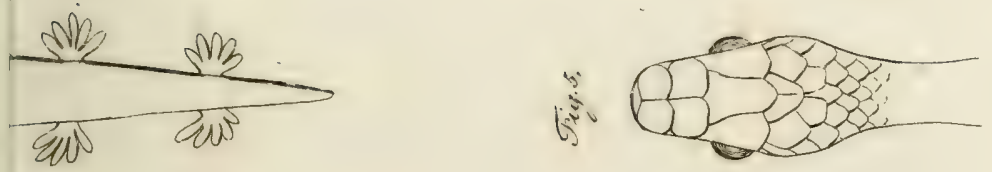

$$
\text { is } \frac{355}{325}
$$

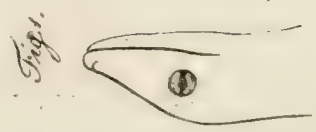



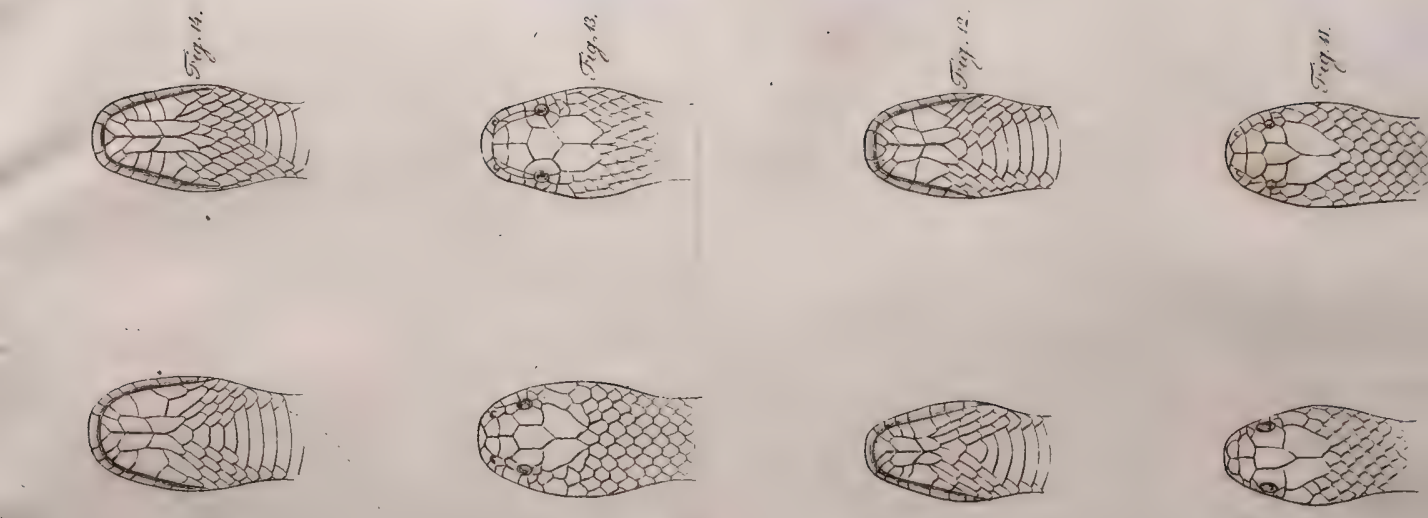

bit

$i^{2}$

6
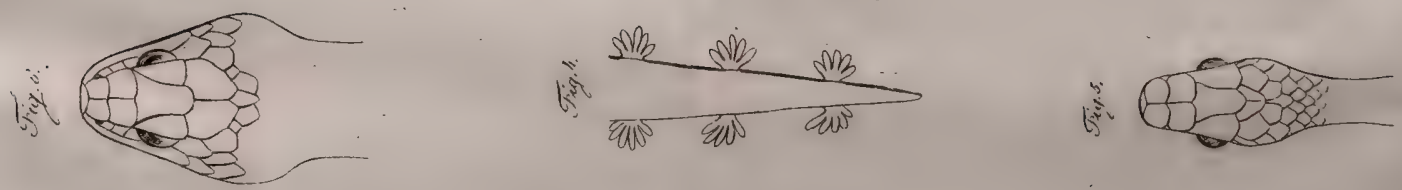

$i^{\infty}-\angle E \equiv$

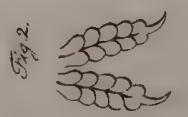

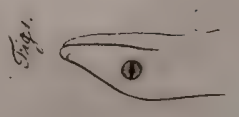




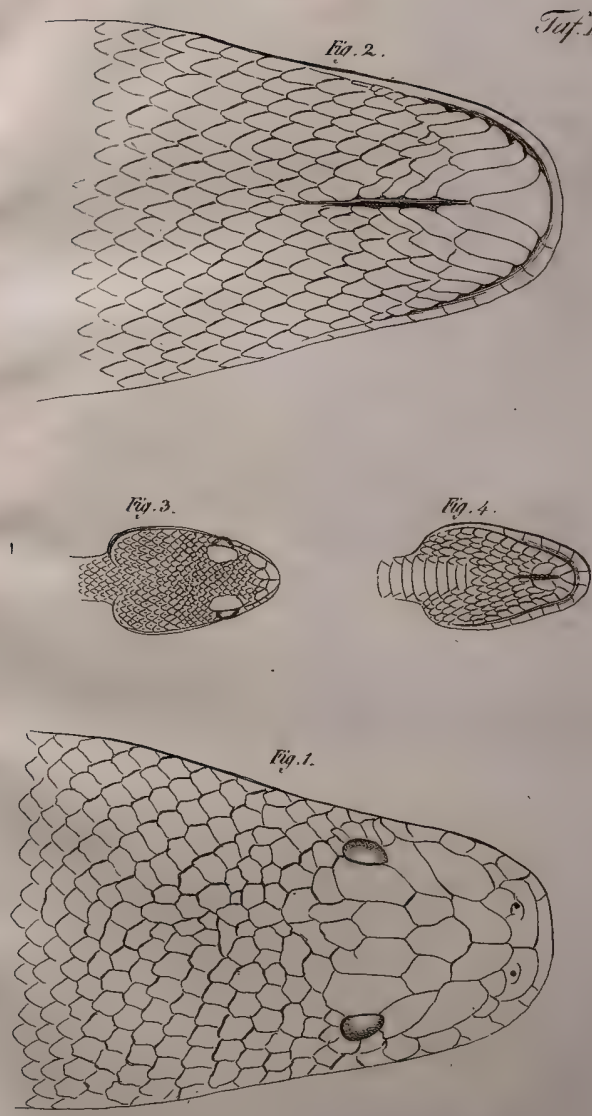
byons tomquatus.
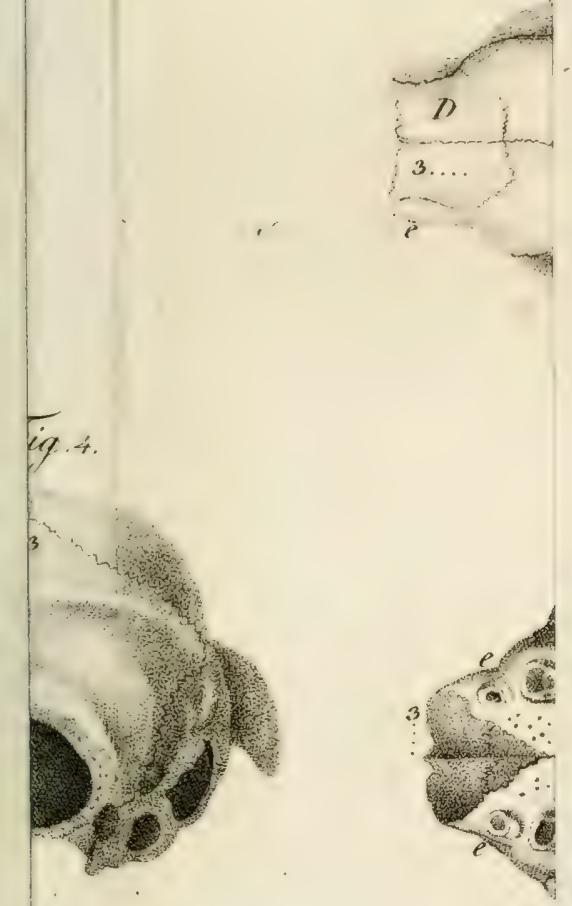

$\therefore$

$$
\begin{aligned}
& \text { Tig. } \\
& \text { sooe } \\
& \text { cooc }
\end{aligned}
$$



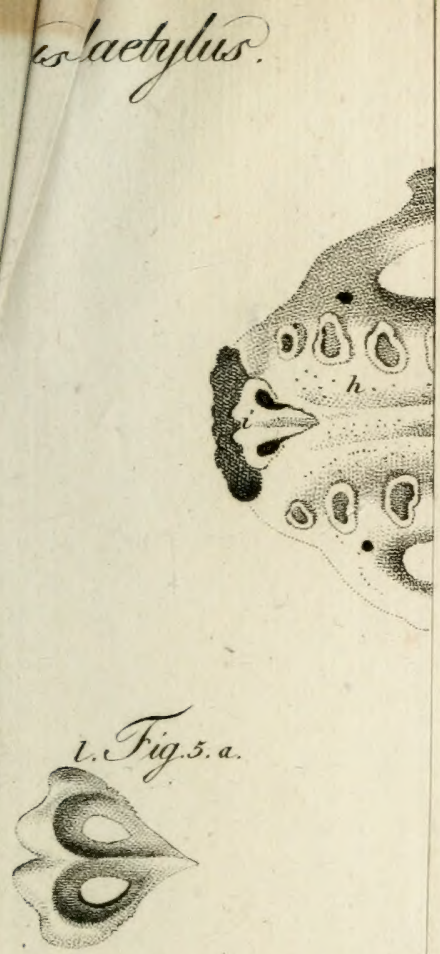

Fig.6.

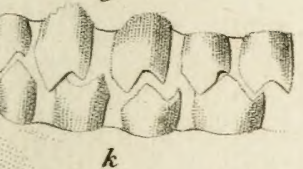

Sig.7.

(1) (a) ${ }^{6}$

k

100 
Bradupus tridactylus.

3 arf.
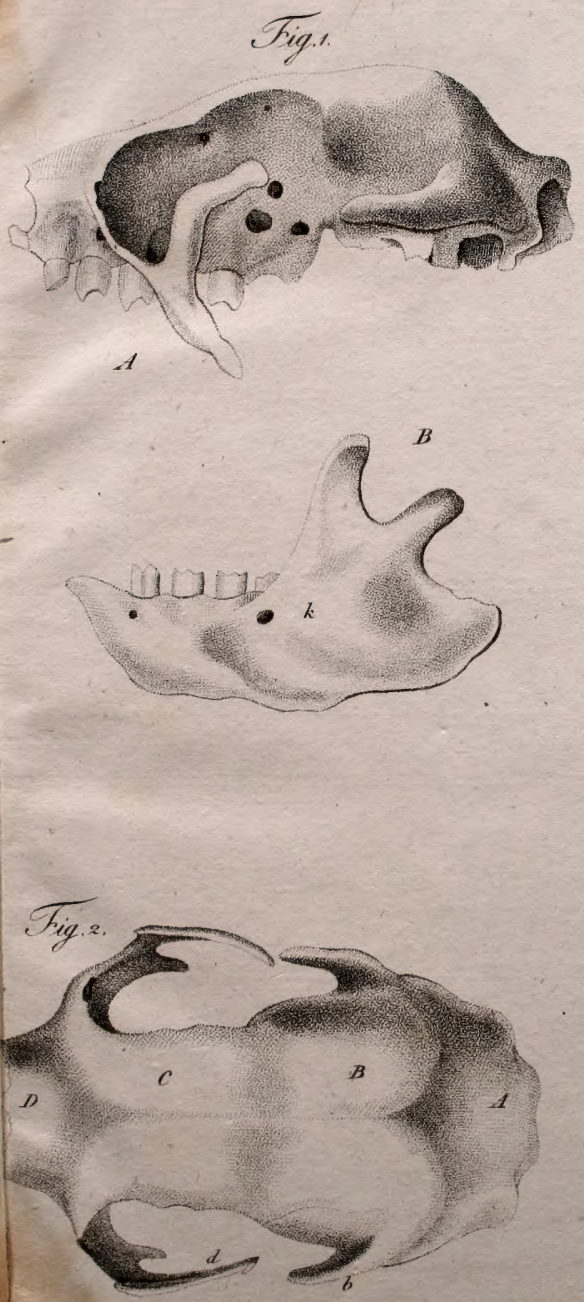
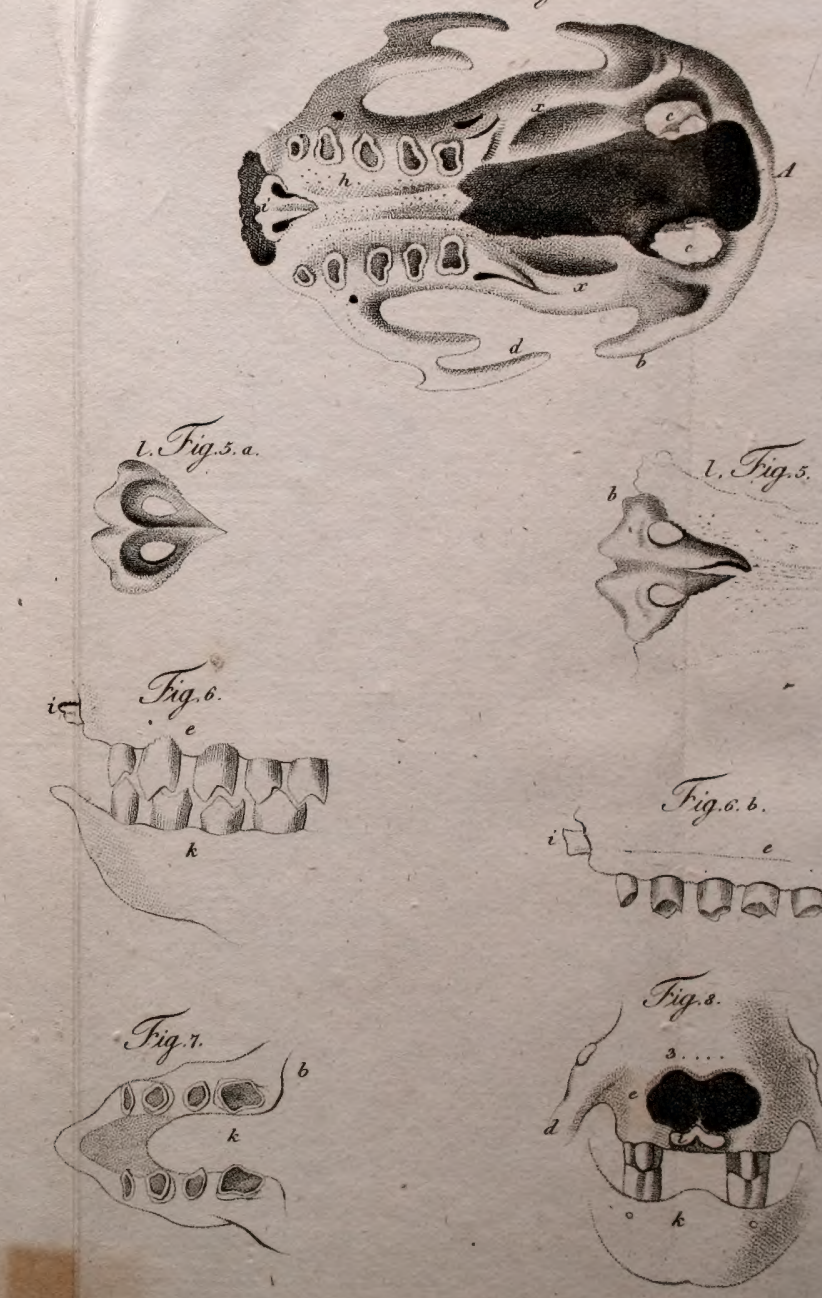

Sig.
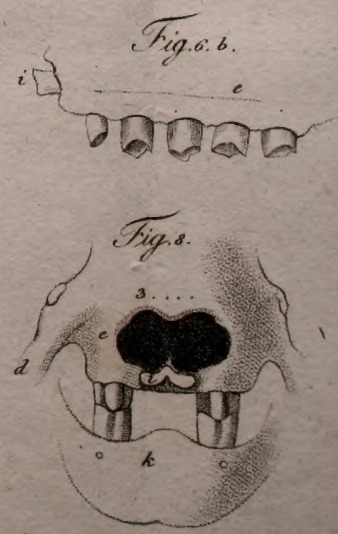


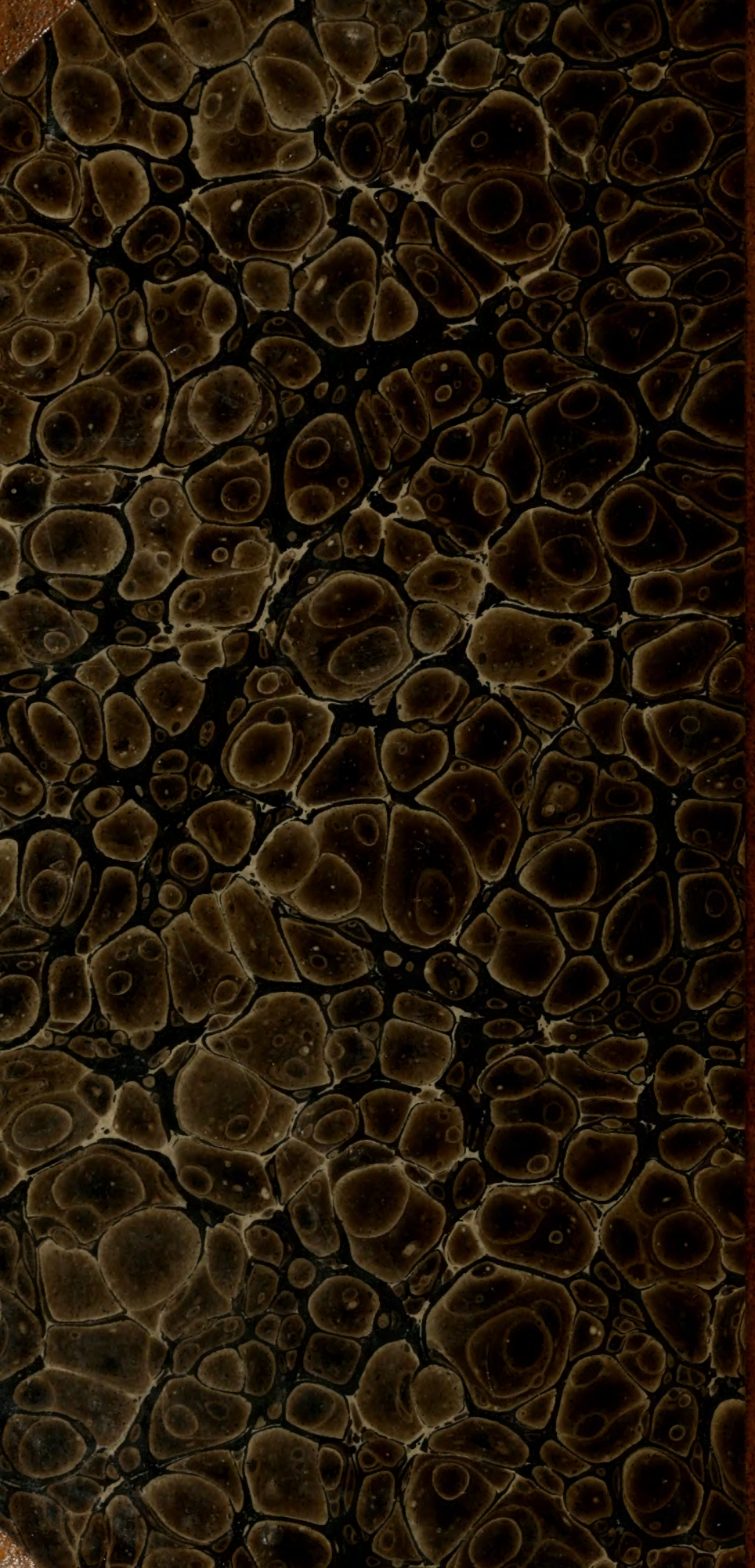

